NUREG/CR-6153

SAND93-2588

\title{
A Simplified Model of \\ Decontamination by BWR \\ Steam Suppression Pools
}

Manuscript Completed: December 1996

Date Published: May 1997

Prepared by

D. A. Powers

Sandia National Laboratories

Albuquerque, NM 87185

J. H. Schaperow, NRC Project Manager

Prepared for

Division of Systems Technology

Office of Nuclear Regulatory Research

U.S. Nuclear Regulatory Commission

Washington, DC 20555-0001

NRC Job Code L2035 


\section{DISCLAIMER}

Portions of this document may be illegible in electronic image products. Images are produced from the best available original document. 


\section{DISCLAIMER}

This report was prepared as an account of work sponsored by an agency of the United States Government. Neither the United States Government nor any agency thereof, nor any of their employees, make any warranty, express or implied, or assumes any legal liability or responsibility for the accuracy, completeness, or usefulness of any information, apparatus, product, or process disclosed, or represents that its use would not infringe privately owned rights. Reference herein to any specific commercial product, process, or service by trade name, trademark, manufacturer, or otherwise does not necessarily constitute or imply its endorsement, recommendation, or favoring by the United States Government or any agency thereof. The views and opinions of authors expressed herein do not necessarily state or reflect those of the United States Government or any agency thereof. 


\begin{abstract}
Phenomena that can decontaminate aerosol-laden gases sparging through steam suppression pools of boiling water reactors during reactor accidents are described. Uncertainties in aerosol properties, aerosol behavior within gas bubbles, and bubble behavior in plumes affect predictions of decontamination by steam suppression pools. Uncertainties in the boundary and initial conditions that are dictated by the progression of severe reactor accidents and that will affect predictions of decontamination by steam suppression pools are discussed.

Ten parameters that characterize boundary and initial condition uncertainties, nine parameters that characterize aerosol property and behavior uncertainties, and eleven parameters that characterize uncertainties in the behavior of bubbles in steam suppression pools are identified. Ranges for the values of these parameters and subjective probability distributions for parametric values within the ranges are defined. These uncertain parameters are used in Monte Carlo uncertainty analyses to develop uncertainty distributions for the decontamination that can be achieved by steam suppression pools and the size distribution of aerosols that do emerge from such pools.

A simplified model of decontamination by steam suppression pools is developed by correlating features of the uncertainty distributions for total decontamination factor, $\mathrm{DF}$ (total), mean size of emerging aerosol particles, $d_{p}$, and the standard deviation of the emerging aerosol size distribution, $\sigma$, with pool depth, $H$. Correlations of the median values of the uncertainty distributions are suggested as the best estimate of decontamination by suppression pools. Correlations of the 10 percentile and 90 percentile values of the uncertainty distributions characterize the uncertainty in the best estimates.
\end{abstract}




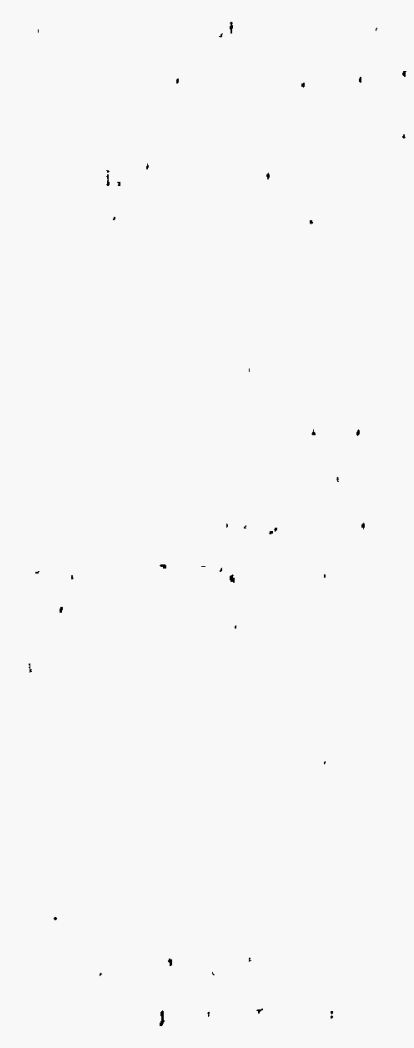


Abstract $\ldots \ldots \ldots \ldots \ldots \ldots \ldots \ldots \ldots \ldots \ldots \ldots \ldots \ldots \ldots \ldots \ldots \ldots \ldots$ iii

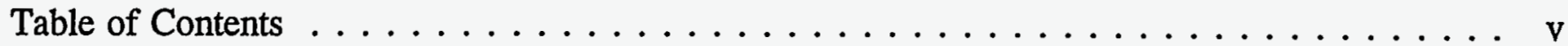

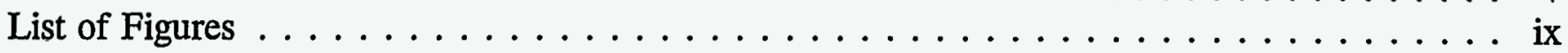

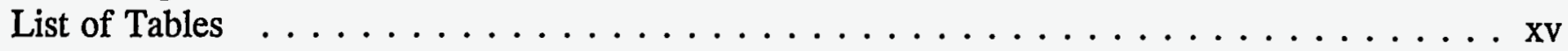

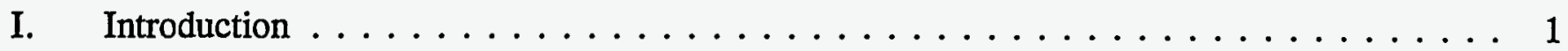

II. Steam Suppression Pools $\ldots \ldots \ldots \ldots \ldots \ldots \ldots \ldots \ldots \ldots$

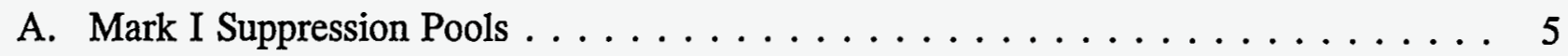

B. Mark II Suppression Pools $\ldots \ldots \ldots \ldots \ldots \ldots \ldots \ldots \ldots \ldots \ldots$

C. Mark III Suppression Pools . . . . . . . . . . . . . . . . . . 11

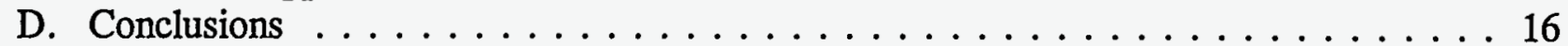

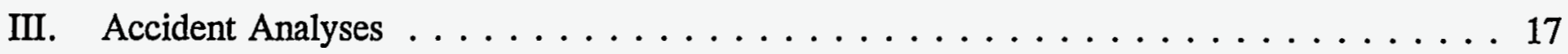

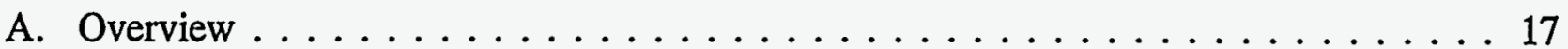

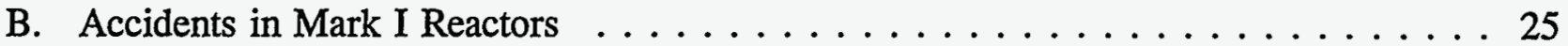

C. Accidents in Mark II Reactors . . . . . . . . . . . . . . . . . 34

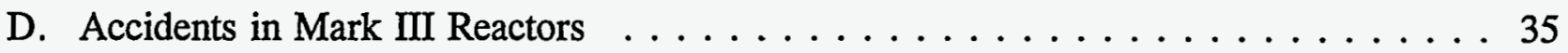

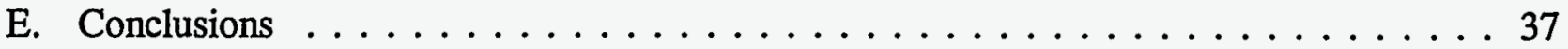

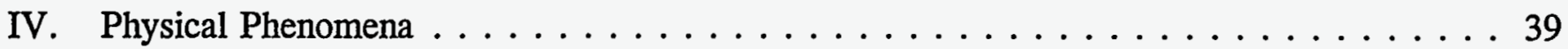

A. Bubble Formation $\ldots \ldots \ldots \ldots \ldots \ldots \ldots \ldots \ldots \ldots$

1. Bubble Formation at Quencher Orifices $\ldots \ldots \ldots \ldots \ldots \ldots \ldots$

2. Models of Bubble Formation . . . . . . . . . . . . . 52

a. The Davidson-Schuler Single-Stage Model . . . . . . . . . . . 52

b. Two-stage Bubble Formation Models . . . . . . . . . . . . . 53

c. Numerical Models . . . . . . . . . . . . . . . . . . . . . 59

3. Bubble Formation at Downcomers . . . . . . . . . . . 61

4. Bubble Formation at Horizontal Vents . . . . . . . . . . . 71

B. Collapse and Disintegration of Large Bubbles . . . . . . . . . . . . 73

C. Bubble Size Distribution and the Coalescence of Bubbles . . . . . . . . . 85

D. Thermodynamics of Bubble Rise . . . . . . . . . . . . . . . . 97

E. Bubble Plumes From Quenchers . . . . . . . . . . . . . . . . . . . 105

F. Overview of Bubble Behavior . . . . . . . . . . . . . . . . . . . . . . . . . 124

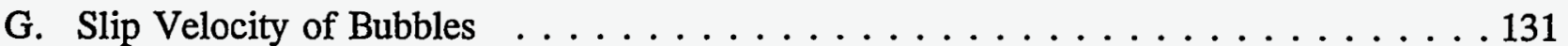

H. Bubble Shapes . . . . . . . . . . . . . . . . . . . . . . . . 134 


\section{Table of Contents (Continued)}

I. Heat and Mass Transport to and Within Bubbles . . . . . . . . . . . . . . 137

1. Heat Transport From Bubbles During Formation . . . . . . . . . . . . . . . . . . . . . . . . . . . . . . . .

2. Heat Transfer After Bubble Detachment . . . . . . . . . . . . . . . . . . . . 141

3. Heat and Mass Transfer During Bubble Rise . . . . . . . . . . . . . . . . 144

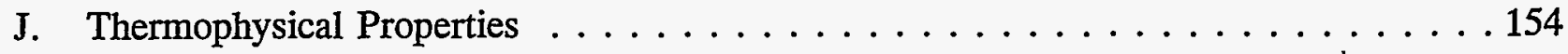

1. Properties of Liquid Water . . . . . . . . . . . . . . . . . . . . 154

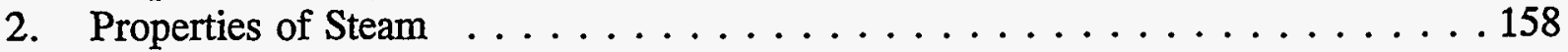

3. Properties of Permanent Gases . . . . . . . . . . . . . . . . . 161

4. Solubility of Gases in Water . . . . . . . . . . . . . . 173

K. Properties of Aerosol Particles . . . . . . . . . . . . . . . . 181

1. Shape Factors . . . . . . . . . . . . . . . . . . . . 183

2. Slip Correction Factors and Accommodation Coefficients . . . . . . . . . . 189

3. Hygroscopicity of Aerosols Produced in Reactor Accidents . . . . . . . . . 200

L. Aerosol Behavior . . . . . . . . . . . . . . . . . . . 203

1. Aerosol Trapping During Bubble Rise . . . . . . . . . . . . . . . . . 204

a. Diffusion of Particles to the Bubble Walls . . . . . . . . . . . . . . 204

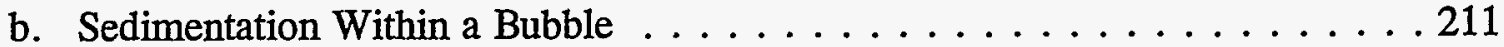

c. Inertial Deposition . . . . . . . . . . . . . . . . . 212

d. Particle Deposition by Diffusiophoresis . . . . . . . . . . . 215

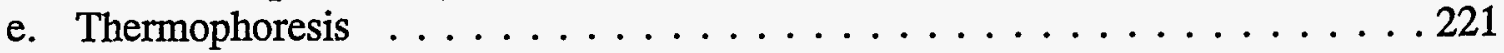

f. Particle Growth by Water Condensation . . . . . . . . . . . . . . . . . . . . . . . . . . . . . . . . . . . . . .

g. Aerosol Capture by Bubble Oscillations . . . . . . . . . . . . . 238

2. Aerosol Trapping During Bubble Collapse $\ldots \ldots \ldots \ldots . \ldots \ldots 2$

3. Aerosol Capture During Bubble Formation . . . . . . . . . . . . . . 244

V. Uncertainty in Predictions of Aerosol Removal by Steam Suppression Pools . . . . . . . 253

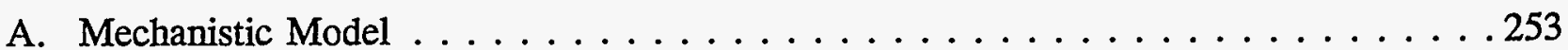

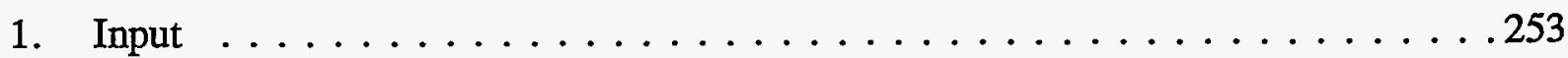

2. Generation of Random Numbers . . . . . . . . . . . . . . . . 255

3. Sampling Uncertain Inputs and Parametric Quantities . . . . . . . . . . . 255

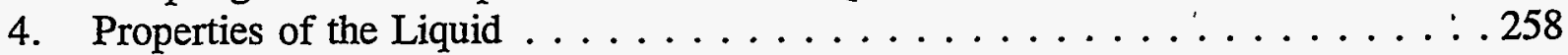

5. Discretization of the Aerosol Size Distribution . . . . . . . . . . . . . 259

6. Formation of Bubbles and Decontamination During Bubble Formation . . . . . 261 


\section{Table of Contents (Continued)}

Page

7. Detachment and Equilibration of the Bubble $\ldots \ldots \ldots \ldots \ldots$

8. Plume Formation . . . . . . . . . . . . . . . . . . . . . . . 261

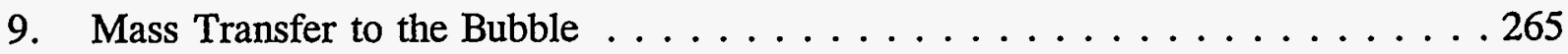

10. Decontamination During Bubble Rise . . . . . . . . . . . . . 265

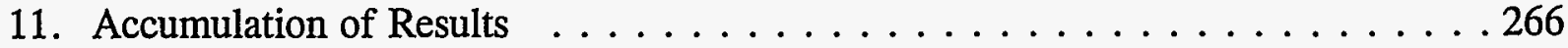

B. Uncertain Models, Inputs and Parametric Quantities . . . . . . . . . . . . . . 266

1. Input and Boundary Condition Uncertainties $\ldots \ldots \ldots$. . . . . . 268

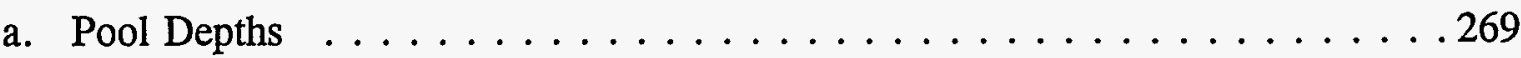

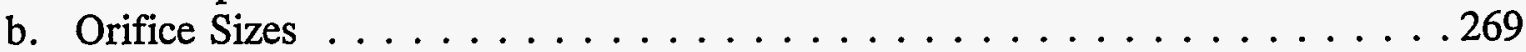
c. Wetwell Pressures . . . . . . . . . . . . . . . . . . . . 269
d. Aerosol Particle Size . . . . . . . . . . . . . . . . . . . 272
e. Aerosol Material Density ... . . . . . . . . . . . . . . . 275
f. Uncertainty in Shape Factors . . . . . . . . . . . . . . . 276
g. Gas Flow Rates . . . . . . . . . . . . . . . . . . . 277

2. Phenomenological Uncertainties in Bubble Behavior . . . . . . . . . 279
a. Uncertainty in Bubble Formation . . . . . . . . . . . . . . . . . 279
b. Uncertainty in the Equilibration Distance . . . . . . . . . . . . . 282
c. Initial Size of Bubbles in the Plume . . . . . . . . . . . . 282

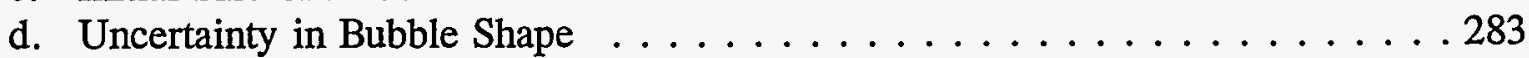
e. Bubble Slip Velocity . . . . . . . . . . . . . . . . . . . . . . . . . . . . . . . . . . . . . . . . . . . . . . . . .
f. Uncertainty in Plume Parameters . . . . . . . . . . . . . . . . . . . . . . . . . . . . . . . . . . . .

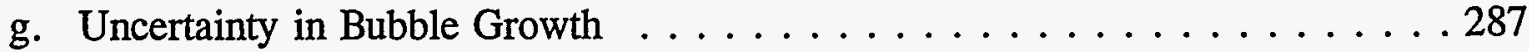
h. Radial Mixing in the Bubble Plume . . . . . . . . . . . . . 288

3. Phenomenological Uncertainties in Aerosol Behavior . . . . . . . . . 288

a. Uncertainty in Aerosol Trapping by Inertial Impaction . . . . . . . . . 288

b. Uncertainty in Aerosol Trapping by Diffusion . . . . . . . . . . . . . . . 295

c. Uncertainty in Slip Correction Factors . . . . . . . . . . . . . . . 296

d. Uncertainty in Accommodation Coefficients . . . . . . . . . . . . . . . . . 296

e. Uncertainty in Aerosol Capture by Bubble Oscillations . . . . . . . . . . . . 297

f. Uncertainty in the Summation of Aerosol Capture Processes . . . . . . . . . . 298

g. Uncertainty in Aerosol Capture During Bubble Formation . . . . . . . . . . 301

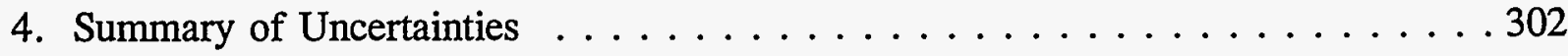




\section{Table of Contents (Concluded)}

\section{Page}

VI. Results of the Uncertainty Analyses 303

A. Decontamination During Release Through ' $T$ ' Quenchers $\ldots \ldots \ldots \ldots \ldots \ldots . \ldots . \ldots . \ldots 304$

B. Decontamination During Release Through ' $\mathrm{X}$ ' Quenchers

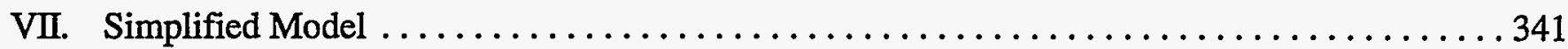

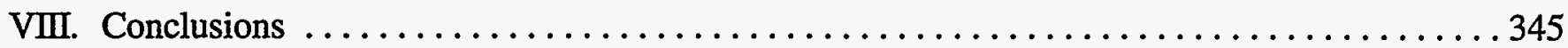

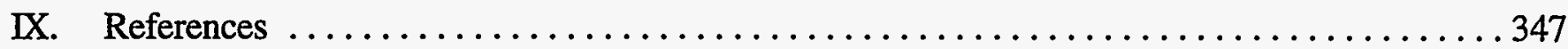

Appendix A Tabulations of Uncertainty Distributions $\ldots \ldots \ldots \ldots \ldots \ldots \ldots \ldots \ldots \ldots \ldots \ldots \ldots \ldots \ldots \ldots$ 


\section{List of Figures.}

Figure

1 Overall configurations of steam suppression pools in Mark I, Mark II, and Mark III

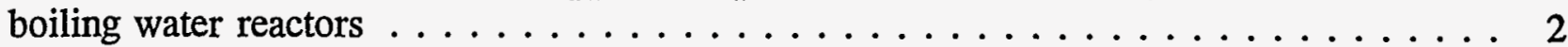

2 Torus suppression pool of a Mark I containment $\ldots \ldots \ldots \ldots \ldots \ldots \ldots \ldots$

3 ' $T$ ' Quencher for a Mark I suppression pool . . . . . . . . . . . . . . . . . 9

4 Various types of vents from the drywells to the suppression pools in Mark I

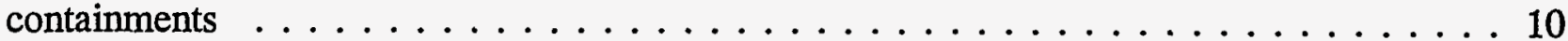

5 Diagrams of the diaphragm floors of various Mark II containments . . . . . . . . 12

6 Positioning of quenchers in the Mark III suppression pool . . . . . . . . . . 13

7 Diagrams of X-quenchers in Mark III suppression pools . . . . . . . . . . . . . 14

8 Horizontal vents in the Mark III suppression pool . . . . . . . . . . . . . . 15

9 Alternative core meltdown scenarios for boiling water reactors . . . . . . . . . . 22

10 Core debris expulsion from the reactor vessel into the drywell as predicted by the BWRSAR code . . . . . . . . . . . . . . . . . . . 23

11 Molar gas flow $(M)$ through the reactor coolant system in a Mark I boiling water

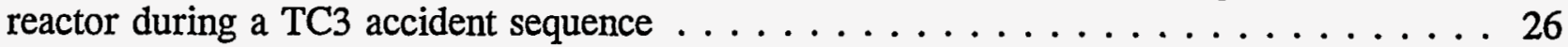

12 Molar flows of gas to the suppression pool during core debris/concrete interactions in a TC3 accident sequence . . . . . . . . . . . . . . . . . 27

13 Size distribution of aerosols in the reactor coolant system predicted with the Source Term Code Package . . . . . . . . . . . . . . . . . . . . . . 29

14 Mean size and material density of aerosols produced during core debris interactions with concrete in a TC3 accident in a Mark I boiling water reactor . . . . . . . 30

15 Molar gas flow (M) through the reactor coolant system in a Mark I boiling water reactor during a TB2 accident sequence . . . . . . . . . . . . . 31

16 Molar flows of gas to the suppression pool during core debris/concrete interactions

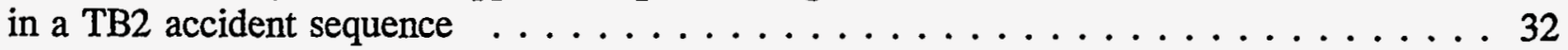

17 Mean size and material density of aerosols produced during core debris interactions with concrete in a TB2 accident in a Mark I boiling water reactor . . . . . . . . . 33

18 Molar flow rates (Mi) through the reactor coolant system in a Mark III boiling water reactor during a station blackout accident and an ATWS accident . . . . . . . 36

19 Schematic representation of bubble behavior when released into a steam suppression pool from a quencher . . . . . . . . . . . . . . . . . 40

20 Bubble injector apparatus used in tests of bubble hydraulics by Paul et al. . . . . . . . 42

21 Comparison of bubble sizes predicted with correlation developed by Paul et al. to bubble sizes observed in various experiments . . . . . . . . . . . . . .

22 Comparison of observed volume equivalent spherical bubble diameter to predictions obtained with the Davidson-Schuler model with various coefficients . . . . . . . . . 46

23 Comparison of Besset's bubble volume/data to the predictions of the modified Davidson-Schuler model . . . . . . . . . . . . . . . . . . . . . . . . 49

24 Fit of Schmidt's bubble volume data to a correlation in terms of the Weber number . . . . 51

25 Comparison of observed volume equivalent spherical bubble diameters to those predicted with the model of Kumar and Kaloor . . . . . . . . . . . . . 55

26 Comparison of observed volume equivalent spherical bubble diameters to those predicted by Ruff's empirically modified model 


\section{List of Figures (Continued)}

Figure

Page

27 Variation in the bubble diameter with orifice orientation predicted with the Kumar and Kaloor model . . . . . . . . . . . . . . . . . . . . . . . . . . . 58

28 Comparison of the diameters of steam bubbles forming in subcooled water observed by Besset to predicted diameters obtained using Ruff's model corrected for

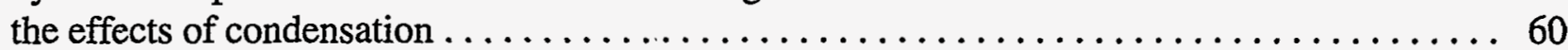

29 Flow regime map developed from results of studies with a small-scale model of a

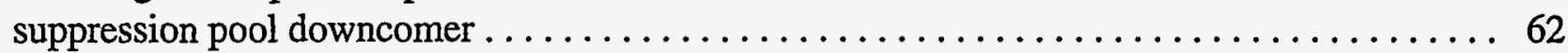

30 Internal "chug" observed in tests by Lee and Chan $\ldots \ldots \ldots \ldots \ldots \ldots \ldots \ldots \ldots \ldots \ldots$

31 "Chugging" with bubble detachment observed in tests by Lee and Chan . . . . . . . . . 65

32 "Chugging" without bubble detachment observed in tests by Lee and Chan ..........66

33 Comparison of various model predictions of the initial size of bubbles formed

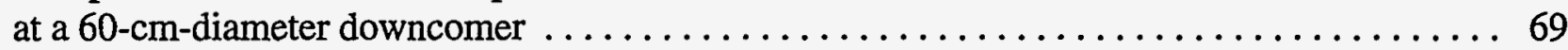

34 Comparison of various model predictions of the initial diameters of bubbles

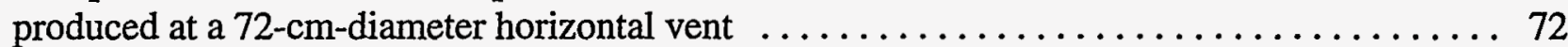

35 Isothermal, inertially-controlled collapse of a $2-\mathrm{cm}$ bubble in water at $319^{\prime} \mathrm{K}$

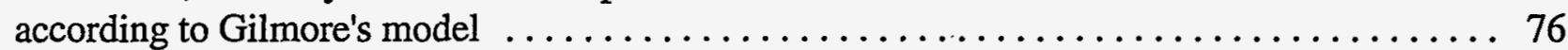

36 Comparison of bubble collapse predictions to data from Levenspiel $\ldots \ldots \ldots \ldots \ldots \ldots \ldots$

37 Comparison of model predictions of bubble collapse to data from Wittke and Chao . . . . . . . 79

38 Comparison of predictions of bubble collapse to data from Wittke and Chao ........ 80

39 Rise velocities for very large bubbles $\ldots \ldots \ldots \ldots \ldots \ldots \ldots \ldots \ldots \ldots \ldots \ldots \ldots \ldots \ldots$

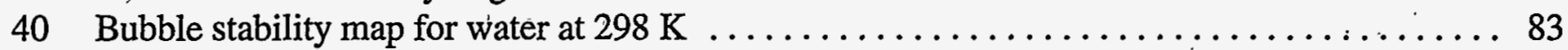

41 Bubble stability map for water at $373 \mathrm{~K} \ldots \ldots \ldots \ldots \ldots \ldots \ldots \ldots \ldots \ldots \ldots \ldots \ldots$

42 Effect of gas injection rate on bubble size distribution $\ldots \ldots \ldots \ldots \ldots \ldots \ldots \ldots \ldots \ldots$

43 Effect of orifice size on the bubble size distribution $\ldots \ldots \ldots \ldots \ldots \ldots \ldots \ldots \ldots \ldots \ldots$

44 Effect of orifice orientation on the bubble size distribution $\ldots \ldots \ldots \ldots \ldots \ldots \ldots \ldots$

45 Effect of the mole fraction of steam in air/steam mixtures on the mean bubble size . . . . . . 92

46 Effect of the mole fraction steam in air/steam mixtures on the geometric standard deviation of the bubble size distribution $\ldots \ldots \ldots \ldots \ldots \ldots \ldots \ldots \ldots \ldots \ldots \ldots \ldots \ldots \ldots \ldots$

47 Efficiency of bubble coalescence as a function of the ionic strength of the

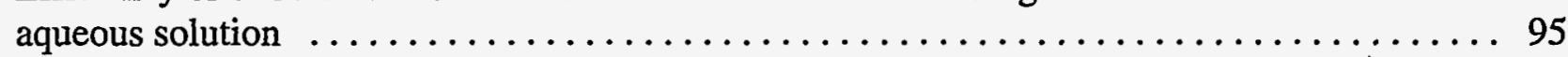

48 Thermodynamic calculation of bubble rise in a water pool $\ldots \ldots \ldots \ldots \ldots \ldots \ldots \ldots \ldots$

49 Results of bubble rise calculation considering finite rates of heat and mass transport

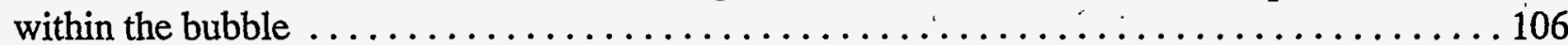

50 Schematic diagrams of bubble plumes: (a) simple plume, (b) plume with dèscending outer annulus and (c) plume with instability intrusions produced by unstable

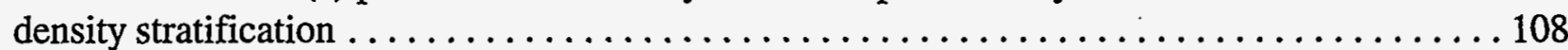

51 Dependence of the entrainment coefficient on the bubble Froude number $\ldots \ldots \ldots \ldots \ldots 114$

52 Dependence of the momentum amplification factor on the phase distribution number $\ldots \ldots 117$

53 Comparison of plume model predictions to data obtained by Milgram in a pool

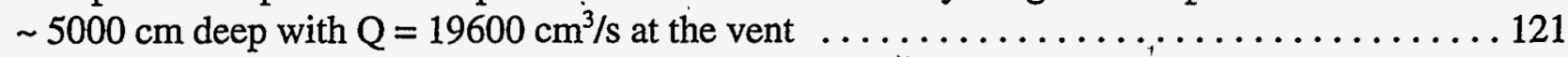

54 Comparison of predictions of the plume model to data obtained by Milgram in

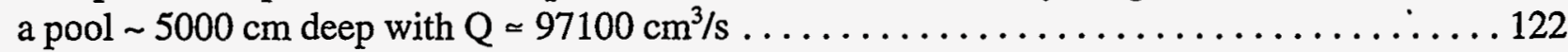

55 Comparison of model predictions to centerline void fractions observed in experiments

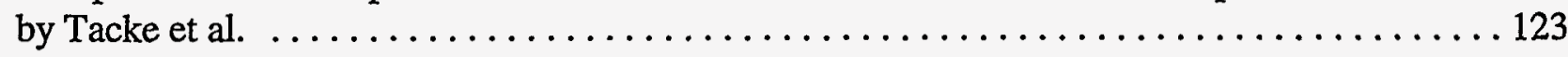




\section{List of Figures (Continued)}

Figure

Page

56 Comparison of model predictions to bubble rise velocities observed in an experiment

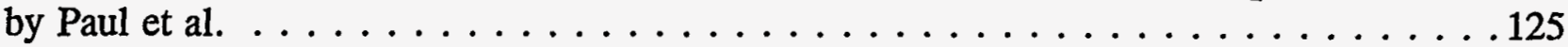

57 Comparison of model predictions to bubble rise velocities at various elevations observed in an experiment by Paul et al. . . . . . . . . . . . . . . . . 126

58 Effect of entrainment coefficient on predictions of bubble rise velocity . . . . . . . . 127

59 Variations in $\log _{10} \mathrm{M}$ and $\mathrm{E}_{\mathrm{o}} / \mathrm{D}_{\mathrm{B}}{ }^{2}$ with temperature in water . . . . . . . . . . . 129

60 Comparison of predictions of bubble rise velocities by several models . . . . . . . . 133

61 Comparison of predicted bubble rise velocities to data for air bubbles in hot $(322 \mathrm{~K})$

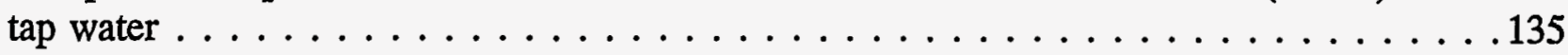

62 Comparison of bubble eccentricity models to experimental data . . . . . . . . . . 138

63 General geometry of a spherical cap bubble . . . . . . . . . . . . . . . . . . 139

64 Heat transfer coefficients for bubbles rising in $373 \mathrm{~K}$ water as functions of bubble diameter . . . . . . . . . . . . . . . . . . . . 143

65 Comparison of predicted and observed mass transport coefficients for $\mathrm{CO}_{2}$ from nearly spherical bubbles . . . . . . . . . . . . . . . . . . . . . . 146

66 Comparison of mass transport coefficients predicted for $\mathrm{CO}_{2}$ in water from nonspherical bubbles to experimental data . . . . . . . . . . . . . . 150

67 External heat transfer coefficients for bubbles in water at $373 \mathrm{~K}$ derived from analogies to mass transport models . . . . . . . . . . . . . . . . . 152

68 Correlation of the long-term Sherwood number in the gas phase for cases with a finite liquid phase Sherwood number . . . . . . . . . . . . . . . . 153

69 Comparison of predictions of the surface tension of water to experimental data . . . . . 157

70 Comparison of the predicted thermal conductivity of water to critically assessed experimental data . . . . . . . . . . . . . . . . . . . . . . 159

71 Comparison of calculated steam viscosity to recommended values derived from experimental data . . . . . . . . . . . . . . . . . . . . . . . . 162

72 Comparison of calculated thermal conductivity of steam with experimental data . . . . 163

73 Comparison of calculated gas viscosities to recommended values derived from

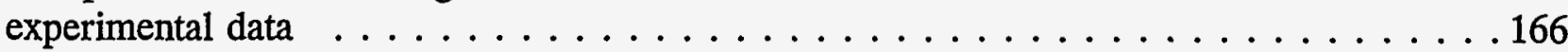

74 Viscosity of hydrogen as a function of temperature . . . . . . . . . . . . . . 167

75 Predicted binary, gaseous diffusion coefficients for the $\mathrm{H}_{2} / \mathrm{H}_{2} \mathrm{O}, \mathrm{N}_{2} / \mathrm{H}_{2} \mathrm{O}$,

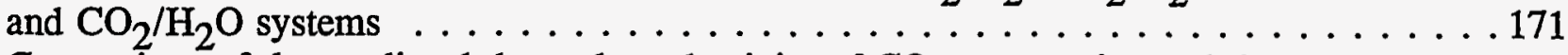

76 Comparison of the predicted thermal conductivity of $\mathrm{CO}_{2}$ to experimental data . . . . . 174

77 Comparison of the predicted thermal conductivity of $\mathrm{O}_{2}$ to experimental data $\ldots \ldots 175$

78 Comparison of the predicted thermal conductivity of $\mathrm{H}_{2}$ to experimental data . . . . . 176

79 Comparison of the predicted thermal conductivity of $\mathrm{CO}$ to experimental data . . . . . 177

80 Comparison of the predicted thermal conductivity of $\mathrm{N}_{2}$ to experimental data . . . . . 178

81 Comparison of the predicted thermal conductivity of $\mathrm{H}_{2} / \mathrm{N}_{2}$ mixtures at $300.5 \mathrm{~K}$ to experimental data . . . . . . . . . . . . . . . . . . . . 179

82 Comparison of the predicted thermal conductivities of $\mathrm{N}_{2} / \mathrm{CO}$ mixtures at $300.5 \mathrm{~K}$ and $\mathrm{N}_{2} / \mathrm{CO}_{2}$ mixtures at $380.5 \mathrm{~K}$ to experimental data $\ldots \ldots \ldots \ldots$

83 Solubilities of gases in water at 1 atmosphere pressure as functions of temperature . . . . 182

84 Dynamic shape factor as a function of particle size for various particle material densities 


\section{List of Figures (Continued)}

Figure

Page

85 Dynamic shape factors for doublets, triplets, and quadruplet agglomerates of spherical particles . . . . . . . . . . . . . . . . . . . 188

86 Comparison of the predicted slip correction factor to values obtained in' experiments with oil droplets and correlations of data for solid particles . . . . . . . . . . . . 192

87 Temperature accommodation coefficient of hydrogen on metal surfaces . . . . . . . . . . 194

88 Temperature accommodation coefficients of various gases on glass surfaces . . . . . . . 195

89 Comparison of slip correction factors for a prolate distorted particle $\left(\mathrm{E}^{\prime}=2.0\right)$ calculated using the adjusted sphere and the volume-equivalent sphere method' . . . . . 201

90 Diffusive deposition velocities according to several models for aerosol particles

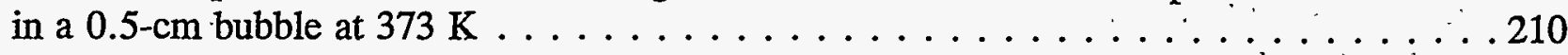

91 Patterns of particle deposition by sedimentation within ellipsoidal bubbles of various eccentricities . . . . . . . . . . . . . . . . . . . .213

92 Sedimentation deposition velocity as a function of particle size $\ldots \ldots \ldots \ldots \ldots \ldots 214$

93 Patterns of particle deposition by inertial impaction in ellipsoidal bubbles of various eccentricities . . . . . . . . . . . . . . . . . 216

94 Inertial impaction deposition velocities as functions of particle size $\ldots \ldots \ldots \ldots \ldots 217$

95 Relative variation in the water vapor pressure gradient at the surfaces of ellipsoidal bubbles of various eccentricities . . . . . . . . . . . . . 222

96 Comparison of dimensionless thermophoretic velocity predicted by the Talbot êt al: model to data for oil drops in hydrogen . . . . . . . . . . . . . . . . 226

97 Comparison of dimensionless thermophoretic velocity predicted by the Talbot et all. model to data for oil drops in carbon dioxide . . . . . . . . . . . . 227

98 Phase shift for motions of particles $\left(\rho_{\mathrm{p}}=2 \mathrm{~g} / \mathrm{cm}^{3}\right)$ of various sizes in bubbles undergoing sinusoidal oscillations . . . . . . . . . . . . . . 240

99 Amplitude magnification factors for motions of particles $\left(\rho_{\mathrm{p}}=2 \mathrm{~g} / \mathrm{cm}^{3}\right)$ of various sizes in bubbles undergoing sinusoidal oscillations $\ldots \ldots \ldots \ldots \ldots \ldots \ldots \ldots \ldots$

100 Natural vibration frequencies of bubbles in water at $373 \mathrm{~K} \ldots \ldots \ldots \ldots \ldots 243$

101 Comparison of various models of aerosol deposition by impaction from the orifice stream . . . . . . . . . . . . . . . . . . . . . . . . . . 247

102 Particle capture by convective mass transport during bubble formation according to the mass transfer correlation developed by Skelland and Minhas . . . . . . . . . 249

103 Essential elements of the mechanistic model of aerosol removal by steam suppression pools . . . . . . . . . . . . . . . . . . . . . . . 254

104 Comparison of uniform, log-uniform, lognormal, and Student's t probability

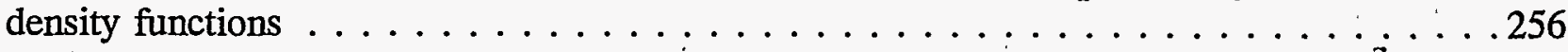

105 Variation of the normalized tangential velocities about a spherical bubble with various amounts of surface immobilization . . . . . . . . . . . . . . 292

106 Variation of the normalized, integrated particle deposition by inertial impaction as a function of the extent of surface immobilization . . . . . . . . . . . . 293

107 Variation of $\mathrm{DF}(\mathrm{FE})$ during gap release through a ' $\mathrm{T}$ ' quencher with quencher submergence . . . . . . . . . . . . . . . . . . . . . . . .310

108 Variation in $\mathrm{DF}(\mathrm{FE})$ during invessel release through a ' $\mathrm{T}$ ' quencher with quencher submergence 


\section{List of Figures (Concluded)}

Figure

$\underline{\text { Page }}$

109 Variation in DF(rise) for gap release through a ' $\mathrm{T}$ ' quencher with quencher

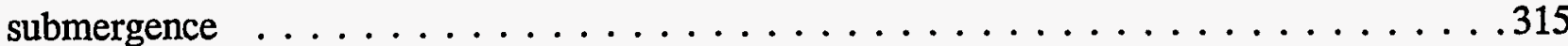

110 Variation in $\mathrm{DF}$ (rise) for invessel release through a ' $\mathrm{T}$ ' quencher with

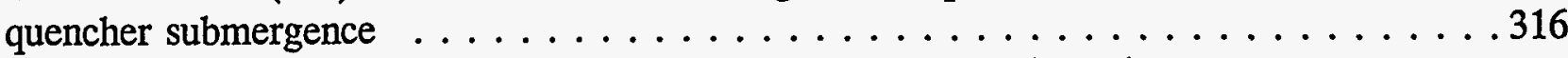

111 Variation in $\mathrm{DF}$ (total) during gap release through a ' $\mathrm{T}$ ' quencher with quencher submergence . . . . . . . . . . . . . . . . . . . . . . . . 319

112 Variation of $\mathrm{DF}$ (total) during invessel release through a ' $\mathrm{T}$ ' quencher with quencher submergence . . . . . . . . . . . . . . . . . . . . . . 320

113 Variation of the mean size of aerosol particles that emerge from a suppression pool during gap release through a ' $\mathrm{T}$ ' quencher with quencher submergence . . . . . . 324

114 Variation of the mean size of aerosol particles that emerge from a suppression pool during invessel release through a ' $T$ ' quencher with quencher submergence . . . . 325

115 Variation of the standard deviation of the size distribution of aerosol particles that emerge from a suppression pool during gap release through a ' $\mathrm{T}$ ' quencher with quencher submergence . . . . . . . . . . . . . . . . . . . 326

116 Variation of the standard deviation of the size distribution of aerosol particles that emerge from a suppression pool during invessel release through a ' $T$ ' quencher with quencher submergence . . . . . . . . . . . . . . . 327

117 Variation of $\mathrm{DF}(\mathrm{FE})$ for invessel release through an ' $\mathrm{X}$ ' quencher with quencher submergence. . . . . . . . . . . . . . . . . . . . . . 334

118 Variation of $\mathrm{DF}$ (rise) for invessel release through an ' $\mathrm{X}$ ' quencher with quencher submergence. . . . . . . . . . . . . . . . . . . 335

119 Variation of DF(total) for invessel release through an ' $\mathrm{X}$ ' quencher with quencher submergence. . . . . . . . . . . . . . . . . . 336

120 Variation of the mean size of aerosol particles emerging from a suppression pool for invessel release through an ' $X$ ' quencher with quencher submergence . . . . . . . 337

121 Variation in the standard deviation of the size distribution of aerosols emerging from a suppression pool for invessel release through an ' $\mathrm{X}$ ' quencher with quencher submergence 



\section{List of Tables}

1 Containment types of existing boiling water reactors $\ldots \ldots \ldots \ldots \ldots \ldots \ldots \ldots \ldots$

2 Characteristics of downcomers in some Mark II containments . . . . . . . . . . . . . 11

3 Proposed severe accident source term for boiling water reactors $\ldots \ldots \ldots \ldots \ldots \ldots \ldots \ldots$

4 Core inventories for a $3578 \mathrm{MW}_{\mathrm{th}} \mathrm{BWR}-6 \ldots \ldots \ldots \ldots \ldots \ldots \ldots \ldots \ldots \ldots \ldots \ldots \ldots \ldots$

5 Sizes of bubbles formed at submerged orifices under constant flow conditions ... . . . . . . 44

6 Besset's data on steam bubble formation in subcooled water $\ldots \ldots \ldots \ldots \ldots \ldots \ldots \ldots$

$7 \quad$ Schmidt's data for steam bubble formation in water $\ldots \ldots \ldots \ldots \ldots \ldots \ldots \ldots \ldots \ldots$

8 Effect of orifice size on the bubble size distribution $\ldots \ldots \ldots \ldots \ldots \ldots \ldots \ldots \ldots \ldots$

9 Effect of orifice orientation on the bubble size distribution $\ldots \ldots \ldots \ldots \ldots \ldots \ldots$

10 Effect of steam concentration on the bubble size distribution $\ldots \ldots \ldots \ldots \ldots \ldots \ldots$

11 Coefficients in the term $\lambda_{1} \overline{(\mathrm{T}, \rho)}$ for thermal conductivity of liquid water $\ldots \ldots \ldots \ldots \ldots 158$

12 Coefficients in the term $\mu_{1} \overline{(T, \rho)}$ for the viscosity of liquid water $\ldots \ldots \ldots \ldots \ldots \ldots$

13 Parameter values for calculation of gas properties $\ldots \ldots \ldots \ldots \ldots \ldots \ldots \ldots \ldots \ldots \ldots$

14 Parameter values for calculating the binary diffusion coefficients of gases $\ldots \ldots \ldots \ldots$

15 Comparison of predicted and observed binary diffusion coefficients in the

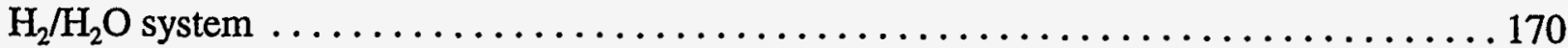

16 Parametric values for correlations of gas thermal conductivities $\ldots \ldots \ldots \ldots \ldots \ldots \ldots 173$

17 Water solubilities of some materials expected to be present in aerosol produced

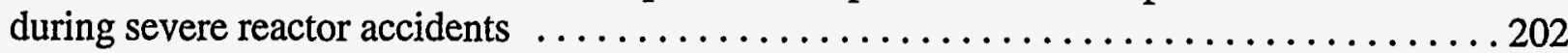

18 Comparison of observed and predicted thermophoretic deposition velocities ........228

19 Determinations of the sticking coefficient cited by Pruppacher and Klett $\ldots \ldots \ldots \ldots . \ldots 233$

20 Dimensionless and example dimensional discretization of the particle size

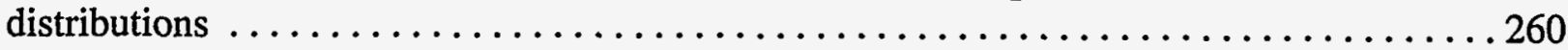

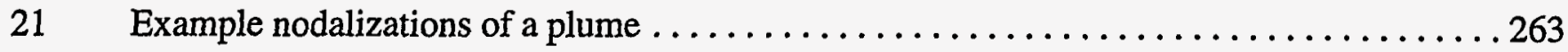

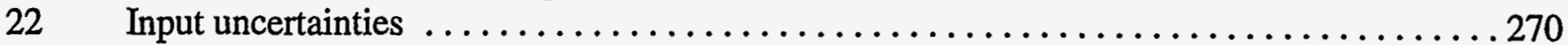

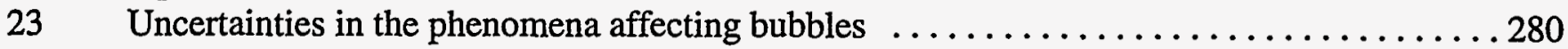

24 Uncertainties in the phenomena affecting aerosol behavior $\ldots \ldots \ldots \ldots \ldots \ldots \ldots \ldots$

25 Effects of coupling between diffusion and gravitational settling . . . . . . . . . . . . 300

26 Uncertainty distribution for the total decontamination of in-vessel release

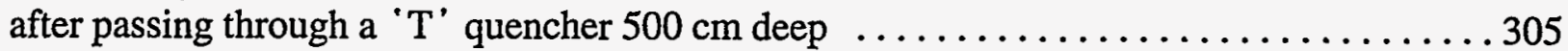

27 Uncertainty distribution for the mean particle size of in-vessel release

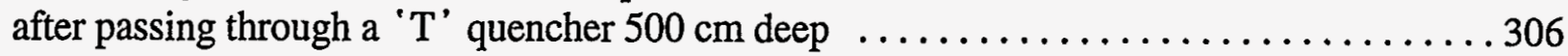

28 Uncertainty distribution for the standard deviation of in-vessel release after passing through a ${ }^{\prime} \mathrm{T}$ ' quencher $500 \mathrm{~cm}$ deep $\ldots \ldots \ldots \ldots \ldots \ldots \ldots \ldots \ldots$

29 Summary of the uncertainty distributions for the decontamination factor associated with formation and equilibration of bubbles, $\mathrm{DF}(\mathrm{FE})$, during gap

release and in-vessel release through ' $T$ ' quenchers $\ldots \ldots \ldots \ldots \ldots \ldots \ldots . \ldots \ldots 9$

30 Summary of the uncertainty distributions for the decontamination factor associated with bubble rise through a suppression pool during gap release and in-vessel release through $\mathrm{a}^{\prime} \mathrm{T}$ ' quencher $\ldots \ldots \ldots \ldots \ldots \ldots \ldots \ldots \ldots \ldots \ldots \ldots \ldots$

31 Summary of the uncertainty distributions for the total decontamination factor for material released to a suppression pool during gap release and in-vessel

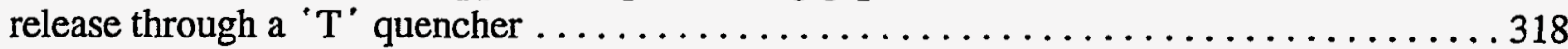




\section{List of Tables (Continued)}

Table

Page

32 Summary of the uncertainty distributions for the-mean size of aerosol particles emerging from a suppression pool during gap release' and in-vessel release through a ' $\mathrm{T}$ ' quencher

33 Summary of the uncertainty distributions for the standard deviation of the size distribution of aerosol particles emerging from a suppression pool during gap release and in-vessel release through'a ' $T$ ' quencher . . . . . . . . . . . . 323

34 Summary of uncertainty distributions for the decontamination factor associated with formation and equilibration of bubbles, DF(FE), during invessel release through an ' $\mathrm{X}$ ' quencher

35 Summary of uncertainty distributions for the decontamination factor associated with bubble rise through a suppression pool, $\mathrm{DF}$ (rise), during invessel release through an ' $X$ ' quencher . . . . . . . . . . . . . . . 330

36 Summary of the uncertainty distributions for the total decontamination factor, $\mathrm{DF}$ (total) for material released to a suppression pool during invessel release through an ' $\mathrm{X}$ ' quencher

37 Summary of uncertainty distributions for the mean size of aerosol particles emerging from a suppression pool during invessel release through an ' $\mathrm{X}$ ' quencher

38 Summary of the uncertainty distributions for the standard deviation of the size distributions of aerosol particles emerging from a suppression pool during invessel release through an ' $X$ ' quencher $\ldots \ldots \ldots \ldots \ldots$

A-1 Uncertainty distribution for decontamination during bubble formation and equilibration of gap release through a ' $T$ ' quencher $100 \mathrm{~cm}$ deep . . . . . . . . 364

A-2 Uncertainty distribution for decontamination of gap release during bubble rise from a ' $\mathrm{T}$ ' quencher $100 \mathrm{~cm}$ deep . . . . . . . . . . . . . . . 365

A-3 Uncertainty distribution for the total gap release decontamination after passing through a ' $\mathrm{T}$ ' quencher $100 \mathrm{~cm}$ deep . . . . . . . . . . . . . . 366

A-4 Uncertainty distribution for the mean particle size of gap release after passing through a ' $\mathrm{T}$ ' quencher $100 \mathrm{~cm}$ deep . . . . . . . . . . . . . . . . 367

A-5 Uncertainty distribution for the standard deviation of gap release after passing through a ' $\mathrm{T}$ ' quencher $100 \mathrm{~cm}$ deep . . . . . . . . . . . . . . . 368

A-6 Uncertainty distribution for decontamination during bubble formation and . equilibration of gap release through a ' $\mathrm{T}$ ' quencher $200 \mathrm{~cm}$ deep

A-7 Uncertainty distribution for decontamination of gap release during bubble rise from a ' $\mathrm{T}$ ' quencher $200 \mathrm{~cm}$ deep . . . . . . . . . . . . . . . . . . 370

A-8 Uncertainty distribution for the total gap release decontamination after passing through a ' $\mathrm{T}$ ' quencher $200 \mathrm{~cm}$ deep . . . . . . . . . . . . . . . 371

A-9 Uncertainty distribution for mean particle size of gap release after flow through a ' $\mathrm{T}$ ' quencher $200 \mathrm{~cm}$ deep . . . . . . . . . . . . . . . . . . . . 372

A-10 Uncertainty distribution for standard deviation of gap release after passing through a ' $T$ ' quencher $200 \mathrm{~cm}$ deep

A-11 Uncertainty distribution for the decontamination of gap release material during bubble formation and equilibration at a ' $\mathrm{T}$ ' quencher $300 \mathrm{~cm}$ deep . . . . . . 374

A-12 Uncertainty distribution for the decontamination of gap release material during bubble rise from a ' $\mathrm{T}$ ' quencher $300 \mathrm{~cm}$ deep . . . . . . . . . . . . 375 


\section{List of Tables (Continued)}

$\underline{\text { Table }}$

A-13 Uncertainty distribution for the total decontamination of gap release

material that has passed through a ' $\mathrm{T}$ ' quencher $300 \mathrm{~cm}$ deep . . . . . . . . . . . . 376

A-14 Uncertainty distribution for the mean particle size of gap release

material after passing through a ' $\mathrm{T}$ ' quencher $300 \mathrm{~cm}$ deep $\ldots \ldots \ldots \ldots \ldots \ldots$

A-15 Uncertainty distribution for the standard deviation of gap release

material after passing through a ' $T$ ' quencher $300 \mathrm{~cm}$ deep $\ldots \ldots \ldots \ldots \ldots \ldots$

A-16 Uncertainty distribution for decontamination during bubble formation

and equilibration for gap release through a ' $\mathrm{T}$ ' quencher $300 \mathrm{~cm}$ deep . . . . . . . . . . . 379

A-17 Uncertainty distribution for decontamination of gap release during

bubble rise from a ' $T$ ' quencher $500 \mathrm{~cm}$ deep . . . . . . . . . . . . . . . . . . 380

A-18 Uncertainty distribution for total gap release decontamination after

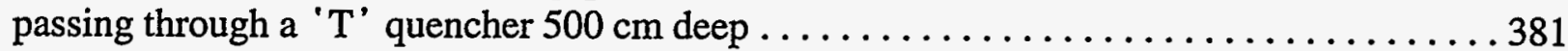

A-19 Uncertainty distribution for the mean particle size of gap release

material after passing through a ' $\mathrm{T}$ ' quencher $500 \mathrm{~cm}$ deep $\ldots \ldots \ldots \ldots \ldots . \ldots . \ldots 38$

A-20 Uncertainty distribution for the geometric standard deviation of

release material after passing through a ' $\mathrm{T}$ ' quencher $500 \mathrm{~cm}$ deep .............. 383

A-21 Uncertainty distribution for decontamination of gap release by bubble

formation and equilibration at a ' $\mathrm{T}$ ' quencher $700 \mathrm{~cm}$ deep ..................... 384

A-22 Uncertainty distribution for decontamination of gap release during

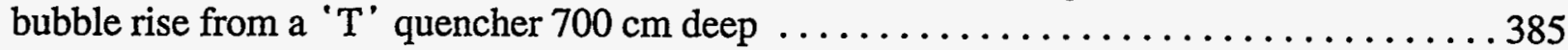

A-23 Uncertainty distribution for total decontamination of gap release

after passing through a ' $\mathrm{T}$ ' quencher $700 \mathrm{~cm}$ deep $\ldots \ldots \ldots \ldots \ldots \ldots \ldots \ldots$

A-24 Uncertainty distribution for the mean particle size of gap release

after passing through a ' $T$ ' quencher $700 \mathrm{~cm}$ deep $\ldots \ldots \ldots \ldots \ldots \ldots \ldots \ldots \ldots \ldots$

A-25 Uncertainty distribution for the standard deviation of gap release

after passing through a ' $T$ ' quencher $700 \mathrm{~cm}$ deep $\ldots \ldots \ldots \ldots \ldots \ldots \ldots . \ldots \ldots$

A-26 Uncertainty distribution for decontamination of invessel release by

bubble formation and equilibration at a ' $\mathrm{T}$ ' quencher $100 \mathrm{~cm}$ deep . . . . . . . . . . . . 389

A-27 Uncertainty distribution for decontamination of invessel release

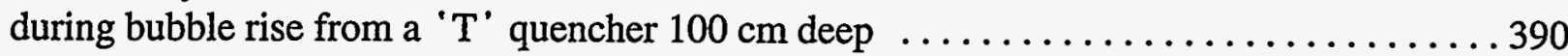

A-28 Uncertainty distribution for total decontamination of invessel

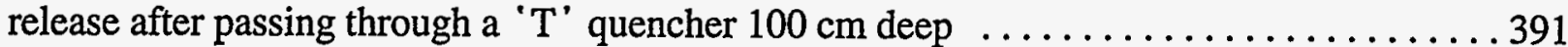

A-29 Uncertainty distribution for the mean particle size of invessel

release after passing through a ' $T$ ' quencher $100 \mathrm{~cm}$ deep $\ldots \ldots \ldots \ldots \ldots 2$

A-30 Uncertainty distribution for the geometric standard deviation of invessel release after passing through a ' $\mathrm{T}$ ' quencher $100 \mathrm{~cm}$ deep

A-31 Uncertainty distribution for decontamination during bubble formation

and equilibration for invessel release through a ' $T$ ' quencher $200 \mathrm{~cm}$ deep ......... 394

A-32 Uncertainty distribution for decontamination for invessel release

during bubble rise from a ' $\mathrm{T}$ ' quencher $200 \mathrm{~cm}$ deep . . . . . . . . . . . . . . . . 395

A-33 Uncertainty distribution for total invessel release decontamination

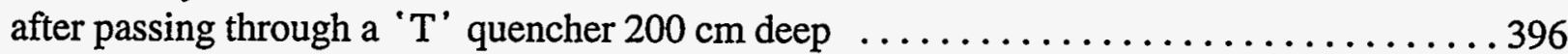

A-34 Uncertainty distribution for mean particle size of invessel release

after flow through a ' $T$ ' quencher $200 \mathrm{~cm}$ deep 


\section{List of Tables (Continued)}

$\underline{\text { Table }}$

$\underline{\text { Page }}$

A-35 Uncertainty distribution for the geometric standard deviation of

invessel release after passing through a ' $\mathrm{T}$ ' quencher $200 \mathrm{~cm}$ deep . . . . . . . . . 398

A-36 Uncertainty distribution for decontamination of invessel release material

by bubble formation and equilibration at a ' $\mathrm{T}$ ' quencher $300 \mathrm{~cm}$ deep . . . . . . . . . . . 399

A-37 Uncertainty distribution for decontamination of invessel release during bubble rise from a ' $\mathrm{T}$ ' quencher $300 \mathrm{~cm}$ deep . . . . . . . . . . . . . . . 400

A-38 Uncertainty distribution for total decontamination of invessel release material after passing through a ' $\mathrm{T}$ ' quencher $300 \mathrm{~cm}$ deep . . . . . . . . . . . 401

A-39 Uncertainty distribution for the mean particle size of invessel release material after passing through a ' $T$ ' quencher $300 \mathrm{~cm}$ deep . . . . . . . . . . . . 402

A-40 Uncertainty distribution for the geometric standard deviation of invessel release material after passing through a ' $T$ ' quencher $300 \mathrm{~cm}$ deep . . . . . . . . . 403

A-41 Uncertainty distribution for the decontamination of invessel release material ,; during formation and equilibration of bubbles at a ' $\mathrm{T}$ ' quencher $500 \mathrm{~cm}$ deep $\ldots$. . . . 404

A-42 Uncertainty distribution for the decontamination of invessel release during bubble rise from a ' $\mathrm{T}$ ' quencher $500 \mathrm{~cm}$ deep . . . . . . . . . . . . . . . 405

A-43 Uncertainty distribution for the total decontamination of invessel release material after passing through a ' $\mathrm{T}$ ' quencher $500 \mathrm{~cm}$ deep . . . . . . . . . . . . . 406

A-44 Uncertainty distribution for the mean particle size of invessel release

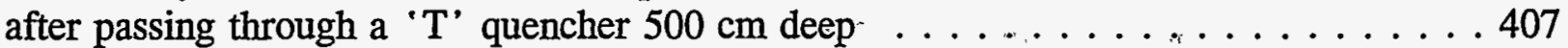

A-45 Uncertainty distribution for the geometric standard deviation of invessel release after passing through a ' $\mathrm{T}$ ' quencher $500 \mathrm{~cm}$ deep . . . . . . . . . . . . . 408

A-46 Uncertainty distribution for decontamination of invessel release during bubble rise from a ' $T$ ' quencher $700 \mathrm{~cm}$ deep . . . . . . . . . . . . . . . . . . 409

A-47 Uncertainty distribution for decontamination of invessel release by bubble formation and decontamination at a ' $\mathrm{T}$ ' quencher $700 \mathrm{~cm}$ deep $\ldots \ldots 410$

A-48 Uncertainty distribution for total decontamination of invessel release after passing through a ' $\mathrm{T}$ ' quencher $700 \mathrm{~cm}$ deep $\ldots \ldots \ldots \ldots$. . . . . . . . 411

A-49 Uncertainty distribution for the mean particle size of invesșel release after passing through a ' $T$ ' quencher $700 \mathrm{~cm}$ deep $\ldots \ldots \ldots \ldots$. . . . . . . . . . . . . . .

A-50 Uncertainty distribution for the standard deviation of invessel release after passing through a ' $T$ ' quencher $700 \mathrm{~cm}$ deep $\ldots \ldots \ldots \ldots$. . . . . . . . 413

A-51 Uncertainty distribution for decontamination of invessel release material during bubble formation and equilibration at an ' $X$ ' quencher $100 \mathrm{~cm}$ deep $\ldots . . .414$

A-52 Uncertainty distribution for decontamination of invessel release material during bubble rise from an ' $\mathrm{X}$ ' quencher $100 \mathrm{~cm}$ deep . . . . . . . . . . . 415

A-53 Uncertainty distribution for the total decontamination of invessel release material after passing through an ' $\mathrm{X}$ ' quencher 100 ' $\mathrm{cm}$ deep . . . . . . . . . 416

A-54 Uncertainty distribution for the mean particle size of invessel release material after passing through an ' $\mathrm{X}$ ' quencher $100 \mathrm{~cm}$ deep . . . . . . . . . . 417

A-55 Uncertainty distribution for the geometric standard deviation of invessel release material after passing through an ' $X$ ' quencher $100^{\circ} \mathrm{cm}$ deep . . . . . . 418

A-56 Uncertainty distribution for decontamination during bubble formation and equilibration of invessel release through an ' $\mathrm{X}$ ' quencher $200 \mathrm{~cm}$ deep . . . . . . . . 419 


\section{List of Tables (Continued)}

Table

Page

A-57 Uncertainty distribution for decontamination of invessel release during

rise from an ' $\mathrm{X}$ ' quencher $200 \mathrm{~cm}$ deep . . . . . . . . . . . . . . . . . . . . 420

A-58 Uncertainty distribution for the total invessel release decontamination after passing through an ' $\mathrm{X}$ ' quencher $200 \mathrm{~cm}$ deep ....................421

A-59 Uncertainty distribution for the mean particle size after passing through

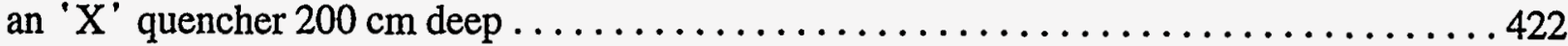

A-60 Uncertainty distribution for the geometric standard deviation of invessel release after passing through an ' $\mathrm{X}$ ' quencher $200 \mathrm{~cm}$ deep $\ldots \ldots \ldots \ldots \ldots \ldots \ldots$

A-61 Uncertainty distribution for the decontamination of invessel release by bubble formation and equilibration at an ' $\mathrm{X}$ ' quencher $300 \mathrm{~cm}$ deep . . . . . . . . . . 424

A-62 Uncertainty distribution for decontamination of invessel release material during bubble rise from an ' $\mathrm{X}$ ' quencher $300 \mathrm{~cm}$ deep $\ldots \ldots \ldots \ldots \ldots \ldots \ldots \ldots$

A-63 Uncertainty distribution for total decontamination of invessel release after

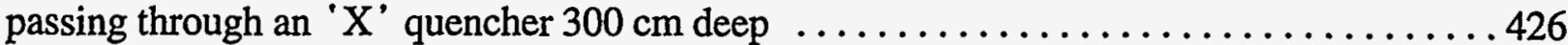

A-64 Uncertainty distribution for the mean particle size of invessel release after Passage through a ' $\mathrm{X}$ ' quencher $300 \mathrm{~cm}$ deep $\ldots \ldots \ldots \ldots \ldots \ldots \ldots \ldots \ldots \ldots \ldots$

A-65 Uncertainty distribution for the geometric standard deviation of invessel release after passing through an ' $X$ ' quencher $300 \mathrm{~cm}$ deep . . . . . . . . . . . . 428

A-66 Uncertainty distribution for decontamination of invessel release by bubble formation and equilibration at an ' $\mathrm{X}$ ' quencher $500 \mathrm{~cm}$ deep .

A-67 Uncertainty distribution for decontamination of invessel release during bubble rise from an ' $X$ ' quencher $500 \mathrm{~cm}$ deep $\ldots \ldots \ldots \ldots \ldots \ldots \ldots \ldots \ldots \ldots \ldots$

A-68 Uncertainty distribution for total decontamination of invessel release after passing through an ' $\mathrm{X}$ ' quencher $500 \mathrm{~cm}$ deep

A-69 Uncertainty distribution for the mean particle size of invessel release material after passing through an ' $\mathrm{X}$ ' quencher $500 \mathrm{~cm}$ deep $\ldots \ldots \ldots \ldots \ldots \ldots \ldots 42$

A-70 Uncertainty distribution for the geometric standard deviation of invessel release material after passing through an ' $\mathrm{X}$ ' quencher $500 \mathrm{~cm}$ deep $\ldots \ldots \ldots \ldots . \ldots 43$

A-71 Uncertainty distribution for decontamination of invessel release by bubble formation and equilibration at an ' $\mathrm{X}$ ' quencher $700 \mathrm{~cm}$ deep $\ldots \ldots \ldots \ldots \ldots \ldots 44$

A-72 Uncertainty distribution for decontamination of invessel release during bubble rise from an ' $\mathrm{X}$ ' quencher $700 \mathrm{~cm}$ deep $\ldots \ldots \ldots \ldots \ldots \ldots \ldots \ldots \ldots \ldots \ldots$

A-73 Uncertainty distribution for total decontamination of invessel release after passing through an ' $\mathrm{X}$ ' quencher $700 \mathrm{~cm}$ deep $\ldots \ldots \ldots \ldots \ldots \ldots \ldots \ldots \ldots$

A-74 Uncertainty distribution for the mean particle size of invessel release after passing through an ' $\mathrm{X}$ ' quencher $700 \mathrm{~cm}$ deep

A-75 Uncertainty distribution for the standard deviation of invessel release after passing through an ' $\mathrm{X}$ ' quencher $700 \mathrm{~cm}$ deep 



\section{Introduction}

Formulation of a simplified model of aerosol removal by boiling water reactor steam suppression pools is described in this report. Development of this simplified model is one part of a program to define the attenuation of severe accident source terms by natural processes and by engineered safety features of nuclear power plants. Previous efforts in this program have led to the development of simplified models of source term attenuation by water pools overlying core debris interacting with concrete [1], aerosol removal by containment sprays [2], and aerosol removal by natural aerosol processes [256].

The simplified models are intended for use in conjunction with the revised severe accident source term proposed by the U.S. Nuclear Regulatory Commission [3]. The simplified models are not intended to replace detailed, mechanistic analyses of specific accidents hypothesized to occur at particular plants. Such detailed accident analyses of specific plants and accidents are best done with integrated accident analysis computer codes such as CONTAIN [4] or MELCOR [5]. Rather, a simplified model is intended to provide readily accessible indications of source term attenuation that can be achieved under generic circumstances. The simplified models are constructed so that selected levels of conservatism can be imposed on the predictions of source term attenuation.

In this document, attentions are directed toward the source term attenuation that can be produced by the steam suppression pools in boiling water reactors. These steam suppression pools were incorporated into the design of boiling water reactors to mitigate containment pressurization by steam in the event of a design-basis accident such as a large break in the reactor coolant system (a large break LOCA) or an anticipated reactor transient without scram (an ATWS accident). Steam vented from either the reactor coolant system or from the reactor drywell is condensed when injected into a steam suppression pool. It has long been recognized that venting steam and noncondensible gases through the suppression pools would also remove radioactive aerosols from the gases even during severe accidents that progressed beyond the design-basis conditions. Removal of radioactive aerosols by the steam suppression pools can significantly reduce risks posed by accidents at boiling water reactors.

Overall, the steam suppression pools in the three major types of boiling water reactor containments have qualitative similarities (see Figure 1). Pressure-relief lines from the reactor coolant system discharge gases and vapors into the suppression pools through quenchers. The drywell atmospheres of the containments vent to the suppression pools through large diameter downcomers or horizontal vents. Details of these venting arrangements are, however, quite different among the major types of boiling water reactor containments. These construction details can affect the efficiency of aerosol removal from gases discharged to the suppression pools and are discussed further in Chapter II of this report.

Flows to the suppression pools during design-basis accidents or during the deliberate depressurization of reactor coolant systems are intense, but of short duration. The flows to the suppression pools during events anticipated in the designs of boiling water reactors consist primarily of steam. Relative to the situation in severe reactor accidents, gases discharged to the suppression pools during design-basis events contain little radioactive material. Suppression pools are designed so that the pool temperature remains below saturation during design-basis events.

On the other hand, during severe reactor accidents when damage to the reactor fuel is taking place and radioactive materials are being released from the fuel, flows to the suppression pool are not especially vigorous. The gas discharged to the suppression pool can contain substantial amounts of noncondensible gas such as hydrogen or other gases produced in the reactor drywell. Substantial quantities of aerosol material; some of which is radioactive, will be present in gases discharged to the suppression pools. 


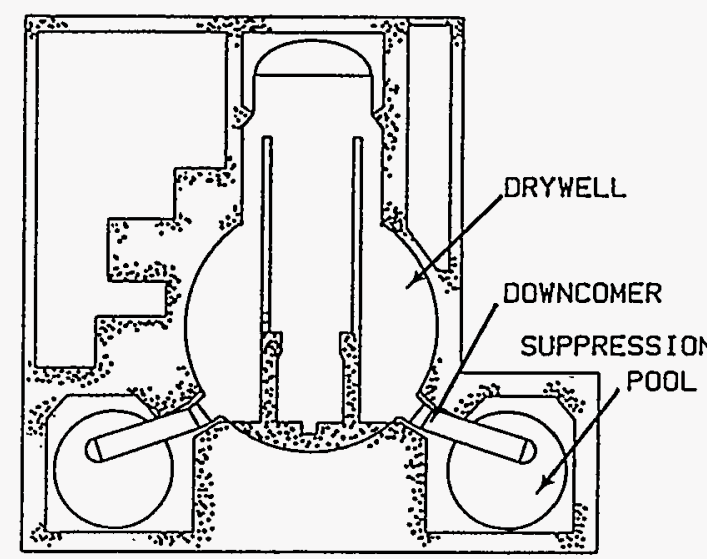

MARK I

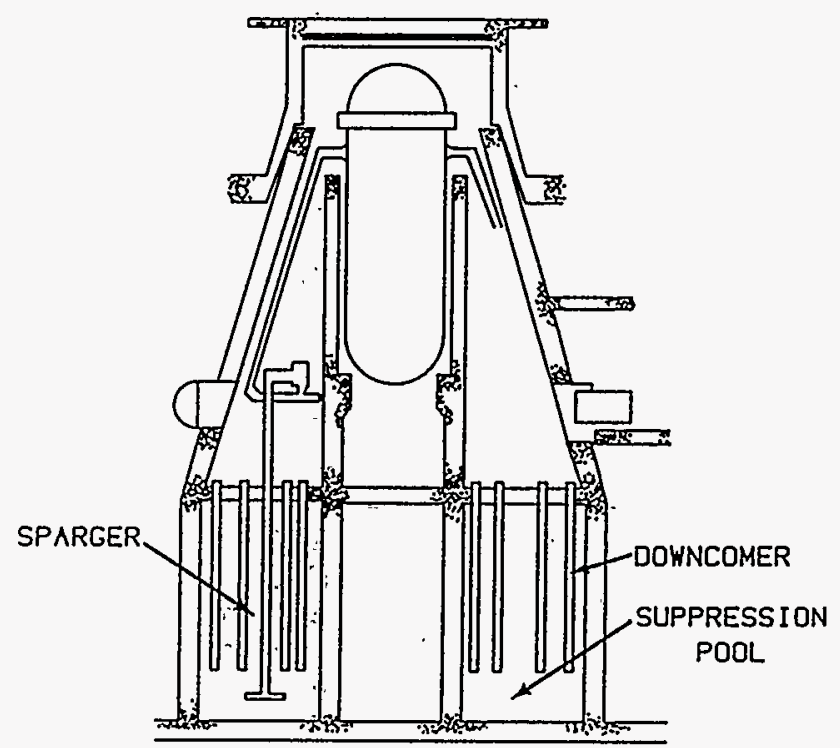

MARK II

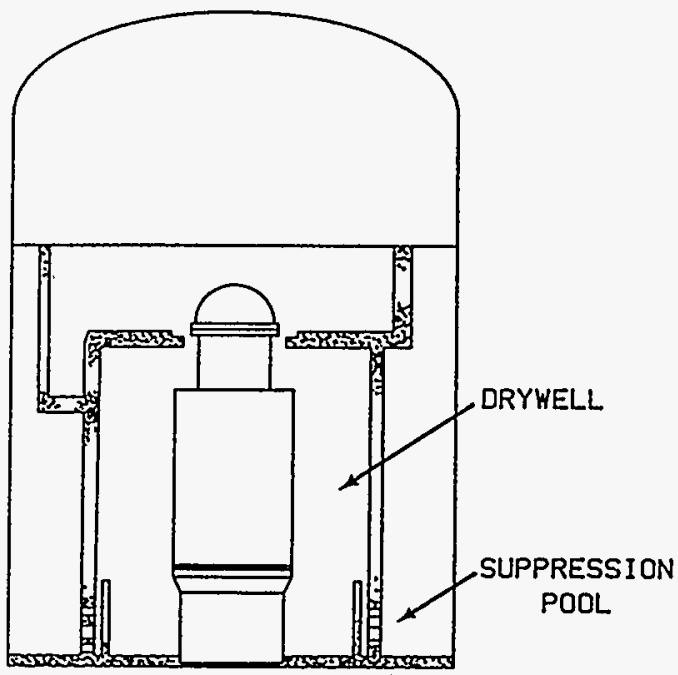

MARK I I I

Figure 1. Overall configurations of steam suppression pools in Mark I, Mark II, and Mark III boiling water reactors 
Sufficient energy can be imparted to the suppression pools that temperatures rise to near the boiling point. The gas discharge rate, gas composition, and the suppression pool temperature all affect the attenuation of the source term that can be produced by the pool. Further descriptions of the features of severe accidents that can affect the ability of suppression pools to remove radioactive aerosols from gas streams are provided in Chapter III of this report.

Steam suppression pools function by dispersing gases as relatively small bubbles into a water pool. Rapid heat and mass transfer from the bubbles to the liquid prevents overpressurization during accidents. Aerosols within the bubbles are captured in the water pool by a variety of mechanisms including inertial impaction, diffusion, gravitational settling, diffusiophoresis and thermophoresis. Detailed descriptions of the behavior of bubbles and the trapping of aerosols are provided in Chapter IV of this report.

The discussions of severe accident conditions in Chapter III and the physical phenomena affecting aerosol removal by suppression pools in Chapter IV identify a number of uncertainties that affect predictions of source term attenuation by suppression pools. These uncertainties include uncertainties in the boundary and initial conditions for suppression pool performance arising from the range of severe accidents thought possible in boiling water reactors as well as uncertainties in the predictions of accident progression. There are also uncertainties in bubble behavior and in the behavior of aerosols. A mechanistic model of aerosol removal by suppression pools is formulated in Chapter V of this report. The model is used to quantitatively characterize the magnitude of uncertainties in predictions of aerosol removal by suppression pools. This mechanistic model builds upon descriptions of aerosol removal by suppression pools found in some available computer codes such as SPARC [6], SUPRA [7,8], and BUSCA [9].

The analyses of uncertainties is done here in a manner similar to that employed in previous uncertainty analyses associated with the development of other simplified models $[1,2]$. Each of the important uncertainties identified in Chapters III and IV is characterized by a parameter that arises in the model used to predict source term attenuation. A plausible range of values for each of the parameters is found by examination of published analyses and experiments, bounding analyses based on physical limitations, or, when no other basis is available, engineering judgement. Parameters that describe the various uncertain aspects of the prediction of source term attenuation are selected so that the parameters are usually mutually independent. When independence of the parameters is thought not to be plausible, additional parameters are defined to describe the correlation among the parameters.

A subjective probability distribution is defined for values of each parameter within its plausible range. The subjective probability distribution is defined according to a set of rules described in Chapter V. The subjective probability distributions are used in a Monte Carlo uncertainty analysis of aerosol removal predicted by a mechanistic model. Parametric values are randomly selected according to the respective probability distribution of each parameter. A set of these parameter values is used to calculate aerosol removal by a suppression pool. The process is repeated until there is a 99 percent confidence that 95 percent of the range of values has been sampled. The accumulated predictions of aerosol removal are then used to construct uncertainty distributions at prescribed levels of confidence using nonparametric, order statistics (see Appendix A of Reference 1). Results of these uncertainty analyses are described in Chapter VI. 
As mentioned above, aerosol-laden gases may be injected into steam suppression pools by way of quenchers or large diameter downcomers or horizontal vents. The method of gas injeetion does affect aerosol removal from the gas. Uncertainty analyses are reported here only for decontamination of gases injected through quenchers.

Results of the uncertainty analyses are used to formulate simplified expressions for aerosol removal by suppression pools. These simplified models are formulated by regression of results of the uncertainty analyses against suppression pool depth as described in Chapter VII. Application of the simplified models produced by this regression requires only minimal input. The user is required only to specify pool depth. Such models requiring minimal input are sought to render them readily useable: The simplified models are, of course, not replacements for mechanistic models or computer codes $[6,7,8,9]$.

Regression analyses are done for the median, 90 percentile and 10 percentile values within the uncertainty distributions found for aerosol removal by suppression pools. For the purposes of this work, median values of the uncertainty distributions are considered "best estimates" of aerosol removal by suppression pools. The 90 percentile and the 10 percentile values are considered "reasonable upper and lower bounds, respectively. From another point of view, the 90 percentile values may be used as conservative estimates of the radioactive material accumulated in a suppression pool. On the other hand, the 10 percentile values may be used as conservative estimates of the amount of radioactive material that escapes a suppression pool. The availability of simplified models for these various quantiles of the uncertainty distributions makes it convenient to estimate the uncertainty in predictions of aerosol removal by steam suppression pools. 


\section{Steam Suppression Pools}

An overview of steam suppression pools in Mark I, Mark II and Mark III boiling water reactor containments is shown in Figure 1. Additional information on boiling water reactors is shown in Table 1. The qualitative similarity of the pools in these three designs lies in the modes of injection of aerosol-laden gases. Gases from an intact reactor coolant system are injected through the quenchers. These quenchers consist of large diameter pipes with many small holes in them. On the other hand, gases from the drywell are injected into the suppression pool through very large diameter vents. In the cases of Mark I and Mark II containments, these vents are downcomers. In the case of Mark III containments, there are horizontal vents from the drywell to the suppression pool.

The authors have not attempted a comprehensive survey of the design features of suppression pools in existing boiling water reactors. In fact, detailed information on these designs proves difficult to acquire from the open literature. It does appear that there can be important differences in the suppression pool designs even within a particular class of boiling water reactor containment types. Descriptions of the suppression pools presented below should, then, be taken as representative and not necessarily definitive for the containment types or even for particular reactors within a class of containments.

\section{A. Mark I Suppression Pools}

The suppression pool in a Mark I containment is a torus surrounding the distinctive "inverted light bulb" drywell as shown in Figure 2. The water volume in the torus is about $2.4 \times 10^{9} \mathrm{~cm}^{3}$. The radius of the torus is about $1699 \mathrm{~cm}$. The internal diameter of the torus is about $472 \mathrm{~cm}$.

There are 12 discharge lines from safety relief valves on the reactor coolant system that go to ' $T$ ' quenchers in the suppression pool. A diagram of a ' $\mathrm{T}$ ' quencher is shown in Figure 3. The ' $\mathrm{T}$ ' quencher has two arms constructed from 30-cm-diameter schedule 80 piping. The inside diameter of such piping is $28.890 \mathrm{~cm}$. The wall thickness is $1.748 \mathrm{~cm}$. The flow area is $655.52 \mathrm{~cm}^{2}$. At the end of each arm of the ' $\mathrm{T}$ ' quenchers are 794 holes. The holes are typically 0.933 to $1.27 \mathrm{~cm}$ in diameter. Arms of the ' $T$ ' quenchers are typically submerged to a depth of $198 \mathrm{~cm}$.

The venting arrangement from the Mark I drywell to the suppression pool is complicated and not well described in the readily accessible literature. There are eight vents symmetrically arrayed around the drywell. Some indication of the design variability of suppression pools in Mark I reactor containments is provided by the diagrams in Figure 4 of three classes of vents into the suppression pools. Typically, these vents are $206 \mathrm{~cm}$ in diameter.

Each vent from the drywell is supported in the suppression pool by two girders. The vents connect to a header about $145 \mathrm{~cm}$ in diameter within the pool. There are 96 downcomers from this header. Typically, the downcomers are 59.7 to $61 \mathrm{~cm}$ in diameter and are submerged to a depth of about $122 \mathrm{~cm}$.

\section{B. Mark II Suppression Pools}

The suppression pool in a Mark II containment is a large body of water $\left(2.3\right.$ to $\left.4.4 \times 10^{9} \mathrm{~cm}^{3}\right)$ below the reactor vessel (see Figure 1). Vent lines from the reactor coolant system discharge to ' $T$ ' quenchers in this pool. The ' $\mathrm{T}$ ' quenchers are rather similar to those used in Mark I suppression pools. They are, however, typically submerged to a depth of about $540 \mathrm{~cm}$ [11]. Each arm has only about 748 holes. 
Table 1. Containment types of existing boiling water reactors

\begin{tabular}{|c|c|c|c|c|c|c|c|}
\hline \multirow[b]{2}{*}{ Reactor } & \multirow[b]{2}{*}{$\begin{array}{c}\text { Power } \\
\left(\mathbf{M W}_{\text {th }}\right)\end{array}$} & \multirow[b]{2}{*}{$\begin{array}{l}\text { BWR } \\
\text { Type }\end{array}$} & \multicolumn{2}{|c|}{ Safety/relief valves } & \multirow{2}{*}{$\begin{array}{c}\text { Water } \\
\text { volume } \\
10^{9} \mathrm{~cm}^{3} \\
\end{array}$} & \multirow{2}{*}{$\begin{array}{c}\text { Wetwell } \\
\text { design } \\
\text { temp. } \\
\text { (K) }\end{array}$} & \multirow{2}{*}{$\begin{array}{c}\text { Design } \\
\text { pressure } \\
\text { (atms) }\end{array}$} \\
\hline & & & Number & Capacity (kg/s) & & & \\
\hline \multicolumn{8}{|c|}{ Mark I Containment Reactors } \\
\hline $\begin{array}{l}\text { Brown's Ferry } 1 \\
\text { Brown's Ferry } 2 \\
\text { Brown's Ferry } 3 \\
\text { Brunswick } 1 \\
\text { Brunswick } 2\end{array}$ & $\begin{array}{l}3293 \\
3293 \\
3293 \\
2436 \\
2436\end{array}$ & $\begin{array}{l}4 \\
4 \\
4 \\
4 \\
4\end{array}$ & $\begin{array}{l}13 \\
13 \\
13 \\
11 \\
11\end{array}$ & $\begin{array}{l}108-109 \\
108-109 \\
108-109 \\
105-114 \\
105-114\end{array}$ & $\begin{array}{l}2.407 \\
2.407 \\
2.407 \\
2.481 \\
2.481\end{array}$ & $\begin{array}{l}411 \\
411 \\
411 \\
377 \\
377\end{array}$ & $\begin{array}{l}3.8 \\
3.8 \\
3.8 \\
4.2 \\
4.2\end{array}$ \\
\hline $\begin{array}{l}\text { Cooper } \\
\text { Dresden } 1 \\
\text { Dresden } 2 \\
\text { Duane Arnold } \\
\text { Fermi 2 }\end{array}$ & $\begin{array}{l}2381 \\
2527 \\
2527 \\
1658 \\
3293\end{array}$ & $\begin{array}{l}4 \\
3 \\
3 \\
4 \\
4\end{array}$ & $\begin{array}{r}11 \\
9 \\
9 \\
8 \\
15\end{array}$ & $\begin{array}{rr}81-110 \\
68-78 \\
68-78 \\
81-105 \\
111-114\end{array}$ & $\begin{array}{l}2.482 \\
3.177 \\
3.177 \\
1.742 \\
3.429\end{array}$ & $\begin{array}{l}411 \\
411 \\
411 \\
411 \\
411\end{array}$ & $\begin{array}{l}3.8 \\
4.2 \\
4.2 \\
3.8 \\
3.8\end{array}$ \\
\hline $\begin{array}{l}\text { Fitzpatrick } \\
\text { Hatch 1 } \\
\text { Hatch 2. } \\
\text { Hope Creek } 1 \\
\text { Hope Creek } 2\end{array}$ & $\begin{array}{l}2436 \\
2436 \\
2436 \\
3293 \\
3293\end{array}$ & $\begin{array}{l}4 \\
4 \\
4 \\
4 \\
4\end{array}$ & $\begin{array}{l}11 \\
11 \\
11 \\
14 \\
14\end{array}$ & $\begin{array}{c}101-108 \\
110 \\
110 \\
111-114 \\
111-114\end{array}$ & $\begin{array}{l}2.973 \\
2.482 \\
2.482 \\
3.429 \\
3.429\end{array}$ & $\begin{array}{l}377 \\
411 \\
411 \\
427 \\
427\end{array}$ & $\begin{array}{l}4.2 \\
3.8 \\
3.8 \\
4.2 \\
4.2\end{array}$ \\
\hline $\begin{array}{l}\text { Millstone } 1 \\
\text { Monticello } \\
\text { Nine Mile Point } 1 \\
\text { Oyster Creek } \\
\text { Peach Bottom } 1 \\
\text { Peach Bottom } 2\end{array}$ & $\begin{array}{l}2011 \\
1670 \\
1850 \\
1930 \\
3293 \\
3293\end{array}$ & $\begin{array}{l}3 \\
3 \\
2 \\
2 \\
4 \\
4\end{array}$ & $\begin{array}{r}6 \\
6 \\
16 \\
16 \\
13 \\
13\end{array}$ & $\begin{array}{c}101 \\
106 \\
80 \\
80 \\
103-117 \\
103-117\end{array}$ & $\begin{array}{l}2.365 \\
2.208 \\
2.520 \\
2.208 \\
3.483 \\
.3 .483\end{array}$ & $\begin{array}{l}411 \\
411 \\
369 \\
369 \\
411 \\
411\end{array}$ & $\begin{array}{l}4.2 \\
3.8 \\
2.4 \\
2.4 \\
3.8 \\
3.8\end{array}$ \\
\hline $\begin{array}{l}\text { Pilgrị } 1 \\
\text { Quad Cit̂ies } 1 \\
\text { Quad-Cities } 2 \\
\text { Vermont Yankee }\end{array}$ & $\begin{array}{l}1998 \\
2511 \\
2511 \\
1593\end{array}$ & $\begin{array}{l}3 \\
3 \\
3 \\
4\end{array}$ & $\begin{array}{l}5 \\
9 \\
9 \\
6\end{array}$ & $\begin{array}{rr}81-101 \\
75- & 81 \\
75- & 81 \\
101- & 117\end{array}$ & $\begin{array}{l}2.379 \\
3.273 \\
3.273 \\
2.208\end{array}$ & $\begin{array}{l}411 \\
411 \\
411 \\
411\end{array}$ & $\begin{array}{l}3.8 \\
3.8 \\
3.8 \\
3.8\end{array}$ \\
\hline
\end{tabular}


Table 1. Containment types of existing boiling water reactors (concluded)

\begin{tabular}{|c|c|c|c|c|c|c|c|}
\hline \multirow[b]{2}{*}{ Reactor } & \multirow[b]{2}{*}{$\begin{array}{c}\text { Power } \\
\left(\text { MW }_{\text {th }}\right)\end{array}$} & \multirow[b]{2}{*}{$\begin{array}{l}\text { BWR } \\
\text { Type } \\
\end{array}$} & \multicolumn{2}{|c|}{ Safety/relief valves } & \multirow{2}{*}{$\begin{array}{c}\text { Water } \\
\text { volume } \\
10^{9} \mathrm{~cm}^{3}\end{array}$} & \multirow{2}{*}{$\begin{array}{l}\text { Wetwell } \\
\text { design } \\
\text { temp. } \\
\text { (K) }\end{array}$} & \multirow{2}{*}{$\begin{array}{c}\text { Design } \\
\text { pressure } \\
\text { (atms) }\end{array}$} \\
\hline & & & Number & $\begin{array}{c}\text { Capacity } \\
(\mathrm{kg} / \mathrm{s})\end{array}$ & & & \\
\hline \multicolumn{8}{|c|}{ Mark II Containment Reactors } \\
\hline La Salle 1 & 3293 & 5 & 17 & 108 & 3.511 & 408 & 3.1 \\
\hline La Salle 2 & 3293 & 5 & 17 & 108 & 3.511 & 408 & 3.1 \\
\hline Limerick 1 & 3293 & 4 & 14 & $114-116$ & 3.811 & 411 & 3.8 \\
\hline Limerick 2 & 3293 & 4 & 14 & $114-116$ & 3.811 & 411 & 3.8 \\
\hline Nine Mile Point 2 & 3323 & 5 & 18 & $114-117$ & 4.383 & 373 & 3.6 \\
\hline Shoreham & 2436 & 4 & 11 & 112 & 2.304 & 380 & 3.3 \\
\hline Susquehanna 1 & 3292 & 4 & 16 & 107 & 3.725 & 377 & 3.6 \\
\hline Susquehanna 2 & 3292 & 4 & 16 & 107 & 3.725 & 377 & 3.6 \\
\hline WNP2 & 3292 & 5 & 18 & $109-114$ & 3.177 & 405 & 3.1 \\
\hline \multicolumn{8}{|c|}{ Mark III Containment Reactors } \\
\hline Clinton 1 & 2894 & 6 & 16 & $107-115$ & 3.843 & 358 & 1.0 \\
\hline Grand Gulf 1 & 3833 & 6 & 20 & $107-115$ & 3.851 & 358 & 1.0 \\
\hline Grand Gulf 2 & 3833 & 6 & 20 & $107-115$ & 3.851 & 358 & 1.0 \\
\hline Perry 1 & 3579 & 6 & 19 & $107-115$ & 3.398 & 358 & 1.0 \\
\hline Perry 2 & 3579 & 6 & 19 & $107-115$ & 3.398 & 358 & 1.0 \\
\hline River Bend 1 & 2894 & 6 & 16 & 115 & 3.623 & 358 & 1.0 \\
\hline
\end{tabular}

Source: P. Lobner, C. Donahoe, and C. Cavallin, Overview and Comparison of U.S. Commercial Nuclear Power Plants, NUREG/CR-5640, SAIC-89/1541, Science Applications International Corp., San Diego, CA, September 1990. 


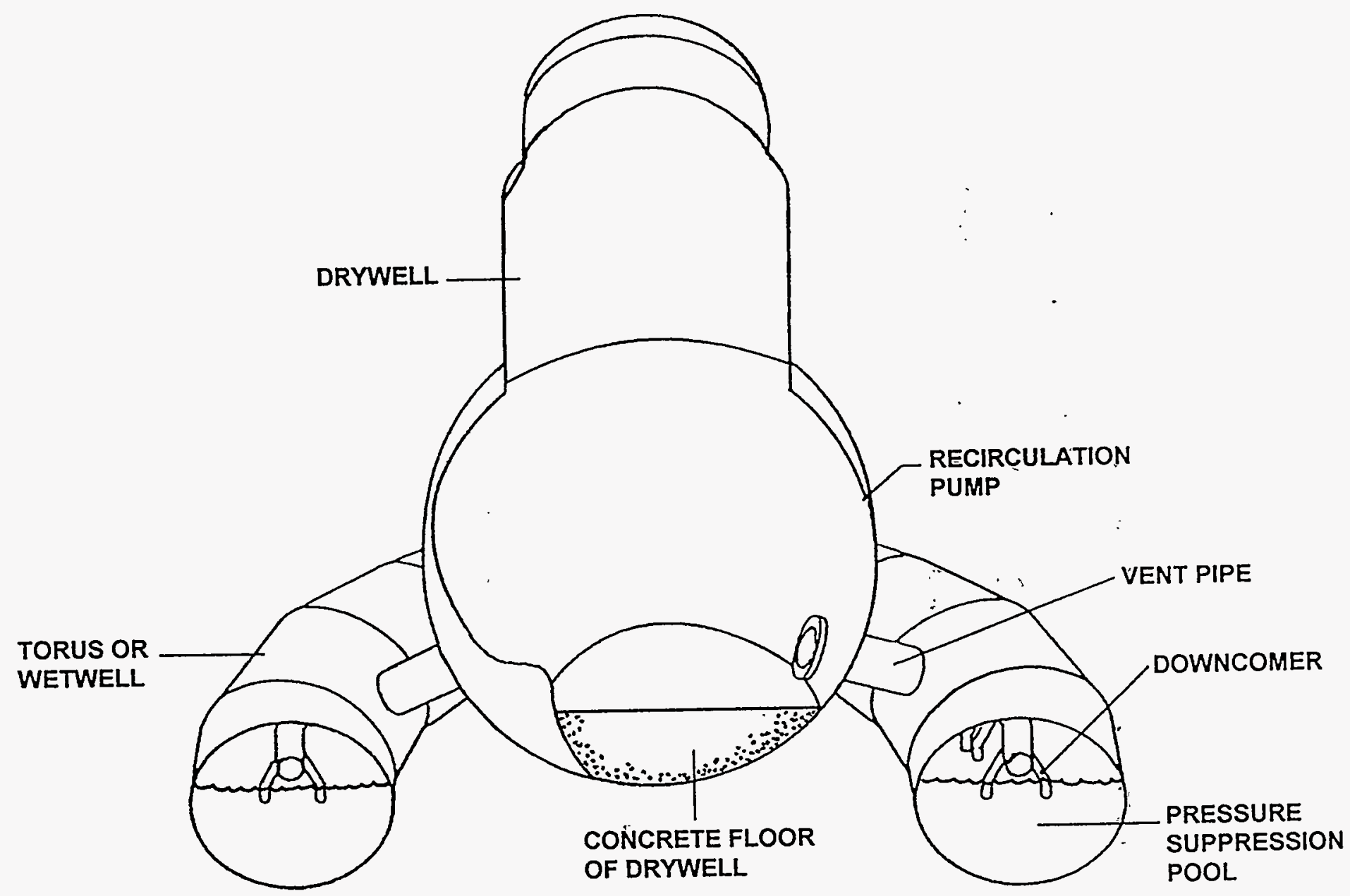

Figure 2. Torus suppression pool of a Mark I containment 


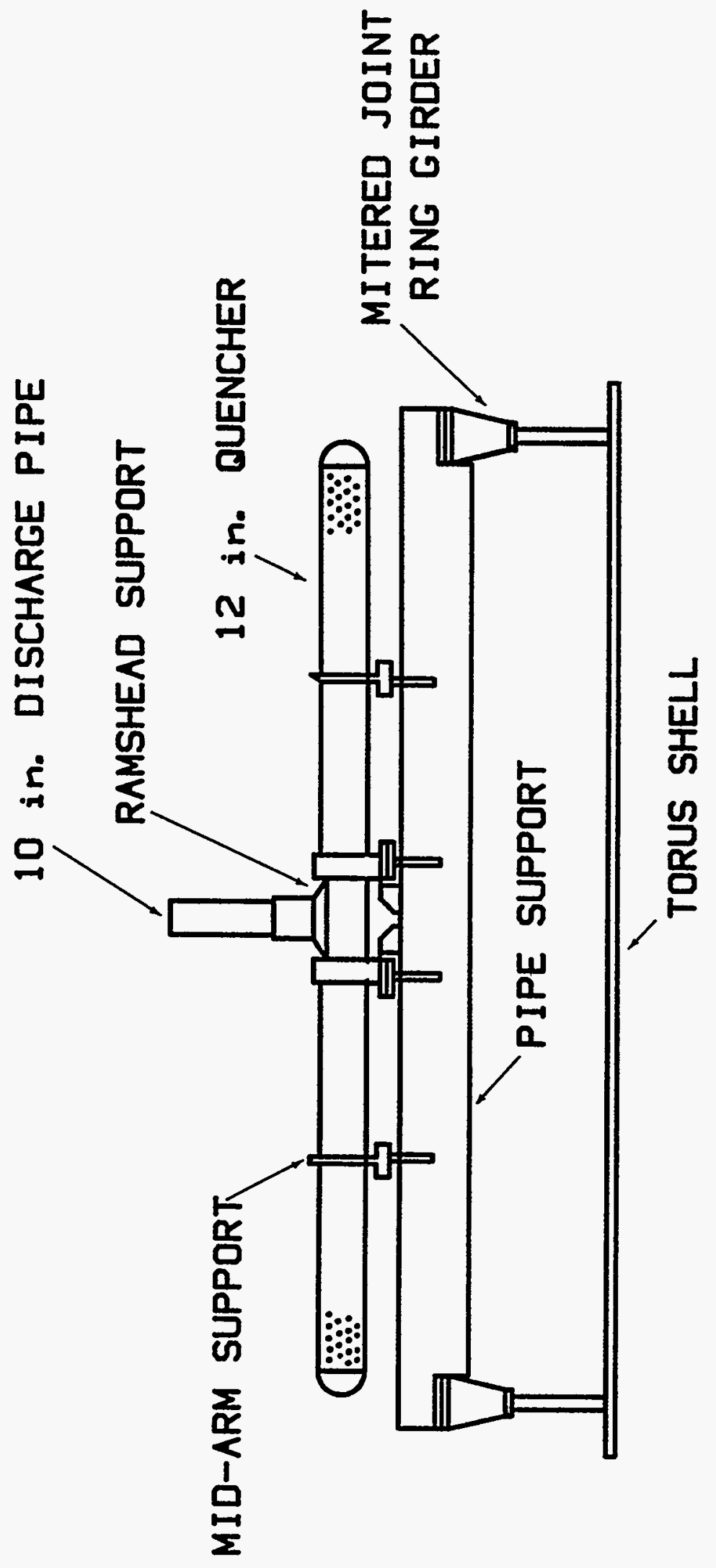

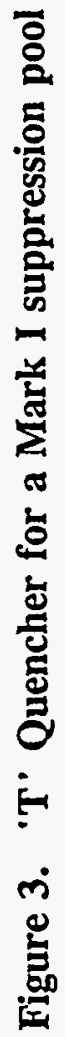


TYPE I

TYPE· II

TYPE III

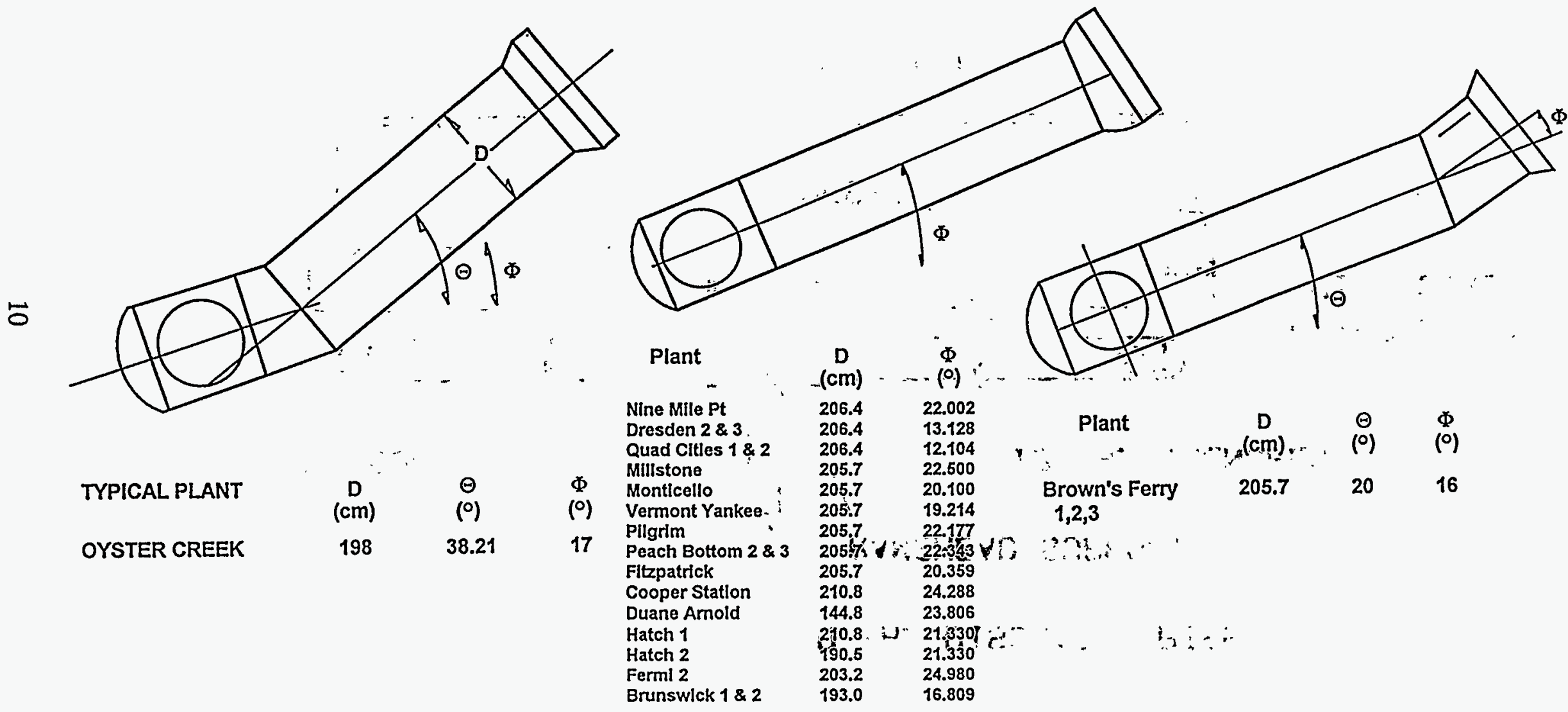

Figure 4. Various types of vents from the drywells to the suppression pools in Mark I containments 
Vertical downcomer pipes connect the Mark II drywell to the suppression pool. There are variations in the designs of these pipes. Some characteristics of the pipes are listed in Table 2. Kuhlman et al. [11] indicate that there may be as many as 136 of these downcomers. The variability in the details of the design can also be seen in the diagrams of the diaphragm floors of various Mark II containments shown in Figure 5.

\section{Mark III Suppression Pools}

The Mark III suppression pool is an annulus surrounding the base of the drywell (see Figure 1). There are eight quenchers fed by lines from 20 relief valves on the reactor coolant system as shown in Figure 6 [12]. The design outlet temperature and pressure for the relief valves are $533 \mathrm{~K}$ and 42.5 atmospheres.

The quenchers used in the Mark III suppression pools are called X-quenchers and are shown in Figure 7. Each arm of the X-quencher is 30 -cm-diameter schedule 80 piping $148.6 \mathrm{~cm}$ long. Each arm has 374 holes $0.993 \mathrm{~cm}$ in diameter. The X-quenchers are submerged to depths of 427 to $579 \mathrm{~cm}$.

The most unusual feature of the Mark III suppression pool is the venting from the drywell to the wetwell. There are 102 to 135 horizontal vents about $72 \mathrm{~cm}$ in diameter [13]. A diagram of the horizontal vents is shown in Figure 8. Vent submergence varies. The centerline of the uppermost vent is $213 \mathrm{~cm}$ below the low water level marked in Figure 8. The next layer of vents have centerlines $340 \mathrm{~cm}$ below the low water level. The bottom layer of vents have center lines at a depth of $465 \mathrm{~cm}$.

A typical Mark III suppression pool volume is about $3.6 \times 10^{9} \mathrm{~cm}^{3}$.

Table 2. Characteristics of downcomers in some Mark $I$ containments [11]

\begin{tabular}{lccc}
\hline & \multicolumn{2}{c}{ Downcomers } & \\
\cline { 2 - 3 } \multicolumn{1}{c}{ Plant } & Ex-pedestal & In-pedestal & $\begin{array}{c}\text { Diameter } \\
\text { (cm) }\end{array}$ \\
\hline Limerick & 87 & 0 & 61.0 \\
LaSalle & 98 & 0 & 59.7 \\
Susquehanna & 82 & 0 & 61.0 \\
WNP-2 & 84 & 18 & $61^{*}$ \\
Nine Mile & 115 & 8 & 59.0 \\
Point Unit 2 & & & 59.0 \\
Shoreham & 78 & 4 & \\
\hline *In-pedestal downcomers are $46 \mathrm{~cm}$ in diameter. & & \\
\hline
\end{tabular}




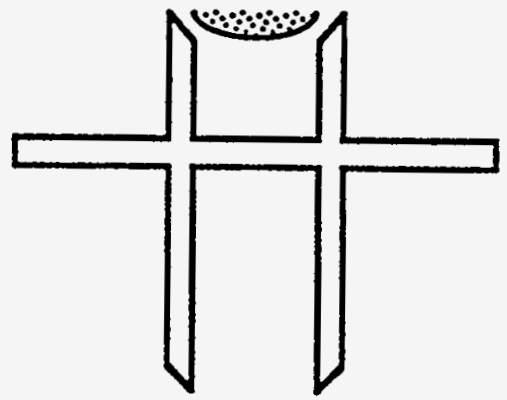

Limerick 1 \& 2

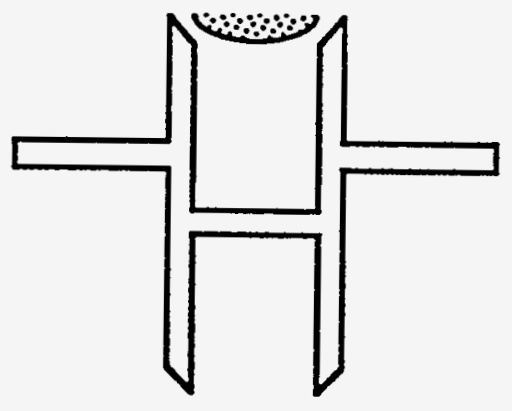

La Salle $1 \& 2$

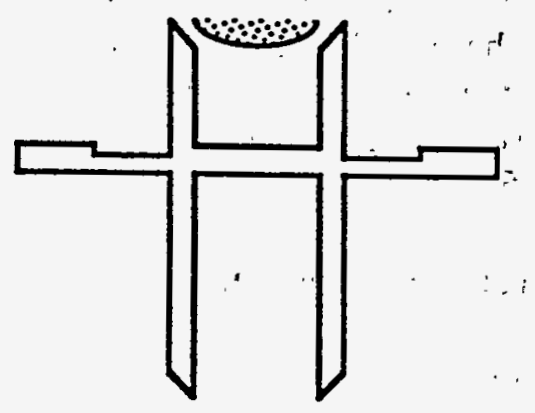

Susquehanna $1 \& 2$

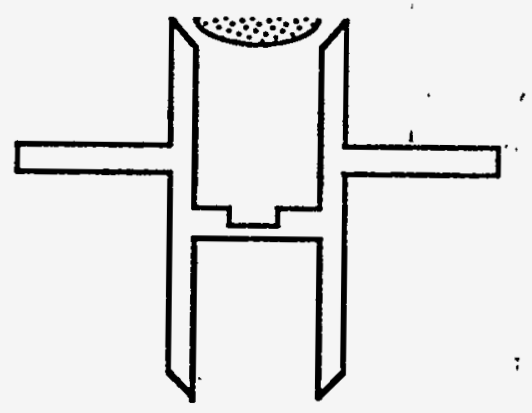

WNP-2

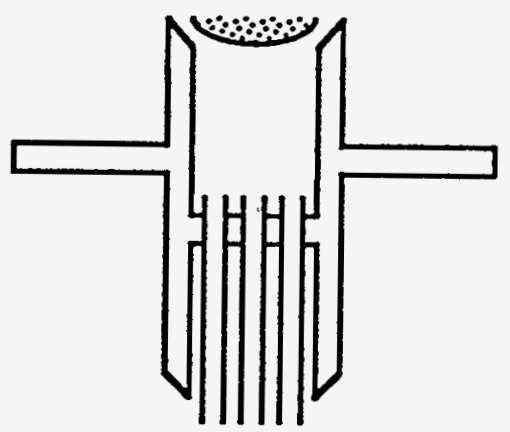

Nine Mile Point.

Figure 5. Diagrams of the diaphragm floors of various Mark II containments [12] 


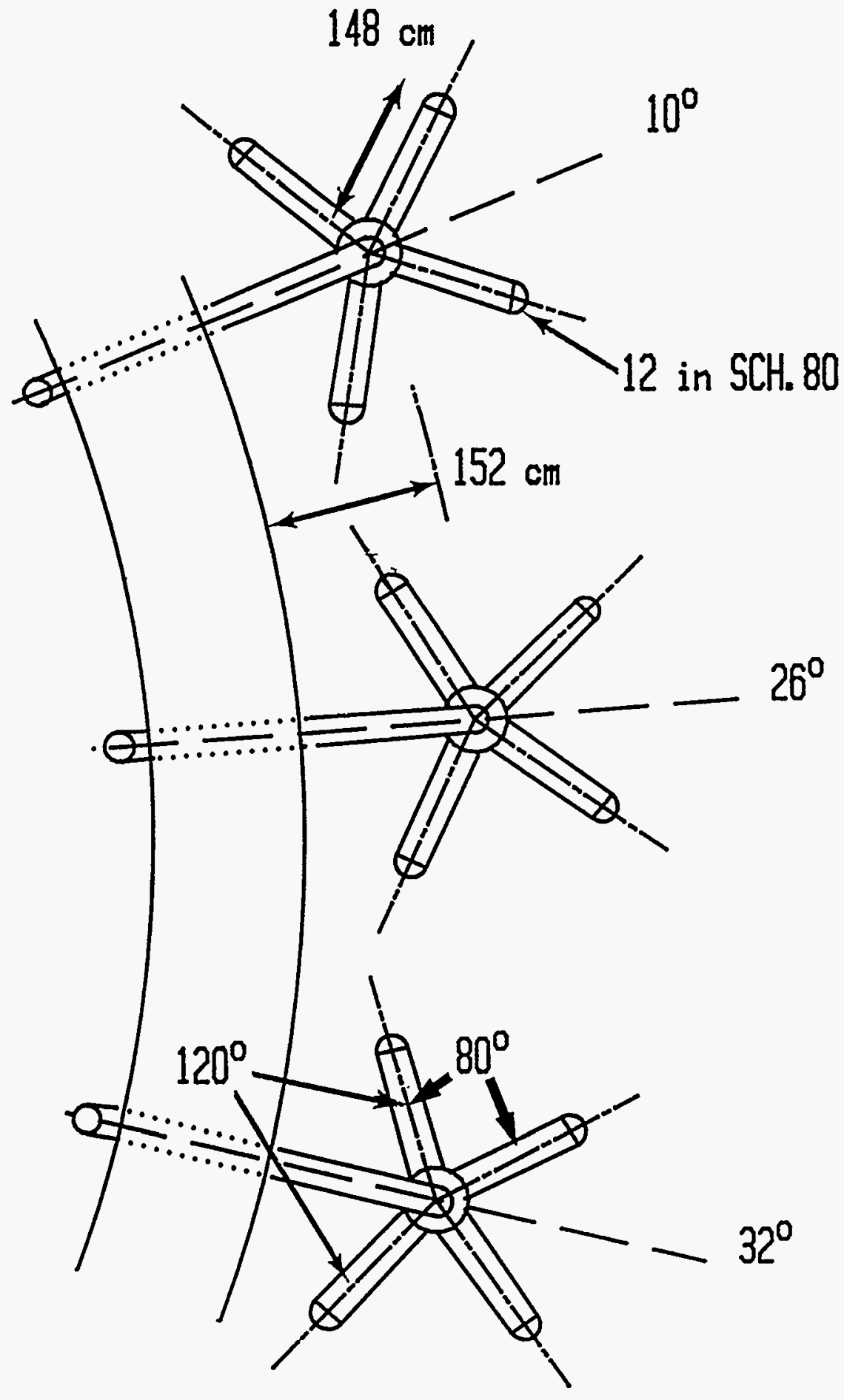

Figure 6. Positioning of quenchers in the Mark III suppression pool [13] 


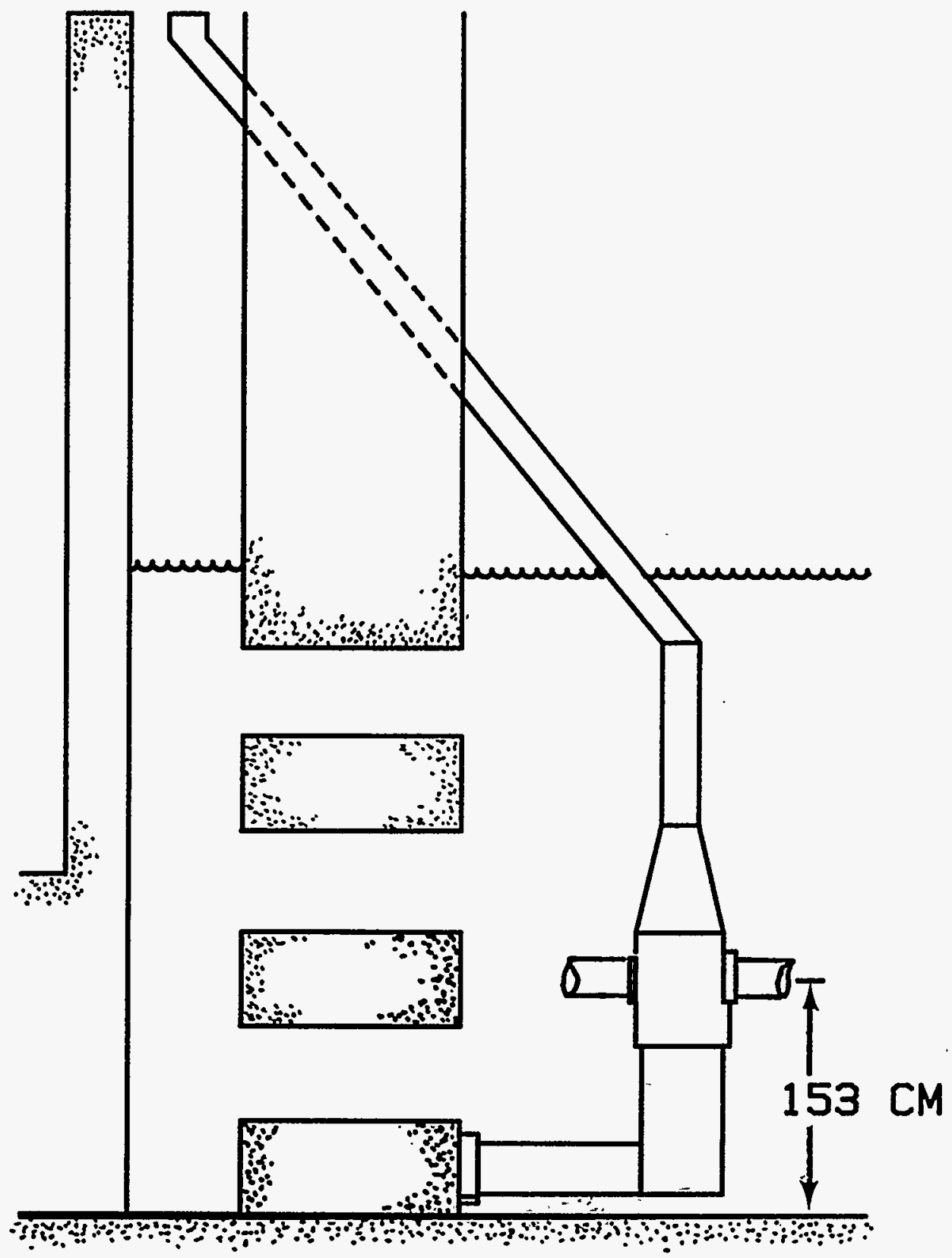

Figure 7. Diagrams of X-quenchers in Mark III suppression pools , 


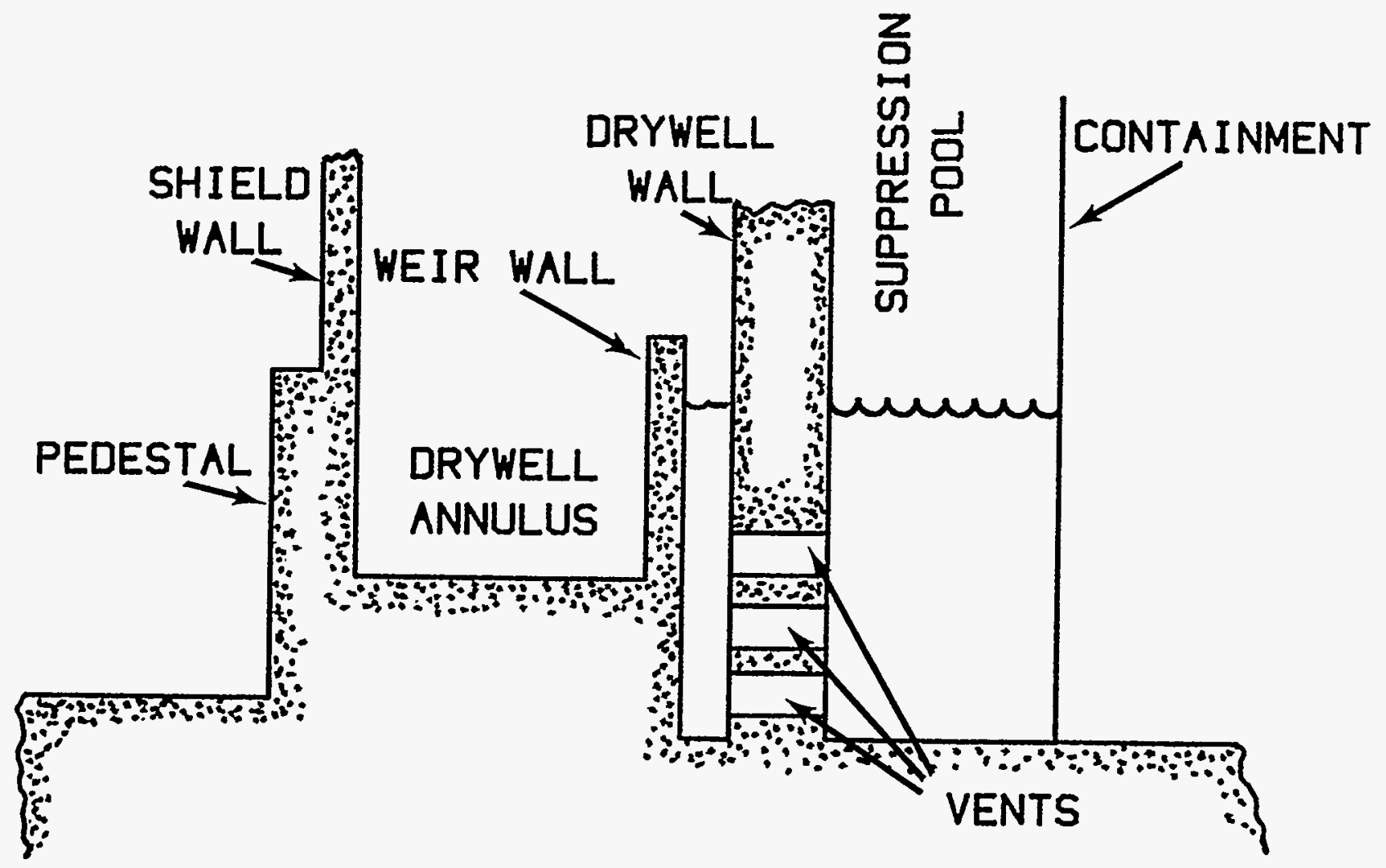

Figure 8. Horizontal vents in the Mark III suppression pool [13] 
Steam

\section{Conclusions}

The details of suppression pool construction vary among classes of plants and even within each particular class of plant. But, similarities in the pool designs are noteworthy in connection with prediction of source term attenuation by steam suppression pools. Injection of aerosol-laden gases by way of quenchers are similar for all three major boiling water reactor containment types. That is, the injection is through small diameter holes clustered at the ends of quencher arms. Similarly, injection from the drywell is by large diameter vents. In the case of the Mark I and Mark II designs, the vents are downcomers. In the case of the Mark III containment, the vents are horizontal.

It appears that a single, simplified model of aerosol removal by steam suppression pools can be defined for gas injection through all types of quenchers. Only the depth of submergence is a significant difference among the various containment types.

A separate, simplified model has to be constructed to predict aerosol removal from gases injected into the suppression pool through large diameter vents. Injection through vents in Mark I and Mark II containment types can be treated with the same model. A different model may be needed for treating aerosol removal from gases injected through horizontal vents in the Mark III contáinment design. A difficulty in modeling the Mark III vent design will be prediction of the number of active vents and the initial sizes of bubbles emerging from these vents. 


\section{Accident Analyses}

\section{A. Overview}

Steam suppression pools were designed to mitigate overpressurization threats posed to the integrity of boiling water reactor containments by design-basis accidents. The models discussed in this document are intended to predict the source term mitigation that suppression pools can achieve during severe reactor accidents that involve core degradation and fission product release well beyond what would be expected in design-basis accidents. The initial conditions and boundary conditions for suppression pool performance during severe reactor accidents are rather different than conditions considered in predicting suppression pool performance during design-basis accidents. The most intense challenges to suppression pools during design-basis accidents occur shortly after initiation of the accident and cease once other engineered safety systems return the nuclear plant to a safe condition. Severe accidents, on the other hand, can last for tens of hours if there is no intervention from outside the plant. During this protracted accident period, the boundary conditions on the suppression pool can change substantially. Prediction of the boundary conditions dictated by the accident progression is still far from an exact science. Uncertainties in the boundary conditions must create uncertainties in the predictions of suppression pool performance. It is necessary, then, to develop some sense of the range of initial and boundary conditions for suppression pool performance during severe accidents.

Among the varying factors affecting suppression pool performance during severe accidents is the nature of aerosols that must be scrubbed from gases sparging through the suppression pool. The severe accident source term for boiling water reactors proposed by the U.S. Nuclear Regulatory Commission [3] is shown in Table 3. The releases are listed in this table as fractions of the core inventory. Inventories for a particular plant are listed in Table 4. Note that the proposed releases include large amounts of nonradioactive materials. With the exception of the noble gases and a small fraction of the iodine, the released materials will be in the form of aerosols when they reach the suppression pool. Particle sizes for aerosols are not specified.

The first significant release of radioactivity occurs when the zircaloy cladding on the fuel ruptures. Volatile species accumulated in the gap between the fuel and the clad are then vented into the reactor vessel. The gap release takes place shortly after coolant has been boiled out of a substantial fraction of the core. The gap release is spread over time because fuel rods in the various regions of the core and even fuel rods within a particular subassembly do not heat at uniform rates. Temperatures necessary to cause the clad to rupture are reached at various times throughout the reactor core.

Gap inventories of volatile materials promptly released when the cladding on the fuel is ruptured are small. Precise values of the gap inventories have been controversial since the time of the Reactor Safety Study [29]. Values picked for NUREG-1465 and the proposed, revised Severe Accident Source Term appear to be conservatively large values. Release of these vapors will, typically, be into steam flowing at relatively high flow rates. Consequently, vapor concentrations will be small. If particles nucleate from the gas phase as the gas temperatures fall, these particles would be expected to remain quite small $(<0.5 \mu \mathrm{m})$ because particle coagulation rates will be slow at the low particle concentrations. Vapors might, instead, condense on relatively coarse $(-50 \mu \mathrm{m})$ fragments of fuel that escape into the flow when the clad ruptures [241]. Such coarse particles might not be carried as far as the suppression pool. If such large particles do reach the pool, they will be quantitatively trapped in the pool. 
Table 3. Proposed severe accident source term for boiling water reactors [3]

\begin{tabular}{|c|c|c|c|c|}
\hline Duration (hours) & $\begin{array}{c}\text { Gap } \\
\text { release } \\
\mathbf{1 . 0} \\
\end{array}$ & $\begin{array}{c}\text { In-vessel } \\
\text { release } \\
1.5 \\
\end{array}$ & $\begin{array}{c}\text { Ex-ressel } \\
\text { release } \\
\mathbf{3 . 0} \\
\end{array}$ & $\begin{array}{c}\text { Late } \\
\text { In-vessel } \\
\text { release } \\
\mathbf{1 0 . 0}\end{array}$ \\
\hline \multicolumn{5}{|l|}{$\begin{array}{l}\text { Release } \\
\text { (fraction of } \\
\text { core inventory) }\end{array}$} \\
\hline Noble Gases & 0.05 & 0.95 & 0 & 0 \\
\hline Iodine & 0.05 & 0.22 & 0.37 & 0.07 \\
\hline Cesium & 0.05 & 0.15 & 0.45 & 0.03 \\
\hline Tellurium & 0 & 0.11 & 0.38 & 0.01 \\
\hline Strontium & 0 & 0.03 & 0.24 & 0 \\
\hline Barium & 0 & 0.03 & 0.21 & 0 \\
\hline Ruthenium & 0 & 0.007 & 0.004 & 0 \\
\hline Cerium & 0 & 0.009 & 0.01 & 0 \\
\hline Lanthanum & 0 & 0.002 & 0.01 & 0 \\
\hline $\begin{array}{l}\text { Nonradioactive } \\
\text { materials (kg) }\end{array}$ & & 780 & 5600 & \\
\hline
\end{tabular}




\section{Table 4. Core inventories for a $3578 \mathrm{MW}_{\text {th }}$ BWR-6}

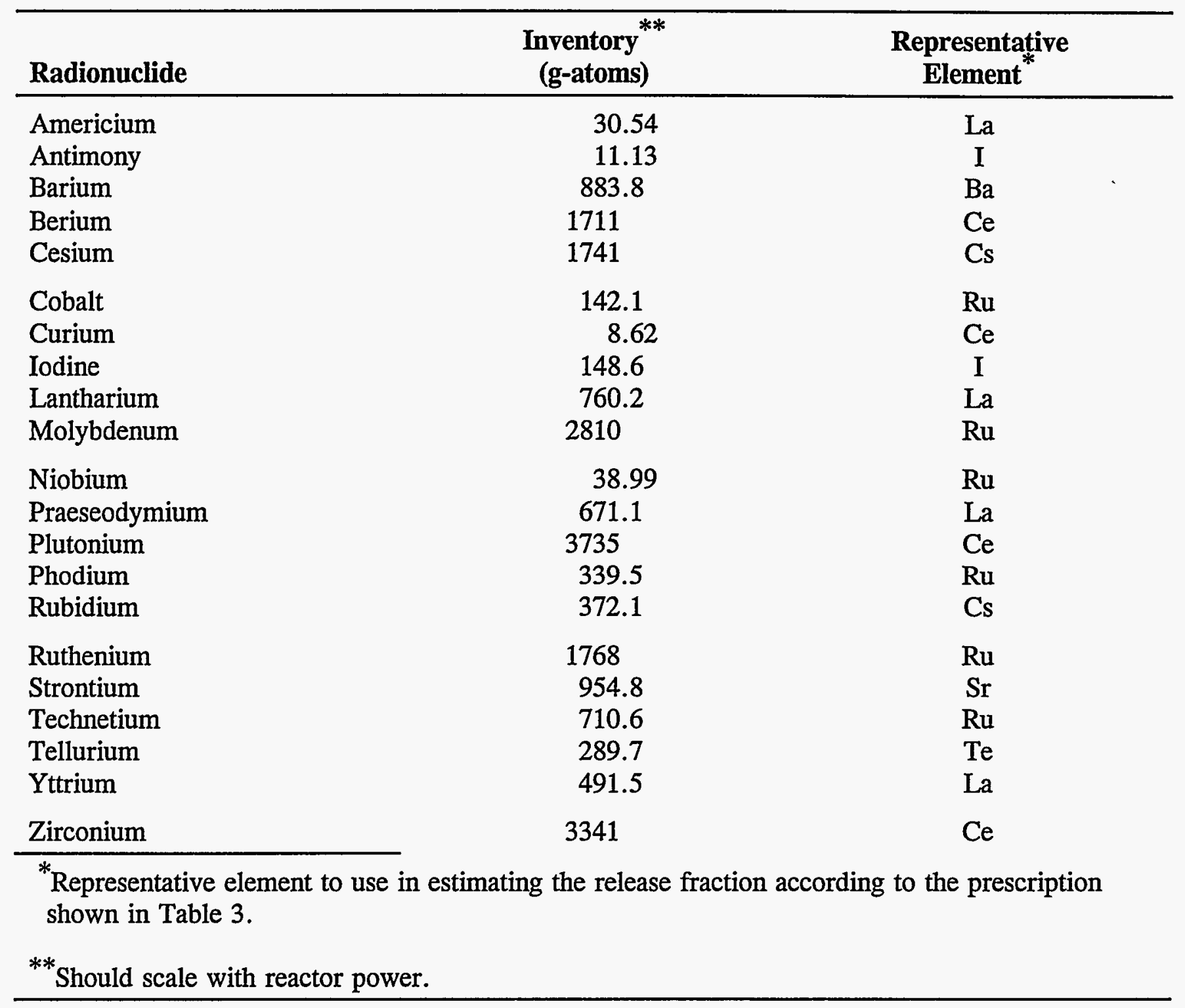


At the time fuel cladding ruptures, temperatures even in the hotter portions of the core will not be especially high. In the case of a depressurized reactor coolant system, clad rupture may occur at temperatures in the vicinity of $1000 \mathrm{~K}$ [247]. If the reactor coolant system is pressurized -at this early stage of the accident, clad rupture may occur at temperatures near the clad melting point, $\sim 2125 \mathrm{~K}$. Even if temperatures are this high in local regions, most of the reactor core is still relatively cool. At low temperatures, steam reactions with the cladding to form hydrogen will be limited by chemical kinetics [10]. Much of the gas that carries aerosol and vapors through the reactor coolant system will be steam.

Temperatures in the reactor core rise slowly early in the accident. Typical rates of temperature inçreașe are less than $1 \mathrm{~K} / \mathrm{s}$. Steam production during this period is not expected to be large. Radiation heat transfer to residual coolant is limited by poor view factors from the hotter fuel rods to lower regions of the reactor vessel where cooling water remains.

Eventually, temperatures are reached by the fuel rods that are so high that the steam reaction with the clad becomes quite rapid. Heat transfer from the fuel rods to the fuel assembly channel boxes, which are made of a zirconium alloy, raises surface temperatures sufficiently that the channel boxes, too, react with steam to form hydrogen. It eventually becomes impossible to supply steam fast enough to meet the reactivity of the clad. Chemical heat produced by the reaction of steam with the clad greatly augments the heating of the fuel by radioactive decay. Fuel temperatures increase at rates of up to $20 \mathrm{~K} / \mathrm{s}$. Gas that emerges from the core is essentially hydrogen. This hydrogen is, however, diluted and cooled by steam that bypasses the core region. Nevertheless, the gas that carries aerosols through the reactor coolant system and into the suppression pool during this period contains much less steam than did the gas during the earlier, gap release stage of the accident.

As temperatures in the fuel rise, there is a corresponding increase in the rate of vaporization of both radionuclides and nonradioactive materials. Nonradioactive materials that can make significant contributions to the aerosol mass include tin from the zircaloy cladding and even $\mathrm{UO}_{2}$ itself. Because the more rapid vaporization of more materials creates higher total aerosol concentrations, the rate of aerosol coagulation greatly increases. Thus, aerosol particles can grow to sizes greater than $1 \mu \mathrm{m}$.

Eventually, cladding on the fuel melts and drains down the fuel rods. Still later, fuel itself can melt or the fuel can collapse within the core into a rubble bed. Melting of cladding and melting or collapse of fuel can increase the rate of steam flow into the core. Relocation of molten cladding, channel boxes and the like bring hot material closer to residual water in the reactor coolant system.

Available accident-analysis models differ in their predictions of the extent to which steam production increases. Models in the Source Term Code Package [14] are based on the hypothesis that molten clad drains into lower, cooler portions of the core where it temporarily forms an impermeable crust. Fuel collapses onto this crust, heats and eventually melts. Once molten material penetrates the crust, it cascades into the lower plenum of the reactor vessel. The sudden interaction of large amounts of high temperature melt with water in the lower plenum produces large amounts of steam that will purge aerosols from the reactor coolant system into the steam suppression pool. Somewhat similar models are employed in the MELCOR code for severe reactor accident analysis [15].

\footnotetext{
*Boiling water reactors are equipped with automatic depressurization systems. Risk dominant accidents in boiling water reactors tend, however, to be those in which this automatic system fails to function.
} 
Models in the BWRSAR code [16] are based on a different hypothesis concerning the behavior of molten material during core degradation (see Figure 9). It is hypothesized that molten material drains completely out of the core region. No crust is formed. Instead, molten material falls into residual water low in the reactor vessel. The continuous draining of small amounts of melt into the water, where it quenches, augments steam production. Decay heat eventually boils the water away, and the debris can heat to melting and cause rupture of the vessel head.

Available models differ in their predictions of the extent to which steam will be reduced to hydrogen. The MAAP code [18] indicates that blockages formed by freezing of molten material in lower, cooler regions of fuel subassemblies prevent steam from reaching and reacting with core debris. The bulk of the steam flow is diverted around the hottest region of the core. The gas that carries aerosol out of the core region to the suppression pool is then expected to be rich in steam. Other models assume local blockages do not completely prevent steam flow through fuel subassemblies so there are opportunities for vigorous reaction of the steam to form hydrogen. The condensible fraction of gases transporting aerosols from the reactor coolant system to the suppression pool is, then, smaller.

Eventually, core debris is expected to rupture the reactor pressure vessel, fall into the drywell and attack concrete. Accident progression models differ on the details of these events. Predictions of the models can be grouped into two classes. Most models predict that a molten pool forms in the lower plenum of the reactor and penetrates the vessel head. A substantial fraction ( $\sim 50$ percent) of the core material is suddenly released into the drywell. The remainder of the core slowly melts and drains into the drywell.

The BWRSAR code [16] predicts a different sequence of events. Core debris that falls from the core region is assumed to quench and form a debris bed in the lower plenum. As the debris bed drys and reheats, constituents of the debris bed melt according to their respective melting points. Melting points of metallic constituents are lowest so the metals form a molten pool that penetrates the vessel. Thus, the first core debris expelled into the drywell is a largely metallic melt. As shown in Figure 10, molten oxide materials drain into the drywell slowly over an extended period of time.

Interaction of core debris with concrete produces aerosols [19] and noncondensible gases such as hydrogen, carbon monoxide, and carbon dioxide [20]. Unless some modifications have been made to the plants to ensure water is in contact with the core debris in the drywell, there is little steam present in the gases generated during core debris interactions with concrete. If metallic zirconium is present in the core debris, water vapor evaporated from concrete exposed to core debris will be nearly completely reduced to hydrogen. (Equilibrium hydrogen-to-steam partial pressure ratios will be on the order of $10^{5}$.) Once zirconium and chromium in the core debris have been oxidized, the hydrogen-tosteam partial pressure ratio in gases evolved during the attack on concrete will be determined by the reaction with iron:

$$
\mathrm{Fe}(\mathrm{l})+\mathrm{H}_{2} \mathrm{O} \rightleftarrows \mathrm{FeO}(\mathrm{l})+\mathrm{H}_{2}
$$

and for most conditions the hydrogen-to-steam partial pressure ratio will be about 2 . 


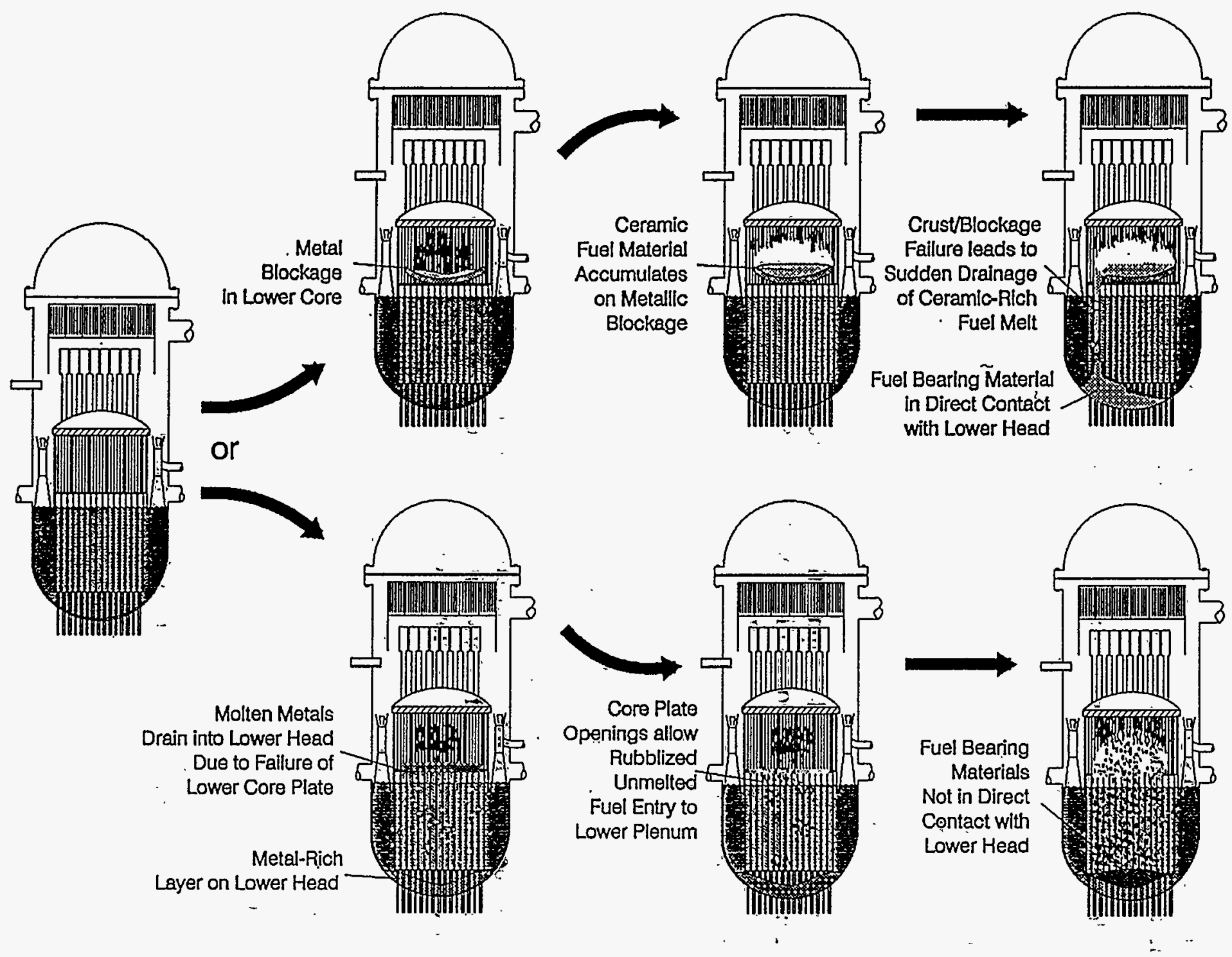

Figure 9. Alternative core meltdown scenarios for boiling water reactors 


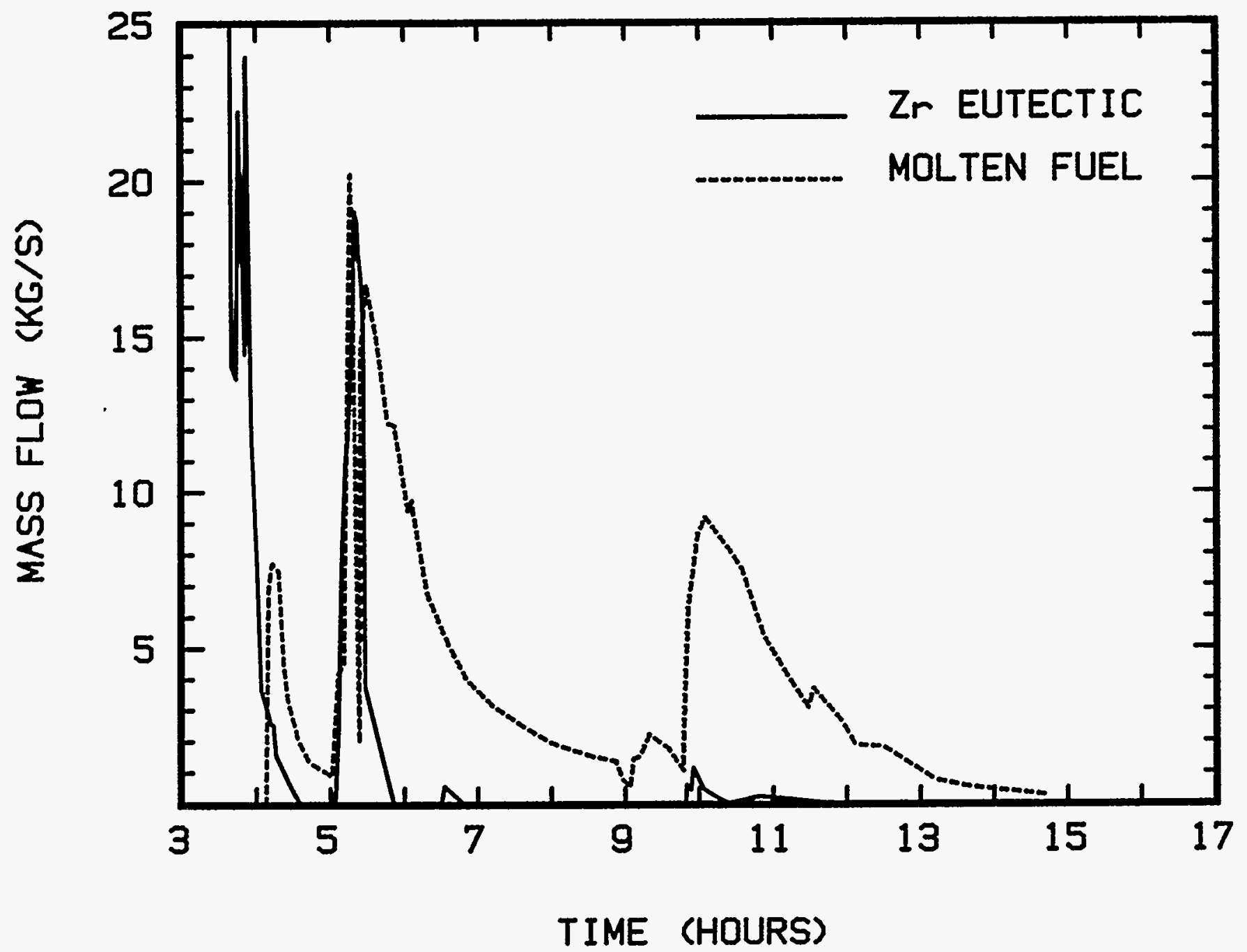

Figure 10. Core debris expulsion from the reactor vessel into the drywell as predicted by the BWRSAR code [16] 
Aerosols and gases produced during core debris interactions with concrete in the reactor drywell will vent through downcomers into the suppression pool.

During the late stages of a reactor accident, volatile radionuclides previously deposited in the reactor coolant system may vaporize. The revaporization of these materials is driven by their continued decay heating. Some fraction of the revaporized materials will be transported out of the reactor coolant system into the drywell and then into the suppression pool. The revaporization release of deposited radionuclides can be a long term process. Analyses with the MAAP code of revaporization during hypothetical accidents at the Peach Bottom Mark I boiling water reactor indicate revaporization can persist for 50 hours after core meltdown started [21].

Quantitative details of the accident progression depend, of course, on the particular acêident scenario. The NUREG-1150 study [22] identified the frequency-dominant accident scenarios caúsed by internal initiators for representative Mark I and Mark III boiling water reactors:

- Mark I:

1. loss of offsite power (mean frequency $=2.2 \times 10^{-6} / \mathrm{yr}$ )

2. anticipated transients without scram (mean frequency $=1.9 \times 10^{-6} / \mathrm{yr}$ )

3. medium size breaks in the reactor coolant system (break areas of 3.7 to $93 \mathrm{~cm}^{2}$ ) (mean frequency $=2.6 \times 10^{-7} / \mathrm{yr}$ )

- Mark III:

1. loss of offsite power (mean frequency $=3.9 \times 10^{-6} / \mathrm{yr}$ )

2. anticipated transients without scram (mean frequency $=1.1 \times 10^{-7} / \mathrm{yr}$ )

Payne [239] has described severe accident frequencies for the La Salle Mark II reactor. Over 70 percent of the risk from accidents caused by internal initiators is due to loss of off-site and on-site power.

For the loss-of-offsite-power accidents and the anticipated-transient-without-scram (ATWS) accidents, the reactor coolant system is intact throughout core degradation. Radionuclides releașend during core degradation vent to the suppression pool through the quenchers. Only after core debris has penetrated the reactor vessel do aerosol-laden gases pass into the suppression pool by way of the downcomers in the drywell.

Loss-of-coolant accidents are not exceptionally important contributors to the core meltdown accident frequency of boiling water reactors if only internal initiators are considered. Loss-of-coolant accidents are expected to make bigger contributions to the core meltdown frequency when external events such as earthquakes and fires are considered as initiators. In loss-of-coolant events, aerosol laden gases can vent from the reactor coolant system to the drywell and then from the drywell to the suppression pool by way of the drywell downcomers. 
For the purposes of this development of a simplified model, scrubbing of aerosol-laden gases produced during the early stages of an accident is considered to occur only by injection into the suppression pool through the quenchers. That is, injection of aerosol-laden gases into the suppression pool through the drywell downcomers is considered to occur only after the core debris has penetrated the reactor vessel. Injection via the downcomers early in an accident, such as might occur during a loss of coolant accident, is neglected.

\section{B. Accidents in Mark I Reactors}

Detailed accident analyses were done for the NUREG-1150 study using the Source Term Code Package [14]. Results of these analyses provide some indication of the range of gas flows and gas compositions that will be discharged to the quenchers. Molar flows through the reactor coolant system for a TC3 sequence [23] are shown in Figure 11. The TC3 sequence is an anticipated transient without scram (ATWS) accident sequence. The reactor coolant system is assumed to remain pressurized during core degradation. The wetwell is assumed to be vented.

It is apparent from results shown in Figure 11 that gap release will take place under conditions of high flow. Molar flow rates during the period immediately following core uncovery vary from about 2500 to 400 moles per second. During this period, hydrogen makes up only about 2 to 3 percent of the gas flow through the core region. Early in-vessel releases will take place at flow rates of only 400 to 180 moles per second. Hydrogen will make up 10 to 95 percent of the gas flow. Core slumping and collapse prompt a huge increase in flow to about 2000 to $2500 \mathrm{moles} / \mathrm{s}$. During this period of rapid flow, hydrogen will make up only 1 to 3 percent of the gas. The rapid flow associated with core slumping and core collapse will drive any aerosols suspended in the reactor coolant system into the suppression pool.

Had the BWRSAR code been used for these calculations instead of the Source Term Code Package, flows during core melting would have been somewhat higher-perhaps as high as $500 \mathrm{moles} / \mathrm{s}$. The huge increase in flow at 86 minutes would not have occurred.

Flows to the suppression pool during the ex-vessel stages of the TC3 sequence are shown in Figure 12. Note that these calculations were done assuming that the concrete was fabricated with limestone aggregate. Limestone concrete produces more gas when it ablates than does siliceous aggregate concrete [24]. On the other hand, it takes more energy to ablate limestone concrete than it does to ablate siliceous concrete. Consequently, had siliceous rather than limestone concrete been assumed, molar flow rates would have been one-half to two-thirds those shown in Figure 12.

Early in the course of the core debris interactions with limestone or siliceous concrete essentially none of the gas is condensible. For the purposes of the analyses presented here, essentially all of the steam has been reduced to hydrogen. Other gases in the flow are noncondensible carbon monoxide and carbon dioxide. After 3 to 6 hours of core debris/concrete interactions [25] when iron is the strongest reducing agent in the core debris, about 12 percent of the gas evolved during interactions with limestone concrete is water vapor. During interactions with siliceous concrete, about 32 percent of the gas can be water vapor late in the interaction.

The Source Term Code Package uses an assumption that primary particles formed from vapors evolved from the core are $0.05 \mu \mathrm{m}$ in diameter. It is also assumed the particle material has a 


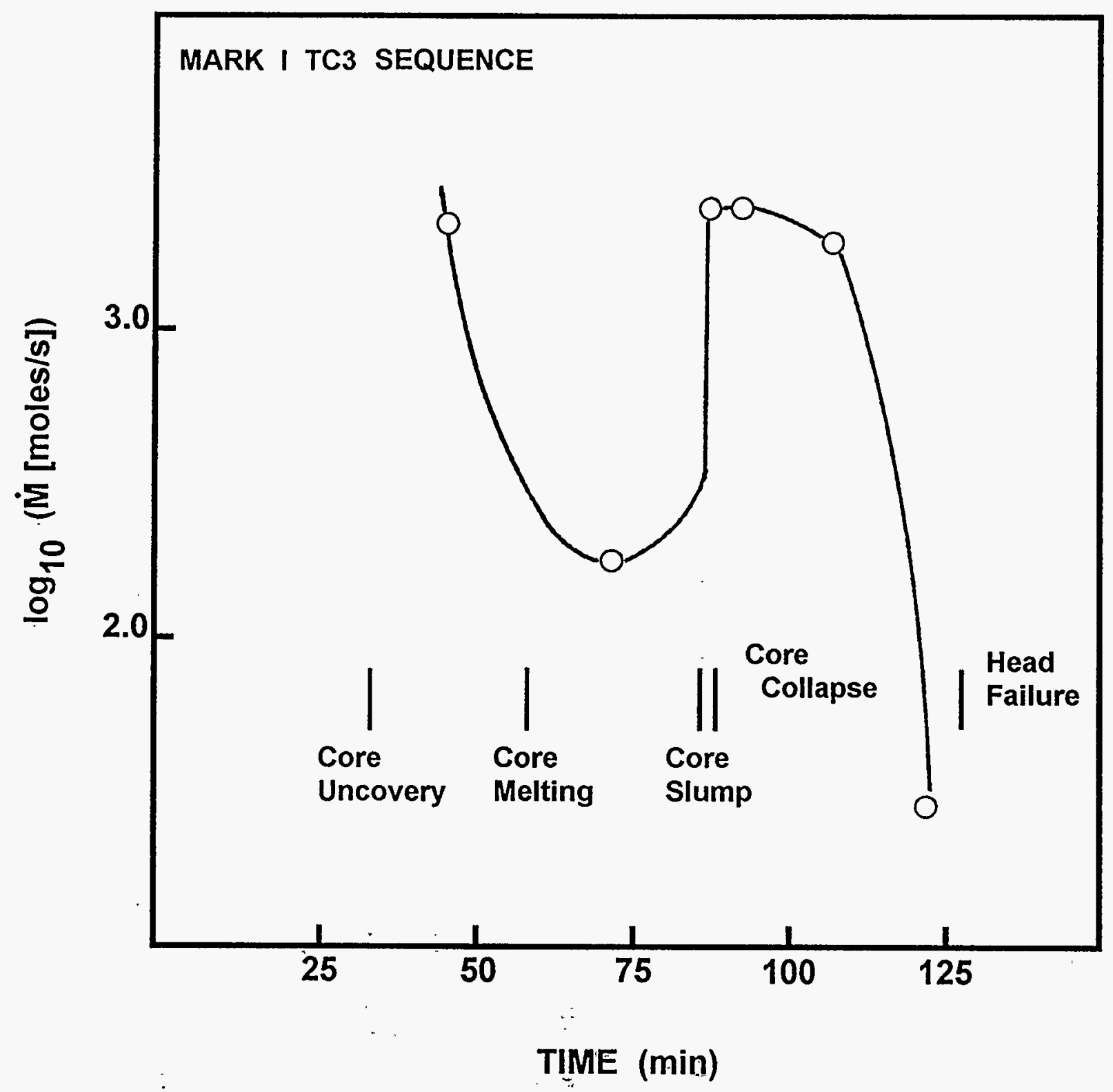

2

TIME (min)

Figure 11. Molar gas flow (Mi) through the reactor coolant systemin a Mark I boiling water reactor during a TC3 accident sequence 


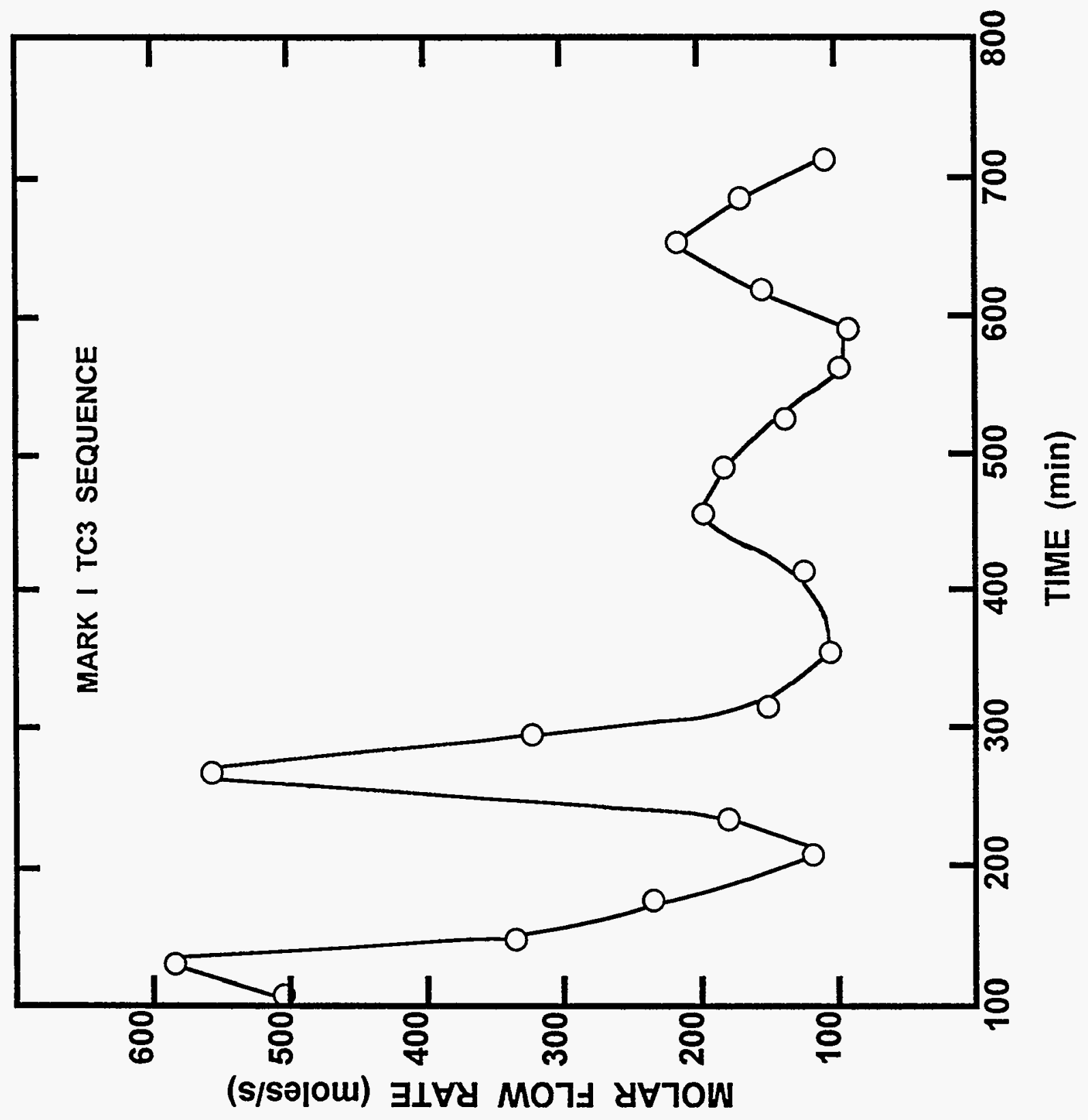


density of $3 \mathrm{~g} / \mathrm{cm}^{3}$. The code does a mechanistic calculation of aerosol growth by vapor condensation and coagulation of particles. Example predictions of aerosol particle size distribution for material venting through the safety relief valves are shown in Figure 13. The mean size of the aerosol particles is predicted to be about $3 \mu \mathrm{m}$. There must, however, be a great deal of uncertainty in this prediction. Despite the many tests of radionuclide release from degrading reactor fuel, there appears to be no suitable data base for comparison to the code predictions. Perhaps, the PHEBUS-FP tests now being planned [257] will provide the needed information on aerosol.particle sizes being yented to the suppression pool from coolant system.

The mean sizes and densities of the aerosol particles predicted by the Source Term Code Package to be produced during core debris interactions with concrete are shown in Figure 14. These sizes are predicted based on fitting to experimental data and assuming that particles grow until the number concentration falls to about $10^{9}$ particles per $\mathrm{cm}^{3}$ [19]. The relatively large particle sizes predicted to be present during the earlý stages of vigorous attack on concrete are consistent with experimental data. The fall in aerosol mean size when aerosol generation rate falls is the product of the assumption concerning the particle growth and must be considered quite uncertain.

The proposed revision to the severe accident source term [3] indicates that the majority of the relêase of radionuclides during, core debris/concrete, interactions takes place during the first two hours of interaction: During this period the aerosol particle sizes are relatively coarse. Mean sizes of the particles are on the order of $1.2 \mu \mathrm{m}$. Aerosol material densities calculated with the Source Term Code Package during this stage of an accident in a Mark I boiling water reactor vary from 4.33 to $3.15 \mathrm{~g} / \mathrm{cm}^{3}$ [23].

The production of aerosol during longer term phases of core debris interactions with concrete does not contribute significantly to the radioactivity releases. These aerosols produced between 2 and 10 hours after the onset of core debris/concrete interactions are composed primarily of constituents of concrete $-\mathrm{SiO}_{2}$, $\mathrm{Na}_{2} \mathrm{O}$, and $\mathrm{K}_{2} \mathrm{O}$. Particle sizes are predicted to be quite small. Mean sizes are on the order of $0.25 \mu \mathrm{m}$. These aerosol particles will mix with radioactive aerosols produced by the revaporization of radionuclides from the reactor coolant system. Material densities of aerosol produced by core debris/concrete interactions have been calculated with the Source Term Code Package [23] to be in the range of 3.15 to $2.65 \mathrm{~g} / \mathrm{cm}^{3}$.

Aerosols produced during core debris/concrete interactions are assumed here to have log-normal size distributions with a geometric standard deviation of 2.3. The geometric standard deviation of aerosols produced in experiments varies from 1.6 to 3.8 [26].

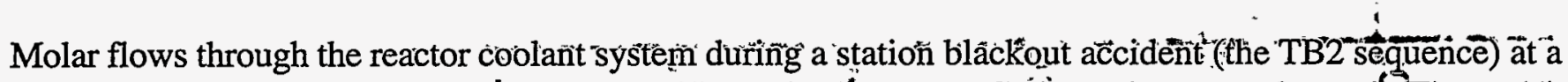
Mark I boiling water reactor as calculated with the Source Term Code Package Though the onset of core degradation is offset in time, molar flows following, core uncovery exhibit qualitative similarities to molar flows calculated for the TC3 ATWS sequence. Molar flow rates to the suppression pool during the ex-vessel stages of the station blackout accident are shown in Figure 16. These flows exhibit qualitative similarities to those calculated for the ATWS sequence. Aerosol particle size and aerosol material density during the melt/concrete interactions in a station blackout accident are shown in Figure 17. Again, the similarities of these results to those calculated for the ATWS swquence are quite noticeable. 


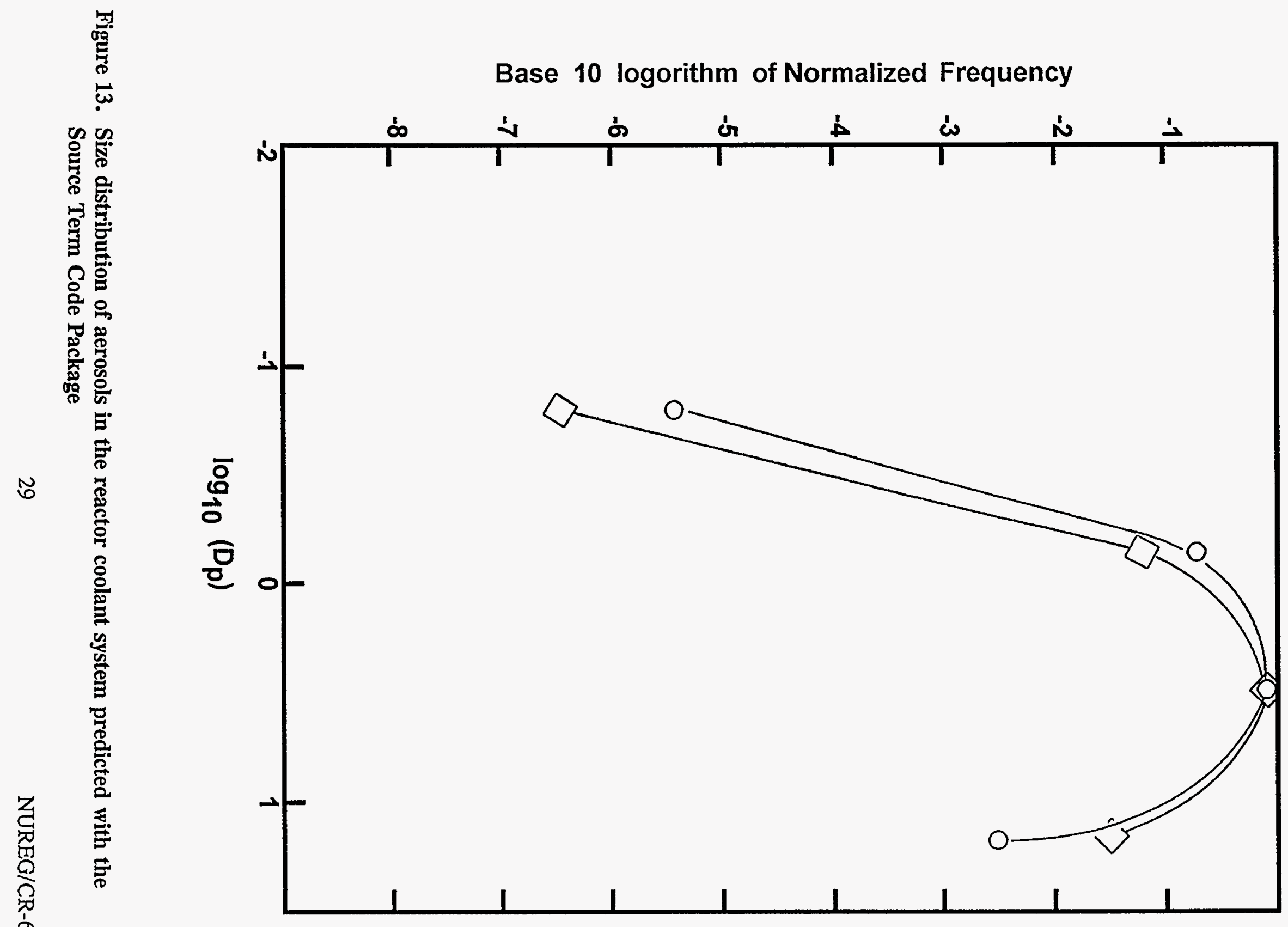




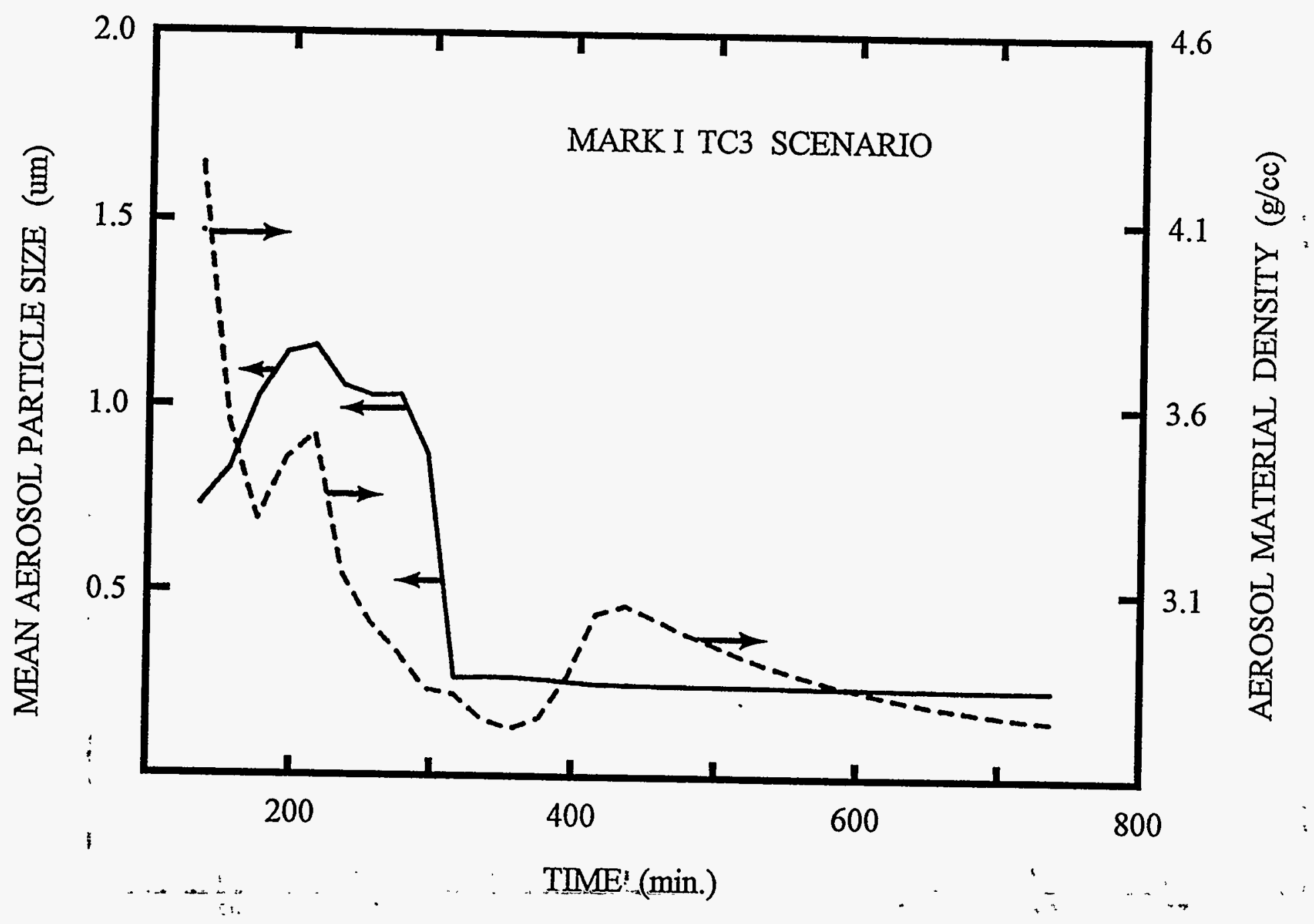

Figure 14. Mean size and material density of aerosols produced during core debris interactions with concrete in a TC3 accident in a Mark I boiling water reactor 


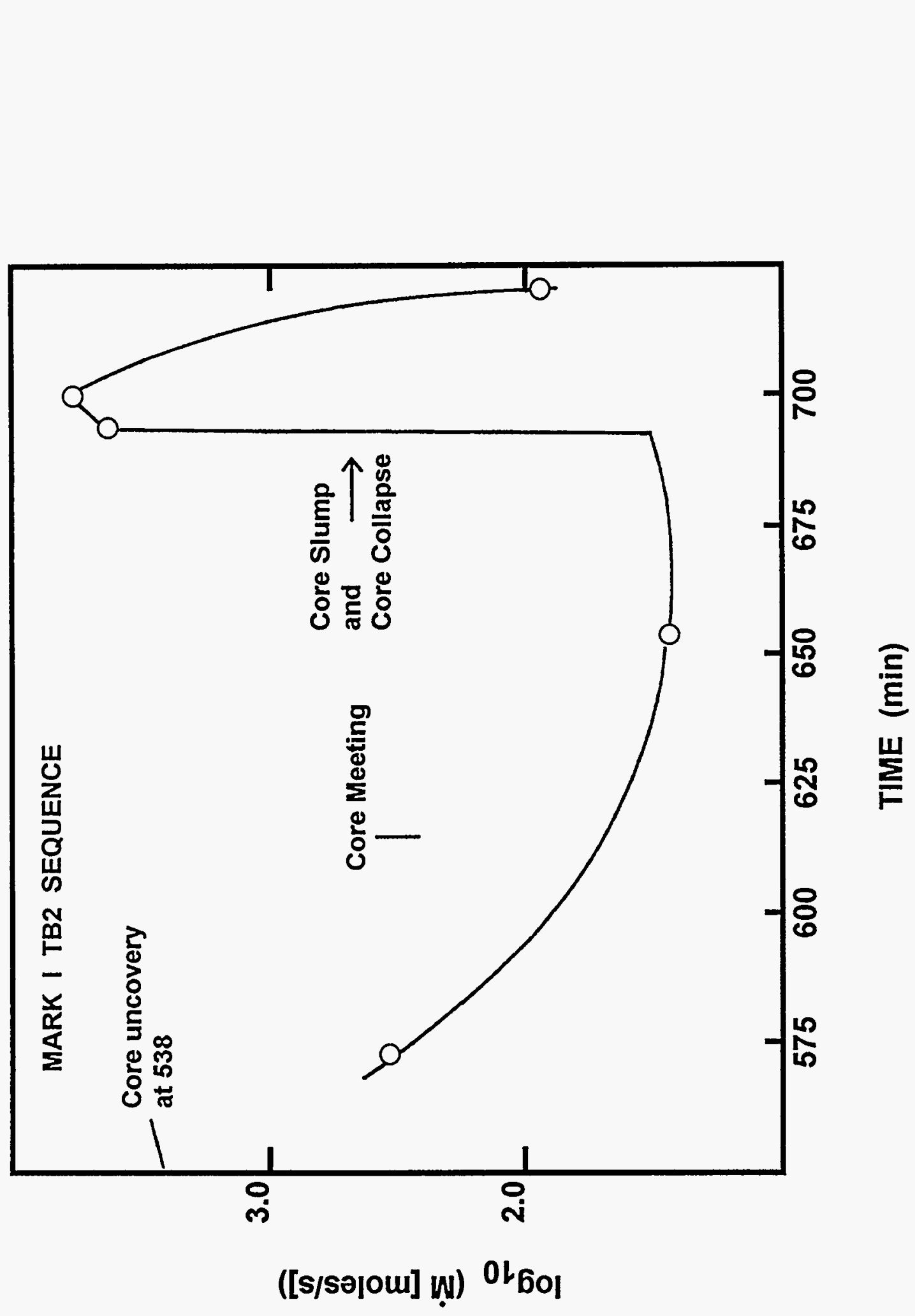

Accident

를를

울

$\sigma$

를

농

త్

닌

3

를

8

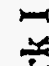

$\sum$

回

总

5

总

눙

త్ర

E

क

을

$\varepsilon$

严

in

造

Ix 


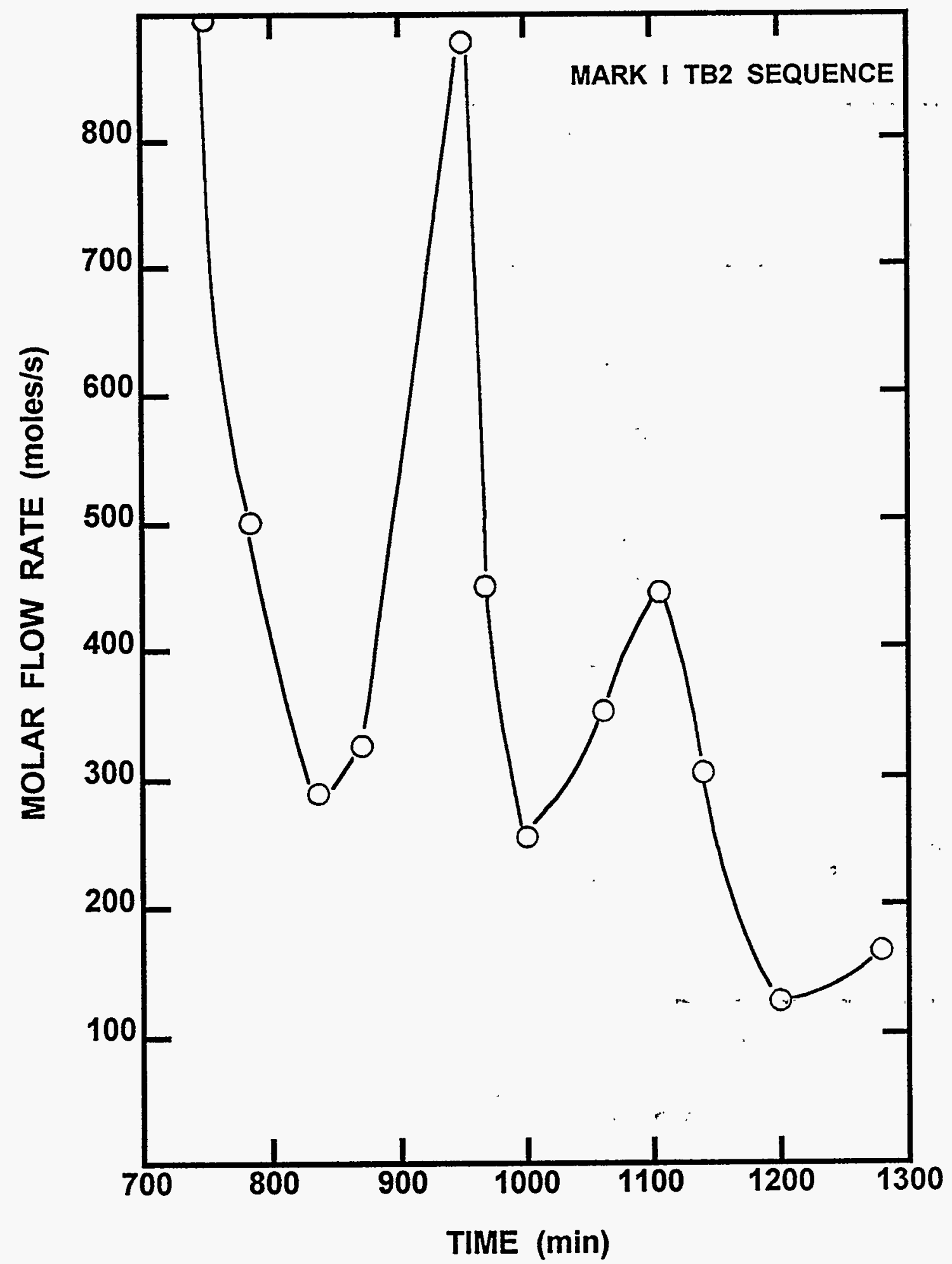

Figure 16. Molar flows of gas to the suppression pool during core debris/concrete interactions in a TB2 accident sequence 


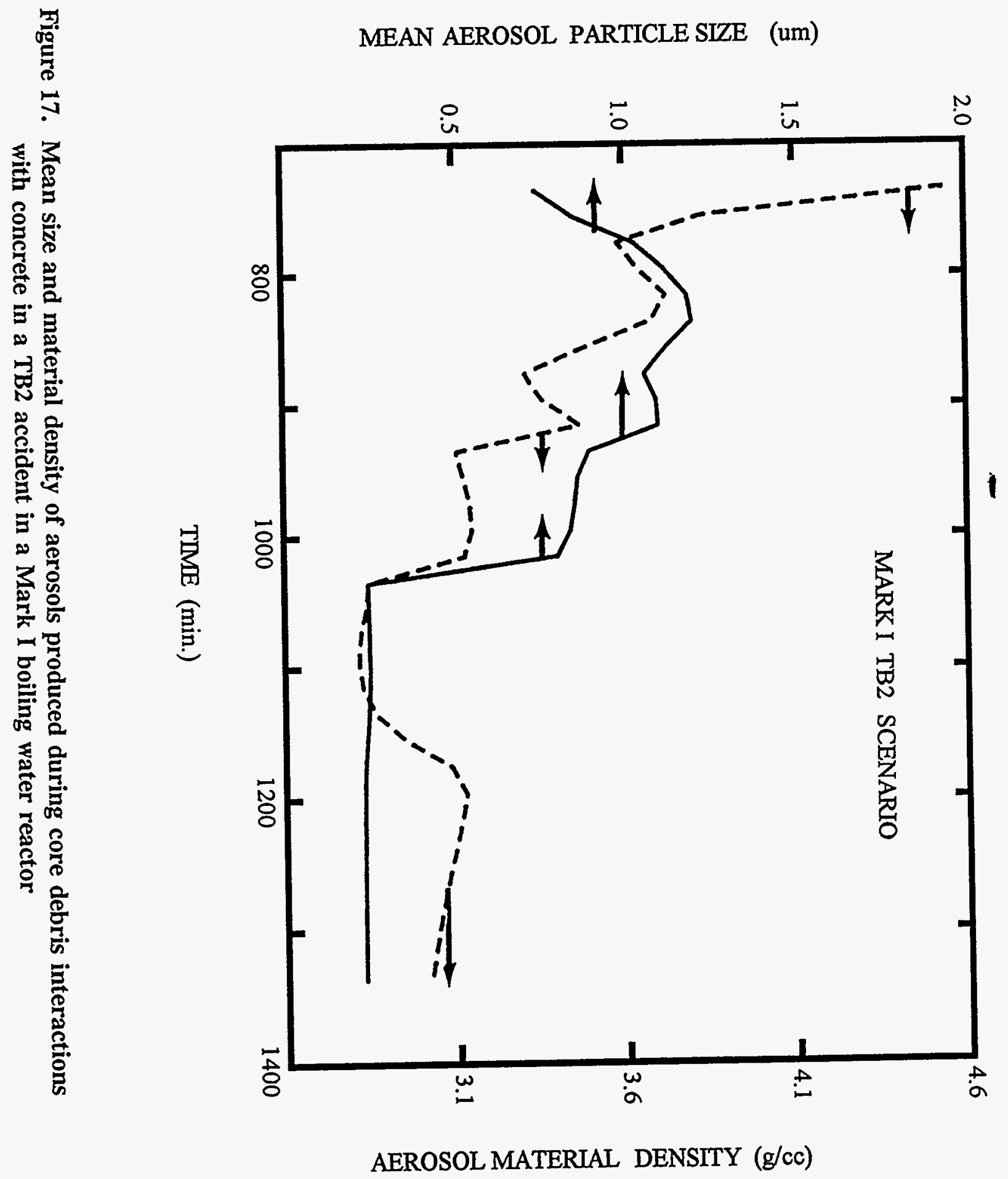




\section{Accidents in Mark II Reactors}

There have been very few severe reactor accident analyses published for Mark II containment boiling water reactors. Dingman et al. [236] have used the MELCOR code to calculate the progression of a station blackout accident at the La Salle Mark II reactor. The progression of the accident is rather similar to the progression of station blackout accidents" at other types of boiling water-reactors. Gap release is predicted to occur over a 46 minute period beginning 73 minutes after accident initiation and 37 minutes after core uncovery. Vessel penetration by core debris occurs 281 minutes after accident initiation. During core degradation, hydrogen is produced at the rate of 94 moles per second.

The most remarkable results obtained by Dingman et al. in their analyses of the station blackout accident concerned the gas.'generation once core debris had been expelled from the reactor vessel. Their analyses indicate that degassing of concrete produces far more gas than do the direct interactions of core debris with structural concrete. Degassing of concrete is predicted to produce 29 moles/s of steam and between 7 and 25 moles/s of carbon dioxide. Hydrogen production during this periọd wheñ core debris is interacting with concrete is reported to average about $1.4 \mathrm{moles} / \mathrm{s}$. Carbon monoxide genêtration rates are not reported.

Steam production by concrete degassing is significant for the prediction of source term attenuation. This steam could be condensed in sufficiently sub-cooled steam suppression pools. Eondensation of the steam could sweep aerosols from gas bubbles rising through the pool.

Shaffer et al. [235] have reported results of 'calculations with the MELCOR model for various types of station blackout accidents at the La Salle plant. For the "high pressure, short term, station blackout" scenario, hydrogen was calculated to be generated at the rate of about $60 \mathrm{moles} / \mathrm{s}$ during the period of gap release and the period of in-vessel release. Steam flow through the safety/relief valvếs fell from about $2400 \mathrm{moles} / \mathrm{s}$ prior to gap release to about $200 \mathrm{moles} / \mathrm{s}$ during the period of extensive core degradation. Sudden eruptions of steam were calculated to occur whenever core debris"fell into the residual water in the reactor vessel.

Hydrogen generation rates calculated to occur during a "low pressure, short term, station blackout" scenario were about $21 \mathrm{moles} / \mathrm{s}$ during gap and in-vessel release: The hydrogen generation ${ }_{r}$ rate during a "long term, station blackout" scenario was about 20 moles/s. Steam flow through the relief valves during the core degradation process was small except for episodic eruptions of steam when core debris relocated.

Shaffer et al. also considered degassing of concrete as well as the interaction of core debris with concrete as sources of gas production during the ex-vessel phases of a severe reactor accident. Total gas production rates and gas compositions during the early stages of ex-vessel core debris interactions for various station blackout scenarios are compared below: 


\begin{tabular}{lccccc} 
& \multirow{2}{c}{$\begin{array}{c}\text { Total } \\
\text { Sas }\end{array}$} & \multicolumn{4}{c}{ Molar Gas Composition (\%) } \\
\cline { 5 - 6 } & $\begin{array}{c}\text { Scenario } \\
\text { Production } \\
\text { (moles/s) }\end{array}$ & $\mathrm{H}_{2}$ & $\mathrm{H}_{2} \mathrm{O}$ & $\mathrm{CO}$ & $\mathrm{CO}_{2}$ \\
\hline $\begin{array}{l}\text { Short term high pressure } \\
\text { station blackout }\end{array}$ & 200 & 26 & 24 & 30 & 20 \\
$\begin{array}{l}\text { Short term low pressure } \\
\text { station blackout }\end{array}$ & 159 & 19 & 20 & 45 & 16 \\
Long term station blackout & 134 & 14 & 31 & 38 & 17
\end{tabular}

Similar comparisons for longer term phases of the ex-vessel core debris interactions which will affect the attenuation of the late in-vessel release are:

\begin{tabular}{ccccccc} 
& Total & & \multicolumn{4}{c}{ Molar Gas Composition (\%) } \\
\cline { 5 - 7 } Scenario & \begin{tabular}{c} 
Gas \\
Production \\
\cline { 5 - 7 }
\end{tabular} & (moles/s) & $\mathrm{H}_{2}$ & $\mathrm{H}_{2} \mathrm{O}$ & $\mathrm{CO}$ & $\mathrm{CO}_{2}$ \\
\hline
\end{tabular}

\begin{tabular}{lccccc}
\hline $\begin{array}{l}\text { Short term high pressure } \\
\text { station blackout }\end{array}$ & 49 & 4.4 & 44 & 13 & 39 \\
$\begin{array}{l}\text { Short term low pressure } \\
\text { station blackout }\end{array}$ & 55 & 5.6 & 42 & 17 & 35 \\
Long term station blackout & 63 & 4.0 & 61 & 6.1 & 29
\end{tabular}

\section{Accidents in Mark III Reactors}

Molar flows to the suppression pool calculated with the Source Term Code Package [27] for a station blackout accident and an ATWS accident sequence in a Mark III reactor are shown in Figure 18. These flows are quite like those calculated for similar accidents in a Mark I reactor. Gas production and aerosol production during core debris interactions with concrete are also quite similar to results calculated for corresponding accidents in Mark I reactors.

Dingman et al. [236] have used the MELCOR code to predict the progression of a station blackout accident at the Grand Gulf Mark III boiling water reactor. Hydrogen production rates during the gap release phase of the accident and during much of the in-vessel release phase are predicted to be about $117 \mathrm{moles} / \mathrm{s}$. This hydrogen production rate decreases to about $22 \mathrm{moles} / \mathrm{s}$ during the period fuel is relocating within the reactor vessel. Hydrogen production rates once fuel has been expelled from the reactor vessel and core debris/concrete interactions begin are about $14 \mathrm{moles} / \mathrm{s}$.

Dingman et al. consider concrete degassing during the ex-vessel phase of the accident. They find steam release rates due to degassing to be about $20 \mathrm{moles} / \mathrm{s}$. Their calculations indicate that the atmosphere of the drywell is 80 to 95 percent steam during most of the ex-vessel phase of the accident. The remainder of the gas is largely hydrogen. Carbon dioxide and carbon monoxide are found to make 


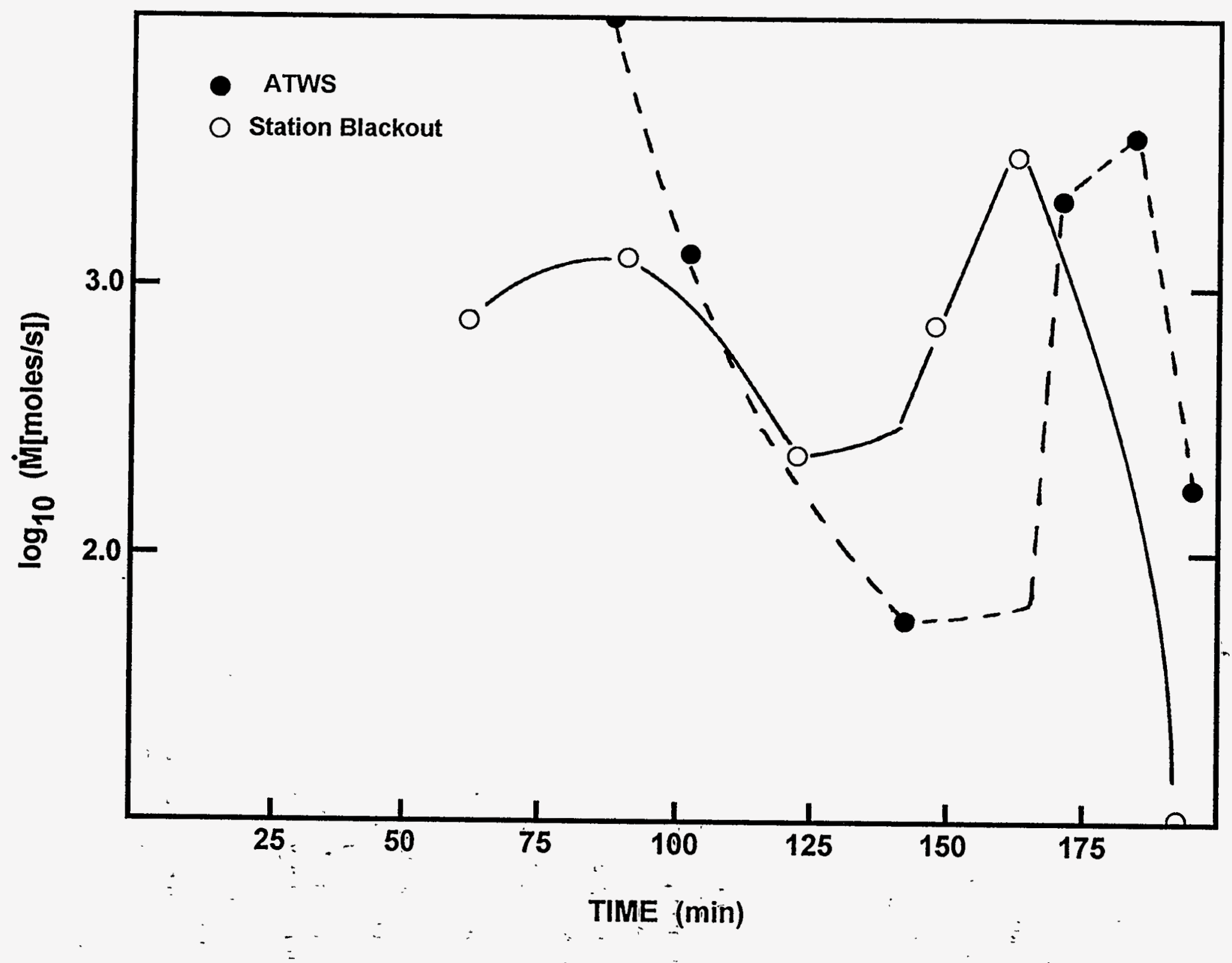

Figure 18. Molar flow rates (în) through the reactor cồolant system in a Mark III boiling water reactor during a station blackout accident ând an ATWS accident 
negligible contributions to the drywell atmosphere composition throughout most of the ex-vessel phase of the accident. Only for a period of about 90 minutes, when gas production from core debris/concrete interactions is very high and presumably radionuclide releases are also high, carbon monoxide makes up 9 to 12 percent of the drywell gas. ${ }^{*}$ During this period, hydrogen is about 3 percent of the drywell gas.

Calculations by Dingman et al. [236] show wildly varying flows through the suppression pool during the ex-vessel phase of the station blackout accident. Flows vary from about $160 \mathrm{moles} / \mathrm{s}$ to about $1055 \mathrm{moles} / \mathrm{s}$. The time averaged flow rate to the steam suppression pool is about $470 \mathrm{moles} / \mathrm{s}$. Much of this flow must come from steam formed from water that floods into the reactor cavity from the Mark III suppression pool.

Greene et al. [234] have used the MELCOR, BWRSAR, and BWR-LTAS codes to analyze station blackout accidents in the Grand Gulf Mark III boiling water reactor. They too find that the drywell atmosphere becomes rich in steam in the later phases of core debris/concrete interactions. The molar composition of the drywell atmosphere during the period of late, in-vessel release is found to vary between about 50 and 95 percent steam depending on the details of the accident scenario.

The QUEST study examined uncertainties in the aerosol produced by core debris interactions with concrete during a station blackout accident at a Mark III boiling water reactor [25]. Mean aerosol particle sizes during the periods of intense aerosol productions were found to vary between 0.9 and $1.1 \mu \mathrm{m}$. Aerosol material densities were calculated to vary from 2.9 to $3.5 \mathrm{~g} / \mathrm{cm}^{3}$ during this period. During later stages of the accident, mean aerosol particle diameters were calculated to be in the range of 0.4 to $0.6 \mu \mathrm{m}$. The aerosol material density was calculated to be 2.9 to $3.1 \mathrm{~g} / \mathrm{cm}^{3}$.

\section{E. Conclusions}

From the several accident analyses described above, it can be concluded that:

- gap release will involve production of rather fine aerosols. Steam production rates during this phase of the accident will vary from 2500 to 400 moles/s. Hydrogen generation rates will vary from about 120 to 20 moles per second.

- early in-vessel release will produce coarser aerosol particles in gas containing 10 to 90 percent hydrogen flowing at rates of 50 to 500 moles/s.

- the last portion of the early in-vessel release may be purged from the reactor coolant system by flows of 2000 to 6000 moles per second of steam containing 2 to 3 percent hydrogen.

- molar flows to the suppression pool during core debris/concrete interactions are 100 to $300 \mathrm{moles} / \mathrm{s}$ with occasional excursions to over 800 moles/s. Aerosols have uncertain sizes of 1.5 to $0.25 \mu \mathrm{m}$.

\footnotetext{
*The eruption of carbon monoxide release predicted in these calculations stems from the treatment of carbon dioxide reactions with molten, metallic zirconium in the core debris. This reaction is predicted to produce elemental carbon until the zirconium is completely oxidized. Then, carbon dioxide and steam from the concrete are predicted to react with the elemental carbon to form carbon monoxide. This type of behavior has not been observed in experiments done to date.
} 


\section{Accident}

- Little of the gas produced durring the early, stages of core debris/concrete interaction in a Mark I boiling water reactor will be condensible. At later times during the so-called "late in-vessel release" stage of the accident, 10 to 35 percent of the gas being discharged to the steam suppression pool will be water vapor.

- Degassing of concrete during the ex-vessel stages of a severe reactor accident in Mark II and Mark III reactors can introduce substantial amounts of water vapor into the gases being discharged to the suppression pools.

There have not been detailed analyses of aerosol particle sizes for the late in-vessel release of. radionuclides by revaporization. Some analyses for revaporization from the pressurized,water retactor Sizewell B suggest these particles can be quite small $(\sim 0.1 \mu \mathrm{m})$ [28]. The aerosols produced by revaporization will be carried into the suppression pool by gases generated during core debris interactions with concrete. 


\section{Physical Phenomena}

The physical phenomena that affect aerosol removal from gases that sparge through steam suppression pools are described in this chapter. The important phenomena can be broadly categorized as those phenomena affecting bubble and gas behavior and those phenomena affecting aerosol behavior. In the discussions of these two categories of phenomena presented below, emphasis is placed on the identification of areas of uncertainty that will affect the accurate prediction of aerosol removal by steam suppression pools. These phenomenological uncertainties, together with uncertainties concerning severe reactor accidents, are summarized in Chapter V and used in an uncertainty analysis of scrubbing by steam suppression pools described in Chapter VI.

\section{A. Bubble Formation}

Gases are injected into steam suppression pools via both quenchers and downcomers. In both cases, the details of the bubble size, shape, rise velocity, and the like significantly affect the extent of aerosol removal. There have been two studies of the behavior of bubbles released from models of quenchers in simulated steam suppression pools $[30,69]$. Both studies showed the same qualitative behavior. A schematic depiction of the observed behavior is shown in Figure 19. Large bubbles form at an orifice, detach and begin to rise. These bubbles collapse and shatter into smaller bubbles because of steam condensation in a subcooled pool or because of simple physical instability. A swarm of small bubbles then rises through the pool as a plume. That is, the rising bubbles entrain water in the upward flow.

The various regimes in the bubble plume have been named. The region near the orifice and to a height of about 10 bubble diameters is called the "injection zone." The injection zone is the region of rapid heat transfer from the bubbles to the liquid. Completion of bubble collapse marks the end of the injection zone and the beginning of the "zone of established flow." The zone of established flow extends to within less than a meter of the surface. The "zone of surface influence" is the region of the plume where the vertical component of water velocity is converted entirely into radial flow.

In the discussions below, models of the injection zone and the zone of established flow will be presented. A detailed description of hydraulics in the zone of surface influence is not included here. Amos [70] has discussed the complexity of this regime and its relative unimportance in the prediction of aerosol scrubbing by steam suppression pools.

Though the scrubbing of aerosols from gases released to a steam suppression pool has some qualitative similarities to aerosol removal by water pools overlying core debris interacting with concrete, there are a number of quantitative differences and several additional phenomena to consider. Certainly, the way bubbles are formed in the water pool is different as is the plume behavior of rising bubbles. Furthermore, gases directed to the suppression pool through quenchers and downcomers can be very rich in condensible water vapor whereas water vapor produced during core debris interactions is largely reduced to hydrogen. These and other physical phenomena that affect bubble behavior are discussed further below. 


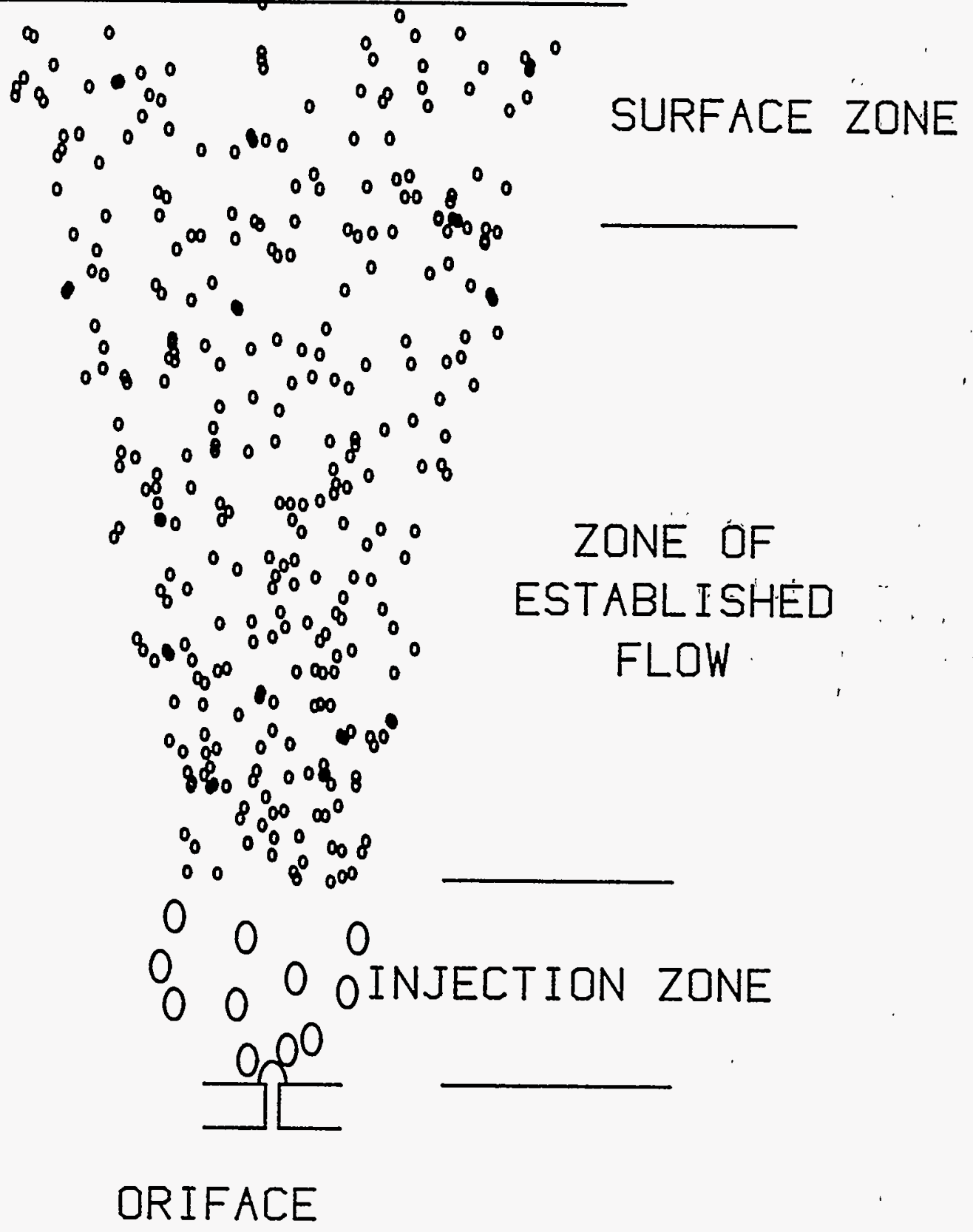

Figure 19. Schematic representation of bubble behavior when released into a steam suppression pool from a quencher 


\section{Bubble Formation at Quencher Orifices}

Paul et al. [30] have examined bubble formation by noncondensible gases $\left(\mathrm{He}, \mathrm{H}_{2}\right.$ and air) at orifices 0.9 to $2.02 \mathrm{~cm}$ in diameter. A schematic diagram of the injection apparatus used in this work is shown in Figure 20. Paul et al. indicate the system capacitance to be 3.25. Tsuge and Hibino [207] indicate that bubble formation is sensitive to variations in system capacitance in this regime.

Volumes of the gas bubbles detaching from orifices were correlated by Paul et al. in terms of a Weber number:

$$
\mathrm{V}_{\mathrm{N}}=3.45 \mathrm{We}^{0.46}
$$

where

$$
\begin{aligned}
\mathrm{V}_{\mathrm{N}} & =\frac{\left(\pi \mathrm{D}_{\mathrm{B}}^{3} / 6\right)}{\left(\pi \mathrm{D}_{\mathrm{o}}^{2} / 4\right)}\left(\rho_{1}-\rho_{\mathrm{g}}\right)^{1 / 2} \mathrm{~g}^{1 / 2} \sigma_{1}^{-1 / 2} \\
\mathrm{We} & =\text { Weber number }=\mathrm{U}_{0}^{2} \rho_{1} \mathrm{D}_{\mathrm{o}} / \sigma_{1}>40 \\
\mathrm{D}_{\mathrm{B}} & =\text { diameter of the sphere with a volume equivalent to the bubble when it detaches from } \\
\mathrm{D}_{\mathrm{O}} & =\text { orifice diameter, } \\
\mathrm{U}_{\mathrm{o}} & =\text { gas velocity in the orifice }=4 \dot{\mathrm{m}} / \rho_{\mathrm{g}}(\mathrm{o}) \pi \mathrm{D}_{\mathrm{o}}^{2}, \\
\mathrm{~m}^{2} & =\text { mass input rate of gas to the pool, } \\
\rho_{\mathrm{g}}(0) & =\text { density of the gas at the orifice, } \\
\rho_{1} & =\text { liquid density, } \\
\mathrm{g} & =\text { gravitational constant, and } \\
\sigma_{1} & =\text { liquid surface tension. }
\end{aligned}
$$

Predictions of this correlation are compared in Figure 21 to data obtained by Paul et al. [30] and data obtained by other investigators [32,36-39]. These data are listed in Table 5. Data are also consistent with the Davidson-Schuler model (see Figure 22) which will be discussed further below.

\footnotetext{
*The authors acknowledge the exemplary documentation provided by Paul et al. [30] for their work.
} 


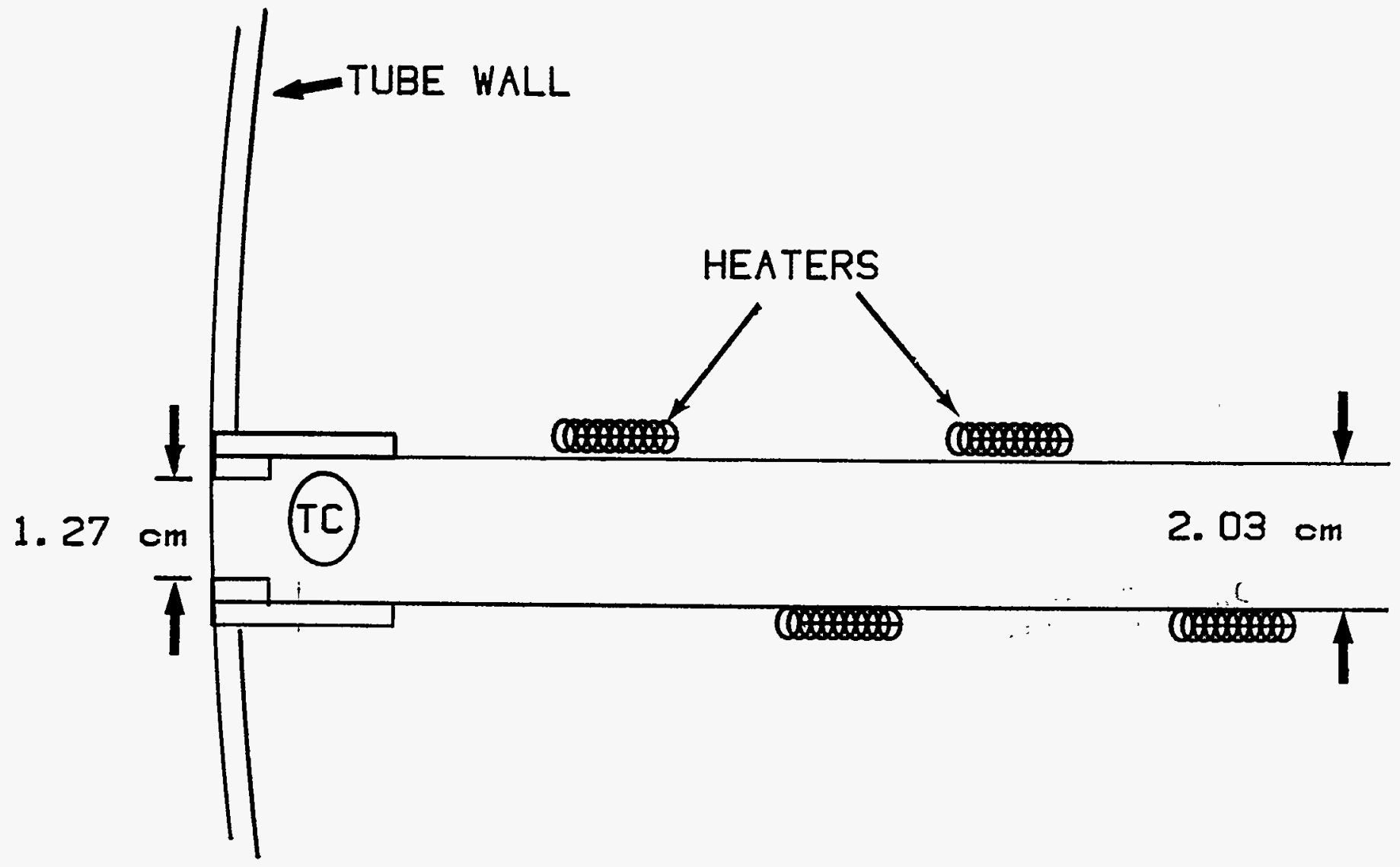

Figure 20. Bubble injector apparatus used in tests of bübble hydraulics by Paul et al. [30]' 
Physical Phenomena

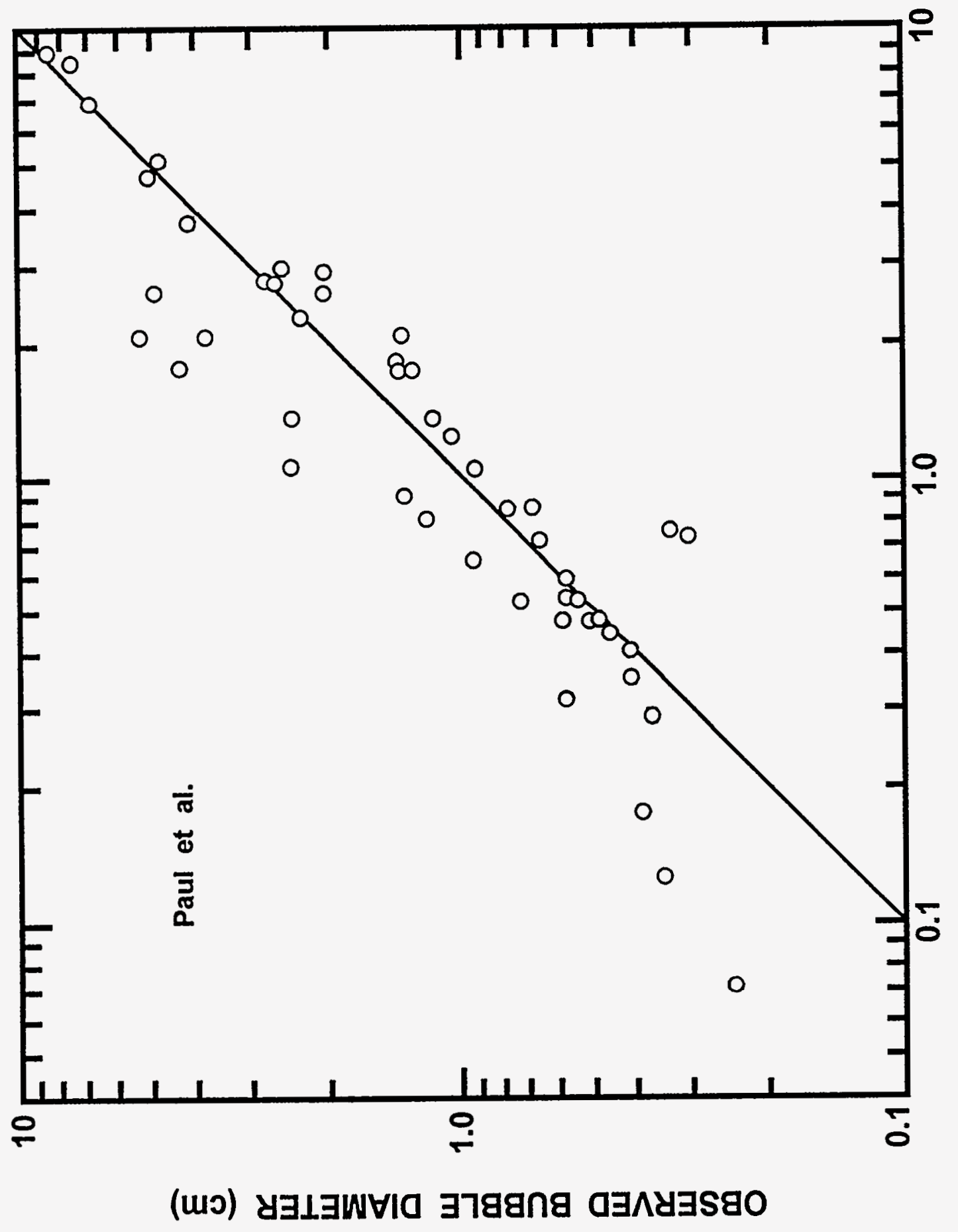

苋

蛋

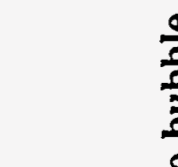

है

ह

스

iI

崖 递

Q गे

m

븐

0

뜸

a

马े

ले

कू ते

के है

응

을

일

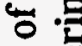

픙

.

芯恣

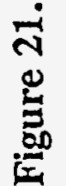


Physical Phenomena

Table 5. Sizes of bubbles formed at submerged orifices under constant flow conditions

\begin{tabular}{|c|c|c|c|c|c|c|c|c|}
\hline Liquid & Gas & $\begin{array}{c}\text { Liquid } \\
\text { viscosity } \\
(\mathrm{g} / \mathrm{cm}-\mathrm{s})\end{array}$ & $\begin{array}{l}\text { Surface } \\
\text { tension } \\
\text { (dyne/cm) }\end{array}$ & $\begin{array}{c}\text { Howrrate } \\
\left(\mathrm{cm}^{3} / \mathrm{s}\right)\end{array}$ & $\begin{array}{c}\text { Orifice } \\
\text { diameter } \\
(\mathbf{c m})\end{array}$ & $\begin{array}{c}\text { Bubble } \\
\left(\mathrm{cm}^{3}\right)\end{array}$ & Ref & \\
\hline Water & Air & 0.012 & 72.8 & 0.0081 & 0.036 & 0.0072 & $\therefore 36$ & : \\
\hline Water & Air & 0.012 & 72.8 & 0.06083 & 0.141 & 0.0292 & 36 & - \\
\hline Water & Air & 0.012 & 72.8 & 0.205 & 0.388 & 0.0984 & 36 & . \\
\hline Water & Air & 0.01 & 72 & 0.025 & 0.102 & 0.0212 & 37 & \\
\hline Water & Air & 0.01 & 72.7 & 0.5 & 0.0668 & 0.026 & 32 & \\
\hline Water & Air & 0.01 & 72.7 & 1.0 & $0: 0668$ & 0.0365 & 32 & \\
\hline Water & Air & 0.01 & 72.7 & 1.5 & 0.0668 & 0.0365 & 32 & \\
\hline Water & Air & 0.01 & 72.7 & 2.0 & 0.0668 & 0.050 & 32 & \\
\hline Water & Air & 0.01 & 72.7 & 2.5 & 0.0668 & 0.068 & 32 & 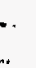 \\
\hline Water & Air & 0.01 & 72.7 & 5.0 & 0.04 & 0.2 & 32 & \\
\hline Water & Air & 0.01 & 72.7 & 10 & 0.04 & 0.42 & 32 & . \\
\hline Water & Air & 0.01 & 72.7 & 20 & 0.04 & 0.90 & 32 & $\therefore$ \\
\hline Water & Air & 0.01 & 72.7 & 30 & 0.04 & 1.3 & 32 & \\
\hline \multirow[t]{11}{*}{ Water } & Air & & & 59.5 & 1.27 & 6.33 & 30 & \\
\hline & & & & 110 & 1.27 & $9.71^{*}$ & 30 & \\
\hline & & & & 140 & 1.27 & 8.62 & 30 & \\
\hline & & & & 4070 & 1.27 & 225 & 30 & \\
\hline & & & & 18000 & 1.27 & 1090 & 30 & $\because$ \\
\hline & & & & 579 & 2.02 & 57.9 & 30 & i \\
\hline & & & & 1590 & 2.02 & 164 & 30 & 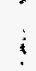 \\
\hline & & & s & 3510 & $.2 .02 \ldots$ & $328 \ldots$ & $=30:=$ & \\
\hline & & & & 128 & 0.99 & 10.9 & 30 & \\
\hline & & & & 349 & 0.99 & 35.9 & 30 & \\
\hline & & & & 730 & 0.99 & 70.2 & 30 & \\
\hline
\end{tabular}


Table 5. Sizes of bubbles formed at submerged orifices under constant flow conditions (concluded)

\begin{tabular}{|c|c|c|c|c|c|c|c|}
\hline Liquid & Gas & $\begin{array}{l}\text { Liquid } \\
\text { viscosity } \\
\text { (g/cm-s) }\end{array}$ & $\begin{array}{c}\text { Surface } \\
\text { tension } \\
\text { (dyne/cm) }\end{array}$ & $\begin{array}{c}\text { Flow rate } \\
\left(\mathrm{cm}^{3} / \mathrm{s}\right)\end{array}$ & $\begin{array}{l}\text { Orifice } \\
\text { diameter } \\
\text { (cm) }\end{array}$ & $\begin{array}{c}\text { Bubble } \\
\text { volume } \\
\left(\mathrm{cm}^{3}\right)\end{array}$ & Ref. \\
\hline \multirow[t]{3}{*}{ Water } & Helium & & & 80.8 & 1.27 & 7.35 & 30 \\
\hline & & & & 309 & 1.27 & 28.1 & 30 \\
\hline & & & & 644 & 1.27 & 61.9 & 30 \\
\hline \multirow[t]{21}{*}{ Water } & Hydrogen & & & 71.7 & 1.27 & 7.63 & 30 \\
\hline & & & & 360 & 1.27 & 42.8 & 30 \\
\hline & & & & 623 & 1.27 & 80.1 & 30 \\
\hline & & & & 1.5 & 0.43 & 0.1 & 39 \\
\hline & & & & 22 & 0.43 & 0.8 & 39 \\
\hline & & & & 1.5 & 0.27 & 0.1 & 39 \\
\hline & & & & 22 & 0.27 & 0.6 & 39 \\
\hline & & & & 1.5 & 0.15 & 0.06 & 39 \\
\hline & & & & 10 & 0.15 & 0.25 & 39 \\
\hline & & & & 1.5 & 0.107 & 0.05 & 39 \\
\hline & & & & 7 & 0.107 & 0.15 & 39 \\
\hline & & & & 1.249 & 0.32 & 0.0833 & 38 \\
\hline & & & & 160 & 0.96 & 4.445 & 38 \\
\hline & & & & 120 & 0.80 & 4.393 & 38 \\
\hline & & & & 60 & 0.79 & 1.335 & 38 \\
\hline & & & & 50 & 0.42 & 1.406 & 38 \\
\hline & & & & 60 & 0.40 & 1.443 & 38 \\
\hline & & & & 60 & 0.32 & 1.098 & 38 \\
\hline & & & & 18 & 0.164 & 0.418 & 38 \\
\hline & & & & 8 & 0.1 & 0.015 & 38 \\
\hline & & & & 9 & 0.1 & 0.019 & 38 \\
\hline
\end{tabular}




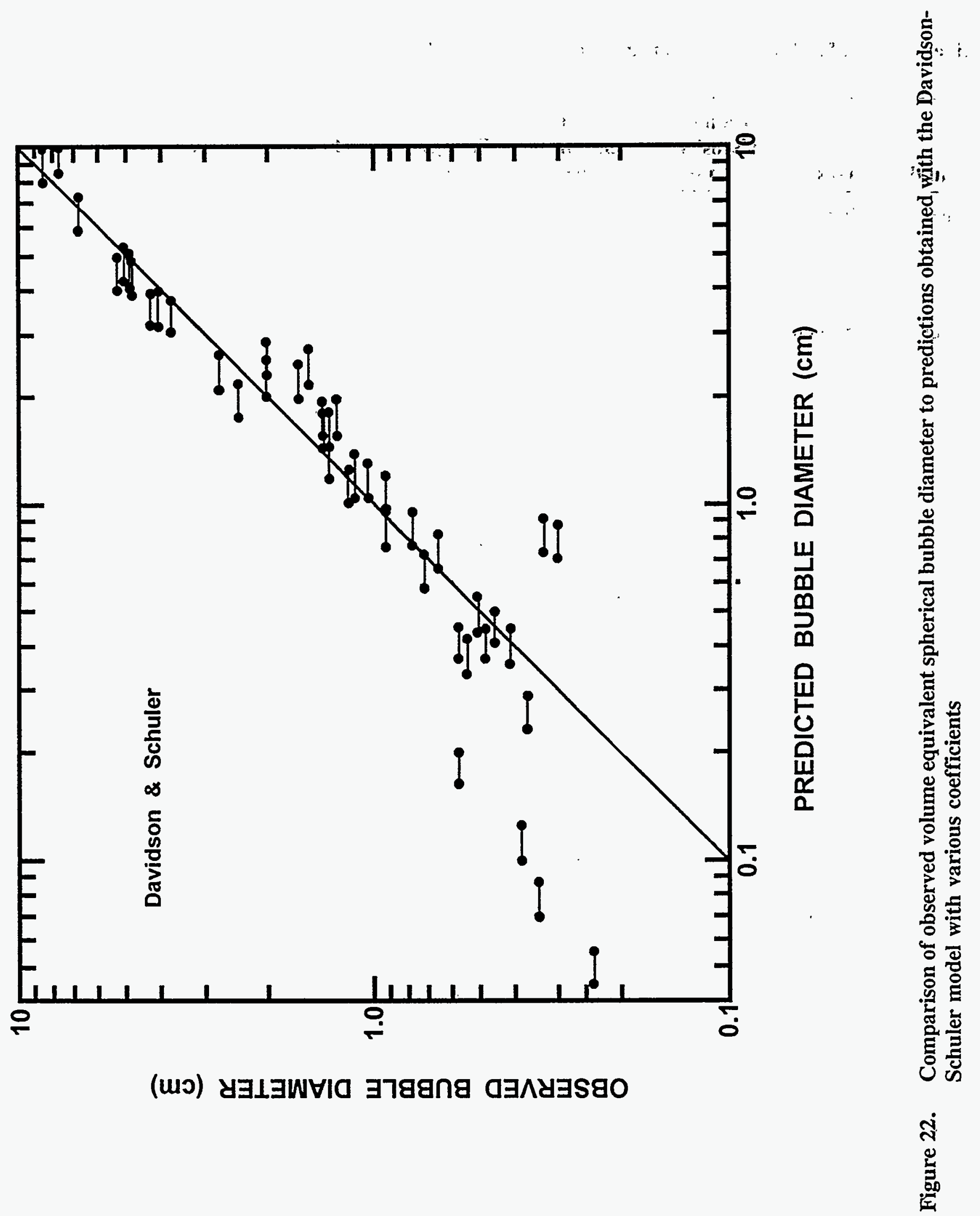


Though Paul et al. did experiments with bubbles supersaturated with steam (relative to the pool), they did not indicate that the above correlation was applicable to condensible gases. Besset [208] has investigated bubble formation with $373 \mathrm{~K}$ steam in subcooled water pools. This work was done with a $0.2-\mathrm{cm}$ orifice. Some of the data she obtained are listed in Table 6 . Besset found her data somewhat similar to predictions of the Davidson-Schuler model. Besset proposed a modification of this model to account for the effects of steam condensation during bubble formation:

$$
\mathrm{V}_{\mathrm{B}}=\frac{1.138 \mathrm{Q}^{6 / 5}}{\mathrm{~g}^{3 / 5}}-\frac{2.5 \times 10^{-4}}{\mathrm{~g} \mathrm{D}_{\mathrm{o}}{ }^{2}} \mathrm{QJa}-3 \mathrm{D}_{\mathrm{o}}^{3}
$$

where

$$
\begin{aligned}
\mathrm{Q} & =\text { volumetric flow rate } \\
\mathrm{Ja} & =\text { Jakob number }=\rho_{1} \mathrm{C}_{\mathrm{p}} \Delta \mathrm{T} / \rho_{\mathrm{g}} \mathrm{L}, \\
\mathrm{C}_{\mathrm{p}} & =\text { heat capacity of water, } \\
\Delta \mathrm{T} & =\mathrm{T}_{\mathrm{o}}-\mathrm{T}_{\mathrm{p}} \\
\mathrm{T}_{\mathrm{O}} & =\text { temperature of the vapor in the orifice, } \\
\mathrm{T}_{\mathrm{p}} & =\text { water pool temperature, and } \\
\mathrm{L} & =\text { latent heat of vaporization of water. }
\end{aligned}
$$

Her data are compared to this correlation in Figure 23. Deviations from the correlation become significant when $\Delta \mathrm{T}$ is greater than about 30 degrees Kelvin. The modified model tends to underpredict bubble sizes when the driving force for condensation is large. This may be complicated by the presence of small amounts of noncondensible gas dissolved in the water or in the steam.

Schmidt [293] has reported data on the formation of steam bubbles in subcooled water with very large driving forces for steam condensation. Some of his data is listed in Table 7. These data are not well predicted by the modified Davidson-Schuler correlation suggested by Besset. The data can be fit to a Weber number correlation similar to that suggested by Paul et al. [30], but the coefficients derived from such a fit are quite different than those found by Paul et al.:

$$
\mathrm{V}_{\mathrm{N}}=0.306 \mathrm{We}^{0.303}
$$

The fit of the data to this correlation is shown in Figure 24. Schmidt suggested a rather different correlation for the data: 
Physical Phenomena

Table 6. Besset's data on steam bubble formation in subcooled water [208]

\begin{tabular}{|c|c|c|c|c|c|}
\hline $\begin{array}{c}\mathrm{T} \text { (water) } \\
\text { (K) }\end{array}$ & 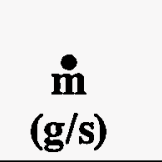 & $\left(\mathrm{cm}_{3} / \mathrm{s}\right)$ & $\begin{array}{c}\text { V(bubble) } \\
\left(\mathrm{cm}^{3}\right)\end{array}$ & $\begin{array}{c}\mathbf{f}= \\
\text { frequency } \\
\text { (bubbles/s) }\end{array}$ & $\begin{array}{c}\text { f V (bubble) } \\
\left(\mathrm{cm}^{3} / \mathrm{s}\right)\end{array}$ \\
\hline 296 & 0.0013 & 2.18 & $0.017 \pm 0.0060$ & $130 \pm 23$ & 2.21 \\
\hline 296 & 0.0016 & 2.68 & $0.008 \pm 0.0034$ & $340 \pm 167$ & 2.72 \\
\hline 296 & 0.0016 & 2.68 & $0.014 \pm 0.0059$ & $200 \pm 64$ & 2.80 \\
\hline 296 & 0.00178 & 2.98 & $0.015 \pm 0.0054$ & $200 \pm 64$ & 3.00 \\
\hline 325 & 0.0033 & 5.52 & $0.050 \pm 0.0085$ & $110 \pm 13$ & 5.50 \\
\hline 325 & 0.0040 & 6.69 & $0.050 \pm 0.014$ & $140 \pm 15$ & 7.00 \\
\hline 325 & 0.0043 & 7.19 & $0.033 \pm 0.012$ & $220 \pm 31$ & 7.26 \\
\hline 325 & 0.0052 & 8.70 & $0.018 \pm 0.0063$ & $450 \pm 99$ & 8.10 \\
\hline 339 & 0.0035 & 5.86 & $0.083 \pm 0.008$ & $75 \pm 5$ & 6.22 \\
\hline 339 & 0.0047 & 7.86 & $0.100 \pm 0.013$ & $80 \pm 7$ & 8.00 \\
\hline 339 & 0.0093 & 15.56 & $0.130 \pm 0.025$ & $120^{\prime} \pm 13$ & 15.60 \\
\hline 339 & 0.0098 & 16.40 & $0.096 \pm 0.021$ & $176 \pm 21$ & 16.90 \\
\hline 347 & 0.0040 & 6.69 & $0.120 \pm 0.011$ & $55 \pm 3$ & 6.60 \\
\hline 347 & 0.0058 & 9.70 & $0.170 \pm 0.019$ & $59 \pm 6$ & 10.03 \\
\hline 347 & 0.013 & 21.75 & $0.250 \pm 0.028$ & $86 \pm 9$ & 21.50 \\
\hline 347 & 0.0195 & 32.62 & $0.290 \pm 0.041$ & $115 \pm 14$ & 33.35 \\
\hline 354 & 0.00058 & 0.97 & $0.040 \pm 0.016$ & $25 \pm 4$ & 1.00 \\
\hline 354 & 0.0095 & 15.89 & $0.320 \pm 0.045$ & $51 \pm 6$ & 16.32 \\
\hline 359 & 0.0013 & 2.18 & $0.056 \pm 0.005$ & $41 \pm 2$ & 2.30 \\
\hline 359 & 0.0076 & 12.72 & $0.340 \pm 0.119$ & $39 \pm 7$ & 13.26 \\
\hline 359 & 0.0092 & 15.39 & $0.410 \pm 0.057$ & $38 \pm 4$ & 15.58 \\
\hline 359 & 0.0108 & 18.07 & $0.460 \pm 0.138$ & $41 \pm 9$ & 18.86 \\
\hline 359 & 0.0155 & 25.93 & $0.700 \pm 0.119$ & $38 \pm 10$ & 26.60 \\
\hline 359 & 0.0293 & 49.02 & $1.100 \pm 0.297$ & $46 \pm 12$ & 50.60 \\
\hline 363 & 0.0022 & 3.68 & $0.098 \pm 0.021$ & $37 \pm 7$ & 3.63 \\
\hline 363 & 0.0045 & 7.53 & $0.210 \pm 0.010$ & $36 \pm 1$ & 7.56 \\
\hline 366 & 0.0016 & 2.68 & $0.093 \pm 0.010$ & $29 \pm 3$ & 2.70 \\
\hline 366 & 0.0108 & 18.07 & $0.450 \pm 0.018$ & $41 \pm 8$ & 18.45 \\
\hline
\end{tabular}




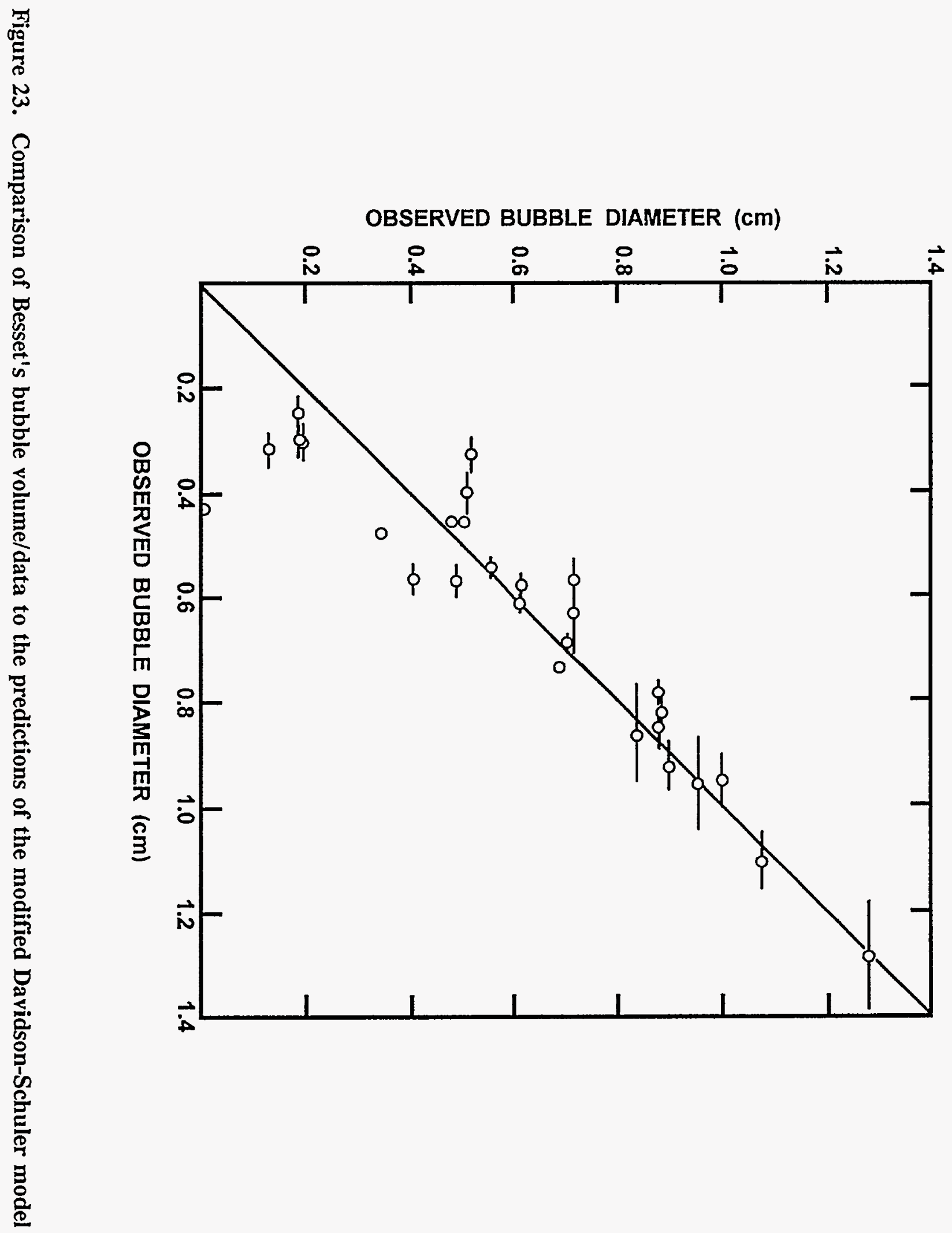

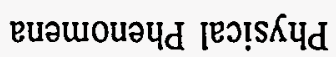


Table 7. Schmidt's data [293] for steam bubble formation in water

\begin{tabular}{|c|c|c|c|c|c|c|}
\hline$\underset{\text { (atms) }}{\mathbf{P}_{\mathbf{a}}}$ & $\begin{array}{c}\mathrm{D}_{0} \\
(\mathbf{c m})\end{array}$ & $\mathrm{T}_{\mathbf{Q}}-\mathrm{T}_{\mathrm{K}}$ & $\underset{(\mathrm{g} / \mathrm{s})}{\stackrel{\circ}{\mathrm{m}}}$ & $\underset{\left(\mathbf{c m}^{3}\right)}{\mathbf{V}_{\mathbf{B}_{3}}}$ & $\left(\mathrm{~cm}^{3} / \mathrm{s}\right)$ & $\underset{\left(\mathbf{c m}^{2}\right)}{\mathbf{A}_{\mathbf{B}_{2}}}$ \\
\hline \multirow[t]{2}{*}{40} & 0.3 & 150 & $\begin{array}{l}2.63 \\
2.74 \\
2.74 \\
4.25 \\
4.93\end{array}$ & $\begin{array}{l}0.140 \\
0.151 \\
0.169 \\
0.159 \\
0.174\end{array}$ & $\begin{array}{l}190.6 \\
198.5 \\
198.5 \\
308 \\
357\end{array}$ & $\begin{array}{l}1.304 \\
1.371 \\
1.478 \\
1.419 \\
1.507\end{array}$ \\
\hline & & & $\begin{array}{l}11.5 \\
11.5 \\
16.1 \\
16.8 \\
19.1\end{array}$ & $\begin{array}{l}0.248 \\
0.276 \\
0.259 \\
0.374 \\
0.326\end{array}$ & $\begin{array}{r}833 \\
833 \\
1167 \\
1217 \\
1384\end{array}$ & $\begin{array}{l}1.909 \\
2.050 \\
1.965 \\
2.510 \\
2.291\end{array}$ \\
\hline \multirow[t]{2}{*}{40} & 0.3 & 100 & $\begin{array}{l}2.54 \\
5.00 \\
6.03 \\
8.24 \\
8.24\end{array}$ & $\begin{array}{l}0.127 \\
0.149 \\
0.192 \\
0.205 \\
0.220\end{array}$ & $\begin{array}{l}167 \\
328 \\
395 \\
540 \\
540\end{array}$ & $\begin{array}{l}1.222 \\
1.359 \\
1.610 \\
1.681 \\
1.762\end{array}$ \\
\hline & & & $\begin{array}{l}9.56 \\
11.5 \\
13.1 \\
16.8 \\
16.8\end{array}$ & $\begin{array}{l}0.262 \\
0.286 \\
0.325 \\
0.290 \\
0.281\end{array}$ & $\begin{array}{r}627 \\
754 \\
859 \\
1102 \\
1102\end{array}$ & $\begin{array}{l}1.989 \\
2.099 \\
2.286 \\
2.119 \\
2.075\end{array}$ \\
\hline \multirow[t]{3}{*}{40} & 0.3 & 200 & $\begin{array}{l}2.63 \\
3.40 \\
6.14 \\
8.24 \\
8.24\end{array}$ & $\begin{array}{l}0.154 \\
0.180 \\
0.220 \\
0.311 \\
0.294\end{array}$ & $\begin{array}{l}208 \\
269 \\
485 \\
651 \\
651\end{array}$ & $\begin{array}{l}1.389 \\
1.542 \\
1.762 \\
2.220 \\
2.138\end{array}$ \\
\hline & & & $\begin{array}{l}11.55 \\
11.55 \\
16.11 \\
16.8 \\
19.1\end{array}$ & $\begin{array}{l}0.325 \\
0.364 \\
0.402 \\
0.465 \\
0.414\end{array}$ & $\begin{array}{r}913 \\
913 \\
1273 \\
1329 \\
1510\end{array}$ & $\begin{array}{l}2.286 \\
2.465 \\
2.634 \\
2.903 \\
2.686\end{array}$ \\
\hline & & & $\begin{array}{c}19.1 \\
8.24 \\
6.14\end{array}$ & $\begin{array}{l}0.339 \\
0.280 \\
0.205\end{array}$ & $\begin{array}{r}1518 \\
651 \\
485\end{array}$ & $\begin{array}{l}2.351 \\
2.070 \\
1.681\end{array}$ \\
\hline 80 & 0.3 & 100 & $\begin{array}{l}3.11 \\
5.09 \\
8.40 \\
9.38 \\
9.54\end{array}$ & $\begin{array}{l}0.0542 \\
0.0752 \\
0.118 \\
0.0918 \\
0.131\end{array}$ & $\begin{array}{l}104 \\
170 \\
283 \\
313 \\
318\end{array}$ & $\begin{array}{l}0: 693 \\
0.862 \\
1: 163 \\
0: 984 \\
1: 247\end{array}$ \\
\hline \multirow[t]{2}{*}{80} & 0.3 & 150 & $\begin{array}{l}1.93 \\
2.59 \\
2.76 \\
3.16 \\
5.00\end{array}$ & $\begin{array}{l}0.0612 \\
0.0656 \\
0.0682 \\
0.0656 \\
0.0856\end{array}$ & $\begin{array}{l}71.9 \\
96.5 \\
103 \\
118 \\
186\end{array}$ & $\begin{array}{l}0.751 \\
0.787 \\
0.807 \\
0.787 \\
0.939\end{array}$ \\
\hline & & & $\begin{array}{l}5.31 \\
6.10 \\
6.64 \\
9.36 \\
9.52\end{array}$ & $\begin{array}{l}0.115 \\
0.109 \\
0.122 \\
0.129 \\
0.163\end{array}$ & $\begin{array}{l}198 \\
227 \\
247 \\
348 \\
355\end{array}$ & $\begin{array}{l}1.144 \\
1.104 \\
1.190 \\
1.235 \\
1.443\end{array}$ \\
\hline
\end{tabular}

${ }^{\mathrm{a}}$ At $40 \mathrm{atms}$, the water temperature is $524 \mathrm{~K}$. Liquid surface tension is 26 dynes/cm and the liquid density is $0.7977 \mathrm{~g} / \mathrm{cm}^{3}$.

At $80 \mathrm{atms}$, the water temperature is $569 \mathrm{~K}$. The liquid surface tension is 15.2 dynes/cm and the liquid density is $0.7206 \mathrm{~g} / \mathrm{cm}^{3}$. 


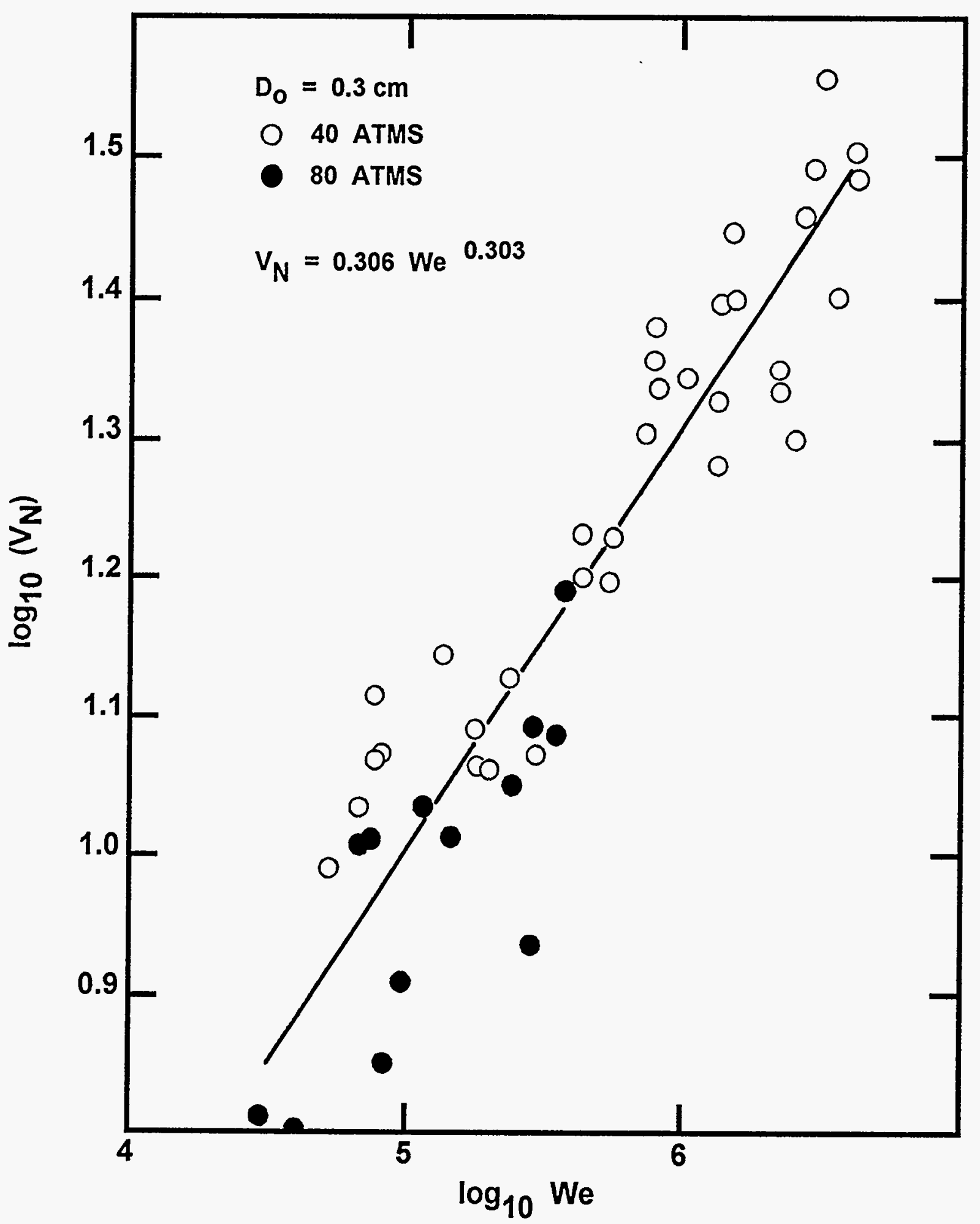

Figure 24. Fit of Schmidt's bubble volume data to a correlation in terms of the Weber number 


$$
A_{B}=1.913 \times 10^{-3} D_{o}^{2} f^{1 / 3}
$$

where

$$
\begin{aligned}
A_{B} & =\text { bubble surface area, and } \\
\mathrm{f} & =(\stackrel{\circ}{\mathrm{m}})^{1.35}\left[\mathrm{C}_{\mathrm{p}}\left(\mathrm{T}_{\mathrm{o}}-\mathrm{T}_{\mathrm{p}}\right) / \mathrm{P}\right]^{2.675} \sigma_{1}^{2} \mathrm{D}_{\mathrm{o}}{ }^{-2.35} \mathrm{~g}^{2} \mu_{1}^{3.35}
\end{aligned}
$$

Note that $f$ is dimensionless so some care must be taken in the selection of units for the heat capacity and the pressure.

\section{Models of Bubble Formation}

The modeling of bubble formation at an orifice has received a great deal of attention. Available models can be categorized as:
a. Single-stage models
b. Two-stage models
c. Numerical models

Some of the many examples of these various models are discussed below.

\section{a. The Davidson-Schuler Single-Stage Model}

The quintessential example of a single-stage model is that developed by Davidson and Schuler [32]. The volume of the bubble at the time it detaches from the orifice is given in this model by:

$$
\mathrm{V}_{\mathrm{B}}=\frac{\pi \mathrm{D}_{\mathrm{B}}^{3}}{6}=\frac{\mathrm{C} \mathrm{Q}^{6 / 5}}{\mathrm{~g}^{3 / 5}}
$$

where $\mathrm{C}$ is a constant and $\mathrm{Q}$ is the volumetric flow rate into the bubble. The original model, developed for constant flow conditions, used $C=1.378$. Empirical correlation of data yields $C=1.722$ [33]. Kumar and Kaloor [31] have shown that a simplification of a two-stage model yields $C=0.976$. An alternative derivation by Davidson and Harrison [34] yields $\mathrm{C}^{*}=1.138$. A critical step in the derivation of the model is the specification of the volume of water that is "attached" to the bubble. It is assumed that this water volume is proportional to the volume of the bubble:- Thee-proportionality constant is often taken to be $11 / 16$. But, values as low as $1 / 2$ have been used. The selection of the proportionality constant will affect the value of $\mathrm{C}$ in the Davidson-Schuler model.

The Davidson-Schuler model has been compared to data for noncondensible gases above (see Figure 22). The derivation of the model does not include treatment of condensation of the gas within the forming bubble. As noted above, when the driving force for steam condensation is not too large, 
observed bubble volumes agree rather well with the Davidson-Schuler model predictions especially if the uncertainty in the multiplicative coefficient $C$ is recognized.

\section{b. Two-stage Bubble Formation Models}

Two-stage bubble formation models make a distinction between the initial growth of a bubble, which is assumed spherical, and growth once the zone of attachment between the bubble and the orifice begins to "neck down." The model suggested by Kumar and Kaloor for constant flow conditions is [31]:

$$
\begin{gathered}
\mathrm{V}_{1}^{5 / 3}=\frac{0.04739 \mathrm{Q}^{2}}{\mathrm{~g}}+\frac{2.418 \mu_{\mathrm{l}} \mathrm{QV}_{1}^{1 / 3}}{\rho_{1} \mathrm{~g}}+\frac{\pi \mathrm{D}_{\mathrm{o}} \sigma_{\mathrm{I}} \mathrm{V}_{1}^{2 / 3} \cos \theta}{\rho_{\mathrm{I}} \mathrm{g}} \\
\mathrm{r}_{1} \cos \theta+0.5 \mathrm{D}_{\mathrm{o}} \sin \theta=\frac{\mathrm{B}\left(\mathrm{V}_{\mathrm{B}}^{2}-\mathrm{V}_{1}^{2}\right)}{2 \mathrm{Q}(\mathrm{A}+1)}-\frac{\mathrm{C}\left(\mathrm{V}_{\mathrm{B}}-\mathrm{V}_{1}\right)}{\mathrm{AQ}}-\frac{3 \mathrm{D}\left(\mathrm{V}_{\mathrm{B}}^{2 / 3}-\mathrm{V}_{1}^{2 / 3}\right)}{2 \mathrm{Q}(\mathrm{A}-1 / 3)}
\end{gathered}
$$

where:

$$
\begin{aligned}
& \mathrm{V}_{\mathrm{B}}=\text { final bubble volume } \\
& \mathrm{V}_{1}=\text { bubble volume at the end of the first growth stage } \\
& \mathrm{r}_{1}=\left(3 \mathrm{~V}_{1} / 4 \pi\right)^{1 / 3} \\
& \mathrm{~A}=1+14.6167 \mathrm{~V}_{1}^{1 / 3} \mu_{1} / \mathrm{Q}\left(\rho_{\mathrm{g}}+11 \rho_{\mathrm{l}} / 16\right) \\
& \mathrm{B}=\left(\rho_{1}-\rho_{\mathrm{g}}\right) \mathrm{g} / \mathrm{Q}\left(\rho_{\mathrm{g}}+11 \rho_{\mathrm{l}} / 16\right) \\
& \mathrm{C}=\pi \mathrm{D}_{\mathrm{o}} \sigma_{1} \cos \theta / \mathrm{Q}\left(\rho_{\mathrm{g}}+11 \rho_{\mathrm{l}} / 16\right) \\
& \mathrm{D}=2.418 \mu_{\mathrm{l}} /\left(\rho_{\mathrm{g}}+11 \rho_{\mathrm{l}} / 16\right)
\end{aligned}
$$

and $\theta$ is the angle describing the orientation of the orifice. When $\theta=0$, the orifice is horizontal with its axis pointing upward. When $\theta=90^{\circ}$, the orifice is vertical with its axis horizontal. The physical descriptions of bubble behavior that are the basis of the Kumar and Kaloor model are questionable for $\theta>60^{\circ}$ and inappropriate for $\theta>90^{\circ}$.

As the volume behind the orifice becomes very large, it becomes better to consider bubble formation to occur at constant pressure rather than at constant flow. Kumar and Kaloor's model for bubble formation at constant pressure is [31]: 


$$
\begin{aligned}
& \mathrm{V}_{1}\left(\rho_{1}-\rho_{\mathrm{g}}\right) \mathrm{g}=\left\{\frac{0.2068 \mathrm{~K}^{2}\left(\rho_{\mathrm{g}}+11 \rho_{1} / 16\right)}{\mathrm{V}_{1}^{2 / 3}}\right\}\left\{\mathrm{P}+0.6204 \rho_{1} \mathrm{gV}_{1}^{1 / 3}-\frac{3.224 \sigma_{1}}{\mathrm{v}_{1}^{2 / 3}}\right\} \\
& -\left\{\frac{0.055556 \mathrm{~K}^{2}\left(\rho_{\mathrm{g}}+11 \rho_{1} / 16\right)}{\mathrm{V}_{1}}\right\} \cdot\left\{2: 4814 \mathrm{PV}_{1} 1 / 3-1.1545 \rho_{1} \mathrm{gV}_{1}^{2 / 3}-10 \sigma \mathrm{d}\right\} \\
& +\frac{2.418 \mathrm{~K} \mu_{1}}{\mathrm{~V}_{1}^{2 / 3}}\left[\mathrm{P}+0.6204 \rho_{1} \mathrm{~g} \mathrm{~V}_{1}^{1 / 3}-\frac{3.224 \sigma_{\mathrm{l}}}{\mathrm{V}_{1}^{1 / 3}}\right]^{1 / 2}+\pi \mathrm{D}_{\mathrm{o}} \sigma_{1} \cos (\theta)
\end{aligned}
$$

and

$$
\mathrm{r}_{1} \cos \theta+0.5 \mathrm{D}_{\mathrm{o}} \sin \theta=\frac{\mathrm{B}\left(\mathrm{V}_{\mathrm{B}}^{2}-\mathrm{V}_{1}^{2}\right)}{2 \mathrm{Q}(\mathrm{A}+1)}-\frac{\mathrm{C}\left(\mathrm{V}_{\mathrm{B}}-\mathrm{V}_{1}\right)}{\mathrm{AQ}}-\frac{3 \mathrm{D}\left(\mathrm{V}_{\mathrm{B}}^{2 / 3}-\mathrm{V}_{1}^{2 / 3}\right.}{2 \mathrm{Q}(\mathrm{A}-1 / 3)}
$$

where $\mathrm{K}$ is a constant peculiar to the system. When multiple orificés'are coninectéd tö the'chamber volume, it is not immediately obvious whether the constant pressure or the constant flow models should

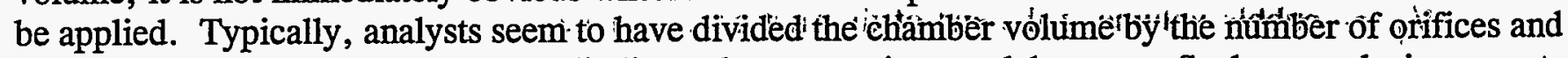
have used the resulting quotient to adjudicate the appropriate model to use. Such an analysis suggests that quenchers would be properly treated as they yielded bubbles formed under constant flow conditions.

The predictions of bubble diameter for noncondensible gases discharged into 'water obtained from the Kumar and Kaloor model are compared to data (Table 5) in Figure 25. It is clear from the comparison in this figure that the Kumar and Kaloor model is a much better predictor of the data thani either the Davidson and Schuler model (see Figure 22) or the correlation developed by Paul et al. (see Figure 21). The Kumar and Kaloor model predicts well data obtained for small orifices at low flow rates.which are not predicted well by the other model and correlation.

Ruff [35] has made empirical modifications to the Kumar and Kaloor model. His modified model is:

$$
\begin{gathered}
\mathrm{V}_{\mathrm{B}}=\mathrm{V}_{\mathrm{B}}{ }^{*} \mathrm{Q}^{6 / 5} \cdot \mathrm{g}^{-3 / 5} \\
\mathrm{~V}_{\mathrm{B}}^{*}=\mathrm{V}^{*}+\Delta \mathrm{V}^{*} \\
\mathrm{~V}^{*}=\frac{0.0578}{\left(\mathrm{~V}^{*}\right)^{2 / 3}}+\frac{2.417 \mu^{*}}{\left(\mathrm{~V}^{*}\right)^{1 / 3}}+0.204 \sqrt{\frac{\mu^{*}}{\mathrm{~V}^{*}}}+\pi\left(\mathrm{D}_{\mathrm{O}} \sigma_{1}\right)^{*}
\end{gathered}
$$


Physical Phenomena

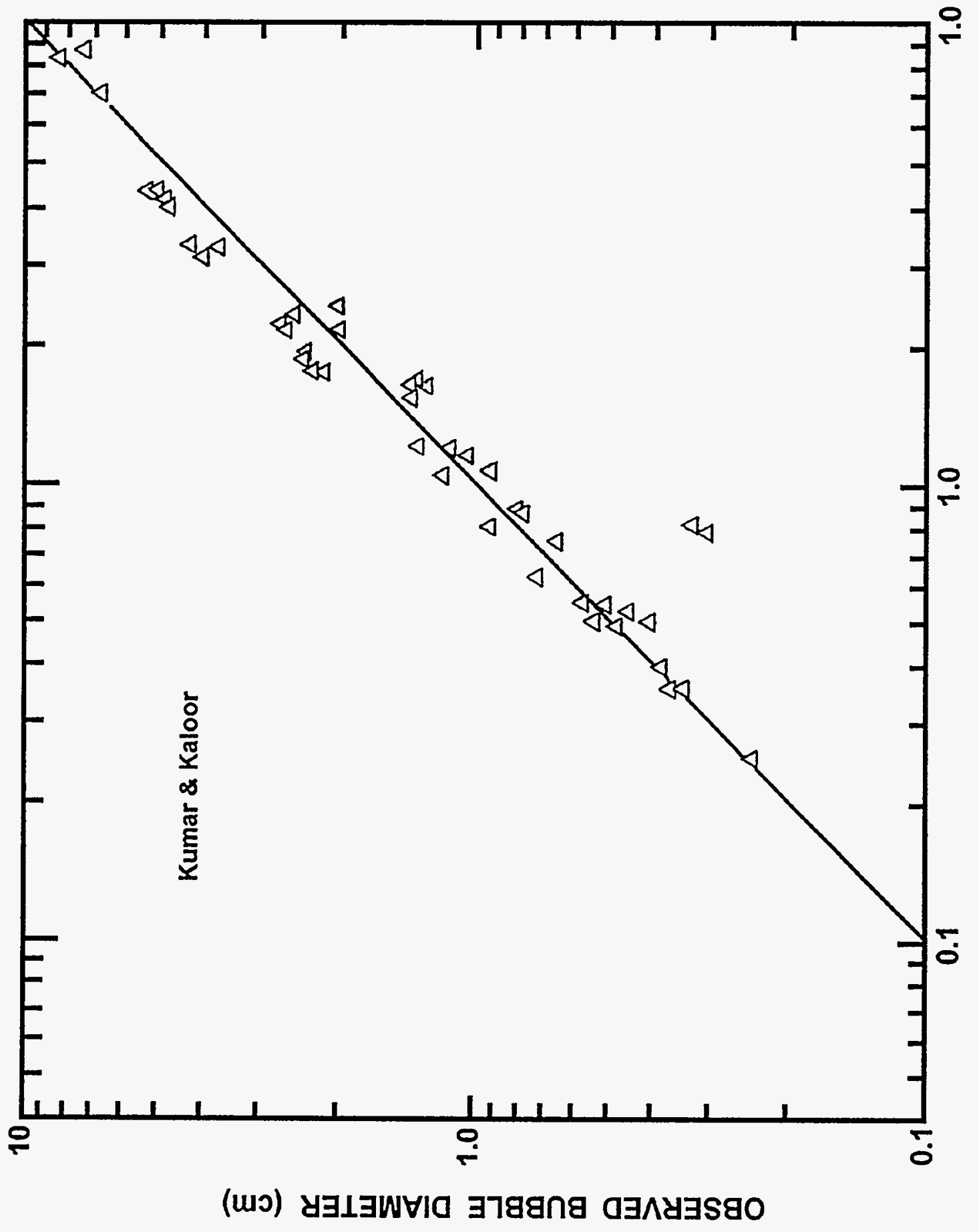

夠

ฐั๊

马

옳

련

马्ठ

$\widehat{E}$

弟

.

때용

岌

这

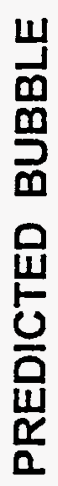


Physical Phenomena

$$
\Delta \mathrm{V}^{*}=1+4\left(\mu^{*}\right)^{3 / 4}
$$

where

$$
\begin{gathered}
\mu^{*}=\mu_{1} / \rho_{1} \mathrm{~g}^{1 / 5} \mathrm{Q}^{3 / 5} \\
\left(\mathrm{D}_{\mathrm{o}} \sigma_{1}\right)^{*}=\mathrm{D}_{\mathrm{o}} \sigma_{1} / \mathrm{g}^{2 / 5} \mathrm{Q}^{6 / 5} \rho_{1}
\end{gathered}
$$

Ruff's empirical corrections modestly improve the prediction of data as is shown in Figure 26.

The variation in the bubble diameter with orifice orientation predicted with the Kumar, and Kaloor model is shown in Figure 27 for air injected into water through a 1.27- $\mathrm{cm}$ orifice. Also shown in Figure 27. is the bubble diameter that would be predicted with Ruff's empirically modified model for a horizontal orifice $(\theta=0)$ and the range of bubble diameters that would be predicted with the Davidson-Schuler model. The prediction obtained with the correlation developed by Paul et al. [30] is off the scale of this figure. The Kumar and Kaloor model predicts that bubble diameter increases with increasing: orifice angle to a broad maximum centered at.about $37^{\circ}$. The bubble diameter decreases noticeably? with increasing orifice angle for angles greater than about $45^{\circ}$. The range of variation is, however, not large in comparison to the scatter in data about the model predictions for horizontal orifices (see Figure 25).

The two-stage models of bubble formation seem to be superior to the single-stage model or the empirical correlation by Paul et al. The superiority is revealed, however, by comparisons to data for orifices much smaller than those encountered in steam suppression pools. It might, then, be argued that the superiority is irrelevant. All of the models and the correlation do equivalently well predicting data fort orifices that are about $1 \mathrm{~cm}$ in diameter. The problem is, however, that the available data do not really: span the entire regime of interest for the analysis of aerosol removal by suppression pools. during severe reactor accidents. Since extrapolations will be necessary, the physically-based model developed by: Kumar and Kaloor is quite attractive. Extrapolations can be done with more confidence since the model does account for so much data.

Attractive as they are, the Kumar and Kaloor model or the empirical modification by Ruff do not account for condensation of water vapor during bubble formation. Perhaps the simplest modification to account for condensation is to correct the volume flow of gas through the orifice for steam condensation. The rate limitation for steam condensation is the convective removal of heat from the bubble by the suppression pool water. Detailed calculation of the rate of heat removal by water during the growth of a bubble would be a challenging undertaking. This also might be substantially more detailed than the available data on bubble formation. A simpler approach is to estimate an average heat transfer over the period of bubble formation. Then, the corrected volume flow of gas -to form the bubble is given by:

$$
\mathrm{Q}^{\prime}=\mathrm{Q}-\frac{\overline{\mathrm{Ah}}}{\mathrm{L}}\left(\mathrm{T}_{\mathrm{B}}-\mathrm{T}_{\mathrm{W}}\right) \frac{\mathrm{RT}_{\mathrm{B}}}{\mathrm{P}}
$$




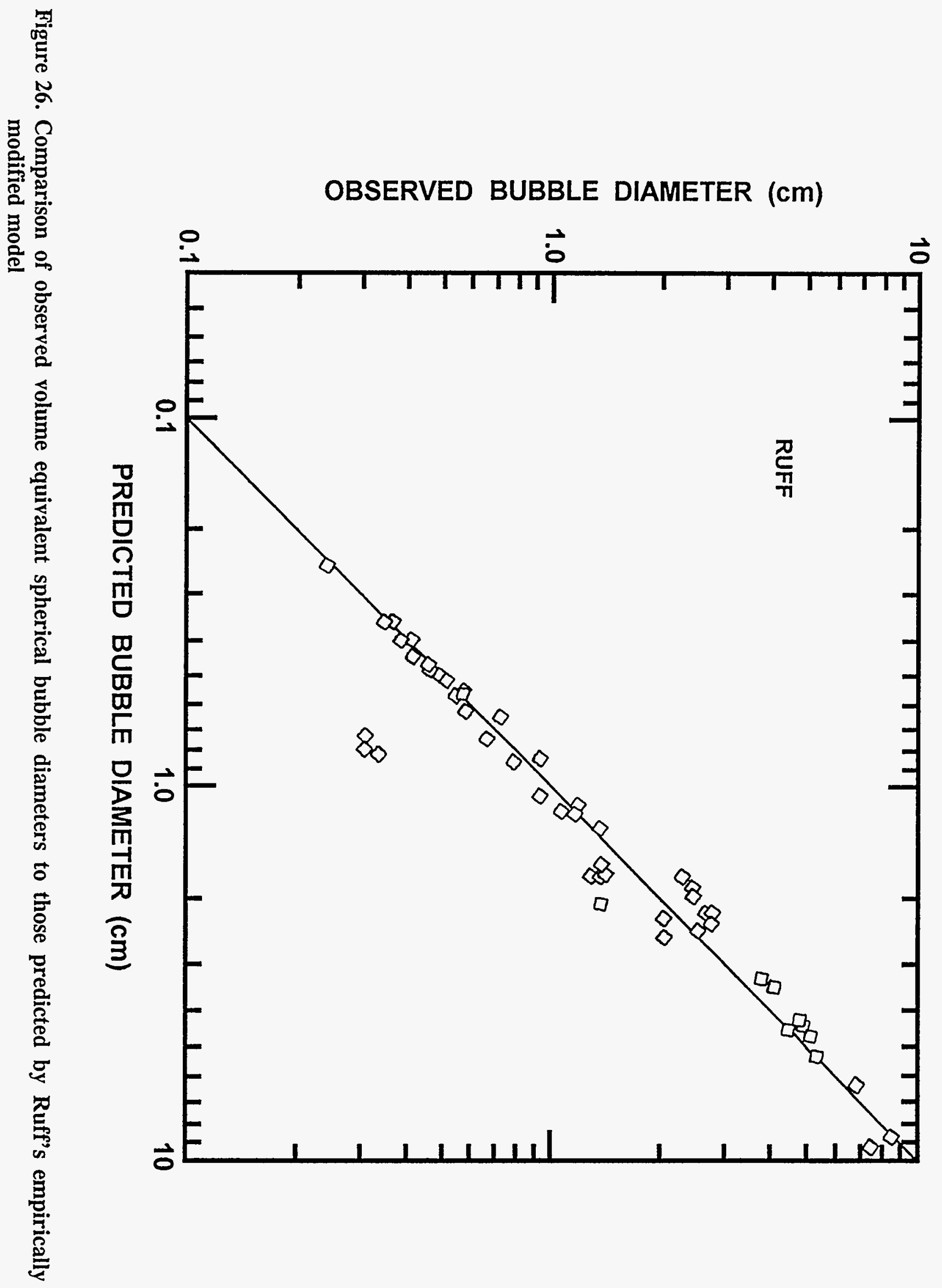

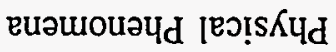




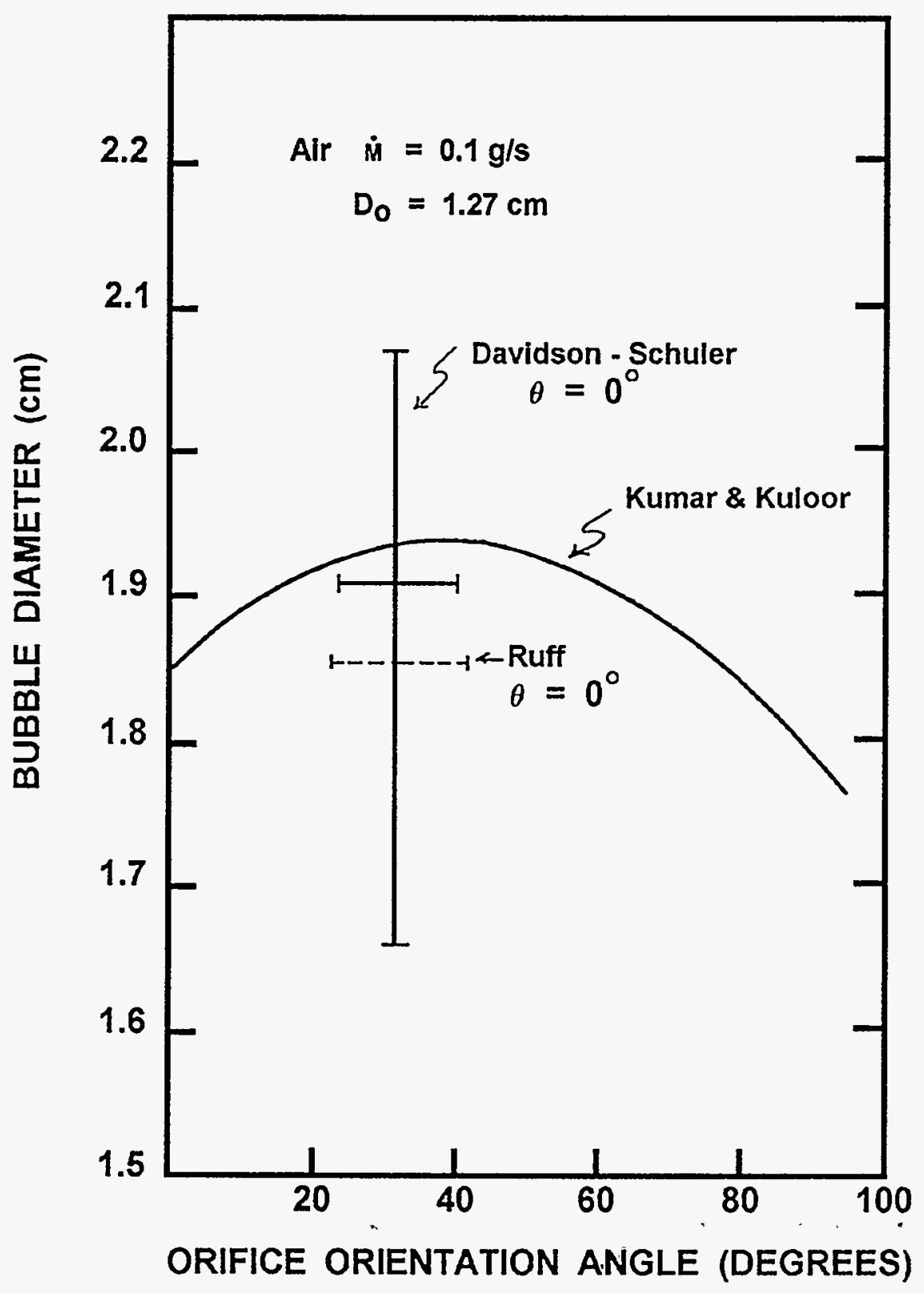

Figure 27. Variation in the bubble diameter with orifice orientation predicted with the Kumar and Kaloor model 
where

$$
\begin{aligned}
& \mathrm{Q}^{\prime}=\text { volume flow corrected for the effect of condensation, } \\
& \mathrm{Q}=\text { measured volume flow } \\
& \overline{\mathrm{Ah}}=\text { average product of bubble area and the heat transfer coefficient, } \\
& \mathrm{T}_{\mathrm{B}}=\text { saturation temperature in the bubble gas, } \\
& \mathrm{T}_{\mathrm{W}}=\text { bulk water temperature, and } \\
& \mathrm{P}=\text { pressure in the bubble. }
\end{aligned}
$$

Similar averaging formulations have been found useful for the estimation of mass transport during bubble formation [82].

Under most conditions hypothesized to develop in steam suppression pools during reactor accidents, the driving force for steam condensation, $\mathrm{T}_{\mathrm{B}}-\mathrm{T}_{\mathrm{W}}$, is not expected to be large. Certainly, it is not expected to be as large as the driving force for steam condensation in Schmidt's experiments [72]. Data obtained by Besset [208] involve conditions more nearly like those expected to exist during bubble formation in a steam suppression pool. Consequently, the Ruff model with the simple average correction for the effects of steam condensation was fit to Besset's data. It was found that a decidedly better fit could be obtained by allowing the heat transfer coefficient to be proportional to the steam flow rate:

$$
\overline{\mathrm{Ah}}=\xi \mathrm{Q}
$$

The value of the proportionality constant derived from the fit is:

$$
\xi=4.24 \times 10^{-3} \mathrm{cal} / \mathrm{cm}^{3}-\mathrm{K}
$$

Predicted and observed bubble diameters are compared in Figure 28. The simple correction for the effects of condensation tends to overpredict bubble sizes for $\mathrm{T}_{\mathrm{B}}-\mathrm{T}_{\mathrm{W}}<50 \mathrm{~K}$. For larger condensation driving forces, the simple model under-predicts bubble size. The differences between predictions and observations are, however, not large.

\section{c. Numerical Models}

In recent years, detailed numerical models of bubble formation at submerged orifices have become more popular than derivation of approximate analytic expressions. The numerical models are able to account for the nonspherical nature of bubbles and other complexities such as flows in the liquid phase. The numerical modeling of bubble formation was, apparently, pioneered by Kupferberg [258]. Since this original work, the method has been developed substantially [207, 259-264]. Recent models are able to show the "necking" of bubbles (that leads to detachment) is a natural consequence of the governing equations [262]. 


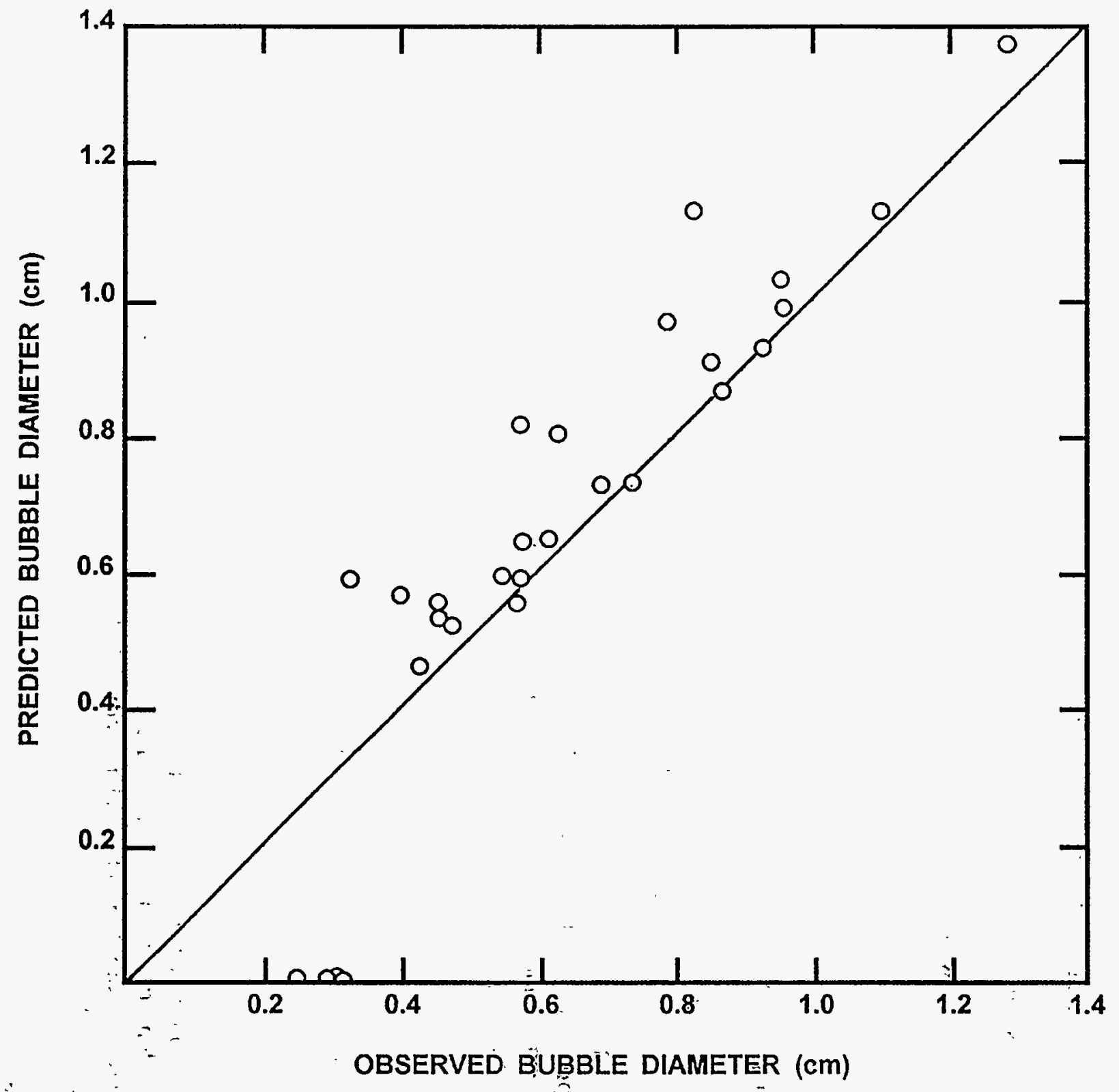


Most of the very detailed, numerical simulations of bubble growth have not considered condensation. In any event, the models are far more detailed than can be used or is needed for this work. Though this topic will be pursued further in connection with aerosol trapping, it is not discussed further here.

\section{Bubble Formation at Downcomers}

The regimes of bubble formation at downcomers have been studied primarily in connection with investigations of steam suppression pool behavior during design-basis accidents. Lee and Chan [40] have reviewed some of this literature. Based on small-scale experiments with a 5.08-cm-diameter downcomer, they produced the flow regime map shown in Figure 29. This work was done for higher mass flows than would be expected for the ex-vessel phases of severe accidents. Also, the vapor of interest in design basis studies is nearly all steam and does not contain the substantial fraction of noncondensible gases (nitrogen, hydrogen, carbon dioxide and carbon monoxide) that would be expected to be present in gases passing through downcomers in a severe accident. The disparities between flow rates and gas compositions in severe accidents versus flow rates and gas compositions in design basis accidents, make it difficult to believe the precise boundaries between regimes found by Lee and Chan are applicable to severe accident source term attenuation that is of interest here. Further doubt on the absolute applicability of the Lee and Chan results is raised by the issues of scaling the findings from tests with a 5-cm diameter vent to full-size vents and downcomers that have diameters of about $60 \mathrm{~cm}$. Certainly, the regime that Lee and Chan indicate will allow steam to escape their small scale pool cannot be extrapolated to actual suppression pools in which the downcomer is more deeply submerged. The qualitative features of flow through a downcomer observed by Lee and Chan may be applicable to issues of severe accidents if allowances are made for the presence of noncondensible gases.

At very low flows, Lee and Chan observed no bubble formation. Steam simply condensed within the piping system. An interface with the liquid in the pipe was maintained. Were substantial amounts of noncondensible gas present, bubbles would form in the downcomer at least episodically. Nevertheless, the important observation that at low flows substantial condensation can take place within the downcomer has a bearing on aerosol removal. Condensation of vapor would sweep out aerosol particles (diffusiophoretic deposition). Temperature gradients within the gas phase could also cause some decontamination (thermophoretic deposition).

Lee and Chan [40] clearly felt most of the vapor condensation took place on the submerged walls of the downcomer. The interface between the liquid and the gas phase within the downcomer was assumed to be quickly steam-saturated. Other theoretical analyses of downcomer performance have considered mechanisms by which condensation at the interface could be important [41].

The focus of studies by Lee and Chan was on "chugging" in the downcomer. Chugging occurs when condensation of steam proceeds more rapidly than supply. A partial vacuum is created and water is pulled up into the downcomer until the rate of condensation falls below the rate of supply of steam. At low flow rates of steam, the chugging phenomenon occurs entirely within the downcomer. A schematic illustration of liquid behavior in such an internal chugging event observed by Lee and Chan is shown in Figure 30. Of course, with substantial amounts of noncondensible gas present, chugging could not be confined entirely to within the downcomer even at very low flows.

With increases in mass flow and decreases in the water pool subcooling, Lee and Chan observed chugging phenomena outside the downcomer. Schematic illustrations of gas behavior in chugging with 


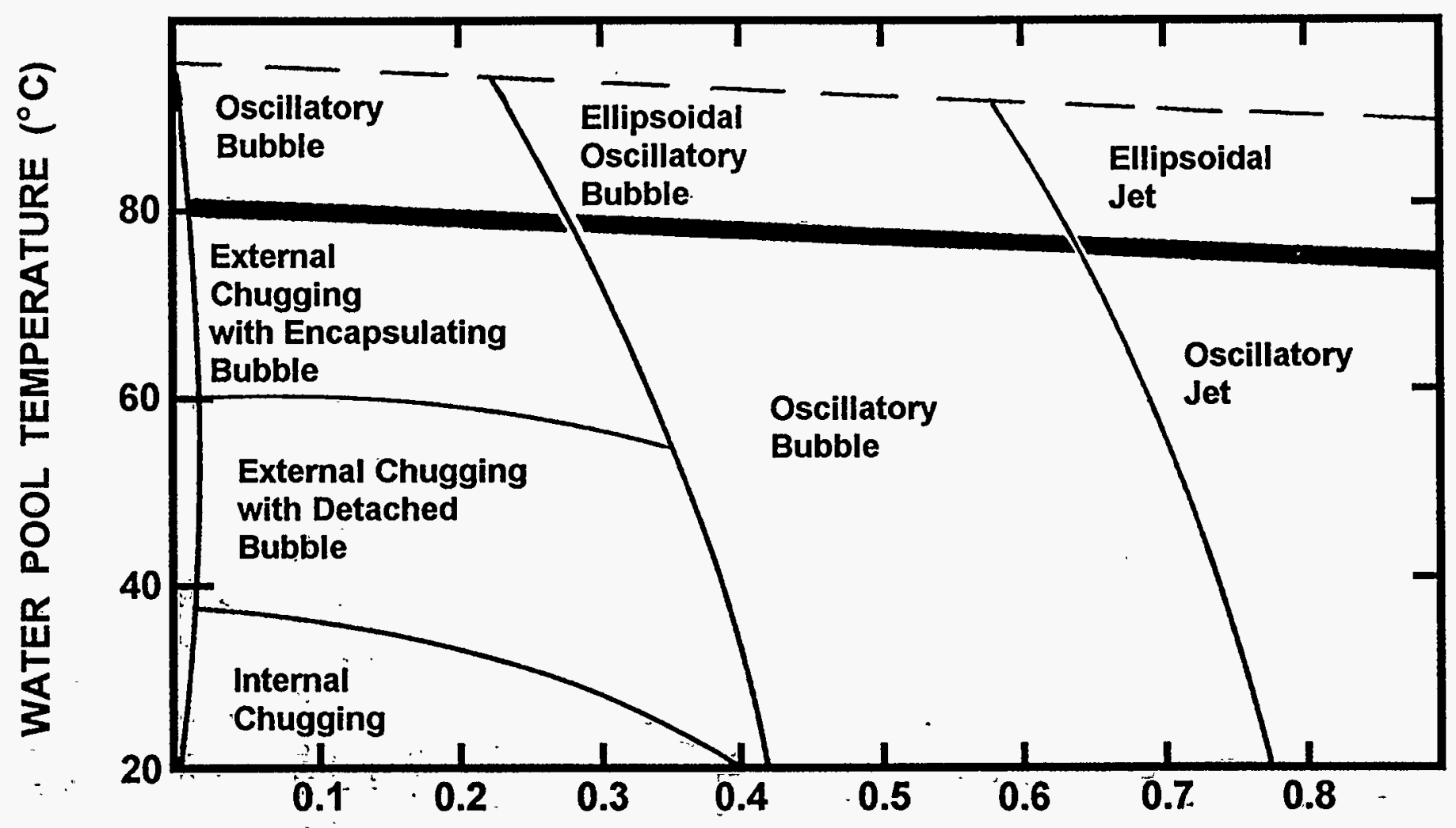

MOLES STEAM PER $\mathrm{cm}^{2}$-S 


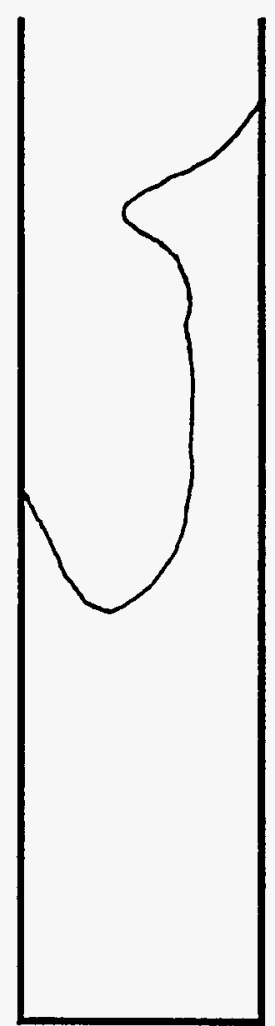

0

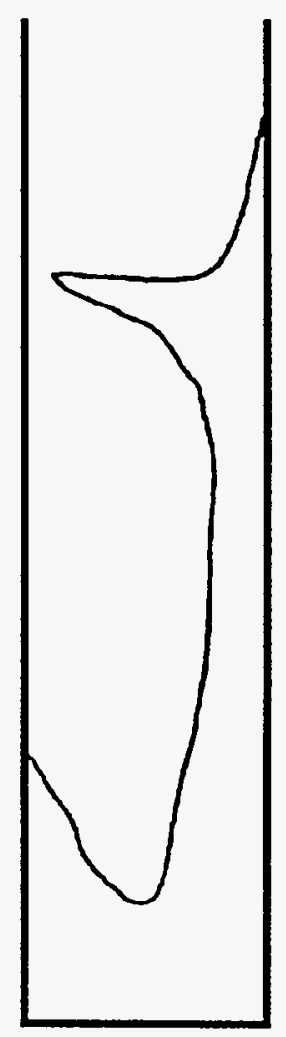

$8 \mathrm{~ms}$

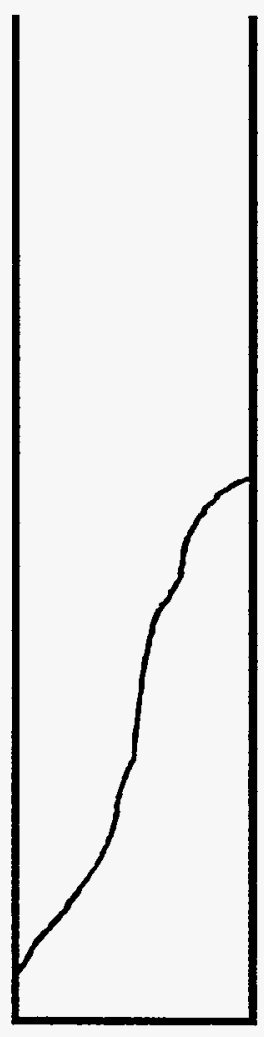

$21 \mathrm{~ms}$

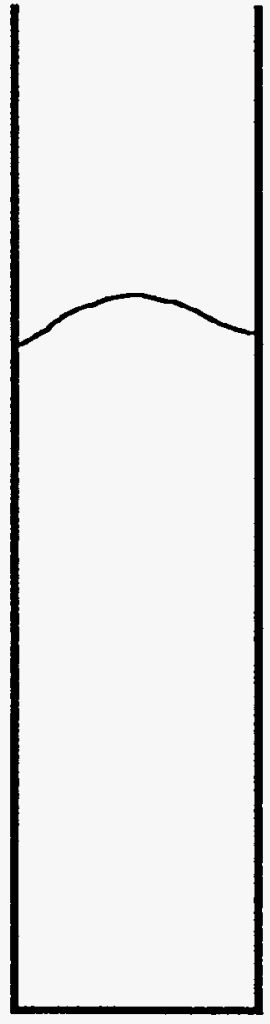

$45 \mathrm{~ms}$

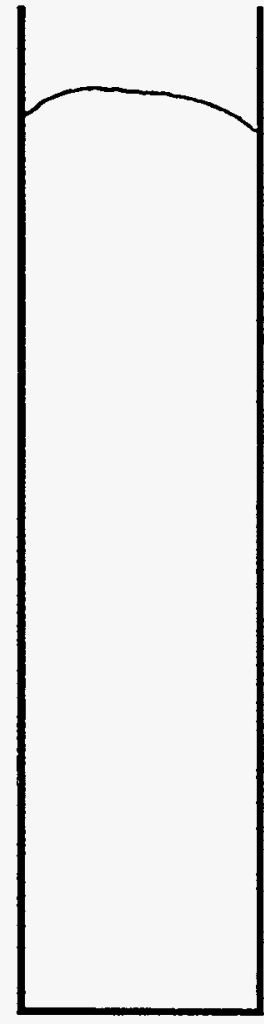

$61 \mathrm{~ms}$

Figure 30. Internal "chug" observed in tests by Lee and Chan [40] 
bubble detachment and without bubble detachment are shown in Figures 31 and 32 . In the case of chugging without bubble detachment, a vapor volume rose up around the downcomer.

Finally, Lee and Chan did not observe chugging at low levels of subcooling. Instead, vapor permanently extended to the end of the downcomer. Bubbles would detach and rise up around the downcomer.

Detached bubbles were observed to collapse and disintegrate as they rose through the subcooled water pool. Lee and Chan describe the collapse as beginning in a smooth fashion. As collapse progressed, indentations and evidence of instability appeared on the surface of the bubble. The appearance of irregularity in the bubble surface marked the beginning of bubble disintegration.

The qualitative observations made by Lee and Chan indiçate that there are two classes of bubble behavior in the case of downcomers. In some cases, bubbles detach from the orifice and disintegrate. This case is not greatly different than the situation considered fọr bubbles forming at orifices on quenchers. The second class of bubble behavior does not involve dẹtachment of the bubblle. Instead, the bubble envelops the downcomer and rises up around it before disintegrating. This lis called the "encapsulating bubble" case.

One would expect that there is some effect of the downcomer on theibubble swarm produced by bubble disintegration. It may be that bubbles rising near the downcomer behave differently than bubbles rising : in the bulk suppression pool. Entrainment of liquid by the rising swarm to form plume (see below) must be affected. This issue is not pursued further here aside from acknowledging it as an uncertainty that might affect predictions of aerosol behavior in the bubbles.

Lee and Chan do not provide much detail concerning bubbles expelled from the downcomer. They consider the bubble volume to be approximately:

$$
\mathrm{V}_{\mathrm{B}}=\frac{\pi}{6} \mathrm{D}^{3}
$$

where $\mathrm{D}$ is the diameter of the downcomer.

The SPARC model [6] uses a Weber number correlation developed from data obtained at the Battelle Columbus Laboratory [42] to describe the bubbles formed by a downcomer:"

$$
\left[\frac{\mathrm{V}_{\mathrm{B}}}{\pi \mathrm{D}^{2 / 4}}\right] \frac{\left(\rho_{1}-\rho_{\mathrm{g}}\right)^{1 / 2} \mathrm{~g}^{1 / 2}}{\sigma_{1}^{1 / 2}}=0.0891 \mathrm{We}^{0.616}
$$

where

$$
\begin{aligned}
& \mathrm{We}=\mathrm{U}_{\mathrm{o}}^{2} \rho_{1} \mathrm{D}_{\mathrm{p}} / \sigma_{1} \\
& \mathrm{D}_{\mathrm{p}}=\text { downcomer diameter }
\end{aligned}
$$



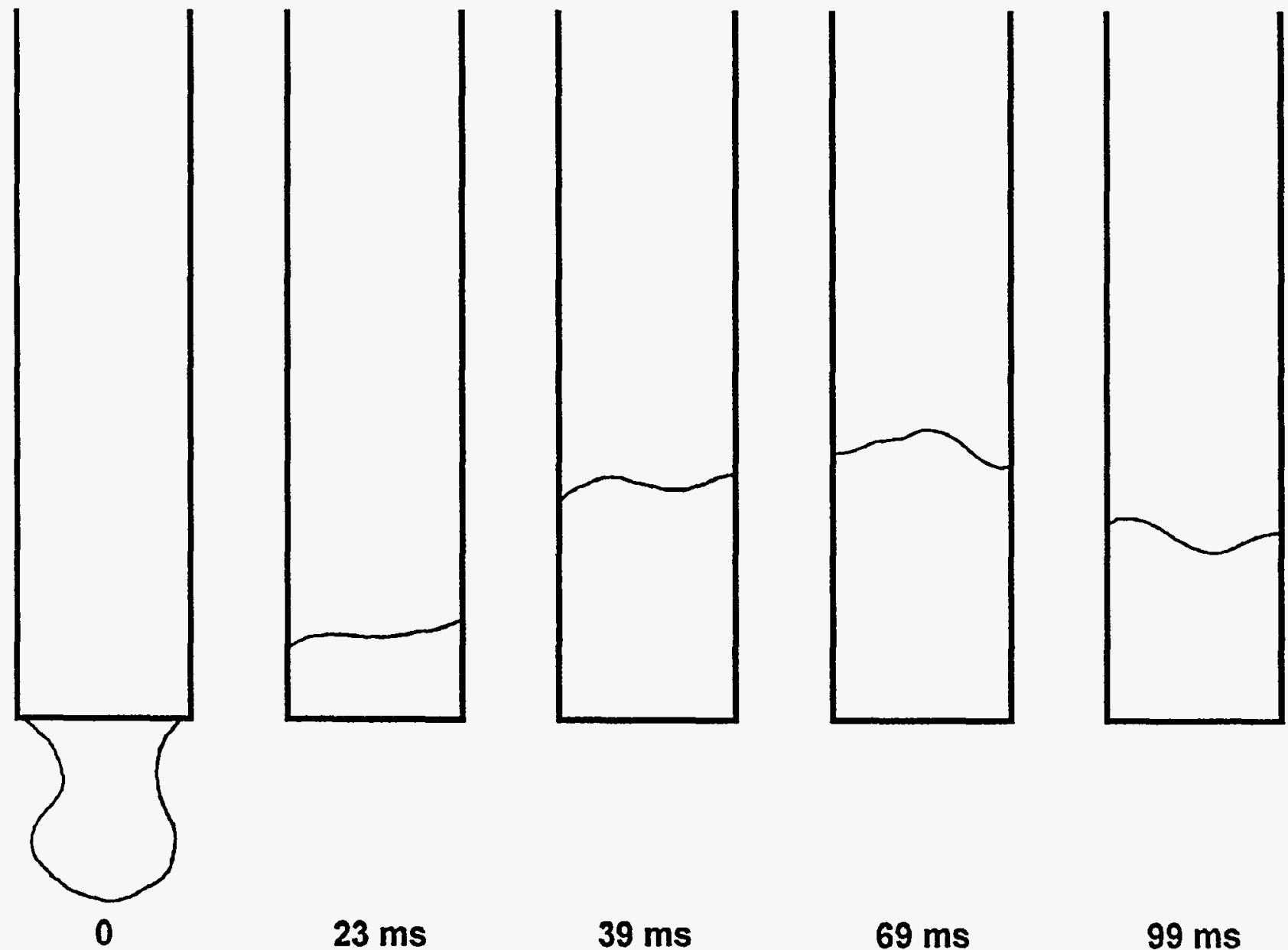

$23 \mathrm{~ms}$

$39 \mathrm{~ms}$

$69 \mathrm{~ms}$

$99 \mathrm{~ms}$

Figure 31. "Chugging" with bubble detachment observed in tests by Lee and Chan [40] 


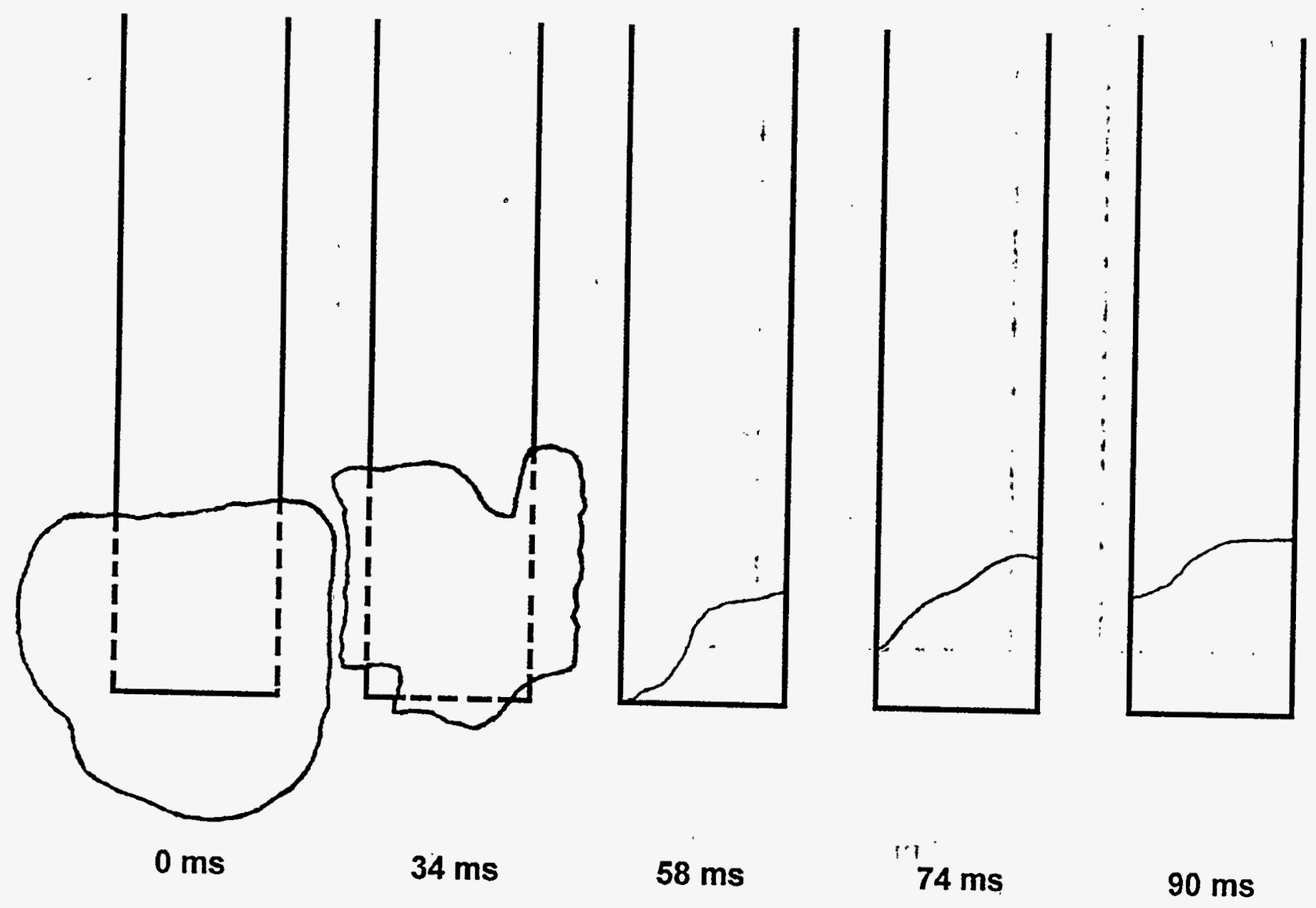

Figure 32. "Chugging" without bubble detachment observed in tests by Eee and:Chan [40] NUREG/CR-6153 
The BUSCA model [9] uses a correlation of data [38] suggested by Paul et al. [30]:

$$
\mathrm{V}_{\mathrm{B}}\left(\mathrm{mm}{ }^{3}\right)=0.0505\left[\mathrm{U}_{0}(\mathrm{~mm} / \mathrm{s})\right]^{0.95}\left[\mathrm{D}_{\mathrm{p}}(\mathrm{mm})\right]^{2.38}
$$

Wraith [214] has developed a description of bubble formation at downward facing nozzles at the same level of approximation as the Davidson-Schuler model of bubble formation at upward facing nozzles. This description yields:

$$
\mathrm{D}_{\mathrm{B}}(\mathrm{cm})=0.327 \mathrm{Q}\left(\mathrm{cm}^{3} / \mathrm{s}\right)^{0.4}
$$

Tsuge et al. [215] have described a two-stage model of bubble formation at a downward facing nozzle. They provide differential equations for the "expansion phase" and the detachment" phase of bubble formation. For constant flow the bubble volume change with time is given by:

$$
\frac{d V_{B}(1)}{d t}=\frac{d(4 / 3) \pi r^{3}}{d t}=Q
$$

where $Q$ is the volumetric flow rate of gas. The expansion phase ends when

$$
\begin{aligned}
& \rho_{1} \mathrm{~g}\left[(4 / 3) \pi \mathrm{r}^{3}-\pi \mathrm{D}^{2}(\mathrm{o}) \mathrm{r} / 2\right]=0.5 \mathrm{C}_{\mathrm{D}} \rho_{1} \pi \mathrm{r}^{2}\left[\frac{\mathrm{dr}}{\mathrm{dt}}\right]^{2} \\
& +\frac{\mathrm{d}}{\mathrm{dt}}\left[(2 / 3) \pi \mathrm{r}^{3} \rho_{1} \frac{\mathrm{dr}}{\mathrm{dt}}\right]+4 \rho_{\mathrm{g}} \mathrm{Q}^{2} / \pi \mathrm{D}(\mathrm{i})^{2}+\pi \mathrm{D}(\mathrm{i}) \sigma_{1}
\end{aligned}
$$

where

$$
\begin{aligned}
& \mathrm{D}(\mathrm{o})=\text { outer diameter of the downcomer, } \\
& \mathrm{C}_{\mathrm{D}}=\text { drag coefficient, and } \\
& \mathrm{D}(\mathrm{i})=\text { inner diameter of the downcomer. }
\end{aligned}
$$

The expansion phase is characterized by:

$$
Q=\frac{d}{d t}\left[4 \pi r^{3} / 3-\pi D^{2}(0)(r+x) / 4\right]=\frac{d V_{B}(3)}{d t}
$$

and

$$
\frac{\mathrm{d} 0.5 \mathrm{~V}_{\mathrm{B}}(3) \rho_{1}}{\mathrm{dt}}=\rho_{1} \mathrm{~V}_{\mathrm{B}}(3) \mathrm{g}-0.5 \mathrm{C}_{\mathrm{D}} \rho_{1} \pi \mathrm{r}^{2}\left[\frac{\mathrm{dx}}{\mathrm{dt}}\right]^{2}-4 \rho_{\mathrm{g}} \mathrm{Q}^{2} / \pi \mathrm{D}^{2}(\mathrm{i})-\pi \mathrm{D}(\mathrm{i}) \sigma_{1}
$$


where $\mathrm{x}$ is the location of the bubble center relative to the opening of the downcomer. The bubble" is taken to detach from the downcomer when $x=r$. The detached bubble volume is:

$$
4 \pi r^{3} / 3-\pi D(0)^{2} r / 2=V_{B}
$$

and

$$
D_{B}=\left(\frac{6 V_{B}}{\pi}\right)^{1 / 3}
$$

Tsuge et al. show good agreement between model predictions and bubble-diameters forl'high' gás flow through downcomers with inner diameters of $1 \mathrm{~cm}$ and less. At lower gas flow's, the mờdèl sóméwhat overpredicts bubble size.

The model developed by Tsug et al. has been used here to calculate bubble volumes for flow Weber numbers of $1 \times 10^{-5}$ to $3.6 \times 10^{4}$ for a $60 \mathrm{~cm}$ diameter downcomer submerged to a depth of $400 \mathrm{~cm}$. The predicted volume-equivalent spherical bubble diameters varied from $73.5 \cdot$ to $75 \mathrm{~cm}$ over this flow range! The essentially constant bubble diameter predicted with the model is not "nensitive to "any significant extent to the submergence of the downcomer.

Predictions of the various models are compared in Figure 33. Predictions derived from the correlations of small bubble sizes at low flow rates are certainly at odds with predictions of the two-stage model developed by Tsuge et al. [215] and do not seem physically reasonable.

Another qualitative observation made by Lee and Chan [40] is that substantial heat transfer from the gas phase takes place within the downcomer itself. Thermal gradients as well as steam condensation taking place within the downcomer could be important mechanisms for the removal of aerosols from the gas phase. Lee and Chan seem to feel that most of the heat transfer is to the submerged walls of the downcomer. They argue that the water interface with gas in the downcomer quickly becomes, steam saturated and does not provide an important heat sink until the bubble forms. Lee and Chan take the heat transfer coefficient to be:

$$
\mathrm{h}=15.8\left[\frac{\mathrm{g} \rho_{\mathrm{w}}^{2} \Delta \mathrm{H}_{\mathrm{fg}} \mathrm{H}^{3}}{\mu_{1} \mathrm{k}_{\mathrm{l}}\left(\mathrm{T}_{\mathrm{s}}-\mathrm{T}_{\mathrm{p}}\right)}\right]^{1 / 4} \frac{\mathrm{k}_{\mathrm{g}}}{\mathrm{D}_{\mathrm{p}} \mu_{\mathrm{g}} \cdot \rho_{\mathrm{g}}}
$$

where

$$
\begin{aligned}
\mathrm{h} & =\text { heat transfer coefficient, } \\
\mathrm{T}_{\mathrm{S}} & =\text { saturation temperature of the gas, } \\
\mathrm{T}_{\mathrm{p}} & =\text { bulk water temperature, }
\end{aligned}
$$




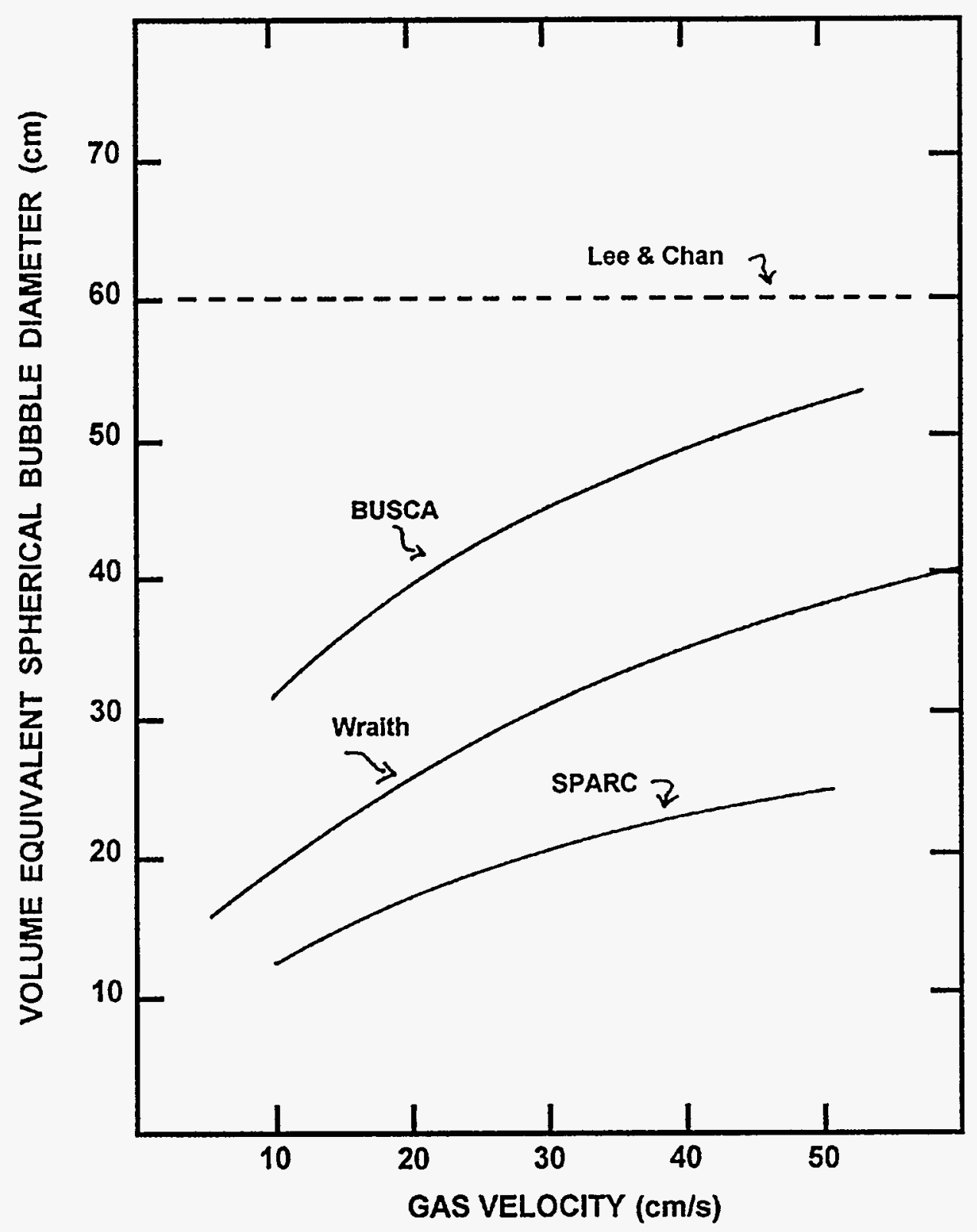

Figure 33. Comparison of various model predictions of the initial size of bubbles formed at a 60-cm-diameter downcomer 


$$
\begin{aligned}
\rho_{\mathrm{W}} & =\text { density of water, } \\
\rho_{\mathrm{g}} & =\text { gas density, } \\
\Delta \mathrm{H}_{\mathrm{fg}} & =\text { latent heat of condensation per unit mass of steam, } \\
\mathrm{k}_{1} & =\text { thermal conductivity of the liqüid, } \\
\mathrm{k}_{\mathrm{g}} & =\text { thermal conductivity of the gas, } \\
\mu_{1} & =\text { viscosity of the liquid, } \\
\mu_{\mathrm{g}} & =\text { viscosity of the gas, and } \\
\mathrm{H} & =\text { submergence length of the downcomer. }
\end{aligned}
$$

This expression, of course, defines a laminar, liquid film, heat transfer coefficient. ITee and Chan acknowledge that this is, at best, a very approximate model of the actual heat transfer taking place in the downcomer. Interestingly, the CHUG1 computer code [43] sets this wall heat transfer coefficient to zero.

Kowalchuk and Sonin [41], on the other hand, focused on heat transfer from the gasis to the liquid interface in the downcomers. They considered that the rate of vapor condensation could be limited by:

- the supply of vapor, or

- turbulent thermal diffusion in the water

The mass rate of steam condensation was estimated to be:

$$
\dot{\mathrm{m}}_{\mathrm{c}}=\frac{\mathrm{St} \rho_{\mathrm{w}} \mathrm{C}_{\mathrm{w}} \overline{\mathrm{V}}\left(\mathrm{T}_{\mathrm{s}}-\mathrm{T}_{\mathrm{p}}\right)}{\Delta \mathrm{H}_{\mathrm{fg}}\left[1+\frac{\pi \mathrm{St}^{2}}{\beta} \frac{\overline{\mathrm{V}} \mathrm{t}}{\mathrm{D}_{\mathrm{p}}}\right]^{1 / 2}}
$$

where

$$
\begin{aligned}
\mathrm{C}_{\mathrm{w}} & =\text { heat capacity of water, } \\
\overline{\mathrm{V}} & =\text { average speed at which water, rises and falls within the downcomer, } \\
\mathrm{St} & =\text { Stanton number taken to be about } 0.1 \text {, and } \\
\beta & =\text { uncertain turbulence parameter taken to have values between } 0.01 \text { and } 0.015 \text {. }
\end{aligned}
$$


The conclusion that can be derived from this expression is that heat transfer and condensation will occur in the downcomers. Quantitative details about the heat transfer are not at all certain. Condensation and heat transfer within the downcomers could be responsible for significant aerosol removal from the gas phase. But, the topic of aerosol removal within the piping system is outside the scope of this work and will be neglected here. The risk in neglecting the mass removal from the gas phase during passage through the downcomers is that the size distribution of aerosols that reach the pool might be altered. As will be discussed at length below, aerosol trapping from bubbles in a suppression pool is very dependent on the aerosol particle size.

\section{Bubble Formation at Horizontal Vents}

The SPARC code [6] incorporates a Weber number correlation derived from experimental data [42] to predict the initial volumes of bubbles formed at horizontal vents:

$$
\frac{4 \mathrm{~V}_{\mathrm{B}}}{\pi \mathrm{D}_{\mathrm{p}}^{2}} \frac{\left(\rho_{1}-\rho_{\mathrm{g}}\right)^{1 / 2} \mathrm{~g}^{1 / 2}}{\sigma_{1}^{1 / 2}}=0.857 \mathrm{We}^{0.73}
$$

where $D_{p}$ is the diameter of the vent. The BUSCA code [9] employs the dimensional correlation suggested by Paul et al. [30] for bubble volumes from horizontal vents:

$$
\mathrm{V}_{\mathrm{B}}\left(\mathrm{mm}^{3}\right)=0.0429\left[\mathrm{U}_{\mathrm{o}}(\mathrm{mm} / \mathrm{s})\right]^{0.92}\left[\mathrm{D}_{\mathrm{p}}(\mathrm{mm})\right]^{2.46}
$$

Presumably, the angle-dependent orifice model developed by Kumar and Kaloor (see Section IV-A2, above) could also be used. Horizontal vent diameters of interest here $(\sim 72 \mathrm{~cm})$ are, of course, very much larger than what was in mind when this model was developed.

Comparison of the predictions of these models are shown in Figure 34. Predictions of the various models diverge with increasing gas velocity. Interestingly, the Davidson-Schuler model predicts results within the range of predictions by the other models.

The essential difficulty with large diameter horizontal vents to the suppression pool is that at lower gas generation rates, water is not expelled completely from the vent during bubble formation. Consequently, for most accident situation, the orifice is not circular and the "effective diameter" of the orifice is not equal to the geometric diameter of the vent. Fischer and Hafner [292] cite data for bubble formation at a $68.6 \mathrm{~cm}$ horizontal orifice obtained by Battelle Columbus Laboratory and unavailable to the authors of this document that can be correlated in terms of the nondimensional bubble size and the bubble Weber number

$$
\mathrm{V}_{\mathrm{N}}=0.594 \mathrm{We} \mathrm{e}^{0.8399}
$$



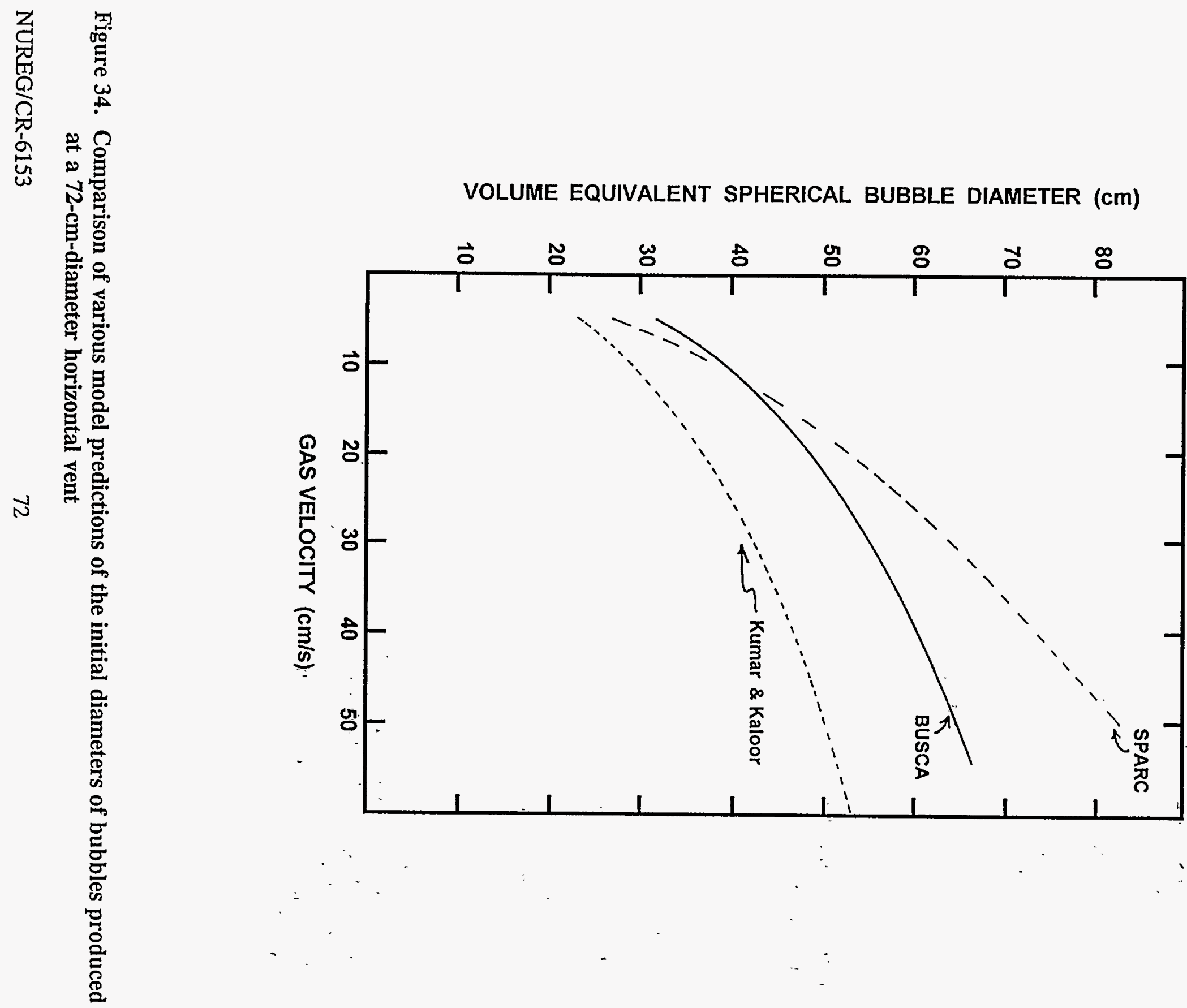
where, as above:

$$
\begin{aligned}
& \mathrm{V}_{\mathrm{N}}=\left(\pi \mathrm{D}_{\mathrm{B}}^{3} / 6\right)\left(\rho_{1}-\rho_{\mathrm{g}}\right)^{1 / 2} \mathrm{~g}^{1 / 2} / \frac{\pi \mathrm{D}_{\mathrm{o}}^{2}}{4} \sqrt{\sigma_{1}} \\
& \mathrm{We}=\mathrm{U}_{0}^{2} \rho_{1} \mathrm{D}_{\mathrm{o}} / \sigma_{1}
\end{aligned}
$$

Note that the geometric vent diameter, $\mathrm{D}_{0}$, is used in the correlation. Fischer and Hafner considered this to be very questionable.

\section{B. Collapse and Disintegration of Large Bubbles}

Bubbles released from orifices and vents in the steam suppression pool may not be stable. The gases that make up the initial bubbles may be supersaturated in steam relative to the bulk water pool temperature. Formation of the bubble is possible only because heat liberated by condensation of steam raises the interface temperature to saturation. Once the bubble detaches from the orifice or vent and begins to rise in the pool, colder water is encountered and heat transfer from the interface becomes more efficient.

The collapse of vapor bubbles has received a lot of attention. Pressure pulses produced by bubble collapse are thought to be responsible for equipment damage during cavitation [90] and during "chugging" in steam suppression pools [40]. The rate of bubble collapse may be limited by inertia or by the rate of heat transfer. Bubble collapse limited by inertial effects alone has received the most attention and models of varying sophistication have been proposed [91]:

- Rayleigh model [92]

- water is treated as incompressible; $C=\infty$

$$
R(t) \frac{\partial^{2} R(t)}{\partial t^{2}}+\frac{3}{2}\left[\frac{\partial R(t)}{\partial t}\right]^{2}=\frac{1}{\rho(\infty)}(P(t)-P(\infty))
$$

- Herring's model [91]

- speed of sound independent of pressure

$$
\begin{aligned}
\frac{R(t) \partial^{2} R(t)}{\partial t^{2}} & +\frac{3}{2}\left[1-\frac{4}{3} \frac{1}{C(\infty)} \frac{\partial R(t)}{\partial t}\right]\left[\frac{\partial R(t)}{\partial t}\right]^{2} \\
& =\frac{1}{\rho(\infty)}\left[P(t)-P(\infty)+\frac{R(t)}{C(\infty)} \frac{2 P(t)}{2 t}\left[1-\frac{1}{C(\infty)} \frac{\partial R(t)}{\partial t}\right]\right]
\end{aligned}
$$


Physical Phenomena

- Gilmore's model [91]

- $\quad$ pressure-dependent speed of sound in water

$$
\begin{aligned}
C(P)= & C(\infty)[(P+B) /(P(\infty)+B)]^{3 / 7} \\
& R(t) \frac{\partial^{2} R(t)}{\partial t^{2}}\left[1-\frac{1}{C(R)} \frac{\partial R(t)}{\partial t}\right] \\
& +\frac{3}{2}\left[\frac{\partial R(t)}{\partial t}\right]^{2}\left[1-\frac{1}{3 C(R)} \frac{\partial R(t)}{\partial t}\right]=H(P)\left[1+\frac{1}{C(R)} \frac{\partial R(t)}{\partial t}\right] \\
& +\frac{R(t)}{C(R)} \frac{\partial H}{\partial t}\left[1-\frac{1}{C(R)} \frac{\partial R(t)}{\partial t}\right] \\
H(P)= & \frac{1}{\rho(\infty)} \frac{7}{6}(P(\infty)+B)\left[((P+B) /(P(\infty)+B))^{6 / 7}-1\right]
\end{aligned}
$$

where

$$
\begin{aligned}
\mathrm{R}(\mathrm{t}) & =\text { bubble radius at time } \mathrm{t} \\
\mathrm{P}(\mathrm{t}) & =\text { pressure at the bubble walls at time } \mathrm{t} \\
\mathrm{C} & =\text { speed of sound in water, and } \\
\mathrm{B} & =2961 \text { atms. }
\end{aligned}
$$

If the collapse is adiabatic, then

$$
\begin{aligned}
& \mathrm{P}(\mathrm{t})=\mathrm{P}(\mathrm{o})\left[\frac{\mathrm{R}(\mathrm{o})}{\mathrm{R}(\mathrm{t})}\right)^{3 \gamma} \\
& \gamma=\mathrm{C}_{\mathrm{p}} \text { (gas) } / \mathrm{C}_{\mathrm{V}} \text { (gas) }
\end{aligned}
$$

In the case where heat transfer from the bubble is rapid relative to collapse:

$$
\mathrm{P}(\mathrm{t})=\mathrm{P}_{\mathrm{eq}}\left(\mathrm{H}_{2} \mathrm{O}\right)+\frac{\mathrm{n}(\mathrm{NC}) \mathrm{RT}}{\frac{4}{3} \pi \mathrm{R}(\mathrm{t})^{3}}
$$


where $\mathrm{P}_{\mathrm{eq}}\left(\mathrm{H}_{2} \mathrm{O}\right)$ is the equilibrium partial pressure of water at the bulk pool temperature $T, R$ is the gas constant and $\mathrm{n}(\mathrm{NC})$ is the moles of noncondensible gas in the bubble.

For the bubbles of interest in the analyses of suppression pool scrubbing, introduction of the compressibility of water hardly affects the predicted results. An example calculation of the timing of bubble collapse under inertial control using Gilmore's model is shown in Figure 35. Note that spherical collapse becomes unstable to nonspherical perturbations once $\mathrm{R}(\mathrm{t})$ / $\mathrm{R}(\mathrm{o})$ falls below 0.2 [93].

Inertially limited bubble collapse is quite rapid. The example shown in Figure 35 would require Nusselt numbers for heat transfer from the bubble on the order of $3 \times 10^{4}$ which, as will be seen in the discussion in a later section, would be difficult to achieve in most situations. It seems likely, then, that heat transfer will be an important if not dominant factor in the collapse of supersaturated bubbles discharged into the suppression pool.

Florschuetz and Chao [94] introduced the parameter B to distinguish regimes of bubble collapse:

$$
B=\left[\frac{\rho_{1} C_{1} \Delta T}{\rho_{\mathrm{g}} \mathrm{L}}\right]^{2} \frac{\mathrm{k}_{1}}{\rho_{\mathrm{l}} \mathrm{C}_{1}} \frac{1}{\mathrm{R}(\mathrm{o})}\left[\frac{\rho_{1}}{\Delta \mathrm{P}}\right]^{1 / 2}
$$

where

$$
\begin{aligned}
\Delta \mathrm{T} & =\mathrm{T}_{\mathrm{s}}-\mathrm{T}_{\mathrm{p}} \\
\Delta \mathrm{P} & =\mathrm{P}_{\text {pool }}-\mathrm{P}_{\mathrm{eq}}\left(\mathrm{T}_{\mathrm{p}}\right)
\end{aligned}
$$

For B values greater than 10 , inertial processes control. For B values less than 0.05 , heat transfer processes control bubble collapse: For values of $\Delta \mathrm{T}$ up to about $50 \mathrm{~K}$, collapse is well within the heat transfer control regime.

Much of the analysis of bubble collapse under heat transfer control has been for stationary bubbles [94,95]. Wittke and Chao [96] have demonstrated there to be a substantial effect of motion on the collapse of bubbles. Moalem and Sideman [97] have developed a simple description of bubble collapse which treats the effects of both motion and the presence of noncondensible gas:

$$
\frac{\mathrm{d} \beta}{\mathrm{d} \tau}=-\frac{1}{\sqrt{\pi}} \frac{\beta^{3}-\beta_{\mathrm{f}}^{3}}{\beta^{13 / 4}}
$$

where

$$
\begin{aligned}
& \beta=\mathrm{R}(\mathrm{t}) / \mathrm{R}(\mathrm{o}) \\
& \tau=\mathrm{Ja} \mathrm{Pe}_{\mathrm{o}}{ }^{1 / 2} \mathrm{Fo}
\end{aligned}
$$




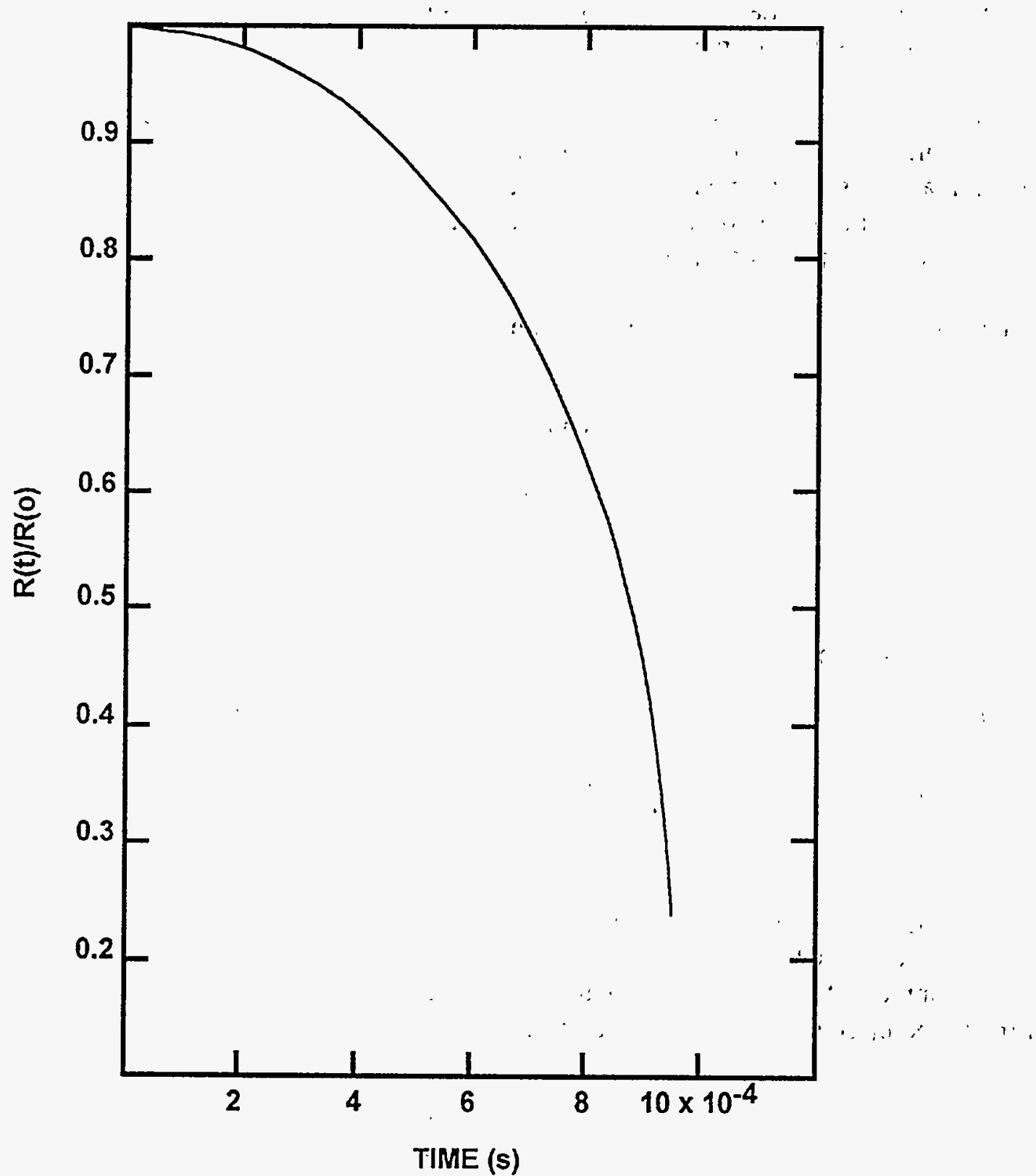

Figure 35. Isothermal, inertially-controlled collapse of a 2-cm bubble in water'at $319 \mathrm{~K}$ according to Gilmore's model 


$$
\begin{aligned}
\mathrm{Ja} & =\rho_{1} \mathrm{C}_{1}\left(\mathrm{~T}_{\text {sat }}-\mathrm{T}(\infty)\right) / \mathrm{L} \rho_{\mathrm{g}} \\
\mathrm{Pe}_{\mathrm{o}} & =2 \mathrm{R}(0) \mathrm{U}_{\mathrm{o}} / \mathrm{k}_{1} / \rho_{1} \mathrm{C}_{1} \\
\mathrm{~F}_{\mathrm{o}} & =\mathrm{k}_{\mathrm{l}} \mathrm{t} / \mathrm{R}(\mathrm{o})^{2} \rho_{1} \mathrm{C}_{1} \\
\mathrm{U}_{\mathrm{o}} & =\text { rise velocity of bubble }
\end{aligned}
$$

They derived this model for potential flow conditions and assurned the Nusselt number to be:

$$
\mathrm{Nu}=\frac{\mathrm{hD}}{\mathrm{k}_{1}}=1.13 \mathrm{Pe}^{1 / 2}
$$

where $\mathrm{h}$ is the heat transfer coefficient. The final dimensionless bubble volume, $\beta_{\mathrm{f}}$, is given by:

$$
\beta_{\mathrm{f}}=\left[\frac{\mathrm{RT}_{\text {sat }}^{2} \mathrm{y}_{\mathrm{o}}}{\mathrm{L}\left(\mathrm{T}_{\mathrm{sat}}-\mathrm{T}(\infty)\right)}\right]^{1 / 3}
$$

where

$$
\begin{aligned}
\mathrm{T}_{\text {sat }} & =\text { saturation temperature corresponding to the initial partial pressure of steam in the bubble } \\
\mathrm{T}(\infty) & =\text { pool temperature } \\
\mathrm{L} & =\text { heat of vaporization of water } \\
\mathrm{y}_{0} & =\text { initial mole fraction of noncondensible gases in the bubble. }
\end{aligned}
$$

Predictions of this model are compared in Figure 36 to data obtained by Levenspiel [98] and in Figures 37 and 38 to data obtained by Wittke and Chao [96]. The agreement between data and model predictions is about the same as that obtained by Wittke and Chao with a more detailed, finitedifference, model. Agreement between the model and the data could probably be improved by using a size dependent model of the bubble rise velocity and a more detailed heat transfer model.

Note that the data for bubble collapse are for bubbles that are much smaller than those expected to form at vents and orifices in steam suppression pools. Bubbles formed initially in the suppression pool can be so large that they are hydrodynamically unstable even if they are not supersaturated in steam. The classic limiting size for a stable bubble is given by Levich [99] to be:

$$
\mathrm{D}_{\text {limit }}=1.0 \sigma_{\mathrm{l}} / \mathrm{U}_{\mathrm{T}}^{2}\left(\rho_{\mathrm{g}} \rho_{1}^{2}\right)^{1 / 3}
$$

Loertschuer et al. [100] have found for large bubbles that the rise velocity in water is given by: 


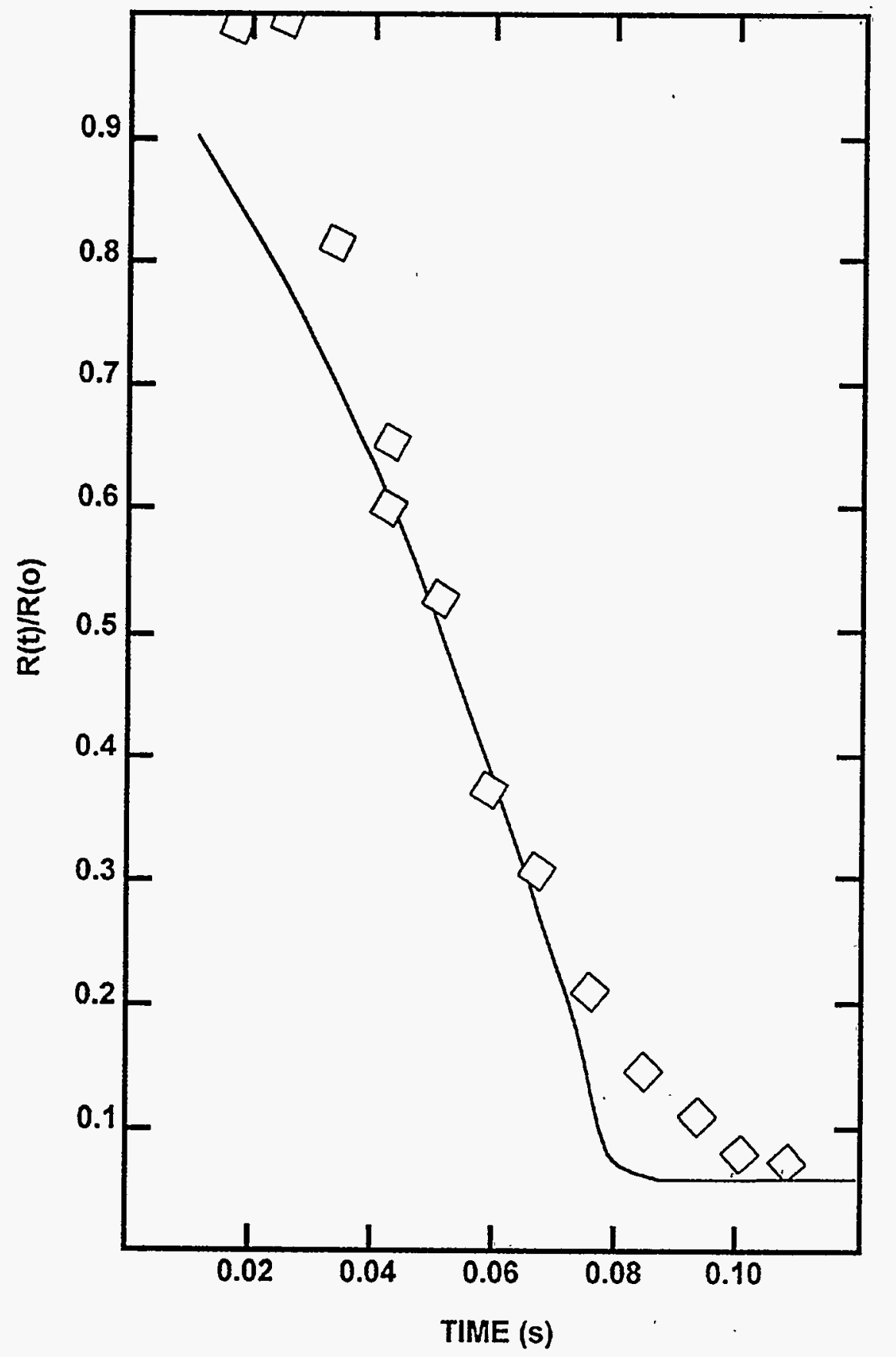

Figure 36. Comparison of bubble collapse predictions to data from Levenspiel [98] 


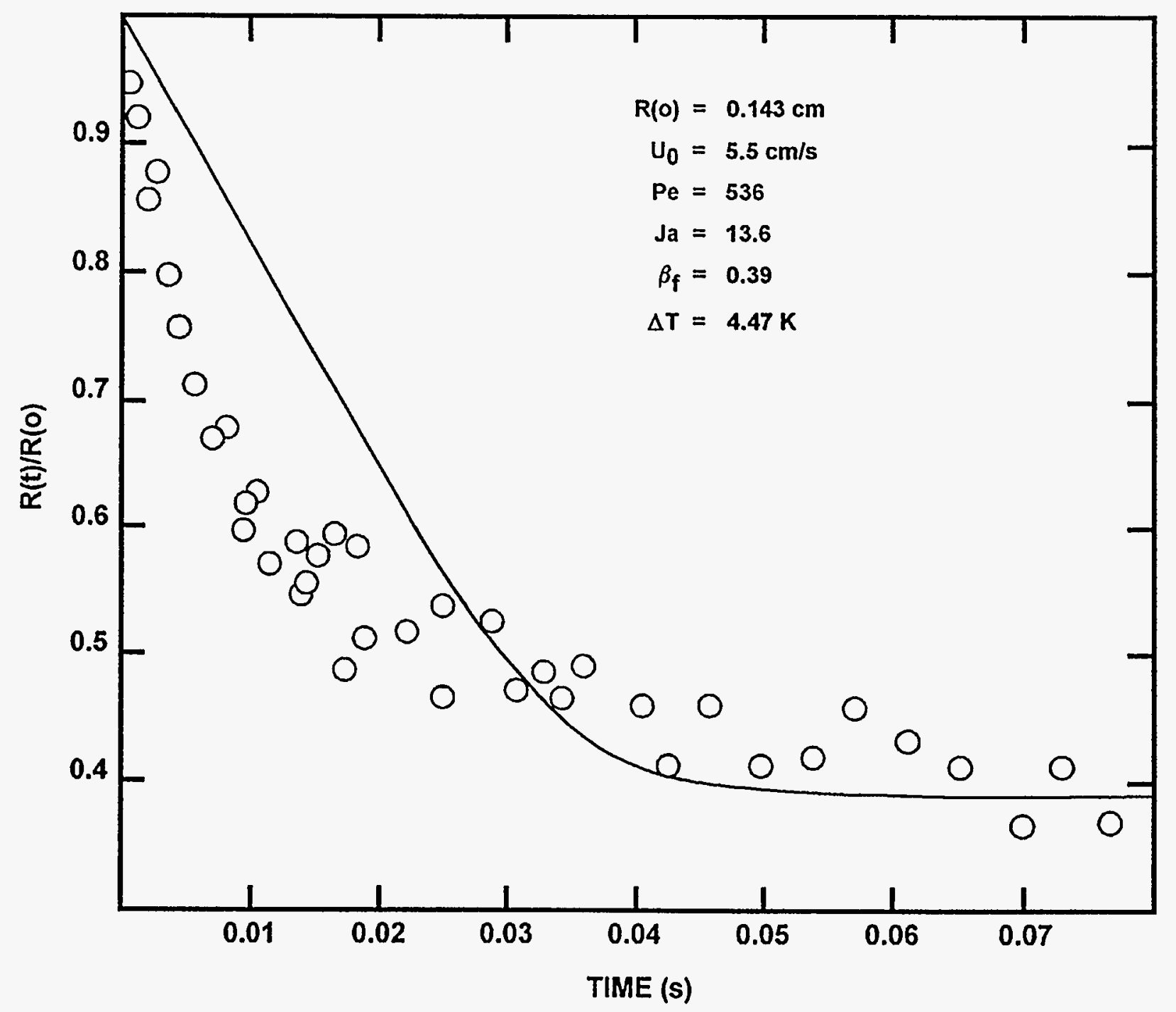

Figure 37. Comparison of model predictions of bubble collapse to data from Wittke and Chao [96] 


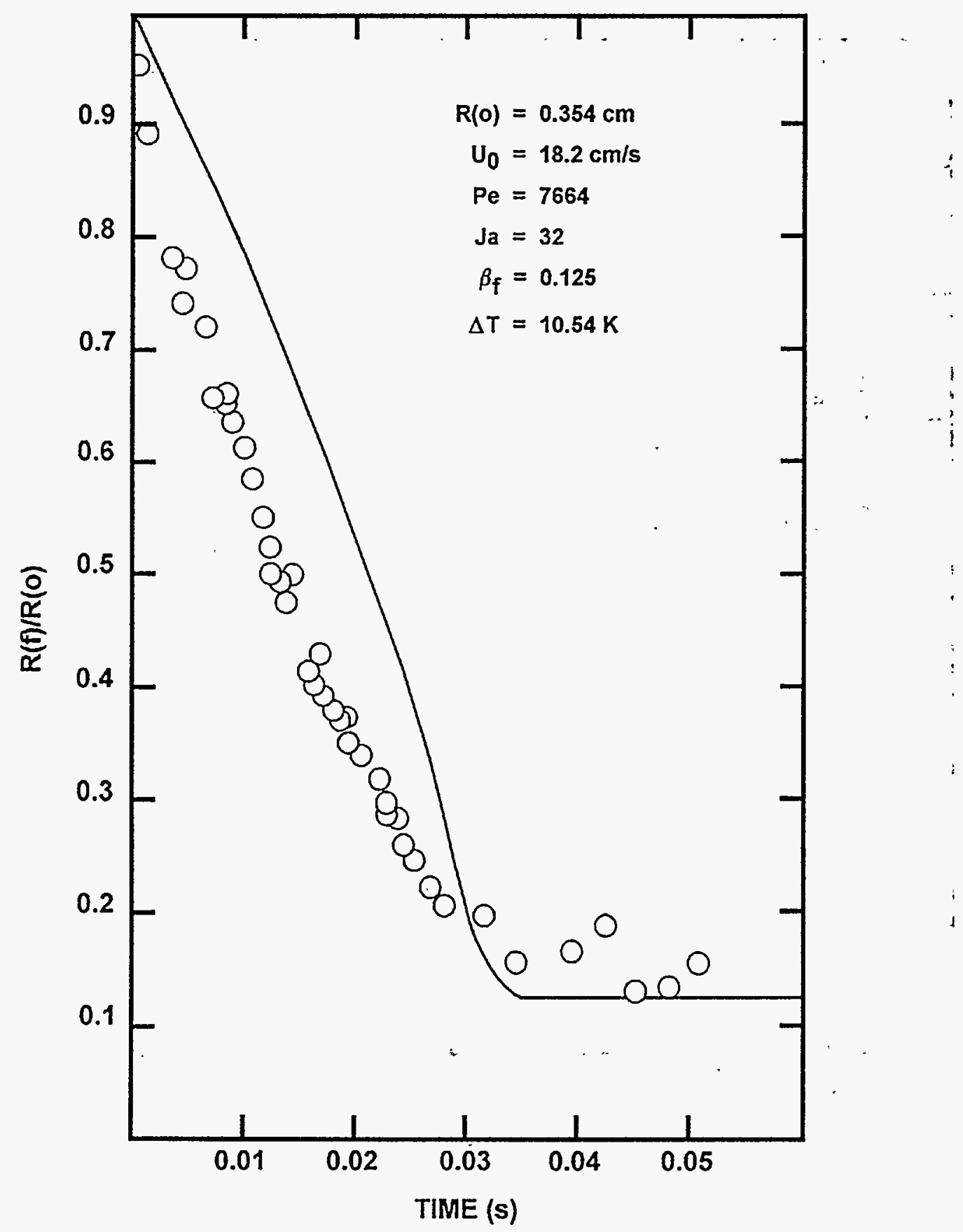

Figure 38. Comparison of predictions of bubble collapse to data from Wittke and Chao [96] 


$$
\mathrm{U}_{\mathrm{T}}(\mathrm{cm} / \mathrm{s})=0.7354 \sqrt{\mathrm{gD}_{\mathrm{B}}}
$$

These data are shown in Figure 39. This, then, yields for the maximum stable bubble size in water about $2 \mathrm{~cm}$.

Grace et al. [101] have conducted a two dimensional Rayleigh-Taylor instability analysis of rising bubbles. They consider the growth of sinusoidal disturbances at the interface of the bubble. Surface tension will prevent the growth of disturbances smaller than a critical wavelength given by:

$$
\lambda_{c}=2 \pi / \sqrt{\rho_{1} g / \sigma_{1}}
$$

Disturbances with larger wavelengths can grow. But, disturbances larger than about $\lambda_{\mathrm{u}}=\pi \mathrm{D}_{\mathrm{B}} / 2$ amount to gross translations of the bubble as a whole and need not be considered responsible for breakup of oversized bubbles.

Disturbances with wavelengths between $\lambda_{c}$ and $\lambda_{u}$ will grow as they are swept along the interface during bubble rise. The time available for disturbances to grow is given by:

$$
\mathrm{t}(\mathrm{a})=\frac{2 \mathrm{D}_{\mathrm{B}}}{\mathrm{U}_{\mathrm{T}}} \ln \left\{\cot \left(\lambda / 4 \mathrm{D}_{\mathrm{B}}\right)\right\}
$$

where

$$
\begin{aligned}
t(a) & =\text { time available for disturbance growth, } \\
D_{B} & =\text { bubble diameter, } \\
U_{T} & =\text { rise velocity, and } \\
\lambda & =\text { wavelength of a disturbance. }
\end{aligned}
$$

Disturbances grow as does exp ( $\alpha t)$ where $\alpha$ is given by:

$$
\begin{aligned}
& {\left[\left(\frac{2 \pi}{\lambda}\right]^{2}+\frac{\alpha \rho_{1}}{\mu_{1}}\right]^{2}+2\left[\left[\frac{2 \pi}{\lambda}\right]^{2}+\frac{\alpha \rho_{1}}{\mu_{1}}\right]-4\left[\left[\frac{2 \pi}{\lambda}\right]^{2}+\frac{\alpha \rho_{1}}{\mu_{1}}\right]^{1 / 2}} \\
& +1+\frac{\lambda}{2 \pi} \frac{\rho_{1}}{\mu_{1}^{2}}\left(\sigma_{1}-\lambda^{2} \mathrm{~g} \rho_{1} / 4 \pi^{2}\right)=0
\end{aligned}
$$

Experience indicates that when the product $\mathrm{t}(\mathrm{a}) \alpha$ exceeds 3.8 for disturbances with wavelengths between $\lambda_{c}$ and $\lambda_{\mu}$, the bubble will break up. Bubble stability maps for water based on this criterion are shown in Figures 40 and 41 . Other discussions of bubble stability are to be found in References 216 and 217. 


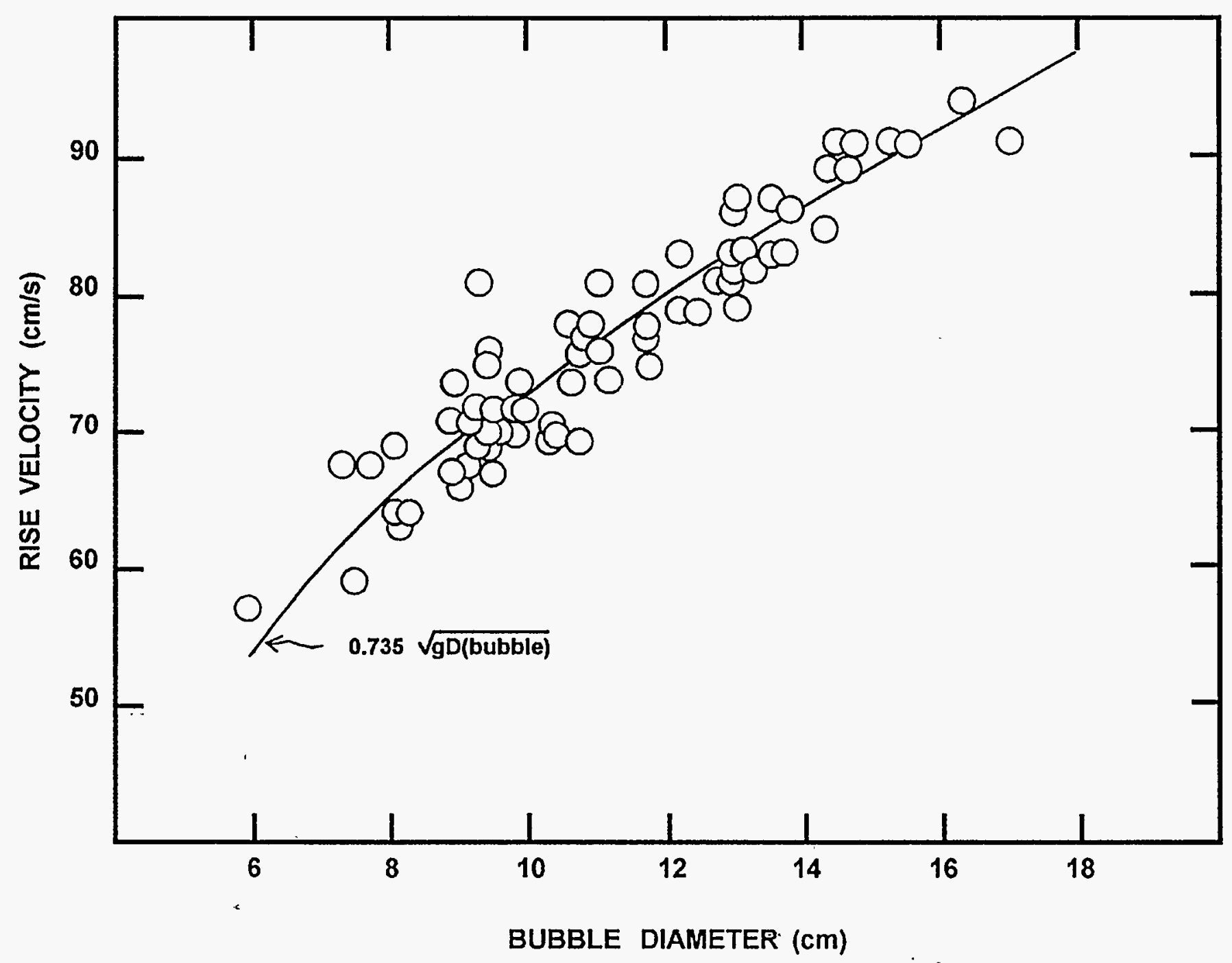

Figure 39. Rise velocities for very large bubbles 


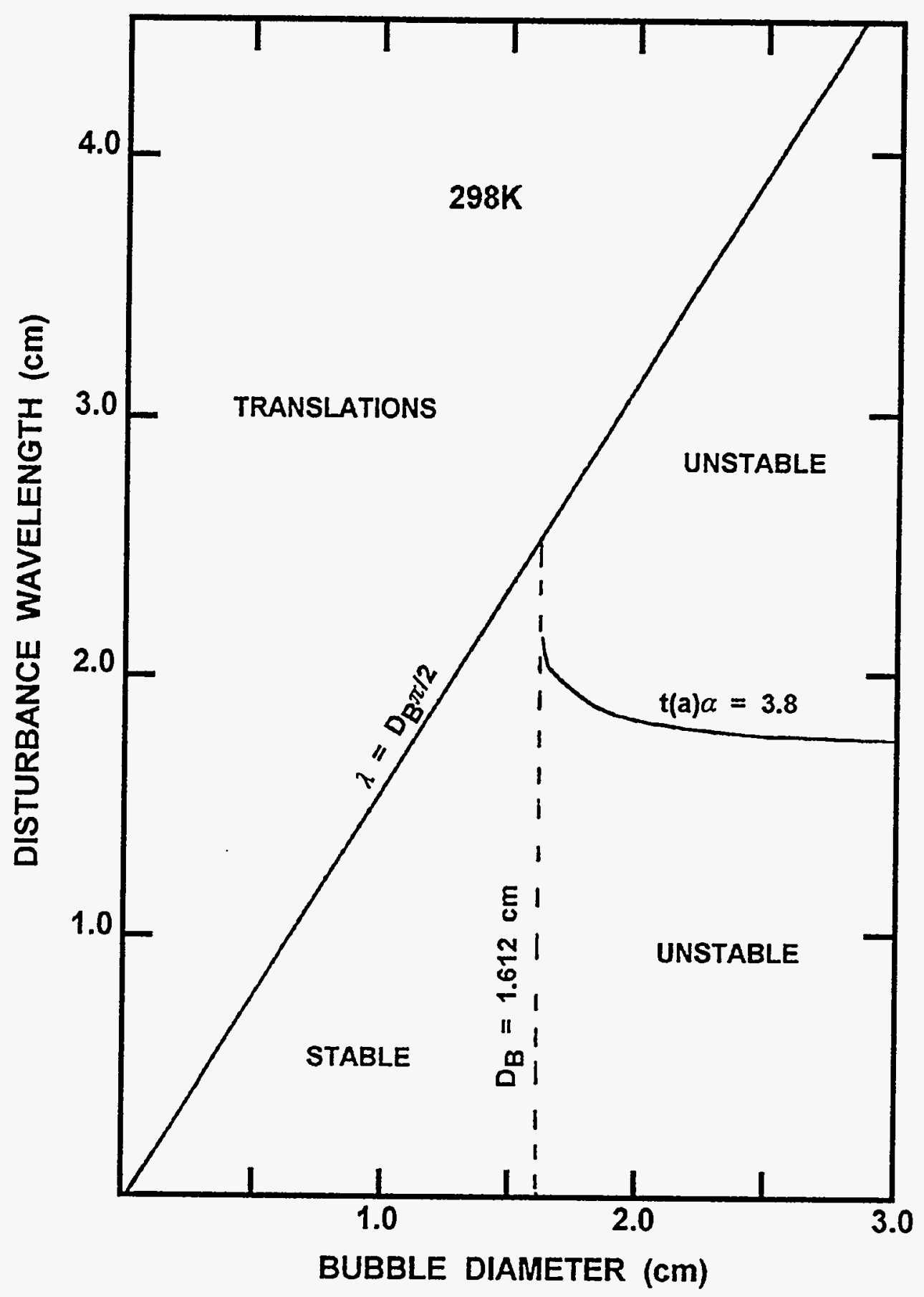

Figure 40. Bubble stability map for water at $298 \mathrm{~K}$ 


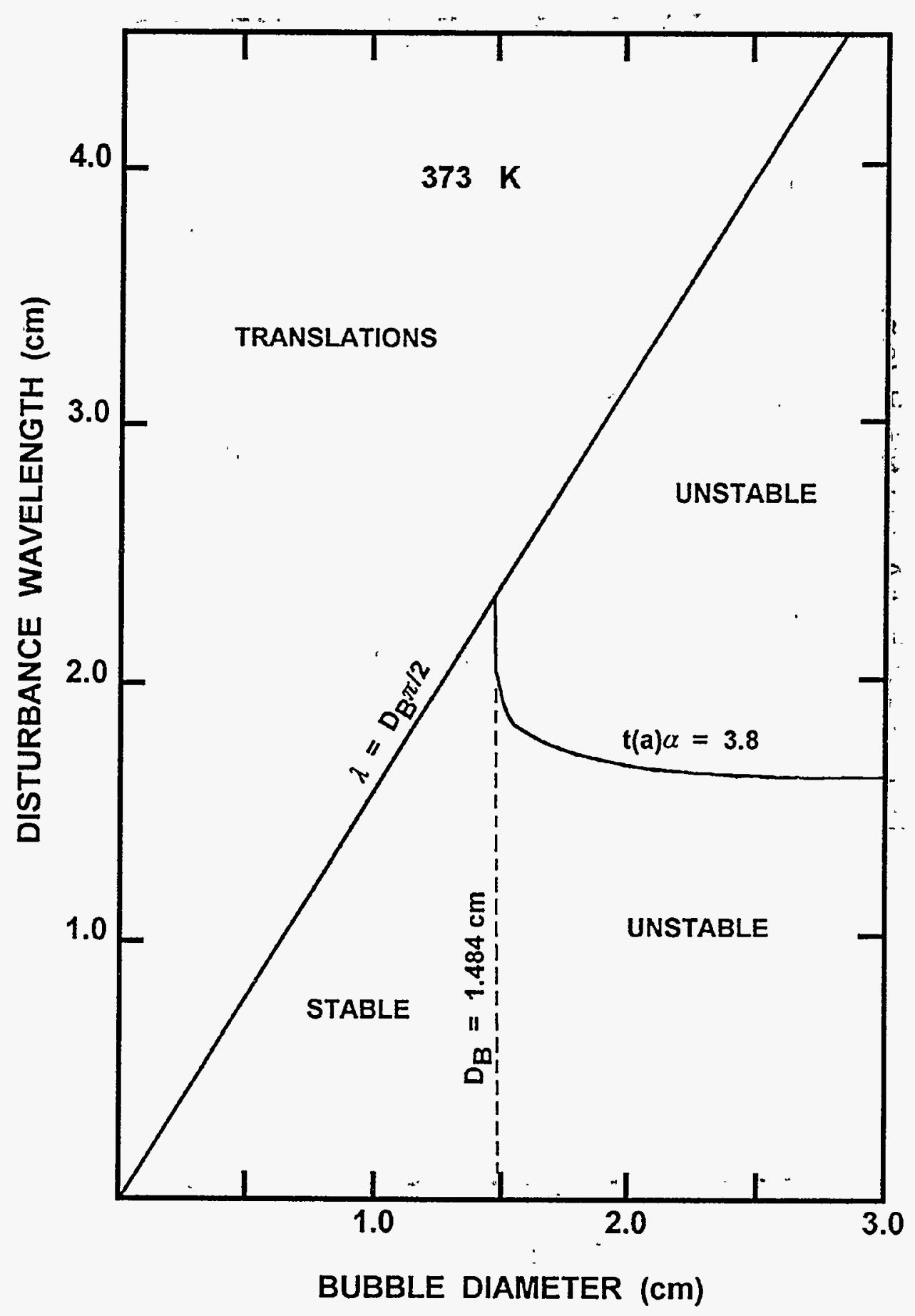

Figure 41. Bubble stability map for water at $373 \mathrm{~K}$ 
The stability analysis indicates that overly large bubbles will break up. The analysis does not indicate the sizes of the bubbles left after the breakup. Empirical evidence suggest that the bubble will "calve" off fragments of fairly random size. Fragments that are small enough to be stable may coalesce to form larger bubbles.

\section{Bubble Size Distribution and the Coalescence of Bubbles}

At the conclusion of the bubble formation and breakup process there will be a swarm of bubbles rising through the suppression pool. Presumably bubbles in the swarm will have a distribution of sizes. As will be discussed further, below, bubble size has an important bearing on the efficiency of aerosol removal. It is, then, necessary to have a good estimate of the bubble size distribution.

Empirical evidence on the size distribution of bubbles rising through suppression pools has been obtained by Paul et al. [30] and by Hakii et al. [69]. Both teams of investigators examined bubble size distributions produced by orifices found on quenchers. Both groups obtained about the same results. The experiments conducted by Paul et al. are especially well documented.

Paul et al. examined bubble size distributions at several elevations above a quencher orifice. They examined the effects on the size distribution of gas injection rate (see Figure 42), orifice orientation (see Figure 43) and orifice size (see Figure 44). Bubble size distributions were found to be approximately lognormal and could be characterized adequately by a mean and a geometric standard deviation.

Mean bubble diameters and geometric standard deviations as functions of gas injection rates are shown in Figure 42. It appears that there may be a dependence of bubble size on gas injection rates for injection rates less than 0.1 moles/s. A dependence on gas injection rates would be expected if very small bubbles were coalescing to form bubbles of a stable size. There is no obvious dependence of the geometric standard deviation on gas injection rates. The logarithmic mean geometric standard deviation is 1.44 to 1.63 . The geometric standard deviation does not appear to be strongly correlated with the mean bubble size.

Bubble size distribution data listed in Table 8 are plotted against orifice size in Figure 43. Though system parameters other than orifice size vary within this data set, it is not obvious that parameters characterizing the bubble size distribution depend on orifice size. Whether this conclusion can be extrapolated to orifices the size of downcomers and horizontal vents is problematic.

Data listed in Table 9 are plotted in Figure 44 against the orientation angle of the orifice (a $90^{\circ}$ orientation corresponds to an orifice opening horizontally). Data for all orientations other than $90^{\circ}$ were obtained at lower gas injection rates than data obtained for the $90^{\circ}$ orientation. The mean diameters of the bubble size distribution are sensitive to gas injection rates in this range. Consequently, data shown in Figure 42 were extrapolated to 0.027 moles/s to obtain data points for the $90^{\circ}$ orientation shown in Figure 44 . There is some indication that bubbles formed after injection at angles greater than $90^{\circ}$ have somewhat larger mean diameters than bubble size distribution produced by gas injection at orientations of 0 to $90^{\circ}$. The effect is, however, not much greater than the expected uncertainty in the measurements. 


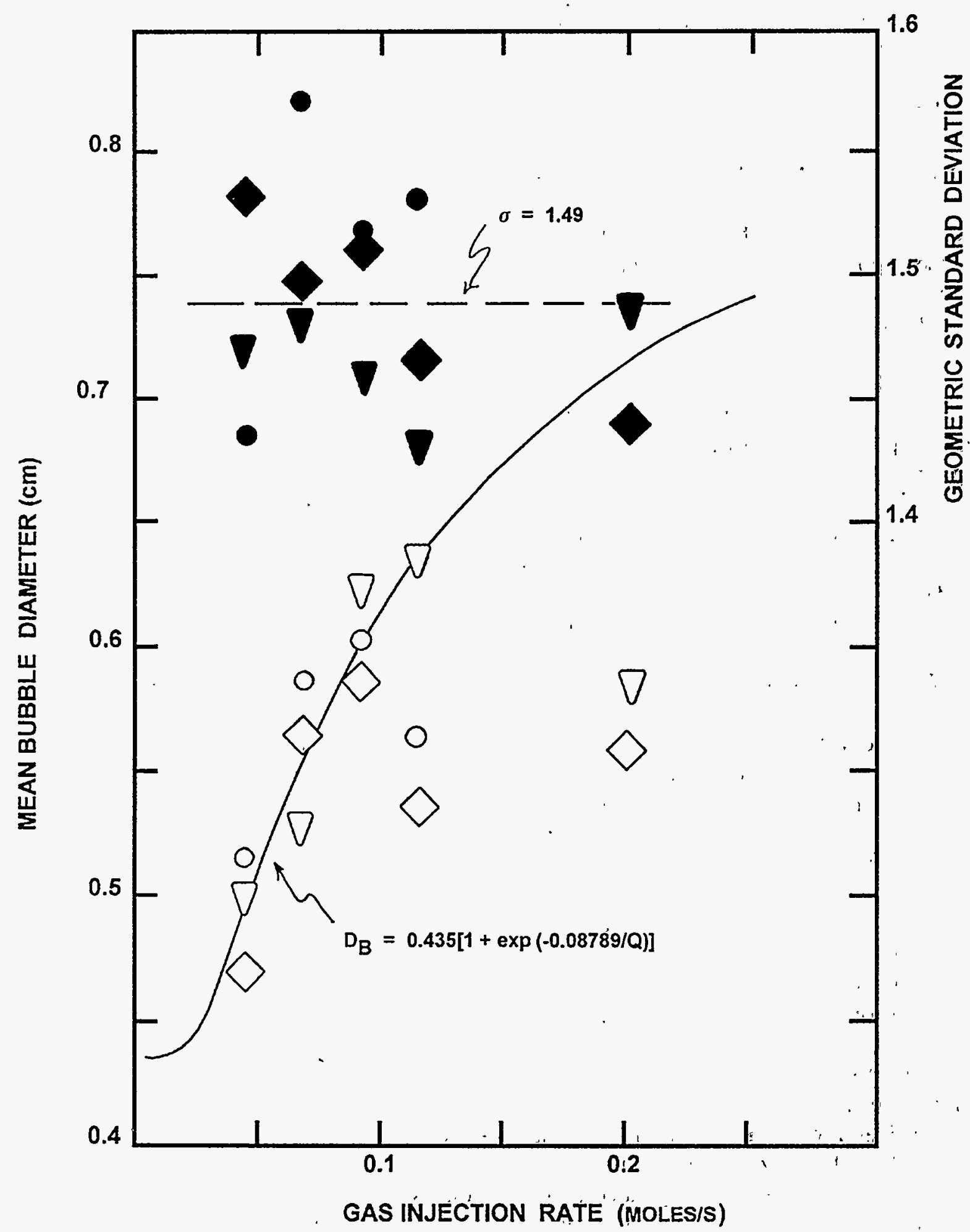

Figure 42. Effect of gas injection rate on bubble size distribution: : Distributitions(were measured at elevations above the orifice of $122 \mathrm{~cm}$ (circles), $198 \mathrm{~cm}$ (diamonds) iand $: 305 \mathrm{~cm}$ (triangle). Open symbols are for mean sizes (left scale) and filed symbols are for the geometric standard deviation (right scale). Air and a $0.99-\mathrm{cm}$ orifice with an orientation of $0^{\circ}$ were used for these tests. 


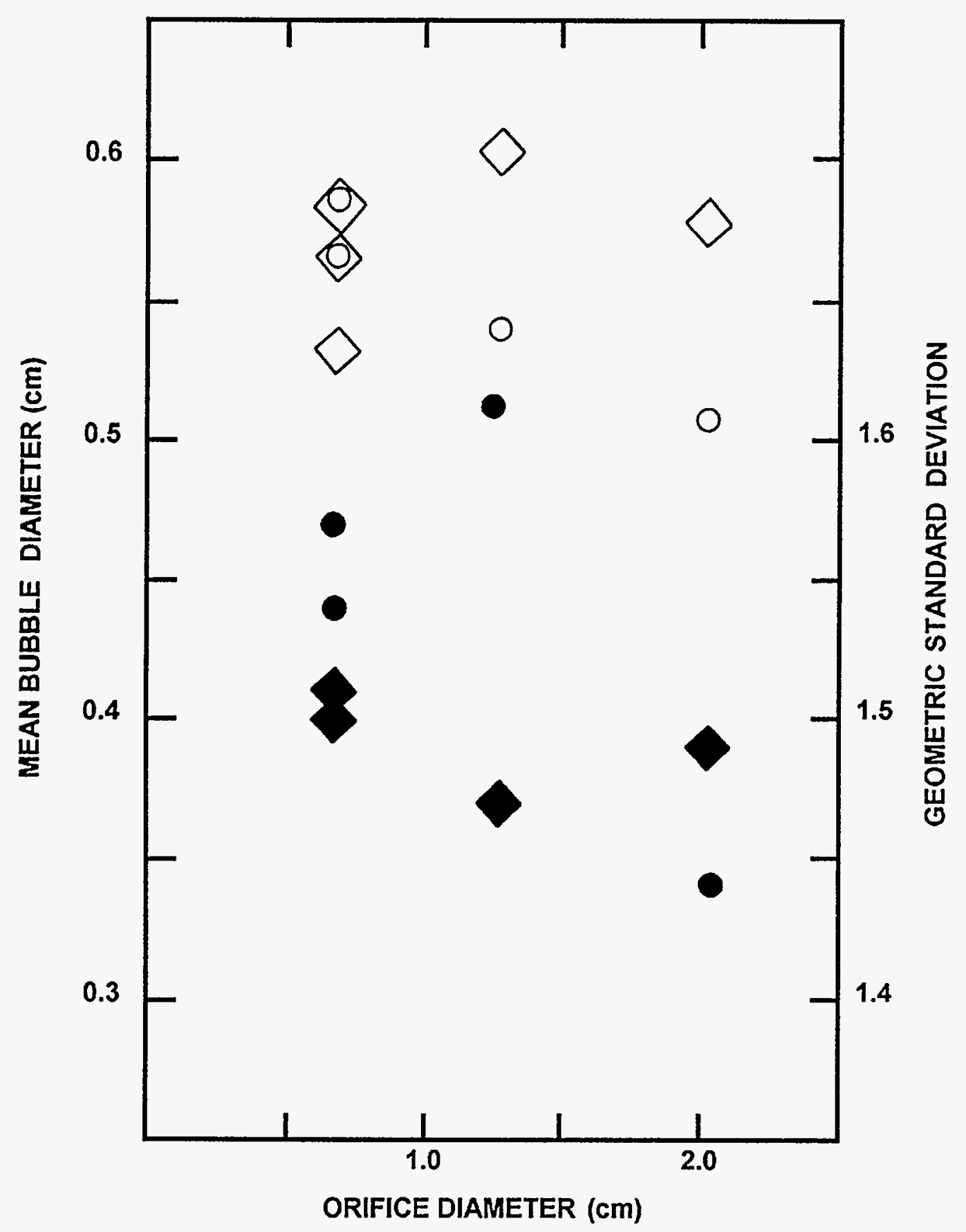

Figure 43. Effect of orifice size on the bubble size distribution. Measurements were taken at $122 \mathrm{~cm}$ (circles) and $198 \mathrm{~cm}$ (diamonds) above the orifice. Open symbols refer to the mean bubble size (left scale). Filled symbols refer to the geometric standard deviation (right scale). 


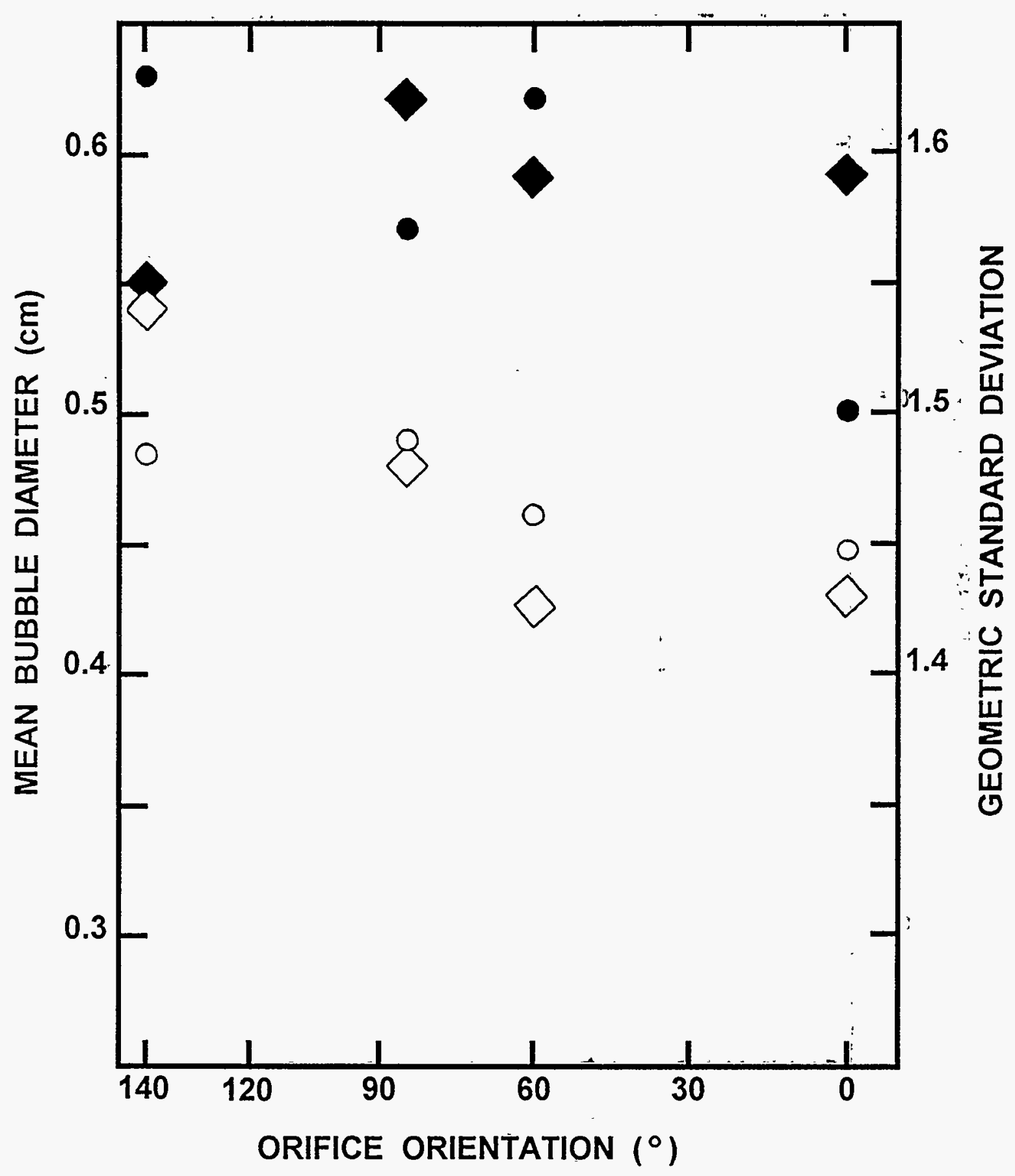

Figure 44. Effect of orifice orientation on the bubble size distribution. Data for air bubbles were measured $122 \mathrm{~cm}$ (circles) and $198 \mathrm{~cm}$ (diamonds) above a 1.27-cm orifice. Open symbols refer to the mean bubble diameter (left scale) and filled symbols refer to the geometric standard deviation (right scale). 
Table 8. Effect of orifice size on the bubble size distribution

\begin{tabular}{ccccc}
\hline $\begin{array}{c}\text { Orifice } \\
\text { diameter } \\
(\mathbf{c m})\end{array}$ & $\begin{array}{c}\text { Gas } \\
\text { injection rate } \\
(\mathbf{m o l e} / \mathbf{s})\end{array}$ & $\begin{array}{c}\text { Elevation } \\
\text { above orifice } \\
(\mathbf{c m})\end{array}$ & $\begin{array}{c}\text { Mean } \\
\text { bubble size } \\
(\mathbf{c m})\end{array}$ & $\begin{array}{c}\text { Geometric } \\
\text { standard deviation } \\
(-)\end{array}$ \\
\hline 0.99 & 0.068 & 122 & 0.586 & 1.57 \\
0.99 & 0.114 & 122 & 0.566 & 1.54 \\
1.27 & 0.070 & 122 & 0.540 & 1.63 \\
2.02 & 0.108 & 122 & 0.509 & 1.44 \\
& & & & \\
0.99 & 0.068 & 198 & 0.564 & 1.50 \\
0.99 & 0.090 & 198 & 0.583 & 1.51 \\
0.99 & 0.114 & 198 & 0.533 & 1.47 \\
1.27 & 0.070 & 198 & 0.603 & 1.55 \\
2.02 & 0.104 & 198 & 0.578 & 1.49 \\
\hline
\end{tabular}

Table 9. Effect of orifice orientation on the bubble size distribution

\begin{tabular}{cccccc}
\hline $\begin{array}{c}\text { Orifice } \\
\text { diameter } \\
(\mathbf{c m})\end{array}$ & $\begin{array}{c}\text { Gas } \\
\text { injection rate } \\
(\mathbf{m o l e s} / \mathbf{s})\end{array}$ & $\begin{array}{c}\text { Orifice } \\
\text { orientation } \\
\left({ }^{\circ}\right)\end{array}$ & $\begin{array}{c}\text { Elevation } \\
\text { above orifice } \\
(\mathbf{c m})\end{array}$ & $\begin{array}{c}\text { Mean } \\
\text { bubble size } \\
(\mathbf{c m})\end{array}$ & $\begin{array}{c}\text { Geometric } \\
\text { standard deriation } \\
(-)\end{array}$ \\
\hline 1.27 & 0.027 & 0 & 122 & 0.446 & 1.50 \\
1.27 & 0.027 & 60 & 122 & 0.461 & 1.62 \\
1.27 & 0.027 & 140 & 122 & 0.485 & 1.57 \\
1.27 & 0.070 & 90 & 122 & 0.540 & 1.63 \\
$(1.27)^{*}$ & $(0.027)$ & $(90)$ & $(122)$ & $(0.49)$ & - \\
1.27 & 0.027 & 0 & 198 & 0.430 & 1.59 \\
1.27 & 0.027 & 60 & 198 & 0.424 & 1.59 \\
1.27 & 0.027 & 140 & 198 & 0.540 & 1.62 \\
1.27 & 0.070 & 90 & 198 & 0.603 & 1.55 \\
$(1.27)^{*}$ & $(0.027)$ & $(90)$ & $(198)$ & $(0.48)$ & - \\
\hline *Extrapolated based on gas injection rate dependence of bubble size. & \\
\hline \multicolumn{5}{r}{} \\
\hline
\end{tabular}


The mean of the final bubble size distribution is strongly affected by 'the mole fraction of steam in the gas initially discharged to the suppression pool. Data for air-steam mixtures are listed in Table 10 and are plotted in Figures 45 and 46 . The mean bubble size data were fit by linear least-squares methods to:

$$
\ln D_{B}=-0.4837-0.5972 y^{2}
$$

where $\mathrm{y}$ is the mole fraction of steam in the initial gas discharged to the pool. (The pool in these tests was cool enough that essentially all of the steam would condense, eventually). The $100(1-\alpha)$ percent confidence bands for predictions derived from this correlation can be obtained from

$$
\ln D_{B}=\left.\ln D_{B}\right|_{r e g} \pm 0.0634 t_{(1-\alpha / 2)}(10)\left[\frac{1}{12}+\frac{\left(y^{2}-0,4434\right)^{2}}{1.1847}\right]^{1 / 2}
$$

where

$\left.\ln \mathrm{D}_{\mathrm{B}}\right|_{\text {reg }}=$ value of $\ln \mathrm{D}_{\mathrm{B}}$ calculated from the regression equation, and

$\mathrm{t}_{(1-\alpha / 2)}(10)=$ critical Student's $\mathrm{t}$ statistic for 10 degrees of freedom and a confidence level of $100(1-\alpha / 2)$ percent.

According to the data shown in Figure 42 there is some small dependence of the mean bubble size on gas injection rate. A multiplicative coefficient can then be derived to yield an overall regression equation for the mean bubble size:

$$
D_{B}=0.435\{1+\exp [-0.08789 / Q]\} \exp \left[-0.5972 y^{2}\right]
$$

Results obtained by Paul et al. [30] and the rather similar results obtained by Hakii et al. [69] are not readily interpreted in terms of mechanism. It appears that oversized bubbles form, break up, and rapidly coalesce to form bubble swarms with mean bubble diameters very near $0.5 \mathrm{~cm}$. A coalescence step is hypothesized because there is nothing in the bubble breakup process that would seem to produce such narrow distributions of bubble sizes as are observed in the experiments.

Coalescence of gas bubbles is known to be a major factor in gas-liquid interactions [72]. Coalescence of bubbles is observed to occur easily in very pure systems if the relative velocities of the interacting bubbles are not too different [73]. Contamination of the liquid with ionic or organic solutes is. found to inhibit bubble coalescence. 
Table 10. Effect of steam concentration on the bubble size distribution

\begin{tabular}{cccccc}
\hline $\begin{array}{c}\text { Orifice } \\
\text { diameter } \\
(\mathbf{c m})\end{array}$ & $\begin{array}{c}\text { Steam } \\
\text { injection rate } \\
(\text { moles/s) }\end{array}$ & $\begin{array}{c}\text { Noncondensible } \\
\text { injection rate } \\
\text { (moles/s) }\end{array}$ & $\begin{array}{c}\text { Elevation } \\
\text { above } \\
\text { orifice } \\
(\mathbf{c m})\end{array}$ & $\begin{array}{c}\text { Mean } \\
\text { bubble size } \\
(\mathbf{c m})\end{array}$ & $\begin{array}{c}\text { Geometric } \\
\text { standard deviation } \\
(-)\end{array}$ \\
\hline 0.99 & 0.0264 & 0.0680 & 122 & 0.556 & 1.54 \\
0.99 & 0.0440 & 0.0452 & 122 & 0.544 & 1.52 \\
0.99 & 0.0677 & 0.0225 & 122 & 0.447 & 1.53 \\
0.99 & 0.0827 & 0.0045 & 122 & 0.374 & 1.36 \\
0.99 & 0.0260 & 0.0687 & 198 & 0.578 & 1.52 \\
0.99 & 0.0432 & 0.0459 & 198 & 0.524 & 1.44 \\
0.99 & 0.0638 & 0.0229 & 198 & 0.498 & 1.61 \\
0.99 & 0.0833 & 0.0046 & 198 & 0.313 & 1.48 \\
0.99 & 0.0276 & 0.0691 & 305 & 0.566 & 1.51 \\
0.99 & 0.0445 & 0.0456 & 305 & 0.566 & 1.46 \\
0.99 & 0.0677 & 0.0227 & 305 & 0.455 & 1.50 \\
0.99 & 0.0855 & 0.0046 & 305 & 0.361 & 1.46 \\
\hline
\end{tabular}

Oolman and Blanch [71] consider bubble coalescence to be a three step process:

- hydrodynamic processes bring bubbles into close proximity so that a liquid layer $10^{-3}$ to $10^{-4} \mathrm{~cm}$ thick separates the bubbles,

- processes driven by surface tension thin the separation layer to a thickness of about $10^{-6} \mathrm{~cm}$, and

- the separation layer ruptures so the bubbles unite.

It has been argued [74] that an electric double layer produced by dissolved ions resists the thinning of the liquid layer between bubbles brought into close proximity by hydrodynamic processes. Oolman and Blanch [71] reject this argument because they believe the electric double layer has too small an effect. They argue, instead, that the resistance to coalescence observed for contaminated liquids is the result of surface tension effects.

Consider two bubbles brought together so that there is a liquid film of thickness $h_{o} \cong 1 \times 10^{-3} \mathrm{~cm}$ between them. At the center, the film is flat and the pressure is the bubble pressure. At the perimeter of the film, there are curvature effects. As a result, there is a pressure variation along the film given by: 


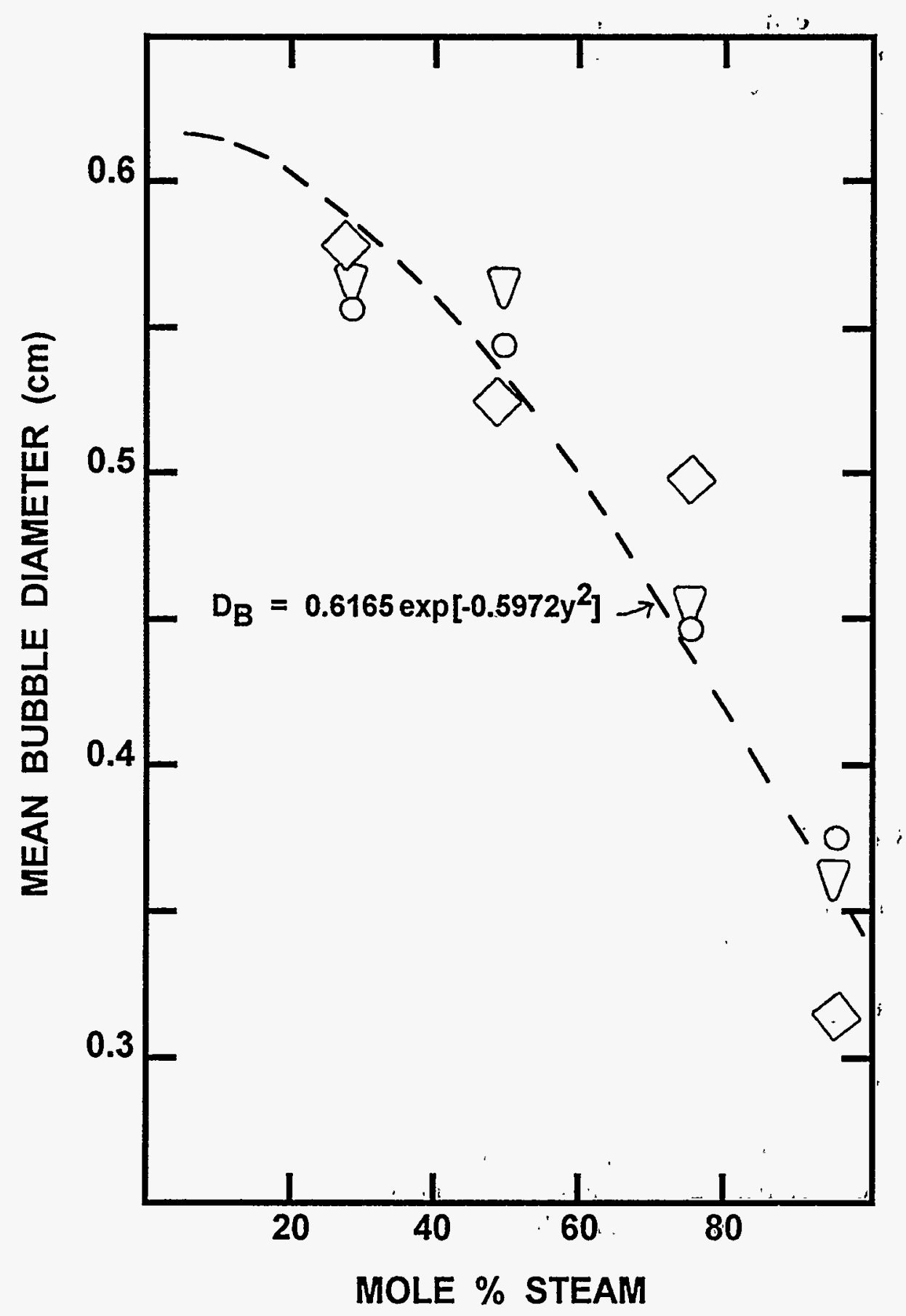

Figure 45. Effect of the mole fraction of steam in air/steam mixtures on the mean bubble size 


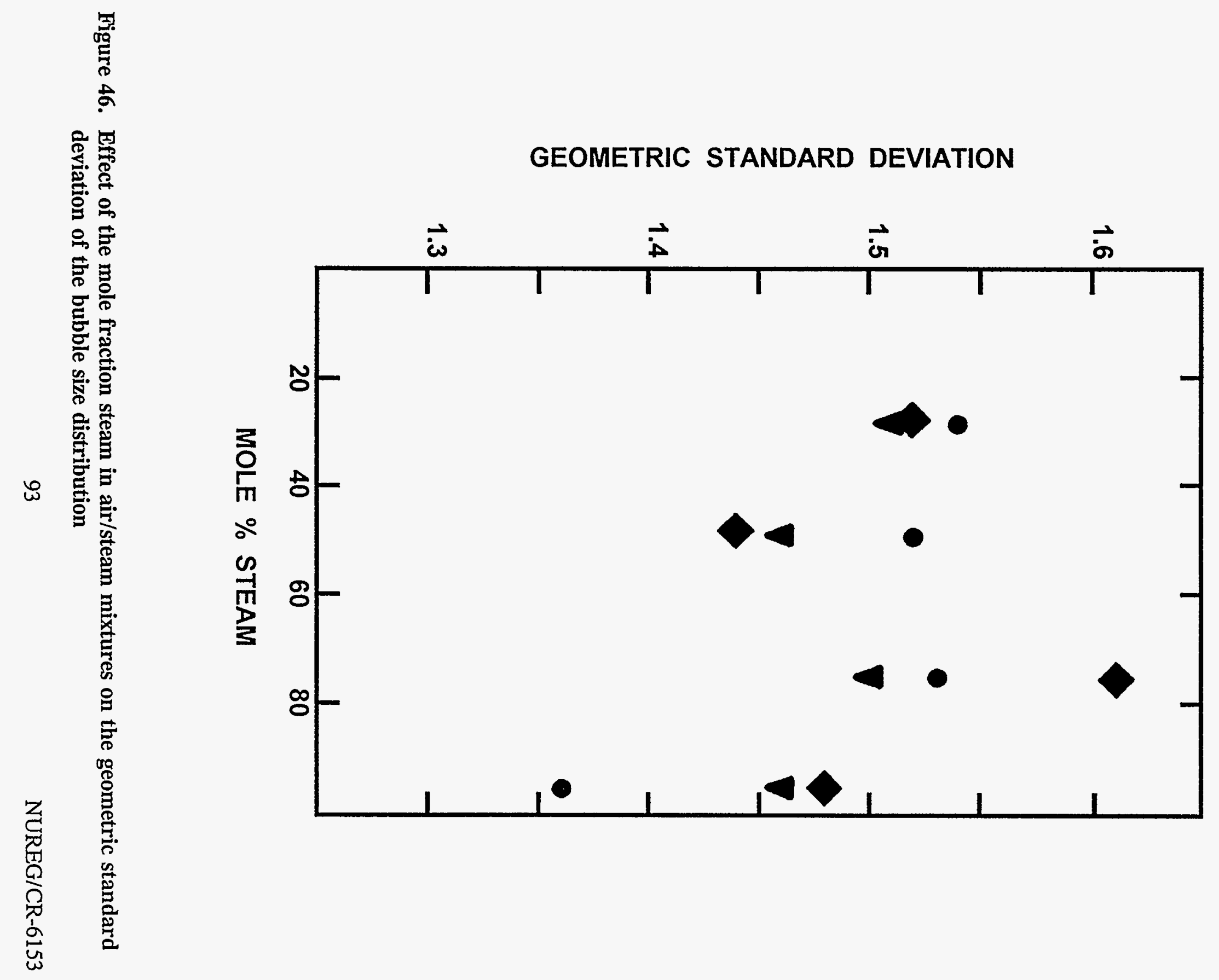


Physical Phenomena

$$
\Delta \mathrm{P}=4 \sigma_{1} / \mathrm{D}_{\mathrm{B}}+\mathrm{A} / 6 \pi \mathrm{h}^{3}
$$

where $A$ is the. Hanamaker constant taken to be $10^{-12}$ ergs. If a solute is present, it will impart an opposing force given by [75]:

$$
\Delta \sigma_{1}=\frac{1}{\mathrm{~h}} \frac{2 \mathrm{c}}{\mathrm{RT}}\left(\frac{\partial \sigma_{1}}{\partial \mathrm{c}}\right)^{2}
$$

where $\mathrm{c}$ is the concentration of the solute in moles per liter. Then, from the Navier-Stokes equation:

$$
\frac{1}{h_{0}} \frac{\partial^{2} h}{\partial \tau^{2}}=\frac{1.5 h_{0}}{h}\left(\frac{\partial h}{\partial \tau}\right)^{2}-\frac{h}{h_{0}} A_{1}-\left(\frac{h}{h_{0}}\right)^{2} A_{2}+\frac{h_{0} A_{3}}{h}
$$

where

$$
\begin{aligned}
\tau & =\left[\frac{\sigma_{1}}{\rho_{1} \mathrm{~h}_{0}^{3}}\right]^{1 / 2} \mathrm{t} \\
\mathrm{A}_{1} & =16 \mathrm{~h}_{\mathrm{o}}^{3} / \mathrm{D}_{\mathrm{B}} \mathrm{r}^{2} \\
\mathrm{~A}_{2} & =2 \mathrm{~A} / 3 \pi \sigma_{1} \mathrm{r}^{2}, \\
\mathrm{~A}_{3} & =\frac{16 \mathrm{c}}{\mathrm{h}_{\mathrm{o}}}\left[\frac{\partial \sigma_{1}}{\partial \mathrm{c}}\right]^{2}\left(1 / \sigma_{1} \mathrm{RT} \mathrm{r}^{2}\right), \text { and } \\
\mathrm{r} & =\text { radius of film disk separating the bubbles. }
\end{aligned}
$$

Solution of this equation for various values of $\mathrm{A}_{3}$ shows there to be a critical solution concentration that marks a transition from rapid bubble coalescence to slow bubble coalescence. Such behavior is observed in the coalescence of bubble pairs rising through aqueous salt solutions [75,76]. Data correlate best when plotted against ionic strength, I, rather than concentration. Data on coalescence efficiency (percent of bubble pairs observed to coalescence for solutions of $\mathrm{KCl}, \mathrm{AlCl}_{3}, \mathrm{Mg}_{2} \mathrm{SO}_{4}, \mathrm{MgCl}_{2}, \mathrm{CaCl}_{2}$, $\mathrm{Na}_{2} \mathrm{SO}_{4}, \mathrm{LiCl}, \mathrm{NaCl}$, and $\mathrm{NaBr}$ are shown in Figure 47. There appears to be a sharp increase in the efficiency of bubble coalescence once the ionic strength dropsibelow about 0.18 . I Prince. and Blaneh [209] indicate that the critical concentration for ionic solutes is given by: 


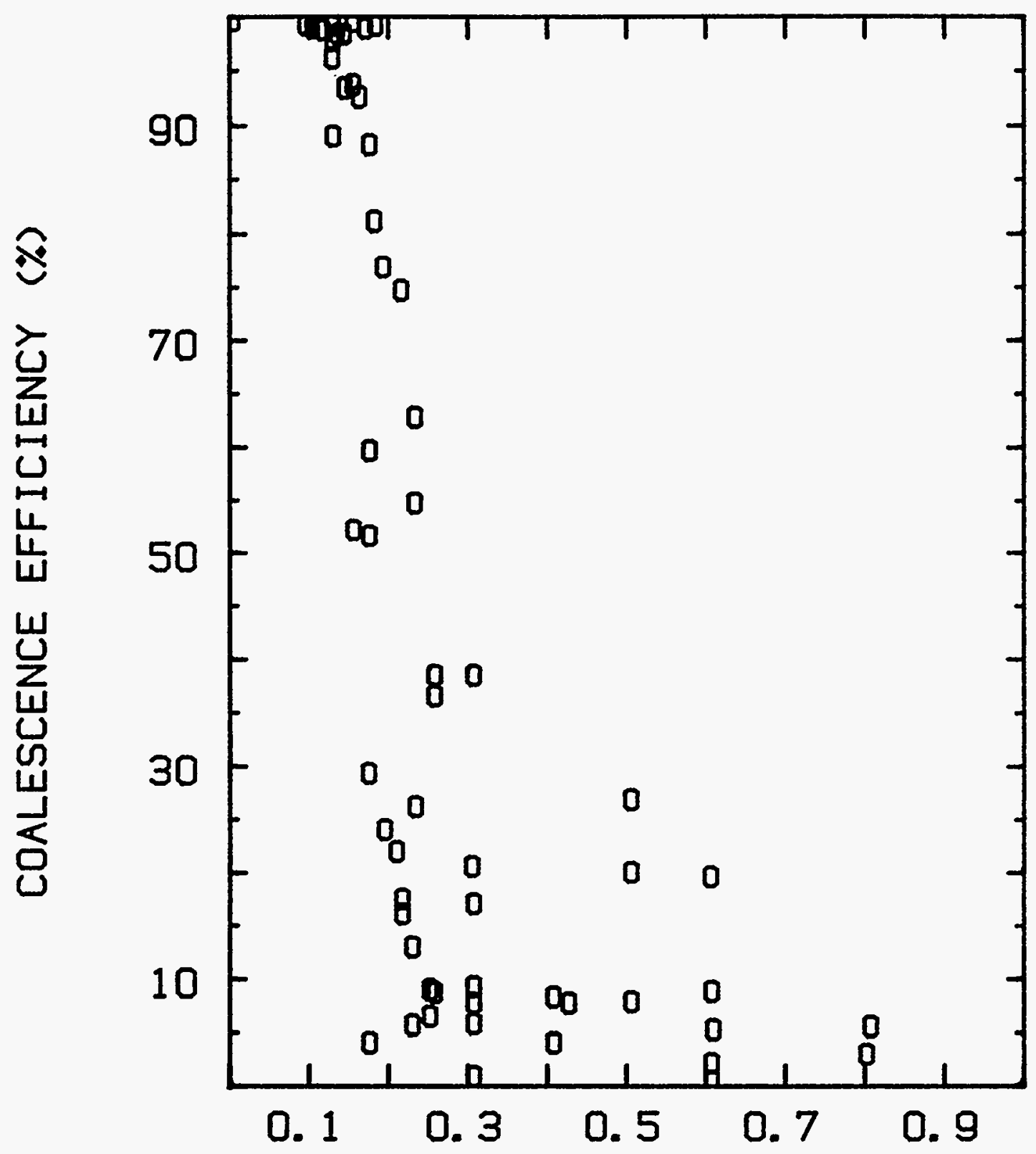

IONIC STRENGTH

Figure 47. Efficiency of bubble coalescence as a function of the ionic strength of the aqueous solution 
Physical Phenomena

$$
\mathrm{C}=1.18 \mathrm{n}( \pm)\left(\frac{2 \mathrm{~B} \sigma_{1}}{\mathrm{D}_{\mathrm{B}}}\right)^{1 / 2} \frac{\mathrm{RT}}{\left(\frac{\partial \sigma_{1}}{\partial \mathrm{c}}\right]^{2}}
$$

where

$$
\begin{aligned}
\mathrm{C} & =\text { concentration of the dissolved salt, } \\
\mathrm{n}( \pm) & =\text { number of ions produced when a "molecule" of salt dissolves, } \\
\mathrm{B} & =1.5 \times 10^{-19} \mathrm{erg} \mathrm{cm}, \text { and } \\
\frac{\partial \sigma_{1}}{\partial c} & =\text { derivative of the liquid surface tension with respect to salt concentration. }
\end{aligned}
$$

Work done by Paul et al. [30] and by Hakii et al. [69] involved essentially juncontaminated "water. In such systems, efficient coalescence of bubbles to produce the observed bubble size distribution could occur. This may not be the situation in reactor accidents. As the accident progresses, the water in the steam suppression pool becomes contaminated. Especially in the late phasses of a reactôr accident, contamination of the steam suppression pool may be sufficient to interfere in the coalescence of gas bubbles. Bubble size distributions different (presumably smaller) than those observed by Paul'et al. [30] or Hakii et al. [69] may form.

The inhibition to coalescence by organic, volatile materials is even more striking than the effect of ionic solutes. Transitions from rapid coalescence to slow coalescence occur at organic volume fractions of $10^{-5}$ to $10^{-3}$. Later in the discussion of phenomena, it will bé shown that organic contaminants affect rise velocities of bubbles and the inertial impaction of aerosol particles.

Lee et al. [220] have developed a probabilistic description of bubble coalescence. They describe the rate of coalescence of bubbles of diameter $d(1)$ and $d(2)$ at number concentrations of $n(1)$ and $n(2)$, respectively, as:

$$
\text { Rate }=C \exp \left\{\frac{-\alpha \epsilon^{1 / 3} t_{c}}{d^{2 / 3}}\right\} \epsilon^{1 / 3} d^{2}\left(d(1)^{2 / 3}+d(2)^{2 / 3}\right)^{1 / 2} n(1) n(2)
$$

where

$$
\begin{aligned}
& \mathrm{d}=\mathrm{d}(1)+\mathrm{d}(2) \\
& \epsilon=\text { turbulent energy dissipation rate per unit mass, }
\end{aligned}
$$




$$
\begin{aligned}
t_{c} & =\text { coalescence time }=t(a)+t(b), \\
t(a) & =24 \pi^{2} \sigma_{1} \mu_{1} h_{f}^{5} z / A_{h}^{2}, \\
t(b) & =\frac{R^{\prime}}{4}\left(\rho_{1} d / 2 \sigma_{1}\right)^{1 / 2} \ln [h(i) / h(f)], \\
A_{h} & =\text { Hanamaker's constant, and }
\end{aligned}
$$

other symbols denote empirical constants. When plotted against bubble size, this rate of coalescence for aqueous systems passes through a minimum at bubble diameters of about $0.25 \mathrm{~cm}$. Coalescence rates decrease with the intensity of turbulent energy dissipation. The coalescence rate, combined with similar expressions developed by Lee et al. on the rates of bubble breakup in turbulent environments, might form the basis for rationalizing the invariance in the final bubble size distribution observed by Paul et al. [30]. The matter is not pursued further here. Moreover, the dependence of coalescence on the turbulent energy dissipation makes it unclear that size distributions for bubbles observed by Paul et al. in tests with one or a few orifices can be unequivocally applied to quenchers with hundreds of orifices at conditions substantially different than those of the tests.

In the simplified model of suppression pool scrubbing developed below, keeping track of ionic strength in the water pool is really impracticable. Water in the suppression pools of boiling water reactors will usually be quite pure at the start of an accident, and bubble coalescence as observed by Paul et al. [30] should be possible. As the accident progresses, the suppression pool will become progressively more contaminated with both soluble and insoluble materials. Surely during the ex-vessel phases of an accident, the contamination will become sufficient to meet the concentration criterion that bubble coalescence is inhibited.

\section{Thermodynamics of Bubble Rise}

Bubbles detach from vents and orifices and begin to equilibrate with the bulk pool. Achieving equilibrium is quite dynamic and can involve disintegration or collapse of the initial bubble and subsequent coalescence of the bubbles. All these dynamic processes take place rather quickly-within 2 to 10 initial bubble diameters of the vents in the suppression pool [30]. A swarm of bubbles then rises through the pool. As bubbles rise, there is a loss of pressure head so the bubbles expand. In order to maintain equilibrium with the water pool, water will have to vaporize into the bubble. There is, then, a flux of water vapor coming off the walls of the bubble. This flux of water vapor will oppose the motion of particles toward the walls. At the same time, expansion of the bubble will cool the gas within the bubble. This will create a temperature difference between the bulk gas and the bubble surface. As a result, there will be a thermophoretic driving force pushing particles away from the bubble surface.

Analysis of the vaporization of water into the bubble must be done in terms of the internal energy of an open system since neither the pressure nor the volume is constant. The analysis below follows in outline the general features of an analysis by Owczarski and Burk [6]. The gas in the bubble is taken to be ideal. Here, aerosols within the bubble are neglected. Aerosols in the bubbles could be heat sinks 


\section{Physical Phenomena}

and sources of decay heat. Concentrations of the aerosols are, however, thought to be sufficiently low so that the aerosols will not significantly perturb the thermodynamic properties of the gas. That is, at an aerosol concentration of $0.1 \mathrm{~g} / \mathrm{m}^{3}$, the aerosol would, typically, only increase the heat capacity of the gas by about 0.01 percent. It is possible that water could condense on aerosol particles within a bubble. Whether or not this happens is dependent on the properties of the aerosol material. This topic is discussed further below. Aerosols could be a source of decay heat. At typical decay heating rates of $0.3 \mathrm{~W} / \mathrm{g}$ and a bubble rise time of 20 seconds, decay heating by aerosols at a concentration of $0.1 \mathrm{~g} / \mathrm{m}^{3}$ would only increase the energy in the gas phase by the equivalent of $5 \times 10^{-4} \mathrm{~K}$. Thus, decay heating is neglected here.

Consider a bubble of initial volume V(i), pressure $\mathrm{P}(\mathrm{i})$, and temperature T(i).. A differential upward displacement of the bubble, $\mathrm{dx}$, is imagined to change the volume, pressure, and temperature to $\mathrm{V}(\mathrm{f})$, $P(f)$ and $T(f)$, respectively. A molar amount of water, $\operatorname{dn}\left(\mathrm{H}_{2} \mathrm{O}\right)$ is also imagined to vaporize into the bubble during the displacement.

Changes in the internal energy of the bubble during the displacement are defined by:

$$
\Delta \mathrm{U}=\Delta \mathrm{Q}-\Delta \mathrm{W}
$$

where

$$
\begin{aligned}
& \Delta \mathrm{U}=\text { change in the internal energy, } \\
& \Delta \mathrm{Q}=\text { change in the heat content, and } \\
& \Delta \mathrm{W}=\text { work done by the bubble. }
\end{aligned}
$$

For the situation of interest here, work is taken to be pressure-volume work:

$$
\Delta W=\int_{V(i)}^{V(f)} P d V^{\prime}
$$

The thermodynamic cycle that can be used to define the change in state associated with'the' differential displacement of the bubble involves the following steps:

- an isothermal vaporization of $\mathrm{dn}\left(\mathrm{H}_{2} \mathrm{O}\right)$ moles of water into the bubble which causes the bubble to expand from $\mathrm{V}(\mathrm{i})$ to $\mathrm{V}^{\prime}$,

- an isothermal expansion from $P(i), V^{\prime}, T(i)$ to $P(f), V^{*}, T(i)$, and

- a constant pressure expansion from $P(f), V^{*}, T(i)$ to $P(f), V(f), T(f)$. 
These steps can be compared to the internal energy change of an isothermal vaporization and a change from $T(i)$ to $T(f)$.

For the first step in the cycle, a constant temperature, constant pressure vaporization of $\operatorname{dn}\left(\mathrm{H}_{2} \mathrm{O}\right)$ moles of water, the work done is:

$$
\Delta W_{1}=\int_{V(i)}^{V^{\prime}} P(i) d V=\int_{n\left(H_{2} O\right)}^{n\left(H_{2} \mathrm{O}\right)+d n\left(H_{2} \mathrm{O}\right)} P(i) d n\left(H_{2} \mathrm{O}\right) R T / P(i)=P(i)\left(V^{\prime}-V(i)\right)
$$

and, thus,

$$
\mathrm{V}^{\prime}=\mathrm{V}(\mathrm{i})+\frac{\mathrm{RT}(\mathrm{i}) \mathrm{dn}\left(\mathrm{H}_{2} \mathrm{O}\right)}{\mathrm{P}(\mathrm{i})}
$$

The work done in the second step, the isothermal expansion from $P(i), V^{\prime}, T(i)$ to $P(f), V^{*}, T(i)$ is:

$$
\begin{aligned}
\Delta W_{2} & =\int_{V^{\prime}}^{V^{*}} P d V=\int_{V^{\prime}}^{V^{*}} \frac{n R T(i)}{V} d V=n R T(i) \ln \left(V^{*} / V^{\prime}\right) \\
& =\left[n_{0}\left(H_{2} O\right)+\operatorname{dn}\left(H_{2} O\right)+n(N C)\right] R T(i) \ln \left(V^{*} / V^{\prime}\right)
\end{aligned}
$$

where

$$
\mathrm{R}=\text { gas constant, }
$$

$\mathrm{n}_{\mathrm{o}}\left(\mathrm{H}_{2} \mathrm{O}\right)=$ moles of water vapor present in the bubble prior to the displacement, and $\mathrm{n}(\mathrm{NC})=$ moles of noncondensible gas in the bubble.

Since, by assumption, the gas is ideal:

$$
\mathrm{V}^{*}=\frac{\mathrm{nRT}(\mathrm{i})}{\mathrm{P}(\mathrm{f})} \text { and } \mathrm{V}^{\prime}=\frac{\mathrm{nRT}(\mathrm{i})}{\mathrm{P}(\mathrm{i})}
$$


Physical Phenomena

Then,

$$
\Delta \mathrm{W}_{2}=\left[\mathrm{n}_{\mathrm{o}}\left(\mathrm{H}_{2} \mathrm{O}\right)+\mathrm{dn}\left(\mathrm{H}_{2} \mathrm{O}\right)+\mathrm{n}(\mathrm{NC})\right]: \mathrm{RT}(\mathrm{i}): \ln [\mathrm{P}(\mathrm{i}) / \mathrm{P}(\mathrm{f})]
$$

The total work done in going from the initial to the final state is:

$$
\begin{aligned}
\Delta \mathrm{W}= & \Delta \mathrm{W}_{1}+\Delta \mathrm{W}_{2}+\Delta \mathrm{W}_{3}=\mathrm{dn}\left(\mathrm{H}_{2} \mathrm{O}\right) \mathrm{RT}(\mathrm{i})+\left[\mathrm{n}_{\mathrm{O}}\left(\mathrm{H}_{2} \mathrm{O}\right)+\mathrm{n}(\mathrm{NC})+\mathrm{dn}\left(\mathrm{H}_{2} \mathrm{O}\right)\right] \mathrm{RT}(\mathrm{i}) \ln \frac{\mathrm{P}(\mathrm{i})}{\mathrm{P}(\mathrm{f})} \\
& +\left[\mathrm{n}_{\mathrm{O}}\left(\mathrm{H}_{2} \mathrm{O}\right)+\mathrm{n}(\mathrm{NC})+\mathrm{dn}\left(\mathrm{H}_{2} \mathrm{O}\right)\right] \mathrm{R}(\mathrm{T}(\mathrm{f})-\mathrm{T}(\mathrm{i}))
\end{aligned}
$$

In the limit of small $\mathrm{dx}$ :

$$
\frac{d W}{d x}=R T \frac{d n\left(H_{2} \mathrm{O}\right)}{d x}-\left[n\left(H_{2} \mathrm{O}\right)+n(N C)\right] R T \frac{d \ln P}{d x}+\left[n\left(H_{2} \mathrm{O}\right)+n(N C)\right] R \cdot \frac{d T}{d x}
$$

The change in the internal energy of an ideal gas is just a function of temperature. Therefore, the internal energy change in going from the initial to the final state is:

$$
\frac{d U}{d x}=n\left(H_{2} \mathrm{O}\right) C_{v}\left(H_{2} O\right) \frac{d T}{d x}+n(N C) C_{v}(N C) \frac{d T}{d x}+\left[L+\int_{T(r e f)}^{T} C_{v}\left(H_{2} O\right) d T\right] \frac{d n\left(H_{2} O\right)}{d x}
$$

where

$$
\begin{aligned}
& \mathrm{C}_{\mathrm{v}}(\mathrm{i})=\text { constant volume heat capacity of species } \mathrm{i} \text {, and } \\
& \mathrm{T}(\mathrm{ref})=\text { reference temperature for the internal energy }
\end{aligned}
$$

The heat input to the bubble during a differential displacement is given by:

$$
\begin{aligned}
\frac{d Q}{d x}= & \frac{d U}{d x}+\frac{d W}{d x}=\left[n\left(H_{2} O\right) C_{p}\left(H_{2} O\right)+n(N C) C_{p}(N C)\right] \frac{d T}{d x} \\
& -\left[n\left(H_{2} O\right)+n(N C)\right] R T \frac{d \ln P}{d x}+\left[L+\int_{T(r e f)}^{T} C_{v}\left(H_{2} O\right) d T+R T\right] \frac{d n\left(H_{2} O\right)}{d x}
\end{aligned}
$$


where use has been made in deriving the above result of the relationship between the constant pressure heat capacity, $\mathrm{C}_{\mathrm{p}}(\mathrm{i})$, and the constant volume heat capacity, $\mathrm{C}_{\mathrm{v}}(\mathrm{i})$ :

$$
C_{p}(i)=C_{v}(i)+R
$$

The differential equation above, along with the assumption that noncondensible gases neither dissolve in the water or vaporize from water into the bubble:

$$
\frac{\mathrm{dn}(\mathrm{NC})}{\mathrm{dx}}=0
$$

define constraints on variations of the thermodynamic variables of the system. Phenomenological descriptions of any three of the derivatives of the thermodynamic variables allows the fourth to be determined.

As the ambient conditions change, the system will respond in a way that minimizes changes to the system. Thus, a reduction in pressure will cause the bubble to expand. To minimize this expansion, the gas will attempt to cool. If heat is supplied, this cooling will be limited and water vapor will evaporate into the bubble.

The flux of water vapor into the bubble is, of course, of interest because it will constitute a flow that opposes particle deposition. On the other hand, if water vapor condenses on the bubble wall, it provides a flow that will enhance particle deposition. The magnitude and direction of the flow can be found by evaluating the above differential expression. The change in pressure associated with bubble rise is found from:

$$
\frac{1}{\mathrm{P}} \frac{\mathrm{dP}}{\mathrm{dx}}=-\rho_{1} g \xi / \mathrm{P}=\frac{\mathrm{d} \ln \mathrm{P}}{\mathrm{dx}}
$$

where $\xi$ is a constant to correct units $\left(1013250 \mathrm{~g} / \mathrm{cm}-\mathrm{s}^{2}=1\right.$ atmosphere). If transfer processes within the bubble are very fast, then the heat supplied to the bubble is:

$$
\frac{\mathrm{dQ}}{\mathrm{dx}}=\mathrm{h}(\mathrm{x}) \pi \mathrm{D}^{2}(\text { bubble })[\mathrm{T}(\infty)-\mathrm{T}]
$$

where $h(x)$ is an external heat transfer coefficient discussed below (see Section IV-I).

The rate of vaporization of water into the bubble must be sufficient to keep the bubble atmosphere at saturation. From the ideal gas equation of state: 
Physical Phenomena

$$
\frac{\mathrm{Pn}\left(\mathrm{H}_{2} \mathrm{O}\right)}{\mathrm{n}(\mathrm{NC})+\mathrm{n}\left(\mathrm{H}_{2} \mathrm{O}\right)}=\mathrm{P}(\mathrm{sat})
$$

where the saturation partial pressure of water vapor, $\mathrm{P}(\mathrm{sat})$, is strictly a function of temperature. Near $373 \mathrm{~K}$, the functional dependence of $\mathrm{P}($ sat) on temperature is approximately,

$$
\ln \mathrm{P}(\mathrm{sat})=13.3349-4976.65 / \mathrm{T}(\mathrm{K})
$$

when $\mathrm{P}$ (sat) is in units of atmospheres.

Then,

$$
\frac{\mathrm{dn}\left(\mathrm{H}_{2} \mathrm{O}\right)}{\mathrm{dx}}=\frac{4976.65 \ddot{\mathrm{n}}(\text { sat })}{\mathrm{T}^{2}(\mathrm{P}-\mathrm{P}(\mathrm{sat}))} \frac{\mathrm{dT}}{\mathrm{dx}}-\frac{\mathrm{n}\left(\mathrm{H}_{2} \mathrm{O}\right)}{\mathrm{P}-\mathrm{P}(\text { sat })} \frac{\mathrm{dP}}{\mathrm{dx}}
$$

and

$$
\frac{\mathrm{dQ}}{\mathrm{dx}}+\frac{\mathrm{dP}}{\mathrm{dx}}\left[\frac{\mathrm{nRT}}{\mathrm{P}}+\frac{\mathrm{n}\left(\mathrm{H}_{2} \mathrm{O}\right) \mathrm{L}}{\mathrm{P}-\mathrm{P}(\mathrm{sat})}\right]=\left[\mathrm{n}\left(\mathrm{H}_{2} \mathrm{O}\right) \mathrm{C}_{\mathrm{p}}\left(\mathrm{H}_{2} \mathrm{O}\right)+\mathrm{n}(\mathrm{NC}) \mathrm{C}_{\mathrm{p}}(\mathrm{NC})+\frac{4976.65 \mathrm{n}(\mathrm{sat}) \mathrm{L}}{\mathrm{T}^{2}\left(\mathrm{P}-\mathrm{P}\left(\mathrm{s}^{\prime}\right)^{\prime}\right)}\right] \frac{\mathrm{dT}}{\mathrm{dx}}
$$

where $n=n\left(\mathrm{H}_{2} \mathrm{O}\right)+\mathrm{n}(\mathrm{NC})$.

Inspection of these equations shows that if heat is not supplied to the bubble, the bubble cools as it rises through the pool. If the cooling rate is rapid enough, water vapor will condense on the bubble surface. Convective heating of the bubble can slow the cooling and cause water vapor to evaporate into the bubble.

Results of an example calculation for a steam-hydrogen bubble in a $400-\mathrm{cm}$-deep pool of water at $373 \mathrm{~K}$ are shown in Figure 48 . The initial bubble size was taken to be $0.5 \mathrm{~cm}$. Growth of the bubble as it rises is quite small initially. Only in the last $100 \mathrm{~cm}$ or so is there an easily measured increase in the bubble diameter. For this example calculation, the convective heat transfer coefficient was taken to be given by:

\footnotetext{
* More accurate expressions for the saturation vapor pressure of water are described later in the chapter.
} 

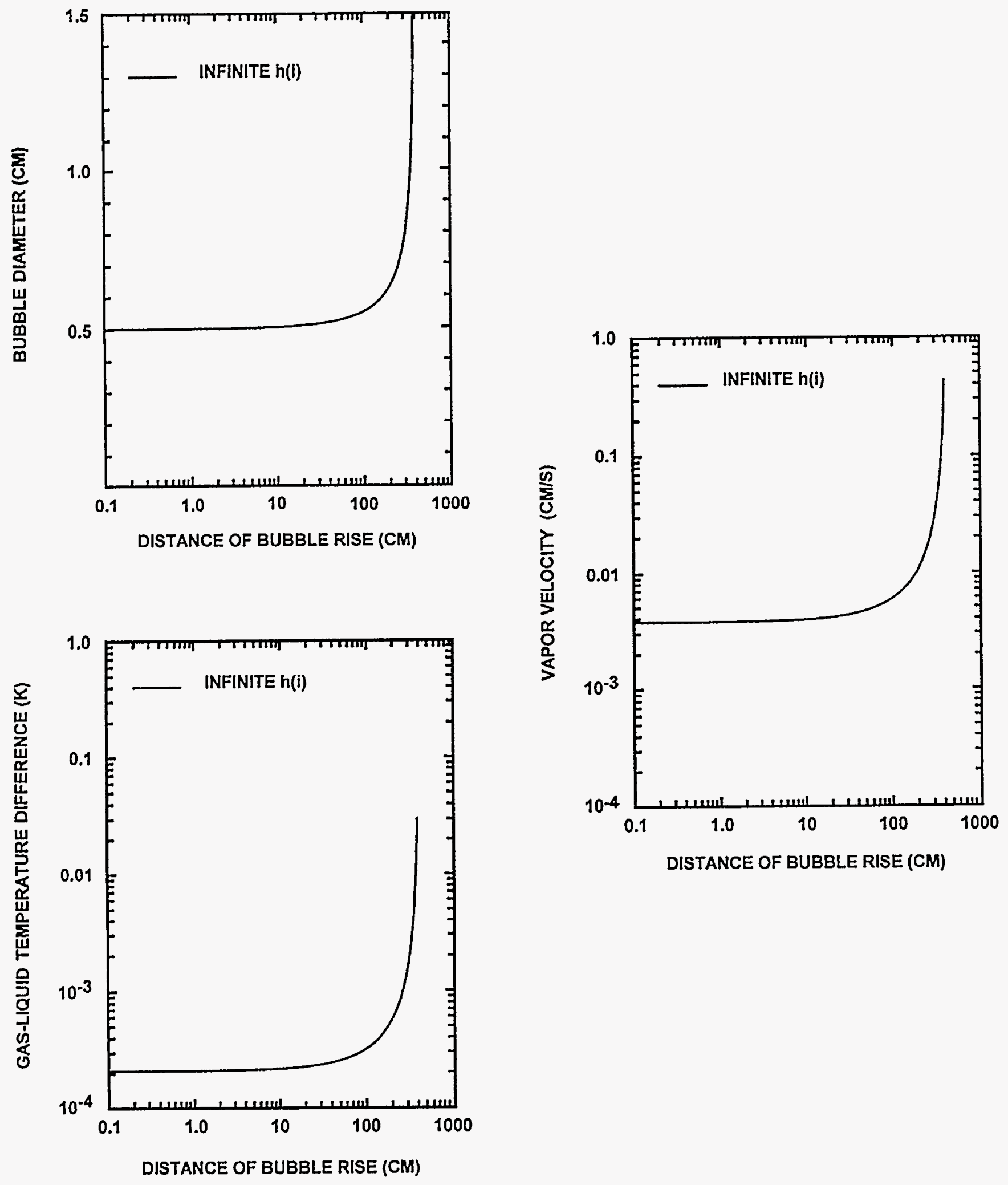

Figure 48. Thermodynamic calculation of bubble rise in a water pool. For this calculation $\mathrm{T}_{\text {pool }}=373.15 \mathrm{~K}, \mathrm{H}=400 \mathrm{~cm}$ and the heat transfer within the bubble is assumed to be infinitely fast. 
Physical Phenomena

$$
\mathrm{Nu}=\mathrm{h}(\mathrm{x}) \mathrm{D}_{\mathrm{B}} / \mathrm{k}_{\mathrm{th}}(\mathrm{l})=1.13 \sqrt{\mathrm{Pe}}
$$

where

$$
\begin{aligned}
\mathrm{Nu} & =\text { Nusselt number, } \\
\mathrm{h}(\mathrm{x}) & =\text { external heat transfer coefficient, } \\
\mathrm{k}_{\mathrm{th}}(\mathrm{l}) & =\text { thermal conductivity of water, } \\
\mathrm{Pe} & =\text { Peclet number }=\frac{\mathrm{U}(\text { bubble }) \mathrm{D}_{\mathrm{B}} \rho_{\mathrm{l}} \mathrm{C}_{\mathrm{p}}(\mathrm{l})}{\mathrm{k}_{\mathrm{th}}(\mathrm{l})}
\end{aligned}
$$

$\mathrm{U}($ bubble $)=$ rise velocity of the bubble, and

$$
\mathrm{C}_{\mathrm{p}}(\mathrm{l})=\text { heat capacity of water. }
$$

Heat transfer to rising bubbles is discussed further below (see Section IV-I).

The velocity of water vapor coming off the bubble walls varies between $10^{-3}$ and $0.1 \mathrm{em} / \mathrm{sr}-$ This vapor velocity is comparable to aerosol deposition velocities discussed below and should retard deposition processes.

The temperature differences between the bulk pool and the bubble surface are always quite small. For this example calculation, heat transfer within the bubble has been assumed to be infinitely rapid. There is, then, no thermophoretic force on particles that might be present.

Incorporation of finite rates of mass and heat transfer within the bubble requires that a distinction be made between the surface temperature of the bubble, $\mathrm{T}(\mathrm{s})$, and the temperature of the bulk gas in the bubble, T. The surface temperature of the bubble is found by assuming a quasi-steady state exists. Then,

$$
h(x)\left[T_{p}-T(s)\right]=\frac{k_{m} L}{R}\left[\frac{P(s a t)}{T(s)}-\frac{P n\left(H_{2} \mathrm{O}\right)}{n T}\right]+h(i)[T(s)-T]
$$

where

$\mathrm{k}_{\mathrm{m}}=$ mass transfer coefficient for steam in the bubble,

$\mathrm{L}=$ molar latent heat of water vaporization, 
$\mathrm{P}=$ pressure including the hydrostatic pressure, and

$\mathrm{h}(\mathrm{i})=$ internal heat transfer coefficient.

Results of an example calculation similar to that discussed above are shown as solid lines in Figure 49. Also shown in Figure 49, as dashed lines, are results for the calculation with infinitely fast transfer processes within the bubble. Mass and heat transfer coefficients for the example calculation were obtained from the Kronig-Brink equation which is discussed further below. This model assumes that the gases in the bubble are well mixed.

In comparison to the results for infinitely fast internal processes, the vapor velocities from the bubble walls are somewhat lower and thus a lower diffusiophoretic resistance to aerosol deposition. On the other hand, there is a difference between the surface temperature of the bubble and the bulk gas in the bubble so there is a predicted potential for thermophoretic resistance to aerosol deposition on the bubble walls. This thermophoretic force is, however, not very large.

\section{E. Bubble Plumes From Quenchers}

Most of the detailed information on bubble behavior has been derived from experiments in which there were elaborate efforts to generate single, well-isolated bubbles. Quenchers and vents in suppression pools will, instead, generate swarms of bubbles. Wakes created by bubbles will affect the behaviors of succeeding bubbles. Perhaps the most important effect of bubble swarms is that they entrain liquid. Because the points of bubble generation are localized within the pool, the entrainment of liquid can have a profound effect on bubble behavior. (Note that this entrainment effect does not arise in such a dramatic fashion in the case of water pools overlying core debris where bubble generation takes place over the entire base of the pool.) Coupling of bubble and liquid motion creates an expanding plume. Bubbles within the plume rise faster than do isolated bubbles because their velocities are augmented by the velocity of the entrained water. Because the bubbles rise more rapidly to the pool surface, there is less opportunity to remove aerosols from the bubble than there is for aerosol removal from isolated bubbles. As discussed at length below, there is a distribution of bubble concentrations and velocities across a plume so that aerosol removal will not be the same for every bubble.

Bubble plumes present some interesting complexities. Significant approximations will be made in the description of bubble plumes adopted here. Plumes will be represented as coming from a point source. In the case of quenchers, the entire arm of a quencher, which may have several hundred orifices, will be treated as a single source. The effect of the submerged pipe will be neglected for bubble plumes created by downcomers. The effects of the weir wall will be neglected in the treatment of bubble plumes from horizontal vents. In all of the analyses, the water pool will be considered infinite in extent. That is, the boundaries of the pool and the presence of other plumes will be assumed to have negligible effects on the quantities of interest.

The description of bubble plumes will follow the integral representations developed by Milgram [44], Tacke et al. [45], Chester et al. [265] and by Sahai and Guthrie [266]. These developments do not treat the condensation and evaporation of water. Analyses of the thermodynamics of bubble rise (Section IV-D, above) suggest that condensation and evaporation ought not affect bubble behavior too much except near the surface. Except for the effect of evaporation of water vapor into the bubble on the momentum equation and the gas continuity equation, condensation and evaporation effects on plume 
Physical Phenomena
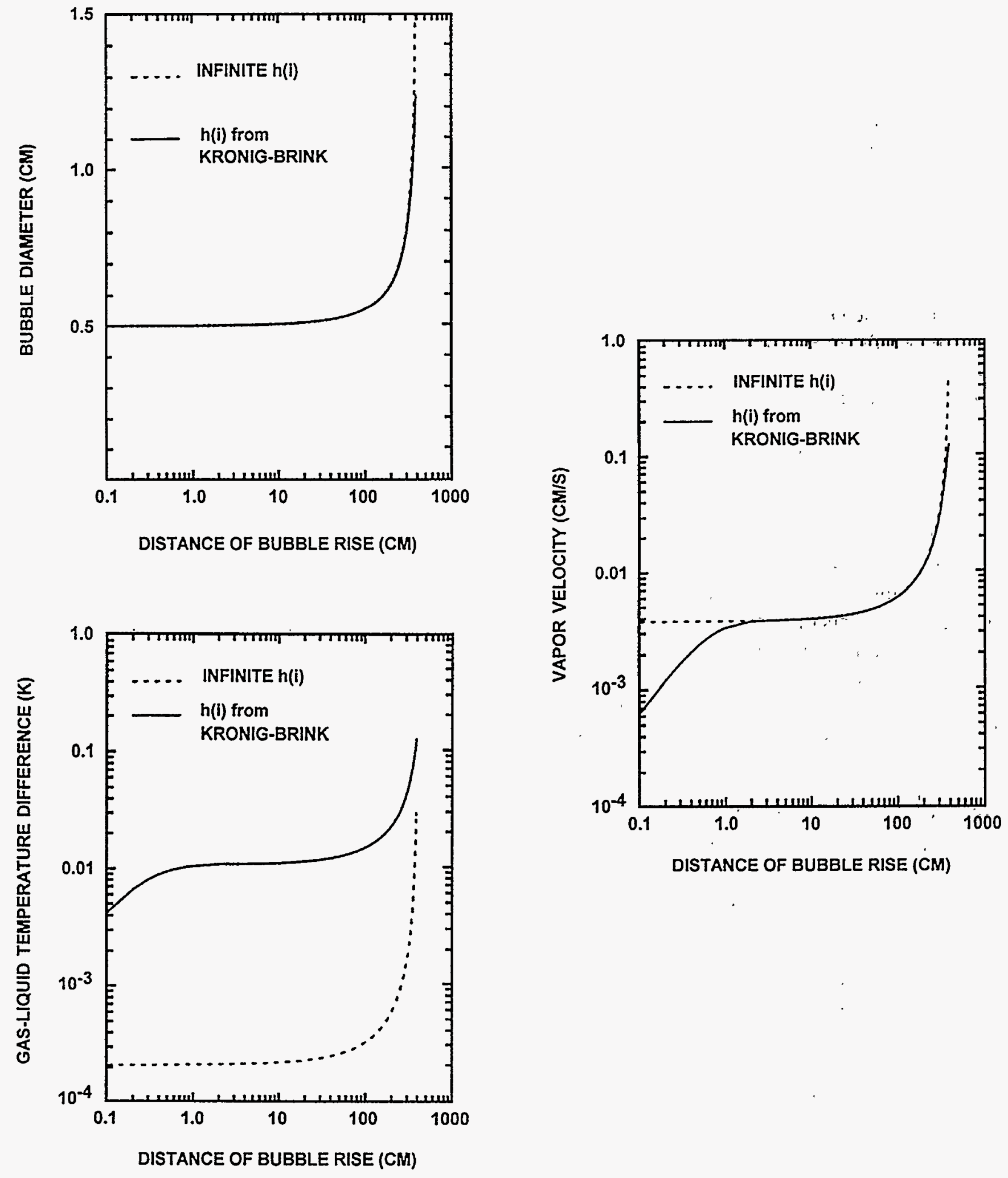

Figure 49. Results of bubble rise calculation considering finite rates of heat and mass transport within the bubble (solid lines). Dashed lines are results obtained assuming infinitely fast transport processes within the bubble. 
behavior will be ignored here. More detailed, differential descriptions of bubble plumes to be found in References 46 to 50 would more easily accommodate detailed treatments of condensation and evaporation than the integral approach used here.

A suppression pool can develop unstable density stratification. Heat is imparted to the pool at a water depth which produces a significant pressure head. The pool surface temperature is limited by the boiling point at the ambient atmospheric pressure. It is possible, then, for a temperature gradient and, consequently, a water density gradient to develop. The stratification of the pool with more dense water on top is unstable. Flow that can develop to relieve this instability can greatly complicate the behavior of plumes [51,52] (see Figure 50). No attempt is made here to account for such effects.

The objective of the analysis of bubble plumes here is to determine the velocities of water and bubbles across the plume and the concentration of bubbles across the plume. A variety of experimental studies including experiments by Paul et al. [30], Tacke et al. [45] as well as studies cited by Milgram [44] suggest that the water at a specified elevation in the plume, $z$, will have a Gaussian velocity distribution:

$$
\mathrm{U}_{1}(\mathrm{r}, \mathrm{z})=\mathrm{U}_{1}(\mathrm{z}) \exp \left[-(\mathrm{r} / \mathrm{b}(\mathrm{z}))^{2}\right]
$$

where

$$
\begin{aligned}
\mathrm{r} & =\text { radial coordinate } \\
\mathrm{z} & =\text { axial coordinate } \\
\mathrm{U}_{\mathrm{l}}(\mathrm{r}, \mathrm{z}) & =\text { upward water velocity at point } \mathrm{r}, \mathrm{z}, \\
\mathrm{U}_{\mathrm{l}}(\mathrm{z}) & =\text { upward velocity along the plume centerline, and } \\
\mathrm{b}(\mathrm{z}) & =\text { distribution parameter that varies with } \mathrm{z} .
\end{aligned}
$$

Bubble velocities are then given by:

$$
\mathrm{U}_{\mathrm{g}}(\mathrm{r}, \mathrm{z})=\mathrm{U}_{\mathrm{l}}(\mathrm{r}, \mathrm{z})+\mathrm{U}(\mathrm{slip})
$$

where $U\left(\right.$ (slip) is the slip velocity which is related to the rise velocity of isolated bubbles, $U_{B}$ (see below and Section IV-G).

It is, then, assumed that the gas fraction in the liquid at a given elevation also has a Gaussian distribution:

$$
\epsilon(\mathrm{r}, \mathrm{z})=\epsilon(\mathrm{z}) \exp \left[-\left(\mathrm{r} / \mathrm{b}_{\epsilon}(\mathrm{z})\right)^{2}\right]
$$



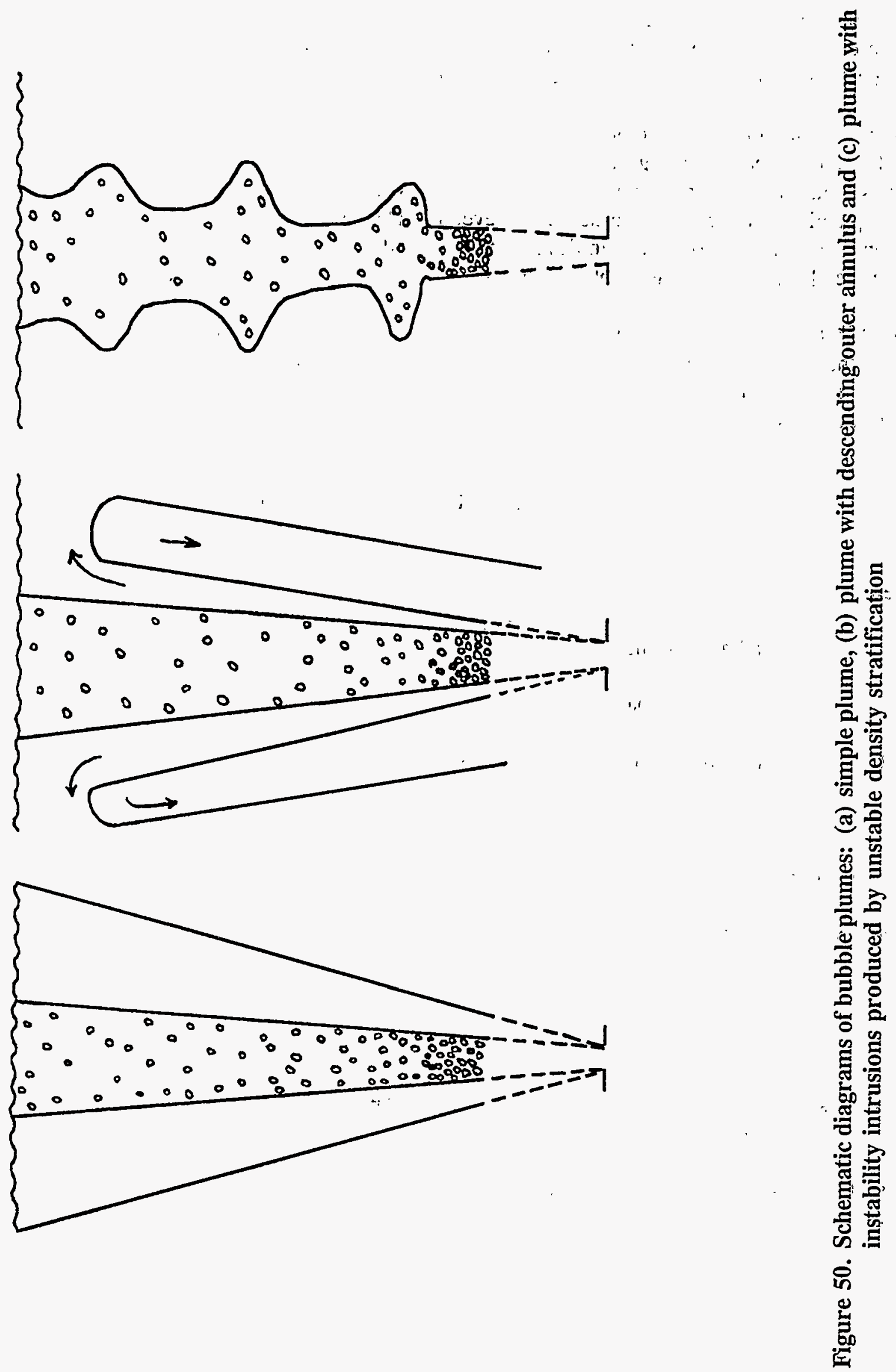
where $\epsilon(r, z)$ is the gas fraction at point $r, z$. The distribution parameter $b_{\epsilon}(z)$ is not necessarily the same as the distribution parameter for water velocity. But, an additional assumption is made that the two parameters are related by

$$
\mathrm{b}_{\epsilon}(\mathrm{z}) / \mathrm{b}(\mathrm{z})=\lambda
$$

where $\lambda$ is independent of elevation. Milgram [44] takes $\lambda$ to be 0.8 , Tacke et al. [45] assume $\lambda=$ 0.7 . Sun and Faeth [47] present results of numerical calculations that indicate $\lambda$ may be as high as 0.96 .

The unknown quantities, centerline velocity, $\mathrm{u}(\mathrm{z})$, centerline gas fraction, $\epsilon(\mathrm{z})$, and the water velocity distribution parameter, $b(z)$, are found by integrating the gas continuity equation, the water continuity equation and the momentum equation.

The gas continuity equation is:

$$
\mathrm{Q}(\mathrm{z})=2 \pi \int_{0}^{\infty} \mathrm{U}_{\mathrm{g}}(\mathrm{r}, \mathrm{z}) \epsilon(\mathrm{r}, \mathrm{z}) \mathrm{rdr}
$$

where $\mathrm{Q}(\mathrm{z})$ is the volumetric gas flow. If evaporation is negligible, $\mathrm{Q}(\mathrm{z})$ varies with elevation:

$$
\mathrm{Q}(\mathrm{z})=\frac{\mathrm{Q}_{\mathrm{T}}\left(\mathrm{P}_{\mathrm{a}}+\xi \rho_{\mathrm{l}} \mathrm{H}\right)}{\mathrm{P}_{\mathrm{a}}+\xi \rho_{1}(\mathrm{H}-\mathrm{z})}
$$

where

$$
\begin{aligned}
\mathrm{P}_{\mathrm{a}} & =\text { ambient pressure (atms), } \\
\mathrm{H} & =\text { pool depth }(\mathrm{cm}) \\
\rho_{1} & =\text { water density }\left(\mathrm{g} / \mathrm{cm}^{3}\right), \\
\xi & =\text { parameter to correct units }=1 / 1033.23, \text { and } \\
\mathrm{Q}_{\mathrm{T}} & =\text { input volumetric flow to the plume. }
\end{aligned}
$$

Here, the input volumetric flow to the plume is not the flow from the gas source. For the calculations of interest here, $\mathrm{Q}_{\mathrm{T}}$ is the gas left after the dynamic events of bubble formation, collapse and coalescence. 
To account for evaporation of water vapor into the bubbles as they rise through the pool, it is assumed that the bubble is always in local equilibrium. Then,

$$
\mathrm{Q}(\mathrm{z})=\mathrm{Q}_{\mathrm{T}}\left\{\frac{\mathrm{P}_{\mathrm{a}}+\rho_{1} \mathrm{H} \xi-\mathrm{P}(\mathrm{sat})}{\mathrm{P}_{\mathrm{a}}+\rho_{1}(\mathrm{H}-\mathrm{z}) \xi-\mathrm{P}(\mathrm{sat})}\right\}
$$

where $\mathrm{P}($ sat $)$ is the saturation partial pressure at the bulk pool temperature which is taken to be invariant throughout the plume. This simplified description is used here to make derivations more "transparent. In the model described in Chapter V, the gas flux is calculated from the thermodynamic description presented in the previous subsection.

Integration of the gas continuity equation yields:

$$
\mathrm{Q}(\mathrm{z})=\pi \lambda^{2} \mathrm{~b}^{2}(\mathrm{z}) \epsilon(\mathrm{z})\left[\frac{\mathrm{U}_{1}(\mathrm{z})}{1+\lambda^{2}}+\mathrm{U}_{\mathrm{B}} \mathrm{f}\right]
$$

where

$$
f= \begin{cases}1 & \text { for } U(\text { slip })=U_{B} \\ 1-\epsilon(\mathrm{z}) / 2 & \text { for } U(\text { slip })=U_{B}(1-\epsilon(r, z)) \\ 1-\epsilon(\mathrm{z})+\epsilon(\mathrm{z})^{2} / 3 & \text { for } \mathrm{U}(\mathrm{slip})=\mathrm{U}_{\mathrm{B}}(1-\epsilon(\mathrm{r}, \mathrm{z}))^{2}\end{cases}
$$

$\mathrm{U}_{\mathrm{B}}=$ rise velocity of an isolated bubble of the same size, and

$\mathrm{U}(\mathrm{slip})=$ slip velocity of bubbles in the plume.

Note that three, relatively simple, descriptions of two phase flow have tbeen considered herre in the definition of $\mathrm{f}$. These are the descriptions considered by Tacke et al. [45]. Other descriptions exist [51].

The liquid continuity equation is formulated assuming that liquid' is entrained by rising ${ }^{-}$bubbles:

$$
\frac{\mathrm{d}}{\mathrm{dz}} \int_{0}^{\infty}[1-\epsilon(\mathrm{r}, \mathrm{z})] \mathrm{U}_{1}(\mathrm{r}, \mathrm{z}) \mathrm{rdr}=2 \pi \mathrm{b}(\mathrm{z}) \alpha \mathrm{U}_{1}(\mathrm{z}) \mathrm{k}(\mathrm{z})
$$


where

$\alpha=$ entrainment coefficient, and

$\mathrm{k}(\mathrm{z})$ = factor to correct for gas concentration in the entraining liquid.

Milgram [44] takes:

$$
k(z)=1
$$

Tacke et al. [45] take:

$$
\mathrm{k}(\mathrm{z})=1-\epsilon(\mathrm{z}) \exp \left(-1 / \lambda^{2}\right)
$$

The authors of this document prefer:

$$
k(z)=1-\lambda^{2} \epsilon(z)\left[1-\exp \left(-1 / \lambda^{2}\right)\right]
$$

Then,

$$
\frac{\mathrm{d}}{\mathrm{dz}} \mathrm{U}(\mathrm{z}) \mathrm{b}^{2}(\mathrm{z})\left[1-\frac{\epsilon(\mathrm{z}) \lambda^{2}}{1+\lambda^{2}}\right]=2 \mathrm{~b}(\mathrm{z}) \alpha \mathrm{U}(\mathrm{z}) \mathrm{k}(\mathrm{z})
$$

Milgram [44] develops the momentum equation considering the momentum of the gas as well as the liquid momentum. Tacke et al. [45] neglect the small contribution of gas momentum. Milgram also introduces the momentum amplification factor, $\gamma$. Neglect of this momentum amplification factor amounts to treating the plume as though it were a single phase. (Milgram notes that measurements by George et al. [53] indicate that $\gamma$ may be as large as 1.07 even in single phase plumes.) Momentum amplification is considered here and the momentum equation is taken to be:

$$
\begin{aligned}
& \frac{\mathrm{d}}{\mathrm{dz}} 2 \pi \gamma \int_{0}^{\infty}\left\{\mathrm{U}_{1}^{2}(\mathrm{r}, \mathrm{z}) \rho_{\mathrm{W}}[1-\epsilon(\mathrm{r}, \mathrm{z})]+\mathrm{U}_{\mathrm{g}}^{2}(\mathrm{r}, \mathrm{z}) \rho_{\mathrm{g}}(\mathrm{z}) \epsilon(\mathrm{r}, \mathrm{z})\right\} \mathrm{rdr}= \\
& =2 \pi \mathrm{g} \int_{0}^{\infty}\left[\rho_{\mathrm{W}}-\rho_{\mathrm{g}}(\mathrm{z})\right] \epsilon(\mathrm{r}, \mathrm{z}) \mathrm{rdr}
\end{aligned}
$$


Physical Phenomena

Then, substituting in expressions for liquid and gas velocities yields:

$$
\begin{aligned}
& \frac{\mathrm{d}}{\mathrm{dz}} \gamma\left\{\mathrm{b}^{2}(\mathrm{z}) \mathrm{U}_{1}^{2}(\mathrm{z})\left[\frac{\rho_{\mathrm{W}}}{2}-\frac{\lambda^{2} \epsilon(\mathrm{z})\left(\rho_{\mathrm{W}}-\rho_{\mathrm{g}}(\mathrm{z})\right)}{2 \lambda^{2}+1}\right]+\mathrm{U}_{\mathrm{B}} \lambda^{2} \mathrm{~b}(\mathrm{z})^{2} \rho_{\mathrm{g}}^{\prime}(\mathrm{z}) \epsilon(\mathrm{z})\left[\mathrm{U}_{\mathrm{l}}(\mathrm{z}) \mathrm{h}(\mathrm{z})+\mathrm{U}_{\mathrm{B}^{\prime}} 1(\mathrm{z})\right]\right. \\
& =\mathrm{g}\left[\rho_{\mathrm{W}}-\rho_{\mathrm{g}}(\mathrm{z})\right] \epsilon(\mathrm{z}) \lambda^{2} \mathrm{~b}^{2}(\mathrm{z})
\end{aligned}
$$

where

$$
\mathrm{h}(\mathrm{z})= \begin{cases}\frac{2}{1+\lambda^{2}} & \text { for } \mathrm{U}(\mathrm{slip})=\mathrm{U}_{\mathrm{B}} \\ \frac{2}{\lambda^{2}+1}-\frac{2 \epsilon(\mathrm{z})}{\lambda^{2}+2} & \text { for } \mathrm{U}(\mathrm{slip})=\mathrm{U}_{\mathrm{B}}(1-\epsilon(\mathrm{r}, \mathrm{z})) \\ \frac{2}{\lambda^{2}+1}-\frac{4 \epsilon(\mathrm{z})}{\lambda^{2}+2}+\frac{2 \epsilon^{2}(\mathrm{z})}{\lambda^{2}+3} & \text { for } \mathrm{U}(\mathrm{slip})=\mathrm{U}_{\mathrm{B}}(1-\epsilon(\mathrm{r}, \mathrm{z}))^{2}\end{cases}
$$

and

$$
1(\mathrm{z})= \begin{cases}1 & \text { for } \mathrm{U}(\mathrm{slip})=\mathrm{U}_{\mathrm{B}} \\ 1-\epsilon(\mathrm{z})+\epsilon^{2}(\mathrm{z}) / 3 & \text { for } \mathrm{U}(\mathrm{slip})=\mathrm{U}_{\mathrm{B}}(1-\epsilon(\mathrm{r}, \mathrm{z})) \\ 1-2 \epsilon(\mathrm{z})+2 \epsilon^{2}(\mathrm{z})-\epsilon^{3}(\mathrm{z})+\epsilon^{4}(\mathrm{z}) / 5 & \text { for } \mathrm{U}(\mathrm{slip})=\mathrm{U}_{\mathrm{B}} \cdot(1-\epsilon(\mathrm{r}, \mathrm{z}))^{2}\end{cases}
$$

Milgram [44] correlated the entrainment coefficient, $\alpha$, with a bubble Froude number, $\mathrm{F}_{\mathrm{B}}$ :

$$
\alpha=\mathrm{kF}_{\mathrm{B}} /\left(\mathrm{A}+\mathrm{F}_{\mathrm{B}}\right)
$$

where

$$
\begin{aligned}
\mathrm{F}_{\mathrm{B}} & =\epsilon(\mathrm{z})^{1 / 3} \mathrm{Q}(\mathrm{z})^{2 / 5} \mathrm{~g}^{3 / 10}\left(\rho_{\mathrm{w}}-\rho_{\mathrm{g}}(\mathrm{z})\right)^{1 / 2} / \sigma_{1}^{1 / 2} \\
\mathrm{k} & =0.165, \text { and } \\
\mathrm{A} & =7.598
\end{aligned}
$$


Milgram apparently found the parametric values in the correlation by linear least squares analysis after recasting the correlation in a form that is linear in $1 / \alpha$ :

$$
1 / \alpha=\frac{\mathrm{A}}{\mathrm{k}} \frac{1}{\mathrm{~F}_{\mathrm{B}}}+1 / \mathrm{k}
$$

Refitting data digitized from a small plot provided by Milgram yielded the coefficients:

$$
\begin{aligned}
& \frac{\mathrm{A}}{\mathrm{k}}=23.0688 \pm 3.0299 \\
& 1 / \mathrm{k}=9.379 \pm 0.815
\end{aligned}
$$

or

$$
\begin{aligned}
& \mathrm{k}=0.1066 \pm 0.0093 \\
& A=2.460 \pm 0.387
\end{aligned}
$$

These are the parametric values adopted here. (It should be noted that if both the Froude number and the entrainment coefficient are considered uncertain, the existence of a correlation between the two become dubious.)

This linear form of the correlation is shown in comparison to the data used by Milgram in Figure 51.

There is, obviously, some substantial scatter in values of $1 / \alpha$ about the regression line. Because the regression line has been determined by linear least-squares methods, the uncertainty in a predicted value of $1 / \alpha$ is distributed according to a Student's $t$ distribution. The uncertainty range for a prediction at a confidence level of $100(1-\beta)$ percent is given by:

$$
1 / \alpha=1 /\left.\alpha\right|_{\text {reg }} \pm \operatorname{st}_{(1-\beta / 2)}(\mathrm{n}-2)\left\{\frac{1}{\mathrm{n}}+\frac{(\mathrm{x}-\overline{\mathrm{x}})^{2}}{\sum_{\mathrm{i}=1}^{\mathrm{n}}(\mathrm{x}(\mathrm{i})-\overline{\mathrm{x}})^{2}}\right\}^{1 / 2}
$$


Physical Phenomena

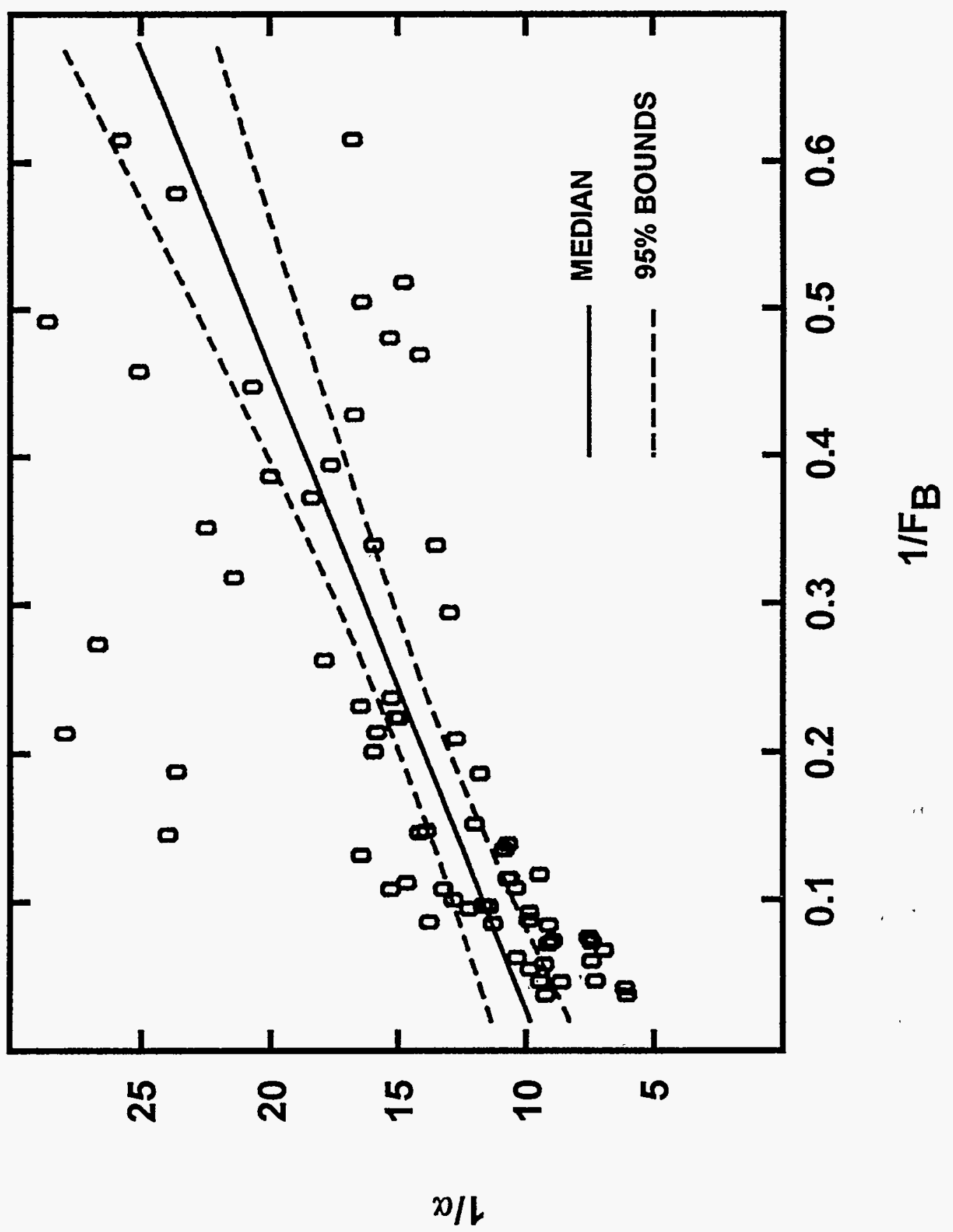

岁 
where

$$
\begin{aligned}
1 /\left.\alpha\right|_{\text {reg }} & =\text { value of } 1 / \alpha \text { calculated from the correlation, } \\
s & =\text { standard error in the regression }=4.185
\end{aligned}
$$

$\mathrm{t}_{(1-\beta / 2)}(\mathrm{n}-2)=$ critical value of the Student's $\mathrm{t}$ statistic for $\mathrm{n}-2$ degrees of freedom at a confidence level of $100(1-\beta / 2)$ percent

$$
\begin{aligned}
n & =\text { number of data points used in the regression }=69 \\
\mathrm{x} & =1 / \mathrm{F}_{\mathrm{B}} \text { for which the estimate of } 1 / \alpha \text { is sought, } \\
\overline{\mathrm{x}} & =\text { mean value of } 1 / \mathrm{F}_{\mathrm{B}} \text { in the data set, and } \\
\mathrm{x}(\mathrm{i}) & =\text { value of } 1 / \mathrm{F}_{\mathrm{B}} \text { for the ith data point. }
\end{aligned}
$$

From data provided by Milgram:

$$
\begin{gathered}
\overline{\mathrm{x}}=0.2145 \\
\sum_{\mathrm{i}=1}^{\mathrm{n}}[\mathrm{x}(\mathrm{i})-\overline{\mathrm{x}}]^{2}=1.8474
\end{gathered}
$$

The 95 percent confidence bounds on predictions of $1 / \alpha$ from Milgram's correlation are plotted as dashed lines in Figure 51.

Milgram [44] presented correlations of the momentum amplification factor, $\gamma$, in terms of the so-called phase distribution number, $\mathrm{N}_{\mathrm{p}}$ :

$$
\gamma=1+\mathrm{C} / \mathrm{N}_{\mathrm{p}}^{\mathrm{a}}
$$

or

$$
\gamma=1.07+\mathrm{C}^{\prime} / \mathrm{N}_{\mathrm{p}}^{\mathrm{a}^{\prime}}
$$


where

$$
\mathrm{N}_{\mathrm{p}}=\frac{\mathrm{U}(\mathrm{z})^{2}\left(\rho_{\mathrm{W}}-\rho_{\mathrm{g}}\right)^{1 / 2}}{\epsilon(\mathrm{z})^{2 / 3} \sqrt{\mathrm{g} \sigma_{\mathrm{l}}}} \text {, and }
$$

$$
\mathrm{a}, \mathrm{c}, \mathrm{c}^{\prime}, \mathrm{a}^{\prime}=\text { parameters. }
$$

Milgram contends that the lower bound on the momentum amplification factor is 1.0 or perhaps 1.07 . He shows, however, values derived by modeling experiments sthat are less than:1.0. Ignoring these values, the correlation can be parameterized by linear, least-squares methods when recast in the form:

$$
\ln (\gamma-1)=\ln \mathrm{C}-\mathrm{D} \ln \mathrm{Np}
$$

where

$$
\begin{aligned}
\ln C & =5.216 \pm 0.835, \text { and } \\
D & =-1.0895 \pm 0.1402 .
\end{aligned}
$$

Uncertainties in $\ln (\gamma-1)$ predicted with this correlation can be found at the $100(1-\beta)$ percent confidence level from:

$$
\ln (\gamma-1)=\left.\ln (\gamma-1)\right|_{\text {reg }} \pm 0.837 t_{(1-\beta / 2)}(45),\left\{\frac{1}{47}+\frac{(x-5.891)^{2}}{35.615}\right\}^{1 / 2}
$$

where

$$
\begin{aligned}
\left.\ln (\gamma-1)\right|_{\text {reg }}= & \text { value of } \ln (\gamma-1) \text { found from the correlation, } \\
t_{1-\beta / 2}(45)= & \text { critical Student's } t \text { statistic for } 45 \text { degrees of freedom at the } \\
& 100(1-\beta / 2) \text { percent confidence level, and } \\
x= & \ln N_{p} .
\end{aligned}
$$

The predicted values of $\gamma$ derived from the correlation, the 95 percent confidence bounds on these predictions, and data presented by Milgram are plotted against the phase distribution number in Figure 52. 


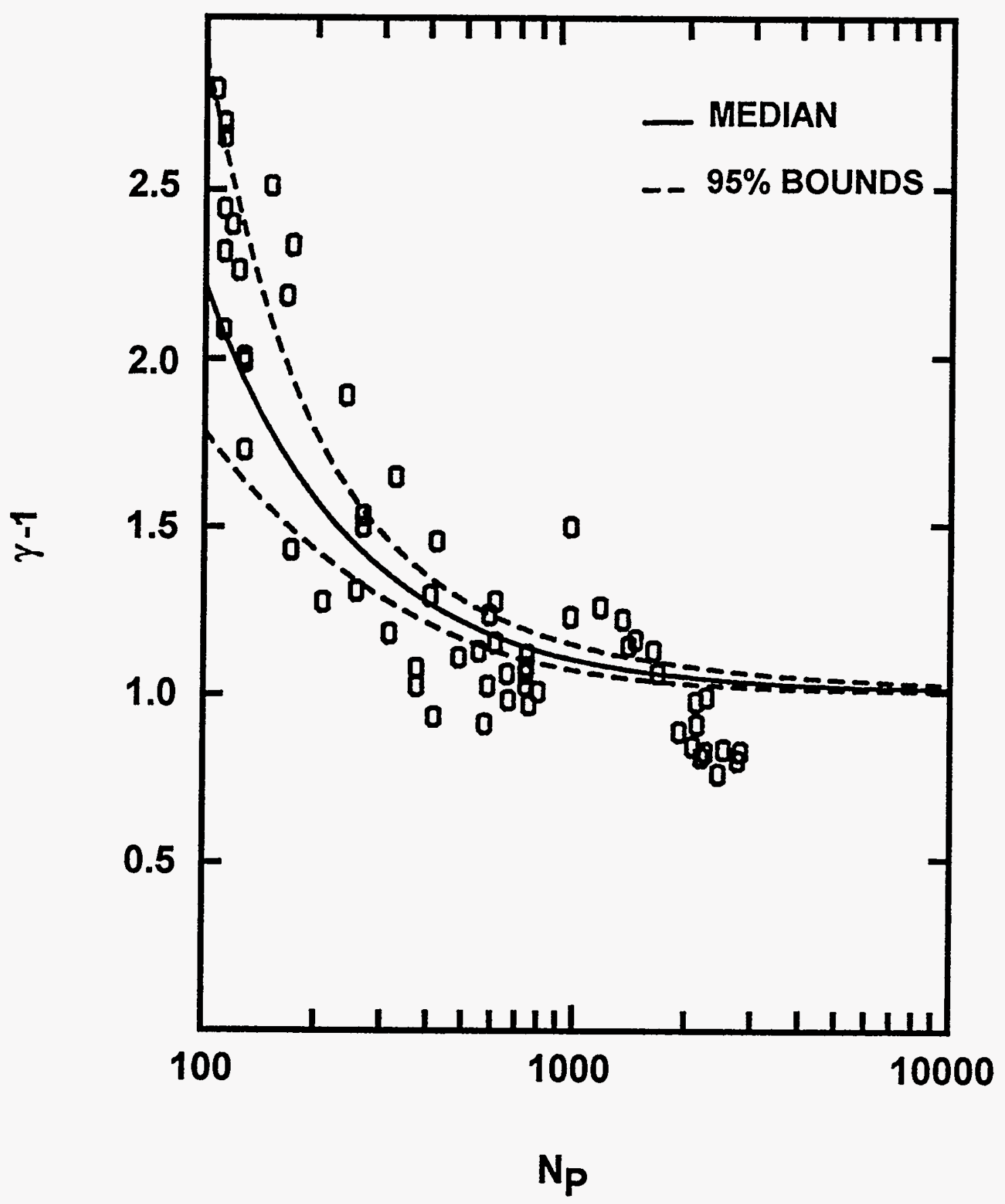

Figure 52. Dependence of the momentum amplification factor on the phase distribution number 
A final issue to confront is the definition of initial conditions for the two differential equations described above. It is clear that the Gaussion profiles for liquid velocity and for gas fraction used in the development above do not apply in the immediate vicinity of the gas source. In the situations of interest here, a lot of dynamic activity takes place before the plume develops. Milgram [44] recommends that initial conditions be defined at an elevation $\mathrm{Z}(\mathrm{E})$ given by:

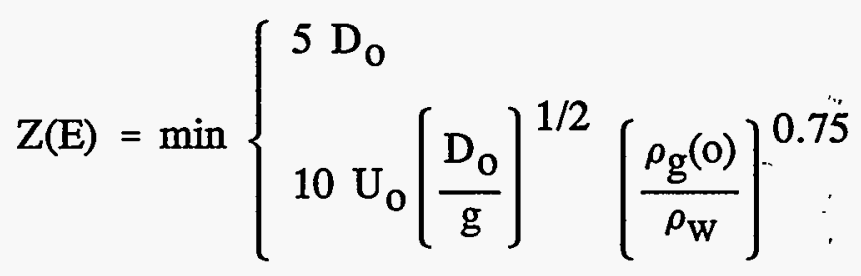

where

$$
\begin{aligned}
\mathrm{D}_{\mathrm{o}} & =\text { orifice diameter, } \\
\mathrm{U}_{\mathrm{O}} & =\text { gas velocity through the orifice, and } \\
\rho_{\mathrm{g}}(\mathrm{o}) & =\text { gas density at the orifice. }
\end{aligned}
$$

For the analysis here, the values of $U_{0}$ and $\rho_{\mathrm{g}}(0)$ should be taken as the hypothetical values that would exist if no condensation of water vapor took place during the formation and initial rise of gas bubbles.

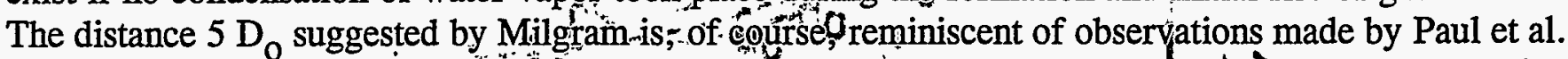
[30]. They observed that bübble breakup was complete in a few initial bubble diâmeters. Following Milgram's suggestion, the plume.model equation would apply to within about $10 \mathrm{~cm}$ of the orifices in quenchers. The equations would apply very close to downcomers and vents according to Milgram. But, observations by Paul et al. [30] and by Lee and Chan [40] suggest plume equations might not be appropriate for several tens of centimeters from the large vents.

The initial conditions specified by Milgram are:

$$
\begin{gathered}
\epsilon(\mathrm{z}(\mathrm{E}))=0.5 \rho_{\mathrm{W}} /\left[\rho_{\mathrm{W}}-\rho_{\mathrm{g}}(\mathrm{z}(\mathrm{E}))\right] \\
\therefore \ldots \\
\text { Momentum }=\mathrm{Q} \rho_{\mathrm{g}}(\mathrm{H}) \mathrm{U}_{\mathrm{o}}+\frac{2 \mathrm{Q}}{\mathrm{U}_{\mathrm{O}}}\left[\rho_{\mathrm{W}}-\rho_{\mathrm{g}}(\mathrm{z}(\mathrm{E} / 2))\right] \mathrm{gz}(\mathrm{E})
\end{gathered}
$$

Milgram notes that initial conditions do not strongly affect calculated results. 
Tacke et al. [45] recommend that the initial state be taken as $\epsilon(z)=0.5$. They then define

$$
\begin{gathered}
\frac{\mathrm{z}(\mathrm{E})}{\mathrm{D}_{\mathrm{o}}}=5.0\left[\frac{\mathrm{Q}_{\mathrm{T}}^{2} \rho_{\mathrm{g}}(\mathrm{o})}{\mathrm{gD}_{\mathrm{o}}{ }^{5} \rho_{\mathrm{W}}}\right]^{0.5} \\
\lambda \mathrm{b}(\mathrm{z}(\mathrm{E}))=0.5045\left[\frac{\mathrm{Q}_{\mathrm{T}}{ }^{2}}{\mathrm{D}_{\mathrm{o}}{ }^{5} \mathrm{~g}}\right]^{1 / 5} \\
\epsilon(\mathrm{z})=50\left[0.2 \frac{\mathrm{z}(\mathrm{E})}{\mathrm{D}_{\mathrm{o}}}\left[\mathrm{g} \frac{\mathrm{D}_{\mathrm{o}}{ }^{5} \rho_{\mathrm{W}}}{\mathrm{Q}_{\mathrm{T}}{ }^{2} \rho_{\mathrm{g}}(\mathrm{o})}\right]\right]^{\psi}
\end{gathered}
$$

where $\psi$ depends on the ratio $\rho_{\mathrm{g}} / \rho_{\mathrm{w}}$ :

$$
\psi= \begin{cases}0.866 & \text { for } \mathrm{He} \text { in water } \\ 1.22 & \text { for } \mathrm{N}_{2} \text { or air in water }\end{cases}
$$

This suggests:

$$
\psi=0.807+360 \rho_{\mathrm{g}} / \rho_{\mathrm{W}}
$$

McDougall [54] recommends:

$$
\begin{gathered}
\mathrm{z}(\mathrm{E})=0.025 \mathrm{H}^{\prime} \\
\frac{\mathrm{U}_{\mathrm{l}}(\mathrm{z}(\mathrm{E}))}{\mathrm{U}_{\mathrm{B}} \mathrm{M}^{1 / 3}}=\mathrm{x}^{-1 / 3}\left[1.609-\frac{0.3195}{\mathrm{M}^{1 / 3}} \mathrm{x}^{1 / 3}+0.06693(\mathrm{x} / \mathrm{M})^{2 / 3}+\mathrm{x}(0.4536-0.0105 / \mathrm{M})\right]
\end{gathered}
$$


Physical Phenomena

$$
\frac{\mathrm{b}(\mathrm{z}(\mathrm{E}))}{2 \alpha \mathrm{H}^{\prime}}=\mathrm{x}\left[0.6+0.01719(\mathrm{x} / \mathrm{M})^{1 / 3}-0.002527(\mathrm{x} / \mathrm{M})^{2 / 3}+\mathrm{x}\left[\frac{0.000031}{\mathrm{M}}-0.04609\right]\right]
$$

where

$$
\begin{aligned}
\mathrm{X} & =\mathrm{z} / \mathrm{H}^{\prime} \\
\mathrm{M} & =\frac{\mathrm{Q}_{\mathrm{T}} \mathrm{P}_{\mathrm{a}}\left(\lambda^{2}+1\right) \xi}{4 \pi \alpha^{2} \rho_{\mathrm{W}} \mathrm{H}^{2} \mathrm{U}_{\mathrm{B}}^{3}} \\
\mathrm{H}^{\prime} & =\mathrm{H}+\mathrm{P} / \rho_{1} \mathrm{~g}
\end{aligned}
$$

None of the initial conditions models is particularly satisfactory. Here Milgram's suggestions are adopted for the example calculations. These suggestions are not, however, applicable to cases involving substantial vapor condensation which can occur in steam suppression pools. Alternate initial conditions for such cases are discussed in Chapter V.

Predictions of the plume model compared with data obtained by Milgram [44] for large and small flows through a $5-\mathrm{cm}$ vent in a natural pool $5000 \mathrm{~cm}$ deep are shown in Figures 53 and 54 . Predictions shown in these figures were based on the assumption that the gas bubbles were, initially, $0.5 \mathrm{~cm}$ in diameter. Bubble slip velocities were taken to be equal to the rise velocity of an isolated bubble which was calculated from the correlation described above (see Section IV-G). The parameter $\lambda$ was taken to be 0.8. Milgram has shown that model predictions are not very sensitive to this parameter. Calculated results shown in the figures as solid lines were obtained using Milgram's correlations to calculate the entrainment coefficient, $\alpha$, and the momentum amplification factor, $\gamma$, at local conditions. Agreement between calculated and observed quantities is good on an overall basis. Agreement can be improved by using selected average values of $\alpha$ and $\gamma$ that are independent of elevation of the plume. Such calculated results are shown as dashed lines in Figure 53.

Model predictions of the void fraction along the centerline of a small-scale plume are compared in Figure 55 to data obtained by Tacke et al [45]. These data were obtained using air flow through a $0.05-\mathrm{cm}$ vent in a $60-\mathrm{cm}^{-}$deep pool. Calculations using Milgram's correlation for the entrainment coefficient $\alpha$ agree only qualitatively with the test data regardless of the value of $\lambda$ in the range from $\lambda=0.7$ (recommended by Tacke et al.) to $\lambda=0.9$ (recommended by Milgram). Increasing the entrainment coefficient to $\alpha=0.1$ independent of elevation in the plume yields quantitatively accurate predictions of the centerline void fraction. Tacke et al. note that there is a great deal of uncertainty in the entrainment coefficient and recommend overall average values in preference to Milgram's correlation. 
Physical Phenomena

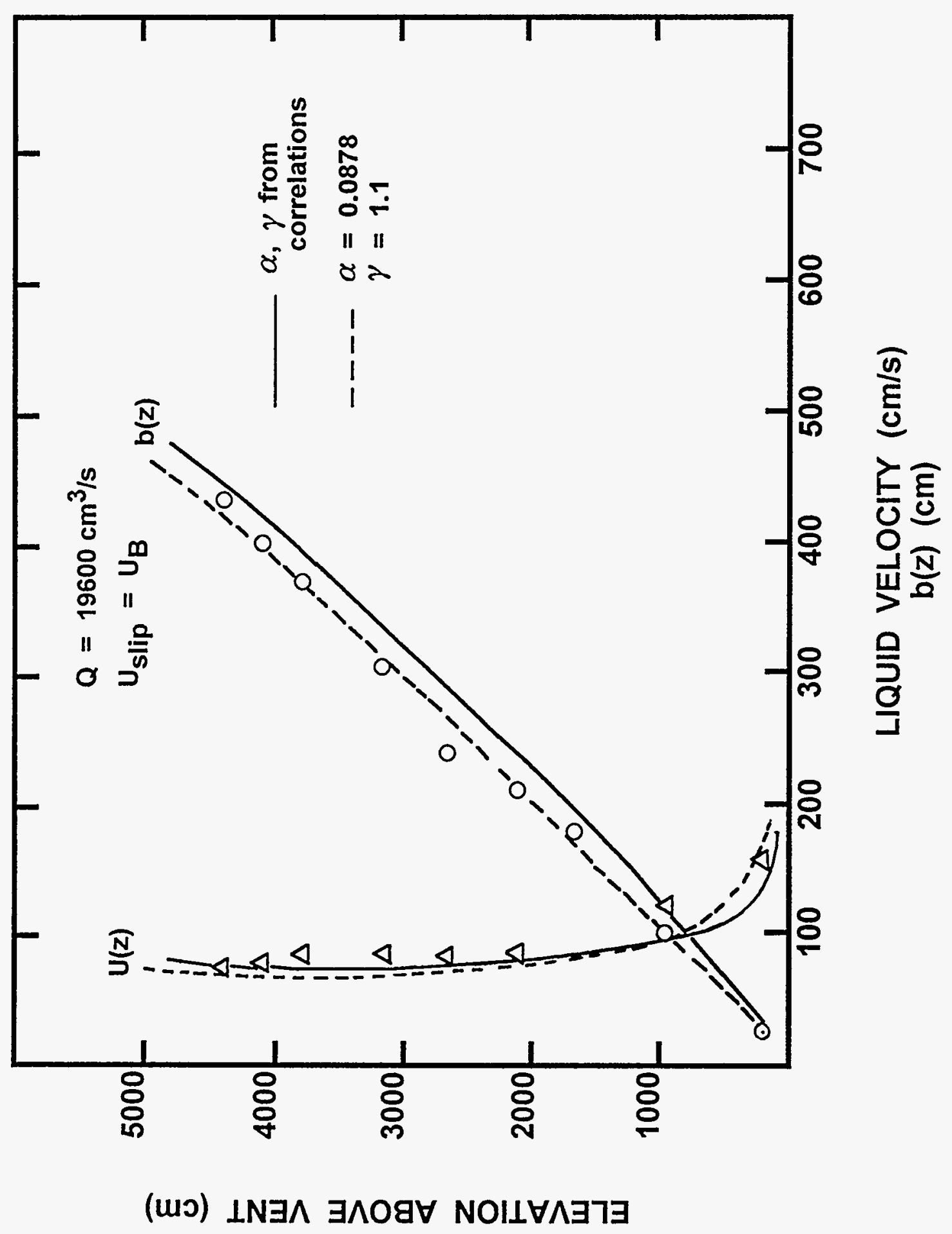

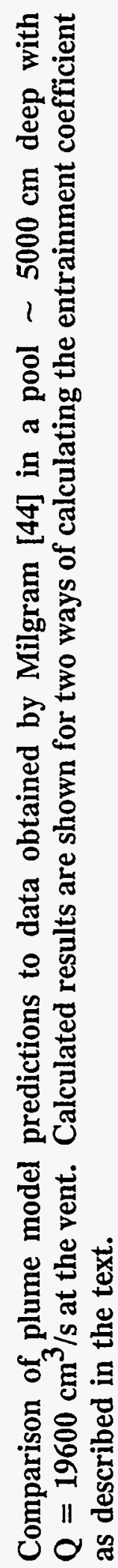

กี่ 


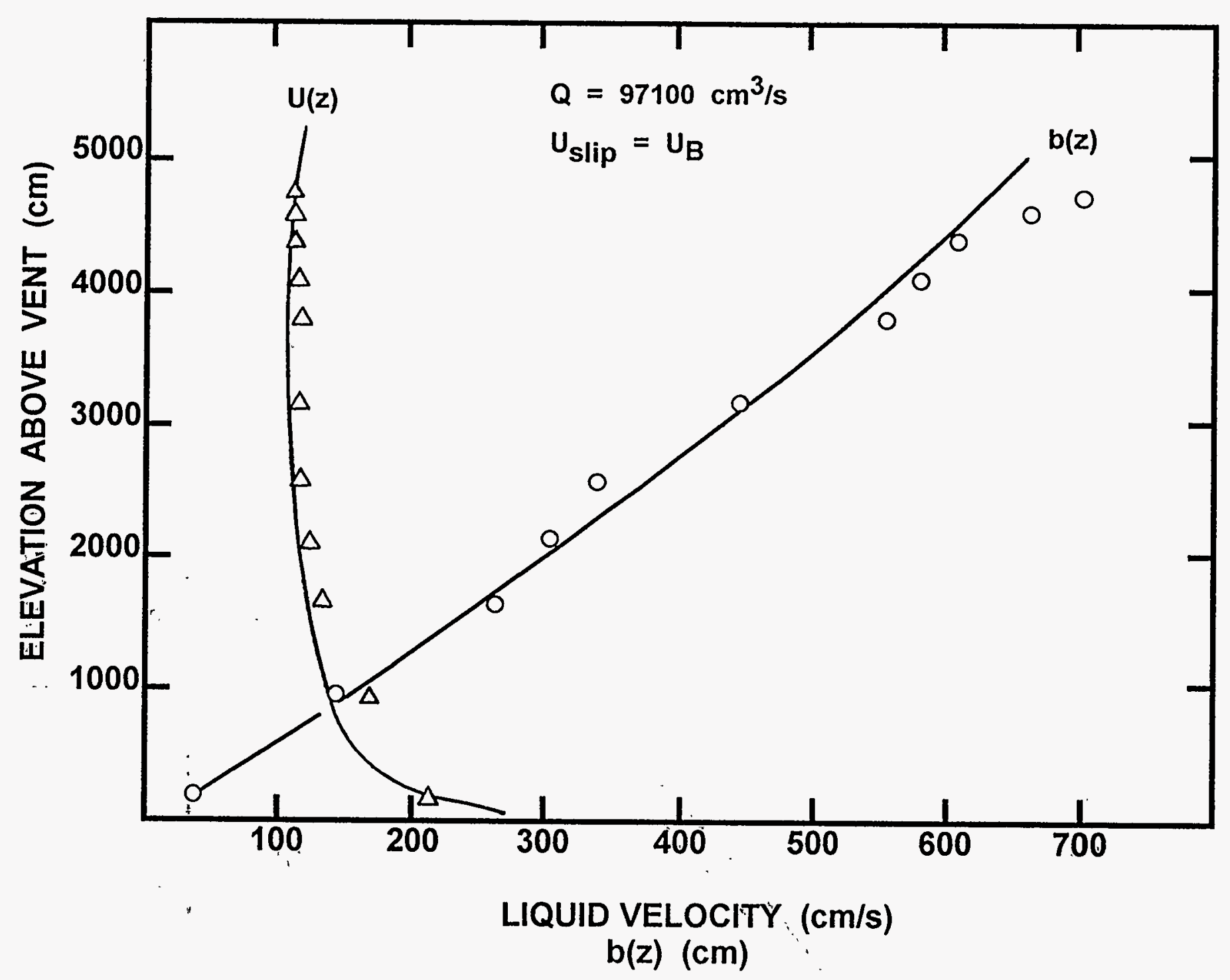

$b(z)(\mathrm{cm})$

Figure 54. Comparison of predictions of the plume model to data obtained by Milgram [44] in a pool $\sim 5000 \mathrm{~cm}$ deep with $Q \simeq 97100 \mathrm{~cm}^{3} / \mathrm{s}$. Calculations are shown for two values of the entrainment coefficient as described in the text. 


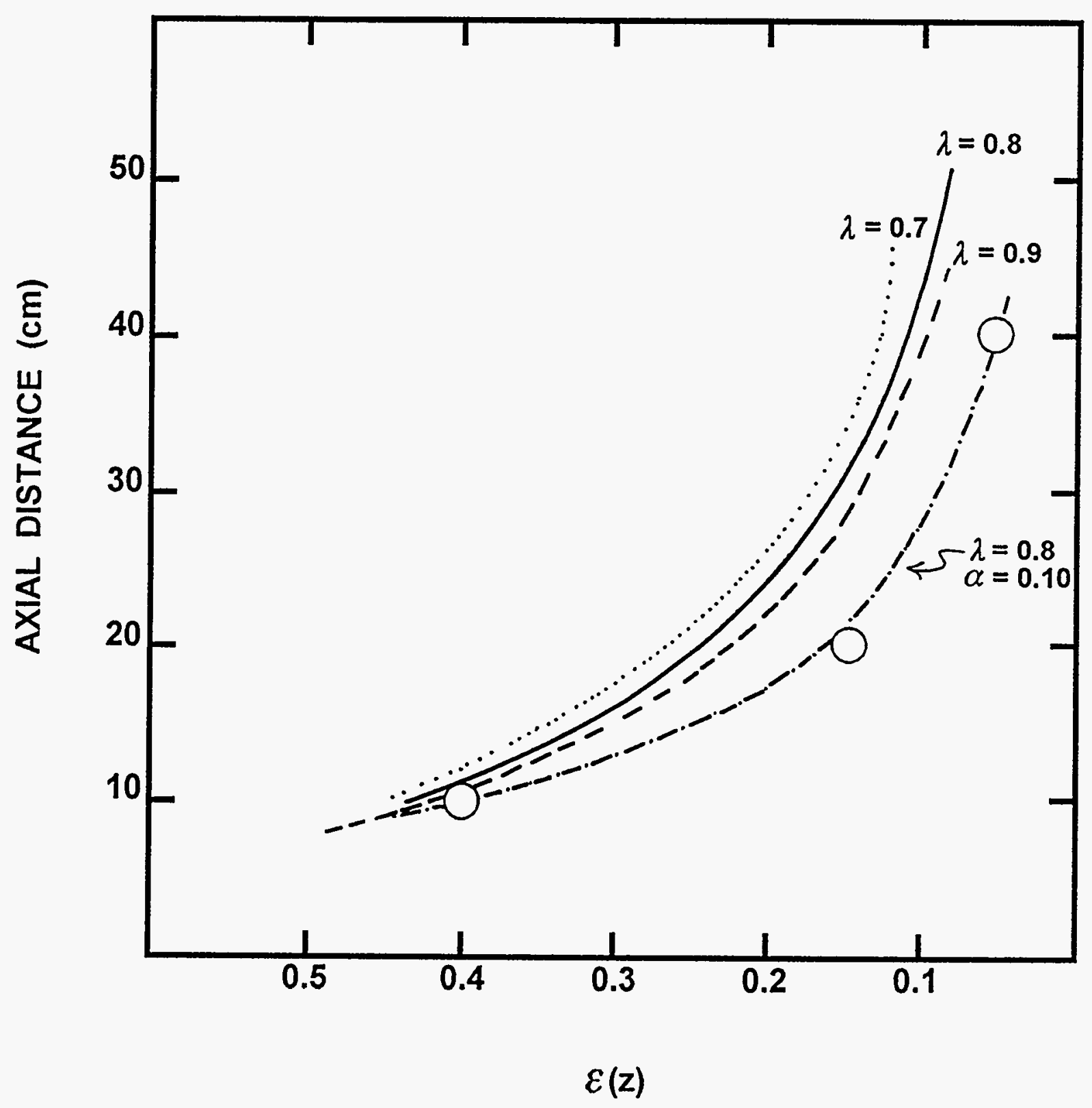

Figure 55. Comparison of model predictions to centerline void fractions observed in experiments by Tacke et al. [45]. Results calculated with various values of $\lambda$ and the entrainment coefficient calculated from Milgram's correlation are shown. Also shown are results calculated with entrainment coefficient fixed at 0.1 . 
Predicted bubble rise velocities as functions of radial distance at various elevations in plumes produced by large and small flows in tests by Paul et al. [30] are shown in Figures 56 and 57. These predictions were obtained using various values of the momentum amplification factor that were independent of elevation. The entrainment coefficient was calculated using local conditions in the plume and Milgram's correlation.

Tacke et al. [45] and other investigators have obtained data that suggest that bubble plumes conform quite closely to the exponential structure assumed above in the development of the plume model. The experimental results for bubble rise velocities obtained by Paul et al. [30] suggest thisjexponential model of the plume structure is only an approximation. These data suggest the plune might be more accurately portrayed as consisting of a central core with nearly constant properties surrounded by a peripheral region with exponentially distributed properties. Nevertheless, it is evident that reasonably good comparisons to data can be obtained by suitable variations in the momentum amplification factor. Comparisons in Figure 58 show that using elevation independent values of the entrainment coefficient rather than local entrainment coefficients provides additional flexibility in matching, prediçted and observed values of the bubble rise velocity.

Some caution should be exercised in drawing conclusions from the comparison of predicted and observed bubble rise velocities shown in Figures 56 through 58. The predictions were prepared assuming that bubbles were uniformly $0.5 \mathrm{~cm}$ in diameter. Paul et al. have shown that bubble sizzes are approximately lognormally distributed in size. Some of the variability between predicted and observed rise velocities may come from distributions of the bubble sizes in experiments.

It is evident that bubbles in a plùme rise much more rapidly than isolated bubbles)(rise velocities of isolated bubbles considered in preparing predictions shown in Figures 56 through-5.8 8 would be about $24 \mathrm{~cm} / \mathrm{s}$ ). The more rapid rise velocities shorten the time available for scrubbing aerosols from the bubbles. Because there is a distribution of rise velocities across a plume, there will, presumably, be a distribution of aerosol removal efficiencies across the plume.

Three essential parameters arise in the characterization of the bubble rise velocities in the plume, $\lambda, \gamma$, and $\alpha$. The parameter $\lambda$ is not especially influential. It can be directly determined in experiments and apparently is widely accepted as being in the range of 0.7 to 1.0. The parameters $\gamma$ and $\alpha$ are influential and cannot be directly measured. These parameters are found from experimental data by calculation, but such calculation yield results depend on other assumptions in the plume model. They do seem to vary with flow and pool depth, but there are not sufficient data to produce reliable correlations of these parameters. The momentum amplification factor is particularly mysterious. Many investigators of plume behavior seem to neglect it. It does, however, have a theoretical basis and provides the flexibility in models to match experimental data.

\section{F. Overview of Bubble Behavior}

The behaviors of individual bubbles enter into the descriptions of bubble swarms and plumes. The features of bubble behavior of interest include rise velocity, which is affected by both bubble size and shape, as well as heat and mass transport coefficients that: can be ascribed,torbubbles. It is convenient to categorize bubble behavior into regimes based on the dimensionless Eotvos and Morton numbers: 
Physical Phenomena

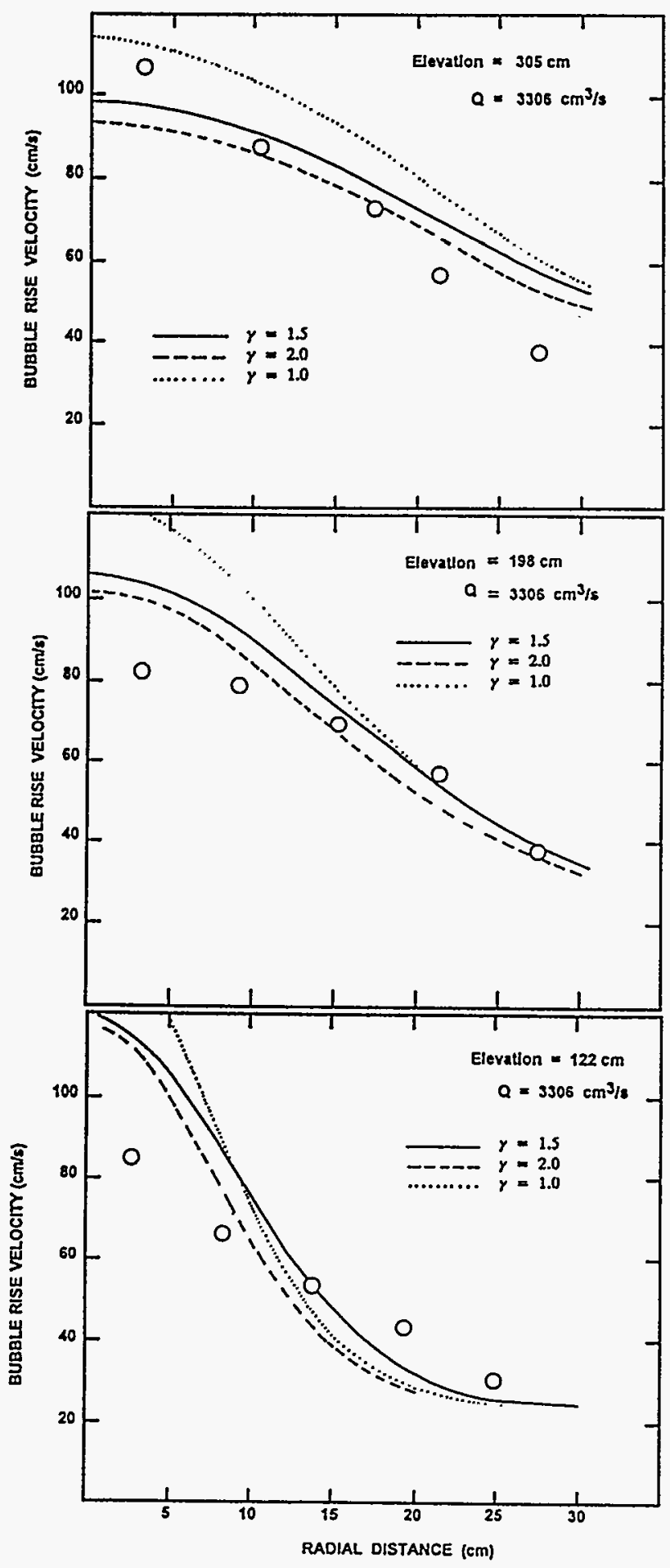

Figure 56. Comparison of model predictions to bubble rise velocities observed in an experiment by Paul et al. 


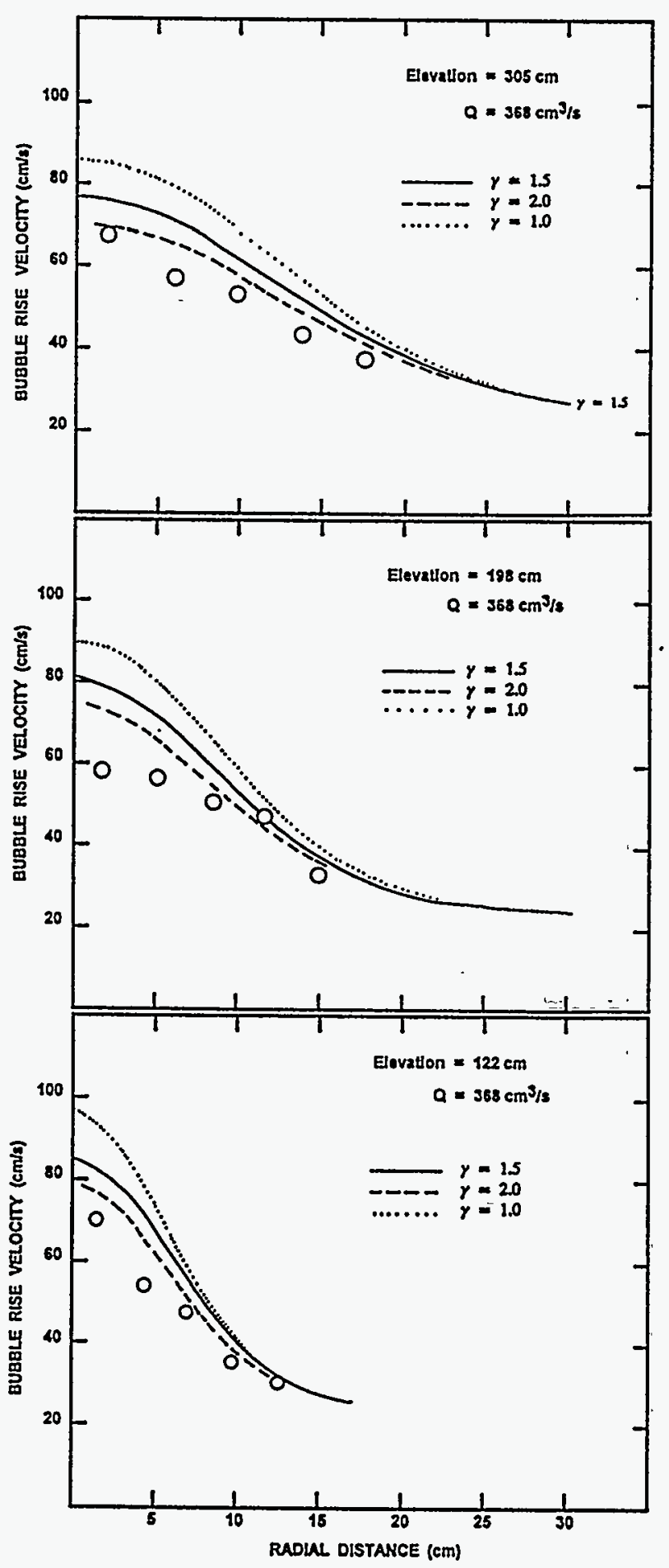

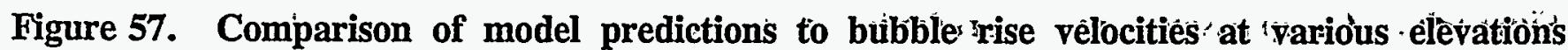
observed in an experiment by Paul et al. 


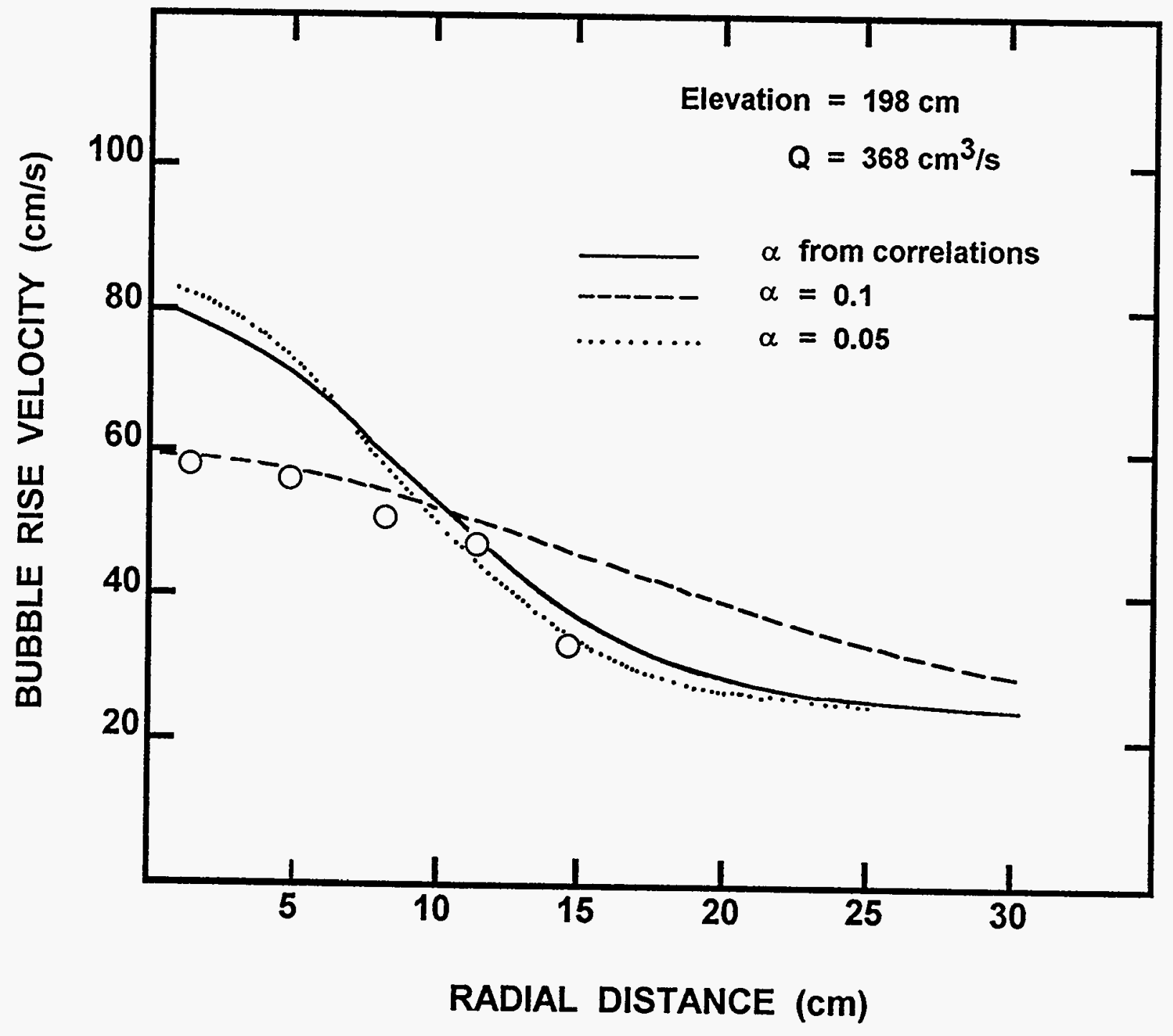

Figure 58. Effect of entrainment coefficient on predictions of bubble rise velocity 


$$
\begin{gathered}
\mathrm{E}_{\mathrm{O}}=\text { Eotvos number }=\mathrm{g}\left(\rho_{1}-\rho_{\mathrm{g}}\right) \mathrm{D}_{\mathrm{B}}^{2} / \sigma_{1} \\
\mathrm{M}=\text { Morton number }=\mathrm{g} \mu_{1}^{4}\left(\rho_{1}-\rho_{\mathrm{g}}\right) / \rho_{1}^{2} \sigma_{1}^{3}
\end{gathered}
$$

The Morton number is a property of the fluid phase. As shown in Figure 59, the Morton number of water varies from $2.6 \times 10^{-11}$ at $298 \mathrm{~K}$ to $7.5 \times 10^{-14}$ in saturated water at $453 \mathrm{~K}$ where the vapor pressure is about 10 atmospheres. The Eotvos number is a property of the bubble and the fluid. At $293 \mathrm{~K}$, a 0.1-cm-diameter bubble in water has an Eotvos number of about 0.13 whereas the Eotvos number of a $1-\mathrm{cm}$-bubble is 13.4 . The Eotvos number of a $1-c m$-diameter bubble in water at $453 \mathrm{~K}$ is 20.6.

At a fixed Morton number, the behavior of bubbles varies with bubble size. Very small, bubbles are essentially spherical and rise through water as though they were rigid spheres $[77,78,79,8,0]$. Somewhat larger bubbles develop internal circulation of gas. They are still spherical but rise through the liquid about 50 percent faster. Still larger bubbles distort into oblate ellipsoid shapes. With further increases in size, the shape becomes unstable, and the bubble can undergo oblate-to-spherical or èyen oblate-toprolate shape oscillations. The onset of shape oscillations is accompanied by a sharp-increase in the drag coefficient of the bubble. With further increases in bubble size, the bubble distorts into a spherical cap shape. As discussed above, bubbles that become too large are unstable and will break up into smaller bubbles.

The onset of internal circulation of gases within a bubble has importañt ramificătións on aeriosol trapping. The circulation of gases makes possible aerosol deposition by inertial impaçtion. On the other hand, the increase in the rise velocity decreases the time aerosols within the bubble are exposed to water. Why gases do not circulate within bubbles of all sizes has been much debated. [81,82]. "It is generally believed that the accumulation of surface active agents at the interface between the gas. and the water is responsible. Because the agents accumulate preferentially at the rear of the rising bubble, a surface tension gradient is created which tends to oppose liquid motion. The effect is often considered small except in very small bubbles. This may well be the case in laboratory situations, in wínich there are efforts to keep water pure. In suppression pools under accident conditions, the water will become very contaminated with a variety of chemical species. Some fraction of these contaminants may be surface active and may affect the mobility of the gas/water interface and consequently the circulation of gases within the bubble.

The usual criterion for the onset of internal circulation is the Bond criterion that $E_{0}>4$. This criterion is applicable only for bubble Reynolds numbers, $\operatorname{Re}_{\mathrm{B}}$, less than 1 where:

$$
\operatorname{Re}_{\mathrm{B}}=\mathrm{U}_{\text {rise }} \rho_{1} \mathrm{D}_{\mathrm{B}} / \mu_{1}
$$

and $U_{\text {rise }}$ is the rise velocity of the bubble. Clift, Grace, and Weber [81] suggest a rise velocity relationship in terms of the modified Eotvos number: 


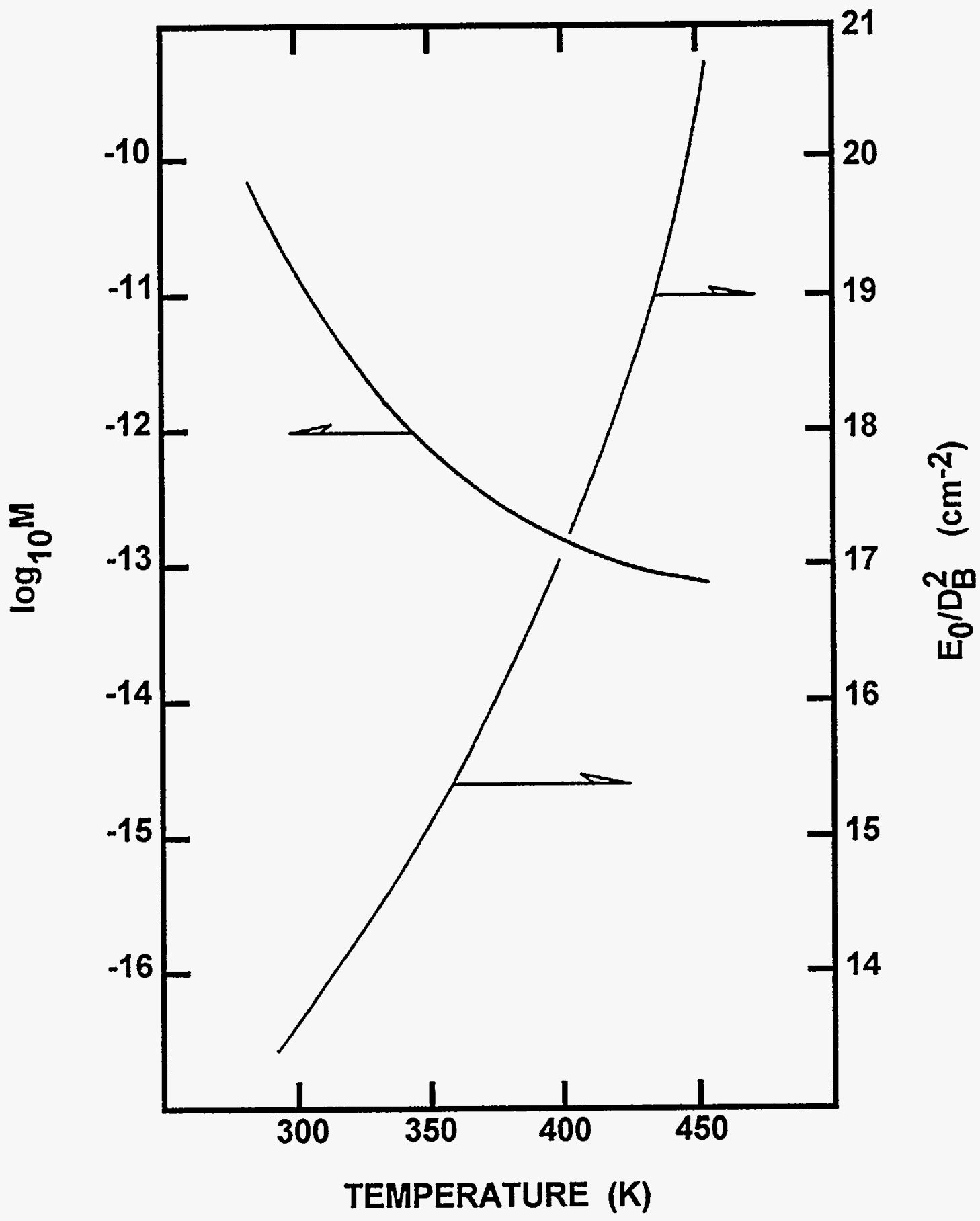

Figure 59. Variations in $\log _{10} M$ and $E_{0} / D_{B}{ }^{2}$ with temperature in water 
Physical Phenomena

$$
\begin{gathered}
\frac{\mathrm{U}}{\mathrm{U}(\text { rigid })}=1+\mathrm{Z} / 2 \\
\mathrm{Z}=\left[\frac{2}{2+3 \mu_{\mathrm{g}} / \mu_{1}}\right](2(\mathrm{y}-1)) \\
\mathrm{y}=1+0.5 \tanh \left(1.9646 \mathrm{E}_{\mathrm{o}}^{\prime}-2.63415\right) \\
\mathrm{E}_{\mathrm{o}}^{\prime}=\mathrm{g}\left(\rho_{1}-\rho_{\mathrm{g}}\right) \mathrm{D}_{\mathrm{B}}^{2} / \Delta \sigma_{1}
\end{gathered}
$$

where $\Delta \sigma_{1}$ is the difference between the surface tension of the pure liquid and the surface tension with a surface active agent present." Sadhal and Johnson [238] suggest a refinemént to this factor used by Clift, Grace, and Weber. They suggest:

$$
\frac{U}{U(\text { rigid) }}=\frac{1}{1-\mathrm{Z} / 3}
$$

where

$$
\begin{aligned}
\mathrm{Z} & =[1-\mathrm{m}(\phi)] /\left(1+\mu / \mu_{1}\right), \\
\mathrm{m}(\phi) & =\frac{1}{2 \pi}[2 \phi+\sin \phi-\sin 2 \phi-1 / 3 \sin 3 \phi], \text { and } \\
\phi & =\begin{array}{l}
\text { polar angle marking the region of the bubble surface immobilized by accumulated } \\
\text { surface active agents. }
\end{array}
\end{aligned}
$$

Various quantitative criteria have been suggested for the onset of shape oscillations. Peebles and Garber [58] found shape oscillations of air bubbles in water when:

$$
\left[\frac{\rho_{1}}{\sigma_{1}} \mathrm{U}_{\mathrm{T}}^{3} \mathrm{D}_{\mathrm{B}}\right]>3.65
$$

Coester [59] observed shape oscillations for air bubbles in water when:

$$
\left[\frac{\rho_{1}}{\sigma_{1}} \mathrm{U}_{\mathrm{T}}^{3} \mathrm{D}_{\mathrm{B}}\right]>2.96
$$

In glycerine-water solutions, oscillations occurred when: 


$$
\left[\frac{\rho_{1}}{\sigma_{1}} \mathrm{U}_{\mathrm{T}}^{3} \mathrm{D}_{\mathrm{B}}\right]>3.44 \text { to } 4.24
$$

The strong dependencies of these criteria on rise velocity suggest that the onset of shape oscillations is delayed by impurities in the water.

Quantitative criteria for the distortion of bubbles from spherical to ellipsoidal and from ellipsoidal to spherical cap are discussed in the subsection below on bubble shape.

\section{G. Slip Velocity of Bubbles}

The slip velocities of bubbles in plumes are related to the rise velocities of isolated bubbles. The rise velocities of bubbles in water have been studied numerous times (see as examples References 78 to 80). Rise velocities do depend on the purity of the water. Even the very low levels of impurities found in distilled water are suspected to influence bubble behavior. Certainly, the water in a steam suppression pool must be considered contaminated-if not initially, it will certainly become contaminated as a reactor accident progresses.

Here a correlation of the rise velocity of gas bubbles in "contaminated" water is adopted [66]:

$$
\mathrm{U}_{\mathrm{T}}=\frac{\mu_{\mathrm{l}}}{\rho_{\mathrm{l}} \mathrm{D}_{\mathrm{B}}} \mathrm{M}^{-0.149}(\mathrm{~J}-0.857)
$$

where

$$
\begin{aligned}
& D_{B}=\text { diameter of the sphere with an equivalent volume of the bubble } \\
& M=\text { Morton number } \\
& J= \begin{cases}0.94 \mathrm{H}^{0.757} & \text { for } 2 \leq \mathrm{H} \leq 59.3 \\
3.42 \mathrm{H}^{0.441} & \text { for } \mathrm{H}>59.3\end{cases} \\
& \mathrm{H}=4 / 3 \mathrm{E}_{\mathrm{O}} \mathrm{M}^{-0.149}\left(\mu_{1} / 0.009\right)^{-0.14} \\
& \mathrm{E}_{\mathrm{o}}=\text { Eotvos number } \\
& \mu_{1}=\text { liquid phase viscosity in poises. }
\end{aligned}
$$

For $\mathrm{H}>1000$, the large bubble correlation discussed above (see Figure 39 ) is used to calculate bubble rise velocity: 
Physical Phenomena

$$
\mathrm{U}_{\mathrm{T}}=0.735 \sqrt{\mathrm{gD}_{\mathrm{B}}(\mathrm{cm})} \mathrm{cm} / \mathrm{s}
$$

For bubbles with $\mathrm{H}<2$, the following correlations in terms of the Reynolds number are used [67]:

a. for $4<\operatorname{Re}<100$ :

$$
\left.\mathrm{U}_{\mathrm{T}}^{2}=\frac{4}{3} \frac{\left(\rho_{1}-\rho_{\mathrm{g}}\right) \mathrm{g} \mathrm{D}_{\mathrm{B}}}{\rho_{1}} \frac{\left[60+\frac{29 \mu_{\mathrm{g}}}{\mu_{\mathrm{l}}}\right]\left[\frac{4+3 \mu_{\mathrm{g}}}{\mu_{\mathrm{l}}}\right]}{3.05\left[783\left[\frac{\mu_{\mathrm{g}}}{\mu_{1}}\right]^{2}+2142 \frac{\mu_{\mathrm{g}}}{\mu_{1}}+1080\right.}\right]
$$

b. for $0.01<\operatorname{Re} \leq 4$

$$
\begin{aligned}
\mathrm{U}_{\mathrm{T}}^{2}= & \frac{4}{3} \frac{\left(\rho_{1}-\rho_{\mathrm{g}}\right) \mathrm{g} \mathrm{D} \mathrm{B}}{\rho_{1}} \frac{1}{\mathrm{C}_{\mathrm{D}}} \\
& \log _{10}\left[\frac{\mathrm{C}_{\mathrm{D}} \operatorname{Re}}{24}-1\right]=-0.881+0.82 \log _{10} \operatorname{Re}-0.05\left(\log _{10} \operatorname{Re}\right)^{2}
\end{aligned}
$$

c. for $\operatorname{Re}<0.01$

$$
\mathrm{U}_{\mathrm{T}}^{2}=\frac{4}{3} \frac{\left(\rho_{1}-\rho_{\mathrm{g}}\right) \mathrm{g} \mathrm{D} \mathrm{B}}{\rho_{1}}\left[\frac{1}{3 / 16+24 / \mathrm{Re}}\right]
$$

These correlations are compared to experimental data in Figure 60.

The SUPRA [7,8] and BUSCA [9] computer codes use a model for bubble rise velocities due to Wallis [85]. Five regimes are considered:

1. If $\mathrm{D}_{\mathrm{B}}>4.66\left(\sigma_{1} / \rho_{1} \mathrm{~g}\right)^{1 / 2}$,

$$
\mathrm{U}_{\mathrm{T}}=0.709 \sqrt{\mathrm{gD}_{\mathrm{B}}}
$$

2. If $\operatorname{Re} \leq 2$,

$$
\mathrm{U}_{\mathrm{T}}=\mathrm{D}_{\mathrm{B}}^{2}{ }^{2} \mathrm{~g} / 18 \mu_{1}
$$




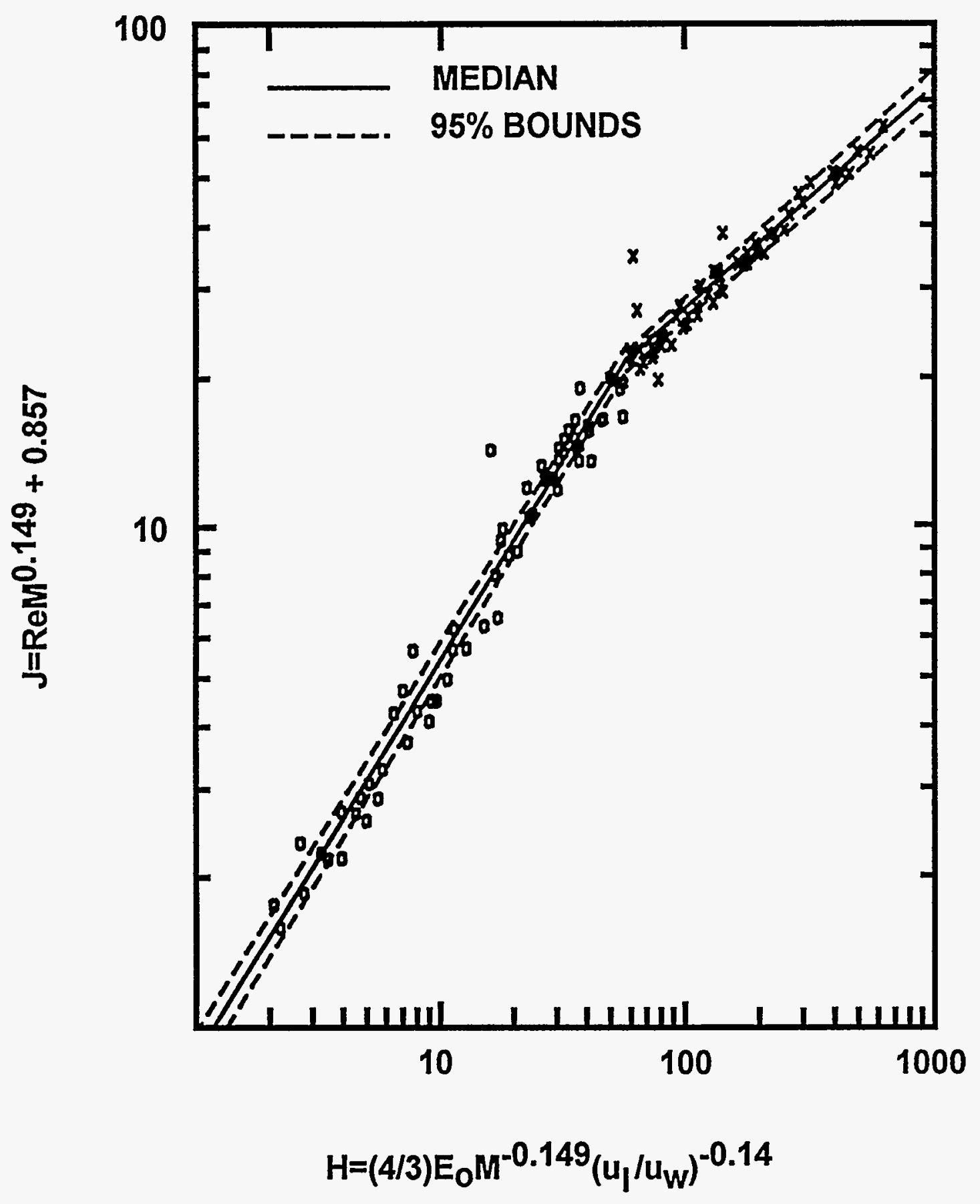

Figure 60. Comparison of predictions of bubble rise velocities by several models 
Physical Phenomena

3. If $2<\operatorname{Re} \leq 4.02 \mathrm{M}^{-0.214}$,

$$
\mathrm{U}_{\mathrm{T}}=0.33 \mathrm{~g}^{0.76}\left[\frac{\rho_{1}}{\mu_{1}}\right]^{0.52}\left(\frac{\mathrm{D}_{\mathrm{B}}}{2}\right)^{1.28}
$$

4. If $4.02 \mathrm{M}^{-0.214}<\operatorname{Re} \leq 3.1 \mathrm{M}^{-0.25}$,

$$
\mathrm{U}_{\mathrm{T}}=1.35\left(2 \sigma_{1} / \rho_{1} \mathrm{D}_{\mathrm{B}}\right)^{1 / 2}
$$

5. If $\operatorname{Re}>3.1 \mathrm{M}^{-0.25}$

$$
\mathrm{U}_{\mathrm{T}}=1.53\left(\mathrm{~g} \sigma_{1} / \rho_{1}\right)^{1 / 4}
$$

where Re is the Reynold's number.

The SPARC code uses a rather simple model [6]:

$$
\mathrm{U}_{\mathrm{T}}= \begin{cases}7.876\left(\sigma_{\mathrm{l}} / \rho_{1}\right)^{1 / 4} & \text { for } \mathrm{D}_{\mathrm{B}} \leq 0.5 \mathrm{~cm} \\ 11.0826\left(\sigma_{1} / \rho_{1}\right)^{1 / 4} \mathrm{D}_{\mathrm{B}}^{0.4927 .5} & \text { for } \mathrm{D}_{\mathrm{B}}>0.5 \mathrm{~cm}\end{cases}
$$

These various descriptions of the rise velocities are compared in Figure 61 for bubbles of various sizes rising through water. The sharp peak in the rise velocity for $\mathrm{D}_{\mathrm{B}}=0.2 \mathrm{~cm}$ exhibited by the model used in the SUPRA and BUSCA computer codes is appropriate for gas bubbles rising in very pure water. Such a peak would not be expected in even modestly contaminated water such as tap water [79]. Certainly, during the progression of a severe reactor accident, water in the suppression pool will become sufficiently contaminated that rise velocities of bubbles will be affected.

\section{H. Bubble Shapes}

The distortion of bubbles from spherical to oblate ellipsoidal is conveniently described in terms of the eccentricity, $E$, which is the length of the semi-major axis, a, divided by the length of the semi-minor axis, b:

$$
E=a / b
$$

The volume and surface area of an oblate ellipsoid of eccentricity $\mathrm{E}$ are: 


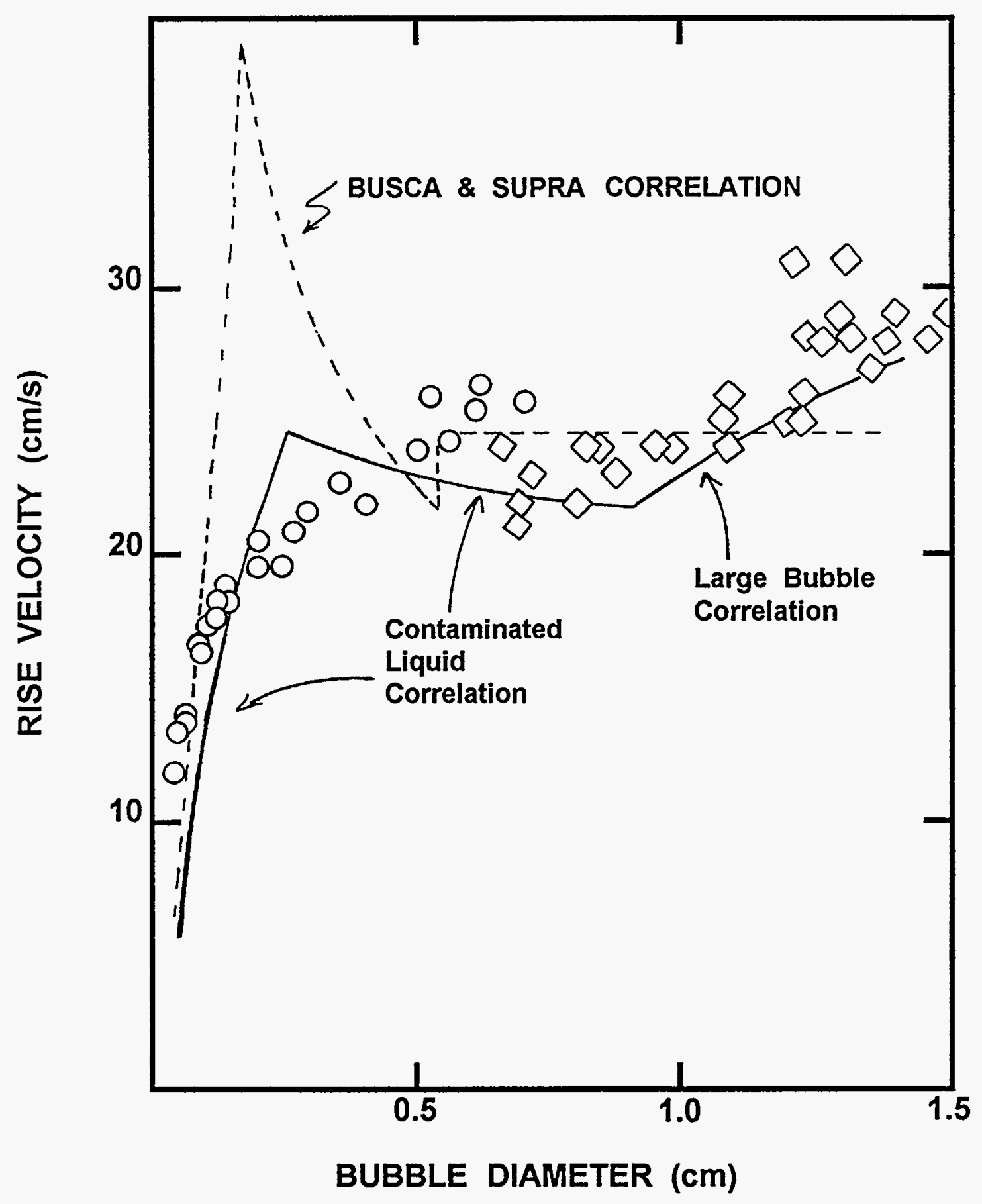

Figure 61. Comparison of predicted bubble rise velocities to data for air bubbles in hot (322 K) tap water [79] 
Physical Phenomena

$$
\begin{aligned}
& V=\frac{4}{3} \pi a^{2} b=\frac{4}{3} \pi a^{3} / E=\frac{\pi}{6} D_{B}^{3}(e) \\
& A=\frac{\pi}{2} D_{B}(e)^{2} E^{2 / 3} \cdot\left\{1+\frac{1}{2 E\left(E^{2}-1\right)^{1 / 2}} \ln \left[\frac{E+\left(E^{2}-1\right)^{1 / 2}}{E-\left(E^{2}-1\right)^{1 / 2}}\right]\right\}
\end{aligned}
$$

where $D_{B}(e)=2 a / E^{1 / 3}$ is the diameter of the sphere with an equivalent volume.

A compact correlation for eccentricities of bubbles is [82]:

$$
\frac{1}{E}= \begin{cases}1 & \text { for } \mathrm{Ta} \leq 1 \\ {\left[0.81+0.206 \tanh \left\{2\left(0.8-\log _{10} \mathrm{Ta}\right)\right\}\right]^{3}} & \text { for } 1 \leq \mathrm{Ta} \leq 39.8 \\ 0.24 & \text { for } \mathrm{Ta}>39.8\end{cases}
$$

where $\mathrm{Ta}=\operatorname{ReM}^{0.23}$. In cases where Ta exceeds 39.8 , the bubble has a spherical cap shápe which will be discussed further below.

The BUSCA code [9] uses à correlation of eccentricity with the Eotvos number, $E_{0}$ :

$$
E= \begin{cases}0.8526+0.22498 \mathrm{E}_{\mathrm{o}}-5.6918 \times 10^{-3} \mathrm{E}_{\mathrm{o}}^{2}+4.86 \times 10^{-5} \mathrm{E}_{\mathrm{o}}^{3} & \text { for } \mathrm{E}_{\mathrm{O}}<38.5 \\ 3.85+7.6472 \times 10^{-5}\left(\mathrm{E}_{\mathrm{o}}-38.5\right) & \text { for } 38.5 \leq \mathrm{E}_{\mathrm{o}} \leq 2000 \\ 4 & \text { for } \mathrm{E}_{\mathrm{o}}>2000\end{cases}
$$

Okhotskii [224] has proposed a theory of bubble eccentricity that yields the implicit expression:

$$
E=1+\left[\frac{2}{3}\right]\left(\frac{1}{E^{1 / 3}}\right]\left(\frac{E_{o}}{1+E_{0} / 4}\right)^{1 / 2}
$$

Paul et al. [30] examined the shapes of bubbles produced in their experiments with quenchers. They developed a regression equation for their data:

$$
\frac{1}{E}= \begin{cases}1 & \text { for } D_{B}(e) \leq 0.15 \mathrm{~cm} \\ 0.68+0.57 \exp \left[-D_{B}(e) / 0.26\right] & \text { for } D_{B}(e)>0.15 \mathrm{~cm}\end{cases}
$$


Their data for bubbles in swarms as well as data for isolated bubbles $[39,79,80]$ are compared to the correlations in Figure 62. It is apparent from this comparison that there is significant scatter, even in the data for isolated bubbles, about the correlation. There appears also to be some indication that bubble distortion is suppressed in swarms.

Bhaga and Weber [84] conducted studies of bubble shapes in liquids with large Morton numbers $\left(\mathrm{M}=10^{-3}\right.$ to $10^{3}$ versus $\mathrm{M}=10^{-10}$ to $10^{-14}$ of interest here). They found eccentricity to be a function of the Reynolds number and independent of the Morton number. They draw attention in their writings to differences between liquids characterized by large Morton numbers and liquids characterized by small Morton numbers. It appears then that results reported by Bhaga and Weber are not applicable to the topics of interest here.

Bubbles predicted to have eccentricitities greater than about 4 are spherical caps. The general geometry of a spherical cap bubble is shown in Figure 63. The spherical portion has a radius, $R$, given by [82]:

$$
\mathrm{R}=\mathrm{D}_{\mathrm{B}}(\mathrm{e}) /\left[2 \mathrm{~g}\left(\theta_{\mathrm{W}}\right)\right]^{1 / 3}
$$

where

$$
\begin{aligned}
\mathrm{g}\left(\theta_{\mathrm{w}}\right) & =2-3 \cos \left(\theta_{\mathrm{w}}\right)+\cos ^{3} \theta_{\mathrm{w}} \\
\theta_{\mathrm{w}} & =50+190 \exp \left[-0.62 \mathrm{Re}^{0.4}\right] \text { degrees }
\end{aligned}
$$

In water, all real spherical cap bubbles have wake angles near $50^{\circ}$ according to this description.

The BUSCA model [9] uses a rather different method to describe the geometrical features of a spherical cap bubble. Eccentricities are calculated from the correlations in terms of the Eotvos number described above. The radius of the spherical portion and the wake angle are then found from:

$$
\begin{aligned}
& R=\frac{D_{b}(e)\left(E^{2}+1\right)}{2\left(3 E^{2}+1\right)^{1 / 3}} \\
& \theta=2 \tan ^{-1}(1 / E)
\end{aligned}
$$

The authors of this document do not understand this model.

\section{Heat and Mass Transport to and Within Bubbles}

Heat transport and mass transport within bubbles and from the water pool to the bubbles are of interest in three regimes of bubble behavior within a suppression pool:

- during bubble formation at orifices and at vents to the pool,

- immediately after bubbles detach and begin to equilibrate with the pool, and 


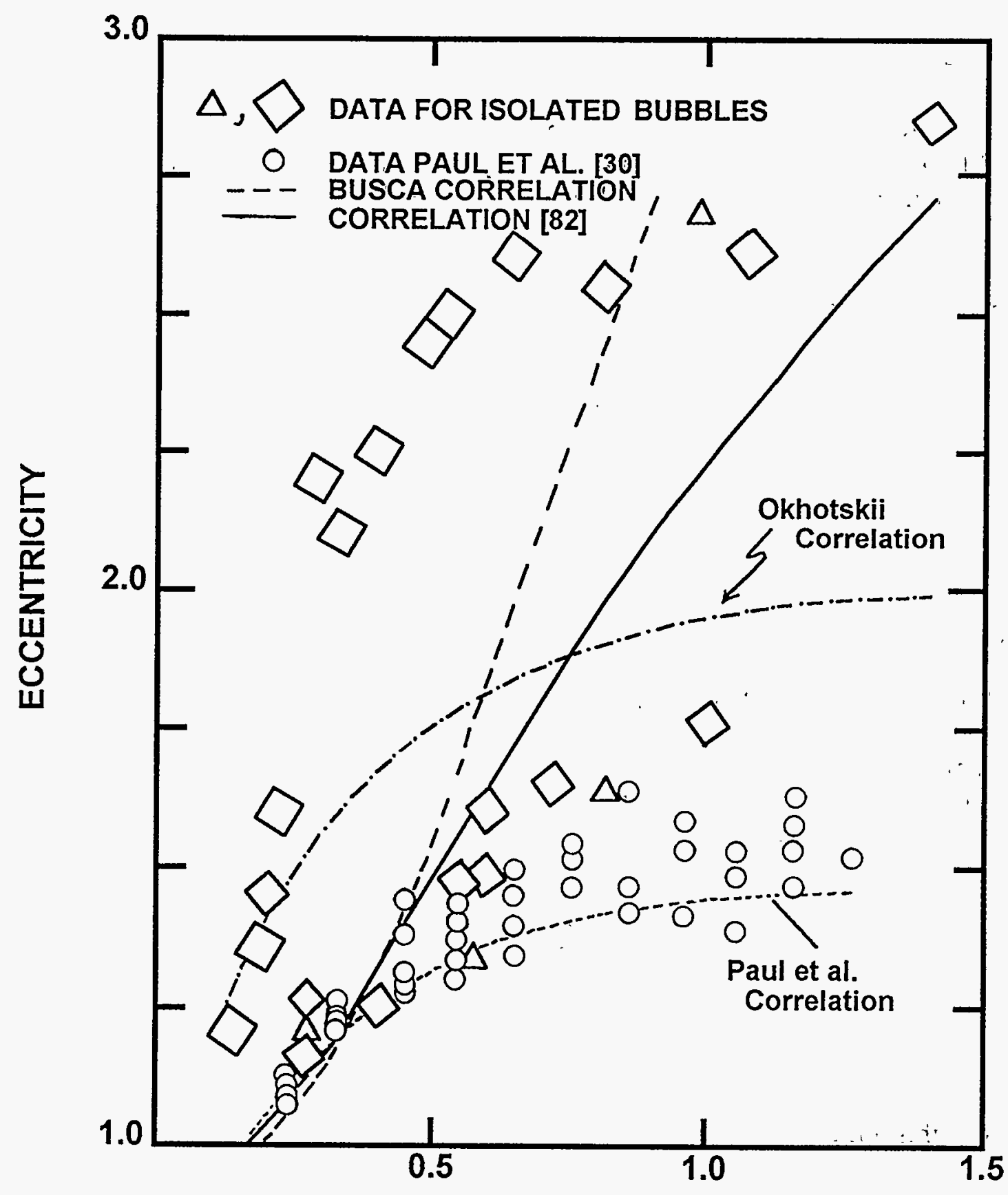

DIAMETER OF VOLUME-EQUIVALENT SPHERE (cm)

Figure 62. Comparison of bubble eccentricity models to experimental data 


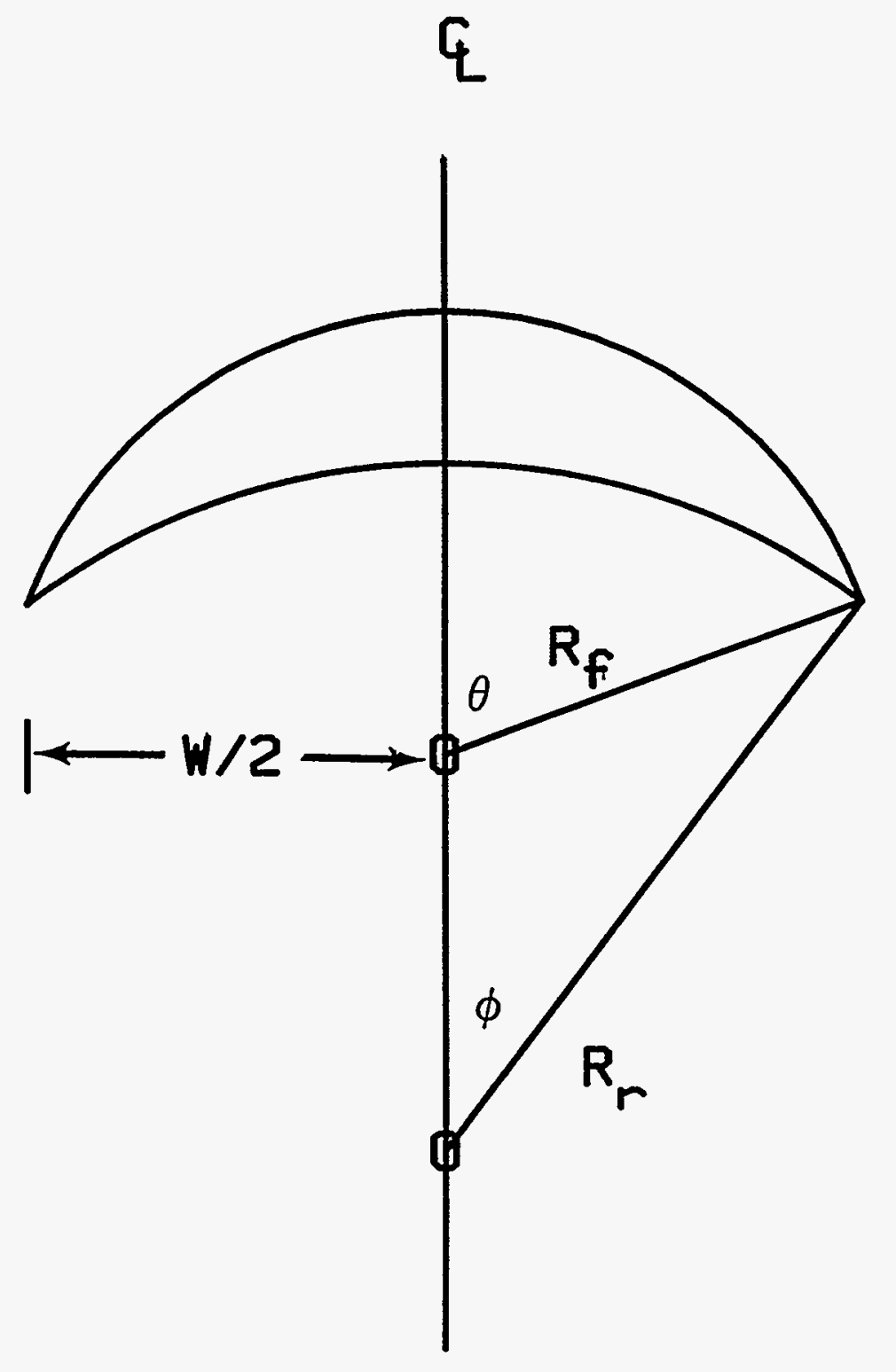

Figure 63. General geometry of a spherical cap bubble 
Physical Phenomena

- during the quasi-steady state as bubbles rise through the pool.

The interest in heat and mass transport does not stem from a need to understand the detailed timing of bubble behavior. Rather, heat transport and mass transport within the bubble are expected to affect aerosol behavior. It is, then, necessary to have some estimate of the heat transport and mass transport coefficients to predict aerosol removal during the three regimes of bubble behavior.

\section{Heat Transport From Bubbles During Formation}

Some aspects of heat transport during bubble formation have been discussed above in Section IV-A-1. It is quite difficult to obtain detailed data on the condensation heat transfer during bubble formation at orifices. Mayinger and Chen [190] have employed a novel, optical-interference pattern method to measure heat transfer from vapor bubbles. They recomniènd:

$$
\mathrm{Nu}=\frac{\hbar \mathrm{D}_{\mathrm{B}}{ }^{*}}{\mathrm{k}_{\mathrm{th}}(1)}=0.185 \cdot \mathrm{Re}^{0.7} \operatorname{Pr}^{1 / 2}
$$

where

$$
\begin{aligned}
\mathrm{n} & =\text { average heat transfer coefficient during bubble formation, } \\
\mathrm{R}_{\mathrm{e}} & =\mathrm{U}_{\mathrm{B}} \mathrm{D}_{\mathrm{B}}^{*} \rho_{1} / \mu_{1} \\
\operatorname{Pr} & =\mu_{1} \mathrm{C}_{\mathrm{p}}(\mathrm{l}) / \mathrm{k}_{\mathrm{th}}(1), \text { and } \\
\mathrm{D}_{\mathrm{B}}^{*} & =\text { bubble diameter at the time the bubble detaches from the orifice. }
\end{aligned}
$$

Unfortunately, Chen and Mayinger do not inidicate clearly what velocity is to be used to calculate the Reynolds number. They mention both the rise velocity of the bubble when it detaches and the relative motion of the bubble and liquid as the bubble grows. An example they provide for:

$$
\mathrm{Ja}=\frac{\rho_{\mathrm{l}}\left(\mathrm{T}_{\mathrm{S}}-\mathrm{T}_{\mathrm{p}}\right)}{\mathrm{L} \rho_{\mathrm{g}}}=10
$$

yields a heat transfer coefficient of $0.13 \mathrm{cal} / \mathrm{cm}^{2}-\mathrm{s}-\mathrm{K}$. The correlation they recommend yields a value about twice that which is measured.

Chen and Mayinger's studies involved bubbles formed at a $0.16-\mathrm{cm}$ upward facing nozzle. These data can be used only with considerable extrapolation to estimate heat transfer from bubbles formed at orifices in quenchers. Jeje et al. [213] observed a sharp decrease in the heat transfer coefficient as bubbles formed at a nozzle $0.5 \mathrm{~cm}$ in diameter. Initial values were as high as $60 \mathrm{cal} / \mathrm{cm}^{2}-\mathrm{s}-\mathrm{K}$. Heat transfer coefficients at the time of bubble detachment were about $1 / 10$ of this. 
Pitts [210] cites work by Engeldiner, unavailable to the authors, for heat transfer from bubbles formed at the end of downcomers. This work was, apparently, done specifically for the study of steam suppression pools. Pitts utilized for the heat transfer coefficient:

$$
\mathrm{h}=8.4+3.6 \times 10^{-4} \mathrm{~A}_{\mathrm{B}}\left(\mathrm{cm}^{2}\right) \quad \mathrm{cal} / \mathrm{cm}^{2}-\mathrm{s}-\mathrm{K}
$$

where $A_{B}$ is the surface area of the bubble at the end of the downcomer. He took the maximum heat transfer coefficient to be $24 \mathrm{cal} / \mathrm{cm}^{2}-\mathrm{s}-\mathrm{K}$ based on experimental studies. This value is quite similar to the value found by Kerney et al. [291] for submerged jets of steam into water, $23 \mathrm{cal} / \mathrm{cm}^{2}-\mathrm{s}-\mathrm{K}$. This value correlated well data for jets from orifices 0.04 to $0.95 \mathrm{~cm}$ in diameter and Kerney et al. suggest a simple correlation for a variety of data:

$$
\mathrm{h}=1.932 \mathrm{C}_{\mathrm{p}}(\mathrm{steam}) \dot{\mathrm{Q}}(\mathrm{m}) / \pi \mathrm{D}_{\mathrm{o}}^{2}
$$

where

$$
\begin{aligned}
\mathrm{C}_{\mathrm{p}} \text { (steam) } & =\text { heat capacity of steam } \\
\dot{\mathrm{Q}}(\mathrm{m}) & =\text { mass flow rate of steam through an orifice, } \\
\mathrm{D}_{\mathrm{o}} & =\text { diameter of the orifice. }
\end{aligned}
$$

The also suggest are more complicated but better correlation:

$$
\frac{\pi \mathrm{hD}_{\mathrm{o}}^{2}}{\mathrm{C}_{\mathrm{p}} \dot{\mathrm{Q}}(\mathrm{m})}=1.395\left[\frac{\Delta \mathrm{H}_{\mathrm{fg}}}{\mathrm{C}_{\mathrm{p}}\left(\mathrm{T}_{\mathrm{g}}-\mathrm{T}_{\mathrm{p}}\right)}\right]^{0.1689}\left[\frac{{\mathrm{z} \pi \mathrm{D}_{\mathrm{o}}^{2}}^{2}}{\dot{\mathrm{Q}(\mathrm{m})}}\right]^{0.1446}
$$

where

$$
\begin{aligned}
\Delta \mathrm{H}_{\mathrm{fg}} & =\text { latent heat of vaporization of water, and } \\
\mathrm{z} & =27.5 \mathrm{~g} \mathrm{steam} / \mathrm{cm}^{2} \text {-s. }
\end{aligned}
$$

\section{Heat Transfer After Bubble Detachment}

As discussed above (Section IV-B), the collapse of bubbles has been the subject of much study. Collapse may be limited by inertial effects or by heat transfer effects. Heat transfer effects dominate when the driving force for condensation is not too large. Mayinger and Chen [190] seem ${ }^{*}$ to recommend:

\footnotetext{
* Mayinger and Chen list the leading coefficient in the correlation as 0.6. But, the text indicates the coefficient is 0.185 and this value yields results in better agreement with plotted data.
} 
Physical Phenomena

$$
\mathrm{Nu}=0.185 \operatorname{Re}^{0.6} \operatorname{Pr} 1 / 2
$$

Values they obtained for the Nusselt number for steam bubbles varied by about \pm 25 percent.

Experimental studies by Brucker and Sparrow [211] with 0.3-cm-diameter, well-isolated, steam bubbles yielded a heat transfer coefficient of $0.24 \mathrm{cal} / \mathrm{cm}^{2}-\mathrm{s}-\mathrm{K}$. These authors recommended as a correlation for the heat transfer coefficient:

$$
\mathrm{Nu}=0.37 \mathrm{Re}^{0.6}
$$

They indicated an uncertainty of \pm 50 percent. In light of this uncertainty, the correlation is consistent with that found by Mayinger and Chen.

Theoretical consideration of bubble collapse in the heat-transfer limited regime [212] yields:

$$
\mathrm{h}=\phi\left[\frac{\mathrm{U}_{\mathrm{B}} \mathrm{C}_{\mathrm{p}}(\mathrm{l}) \rho_{\mathrm{l}} \mathrm{k}_{\mathrm{th}}(\mathrm{l})}{\mathrm{D}_{\mathrm{B}}^{*}}\right]^{1 / 2}
$$

where $\phi$ can be 0.42 to 0.35 .

These various correlations of the heat transfer coefficient from bubbles rising in water at $373 \mathrm{~K}$ are shown in Figure 64 as functions of bubble diameter.

The correlations give fairly consistent values in light of the uncertainties ascribed to them. It is apparent that the correlation recommended by Bruckner and Sparrow and the theoretical analysis by Moalem and Sideman [212] describe the uncertainty range for the heat transfer coefficients.

Lee [71] recommends an average heat transfer for bubbles that detach from downcomers:

$$
\begin{gathered}
\overline{\mathrm{hA}}=2 / 3 \mathrm{~A}(\mathrm{i}) \mathrm{h}_{\mathrm{o}} \\
\frac{\mathrm{h}_{\mathrm{o}} \mathrm{D}_{\mathrm{p}}}{\mathrm{k}_{\mathrm{th}}(\mathrm{l})}=0.04 \mathrm{Re}^{7 / 8} \mathrm{Pr}^{1 / 2}
\end{gathered}
$$

where

$\mathrm{D}_{\mathrm{p}}=$ diameter of the downcomer,

hA $=$ average of the product of the heat transfer coefficient and the bubble surface area, and $A(i)=$ initial surface area of the bubbles. 


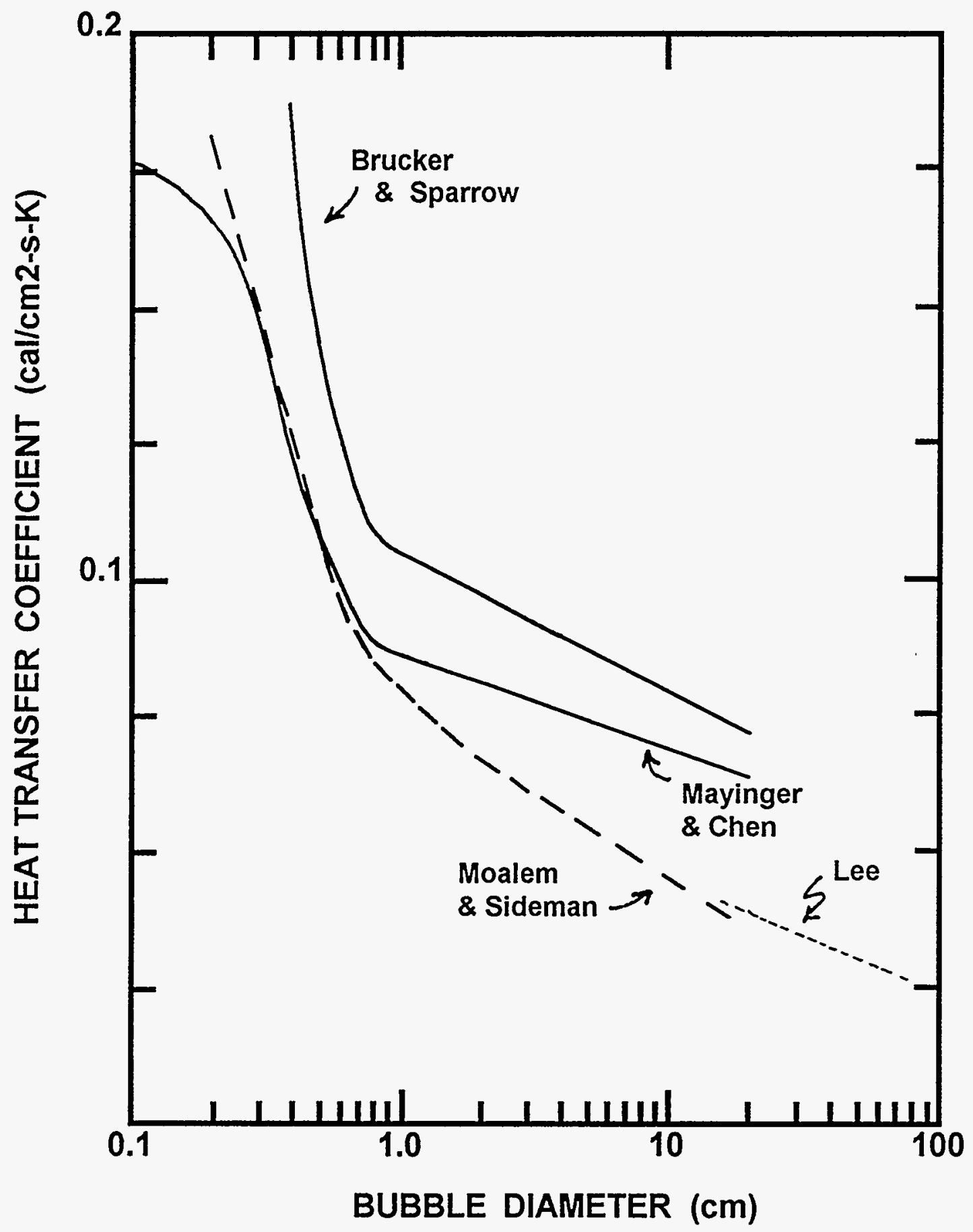

Figure 64. Heat transfer coefficients for bubbles rising in $373 \mathrm{~K}$ water as functions of bubble diameter 
Values of $h_{0}$ for large bubbles expected to form at downcomers are also shown in Figure 64.

For bubbles that encapsulate the downcomer as they rise, Lee [71] found the heat transfer coefficient to be $3.6 \mathrm{cal} / \mathrm{cm}^{2}-\mathrm{s}-\mathrm{K}$ independent of the bubble Reynolds number.

\section{Heat and Mass Transfer During Bubble Rise}

Once the bubbles have equilibrated with the pool and have begun a quasi-steady state rise through the suppression pool, both external heat transfer and mass transport within the bubble are of interest as discussed in connection with the thermodynamics of bubbles (see Section IV-D). It is eertainly not evident that the external heat transfer coefficients for steam-rich large bubbles are applicable to the quasi-steady state bubble rise.

The vast bulk of information on external transport to bubbles comes from mass transport analogy between mass transport and heat transport must, then, be used to get the heat transport coefficient.

Spherical bubbles have received by far the most attention. For Reynolds numbers up to-ạbout 1 and for all Peclet numbers, Pe, the Sherwood number for external mass transport is given by [82]:

$$
\mathrm{Sh}_{\mathrm{A}}=1+(1+\mathrm{Pe})^{1 / 3}
$$

where

$$
\begin{aligned}
\mathrm{Sh} & =\mathrm{k}_{\mathrm{m}} \mathrm{D}_{\mathrm{B}} / \oplus \\
\mathrm{Pe} & =\mathrm{D}_{\mathrm{B}} \mathrm{U}_{\text {slip }} \\
\mathrm{k}_{\mathrm{m}} & =\text { mass transport coefficient } \\
\boxplus & =\text { diffusion coefficient }
\end{aligned}
$$

By analogy, the Nusselt number for heat transport is given by:

$$
\mathrm{Nu}=\mathrm{hD}_{\mathrm{B}} / \mathrm{k}_{\mathrm{th}}=1+\left[1+\frac{\mathrm{D}_{\mathrm{B}} \mathrm{U}_{\text {slip }} \rho_{1} \mathrm{C}_{1}}{\mathrm{k}_{\mathrm{th}}(\mathrm{l})}\right]^{1 / 3}
$$

where

$$
\begin{aligned}
\mathrm{Nu} & =\text { Nusselt number } \\
\mathrm{k}_{\mathrm{th}}(\mathrm{l}) & =\text { thermal conductivity of the liquid }
\end{aligned}
$$


For Reynolds numbers greater than about 70 ,

$$
\operatorname{Sh}_{B}=1+\frac{2}{\sqrt{\pi}}\left[1-\frac{\frac{2+3 \xi}{3(1+\xi)}}{\left\{1+\left[\frac{(2+3 \xi) \operatorname{Re}^{1 / 2}}{(1+\xi)\left(8.67+6.45 \xi^{0.64}\right)}\right]^{\mathrm{n}}\right\}^{1 / \mathrm{n}}}\right]^{1 / 2} \mathrm{Pe}^{1 / 2}
$$

where

$$
\begin{aligned}
& \mathrm{n}=4 / 3+3 \xi \\
& \xi=\mu_{\mathrm{g}} / \mu_{1}
\end{aligned}
$$

A somewhat ad hoc transition between the model for $\operatorname{Re} \leq 1$ and $\operatorname{Re}>70$ is provided by:

$$
\mathrm{Sh}=\frac{\mathrm{Sh}_{\mathrm{A}}+\operatorname{ReSh}_{\mathrm{B}} / 50}{1+\operatorname{Re} / 50}
$$

Predictions of the mass transport coefficient obtained with this model for $\mathrm{CO}_{2}$ transport in water at room temperature are compared to data $(86,87)$ in Figure 65 . For this comparison the aqueous phase diffusion coefficient of $\mathrm{CO}_{2}$ was taken to be $1.95 \times 10^{-5} \mathrm{~cm}^{2} / \mathrm{s}$. The data show a substantial scatter. The theoretical model seems to provide an upper bound on the data for bubbles larger than about $0.25 \mathrm{~cm}$. For smaller bubbles, predictions and data diverge.

For ellipsoidal bubbles without shape oscillations, Clift, Grace and Weber [82] recommend for contaminated systems:

$$
\frac{\overline{\mathrm{k}_{\mathrm{m}}^{\mathrm{A}}}}{\mathrm{A}_{\mathrm{e}} \boxplus^{1 / 2}}=6.5 \quad \mathrm{~s}^{-1 / 2}
$$

or

$$
\frac{\hbar \mathrm{hA}}{\mathrm{A}_{\mathrm{e}}\left(\mathrm{k}_{\mathrm{th}} / \rho_{1} \mathrm{C}_{1}\right)^{1 / 2}}=6.5 \quad \mathrm{~s}^{-1 / 2}
$$




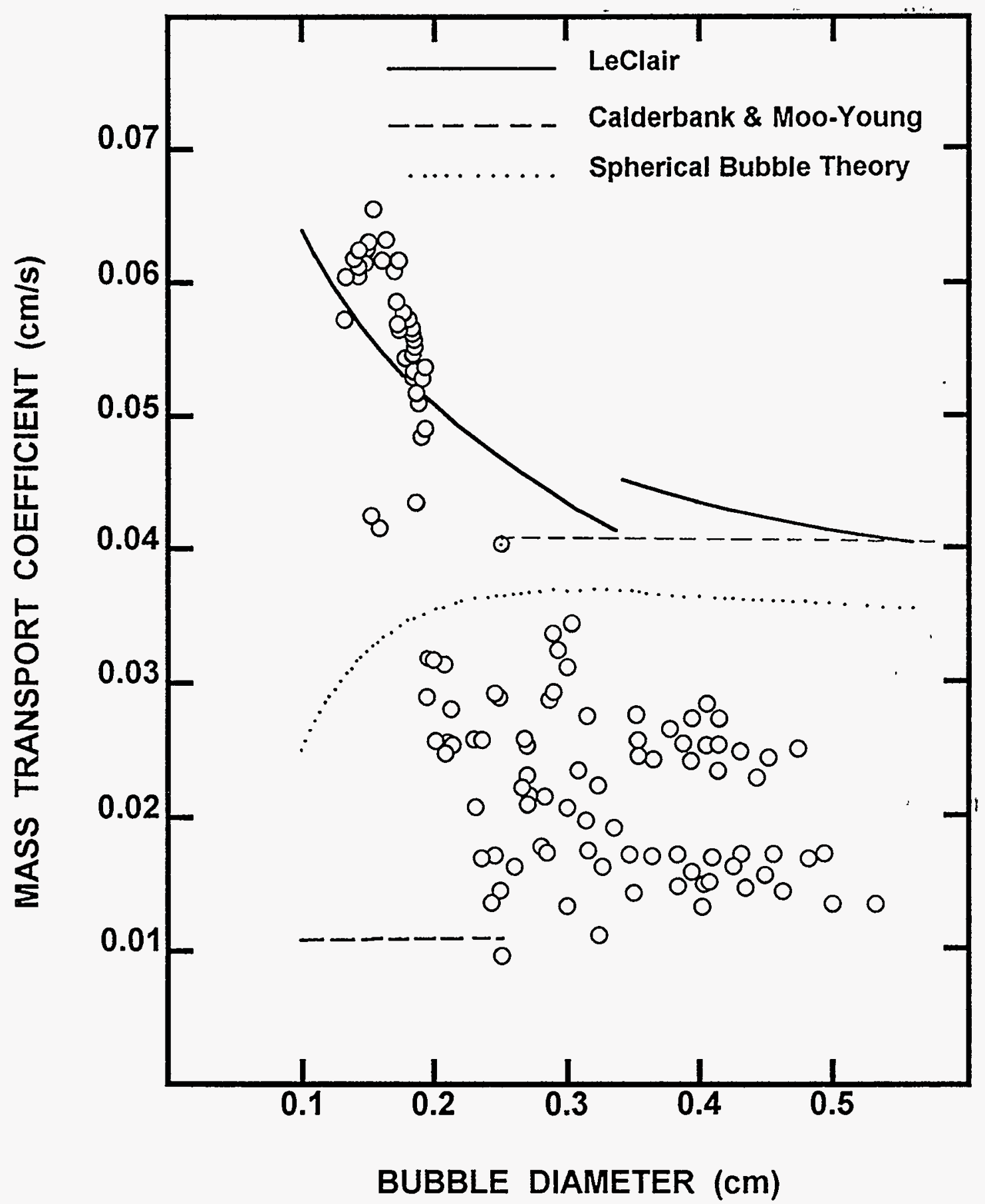

Figure 65. Comparison of predicted and observed mass transport coefficients for $\mathrm{CO}_{2}$ from nearly spherical bubbles. The spherical bubble theory is for isolated bubbles. Other models are for bubble swarms. 
where

$$
\begin{aligned}
\overline{\mathrm{K}_{\mathrm{m}} \mathrm{A}} & =\begin{array}{l}
\text { average product of the surface area of the bubble and the mass transport } \\
\text { coefficient, and }
\end{array} \\
\mathrm{A}_{\mathrm{e}} & =\text { surface area of the sphere with the equivalent volume }=\pi \mathrm{D}_{\mathrm{B}}^{2}(\mathrm{e})
\end{aligned}
$$

For pure systems, they recommend

$$
\frac{\overline{\mathrm{K}_{\mathrm{m}} \mathrm{A}}}{\mathrm{A}_{\mathrm{e}} \boxplus^{1 / 2}}=\frac{0.14}{\mathrm{D}_{\mathrm{B}}(\mathrm{e})}+\frac{6.94}{\mathrm{D}_{\mathrm{B}}(\mathrm{e})^{1 / 2}} \mathrm{~s}^{-1 / 2}
$$

They prefer these empirical correlations over the theoretical expression for potential flow conditions [267]:

$$
\mathrm{Sh}=\frac{\frac{2}{\sqrt{\pi}} \operatorname{Pe}^{1 / 2}\left\{\frac{8\left(E^{2}-1\right)^{3 / 2}}{3 E^{10 / 3} \sin ^{-1}\left[\left(E^{2}-1\right)^{3 / 2} / E^{2}(E+1)\right]}\right\}^{1 / 2}}{1+\frac{1}{2 E\left(E^{2}-1\right)^{1 / 2}} \ln \left[\frac{E+\left(E^{2}-1\right)^{1 / 2}}{E-\left(E^{2}-1\right)^{1 / 2}}\right]}+1
$$

or

$$
\frac{\overline{\mathrm{k}_{\mathrm{m}}^{\mathrm{A}}}}{\mathrm{A}_{\mathrm{e}^{\boxplus}}}=2 \sqrt{\frac{2}{3 \pi}} \frac{\mathrm{U}_{\mathrm{slip}}^{1 / 2}}{\mathrm{D}_{\mathrm{B}}^{1 / 2} \mathrm{E}}\left\{\frac{\left(\mathrm{E}^{2}-1\right)^{3 / 2}}{3 \sin ^{-1}\left[\left(\mathrm{E}^{2}-1\right)^{3 / 2} / \mathrm{E}^{2}(\mathrm{E}+1)\right]}\right\}^{1 / 2}
$$

Johnson et al. [86] found they could account for mass transport of $\mathrm{CO}_{2}$ and other gases from bubbles with equivalent diameters of 0.6 to $4.0 \mathrm{~cm}$ rising in water with the expression:

$$
\mathrm{Sh}=2+1.13 \mathrm{Pe}^{1 / 2}\left[\frac{\mathrm{D}_{\mathrm{B}}(\mathrm{e})}{0.45+0.2 \mathrm{D}_{\mathrm{B}}(\mathrm{e})}\right]^{1 / 2}
$$

They found, in fact, fairly good agreement between experimental results and predictions with this correlation for Reynolds numbers from 500 to 8000 . 
Physical Phenomena

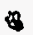

For ellipsoidal bubbles with shape oscillations, Clift, Grace, and Weber [82] consider the surface stretch model:

$$
\frac{\mathrm{k}_{\mathrm{m}^{\mathrm{A}}}}{\mathrm{A}_{\mathrm{e}}}=\frac{Ð}{\mathrm{D}_{\mathrm{B}}(\mathrm{e})} \frac{2}{\sqrt{\pi}} \sqrt{\frac{\mathrm{D}_{\mathrm{B}}{ }^{2} \mathrm{f}}{\mathrm{D}}}\left(1+\delta+\frac{3 \delta^{2}}{8}\right)^{1 / 2}
$$

and the fresh surface model:

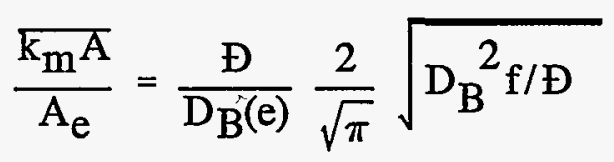

where

$$
\begin{aligned}
1+\delta & =\begin{array}{l}
\text { ratio of the maximum surface area to the minimum surface area } \\
\text { over an oscillation cycle, and }
\end{array} \\
f= & \text { frequency of oscillation }
\end{aligned}
$$

For oblate-to-spherical oscillations,

$$
1+\delta=\frac{1}{2} E^{2 / 3}\left\{1+\frac{1}{2 E\left(E^{2}-1\right)^{1 / 2}} \ln \left[\frac{E+\left(E^{2}-1\right)^{1 / 2}}{E-\left(E^{2}-1\right)^{1 / 2}}\right]\right\}
$$

The frequency of oscillations is difficult to predict. The natural frequencies for a spherical bubble in a viscous medium are given by [61]:

$$
(2 \pi f)^{2}=\frac{8 n(n+1)(n-1)(n+2) \sigma_{1}}{\left[(n+1) \rho_{1}+n \rho_{g}\right] D_{B}^{3}}
$$

where $n$ is a small integer. The first meaningful frequency is at $n=2$, but Schmidt [293] finds $n=3$ to be a more important oscillation frequency.

At Reynolds numbers less than 110 , mass transfer to spherical cap bubbles is given approximately by [82]:

$$
\frac{\overline{\mathrm{K}_{\mathrm{m}}^{\mathrm{A}}}}{\mathrm{Ae}}=2.83\left[\frac{\mathrm{Pe}}{\pi}\right]^{1 / 2} \frac{\mathrm{D}}{\mathrm{D}_{\mathrm{B}}(\mathrm{e})}
$$


At higher Reynolds numbers, assuming that mass transfer to the spherical portion and the base of the bubble are independent, the average mass transport is given by [82]:

$$
\frac{\overline{\mathrm{k}_{\mathrm{m}}^{\mathrm{A}}}}{\mathrm{A}_{\mathrm{e}}}=\frac{2 Ð}{\mathrm{D}_{\mathrm{B}}(\mathrm{e})}\left[\frac{\mathrm{Pe}}{\pi}\right]^{1 / 2}+\frac{\mathrm{Sr} \sin ^{3} \theta_{\mathrm{w}}}{4 \pi}\left[\frac{2 \mathrm{a}}{\mathrm{D}_{\mathrm{B}}(\mathrm{e})}\right]^{3 / 2}\left[\frac{\mathrm{U}_{\mathrm{slip}} \boxplus}{\mathrm{D}_{\mathrm{B}}(\mathrm{e})}\right]^{1 / 2}
$$

where

$$
\begin{aligned}
& \mathrm{Sr}=2 \mathrm{f}_{\mathrm{W}} \mathrm{a} \sin \theta_{\mathrm{w}} / \mathrm{U}_{\mathrm{slip}} \\
& \theta_{\mathrm{w}}=50+190 \exp \left(-0.62 \mathrm{Re}^{0.4}\right) \\
& \mathrm{f}_{\mathrm{w}}=\text { wake shedding frequency }
\end{aligned}
$$

At Reynolds numbers greater than about $150, \mathrm{Sr}$ has values of 0.2 to 0.5 .

The various models of mass transport coefficients are compared in Figure 66 to data on the mass transport of $\mathrm{CO}_{2}$ in water at room temperature $(86,87,218)$. All of the models predict similar results to within about a factor of 3 . These predictions are in accord with the scattered data.

The discussions to this point have focused on external transfer processes to isolated bubbles. Convective transport processes to bubbles in swarms might be expected to be different. Calderbank and Moo-Young [64] have correlated data for bubbles in swarms by

$$
\mathrm{k}_{\mathrm{m}}= \begin{cases}0.31\left(\mu_{1} \mathrm{~g} / \rho_{1}\right)^{1 / 3} \mathrm{Sc}^{-2 / 3} & \text { for } \mathrm{D}_{\mathrm{B}}(\mathrm{e})<0.25 \mathrm{~cm} \\ 0.42\left(\mu_{1} \mathrm{~g} / \rho_{1}\right)^{1 / 3} \mathrm{Sc}^{-1 / 2} & \text { for } \mathrm{D}_{\mathrm{B}}(\mathrm{e})>0.25 \mathrm{~cm}\end{cases}
$$

where

$$
\mathrm{Sc}=\mu_{1} / \rho_{1} \boxplus
$$

LeClair and Hamielec [65] have developed a theoretical expression for mass transfer to bubbles in swarms: 


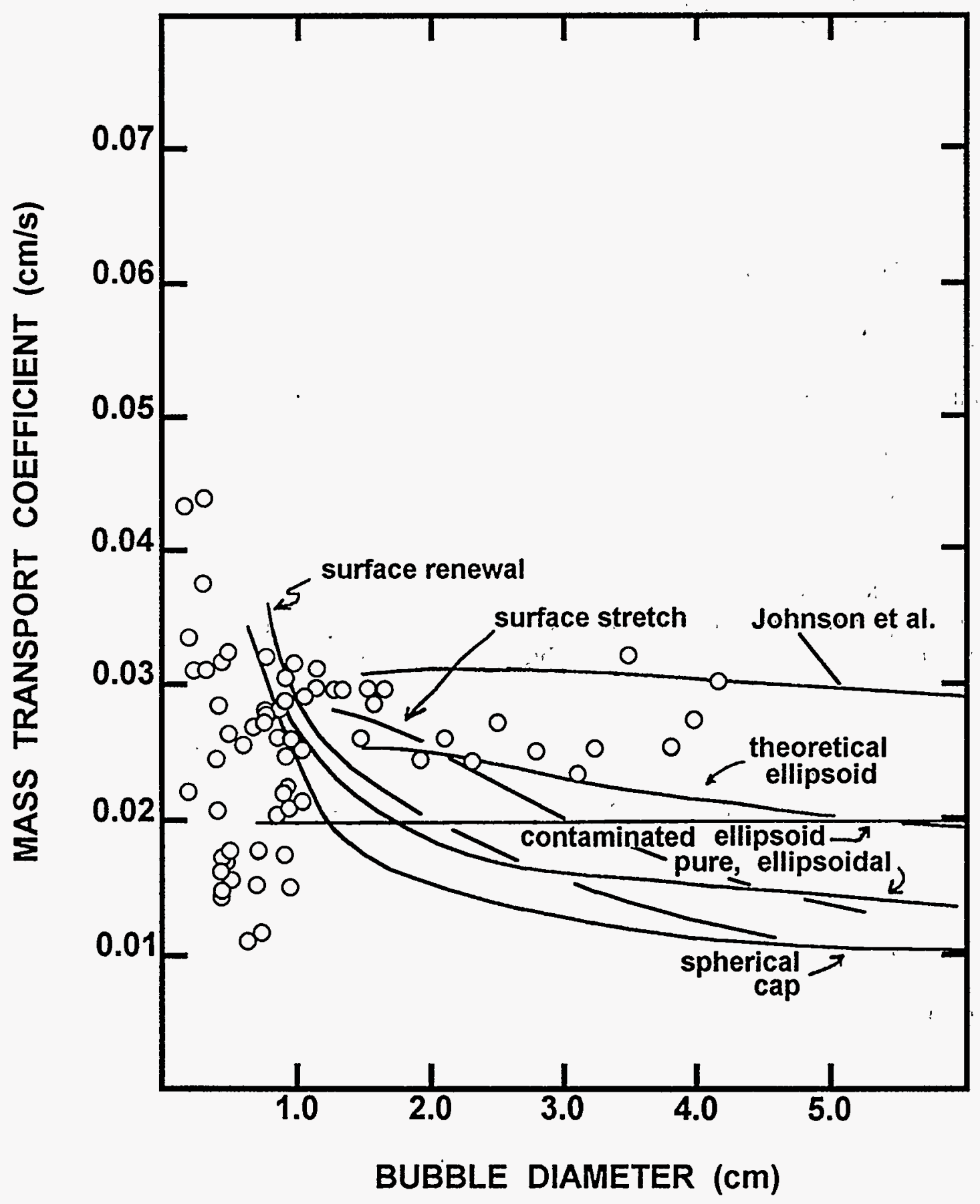

Figure 66. Comparison of mass transport coefficients predicted for $\mathrm{CO}_{2}$ in water from nonspherical bubbles to experimental data. Bubble diameter in this figure refers to the spherical bubble with an equivalent volume. 


$$
S h= \begin{cases}1.13 \mathrm{Pe}^{1 / 2} / \sqrt{1-\epsilon} & \text { for } \operatorname{Re} \rightarrow \infty \\ 2.213 \mathrm{Pe}^{1 / 2} / \operatorname{Re}^{0.108} \sqrt{1-\epsilon} & \text { for } 10 \leq \operatorname{Re} \leq 1000 \\ \frac{\left(0.65+0.06 \operatorname{Re}^{1 / 2}\right) \mathrm{Pe}^{1 / 2}}{\left[\frac{5-6(\epsilon)^{1 / 3}+(\epsilon)^{2}}{5(1-\epsilon)}\right]^{1 / 2}} & \text { for } \operatorname{Re}<10 \\ {[} & \end{cases}
$$

where $\epsilon$ is the volume fraction gas.

Predictions of the Calderbank and Moo-Young correlations and the LeClair and Hamielec theoretical models are compared to experimental data in Figures 65 and 66. The Calderbank-Moo-Young correlation provides an upperbound on data for bubbles larger than $0.25 \mathrm{~cm}$. The predictions for these bubbles are consistent with theoretical predictions for isolated spherical bubbles. The discontinuous shift in the correlation prediction for bubbles smaller than $0.25 \mathrm{~cm}$ seems to be opposite the trend in the data.

The predictions of LeClair-Hamielec model are shown in Figures 65 and 66 in the limit of zero gas fraction. The model seems to predict well data for very small bubbles. Like the Calderbank-MooYoung correlation and the theoretical model for isolated spherical bubbles, the LeClair-Hamielec theoretical model bounds from above the experimental data.

The heat transfer coefficients that can be derived by analogy to the mass transport models and correlations are shown as functions of bubble diameter in Figure 67. The heat transfer coefficients shown in this figure are for water at $373 \mathrm{~K}$. The analogy drawn from the Calderbank-Moo-Young correlation appears to be at odds with predictions derived from analogies to other models. The predicted heat transfer coefficients are about a factor of 2 higher than heat transfer coefficients derived above for steam bubbles.

Internal transfer processes in small bubbles are expected to be quite rapid. Only theoretical expressions for transfer rate coefficients are available. The case in which there is circulation within the bubble yields the Kronig-Brink solution [88] for $4 \oplus t / \mathrm{D}_{\mathrm{B}}{ }^{2}(\mathrm{e}) \rightarrow \infty$ :

$$
\text { Sh }=17.66
$$

The long term limit without internal circulation [89] is:

$$
\mathrm{Sh}=6.58
$$

The Kronig-Brink model was derived for conditions in which mass transport in the liquid phase is infinitely fast. The long-time, internal Sherwood number when the external mass transport rate is finite is shown as a function of the external Sherwood number [102] in Figure 68. The correlation line in this figure is given by: 


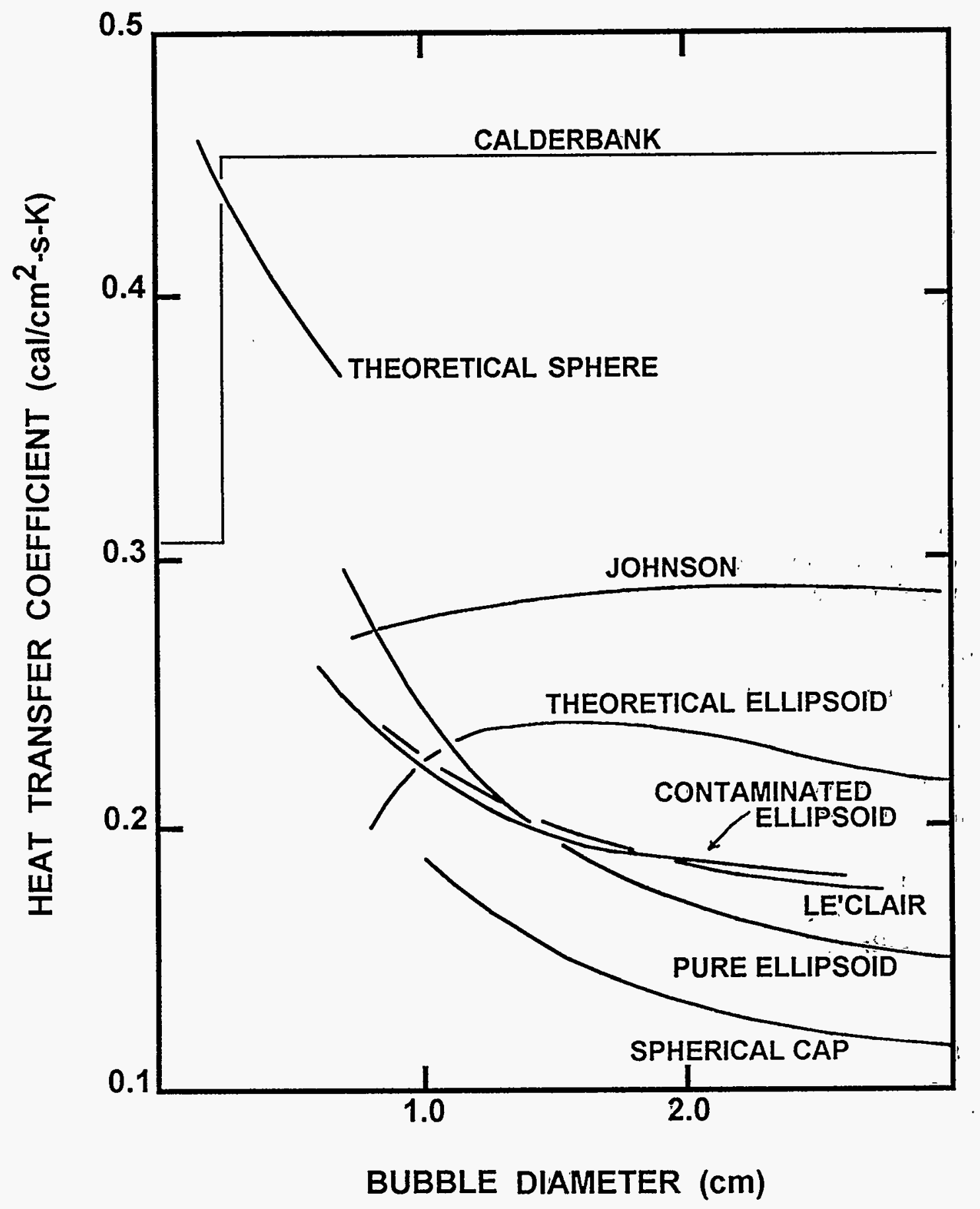

Figure 67. External heat transfer coefficients for bubbles in water at $373 \mathrm{~K}$ derived from analogies to mass transport models 
Physical Phenomena

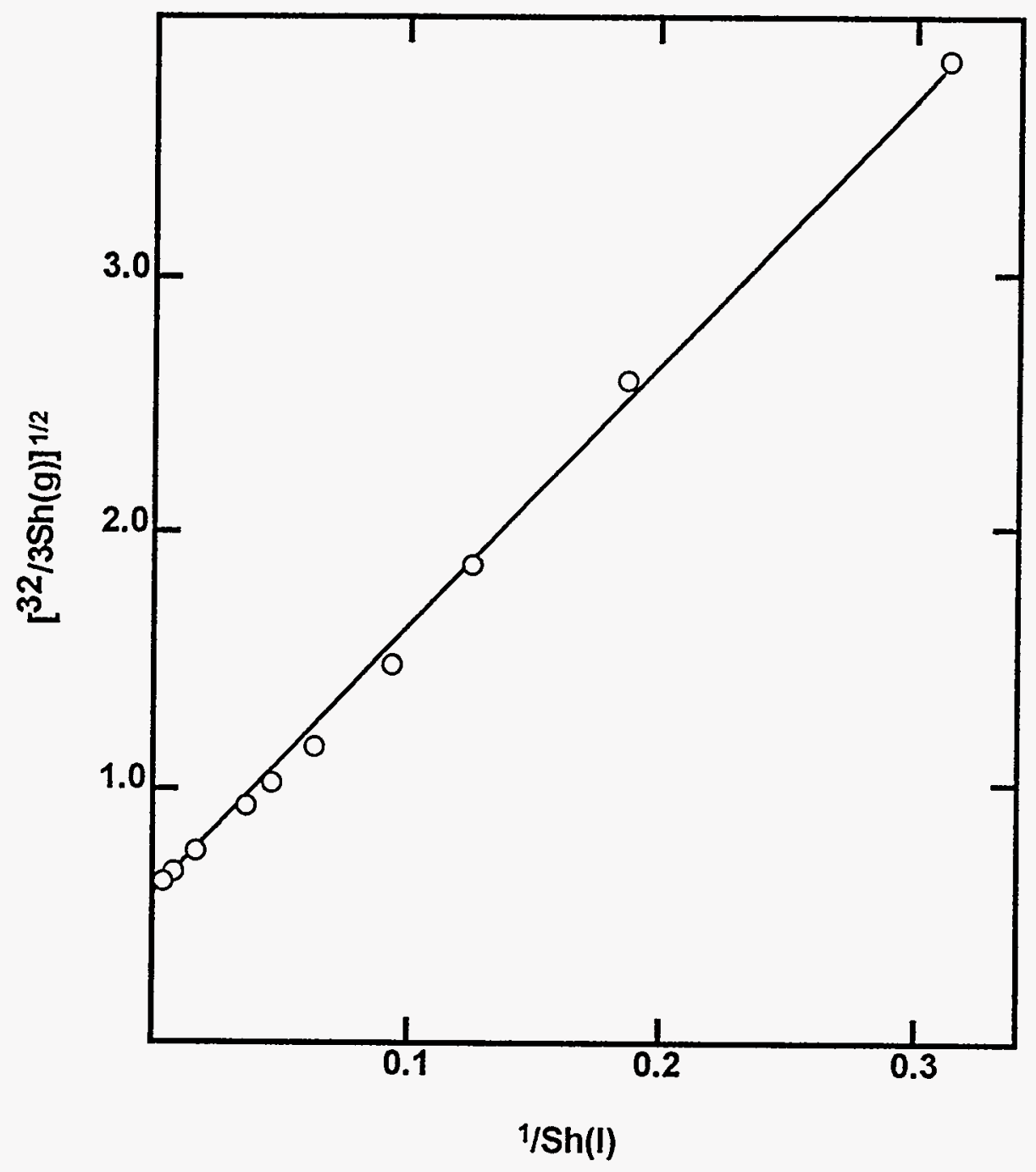

Figure 68. Correlation of the long-term Sherwood number in the gas phase for cases with a finite liquid phase Sherwood number 
Physical Phenomena

$$
\left[\frac{32}{3 \operatorname{Sh}(g)}\right]^{1 / 2}=\frac{1}{1.656}+10.20874 / \operatorname{Sh}(1)
$$

where

$$
\begin{aligned}
& \operatorname{Sh}(g)=\text { Sherwood number in the gas phase, and } \\
& \operatorname{Sh}(1)=\text { Sherwood number in the liquid phase. }
\end{aligned}
$$

\section{J. Thermophysical Properties}

The thermophysical properties of water, steam and permanent gases used in this study are described in the subsections below.

\section{Properties of Liquid Water}

Properties of suppression pool water were calculated assuming that the liquid was pure water. Powers and Sprung [1] have discussed the effects dissolved and suspended impurities can have on the properties of water. If the impurities are not strongly surface active, concentrations are expected to be so low in the suppression pool that any error arising from neglect of the impurity effects on wăter properties is likely to be negligible in comparison to other uncertainties.

The thermodynamic quantities enthalpy, vapor pressure, and density were calculated üsing correlations recently recommended by the Association for the Properties of Water and Steam [83]:

- Enthalpy (cal/gm)

$$
\begin{gathered}
\mathrm{h}=\alpha+\frac{\mathrm{T}}{\rho} \frac{\mathrm{dP}}{\mathrm{dT}} \\
\alpha=0.23900\left[\mathrm{~d}_{\alpha}+\mathrm{d}_{1} \theta^{-19}+\mathrm{d}_{2} \theta+\mathrm{d}_{3} \theta^{4.5}+\mathrm{d}_{4} \theta^{5}+\mathrm{d}_{5} \theta^{54.5}\right]
\end{gathered}
$$

- Vapor pressure (atmospheres)

$$
\ln \frac{\mathrm{P}}{\mathrm{P}_{\mathrm{c}}}=\frac{\mathrm{T}_{\mathrm{c}}}{\mathrm{T}}\left[\mathrm{a}_{1} \tau+\mathrm{a}_{2} \tau^{1.5}+\mathrm{a}_{3} \tau^{3}+\mathrm{a}_{4} \tau^{3.5}+\mathrm{a}_{5} \tau^{4}+\mathrm{a}_{6} \tau^{7.5}\right]
$$

- Density $\left(\mathrm{g} / \mathrm{cm}^{3}\right)$ of the saturated liquid

$$
\frac{\rho}{\rho_{\mathrm{c}}}=1+\mathrm{b}_{1} \tau^{1 / 3}+\mathrm{b}_{2} \tau^{2 / 3}+\mathrm{b}_{3} \tau^{5 / 3}+\mathrm{b}_{4} \tau^{16 / 3}+\mathrm{b}_{5} \tau^{43 / 3}+\mathrm{b}_{6} \tau^{110 / 3}
$$


where

$$
\begin{aligned}
& \theta=\mathrm{T} / \mathrm{T}_{\mathrm{c}} \\
& \tau=1-\mathrm{T} / \mathrm{T}_{\mathrm{c}} \\
& \mathrm{y}=\tau \\
& \mathrm{T}_{\mathrm{c}}=647.096 \mathrm{~K} \\
& \mathrm{P}_{\mathrm{c}}=217.755 \mathrm{atms} \\
& \rho_{\mathrm{c}}=0.322 \mathrm{~g} / \mathrm{cm}^{3} \\
& \mathrm{~d}_{\alpha}=-1135.905627715 \\
& \mathrm{~d}_{1}=-5.65134998 \times 10^{-8} \\
& \mathrm{~d}_{2}=2690.66631 \\
& \mathrm{~d}_{3}=127.287297 \\
& \mathrm{~d}_{4}=-135.003439 \\
& \mathrm{~d}_{5}=0.981825814 \\
& \mathrm{a}_{1}=-7.85951783 \\
& \mathrm{a}_{2}=1.84408259 \\
& \mathrm{a}_{3}=-11.7866497 \\
& \mathrm{a}_{4}=22.6807411 \\
& \mathrm{a}_{5}=-15.9618719 \\
& \mathrm{a}_{6}=1.80122502 \\
& \mathrm{~b}_{1}=1.99274064 \\
& \mathrm{~b}_{2}=1.09965342 \\
& \mathrm{~b}_{3}=-0.510839303 \\
& \mathrm{~b}_{4}=-1.75493479 \\
& \mathrm{~b}_{5}=-45.5170352 \\
& \mathrm{~b}_{6}=-6.74694450 \times 10^{5}
\end{aligned}
$$

Internal energy was derived from the expression: 
Physical Phenomena

$$
\mathrm{h}-\mathrm{P} / \mathrm{\rho}=\mathrm{U}
$$

Heat capacities at constant pressure, $C_{p}$, and at constant volume ${ }_{*} C$, were found by numerically differentiating with respect to temperature expressions for enthalpy and internal energy, respectively.

Surface tension was calculated from the expression [56]:

$$
\sigma(\text { dynes } / \mathrm{cm})=235.8\left[\frac{0.999686-\overline{\mathrm{T}}}{0.999686}\right]^{1.256}\left(1-0.625\left[\frac{0.999686-\overline{\mathrm{T}}}{0.999686}\right]\right)
$$

where $\mathrm{T}=\mathrm{T} / 647.27$. Predictions of this correlation are compared to experimental data [103] in Figure 69. The thermal conductivity of saturated liquid water was calculated from [55]:

$$
\frac{\lambda}{\lambda^{*}}=\lambda_{0}(\overline{\mathrm{T}}) \lambda_{1}(\overline{\mathrm{T}}, \bar{\rho})
$$

where

$$
\begin{aligned}
\lambda^{*} & =0.4945 \mathrm{~W} / \mathrm{m}-\mathrm{K}=1.1819 \times 10^{-3} \mathrm{cal} / \mathrm{cm}-\mathrm{s}-\mathrm{K} \\
\lambda_{0}(\overline{\mathrm{T}}) & =\sqrt{\mathrm{T}} /\left\{1+6.978267 / \overline{\mathrm{T}}+2.599096 / \overline{\mathrm{T}}^{2}-0.998254 / \overline{\mathrm{T}}^{3}\right\} \\
\lambda_{1}(\overline{\mathrm{T}}, \bar{\rho}) & =\exp \left[\bar{\rho} \sum_{\mathrm{i}=1}^{5} \sum_{\mathrm{j}=1}^{6} \mathrm{~L}(\mathrm{i}, \mathrm{j})\left(\frac{1}{\overline{\mathrm{T}}}-1\right)^{(\mathrm{i}-1)}(\bar{\rho}-1)^{(\mathrm{j}-1)}\right] \\
\bar{\rho} & =\rho / 0.317763 \\
\rho & =\operatorname{density~}\left(\mathrm{g} / \mathrm{cm}^{3}\right)
\end{aligned}
$$

The nonzero coefficients $L(i, j)$ are listed in Table 11. Predictions of the correlation are compared to data in Figure 70.

The viscosity of saturated liquid water was calculated from [55]:

$$
\mu(\mathrm{g} / \mathrm{cm}-\mathrm{s})=5.5 \times 10^{-4} \mu_{\mathrm{o}}(\overline{\mathrm{T}}) \mu_{1}(\overline{\mathrm{T}}, \bar{\rho})
$$




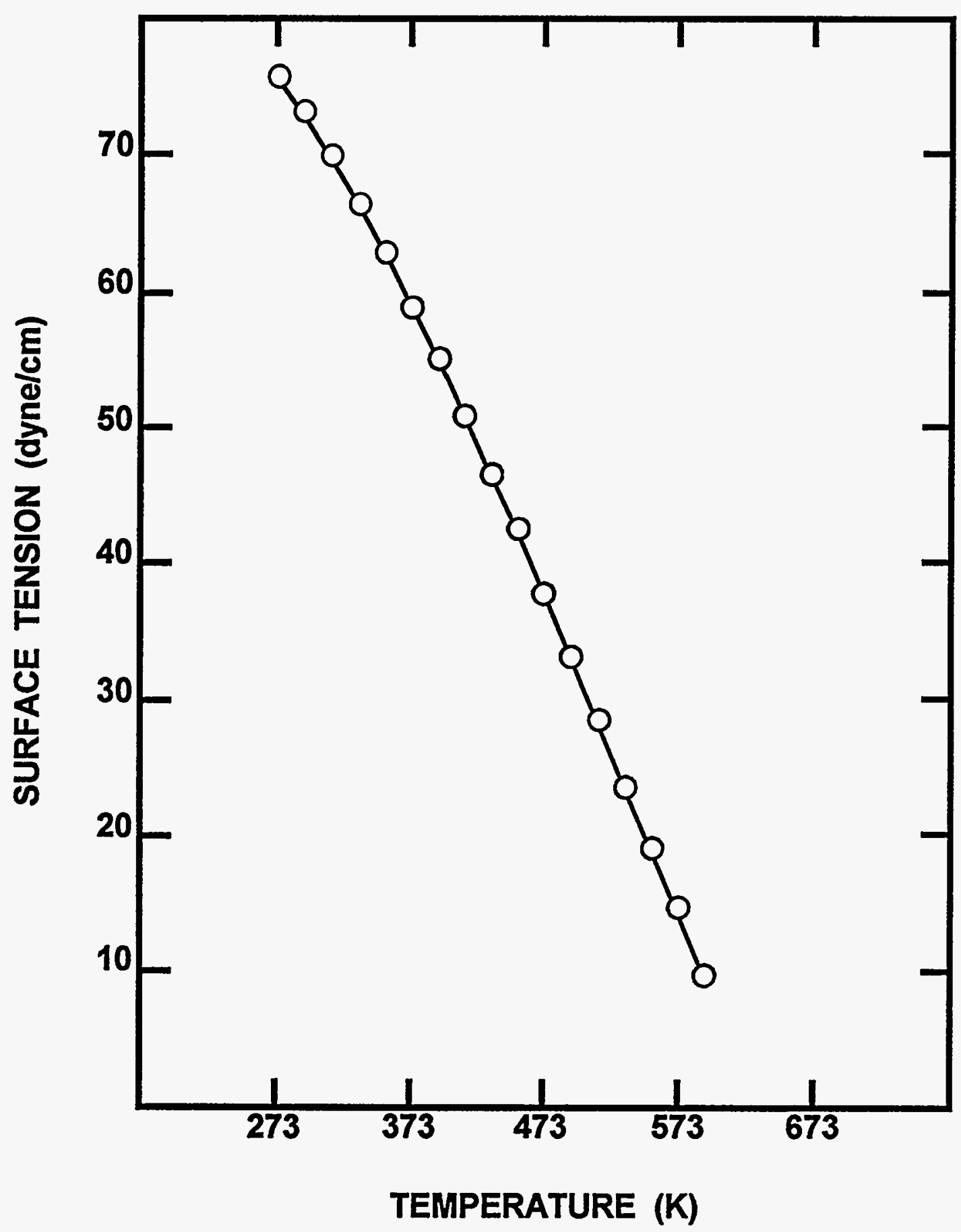

Figure 69. Comparison of predictions of the surface tension of water to experimental data [103] 
Physical Phenomena

Table 11. Coefficients in the term $\lambda_{1} \overline{(T, \rho)}$ for thermal conductivity of liquid water

\begin{tabular}{lcccccc}
\hline & $\mathbf{j}=\mathbf{1}$ & $\mathbf{2}$ & $\mathbf{3}$ & $\mathbf{4}$ & \multicolumn{1}{c}{$\mathbf{5}$} \\
\hline $\mathrm{L}(1, \mathrm{j})$ & 1.3293046 & 1.7018363 & 5.22461 .58 & $\cdots$ & -8.7127675 & -1.8525999 \\
$\mathrm{~L}(2, \mathrm{j})$ & -0.40452437 & -2.2156845 & -10.124111 & -9.5000611 & 0.93404690 \\
$\mathrm{~L}(3, \mathrm{j})$ & 0.24409490 & 1.6511057 & 4.9874687 & 4.3786606 & 0 \\
$\mathrm{~L}(4, \mathrm{j})$ & 0.018660751 & -0.76736002 & -0.27297694 & -0.91783782 & 0 \\
$\mathrm{~L}(5, \mathrm{j})$ & -0.12961068 & 0.37283344 & -0.4308393 & 0 & 0 \\
$\mathrm{~L}(6, \mathrm{j})$ & 0.044809953 & -0.11203160 & 0.13333849 & 0 & 0 \\
\hline
\end{tabular}

where:

$$
\begin{aligned}
& \overline{\mathrm{T}}=\mathrm{T}(\mathrm{K}) / 647.27 \\
& \mu_{0}(\overline{\mathrm{T}})=\sqrt{\mathrm{T}} /\left\{1+\frac{0.978197}{\overline{\mathrm{T}}}+\frac{0.579829}{\overline{\mathrm{T}}^{2}}-\frac{0.202354}{\overline{\mathrm{T}}^{3}}\right\} \\
& \mu_{1}(\bar{T}, \bar{\rho})=\exp \left[\bar{\rho} \sum_{i=1}^{6} \sum_{j=1}^{7} H(i, j)\left(\frac{1}{\bar{T}}-1\right)^{(i-1)}(\bar{\rho}-1)^{(j-1)}\right] \\
& \bar{\rho}=\rho\left(\mathrm{g} / \mathrm{cm}^{3}\right) / 0.317763
\end{aligned}
$$

The coefficients $\mathrm{H}(\mathrm{i}, \mathrm{j})$ are listed in Table 12.

\section{Properties of Steam}

The thermodynamic properties of steam (enthalpy, internal energy, and heat capacities),were calculated from the expressions described for liquid water, above, using the density of steam in place of the density of liquid water. The density of saturated steam is given by [83]:

$$
\left[\frac{\rho\left(\mathrm{g} / \mathrm{cm}^{3}\right)}{0.322}\right]=\exp \left(\mathrm{C}_{1} \tau^{1 / 3}+\mathrm{C}_{2} \tau^{2 / 3}+\mathrm{C}_{3} \tau^{4 / 3}+\mathrm{C}_{4} \tau^{3}+\mathrm{C}_{5} \tau^{37 / 6}+\mathrm{C}_{6} \tau^{71 / 6}\right)
$$




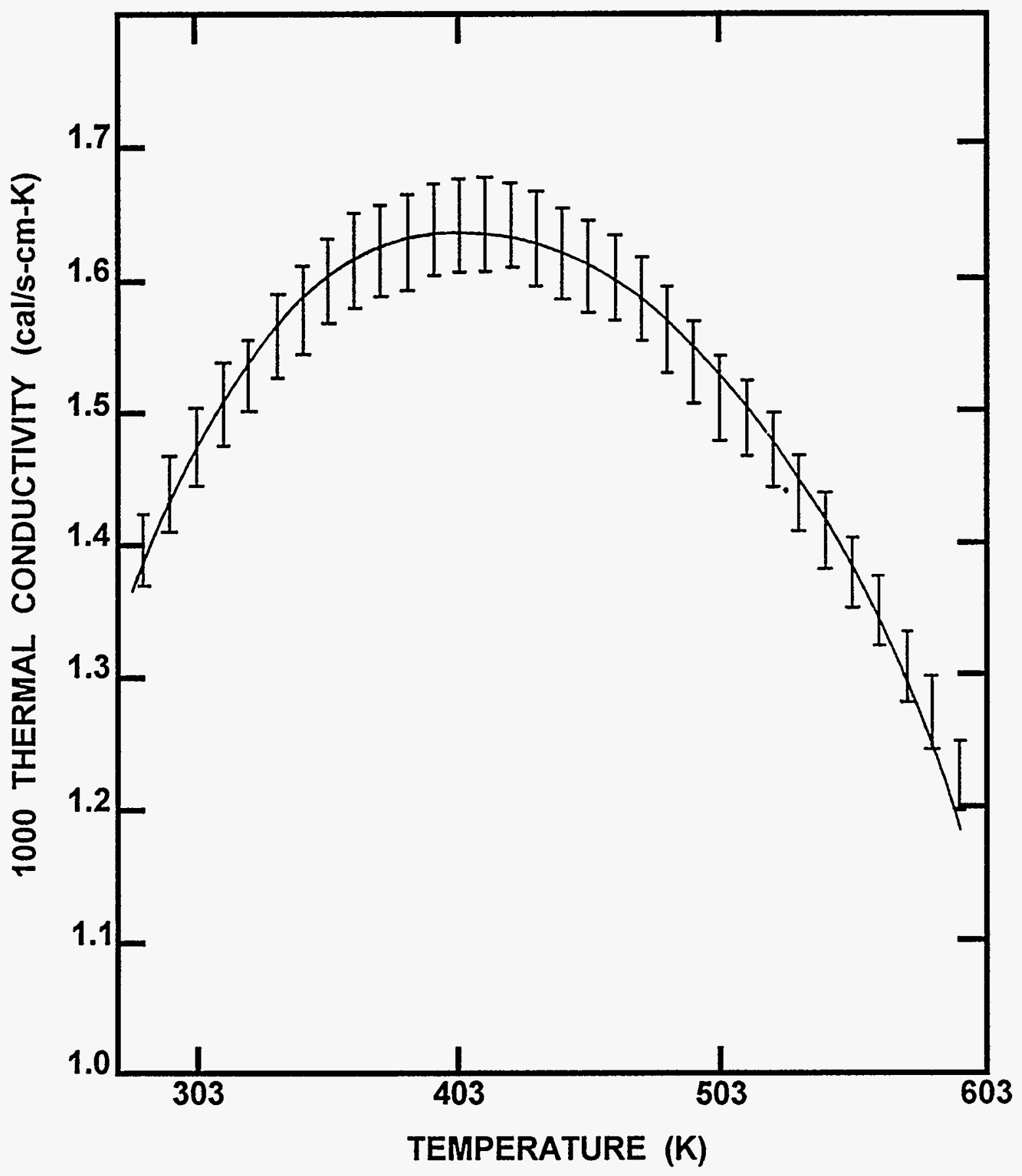

Figure 70. Comparison of the predicted thermal conductivity of water to critically assessed experimental data [223] 
Table 12. Coefficients in the term $\mu_{1}(\bar{T}, \bar{\rho})$ for the viscosity of liquid water

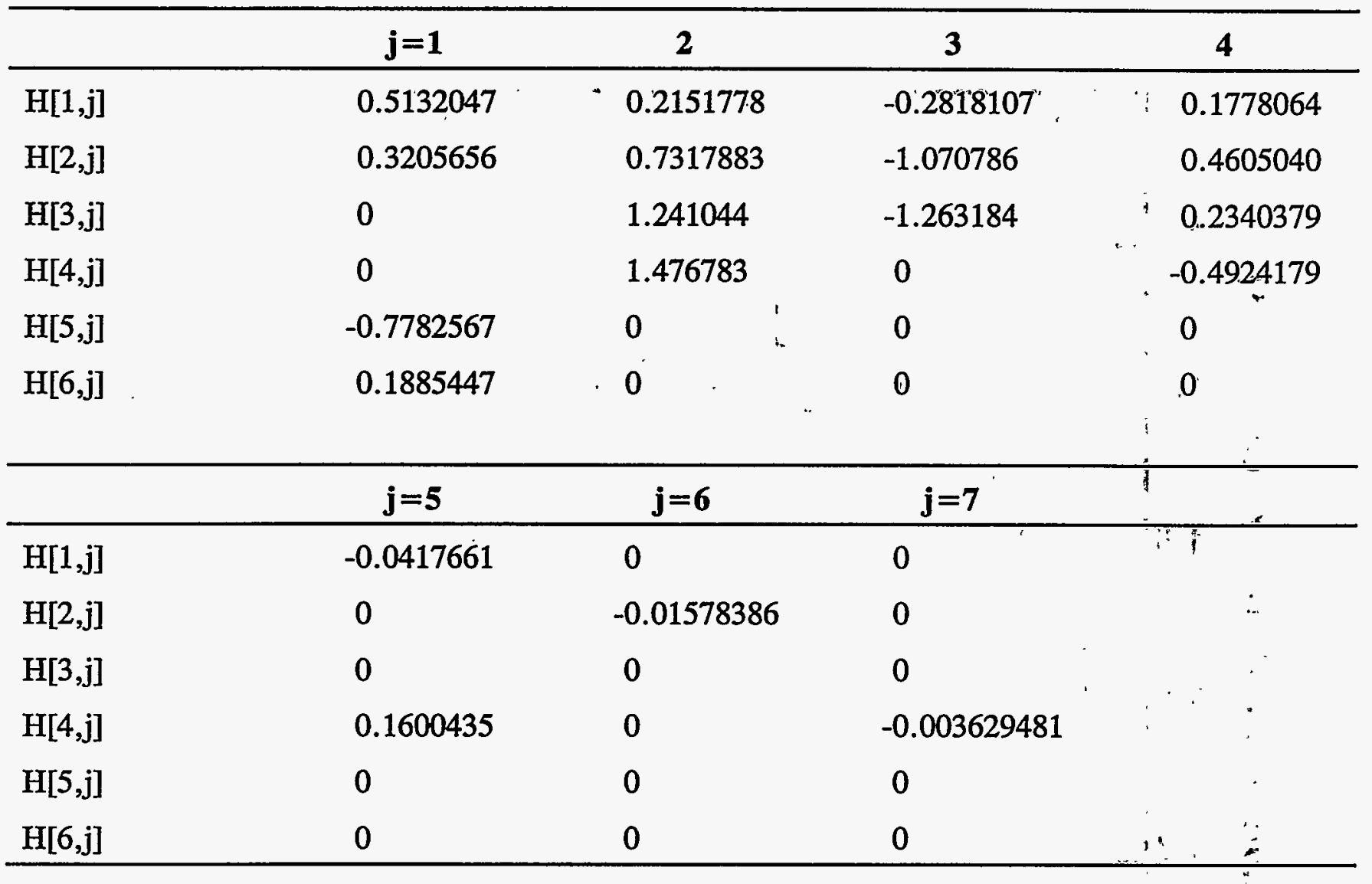

where

$$
\begin{aligned}
\tau & =1-\mathrm{T} / 647.096 \\
\mathrm{C}_{1} & =-2.0315024 \\
\mathrm{C}_{2} & =-2.6830294 \\
\mathrm{C}_{3} & =-5.38626492 \\
\mathrm{C}_{4} & =-17.2991605 \\
\mathrm{C}_{5} & =-44.7586581 \\
\mathrm{C}_{6} & =-63.9201063
\end{aligned}
$$

Similarly, the viscosity and thermal conductivity of steam were calculated from correlations used for liquid water substituting the density of steam for the density of water in the formulae described above. 
The calculated viscosities and thermal conductivities are compared to critically evaluated data in Figures 71 and 72 , respectively.

\section{Properties of Permanent Gases}

The gas phase injected into the suppression pool during the in-vessel phases of an accident is assumed to be a mixture of hydrogen and steam. During the ex-vessel stages of an accident, air (assumed here to be a mixture of nitrogen and oxygen) nitrogen, as well as the gaseous products of concrete decomposition, carbon dioxide and carbon monoxide, can contribute to gases injected into the steam suppression pool. Properties of the permanent gases that are of interest, density, viscosity, and thermal conductivity, are calculated from conventional gas kinetic theory as described in the subsections below.

Viscosity

The viscosities of $\mathrm{N}_{2}, \mathrm{CO}, \mathrm{CO}_{2}$ and $\mathrm{O}_{2}$ can be calculated using [294]:

$$
\mu(\mathrm{T})=\frac{5}{16}\left[\frac{\mathrm{MRT}}{\pi}\right]^{1 / 2} \frac{\mathrm{f}(\eta)}{\mathrm{N}_{\mathrm{A}} \sigma^{2}{ }^{(2,2)}}
$$

where

$$
\begin{aligned}
\mathrm{M} & =\text { molecular weight of the gaseous species } \\
\mathrm{R} & =\text { gas constant }=8.31451 \times 10^{7} \mathrm{ergs} / \mathrm{mole}-\mathrm{K} \\
\mathrm{N}_{\mathrm{A}} & =\text { Avogadro's number }=6.0221367 \times 10^{23} \\
\sigma & =\text { collision cross section } \\
\mathrm{f}(\eta) & =1+\frac{3}{196}\left(8 \mathrm{E}^{*}-7\right)^{2} \\
\Omega^{(2,2)} & =\text { collision integral } \\
\mathrm{E}^{*} & =1+0.25 \mathrm{~T}^{*} \mathrm{~d} \ln \Omega^{(2,2)} / \mathrm{dT}^{*}
\end{aligned}
$$

The collision integral is found from:

$$
\begin{aligned}
\Omega^{(2,2)} & =\exp \left[0.46641-0.56991 \mathrm{z}+0.19591 \mathrm{z}^{2}-0.03879 \mathrm{z}^{3}+0.00259 \mathrm{z}^{4}\right] \text { for } 1 \leq \mathrm{T}^{*} \leq 10 \\
\mathrm{z} & =\ln \mathrm{T}^{*} \\
\mathrm{~T}^{*} & =\mathrm{kT} / \epsilon
\end{aligned}
$$




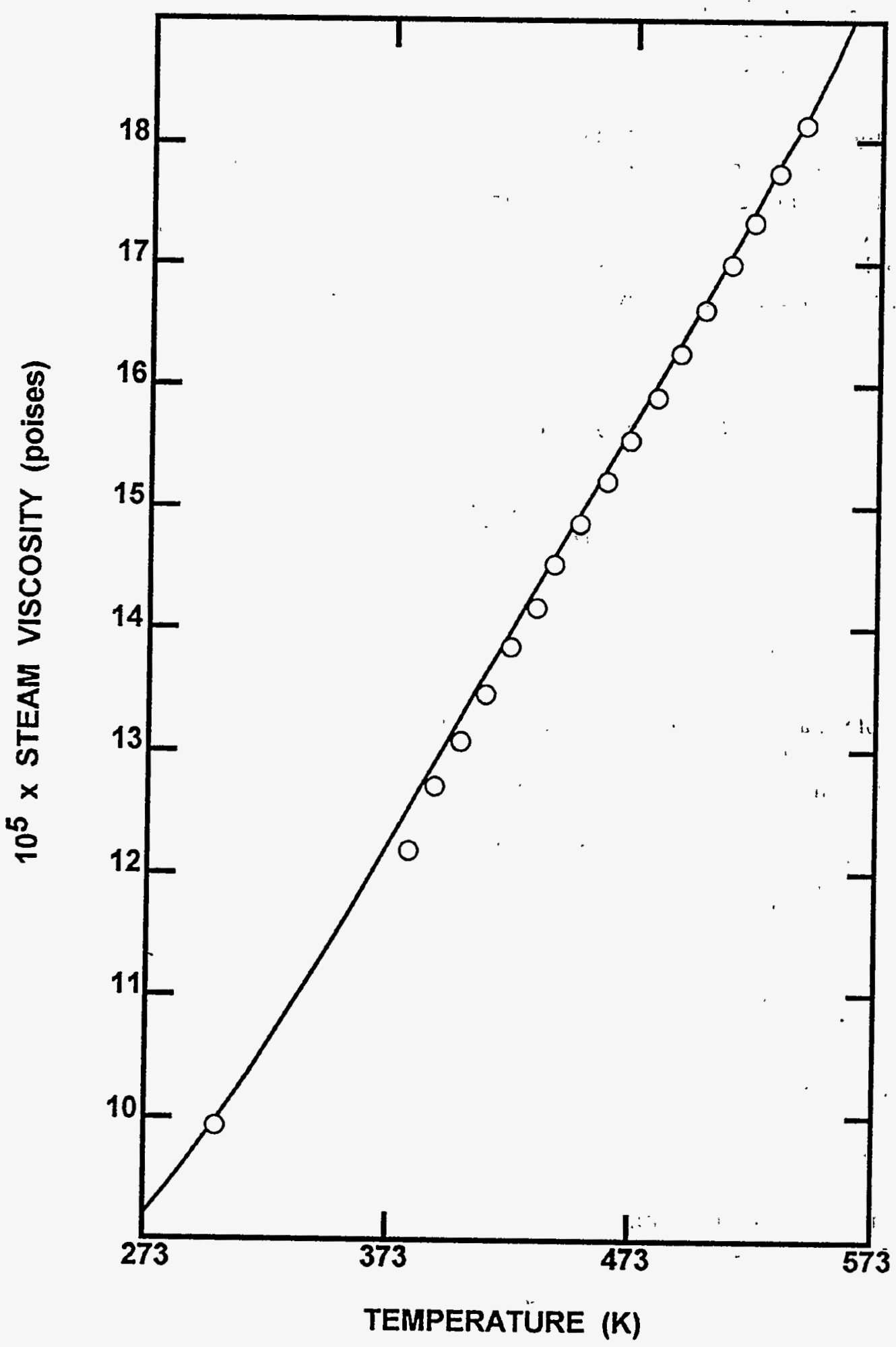

Figure 71. Comparison of calculated steam viscosity to recommended values derived from experimental data [106] 


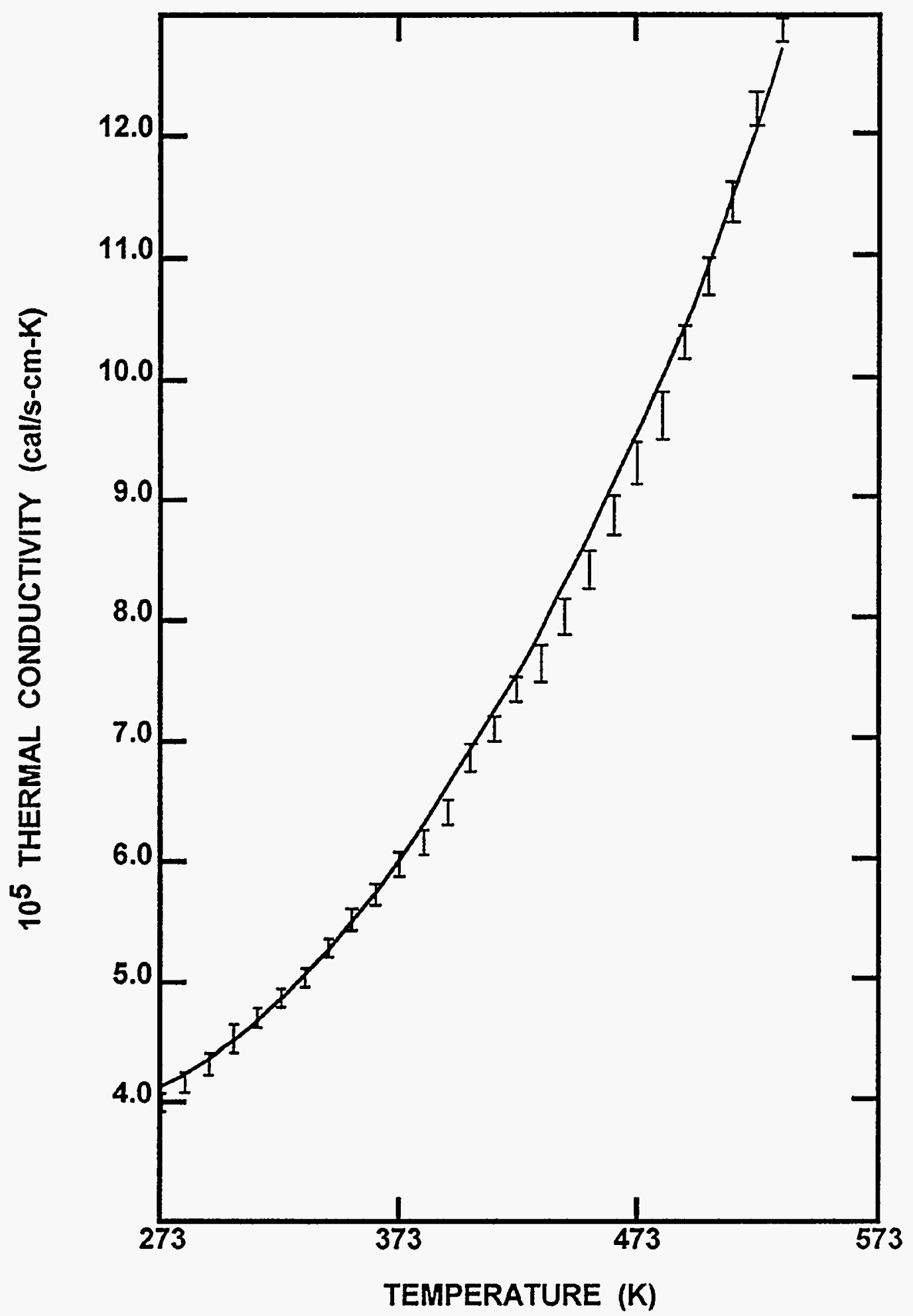

Figure 72. Comparison of calculated thermal conductivity of steam with experimental data [55] 
Physical Phenomena

$$
\begin{aligned}
& \mathrm{k}=\text { Boltzmann's constant }=1.380658 \times 10^{-16} \mathrm{ergs} / \mathrm{K} \\
& \epsilon=\text { energy scaling parameter }
\end{aligned}
$$

At higher temperatures,

where

$$
\Omega^{(2,2)}=\left(\rho^{*}\right)^{2} \alpha\left[1.04+a_{1} / z+a_{2} / z^{2}+a_{3} / z^{3}+a_{4} / z^{4}\right] ; \text { for } \mathrm{T}^{*} \geq 10
$$

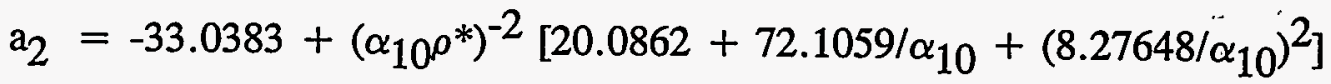

$$
\begin{aligned}
& a_{3}=101.571-\left(\alpha_{10^{\rho *}}\right)^{-2}\left[56.4472+286.393 / \alpha_{10}+\left(17.7610 / \alpha_{10}\right)^{2}\right] \\
& \mathrm{a}_{4}=-87.7036+\left(\alpha_{10^{\rho}}\right)^{-2}\left[46.3130+277.146 / \alpha_{10}+\left(19.0573 / \alpha_{10}\right)^{2}\right] \\
& \alpha_{10}=\ln \left(\mathrm{V}_{\mathrm{o}} * / 10\right) \\
& \rho^{*}=\rho / \sigma \\
& \mathrm{V}_{\mathrm{o}} *=\mathrm{V}_{\mathrm{o}} / \epsilon
\end{aligned}
$$

6

$\because$

The various parameter values used in the theoretical expressions are listed in Table 13. The calculated viscosities are compared to experimental data in Figure 73.

The viscosity of hydrogen was correlated using recommended values $[103,106]$ to the expression

$$
\mu(\mathrm{g} / \mathrm{cm}-\mathrm{s})=10^{-6}\left\{20.9161+248.797 \xi-83.6226 \xi^{2}+\ddot{19} .551 \xi^{3}\right\}
$$

where $\xi=\mathrm{T}(\mathrm{K}) / 1000$. The recommended values of the viscosity. of hydrogen and predictions from the regression equation are shown in Figure 74.

\section{Viscosities of Gaseous Mixtures}

The viscosities of gaseous mixtures can be estimated from the Herning-Zipperer equation [289]:

$$
\mu(\operatorname{mix})=\sum_{i=1}^{N} \mu(\mathrm{i}) \mathrm{x}(\mathrm{i}) \mathrm{M}(\mathrm{i})^{1 / 2} / \sum_{\mathrm{i}=1}^{\mathrm{N}} \mathrm{x}(\mathrm{i}) \mathrm{M}(\mathrm{i})^{1 / 2}
$$

where

$$
\mu(\mathrm{i})=\text { viscosity of the pure, } \mathrm{i}^{\text {th }} \text { constituent }
$$


Table 13. Parameter values for calculation of gas properties

\begin{tabular}{llllll}
\hline & \multicolumn{1}{c}{$\mathrm{N}_{2}$} & \multicolumn{1}{c}{$\mathrm{O}_{2}$} & \multicolumn{1}{c}{$\mathrm{CO}$} & \multicolumn{1}{c}{$\mathrm{CO}_{2}$} & $\mathrm{H}_{2}$ \\
\hline $\mathrm{M}(\mathrm{g} / \mathrm{mole})$ & 28.0135 & 31.9988 & 28.010 & 44.010 & \\
$\sigma(\mathrm{cm})$ & $3.652 \times 10^{-8}$ & $3.407 \times 10^{-8}$ & $3.652 \times 10^{-8}$ & $3.769 \times 10^{-8}$ & \\
$\epsilon / \mathrm{k}(\mathrm{K})$ & 98.4 & 121.1 & 98.4 & 245.3 & \\
$\rho^{*}$ & 0.1080 & 0.0745 & 0.1080 & 0.0720 & \\
$\mathrm{~V}_{\mathrm{o}}{ }^{*}$ & $5.308 \times 10^{4}$ & $1.322 \times 10^{6}$ & $5.308 \times 10^{4}$ & $2.800 \times 10^{6}$ & \\
$\mathrm{C}_{6}{ }^{*}$ & 2.18 & 2.27 & 2.63 & 1.86 & \\
$\mathrm{a}(\mathrm{cal} / \mathrm{mole}-\mathrm{K})$ & 6.37936 & 7.27376 & 6.54038 & 10.6120 & 6.12942 \\
$\mathrm{~b}\left(\mathrm{cal} / \mathrm{mole}-\mathrm{K}^{2}\right)$ & $1.66422 \times 10^{-3}$ & $1.17309 \times 10^{-3}$ & $1.61207 \times 10^{-3}$ & $2.96216 \times 10^{-3}$ & $1.22008 \times 10^{-3}$ \\
$\mathrm{c}\left(\mathrm{cal} / \mathrm{mole}-\mathrm{K}^{3}\right)$ & $-2.76494 \times 10^{-7}$ & $-1.38817 \times 10^{-7}$ & $-2.7182 \times 10^{-7}$ & $-5.03906 \times 10^{-7}$ & $-1.0301 \times 10^{-7}$ \\
$\mathrm{~d}\left(\mathrm{cal}-\mathrm{K} / \mathrm{mole}^{2}\right)$ & 0.0614977 & -0.589293 & -0.0766475 & -2.43100 & 0.410398 \\
\hline
\end{tabular}

$$
\begin{aligned}
x(i) & =\text { mole fraction of the } i^{\text {th }} \text { constituent } \\
M(i) & =\text { molecular weight of the } i^{\text {th }} \text { constituent } \\
N & =\text { number of constituents. }
\end{aligned}
$$

\section{Heat Capacities}

Heat capacities of the gases $\mathrm{H}_{2}, \mathrm{~N}_{2}, \mathrm{O}_{2}, \mathrm{CO}$, and $\mathrm{CO}_{2}$ were evaluated at the ideal gas limit. Data from the JANAF Tables $[104,105]$ were correlated with temperature using the expression

$$
C_{p}=a+b T+c T^{2}+d \times 10^{5} / T^{2}
$$

using nonlinear least-squares methods. Derived parameter values are listed in Table 13. In the ideal gas limit, the constant volume heat capacity is related to the constant pressure heat capacity by:

$$
C_{p}=C_{v}+R
$$

where $\mathrm{R}$ is the gas constant. 


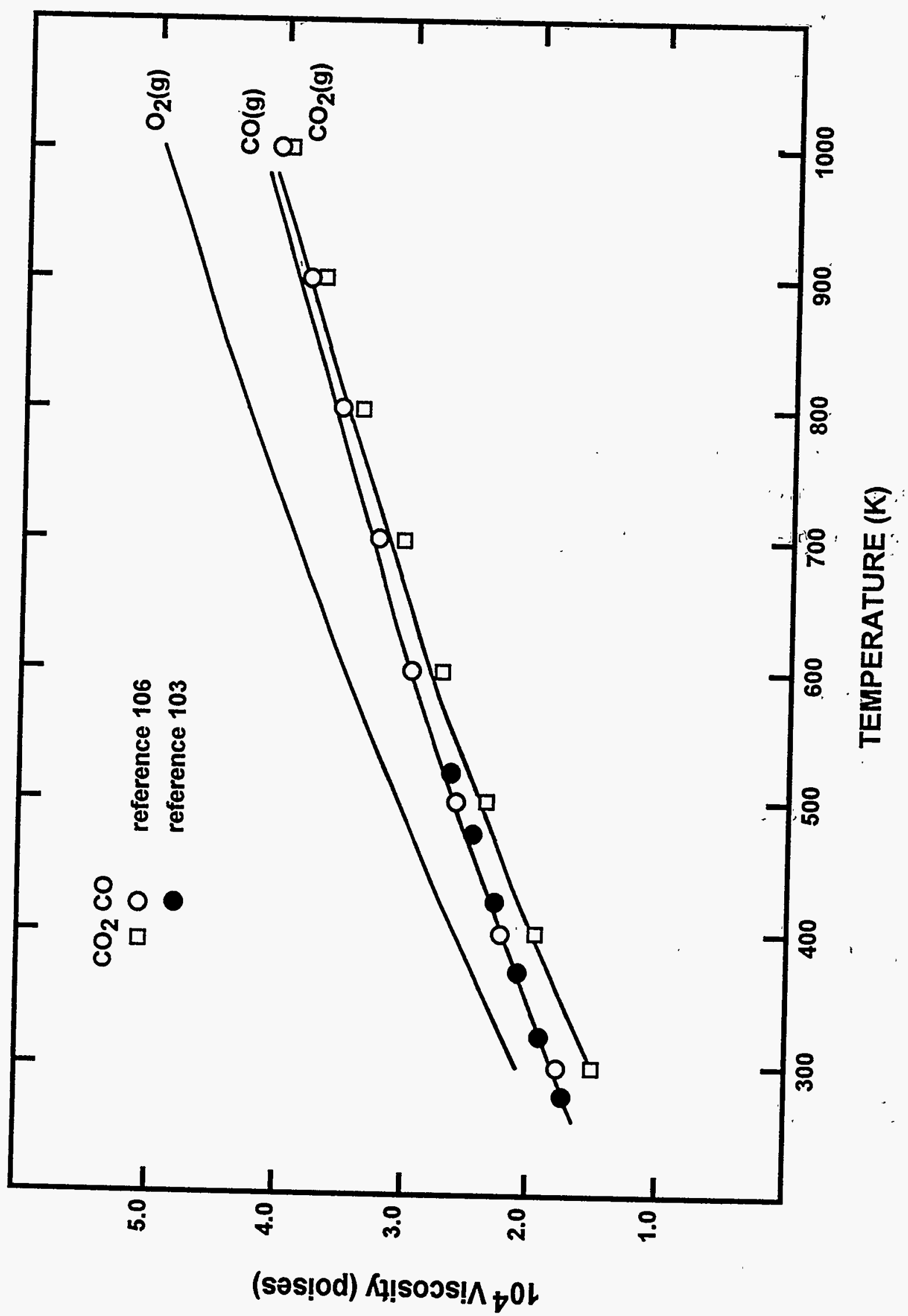

రీ 


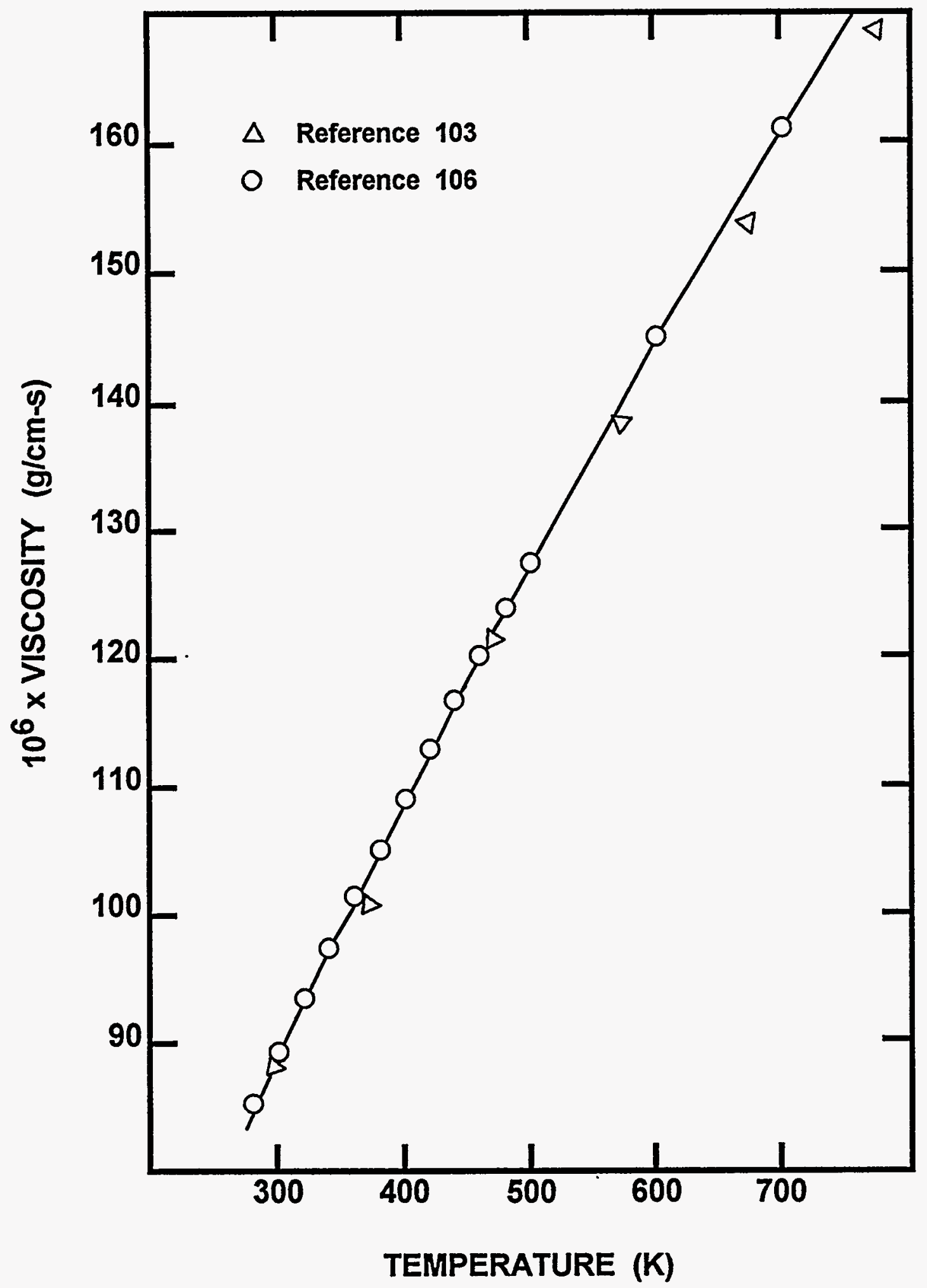

Figure 74. Viscosity of hydrogen as a function of temperature. Solid line calculated from the regression equation described is in the text. 


\section{Gaseous Diffusion Coefficients}

Molecular mechanics and gas kinetic theory give rise to elaborate theoretical expressions for binary diffusion coefficients. Theory is best developed for gases that are not polar and do not have internal structure. Unfortunately, the polarity of $\mathrm{H}_{2} \mathrm{O}$ poses a challenge to completely the thetetical expressions for binary diffusion coefficients. Reid, Prausnitz and Poling [127], find the accuracy of theoretical models to be erratic. These authors recommend an empirical formulation by Fuller et al. [128,129]:

$$
\bigoplus_{A B}=\frac{0.00143 \mathrm{~T}^{1.75}}{\mathrm{P}_{\mathrm{AB}}^{1 / 2}\left[\mathrm{~V}_{\mathrm{D}}(\mathrm{A})^{1 / 3}+\mathrm{V}_{\mathrm{D}}(\mathrm{B})^{1 / 3}\right]^{2}} \mathrm{~cm}^{2} / \mathrm{s}
$$

where

$$
\begin{aligned}
& \mathrm{M}_{\mathrm{AB}}=2 /[1 / \mathrm{M}(\mathrm{A})+1 / \mathrm{M}(\mathrm{B})], \text { and } \\
& \mathrm{V}_{\mathrm{D}}(\mathrm{i})=\text { diffusion volume (listed in Table 14) }
\end{aligned}
$$

Other studies [131-135] have supported use of this formulation or one by Wilke and Lee [130]:

$$
\boxplus_{A B}=\frac{0.001\left[3.03-\left(0.98 / \mathrm{M}_{A B}^{1 / 2}\right)\right] \mathrm{T}^{3 / 2}}{\mathrm{P} \mathrm{M}_{\mathrm{AB}}^{1 / 2} \sigma_{\mathrm{AB}}^{2} \mathrm{\Omega}_{\mathrm{D}}}
$$

where

$$
\begin{aligned}
\sigma_{\mathrm{AB}} & =1 / 2\left(\sigma_{\mathrm{A}}+\sigma_{\mathrm{B}}\right) \\
\Omega_{\mathrm{D}} & =\text { collision integral }
\end{aligned}
$$

The collision integral, $\Omega_{\mathrm{D}}$, is given by [136]:

$$
\Omega_{D}=\frac{A}{\left(T^{*}\right)^{B}}+\frac{C}{\exp \left(\mathrm{DT}^{*}\right)}+\frac{E}{\exp \left(\mathrm{FT}^{*}\right)}+\frac{\mathrm{G}^{*}}{\exp \left(\mathrm{HT} \mathrm{T}^{*}\right)}
$$

where
$\mathrm{A}=1.06036$
$\mathrm{B}=0.15610$
$\mathrm{C}=0.193$
$\mathrm{D}=0.47635$ 
Table 14. Parameter values for calculating the binary diffusion coefficients of gases

\begin{tabular}{|c|c|c|c|c|c|}
\hline Gas & $\begin{array}{c}\text { M(i) } \\
\text { (g/mole) }\end{array}$ & $\begin{array}{c}\mathrm{V} \\
\left(\mathrm{cm}^{3} / \mathrm{mole}\right)^{(\mathbf{i})}\end{array}$ & $\begin{array}{c}\sigma(\mathbf{i}) \\
\left(\mathbf{A}^{\circ}\right)^{*}\end{array}$ & $\begin{array}{l}\epsilon(\mathbf{i}) / \mathbf{k} \\
(\mathbf{K})^{*}\end{array}$ & $\underset{\left(\mathrm{cm}^{3} / \mathbf{m o l e}^{\mathbf{V}}\right.}{\mathbf{V}} \mathbf{A}^{(\mathbf{i})}$ \\
\hline $\mathrm{H}_{2}$ & 2.01594 & 6.12 & 2.827 & 59.7 & 28.5 \\
\hline $\mathrm{H}_{2} \mathrm{O}$ & 18.01534 & 13.1 & 2.641 & 809.1 & 18.7 \\
\hline $\mathrm{N}_{2}$ & 28.0134 & 18.5 & 3.798 & 71.4 & 34.7 \\
\hline $\mathrm{O}_{2}$ & 31.9988 & 16.3 & 3.467 & 106.7 & 27.9 \\
\hline $\mathrm{CO}$ & 28.01050 & 18.0 & 3.690 & 91.7 & \\
\hline $\mathrm{CO}_{2}$ & 44.0099 & 26.9 & 3.941 & 195.2 & 37.3 \\
\hline & & & & & \\
\hline
\end{tabular}

$$
\begin{aligned}
& E=1.03587 \\
& F=1.52996 \\
& G=1.76474 \\
& H=3.89411
\end{aligned}
$$

Perhaps the most important binary, gaseous diffusion couple of interest here is the $\mathrm{H}_{2} / \mathrm{H}_{2} \mathrm{O}$ mixture. Predictions of the binary diffusion coefficient in this system obtained from the two empirical correlations are compared to data [223] in Table 15 . The correlation by Fuller et al. usually yields values somewhat higher than those observed whereas the correlation by Wilke and Lee yields values that are consistently low in comparison to the data. Modifications of the correlations to account for the dipole moment of $\mathrm{H}_{2} \mathrm{O}$ and the polarizability of $\mathrm{H}_{2}$ do not greatly improve the agreement between predictions and the observations.

The predicted diffusion coefficients of steam in $\mathrm{H}_{2}, \mathrm{~N}_{2}$, and $\mathrm{CO}_{2}$ at 1 atms predicted with the correlations are shown in Figure $\mathbf{7 5}$ as functions of temperature. 
Table 15. Comparison of predicted and observed binary diffusion coefficientsi in the $\mathrm{H}_{2} / \mathrm{H}_{2} \mathrm{O}$ system

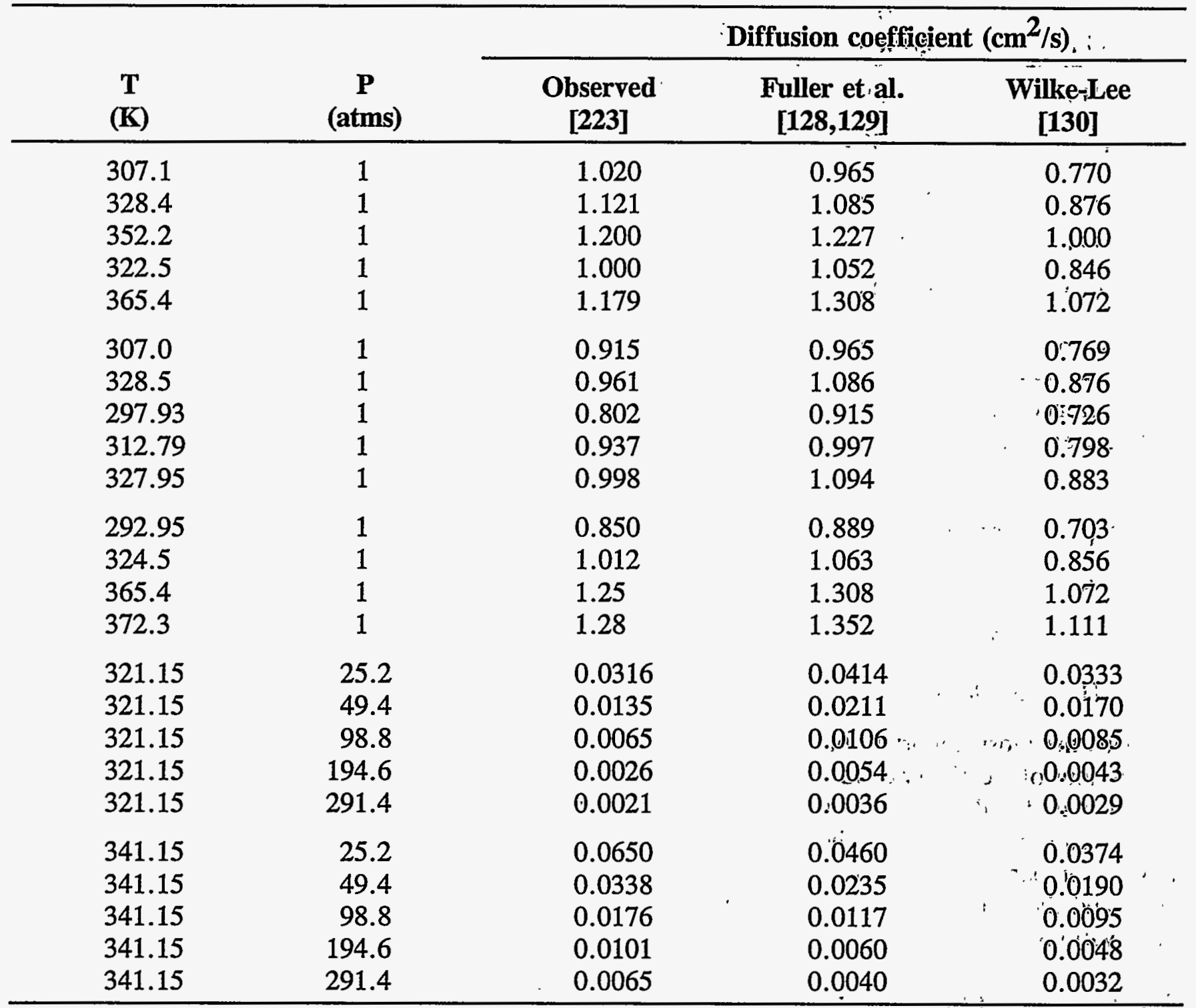




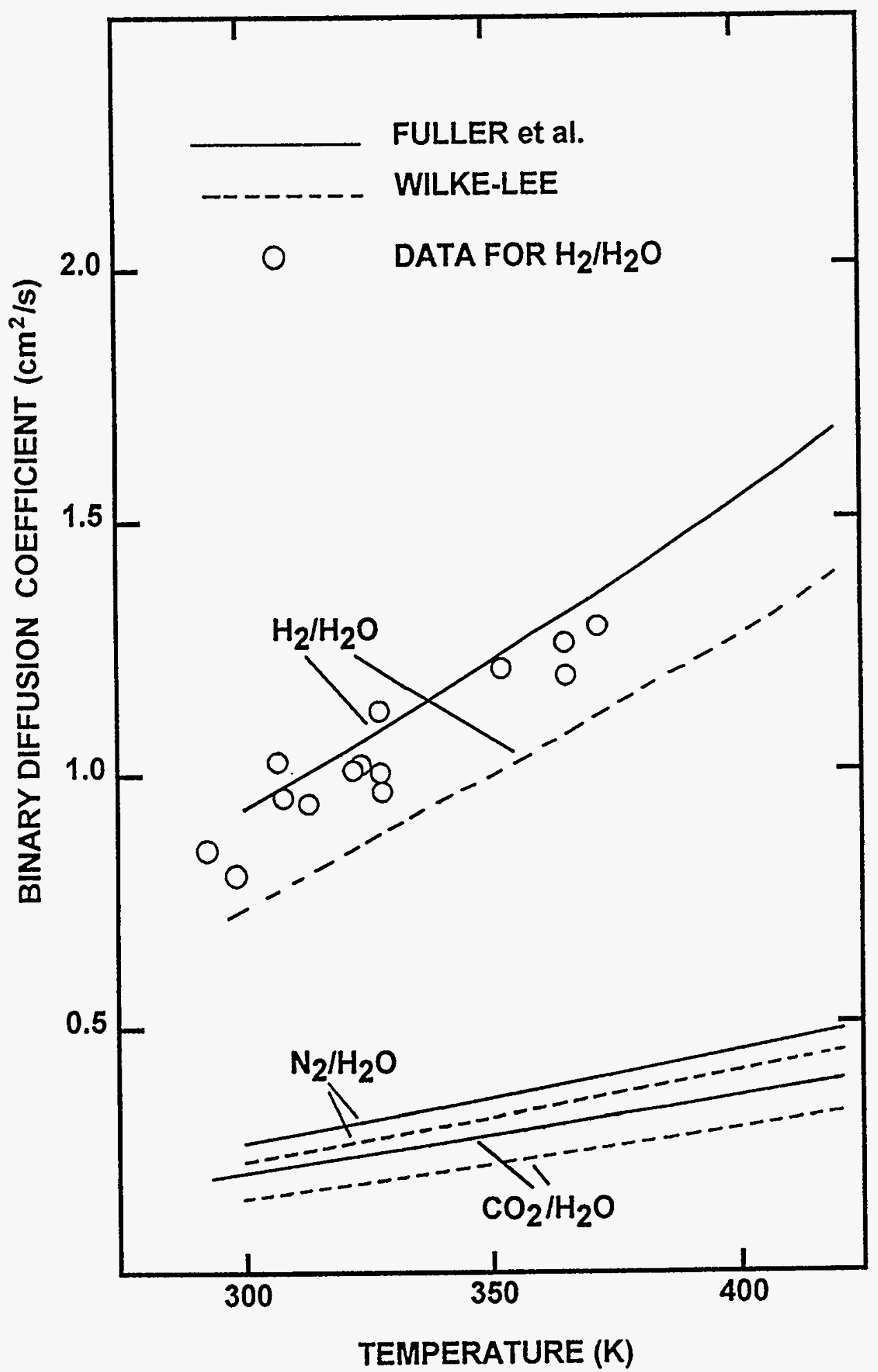

Figure 75. Predicted binary, gaseous diffusion coefficients for the $\mathrm{H}_{2} / \mathrm{H}_{2} \mathrm{O}, \mathrm{N}_{2} / \mathrm{H}_{2} \mathrm{O}$, and $\mathrm{CO}_{2} / \mathrm{H}_{2} \mathrm{O}$ systems 


\section{Thermal Conductivity}

Uribe et al. [107] have developed elaborate theoretical expressions for the thermal conductivities of the gases $\mathrm{N}_{2}, \mathrm{O}_{2}, \mathrm{CO}$, and $\mathrm{CO}_{2}$ in the limit of zero density. These theoretical models allow contributions from the molecular translations, rotations, and vibrations as well as electronic states to be separiately determined. Such models appear overly sophisticated for the purposes of this work. Consequently, results obtained by Uribe et al. were simply used to fit a simple polynomial expression:

$$
\mathrm{k}_{\mathrm{th}}\left(\frac{\mathrm{cal}}{\mathrm{cm}-\mathrm{s}-\mathrm{K}}\right)=\frac{10^{-2}}{4.184}\left[\mathrm{~L}_{0}+\mathrm{L}_{1} \mathrm{~T}+\mathrm{L}_{2} \mathrm{~T}^{2} / 1000+\mathrm{L}_{3} \mathrm{~T}^{3} / 10^{6}\right]
$$

using nonlinear least-squares methods. Parameters determined in this way are shown in Table 16. Predictions obtained with the regression equations are compared to experimental data in Figures $7 ; 6$ through 80. A similar expression for the temperature-dependence of the thermal conductivity of hydrogeniwas found by fitting the above expression to recommended values of the thermal conductivity [103].

The thermal conductivity of mixtures can be estimated from the thermal conductivities of individual gases using an expression recommended by Mason and Saxena [120]:

$$
\begin{aligned}
\mathrm{k}_{\mathrm{th}}(\operatorname{mix}) & =\sum_{\mathrm{i}=1}^{\mathrm{n}}\left\{\mathrm{k}_{\mathrm{th}}(\mathrm{i}) /\left[1+\sum_{\mathrm{j} \neq \mathrm{i}}^{\mathrm{n}} \phi(\mathrm{i}, \mathrm{j}) \mathrm{x}(\mathrm{j}) / \mathrm{x}(\mathrm{i})\right]\right\} \\
\phi(\mathrm{i}, \mathrm{j}) & =\frac{\mathrm{C}}{2 \sqrt{2}} \frac{\left[1+\left(\frac{\mathrm{k}_{\mathrm{th}}(\mathrm{i})}{\mathrm{k}_{\mathrm{th}}(\mathrm{j})}\right)^{1 / 2}\left(\frac{\mathrm{M}(\mathrm{i})}{\mathrm{M}(\mathrm{j})}\right)^{1 / 4}\right]^{2}}{\left[1+\frac{\mathrm{M}(\mathrm{i})}{\mathrm{M}(\mathrm{j})}\right]^{1 / 2}}
\end{aligned}
$$

where

$$
\begin{aligned}
\mathrm{k}_{\mathrm{th}}(\mathrm{mix}) & =\text { thermal conductivity of the mixture, } \\
\mathrm{k}_{\mathrm{th}}(\mathrm{i}, \mathrm{j}) & =\text { thermal conductivity of the } \mathrm{i}^{\text {th }} \text { constituent of the mixture, } \\
\mathrm{x}(\mathrm{i}) & =\text { mole fraction of the } \mathrm{i}^{\text {th }} \text { constituent in the mixture, } \\
\mathrm{M}(\mathrm{i}) & =\text { molecular weight of the } \mathrm{i}^{\text {th }} \text { constituent in the mixture, } \\
\mathrm{C} & =\text { constant. }
\end{aligned}
$$


Table 16. Parametric values for correlations of gas thermal conductivities

\begin{tabular}{lllll}
\hline \multicolumn{1}{c}{ Gas } & \multicolumn{1}{c}{$\mathbf{L}_{\mathbf{0}}$} & $\mathbf{L}_{1}$ & $\mathbf{L}_{2}$ & $\mathbf{L}_{3}$ \\
\hline $\mathrm{H}_{2}$ & $1.87 \times 10^{-2}$ & $0.5886 \times 10^{-3}$ & $-0.226342 \times 10^{-3}$ & $7.50673 \times 10^{-6}$ \\
$\mathrm{~N}_{2}$ & $2.78051 \times 10^{-3}$ & $7.89354 \times 10^{-5}$ & $-1.22826 \times 10^{-5}$ & $1.53154 \times 10^{-6}$ \\
$\mathrm{O}_{2}$ & $1.52688 \times 10^{-4}$ & $9.38983 \times 10^{-5}$ & $-1.87753 \times 10^{-5}$ & $2.74421 \times 10^{-6}$ \\
$\mathrm{CO}$ & $1.60784 \times 10^{-3}$ & $8.04387 \times 10^{-5}$ & $-1.22788 \times 10^{-5}$ & $1.43727 \times 10^{-6}$ \\
$\mathrm{CO}_{2}$ & $-1.10485 \times 10^{-2}$ & $9.74176 \times 10^{-5}$ & $-1.72780 \times 10^{-5}$ & $1.77916 \times 10^{-6}$ \\
\hline
\end{tabular}

Mason and Saxena recommend $C=1.065$. Tondon and Saxena [121] recommend $C=0.85$ for mixtures of polar and nonpolar gases.

The predictions obtained from the Saxena and Mason formula for the thermal conductivities of mixtures are compared to data for $\mathrm{H}_{2} / \mathrm{N}_{2}$ [118], $\mathrm{N}_{2} / \mathrm{CO}$ [113] and $\mathrm{N}_{2} / \mathrm{CO}_{2}$ [116] mixtures in Figures 81 and 82 .

\section{Solubility of Gases in Water}

The solubilities of gases in water are conveniently expressed by Henry's law:

$$
\mathrm{P}(\mathrm{i})=\mathrm{H}(\mathrm{i}) \mathrm{x}(\mathrm{i})
$$

where

$P(i)=$ partial pressure (atms) of species $i$ in equilibrium with water,

$x(i)=$ mole fraction of species $\mathrm{i}$ in the mixture with water, and

$H(i)=$ Henry's Law coefficient for species $i$ and water. 


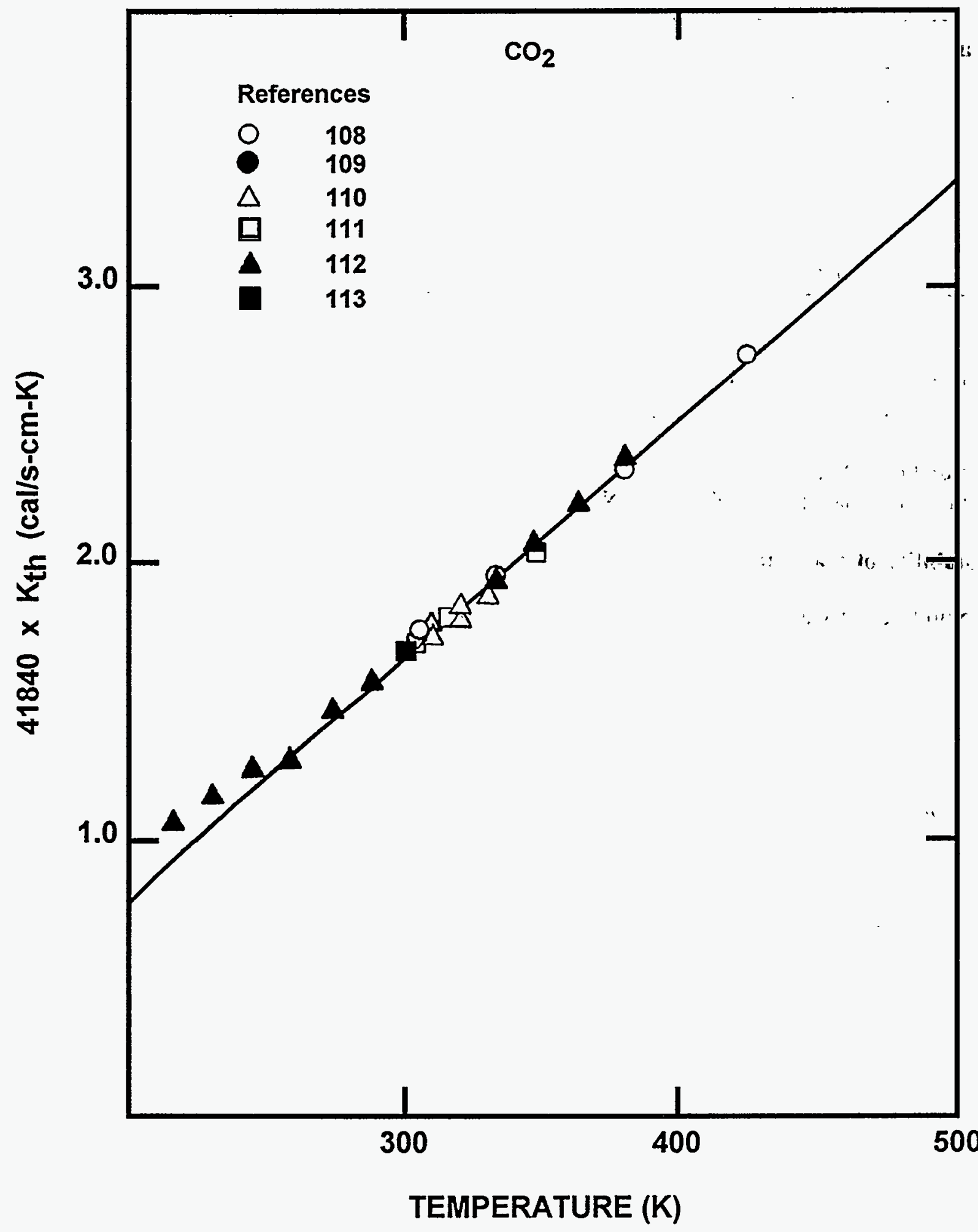

Figure 76. Comparison of the predicted thermal conductivity of $\mathrm{CO}_{2}$ to experimental data [108-113] 


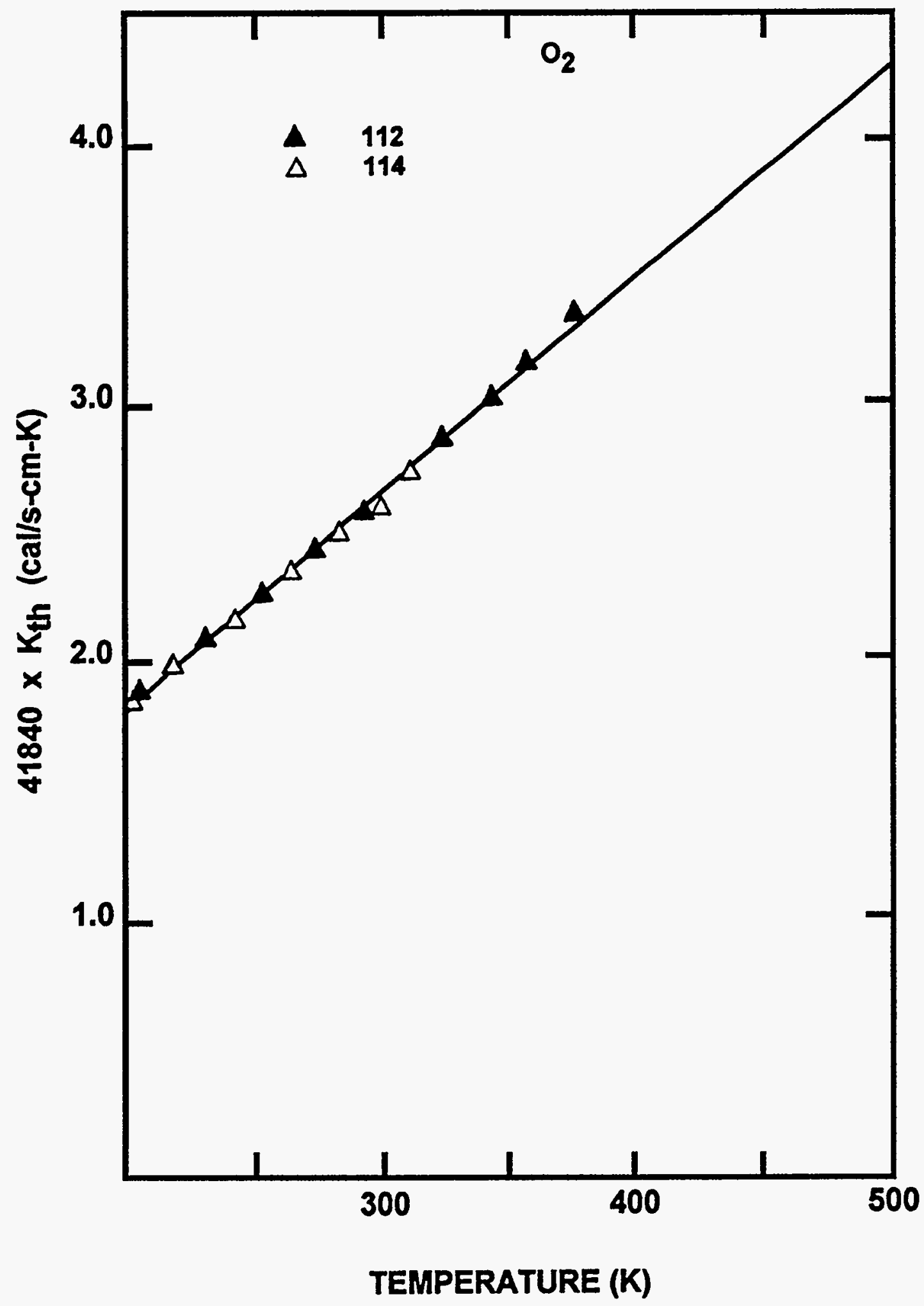

Figure 77. Comparison of the predicted thermal conductivity of $\mathrm{O}_{2}$ to experimental data 
Physical Phenomena

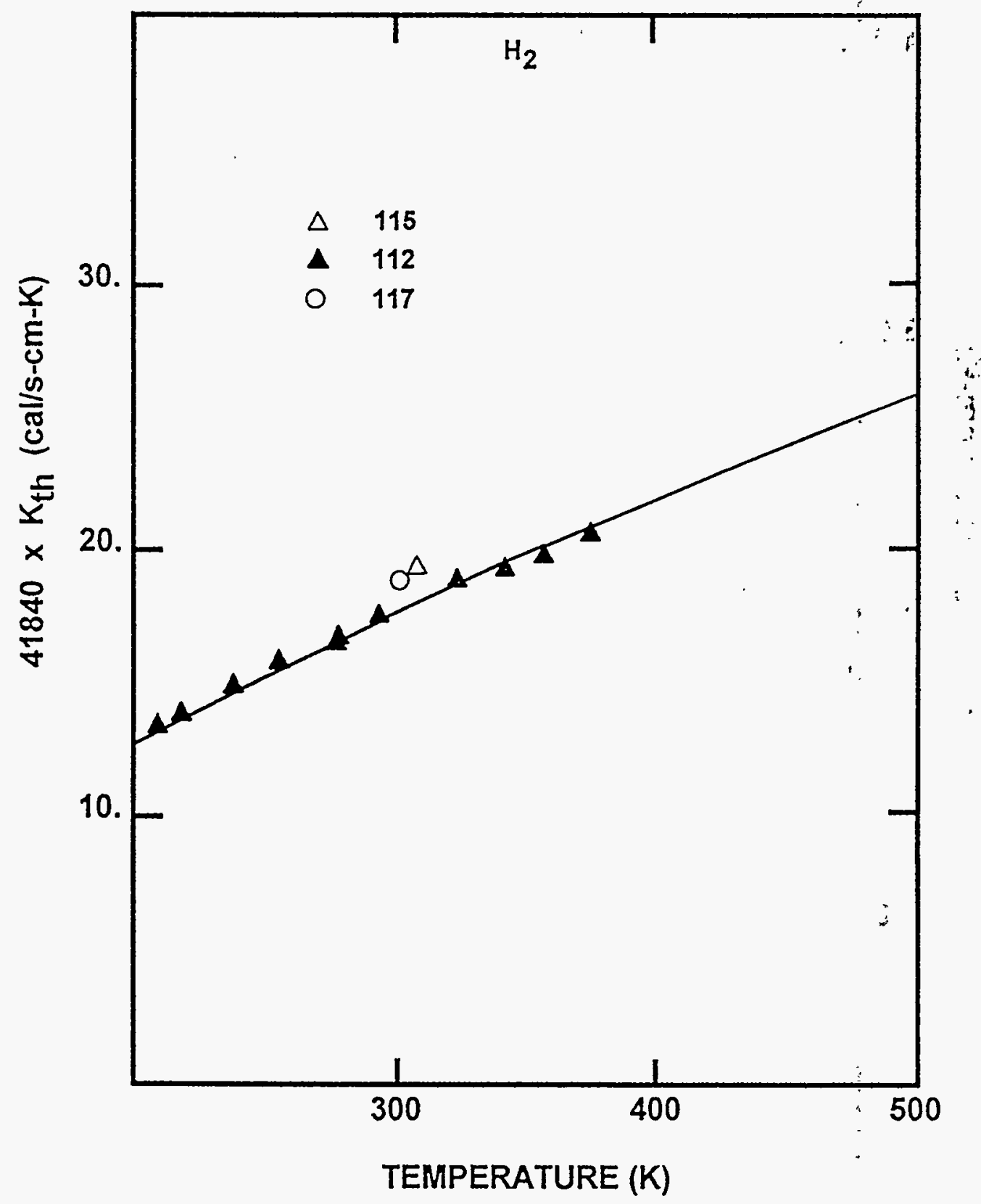

Figure 78. Comparison of the predicted thermal condüctivity of $\mathrm{H}_{2}$ to experimental'data 


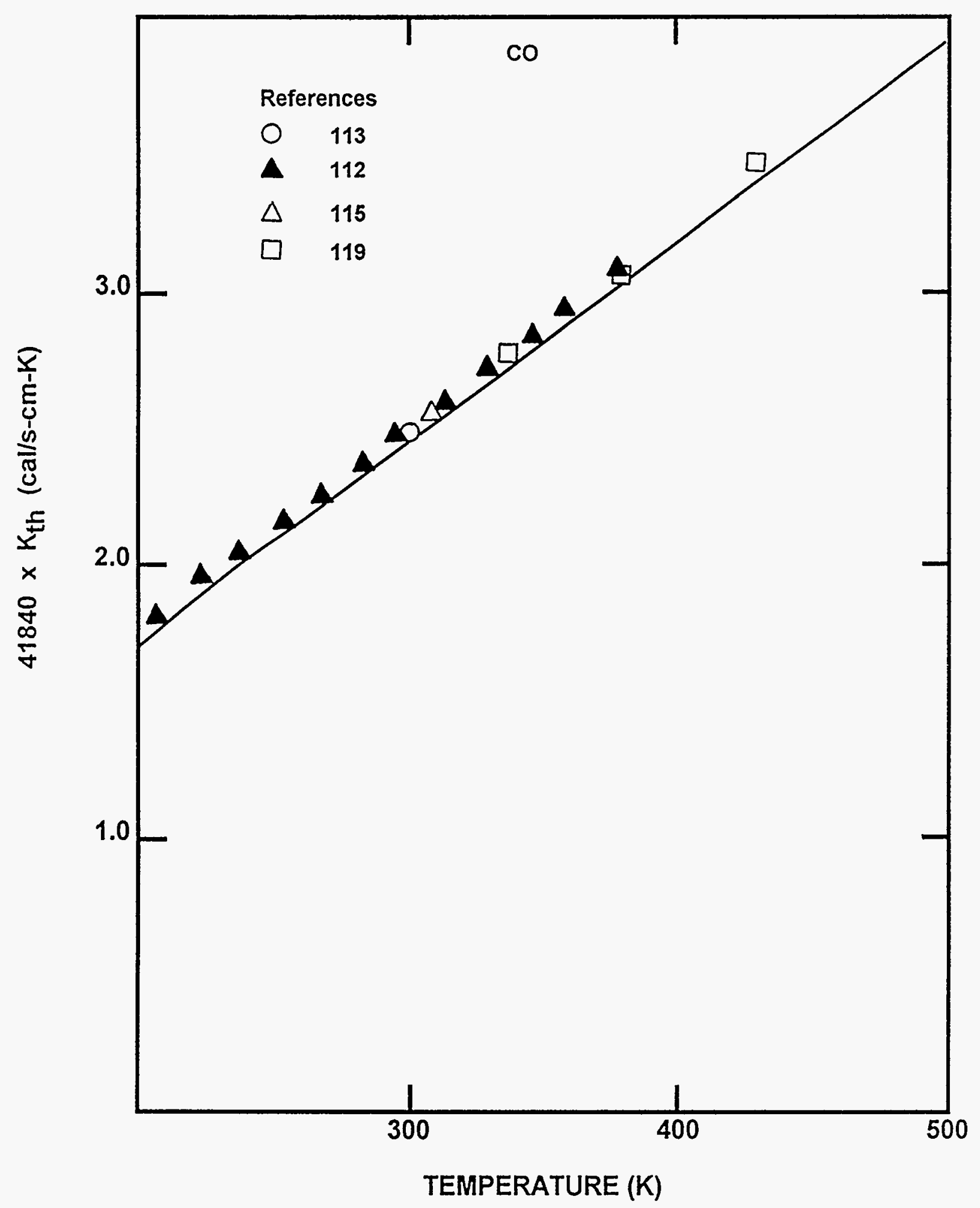

Figure 79. Comparison of the predicted thermal conductivity of $\mathrm{CO}$ to experimental data 


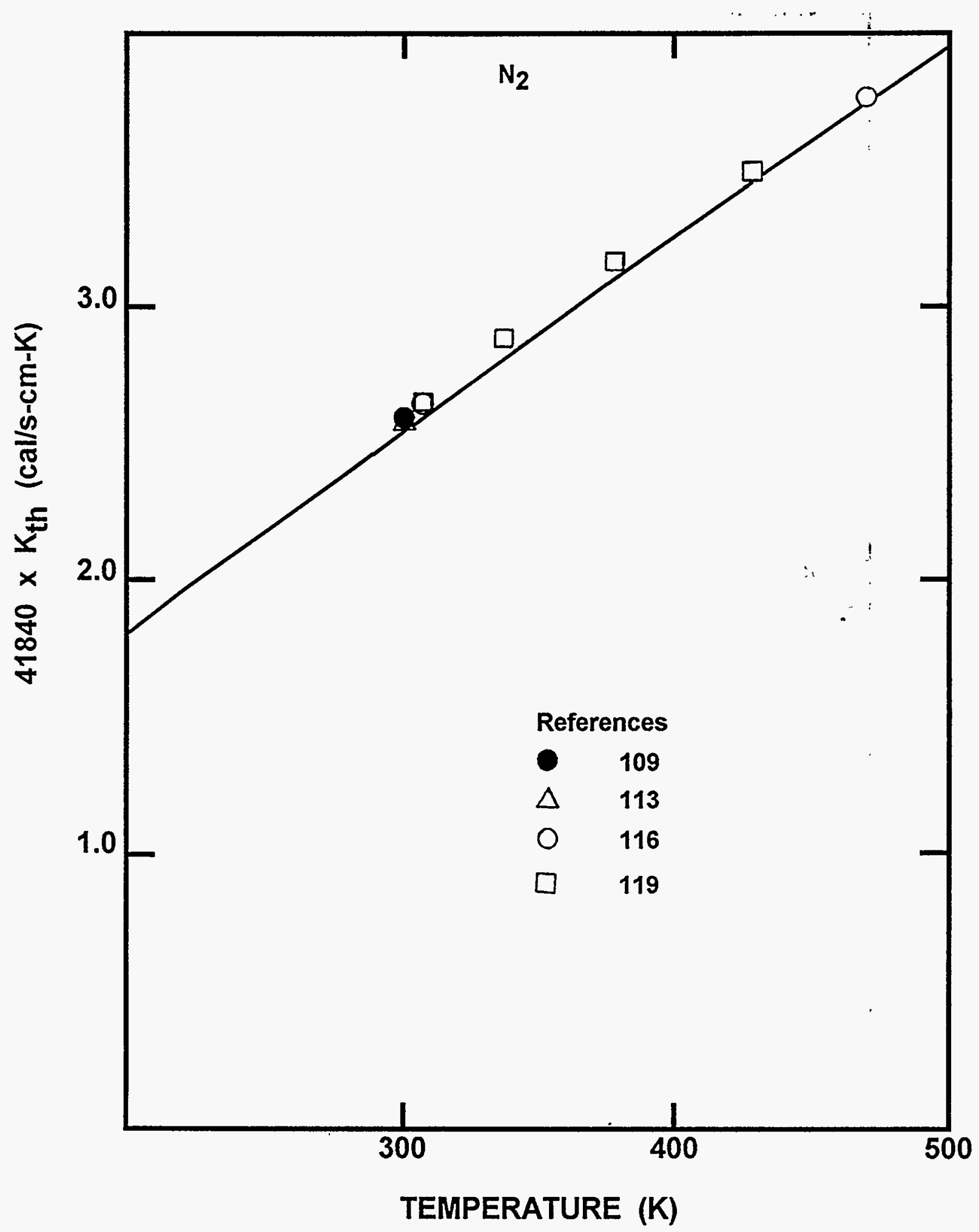

Figure 80. Comparison of the predicted thermal conductivity of $\mathrm{N}_{\mathbf{2}}$ to experimental data 


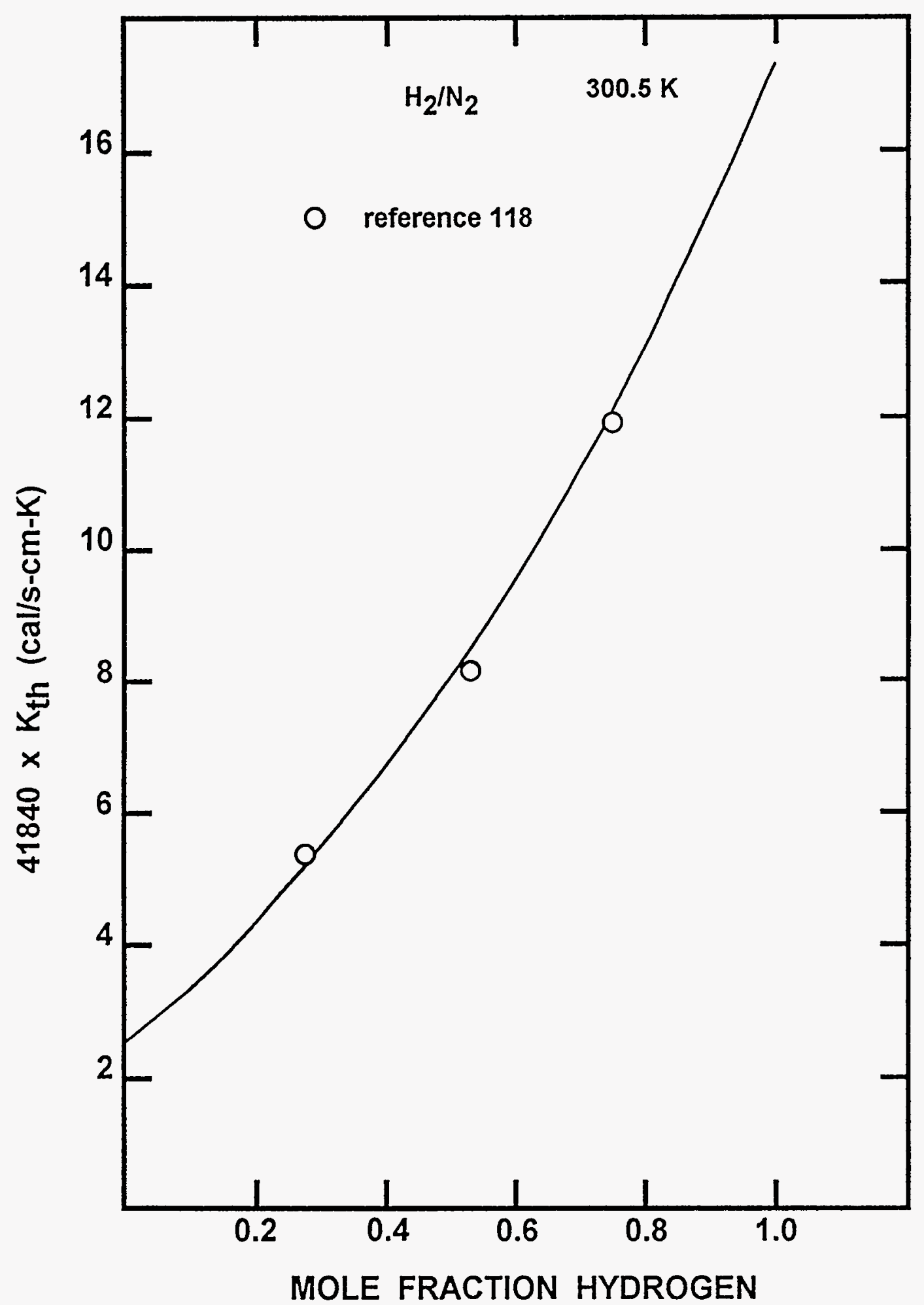

Figure 81. Comparison of the predicted thermal conductivity of $\mathrm{H}_{2} / \mathrm{N}_{2}$ mixtures at $300.5 \mathrm{~K}$ to experimental data 


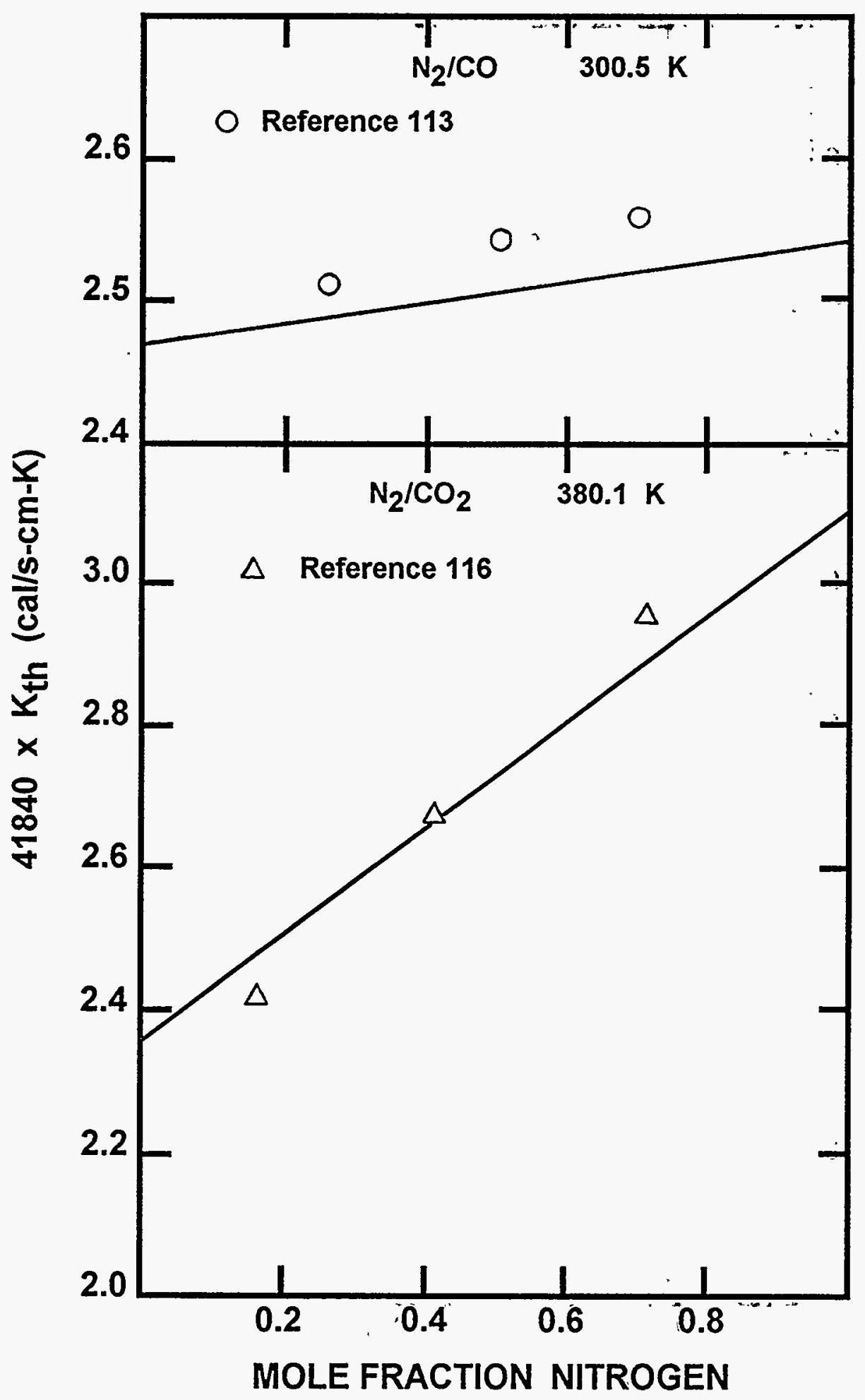

Figure 82. Comparison of the predicted thermal conductivities of, $\mathrm{N}_{2} / \mathrm{CO}$ mixtures at $300.5 \mathrm{~K}$ and $\mathrm{N}_{2} / \mathrm{CO}_{2}$ mixtures at $380.5 \mathrm{~K}$ to experimental data , 
Henry's Law coefficients are functions of temperature. Correlations of these coefficients used here are:

- $\mathrm{CO}[122]$

$\ln \mathrm{H}(\mathrm{CO})=115.22767-152.599953 / \xi-67.8429542 \ln \xi+7.04595359 \xi$

- $\mathrm{CO}_{2}[123]$

$$
\ln \mathrm{H}\left(\mathrm{CO}_{2}\right)=-4.54518+128.17 / \xi-376.68 / \xi^{2}+299.7 / \xi^{3}
$$

- $\mathrm{H}_{2}[124]$

$$
\ln \mathrm{H}\left(\mathrm{H}_{2}\right)=48.1611-55.2845 / \xi-16.8893 \ln \xi
$$

- $\mathrm{O}_{2}[125]$

$$
\ln \mathrm{H}\left(\mathrm{O}_{2}\right)=66.73538-87.47547 / \xi-24.45264 \ln \xi
$$

- $\quad \mathrm{N}_{2}[126]$

$$
\ln \mathrm{H}\left(\mathrm{N}_{2}\right)=67.38765-86.32129 / \xi+24.79808 \ln \xi
$$

where $\xi=T(K) / 100$ and pressure is in atmospheres. Solubilities of gases predicted with these correlations for gas partial pressures of 1 atmosphere are shown in Figure 83. Reliable data only extend up to about the boiling point of water for the gases except $\mathrm{CO}_{2}$. The correlation for the Henry's law coefficient of $\mathrm{CO}_{2}$ listed above can be used for temperature up to about $430 \mathrm{~K}$. Over the temperature range for which there are suitable data, the gas solubility decreases with increasing temperature. This trend must eventually reverse since at the critical point of water the gases become completely miscible with water.

It is evident from the curves shown in Figure 83 that, until the water pool is saturated, diffusiophoresis by soluble gases can contribute to aerosol removal from bubbles in cold water. The effect might be especially important in the late stages of an accident in which $\mathrm{CO}_{2}$ from concrete is an important constituent of gases entering suppression pools. Unlike the case of a water pool overlying core debris interacting with concrete, there are no alternate mechanisms to gas sparging to saturate the pool with $\mathrm{CO}_{2}$. Of course, late in the accident, pool temperatures can be quite high and $\mathrm{CO}_{2}$ solubility low.

\section{K. Properties of Aerosol Particles}

Discussions in the next section of this report will show how the rate of aerosol trapping depends on the properties of aerosol particles. Certainly, the size of aerosol particles will indeed affect rates of trapping. The discussions of aerosol size distributions are included in Chapter V as part of the 


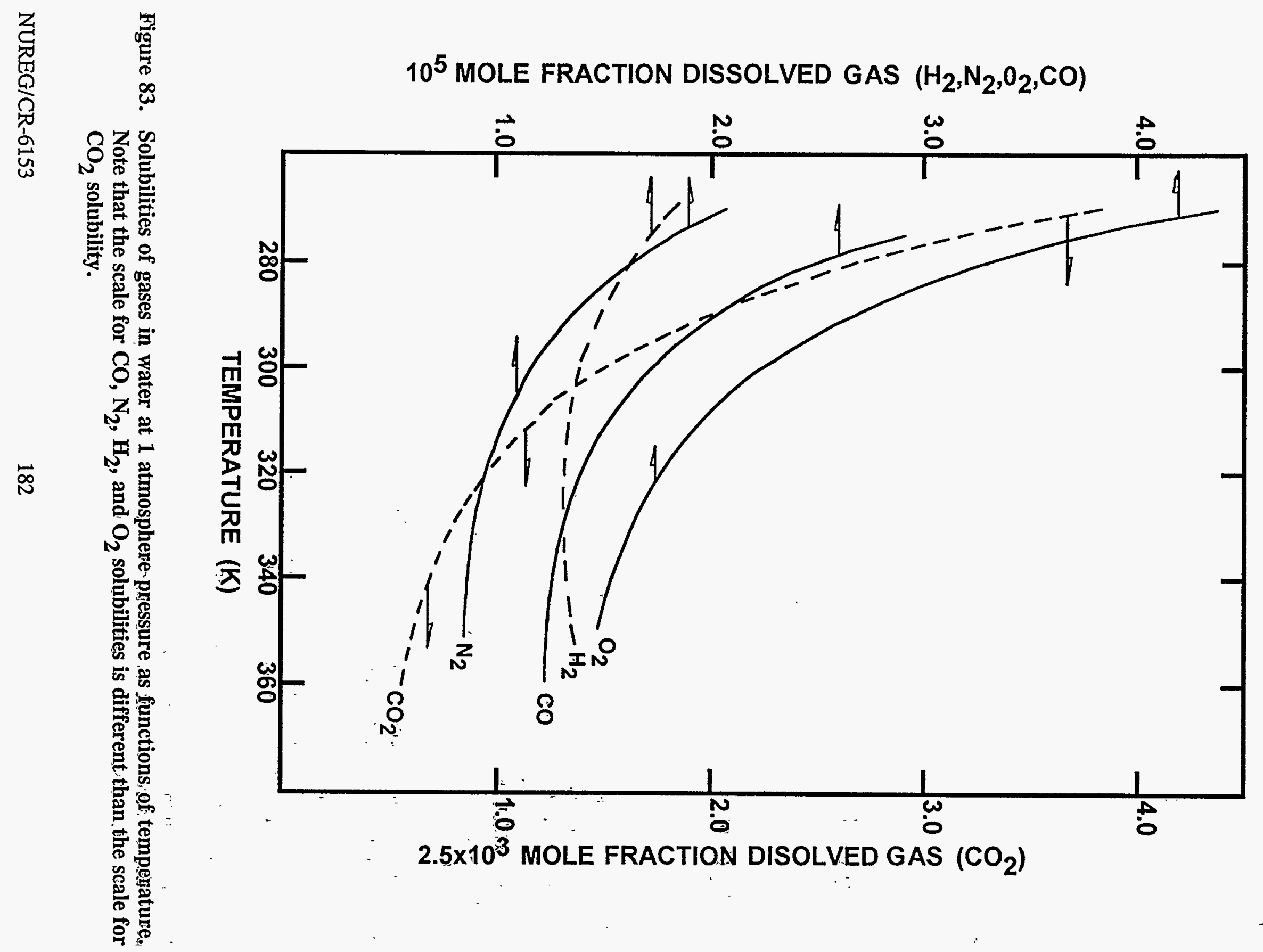


discussion of uncertainties that arise from details of severe accident progression. Similarly, the density of materials that make up the aerosol particles will be discussed in connection with accident progression uncertainties.

In this section, discussions focus on three properties of aerosol particles:

- shape factors,

- slip correction factors, and

- hygroscopicity of aerosols.

\section{Shape Factors}

The equations of aerosol physics are written for spherical aerosol particles. Of course, real aerosol particles are not spheres. To approximately account for nonspherical shapes, shape factors are introduced into the equations. Of most interest here is the dynamic shape factor, $\chi$. Of somewhat less interest is the collision shape factor, $\gamma$. The dynamic shape factor accounts for the increase in the drag on a nonspherical particle. The collision shape factor accounts for the increase in the collisional cross section of a nonspherical particle.

In principle, the deviation of aerosols from spherical shape can be dramatic, especially when primary particles agglomerate to form chains of adhering particles [164]. Very large values of the shape factors occur only when the aerosol is kept dry. For the application of interest here, water will be present in abundance. Adsorption of water onto particle agglomerates will draw particle chains into nearly spherical compacts. Brockmann [164] has suggested that under these conditions, the dynamic shape factor and the collision shape factor are equal and that they are determined by the packing density of the aerosol:

$$
\chi=\gamma=1 / \alpha^{1 / 3}
$$

where $\alpha$ is the effective density of the aerosol particle divided by the density of the material making up the primary particles.

It is likely that voids in compacted particles will be filled with condensed water in the situation of interest here. These voids within the particle can be likened to "ink bottle" pores in solids [174]. That is, the pores have entrances that are narrower than the body of the pore. The prototype pore is one formed by the close packing of four spheres to form a tetrahedron. The approximate diameter of the pore body is:

$$
(\sqrt{3}-1) d_{p} \cong 0.73 d_{p}
$$

where $d_{p}$ is the diameter of a sphere. The entrance to the pore, however, has a diameter of only: 
Physical Phenomena

$$
\mathrm{d}_{\mathrm{p}}(2-\sqrt{3}) / \sqrt{3}=0.15 \mathrm{~d}_{\mathrm{p}}
$$

The pore will fill with condensed water when the ambient partial pressure of steam is:

$$
P_{\text {fill }}=P_{\text {eq }} \exp \left[-\sigma_{1} \bar{v} / 0.366 d_{p} R T\right]
$$

where $P_{e q}$ is the equilibrium partial pressure of water at the prevailing temperature. The pore will empty when the steam partial pressure is:

$$
P_{\text {empty }}=P_{\text {eq }} \exp \left[-2 \sigma_{1} \bar{v} / 0.0774 d_{p} \text { RT }\right]
$$

At $373 \mathrm{~K}$ and for primary particles $0.1 \mu \mathrm{m}$ in diameter,

$$
\begin{gathered}
\mathrm{P}_{\text {fill }}=0.991 \mathrm{atms} \\
\mathrm{P}_{\text {empty }}=0.915 \mathrm{atms}
\end{gathered}
$$

There is, then, hysteresis in the isotherm for water adsorption by the pore. It might be anticipated, because the primary particles in aerosols have variable sizes so that pores have yariable geometry, that the hysteresis will be of Barrer's Type C [175]. The essential points are that water can condense in the pores of particle agglomerates at partial pressures less than saturation and that the presence of the condensed water is stable to small fluctuations in the ambient partial pressure of steam..

Condensation of water in the internal voids of particle agglomerates is even more likely if the aerosol. material is soluble in water. Dissolution of aerosol material will reduce the chemical activity and. consequently the vapor pressure of the condensed water.

If water condensed in the pores of the particle aggregates is considered, then

$$
\alpha=\left(\epsilon \rho_{\mathrm{p}}+(1-\epsilon) \rho_{\mathrm{W}}\right) / \rho_{\mathrm{p}}
$$

where $\epsilon$ is the packing fraction and $\rho_{\mathrm{W}}$ is the density of water. (Of course, if water does not condense in the internal voids of the particle agglomerates, then $\alpha \cong$.) Random packing of equal sized spheres produces $\epsilon=0.63$. Experimental studies of the packing fraction cited by Brockman, [164] typically yielded values of $\epsilon=0.18$ to 0.5 . An exceptional case produced $\epsilon=3 \times 10^{-4}$.

Neglecting the exceptional case, the dynamic shape factors for aerosol particles discharged to the suppression pool ought to be between 1.0 and 1.6 with values in the vicinity of 1.15 likely. Over the last several years, there have been many studies of aerosol particle growth in terms of fractal geometry. That is, the aggregation of primary particles to form a composite particle is such that the geometric size of the composite is related to the volume of aerosol material by a fractal dimension:

$$
\mathrm{d}_{\mathrm{p}}=\mathrm{kn}^{1 / \mathrm{d}_{\mathrm{f}}}
$$


where

$$
\begin{aligned}
\mathrm{n} & =\text { number of primary (fully dense) aerosol particles that make up the composite, } \\
\mathrm{d}_{\mathrm{p}} & =\text { geometric diameter of the composite, } \\
\mathrm{k} & =\text { proportionality constant, and } \\
\mathrm{d}_{\mathrm{f}} & =\text { fractal dimension of the composite. }
\end{aligned}
$$

Were the composite particle fully dense, then the fractal dimension, $\mathrm{d}_{\mathrm{f}}$, would be 3 . A large number of experimental and analytic studies suggest that the fractal dimension is less than 3:

- Forrest and Witten [275] found fractal dimensions of inorganic "smoke" particles including iron and zinc particles to be 1.5 to 1.7 ,

- Meakin [276] calculated fractal dimensions for aerosol particles growing by Brownian processes to be between 1.40 and 1.45 ,

- Richter et al. [277] calculated fractal dimensions as high as 2.4 ,

- Feder et al. [278] reported fractal dimensions for carbon black as high as 2.3, but dimensions may actually have been lower,

- Martin et al. [279] measured fractal dimensions of particles by x-ray and light scattering to be $1.84 \pm 0.08$,

- Mountain et al. [280] calculated fractal dimensions in the free molecular and the continuum flow regimes to be 1.7 to 1.9 ,

- experimental studies by Samson et al. [281] yielded fractal dimensions of 1.5 to 1.6 ,

- data obtained by Hurd and Fowler [282] for flame generated $\mathrm{SiO}_{2}$ particles indicated fractal dimensions of $1.49 \pm 0.15$,

- Zhang et al. [283] measured fractal dimensions for aerosol particles of $1.62 \pm 0.06$ by light scattering and $1.72 \pm 0.10$ by transmission electron microscopy,

- Mulholland et al. [284] calculated fractal dimensions in the free molecular regime of $2.07 \pm 0.08$ to $1.89 \pm 0.08$,

- Lesaffre [285] found the fractal dimensions of aerosol particles formed from $\mathrm{TiCl}_{4}$ in moist air to increase from $1.52-1.57$ to $1.71-1.83$ as the relative humidity increased from 13.3 percent to 87.4 percent,

- Meakin et al. [286] found calculated fractal dimensions of 1.8 to 2.12 depending on the detail collision and trajectory models used in the calculation, 
- Megaridis and Dobbins [287] measured fractal dimensions of particles of 1.62 to 1.74 , and

- Charalampopoulos and Chang [288] reported measured fractal dimensions of $1.7 \pm 0.08$.

If, as is suggested by these many studies, aerosol particles do have fractal dimensionality, then the packing fraction and, consequently, the shape factors depend on particle size. If the primary particle size is $\mathrm{d}(\mathrm{pr})$ and the packing fraction, $\epsilon$, goes to one as the particle size $\mathrm{d}_{\mathrm{p}}$ approaches the primary particle size, then

$$
\epsilon=\left[\frac{d(p r)}{d_{p}}\right]^{3-d_{f}}
$$

or, to avoid physical impossibilities for continuous size distributions

$$
\epsilon=\min \left[\left[1, \frac{\mathrm{d}(\mathrm{pr})}{\mathrm{d}_{\mathrm{p}}}\right]^{3-\mathrm{d}_{\mathrm{f}}}\right]
$$

Both the fractal dimension, $\mathrm{d}_{\mathrm{f}}$, and the primary particle size in this expression are uncertain:

Calculated shape factors for particles of various material densities are shown as functions of particle size in Figure 84. For these calculations the fractal dimennsion was taken to be 1.7 .8 ' and the thrituary particle size was taken to be $0.05 \mu \mathrm{m}$. Water was assumed to fill the voids in the agglomerated particles. Shape factors are calculated to increase rapidly with particle size for sizes in the vicinity of the primary particle size. The shape factors become nearly size-independent and different' than'one for large particles.

The model can be refined somewhat by recognizing that agglomerates containing 2,3 , 'and peinhaps 4 primary particles will not have concave voids that can fill with water unless the material is quite hygroscopic (see below). The agglomerates of small numbers of spherical particles will be quite distorted from spherical and, consequently, shape factors for these agĝlomerates need to be defined. Hansen and Ahlberg [168] have reviewed experimental data on the dynamic shape factors of agglomerates composed of 2 to 5 spheres. They argue that there is a dependence of theldynamic shape factor on the Knudsen number. Certainly, the scatter and uncèrtainty in data for dêublêts 'aré large enough that it is difficult to confidently identify a dependence on Knudsen number (see Figure 85). The

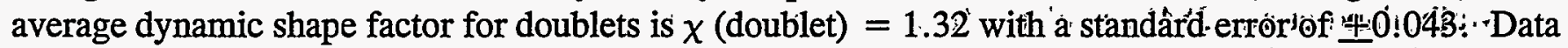
for triplets and quadruplets might arguably be weakly dependent on the Knudsenn numbier. The hypothesis that the slope of a linear correlation of the shape factor with Knudsen number is different than zero can be rejected at fairly high confidence. Shape factors are taken here to be indepèndent of the Knudsen number:

$$
\begin{gathered}
\chi(\text { triplet })=1.554 \pm 0.026 \\
\chi(\text { quadruplet })=1.765 \pm 0.038
\end{gathered}
$$


Physical Phenomena

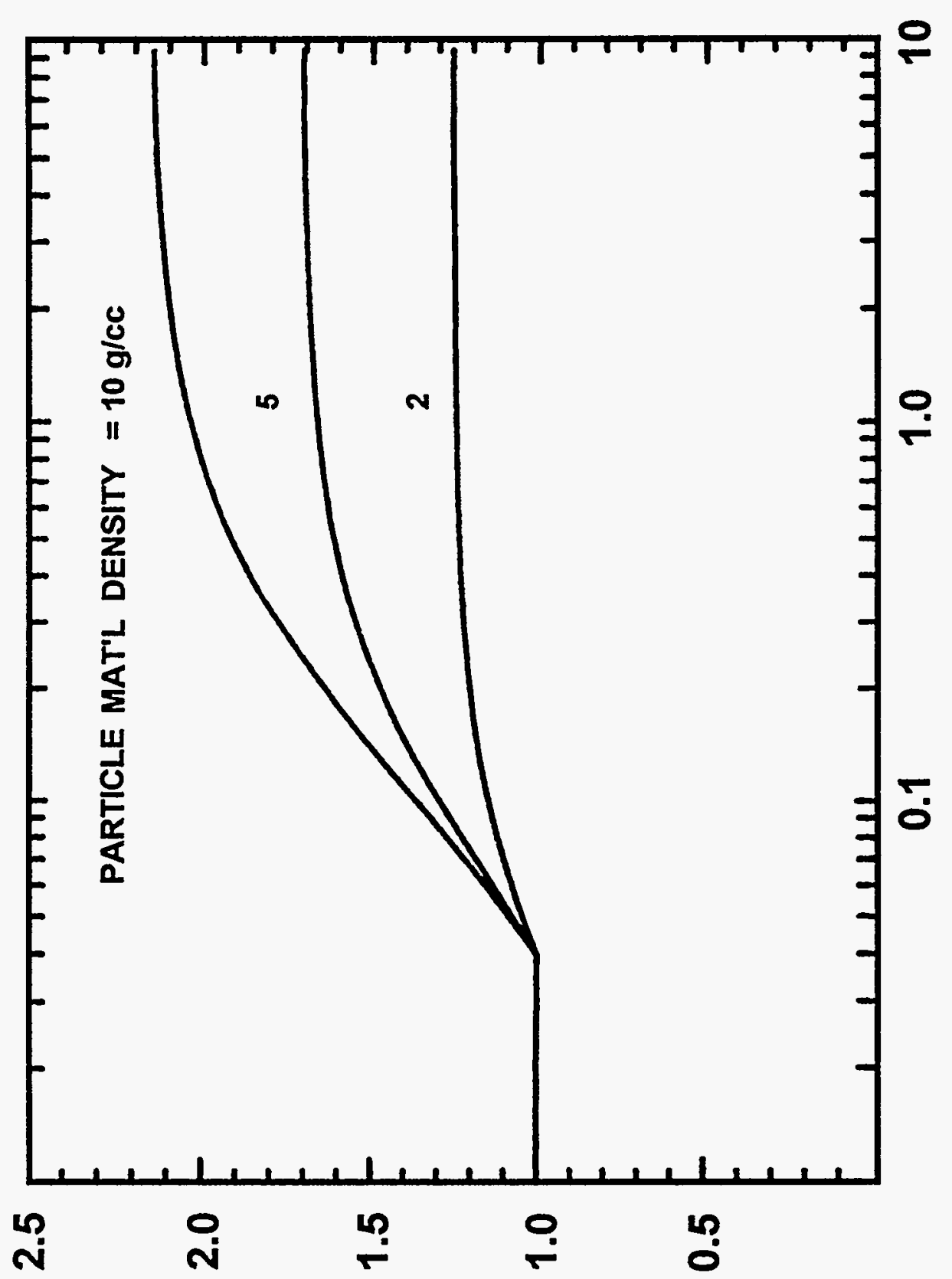

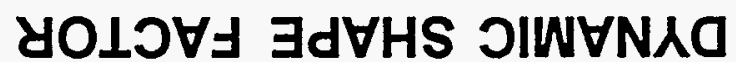

ปั.

通

중

E

피

$\frac{1}{2}$

કั

.

$\frac{11}{\frac{1}{\alpha}}$

导

용

을

胥

๙

\%ั.

농

.马

实

के

.

藏苞

宫参

\&i

矛 


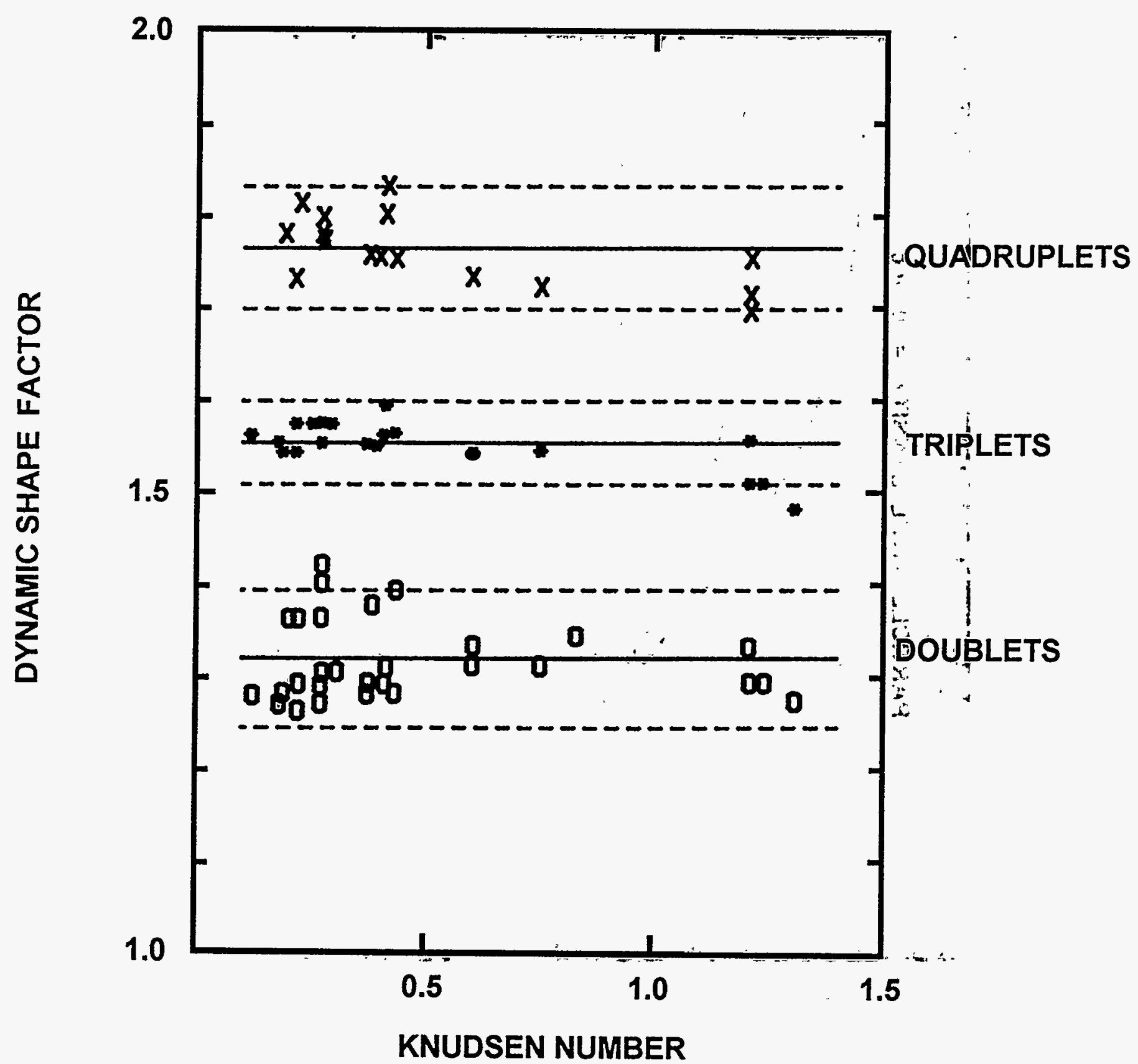

Figure 85. Dynamic shape factors for doublets, triplets, and quadruplet agglomerates of spherical particles. Solid lines indicate mean values. Dashed lines define 95 percent confidence bounds. 


\section{Slip Correction Factors and Accommodation Coefficients}

The friction drag on a spherical particle is taken to be

$$
\mathrm{F}_{\mathrm{D}}=3 \pi \mu_{\mathrm{g}} \mathrm{d}_{\mathrm{p}} \chi / \mathrm{C}
$$

where

$$
\begin{aligned}
\mathrm{F}_{\mathrm{D}} & =\text { drag force } \\
\mu_{\mathrm{g}} & =\text { viscosity of the gas phase, } \\
\chi & =\text { dynamic shape factor, and } \\
\mathrm{C} & =\text { slip correction factor. }
\end{aligned}
$$

The slip correction factor is included so that the expression can apply to particles smaller than the mean free path of gas molecules as well as to particles so large that the gas phase can be treated as a continuum. The Knudsen number,

$$
\mathrm{Kn}=2 \lambda / \mathrm{d}_{\mathrm{p}}
$$

where $\lambda$ is the mean free path of gas molecules, characterizes the range of application. The mean free path of gas phase molecules is the average distance of travel of gas molecules before they collide with other gas molecules. It is a concept that only makes sense if gas molecules are approximated as rigid, noninteracting particles. Indeed, this is the approximation adopted in nearly all of the analysis of aerosol behavior. Within this approximation, the mean free path is given by:

$$
\lambda=\mathrm{kT} / \sqrt{2} \mathrm{P} \pi \sigma^{2}
$$

where

$$
\begin{aligned}
& \sigma=\text { collision cross section of the gas molecules (see Table 14), } \\
& \mathrm{k}=\text { Boltzmann's constant, and } \\
& \mathrm{P}=\text { pressure in rational units. }
\end{aligned}
$$

In conventional units,

$$
\lambda(\mathrm{cm})=3.065 \times 10^{-7} \mathrm{~T}(\mathrm{~K}) / \mathrm{P}(\mathrm{atms}) \sigma^{2}\left(\mathrm{~A}^{\circ}\right)
$$


Physical Phenomena

More empirical expressions for $\lambda$ are often used:

$$
\lambda=2\left(\frac{\mathrm{m}}{2 \mathrm{kT}}\right]^{1 / 2} \mu_{\mathrm{g}} / \rho_{\mathrm{g}}=\left[\frac{2 \mathrm{M}}{\mathrm{RT}}\right]^{1 / 2} \frac{\mu_{\mathrm{g}}}{\rho_{\mathrm{g}}}
$$

or

$$
\lambda(\mathrm{cm})=0.0127 \mu_{\mathrm{g}}(\mathrm{T} / \mathrm{M})^{1 / 2}
$$

where

$$
\begin{aligned}
& \mathrm{m}=\text { mass of a gas molecule and } \\
& \mathrm{M}=\text { molecular weight of the gas }
\end{aligned}
$$

These expressions make it somewhat easier to define a parameter that can be called the mêan free path for gas mixtures.

Empirical expressions for the slip correction factors for spheres (also called Cunningham slip correction factors) have been made famous by Milliken as part of his work with oil droplets (see Reference 143 for some interesting comments on this work.) Milliken found for oil dröplets:

$$
C=1+\operatorname{Kn}[1.23+0.414 \exp (-0.876 / \mathrm{Kn})]
$$

Since then, other expressions have been determined:

- Allen and Raabe [143] for solid particles

$$
C=1+K n[1.142+0.588 \exp (-0.999 / \mathrm{Kn})]
$$

- Davies [144]

$$
C=1+\operatorname{Kn}[1.257+0.400 \exp (-1.10 / \mathrm{Kn})]
$$

- Annis [295]

$$
C=1+K n[1.558+0.173 \exp (-0.769 / \mathrm{Kn})]
$$

- Jennings [185]

$$
\mathrm{C}=1+\mathrm{Kn}[1.255+0.399 \exp (-1.10 / \mathrm{Kn})]
$$

There is no significant difference among these expressions. They exhibit a classic "compensation" effect among parameters determined by least squares fitting. 
All of the empirical expressions treat the slip correction as strictly a function of geometry. Phillips [145], however, finds theoretically:

$$
C=\frac{15+12 C_{1} K n+9\left(C_{1}^{2}+1\right) K n^{2}+18 C_{2}\left(C_{1}^{2}+2\right) K n^{3}}{15-3 C_{1} K n+C_{2}\left(8+\pi \alpha_{t}\right)\left(C_{1}^{2}+2\right) K n^{2}}
$$

where

$$
\begin{aligned}
\alpha_{\mathrm{m}} & =\text { momentum accommodation coefficient, } \\
\alpha_{\mathrm{t}} & =\text { energy accommodation coefficient, } \\
\mathrm{C}_{1} & =\left(2-\alpha_{\mathrm{m}}\right) / \alpha_{\mathrm{m}}, \text { and } \\
\mathrm{C}_{2} & =1 /\left(2-\alpha_{\mathrm{m}}\right)
\end{aligned}
$$

Phillips' analysis suggests that the slip correction is dependent on the gas and the particle properties by means of the momentum accommodation coefficient. Comparison of the slip correction factors predicted with Phillips' model to data for oil droplets [146,147] using $\alpha_{m}=0.895$ [145] and to predictions obtained from the empirical correction by Allen and Raabe [143] are shown in Figure 86.

Accommodation coefficients arise frequently in the discussion of gas interactions with aerosol particles. There are four so-called Knudsen accommodation coefficients:

- accommodation of normal momentum

- accommodation of tangential momentum

- accommodation of energy, and

- the radiometric accommodation coefficient.

Here, interests are confined to the accommodation of normal momentum and energy. Because the energy of an ideal monatomic gas is a function of temperature and because the concept of accommodation arose in the study of heat transfer at low pressures, the energy accommodation coefficient is often called the temperature accommodation coefficient. Accommodation is most intuitively defined in terms of temperature. Consider a gas of temperature $\mathrm{T}(\mathrm{g})$ and a surface of temperature $T(s)$. Gas species that collide with the surface reflect back into the gas phase with properties indicative of a temperature $T(r)$. Then, the temperature accommodation coefficient, $\alpha_{t}$, is defined by: 


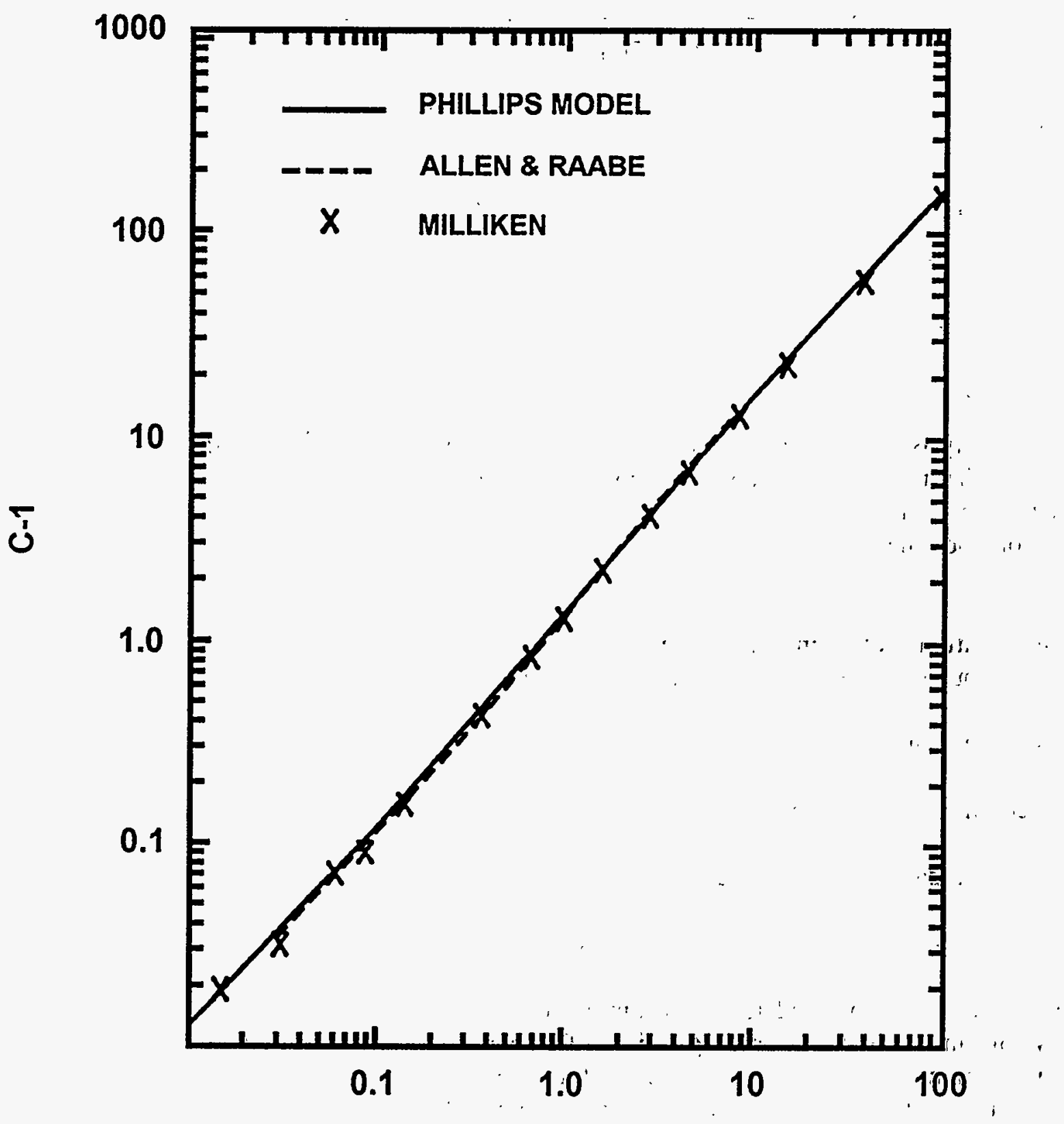

KNUDSEN NUIMBERR :

Figure 86. Comparison of the predicted slip correction factor to values obtained in experiments with oil droplets [146,147] and correlations of data for solid particles [143]. 
Physical Phenomena

$$
\alpha_{\mathrm{t}}=\lim _{\mathrm{T}(\mathrm{g}) \rightarrow \mathrm{T}(\mathrm{s})} \frac{\mathrm{T}(\mathrm{r})-\mathrm{T}(\mathrm{g})}{\mathrm{T}(\mathrm{s})-\mathrm{T}(\mathrm{g})}
$$

The definition is more rigorously correct if energy rather than temperature is used in the equation. Similar definitions can be constructed for the other accommodation coefficients. From these definitions, it appears that accommodation coefficients can assume values between 0 and 1 . Closer examination of the gas-solid interaction process shows the conceivable range for the accommodation coefficients is not so narrowly restricted. But, in reality, measurements of these coefficients are nearly always in this range.

Measurements of accommodation coefficients for aerosol particles of interest here are, of course, nonexistent. Momentum accommodation coefficients have been derived from the data used to define slip correction factors. Rader [160] seems to consider the momentum accommodation coefficient a function of the gas and provides:

$\begin{array}{cc}\text { Gas } & \alpha \mathrm{m} \\ \text { air } & 0.8972 \\ \mathrm{Ar} & 0.8891 \\ \mathrm{He} & 0.8694 \\ \mathrm{H}_{2} & 0.9251 \\ \mathrm{CH}_{4} & 0.9195 \\ \mathrm{C}_{2} \mathrm{H}_{6} & 0.8784 \\ \mathrm{~N}_{2} \mathrm{O} & 0.8972 \\ \mathrm{CO}_{2} & 0.8968\end{array}$

There are few surface materials for which momentum accommodation has been measured. Nearly all the data examined by Rader were for oil droplets. Indeed, the only systemmatics in the results he cites is a rough correlation of momentum accommodation with the molecular weight of the gas and the solubility of the gas in oil. One would also expect that surface roughness on a molecular level would lead to higher accommodation coefficients. Such roughness would seem to make it more likely that a colliding gas species would be trapped or adsorbed on the surface at least temporarily and there would be an opportunity for the gas species to equilibrate with the surface.

Data available for review by Rader were obtained at temperatures not too different than room temperature. If the view that transient adsorption of gases on surfaces leads to higher accommodation coefficients is true, then the accommodation coefficient should be somewhat temperature-dependent. As temperature increases and the mean speed of gas phase species increases, larger fractions of the collisions should be too energetic to lead to adsorption. The accommodation coefficient might be expected, then, to decrease with temperature.

A great deal more is known about temperature accommodation. Saxena and Joshi [242] have reviewed the available data. The accommodation of hydrogen on metals is shown in Figure 87. The temperature accommodation coefficient for various gases on glass is shown in Figure 88. The most noticeable feature of these data is that temperature accommodation coefficients are typically smaller than the momentum accommodation coefficients cited by Rader. The temperature accommodation coefficients 


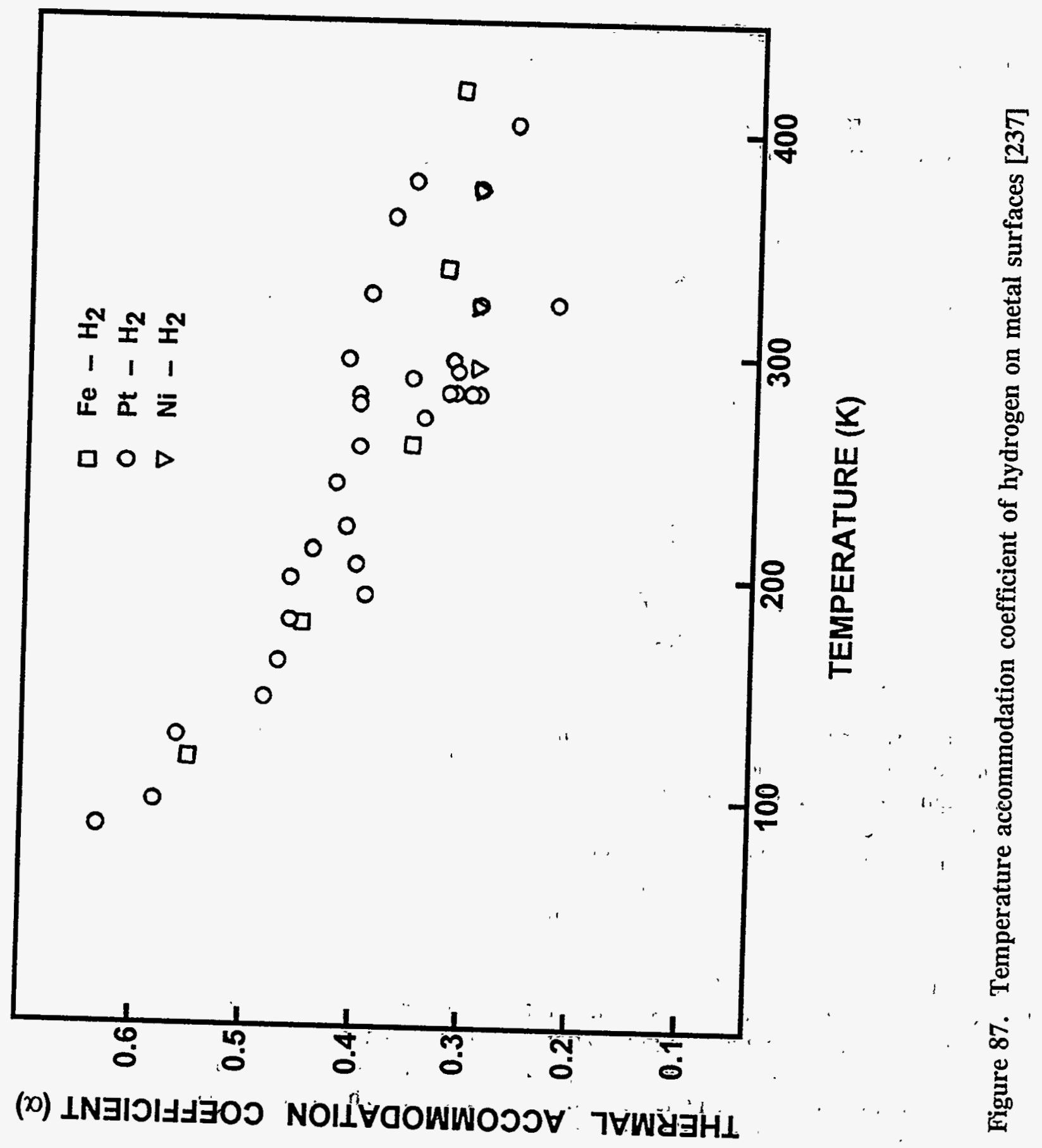




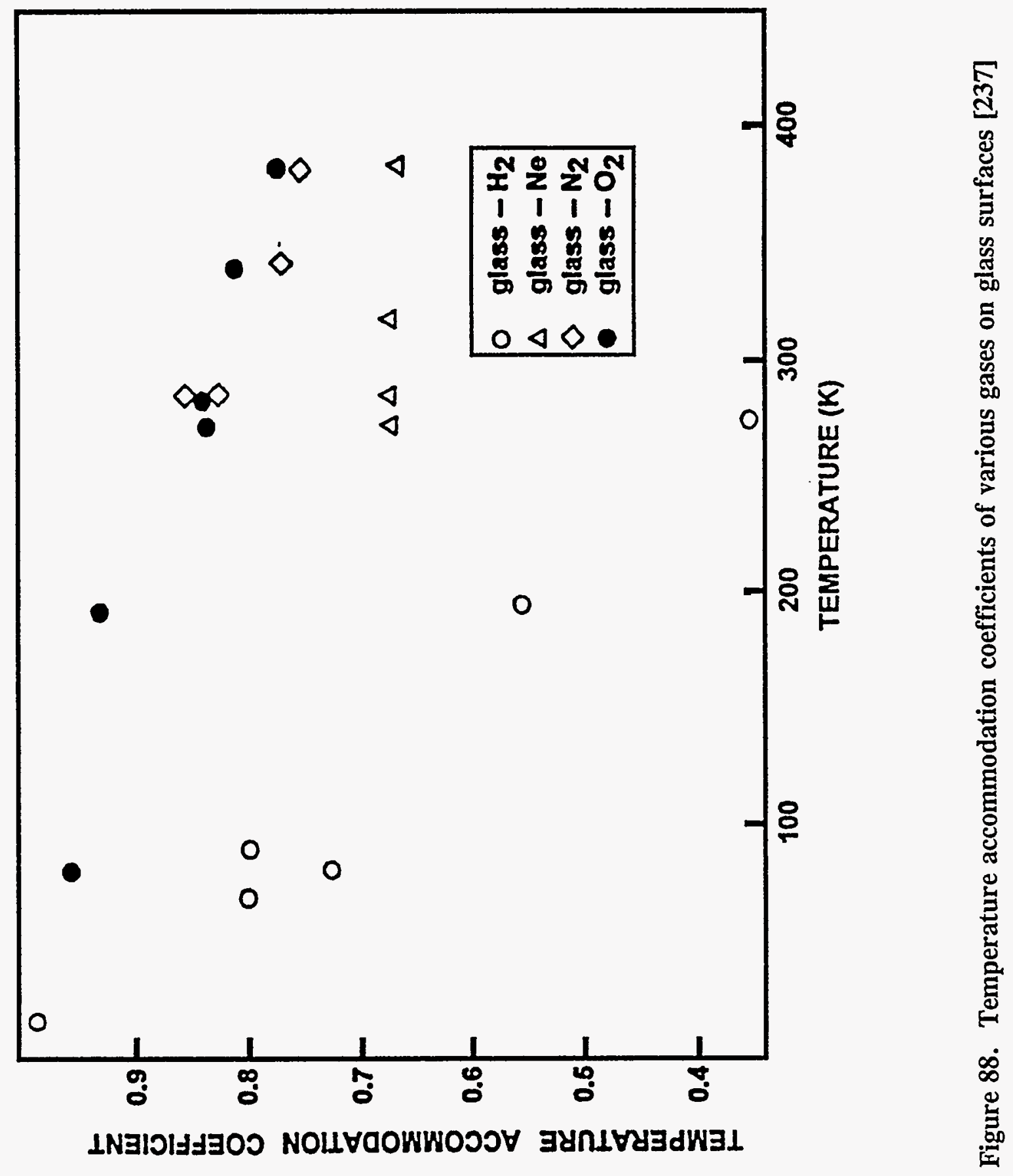


do seem to decrease with temperature. Also, the accommodation coefficient does seem to decrease with the molecular weight of the gas.

There have been numerous theoretical studies of the temperature accommodation coefficient $[162,163,237]$. Simple expressions for the accommodation-coefficient-are: $\quad \ldots \ldots \ldots$

- Baule hard-sphere model

$$
\alpha_{\mathrm{t}}=2 \eta /(1+\eta)^{2}
$$

- Empirical modification of the Baule equation:

$$
\alpha_{\mathrm{t}}=2.4 \eta /(1+\eta)^{2}
$$

- Effective surface mass:

$$
\alpha_{\mathrm{t}}=2 \eta^{\prime} /(1+\eta)^{2}
$$

where

$$
\begin{aligned}
& \eta=\mathrm{MW}(\mathrm{gas}) / \mathrm{MW} \text { (surface atom) } \\
& \eta^{\prime}=\mathrm{MW}(\mathrm{gas}) / \mathrm{MW}(\text { effective), and } \\
& \mathrm{MW}\left(\text { effective) }=\begin{array}{l}
\text { effective molecular weight of the surface atom which can be sevieral times the } \\
\text { actual molecular weight }
\end{array}\right.
\end{aligned}
$$

As noted by Goodman and Wachman [243], none of the simple formulae "yields extensive agreement with experimental data although each may be valid under particular sets of conditions. "| As a result, theorectical studies have produced rather complex expressions for the temperature accommodation coefficient that involve properties of the solid and the gas-solid interactions. Such information is unlikely to be available for aerosol materials of interest here.

Estimation of temperature accommodation coefficients for situations of interest here is complicated by the fact that gas mixtures are present. Definition of a single value for the coefficient when it is likely the various gases accommodate differently is a difficulty. Also, it is not obvious what the properties of the surface are. If, in fact, water absorbs on the surfaces of aerosol particles, then the relevant issue is the accommodation of gases by liquid water rather than sölid 'surfaces.

It is clear that accommodation coefficients will not be known accurately for the systems and temperatures of interest here. Simple models of these accommodation coefficients are not available. Consequently, accommodation coefficients will be sources of uncertainty and will have to be treated in a substantially parametric fashion. 
The slip correction becomes important only for very small particles. The slip correction factor described above is for perfect spheres. There is, however, no assurance that primary particles will be so geometrically simple. At a minimum, some distortion into oblate or prolate ellipsoids might be expected. Slip corrections are not known for ellipsoids over the entire range of Knudsen numbers. Dahneke has, however, derived expressions for the drag force on oblate and prolate ellipsoids in the free molecular regime [169] and in the continuum regime [170]. He has defined a procedure for estimating the slip correction factor for ellipsoids at arbitrary Knudsen numbers.

Recognize that the slip correction factor is, by definition, given by:

$$
F=F(\text { cont }) / C
$$

where

$$
\begin{aligned}
\mathrm{F} & =\text { the actual drag force on a particle, } \\
\mathrm{F}(\text { cont }) & =\text { the actual drag force on a particle if the gas could be treated as a continuum, and } \\
\mathrm{C} & =\text { slip correction factor. }
\end{aligned}
$$

Dahneke proposes to define a spherical particle whose diameter is such that the slip correction factor in the free molecular regime is the same as that for the distorted particle. He finds this diameter from:

$$
\frac{\mathrm{F}(\mathrm{cont})}{\mathrm{F}(\mathrm{fm})}=\mathrm{C}=1+\mathrm{Kn}[\alpha+\beta \exp (-\delta / \mathrm{Kn})]
$$

where

$$
\mathrm{F}(\mathrm{fm})=\text { drag force on the distorted particle in the free-molecular regime }(\mathrm{Kn}>>1)
$$

and the formula for the slip correction factor is any one of those described above. Since the slip correction factor for the hypothetical spherical particle is the same as that of the distorted particle in both the free-molecular regime and the continuum regime, he assumes that calculated slip correction factors for the hypothetical sphere will yield good estimates of the slip correction factor for the distorted particle under conditions intermediate between the extremes of the continuum and free-molecular regimes. 
Physical Phenomena

Dahneke defines the forces on particles modestly distorted from spherical to be:

$$
\begin{gathered}
F(\text { cont })=-C_{o} \mu_{g} L_{c} V \\
F(f m)=\frac{-\pi \mu_{g} L_{c} V}{K n(e)} f\left(E, \alpha_{m}\right)
\end{gathered}
$$

where

$$
\begin{aligned}
& \mathrm{V} \quad=\text { velocity of the particle, } \\
& \mathrm{L}_{\mathrm{c}} \quad=\text { critical dimension of the particle, } \\
& \mathrm{E} \quad=\text { aspect ratio of the distorted particle }(\mathrm{E} \geq 1) \\
& \alpha_{\mathrm{m}} \quad=\text { momentum accommodation factor or the fraction of gas atoms scattered diffusely, and } \\
& \mathrm{Kn}(\mathrm{e}) \quad=\text { the Knudsen number for the distorted particle. }
\end{aligned}
$$

The geometry factors $\mathrm{C}_{\mathrm{o}}$ and $\mathrm{f}\left(\mathrm{E}, \alpha_{\mathrm{m}}\right)$ are discussed further below. . The defining equation, rthen is:.

$$
\frac{\mathrm{Kn}(\mathrm{e}) \mathrm{C}_{\mathrm{o}} \mu_{\mathrm{g}} \mathrm{L}_{\mathrm{c}} \mathrm{V}}{\pi \mu_{\mathrm{g}} \mathrm{L}_{\mathrm{c}} \operatorname{Vf}\left(\mathrm{E}, \alpha_{\mathrm{m}}\right)}=1+\mathrm{Kn}(\mathrm{s})[\alpha+\beta \exp (-\delta / \mathrm{Kn}(\mathrm{s})]
$$

or

$$
\left[\frac{\mathrm{C}_{0} \mathrm{Kn}(\mathrm{e})}{\pi \mathrm{f}\left(\mathrm{E}, \alpha_{\mathrm{m}}\right)}-1\right] /[\alpha+\beta \exp (-\delta / \mathrm{Kn}(\mathrm{s})]=\mathrm{Kn}(\mathrm{s})
$$

where $\mathrm{Kn}(\mathrm{s})$ is the Knudsen number for the adjusted spherical particle. The diameter of the equivalent spherical particle is:

$$
\mathrm{d}_{\mathrm{p}} \text { (equiv.) }=\frac{1}{2} \mathrm{~L}_{\mathrm{c}} \mathrm{Kn}(\mathrm{e}) / \mathrm{Kn}(\mathrm{s})
$$

The geometric factors $C_{o}$ and $f\left(E, \alpha_{m}\right)$ depend on the geometry and the orientation of the particle. For prolate ellipsoids with semi-major axis a and semi-minor axis $b$ : 


$$
\begin{aligned}
f\left(E, \alpha_{m}\right)= & \sin ^{2} \theta\left[X_{p}\left\{4+\left(\frac{\pi}{2}-1\right) \alpha_{m}\right\}+\frac{Z_{p}}{Y_{p}^{2}}\left\{2+\left[\frac{4 Y_{p}^{2}+\pi-6}{4}\right] \alpha_{m}\right]+\right. \\
& +\cos ^{2} \theta\left[2 X_{p} \alpha_{m}+\frac{Z_{p}}{Y_{p}^{2}}\left\{Y_{p}^{2}\left(4-2 \alpha_{m}\right)-4+\left[3-\frac{\pi}{2 E^{2}}\right] \alpha_{m}\right\}\right] \\
C_{o}= & \frac{16 \pi\left(E^{2}-1\right) \sin ^{2} \theta}{\left[\frac{2 E^{2}-3}{\sqrt{E^{2}-1}}\right] E \ln \left(E+\sqrt{E^{2}-1}\right)+E^{2}}+\frac{2 E^{2}-1}{\left.\sqrt{E^{2}-1}\right] E \ln \left(E+\sqrt{E^{2}-1}\right)-E^{2}}
\end{aligned}
$$

where

$$
\begin{aligned}
\mathrm{E} & =\mathrm{a} / \mathrm{b}>1 \\
\mathrm{Kn} & =\lambda / \mathrm{b} \\
\mathrm{X}_{\mathrm{p}} & =\frac{\sin ^{-1}\left(\mathrm{Y}_{\mathrm{p}}\right)}{\mathrm{Y}_{\mathrm{p}}} \\
\mathrm{Y}_{\mathrm{p}} & =\left(1-1 / \mathrm{E}^{2}\right)^{1 / 2} \\
\mathrm{Z}_{\mathrm{p}} & =1 / \mathrm{E}-\mathrm{X}_{\mathrm{p}} \text {, and } \\
\theta & =\text { angle of transport relative to the polar axis of the particle. }
\end{aligned}
$$

For oblate ellipsoids with semi-major axis a and semi-minor axis b, Dahneke finds:

$$
\begin{aligned}
\mathrm{f}\left(\mathrm{E}, \alpha_{\mathrm{m}}\right)= & \sin ^{2} \theta\left[\mathrm{X}_{\mathrm{o}}^{2} \mathrm{Y}_{\mathrm{o}}\left\{\frac{(6-\pi) \alpha_{\mathrm{m}}}{4}-2\right\}+\mathrm{Z}_{\mathrm{o}}\left\{4-\frac{(4-\pi)}{2} \alpha_{\mathrm{m}}\right\}+\mathrm{E} \alpha_{\mathrm{m}}\right]+ \\
& +\cos ^{2} \theta\left[\mathrm{X}_{\mathrm{o}}^{2} \mathrm{Y}_{\mathrm{o}}\left\{4-\frac{(6-\pi)}{2} \alpha_{\mathrm{m}}\right\} \mathrm{E}^{2}+\mathrm{Z}_{\mathrm{o}} \alpha_{\mathrm{m}}+\mathrm{E} \alpha_{\mathrm{m}}\right]
\end{aligned}
$$




$$
C_{0}=\frac{16 \pi\left(E^{2}-1\right) \sin ^{2} \theta}{\left[\frac{3 E^{2}-2}{\sqrt{E^{2}-1}}\right] \operatorname{atn}\left(\sqrt{\left.E^{2}-1\right)}-1\right.}+\frac{8 \pi\left(E^{2}-1\right) \cos ^{2} \theta}{\left[\frac{E^{2}-2}{\sqrt{E^{2}-1}}\right] \operatorname{atn}\left(\sqrt{\left.E^{2}-1\right)}+1\right.}
$$

where

$$
\begin{aligned}
E & =a / b>1, \\
\mathrm{Kn} & =\lambda / \mathrm{a} \\
\mathrm{X}_{\mathrm{O}} & =1 / \sqrt{\mathrm{E}^{2}-1} \\
\mathrm{Y}_{\mathrm{O}} & =\mathrm{E}-\mathrm{Z}_{\mathrm{O}} \\
\mathrm{Z}_{\mathrm{O}} & =\mathrm{X}_{\mathrm{O}} \ln \left(\mathrm{E}+1 / \mathrm{X}_{\mathrm{O}}\right), \text { and }
\end{aligned}
$$

again $\theta$ is the angle from the polar (semi-minor) axis of the particle.

The distorted particles are, presumably, randomly oriented and do not rotate for most situations [165]. The statistical average force is taken by Dahneke to be found from:

$$
\frac{1}{\mathrm{f}(\operatorname{avg})}=\frac{1}{3}\left[\frac{1}{\mathrm{f}\left(\theta=0^{\circ}\right)}+\frac{2}{\mathrm{f}\left(\theta=90^{\circ}\right)}\right]
$$

and

$$
\frac{1}{\mathrm{C}_{\mathrm{o}}(\mathrm{avg})}=\frac{1}{3}\left[\frac{1}{\mathrm{C}_{\mathrm{o}}\left(\theta=0^{\circ}\right)}+\frac{2}{\mathrm{C}_{\mathrm{o}}\left(\theta=90^{\circ}\right)}\right]
$$

A plot of the statistically averaged slip correction factor for a prolate distorted particle calculated using Dahneke's method is shown in Figure 89. Also shown in the figure, is the slip correction factor, calculated using the volume equivalent sphere methods. For small distortions from spherical that are of interest here, the differences between the slip correction factors calculated by the two methods are not especially large. The extent of distortion and whether it is oblate or prolate distortion are uncertainties of equivalent or greater importance.

\section{Hygroscopicity of Aerosols Produced in Reactor Accidents}

The analyses of water condensation presented above show that if the chemical activity of water condensing on the aerosol surface can be reduced sufficiently, the aerosol particle will grow. Growth 


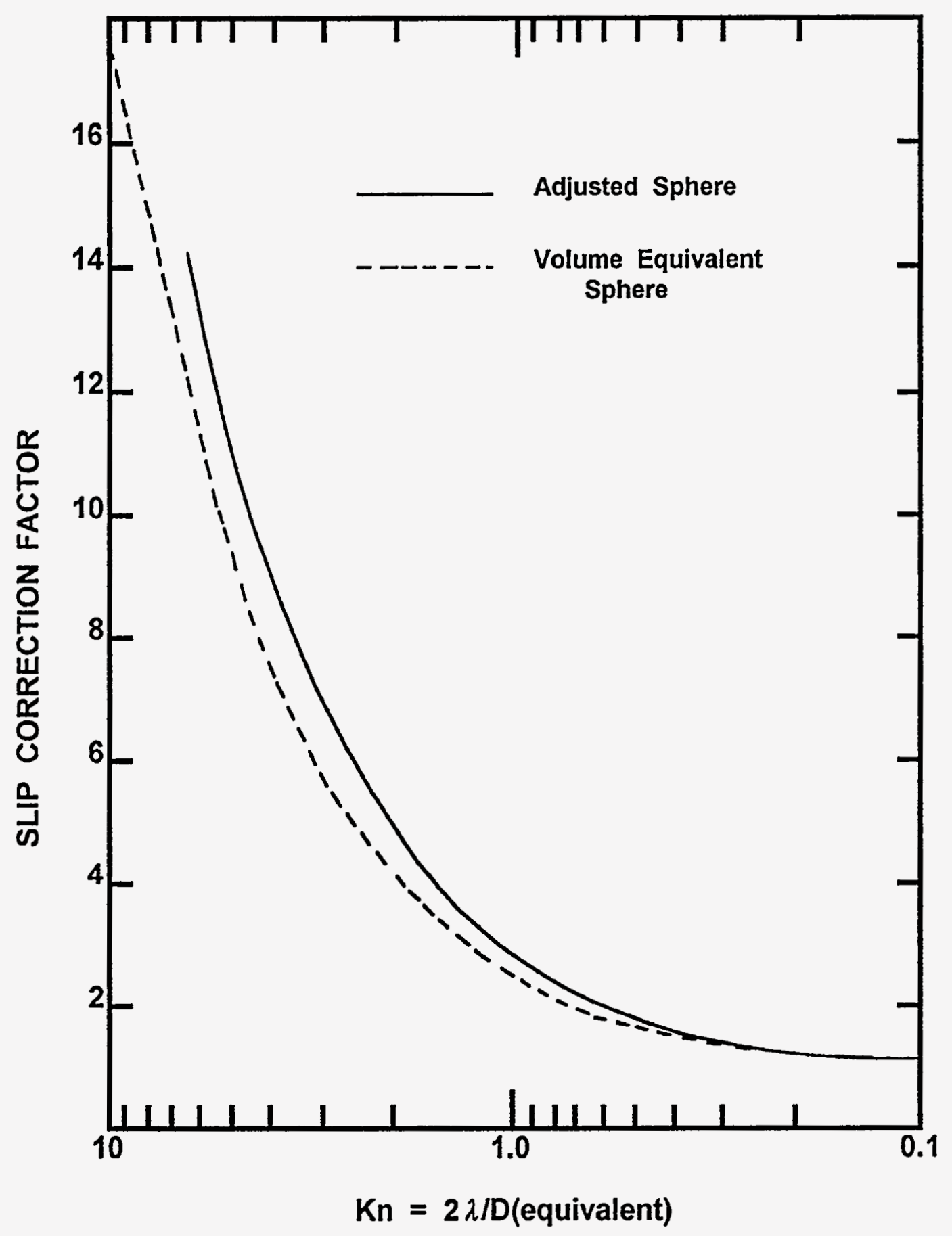

Figure 89. Comparison of slip correction factors for a prolate distorted particle $(E=2.0)$ calculated using the adjusted sphere and the volume-equivalent sphere method 
can be quite rapid. When the growth occurs, even quite small particles can become large enough that one or more of the aerosol trapping mechanisms discussed above will become efficient.

The reduction in the chemical activity of condensed water is the key to the growth of aerosol particles. The reduction must be sufficient to overcome both the Knudsen effect and therslightrundersaturation of the bubble atmosphere as it rises through the pool. The only readily apparent mechanism for the reduction in the chemical activity of condensing water is for the water to dissolve sóme of the aerosol material. The question then becomes how soluble will aerosols produced in reactor accidents be?

Models of radionuclide releases during severe reactor accidents.often treat the chemicâl form of aerosol materials quite crudely. These models often speak of chemical species such as CsOH, CsI, and inert aerosols $[14,23,25]$. Certainly, $\mathrm{CsOH}$ and $\mathrm{CsI}$ are quite soluble in water as is shown:by the data in Table 17. Were these materials to make up the aerosols entering the suppression pool, there is little doubt that water condensation would lead to particle growth.

It is, however, not evident that $\mathrm{CsOH}$ and $\mathrm{CsI}$ will be aerosol materials. In the last few years, more attention has been paid to the issue of chemical form of the aerosol produced during severe accidents [268]. Rich opportunities for reaction of chemically reactive species like Cs OH have been foünd. Some important reactions include:

$$
\begin{aligned}
& \mathrm{CsOH}+\mathrm{HBO}_{2} \rightleftarrows \mathrm{CsBO}_{2} \cdot \mathrm{H}_{2} \mathrm{O} \\
& 2 \mathrm{CsOH}+\mathrm{ZrO}_{2} \rightleftarrows \mathrm{Cs}_{2} \mathrm{ZrO}_{3}+\mathrm{H}_{2} \mathrm{O} \\
& \mathrm{CsI}+\mathrm{Ag}+\mathrm{H}_{2} \mathrm{O} \rightleftarrows \mathrm{CsOH}+\mathrm{AgI}+1 / 2 \mathrm{H}_{2} \\
& 2 \mathrm{CsI}+\mathrm{CdO}+\mathrm{H}_{2} \mathrm{O} \rightleftarrows 2 \mathrm{CsOH}+\mathrm{CdI}_{2}
\end{aligned}
$$

Table 17. Water solubilities of some materials

\begin{tabular}{|c|c|c|c|}
\hline \multicolumn{2}{|c|}{$\mathrm{CsOH}$} & \multicolumn{2}{|c|}{ CsI } \\
\hline $\begin{array}{c}\mathbf{T} \\
(\mathbf{K})\end{array}$ & $\begin{array}{c}\text { Solubility } \\
\text { (moles/kg } \\
\left.\mathrm{H}_{2} \mathrm{O}\right) \\
\end{array}$ & $\begin{array}{c}\mathbf{T} \\
(\mathbf{K})\end{array}$ & 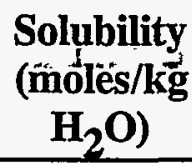 \\
\hline 288 & 2.94 & 273 & 1.17 \\
\hline 344 & 3.50 & 293 & 1.68 \\
\hline 374 & 3.66 & 313 & 2.06 \\
\hline \multirow[t]{3}{*}{402} & 3.92 & 333 & 2.31 \\
\hline & & 353 & 2.52 \\
\hline & & 373 & 2.64 \\
\hline
\end{tabular}
expected to be present in aerosol produced during severe reactor accidents 
For exactly the same reasons $\mathrm{CsOH}$ absorbs water so extensively, $\mathrm{CsOH}$ is also quite reactive towards other oxides to form materials of much lower water solubility. Dissolution of these materials may not produce the reduction in the chemical activity of water needed to promote particle growth.

Another development in the understanding of severe reactor accident phenomena has been the recognition that nonradioactive materials are far more abundant contributors to the aerosols than are radionuclides. The situation is particularly extreme in the case of core debris interactions with concrete. Typically, it is found in analyses of these interactions that radionuclides constitute only 1 percent of the total aerosol mass being evolved. Most of the aerosol mass comes from constituents of concrete such as $\mathrm{CaO}, \mathrm{SiO}_{2}, \mathrm{FeO}$, etc. Early in the course of core debris interactions when the molten core debris is quite hot and the most extensive releases of radionuclides take place, the nonradioactive aerosol materials might be expected to form chemical species with very low water solubilities. Adams [248] found that condensing steam did not accentuate the deposition of aerosols produced by feeding concrete into a plasma torch though condensing steam did accelerate deposition of $\mathrm{Fe}_{2} \mathrm{O}_{3}$ and $\mathrm{U}_{3} \mathrm{O}_{8}$ aerosols formed in a similar fashion.

Aerosol particles produced during severe reactor accidents are not likely to be composed of a single chemical species. It is, in fact, usually assumed that at least within given a size class aerosol particles will be composed of mixtures of materials with varying water solubilities. The two issues of interest, then, are, (1) can water soluble material making up a few percent of an aerosol particle produce the reduction in chemical activity necessary to promote growth by water condensation and, (2) can the dissolution occur fast enough to affect the particle during its transport through the suppression pool. Dissolution kinetics may be especially troublesome if the water soluble material is encased in materials that are not especially soluble. Particle morphology and structure as well as chemical composition must be understood to resolve the issues of particle growth by water condensation.

\section{Aerosol Behavior}

The trapping of aerosol is, of course, the process of main interest here. It is convenient to consider aerosol trapping in four regimes of particle transport:

- aerosol trapping during transport to the steam suppression pool,

- aerosol trapping during bubble formation,

- aerosol trapping during collapse or disintegration of bubbles immediately after bubbles detach from orifices or vents in the suppression pool, and

- aerosol trapping during the quasi-steady state rise of bubbles through the pool.

The first of the regimes, aerosol trapping during transport to the pool, is considered outside the scope of this work. Trapping aerosols by diffusiophoresis within downcomers has been mentioned above. Other phenomena that lead to aerosol trapping during transport to the suppression pool are described below (Section IV L-4). These phenomena are not further pursued. They might, however, affect not only the mass of aerosol to be removed by the pool, but also the size distribution of the aerosol particles that enter the suppression pool. The discussion below will show that many of the phenomena that can lead to aerosol trapping in the suppression pool are sensitive to the aerosol particle size. 
Attentions here are focused on the trapping of aerosol by the suppression pool itself:" The assumption is made here that a particle that contacts the water in the suppression pool is permanently trapped' in the pool. Gross re-entrainment of particle-ladden liquid droplets by spargingi gases has been neglected hère. Models of this entrainment phenomenon are available [200-202]. Typically, such models predict that the mass of liquid entrained by gas sparging is about $10^{-4}$ of the imass of sparging igas. Untill the pool becomes very concentrated in radionuclides, this re-entrainment will not significantly' reverse the decontamination produced by the suppression pool. Neglect of this re entrainmenit processı'does's, however, mean that some limit ought to be imposed on the decontamination that is predicted:by the models of aerosol trapping that are discussed here. In general, the authors feel that predicted. decontamination factors* in excess of $10^{6}$ should be viewed with suspicion because entrainment and the possible enrichment of surfaces with particulate relative to the-bulk liquid have been neglected.

Rather than discussing aerosol trapping processes in the sequence they. would be experienced by the : aerosol produced in a reactor accident, the discussions of aerosol trapping aré presented inisubsections beginning with aerosol trapping during bubble rise through the pool. This is doner because the trapping phenomena have been more thoroughly described for rising bubbles. These phenomena will be more familiar to the reader and can be used to obtain an understanding of: the more complex: phenomena associated with aerosol trapping during bubble collapse and during bubble formation.

\section{Aerosol Trapping During Bubble Rise}

The removal of aerosol particles from gas bubbles' rising through water is 'ar classic iproblem that has' been addressed by a number of authors $[148-150,153]$ : Usually, aerosol removalufrom the gas is ; considered to occur as a result of particle sedimentation within the bubble, sdiffusion of particles to the' bubble walls and, in cases where gases circulate within the bubble, as a result of inential impaction of: particles on the bubble walls. For the particular situation of interest here, it is necessary to consider two additional phenomena that lead to aesosol trapping. Both of these additional phenomena 'arise because of the behavior of water vapor within a rising bubble as was discussed above (see Section IV-D). Analyses of the thermodynamics of bubbles rising through a water pool showed that water vapor will evaporate from the walls and diffuse or convect into the bulk gas of the bubble. The evaporating water imposes a Stefan flow and a diffusiophoretic force on aerosol particles near the bubble surface. The thermodynamic analyses also showed that there could be a thermal gradient near the bubble walls. This thermal gradient will create a thermophoretic force on particles that will oppose particle deposition. In the discussions of the various aerosol trapping mechanisms presented below, the bubbles are assumed to be smooth ellipsoids. This is, of course, an idealization. In reality the surfaces of the bubbles, especially surfaces of bubbles in swarms, will be continuously deformed and reformed. Aerosol trapping by the shape oscillations of bubbles is also discussed in this subsection. .

\section{a. Diffusion of Particles to the Bubble Walls}

Diffusion of aerosol particles to the walls of bubbles is caused by the Brownian motion of $/$ the particles and the stochastic nature of impulses imparted to the particles, during collisions .with gas molecules. There are a variety of possible treatments of diffusion of aerosol particles. Most frequently adopted is

\footnotetext{
*The decontamination factor, as used throughout this document, is the dry aerosol mass injected into the suppression pool divided by the dry aerosol mass that emerges from the pool.
} 
an argument developed by Fuchs [148]. This treatment of particle diffusion to the walls of bubbles is somewhat peculiar. The argument is reproduced below for a spherical bubble. The development of the argument for an ellipsoidal bubble has been presented elsewhere [150].

Fuchs assumes that gases within the bubble circulate. Certainly, the discussions above show that this may not be the case. Ideally, when gases do circulate within a spherical bubble, the gas velocity tangential to the walls is:

$$
\mathrm{U}_{\text {tang }}=1.5 \mathrm{U}_{\mathrm{B}} \sin \theta
$$

where

$$
\begin{aligned}
\mathrm{U}_{\text {tang }} & =\text { tangential velocity, } \\
\mathrm{U}_{\mathrm{B}} & =\text { rise velocity of the bubble, and } \\
\theta & =\text { angle from the pole of the bubble. }
\end{aligned}
$$

The rate at which particles of size $d_{p}$ flow through a region between the bubble surface and a stream line (actually a stream surface) displaced a distance $\delta_{0}$ from the surface of the bubble at the equator is:

$$
\frac{\mathrm{dN}}{\mathrm{dt}}=\delta_{\mathrm{o}} \mathrm{D}_{\mathrm{B}} \pi \mathrm{n} \sin \theta \mathrm{U}_{\mathrm{tang}}=1.4 \delta_{\mathrm{o}} \mathrm{D}_{\mathrm{B}} \mathrm{U}_{\mathrm{B}} \pi \mathrm{n} \sin ^{2} \theta
$$

where $\mathrm{n}$ is the number concentration of particles of size $d_{p}$. Fuchs makes the questionable assumption that diffusion to the bubble surface is negligible except between polar angles of $\pi / 4$ and $3 \pi / 4$. In the above specified region, the time required for particles to traverse this arc is

$\mathrm{t}=\int_{\pi / 4}^{3 \pi / 4} \frac{0.5 \mathrm{D}_{\mathrm{B}} \mathrm{d} \theta}{\mathrm{U}_{\operatorname{tang}}}=\int_{\pi / 4}^{3 \pi / 4} \frac{\mathrm{D}_{\mathrm{B}}}{3 \mathrm{U}_{\mathrm{B}}} \frac{\mathrm{d} \theta}{\sin \theta}=\left.\frac{-\mathrm{D}_{\mathrm{B}}}{6 \mathrm{~V}_{\mathrm{B}}} \ln \left[\frac{1+\cos \theta}{1-\cos \theta}\right]\right|_{\theta=\pi / 4} ^{\theta=\frac{3 \pi}{4}} \cong 0.588 \mathrm{D}_{\mathrm{B}} / \mathrm{U}_{\mathrm{B}}$

During this time period the random walk displacement of particles by Brownian motion, $\delta$, is given by:

$$
\delta=2 \sqrt{\frac{Ð t}{\pi}}=0.8650 \sqrt{\boxplus D_{B} / U_{B}}
$$

where

$$
\begin{aligned}
\boxplus & =\text { particle diffusion coefficient, } \\
& =\mathrm{CKT} / 3 \pi \mu_{\mathrm{g}} \mathrm{d}_{\mathrm{p}} \chi
\end{aligned}
$$


Physical Phenomena

$$
\begin{aligned}
& \mathrm{C}=\text { Cunningham slip correction factor (see Section IV K-2), } \\
& \chi=\text { dynamic shape factor, and } \\
& \mathrm{k}=\text { Boltzmann's constant. }
\end{aligned}
$$

Over the interval from $\theta=\pi / 4$ to $\theta=\pi / 2$, the separation between the reference stream line and the bubble wall varies from $2 \delta_{0}$ to $\delta_{0}$. Fuchs defines the reference streamline by:

$$
\bar{\delta}=1.5 \delta_{\mathrm{o}}
$$

He then makes the somewhat startling assumption that all of the particles in the region deposit on the wall. That is, he has very roughly divided the zone in half to account for the fact that half the particles will move toward the wall as a result of Brownian motion and half will move away. For cálculational purposes, he segments these two classes of particles on either side of the boundary line $\delta=1.5 \delta_{0}$. The particle deposition rate is then given by:

$$
\frac{\mathrm{dN}}{\mathrm{dt}}=1.5 \delta_{\mathrm{o}} \pi \mathrm{D}_{\mathrm{B}} \mathrm{U}_{\mathrm{B}} \mathrm{n}=\delta \mathrm{D}_{\mathrm{B}} \mathrm{U}_{\mathrm{B}} \pi \mathrm{n} \cong 0.8650 \pi \mathrm{n}\left(\mathrm{D} \mathrm{D}_{\mathrm{B}}^{3} \mathrm{U}_{\mathrm{B}}\right)^{1 / 2} \cong 2.717 \mathrm{n}\left(\mathrm{D}_{\mathrm{B}}^{3} \mathrm{U}_{\mathrm{B}}\right)^{1 / 2}
$$

An overall deposition velocity, referenced to the entire surface area of the bubble even though the deposition is taking place only over 70.7 percent of the bubble surface, can be defined as:

$$
\frac{1}{\pi D_{B}^{2}} \frac{d N}{d t}=V_{D^{n}}=0.8650 n\left(\frac{Ð U_{B}}{D_{B}}\right]^{1 / 2}
$$

or

$$
V_{D}=0.8650\left[\frac{\bigoplus U_{B}}{D_{B}}\right]^{1 / 2}
$$

Similarly, the deposition coefficient for the fraction of particles deposited per 'unit bubble rise, $\alpha$ (D), can be defined as:

$$
\frac{6}{\pi \mathrm{D}_{\mathrm{B}}^{3} \mathrm{n}} \frac{\mathrm{dN}}{\mathrm{dx}}=\alpha(\mathrm{D})=5.190\left(\frac{\mathrm{U}_{\mathrm{B}} \mathrm{D}}{\mathrm{U}_{\text {rise }}^{2} \mathrm{D}_{\mathrm{B}}^{3}}\right)^{1 / 2}
$$


where $\mathrm{x}$ is the distance of bubble rise. Here, it is useful to make distinctions among the rise velocity of an isolated bubble, $\mathrm{U}_{\mathrm{B}}$, the rise velocity of the bubble relative to the water, $\mathrm{U}_{\text {slip }}$, and the velocity relative to the fixed coordinate frame of the pool. Then,

$$
\alpha(\mathrm{D})=5.190\left[\frac{\boxplus \mathrm{U}_{\text {slip }}}{\mathrm{D}_{\mathrm{B}}^{3} \mathrm{U}_{\text {rise }}^{2}}\right]^{1 / 2}
$$

For an oblate ellipsoidal bubbles of eccentricity* E, expressions derived from arguments completely parallel to those made by Fuchs for spherical bubbles are [150]:

$$
V_{D}=\frac{\frac{2}{E^{2 / 3}} \sqrt{\frac{\oplus U_{\text {slip }}}{8 \pi D_{B}}}\left[\frac{\left(E^{2}-1\right)}{1+\left(4+2\left(E^{2}-1\right)\right)^{1 / 2}}\right]\left[\frac{1.76 E^{2}}{\left(E^{2}-1\right)}-\sqrt{2}\right]^{1 / 2}}{\left\{1+\frac{\ln \left[\frac{E+\sqrt{\left(E^{2}-\right)}}{E-\sqrt{\left(E^{2}-1\right)}}\right]}{2 E \sqrt{\left(E^{2}-1\right)}}\right]\left\{\frac{E^{2} \tan ^{-1}\left[\left(E^{2}-1\right)^{1 / 2}\right]}{\sqrt{\left(E^{2}-1\right)}-1}\right\}^{1 / 2}}
$$

and

$$
\alpha(D)=\frac{6 \sqrt{\frac{Ð U_{\text {slip }}}{8 \pi D_{B}^{3} U_{\text {rise }}^{2}}\left[\frac{\left(E^{2}-1\right)}{1+\left(4+2\left(E^{2}-1\right)\right)^{1 / 2}}\right]\left[\frac{1.76 E^{2}}{\left(E^{2}-1\right)}-\sqrt{2}\right]^{1 / 2}}}{\left\{\frac{E^{2} \tan ^{-1}\left[\left(E^{2}-1\right)^{1 / 2}\right]}{\sqrt{\left(E^{2}-1\right)}}-1\right\}^{1 / 2}}
$$

It should be noted, however, that these expressions for an oblate ellipsoidal bubble have been derived assuming that vortex flows in an oblate ellipsoidal bubble are simple geometric distortions of Hill's vortex in spherical bubbles. This is probably not an accurate representation of the vortex flow in an oblate ellipsoid [203]. In fact, oblate distortions of a Hill's vortex asymptotically approach a vortex ring which is a rather different structure than that assumed for the derivations of these expressions.

Certainly, the Fuchs derivation is sufficiently peculiar that it is surprising that it has been so widely used in the absence of any real validation. Mills and Hoseyni [204] have criticized the derivation on the basis of inconsistency. Consider the deposition velocity, V(D), which is a mass transport coefficient. Cast in terms of a Sherwood number, the mass transport coefficient is:

*Eccentricity is defined here as the ratio of the semi-major axis length divided by the length of the semi-minor axis. 
Physical Phenomena

$$
S h=\frac{V(D) D_{B}}{Ð}=f(E)\left[\frac{U_{\text {slip }} D_{B}}{Ð}\right]^{1 / 2}=f(E) \mathrm{Pe}^{1 / 2}
$$

where Pe is the Peclet number. This relationship between the Peclet number and the Sherwood number is the expected result from penetration theory for mass transport. Penetration theory is based on the assumption of a well-mixed bulk fluid and not vortex flow. Mills and Hoseyni correctly note that the Kronig-Brink solution is the proper solution for the case of vortex flows [88]:

$$
\mathrm{Sh}=\frac{\sum_{\mathrm{i}=1}^{\infty} \mathrm{A}_{\mathrm{n}}{ }^{2} \lambda_{\mathrm{n}} \exp \left[\begin{array}{ll}
-16 \lambda_{\mathrm{n}} \tau_{\mathrm{p}}
\end{array}\right]}{\sum_{\mathrm{i}=1}^{\mathrm{n}} \mathrm{A}_{\mathrm{n}}{ }^{2} \exp \left[\begin{array}{lll}
-16 & \lambda_{\mathrm{n}} \tau_{\mathrm{p}}
\end{array}\right]}
$$

where

$$
\tau_{\mathrm{p}}=4 \mathrm{Dt} / \mathrm{D}_{\mathrm{B}}{ }^{2}
$$

and the values of the parameter $\lambda_{n}$ and $A_{n}$ for the first seven terms are [205]:

$\begin{array}{lll}\mathrm{n} & \lambda_{\mathrm{n}} & \mathrm{A}_{\mathrm{n}} \\ 1 & 1.656 & 1.29 \\ 2 & 9.08 & 0.596 \\ 3 & 22.2 & 0.386 \\ 4 & 38.5 & 0.35 \\ 5 & 63.0 & 0.28 \\ 6 & 89.8 & 0.22 \\ 7 & 123.8 & 0.16\end{array}$

In the very long term $\left(\tau_{\mathrm{p}} \rightarrow \infty\right)$,

$$
\mathrm{Sh}=17.66
$$

which is independent of the rise velocity. The time averaged mass transport coefficient is given by:

$$
\operatorname{Sh}=\frac{-2}{3 \tau_{\mathrm{p}}} \ln \left\{\frac{3}{8} \sum_{\mathrm{n}=1}^{\infty} \mathrm{A}_{\mathrm{n}}^{2} \exp \left[\begin{array}{ll}
-16 & \lambda_{\mathrm{n}} \tau_{\mathrm{p}}
\end{array}\right]\right\}
$$


Mills and Hoseyni suggest, based on work by Calderbank and Korchinski [206]:

$$
\mathrm{Sh}=\frac{3 \pi^{2}}{4} \frac{\alpha(\mathrm{t})}{\sqrt{1-\alpha(\mathrm{t})}(1-\sqrt{1-\alpha(\mathrm{t})})}
$$

where

$$
\alpha(\mathrm{t})=\exp \left[\frac{-9 \pi^{2}}{4} \tau_{\mathrm{p}}\right]
$$

In the long term,

$$
\mathrm{Sh}=14.6
$$

Circulation of gases within the smaller bubbles is not assured especially in the contaminated water of the suppression pool. If the gas is essentially stagnant, the Sherwood number is given by [148]:

$$
\mathrm{Sh}=\frac{\frac{2 \pi^{2}}{3} \sum_{n=1}^{\infty} \exp \left[\begin{array}{lll}
-\mathrm{n}^{2} & \pi^{2} \tau_{\mathrm{p}}
\end{array}\right]}{\sum_{\mathrm{n}=1}^{\infty} \frac{1}{\mathrm{n}^{2}} \exp \left[\begin{array}{lll}
-\mathrm{n}^{2} & \pi^{2} \tau_{\mathrm{p}}
\end{array}\right]}
$$

The long-term asymptote of this expression is:

$$
\mathrm{Sh}=6.58
$$

The time-average Sherwood number in this case is:

$$
\text { Sh }=\frac{-2}{3 \tau_{\mathrm{p}}} \ln \left\{\frac{6}{\pi^{2}} \sum_{\mathrm{n}=1}^{\infty} \frac{1}{\mathrm{n}^{2}} \exp \left(\begin{array}{lll}
-\mathrm{n}^{2} & \pi^{2} & \tau_{\mathrm{p}}
\end{array}\right)\right\}
$$

Deposition velocities for particles of various sizes computed with these alternative models are shown in Figure 90. Time-average values shown in this figure were taken to be for 10 seconds which is about the time required for a bubble to rise through a suppression pool. Deposition velocities calculated using Fuchs' model are very high compared to those calculated with other models. Mills and Hoseyni feel, based on findings by Brunson and Wellek [206], that Fuchs' model might be more appropriate for oscillating bubbles. It is also evident from the results shown in Figure 90 that there are substantial differences between the time-average values of the deposition velocity and the long-term asymptote values. This suggests that the dynamic expressions for the Sherwood number, Sh, or deposition velocity ought to be used for analysis of aerosol decontamination by diffusion. 


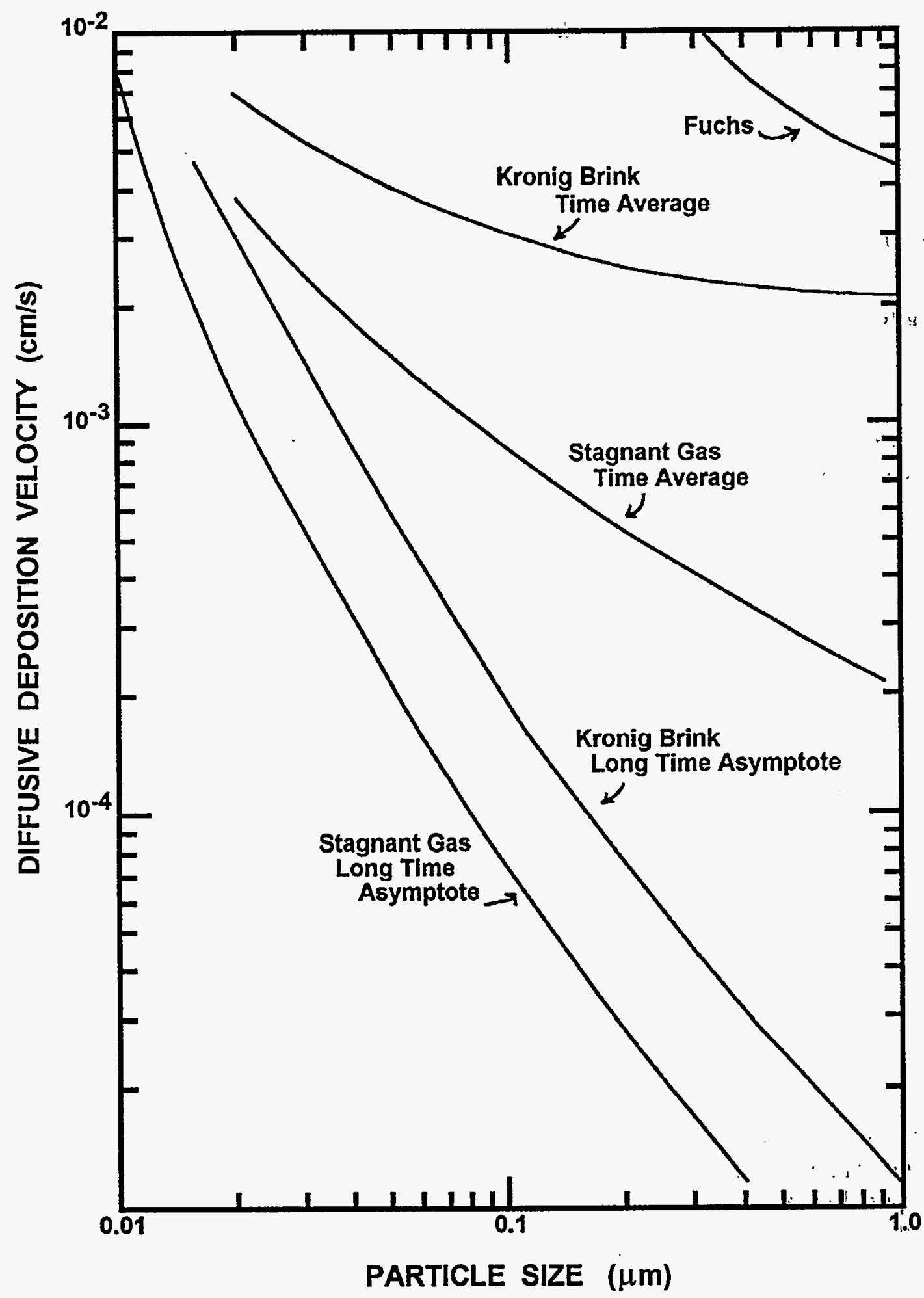

Figure 90. Diffusive deposition velocities according to several models for aerosól particles in a $0.5-\mathrm{cm}$ bubble at $373 \mathrm{~K}$ 
In summary, it is apparent that there is a significant uncertainty in the diffusive deposition of aerosol particles. As discussed below, diffusive deposition is most important for very small particles $(<0.1 \mu \mathrm{m})$. Since small particles will contribute so little to the aerosol mass expected in a reactor accident, the uncertainties in diffusive deposition are not likely to create very large uncertainties in the total decontamination factor achieved by suppression pools. But, the relative magnitude of diffusive deposition (which increases in efficiency with decreasing particle size) is important in comparison to other aerosol deposition processes such as inertial impaction and sedimentation (which decrease in efficiency with decreasing particle size). These relative magnitudes will determine the aerosol particle size least efficiently removed by the suppression pool and consequently the particle size of aerosols most likely to penetrate the pool and become available for release from the plant.

\section{b. Sedimentation Within a Bubble}

The coefficient for aerosol sedimentation per unit rise of an ellipsoidal bubble is:

$$
\alpha(\mathrm{s})=1.5 \mathrm{E}^{2 / 3} \mathrm{~J} / \mathrm{D}_{\mathrm{B}} \mathrm{U}_{\text {rise }}
$$

where

$$
\begin{aligned}
\mathrm{E} & =\text { eccentricity of the bubble, } \\
\mathrm{J} & =\gamma \mathrm{g} \rho_{\mathrm{p}} \mathrm{d}_{\mathrm{p}}{ }^{2} \mathrm{C} / 18 \mu_{\mathrm{g}} \chi \\
\rho_{\mathrm{p}} & =\text { aerosol material density, and } \\
\gamma & =\text { collision shape factor. }
\end{aligned}
$$

The deposition velocity into just the projected area of the lower half of the ellipsoid is:

$$
\mathrm{V}(\mathrm{D})=\mathrm{J}
$$

The deposition velocity normal to the surface of the ellipsoid is:

$$
\mathrm{V}(\text { normal })=\frac{-\mathrm{JE} \cos (\eta)}{\left[\left(\mathrm{E}^{2}-1\right) \cos ^{2}(\eta)+1\right]^{1 / 2}}
$$

for $\eta=\pi / 2$ to $\pi$. The normal deposition velocity is zero for $\eta=0$ to $\pi / 2$. The differential area for deposition is:

$$
\mathrm{dA}=\frac{\pi \mathrm{D}_{\mathrm{B}}^{2}}{2 \mathrm{E}^{1 / 3}} \sqrt{\left(\mathrm{E}^{2}-1\right)}\left[\frac{1}{\mathrm{E}^{2}-1}+\cos ^{2}(\eta)\right]^{1 / 2} \sin (\eta) \mathrm{d} \eta
$$


A plot of $\frac{\mathrm{V}(\text { normal })}{\pi \mathrm{D}_{\mathrm{B}}^{2} \mathrm{~J}} \frac{\mathrm{dA}}{\mathrm{d} \eta}$ as a function of $\eta$ is shown in Figure 91 for values of the eccenitricitý from 1.1 to 4 .

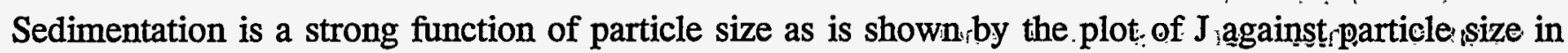
Figure 92. It is likely that most particles large enough to deposit by sedimentation during bubble rise through a suppression pool would have been removed by deposition processes during transport to the pool.

\section{c. Inertial Deposition}

Circulation of gases within a bubble can lead to deposition because large particles are unable to follow stream lines in the flow. Deposition from the circulation vortex in a spherical bubble has been derived by Fuchs [148]. Derivation of the deposition from an oblate ellipsoid has been based on the consideration of simple geometric distortion of the Hill's vortex in spherical bubbles [149,150]. As noted above, this is not an accurate portrayal of the circulation in an oblate ellipsoidal bubble [203]. The deposition coefficient for the fraction of particles deposited per unit rise of a bubble of eccentricity $\mathrm{E}$ is:

$$
\alpha(I)=\frac{6 U_{\text {slip }}^{2} \tau E^{4 / 3}}{D_{B}{ }^{2} U_{\text {rise }}} \frac{\left\{\left(E^{2}-1\right)^{2}+\left(E^{2}-1\right)^{1 / 2}\left(E^{2}-2\right) \tan ^{-1}\left[\sqrt{\left(E^{2}-1\right)}\right]\right\}}{\left\{\sqrt{\left(E^{2}-1\right)}-E^{2} \tan ^{-1}\left[\sqrt{\left(E^{2}-1\right)}\right]\right\}^{2}}
$$

where

$$
\begin{aligned}
\tau & =\mathrm{J} / \mathrm{g}=\gamma \rho_{\mathrm{p}} \mathrm{d}_{\mathrm{p}}{ }^{2} \mathrm{C} / 18 \mu_{\mathrm{g}} \chi, \text { and } \\
\gamma & =\text { collision shape factor }
\end{aligned}
$$

A deposition velocity over the entire surface area of the bubble is:

$$
\mathrm{V}(\mathrm{I})=\frac{2 \mathrm{U}_{\operatorname{slip}}^{2} \tau \mathrm{E}^{2 / 3}\left\{\left(\mathrm{E}^{2}-1\right)^{2}+\left(\mathrm{E}^{2}-1\right)^{3 / 2}\left(\mathrm{E}^{2}-2\right) \tan ^{-1}\left[\sqrt{\left(\mathrm{E}^{2}-1\right)}\right]\right\}}{\mathrm{D}_{\mathrm{B}}\left\{1+\frac{\ln \left[\frac{\mathrm{E}+\left(\mathrm{E}^{2}-1\right)^{1 / 2}}{\mathrm{E}-\left(\mathrm{E}^{2}-1\right)^{1 / 2}}\right]}{2 \mathrm{E}\left(\mathrm{E}^{2}-1\right)^{1 / 2}}\right]\left\{\sqrt{\left(\mathrm{E}^{2}-1\right)}-\mathrm{E}^{2} \tan ^{-1}\left[\left(\mathrm{E}^{2}-1\right)^{1 / 2}\right]\right\}^{2}}
$$




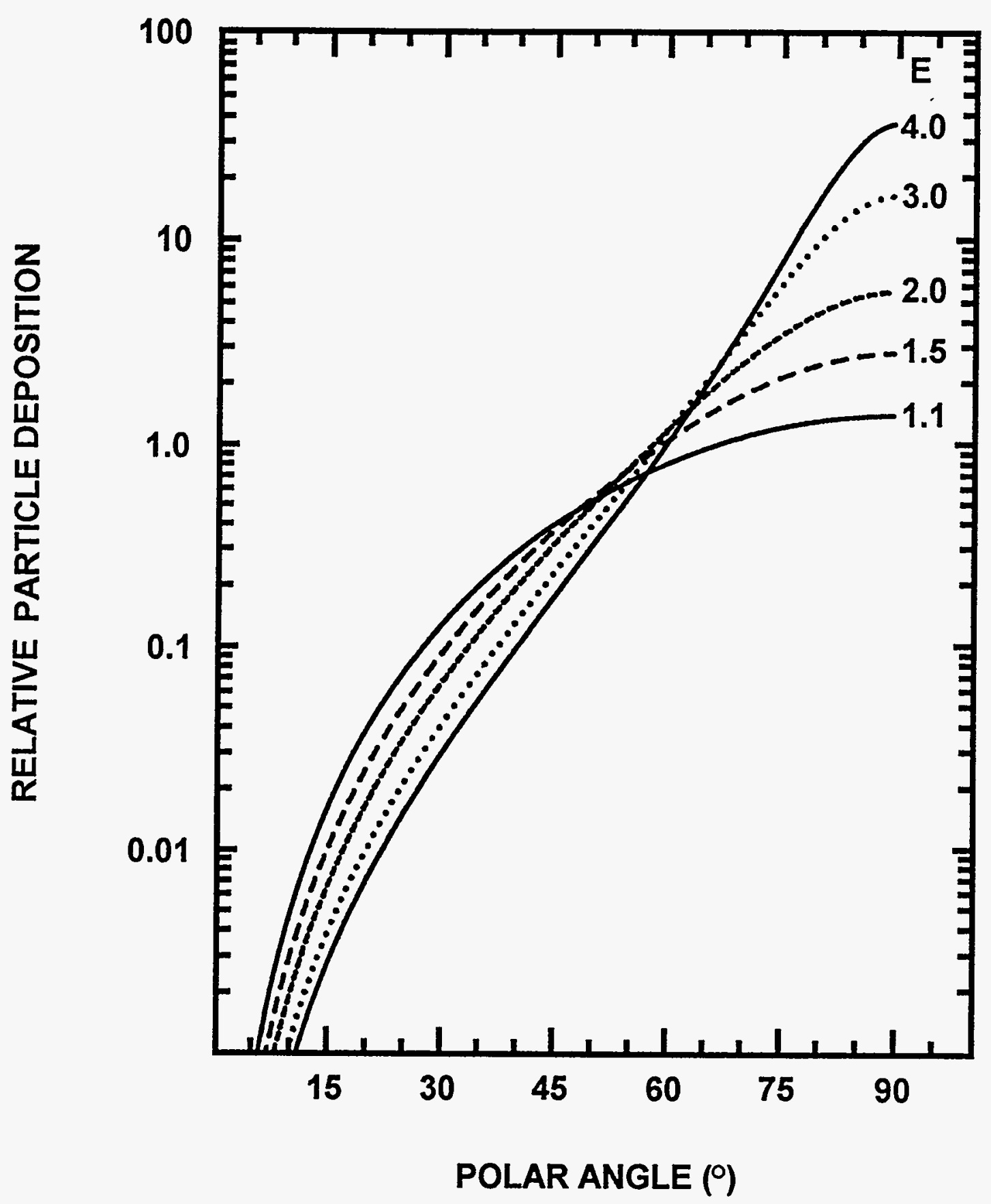

Figure 91. Patterns of particle deposition by sedimentation within ellipsoidal bubbles of various eccentricities 


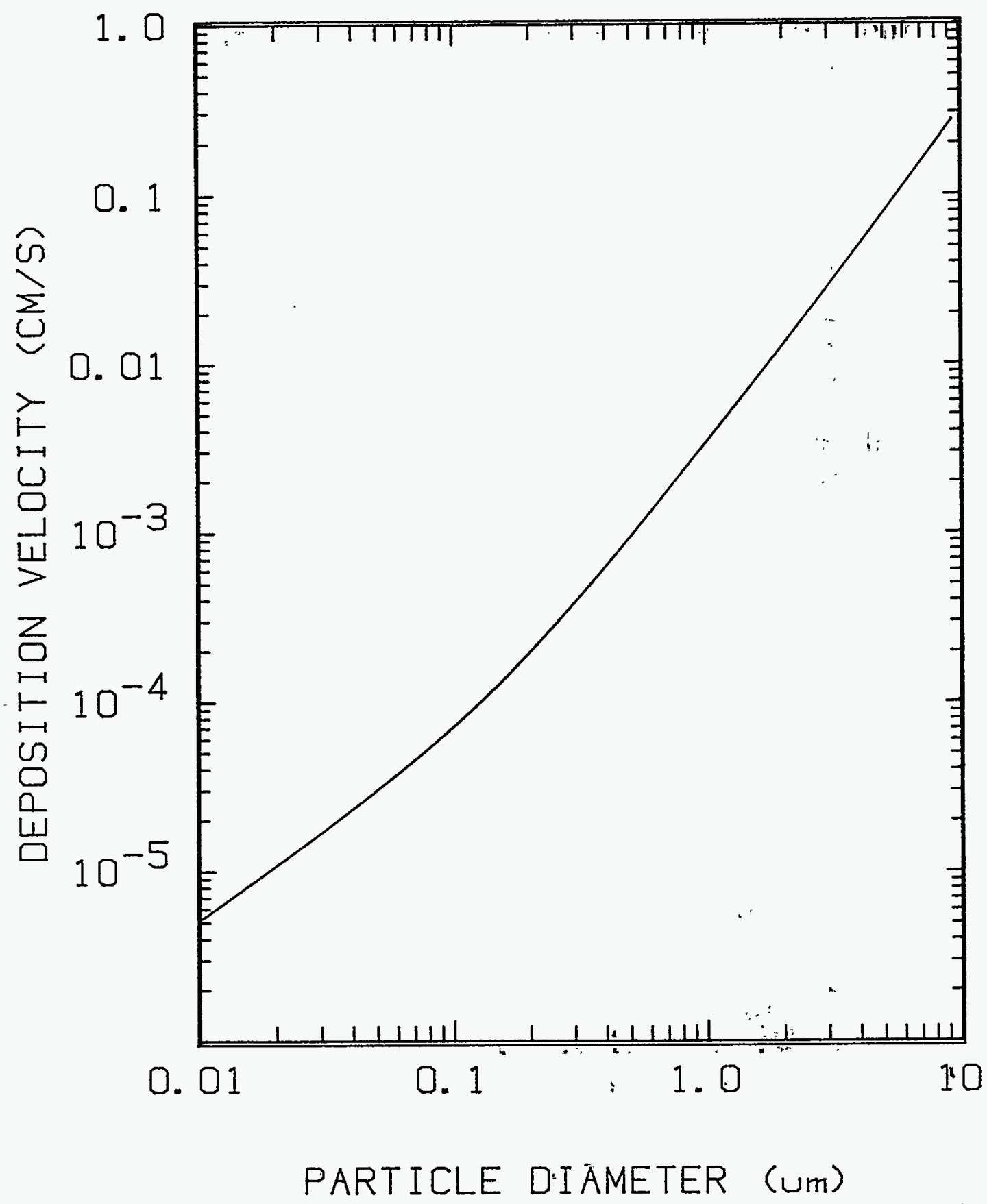

Figure 92. Sedimentation deposition velocity as a function of particle size 
The centrifugal acceleration responsible for the deposition is given by:

$$
\text { acceleration }=\mathrm{a}=\frac{2 \mathrm{U}_{\text {slip }}^{2} \sin ^{2}(\eta) \sqrt{\mathrm{E}^{2}-1} \mathrm{E}^{5 / 3}}{\mathrm{D}_{\mathrm{B}}\left\{\cos ^{2}(\eta)+\frac{1}{\mathrm{E}^{2}-1}\right\}^{5 / 2}\left\{\sqrt{\mathrm{E}^{2}-1}-\mathrm{E}^{2} \tan ^{-1}\left[\sqrt{\mathrm{E}^{2}-1}\right]\right\}^{2}}
$$

where $\eta$ is the polar angle of a vector from the origin of the ellipsoid to a point on the surface. The local deposition velocity is given by

$$
\frac{\gamma \rho_{\mathrm{p}} \mathrm{d}_{\mathrm{p}}^{2} \mathrm{C} \mathrm{a}}{18 \mu_{\mathrm{g}} \chi}=\mathrm{V}_{\mathrm{D}}(\text { local })=\mathrm{a} \tau
$$

The differential area for deposition is:

$$
\mathrm{dA}=\frac{\pi \mathrm{D}_{\mathrm{B}}^{2}}{2 \mathrm{E}^{1 / 3}} \sqrt{\mathrm{E}^{2}-1}\left\{\frac{1}{\mathrm{E}^{2}-1}+\cos ^{2}(\eta)\right\}^{1 / 2} \sin (\eta) \mathrm{d} \eta
$$

for $\eta=0$ to $\pi$. Plots of the patterns of deposition of particles by inertial impaction in ellipsoidal bubbles of various eccentricities are shown in Figure 93. It is apparent from results shown in this figure that most of the inertial impaction of particles occurs in a region around the midplane of the bubble. This region becomes narrower as the eccentricity of the bubble increases.

Deposition velocities due to inertial impaction are shown in Figure 94 as functions of particle size for bubbles of various sizes and eccentricities. These results show that inertial impaction can affect particles that are smaller than those affected by gravitational settling but does not affect particles that are efficiently deposited by diffusion. Combining the three classic mechanisms of aerosol depositiondiffusion, sedimentation and inertial impaction-produces an overall deposition velocity that passes through a minimum when plotted against particle size. The exact position of this minimum deposition velocity does depend on bubble size and system properties, but it is typically in the vicinity of 0.1 to $0.3 \mu \mathrm{m}$ diameter particles.

\section{d. Particle Deposition by Diffusiophoresis}

In general, the gas within a bubble will not be in equilibrium with the water pool. As discussed above (see Section IV-D) the partial pressure of water vapor in a bubble will be depressed below the equilibrium partial pressure of water vapor in the suppression pool. There will, then, be a flux of water vapor from the bubble surface directed into the bubble which will oppose particle deposition. In principle, gases such as $\mathrm{H}_{2}, \mathrm{CO}$, and $\mathrm{CO}_{2}$ will diffuse from the bubble into the water until the water pool becomes saturated. As discussed above, the saturation concentrations of these gases are so low that this flux of gas, which would tend to enhance deposition, is thought to be negligible. Attentions here are, then, fixed upon the inhibition to deposition by the water vapor flux into the bubble-diffusiophoresis. In the analysis of diffusiophoresis, temperature gradients between the bulk 


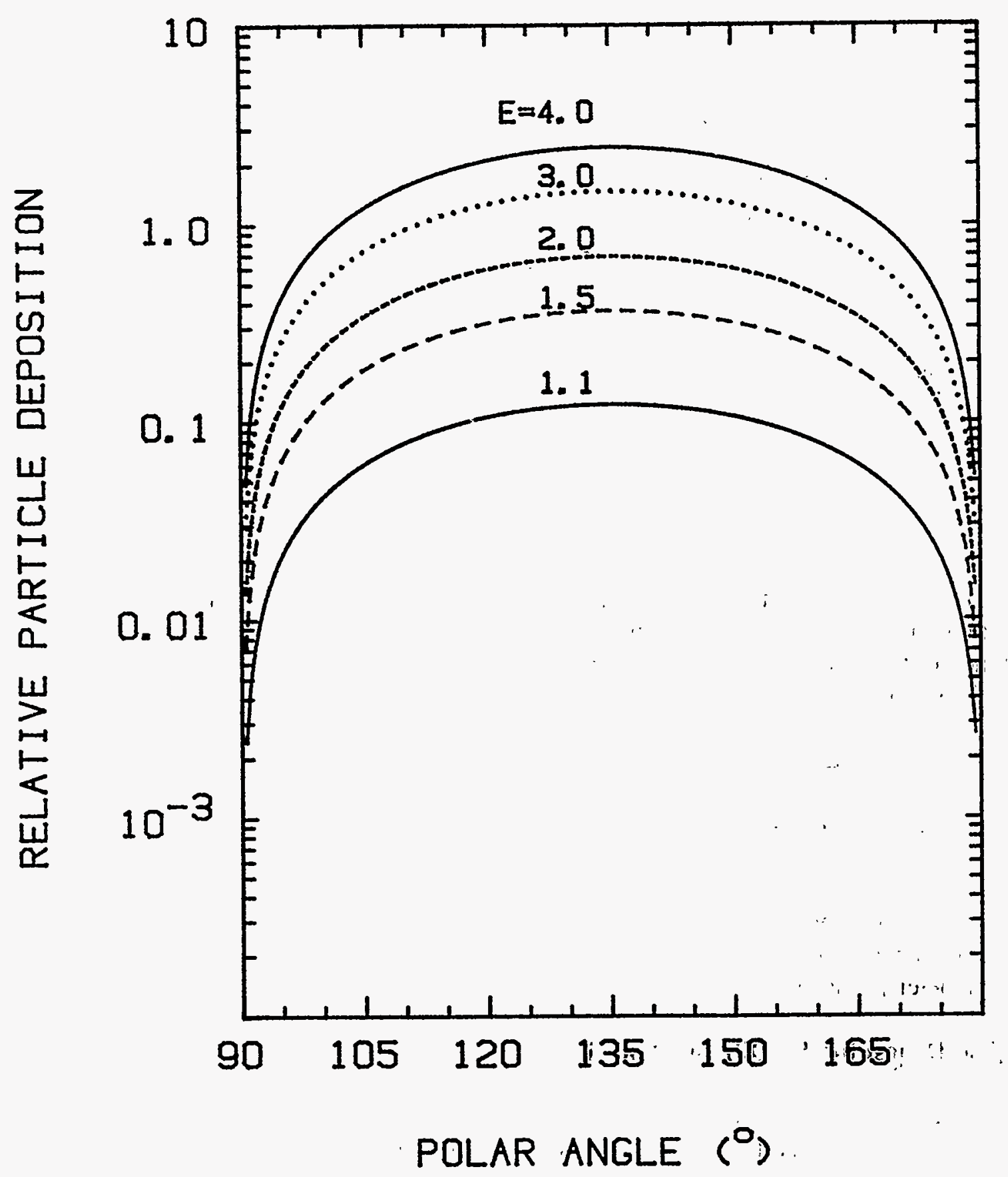

Figure 93. Patterns of particle deposition by inertial impaction in ellipsọidal bububles of various eccentricities. Note that the deposition pattern is symmetrical about a polar angle of $90^{\circ}$. 


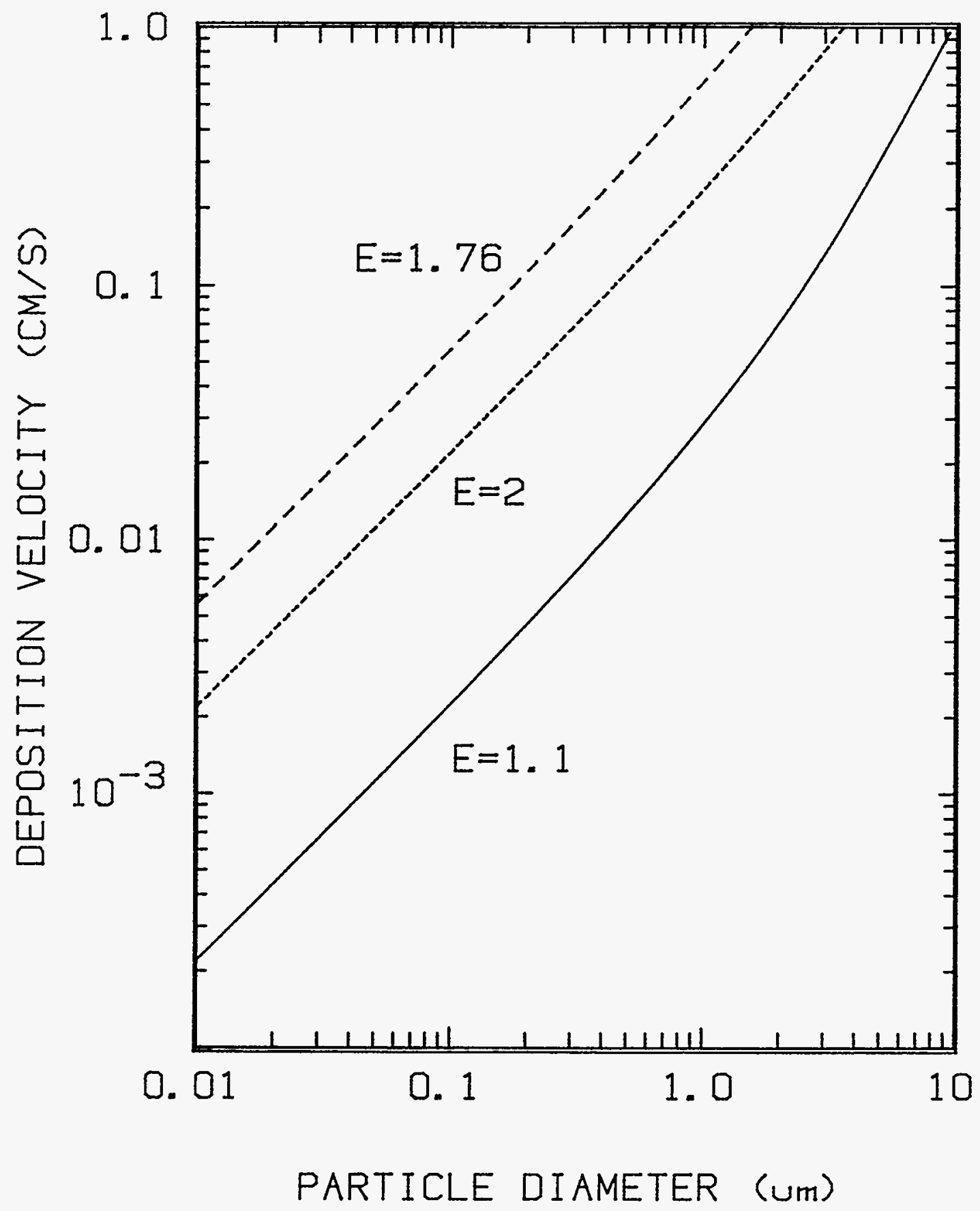

Figure 94. Inertial impaction deposition velocities as functions of particle size 
gas and the bubble wall will be neglected. Thermodynamic calculations presented above show these gradients are small. The effect of the temperature gradients is to induce a thermophoretic velocity to the particles. This thermophoretic effect and the combined effects of diffusiophoresis and thermophoresis will be discussed in the next subsection.

Because the rising bubble is slightly unsaturated in water vapor, there will be a water vapor concentration gradient in the bubble near the bubble wall. The flux of water vapor away from the wall will subject aerosol particles to a Stefan flow and a diffusiophoretic force. According to Waldmann and Schmidt [166], the Stefan flow is given by:

$$
\mathrm{V}(\text { Stefan })=\frac{\boxplus\left(\mathrm{H}_{2} \mathrm{O}\right)}{\mathrm{P}_{\mathrm{T}}-\mathrm{P}\left(\mathrm{H}_{2} \mathrm{O}\right)} \nabla \mathrm{P}\left(\mathrm{H}_{2} \mathrm{O}\right)
$$

The diffusiophoretic force is given by:

$$
\mathrm{F}_{\mathrm{D}}=-\sigma_{12} \frac{\boxplus\left(\mathrm{H}_{2} \mathrm{O}\right)}{\mathrm{P}_{\mathrm{T}}} 3 \pi \mu_{\mathrm{g}} \mathrm{d}_{\mathrm{p}} \nabla \mathrm{P}\left(\mathrm{H}_{2} \mathrm{O}\right)
$$

where

$$
\begin{aligned}
\boxplus\left(\mathrm{H}_{2} \mathrm{O}\right) & =\text { diffusion coefficient of water vapor in a noncondensible gas within a bubble, } \\
\mathrm{P}_{\mathrm{T}} & =\text { total pressure, and } \\
\sigma_{12} & =\text { collision integral to be discussed below. }
\end{aligned}
$$

The deposition velocity of aerosol particles due to both diffusiophoresis and Stefan flow is:

$$
\mathrm{V}_{\mathrm{D}}=\frac{\mathrm{C}}{\chi}\left[\frac{\chi}{\mathrm{C}}+\sigma_{12}\left(1-\mathrm{P}\left(\mathrm{H}_{2} \mathrm{O}\right) / \mathrm{P}_{\mathrm{T}}\right)\right] \frac{\bigoplus\left(\mathrm{H}_{2} \mathrm{O}\right)}{\left[\mathrm{P}_{\mathrm{T}}-\mathrm{P}\left(\mathrm{H}_{2} \mathrm{O}\right)\right]} \dot{\nabla}\left(\mathrm{H}_{2} \mathrm{O}\right)
$$

Waldmann and Schmitt [166] indicate that the quantity $\sigma_{12}$ is theoretically:

$$
\sigma_{12}=\frac{\mathrm{m}\left(\mathrm{H}_{2} \mathrm{O}\right)-\mathrm{m}(\mathrm{gas})}{\mathrm{m}+\left(\mathrm{m}\left(\mathrm{H}_{2} \mathrm{O}\right) \mathrm{m}(\mathrm{gas})\right)^{1 / 2}}
$$

where $\mathrm{m}=\mathrm{m}\left(\mathrm{H}_{2} \mathrm{O}\right)+\mathrm{m}(\mathrm{gas})$. But, to match experimental data well, they find

$$
\sigma_{12}=\frac{0.95\left(\mathrm{~m}\left(\mathrm{H}_{2} \mathrm{O}\right)-\mathrm{m}(\mathrm{gas})\right)}{\mathrm{m}\left(\mathrm{H}_{2} \mathrm{O}\right)+\mathrm{m}(\mathrm{gas})}-1.05 \frac{\left(\sigma\left(\mathrm{H}_{2} \mathrm{O}\right)-\sigma(\mathrm{gas})\right)}{\sigma\left(\mathrm{H}_{2} \mathrm{O}\right)+\sigma(\mathrm{gas})}
$$


In the free molecular regime, Waldmann and Schmitt recommend:

$$
\begin{aligned}
& 1+\sigma_{12}\left(\mathrm{P}-\mathrm{P}\left(\mathrm{H}_{2} \mathrm{O}\right) / \mathrm{P}=\right. \\
& =\frac{\mathrm{P}\left[1+\pi \alpha_{\mathrm{t}}\left(\mathrm{H}_{2} \mathrm{O}\right) / 8\right] \sqrt{\mathrm{m}\left(\mathrm{H}_{2} \mathrm{O}\right)}}{\mathrm{P}\left(\mathrm{H}_{2} \mathrm{O}\right)\left[1+\pi \alpha_{\mathrm{t}}\left(\mathrm{H}_{2} \mathrm{O}\right) / 8\right] \sqrt{\mathrm{m}\left(\mathrm{H}_{2} \mathrm{O}\right)}+\left(\mathrm{P}-\mathrm{P}\left(\mathrm{H}_{2} \mathrm{O}\right)\right)\left(1+\pi \alpha_{\mathrm{t}}(\mathrm{gas}) / 8\right) \sqrt{\mathrm{m}(\mathrm{gas})}}
\end{aligned}
$$

where

$$
\begin{aligned}
\mathrm{m}\left(\mathrm{H}_{2} \mathrm{O}\right) & =\text { molecular weight of } \mathrm{H}_{2} \mathrm{O} \\
\mathrm{m}(\mathrm{gas}) & =\text { molecular weight of the noncondensible gas } \\
\alpha_{\mathrm{t}}\left(\mathrm{H}_{2} \mathrm{O}\right) & =\text { thermal accommodation coefficient of } \mathrm{H}_{2} \mathrm{O} \\
\alpha_{\mathrm{t}} \text { (gas) } & =\text { thermal accommodation coefficient of the noncondensible gas. }
\end{aligned}
$$

The molar flux of water vapor to the bubble surface is given by:

$$
\mathrm{j}\left(\mathrm{H}_{2} \mathrm{O}\right)=\frac{-Ð\left(\mathrm{H}_{2} \mathrm{O}\right)}{\mathrm{RT}} \frac{\nabla \mathrm{P}\left(\mathrm{H}_{2} \mathrm{O}\right)}{\left(1-\mathrm{P}\left(\mathrm{H}_{2} \mathrm{O}\right) / \mathrm{P}_{\mathrm{T}}\right)}
$$

It is assumed here that the partial pressure of steam varies only with the normal distance from the bubble walls. Then, in oblate ellipsoidal coordinates*, the gradient is:

$$
\nabla \mathrm{P}\left(\mathrm{H}_{2} \mathrm{O}\right)=\frac{\partial \mathrm{P} / \partial \xi}{\left[\mathrm{C}^{2} \cos ^{2}(\eta)+\mathrm{C}^{2} \sinh ^{2}(\xi)\right]^{1 / 2}}
$$

and,

$$
\mathrm{j}\left(\mathrm{H}_{2} \mathrm{O}\right)=\frac{\boxplus\left(\mathrm{H}_{2} \mathrm{O}\right)}{\mathrm{RT}} \mathrm{P}_{\mathrm{T}} \frac{\partial \ln \mathrm{P}\left(\mathrm{H}_{2} \mathrm{O}\right) / \partial \xi}{\left[\mathrm{C}^{2} \cos ^{2}(\eta)+\mathrm{C}^{2} \sinh ^{2}(\xi)\right]^{1 / 2}}
$$

The total rate of mass transfer to the bubble surface is:

*Cartesian coordinates $\mathrm{x}$ and $\mathrm{y}$ in terms of the oblate ellipsoidal coordinates are:

$$
\begin{aligned}
& x_{2}=C 2 \sinh (\xi) \cos (\eta) \quad y=C \cosh (\xi) \sin (\eta) \\
& C^{2}=a^{2}-b^{2}
\end{aligned}
$$

where $a$ and $b$ are the length of the semi-major and semi-minor axes, respectively. 
Physical Phenomena

$$
\begin{gathered}
\int_{A} j\left(\mathrm{H}_{2} \mathrm{O}\right) \mathrm{dA}=\int \mathrm{j}\left(\mathrm{H}_{2} \mathrm{O}\right) 2 \pi \mathrm{y} d \mathrm{~s} \\
\mathrm{ds}=\frac{\mathrm{a}\left(\mathrm{E}^{2}-1\right)^{1 / 2}}{\mathrm{E}}\left[\frac{1}{\mathrm{E}^{2}-1}+\cos ^{2}(\eta)\right]^{1 / 2} \sin (\eta) \mathrm{d} \eta
\end{gathered}
$$

so,

$$
\int \mathrm{j}\left(\mathrm{H}_{2} \mathrm{O}\right) \mathrm{dA}=\left.\frac{\pi^{2} \mathrm{a} \boxplus\left(\mathrm{H}_{2} \mathrm{O}\right) \mathrm{P}_{\mathrm{T}}}{\mathrm{RT}} \frac{\partial \ln \mathrm{P}\left(\mathrm{H}_{2} \mathrm{O}\right)}{\partial \xi}\right|_{\xi=\xi_{\mathrm{O}}}
$$

Similarly,

$$
\int \mathrm{j}\left(\mathrm{H}_{2} \mathrm{O}\right) \mathrm{dA}=-\mathrm{k}_{\mathrm{m}} \mathrm{A}\left[\mathrm{P}(\text { sat })-\mathrm{P}\left(\mathrm{H}_{2} \mathrm{O}\right)\right] / \mathrm{RT}
$$

where

$$
\begin{aligned}
& A=2 \pi a^{2}\left\{1+\frac{1}{2 E \sqrt{E^{2}-1}} \ln \left[\frac{E+\sqrt{E^{2}-1}}{E-\sqrt{E^{2}-1}}\right]\right\}, \text { and } \\
& a=D_{B} E^{1 / 3} / 2
\end{aligned}
$$

Then,

$$
\left.\frac{\mathrm{d} \ln \mathrm{P}\left(\mathrm{H}_{2} \mathrm{O}\right)}{\mathrm{d} \xi}\right|_{\xi=\xi_{\mathrm{O}}}=\frac{-\mathrm{A}\left[\mathrm{P}(\mathrm{sat})-\mathrm{P}\left(\mathrm{H}_{2} \mathrm{O}\right)\right] \mathrm{k}_{\mathrm{m}}}{\pi^{2} \mathrm{a} \boxplus\left(\mathrm{H}_{2} \mathrm{O}\right) \mathrm{P}_{\mathrm{T}}}
$$

and

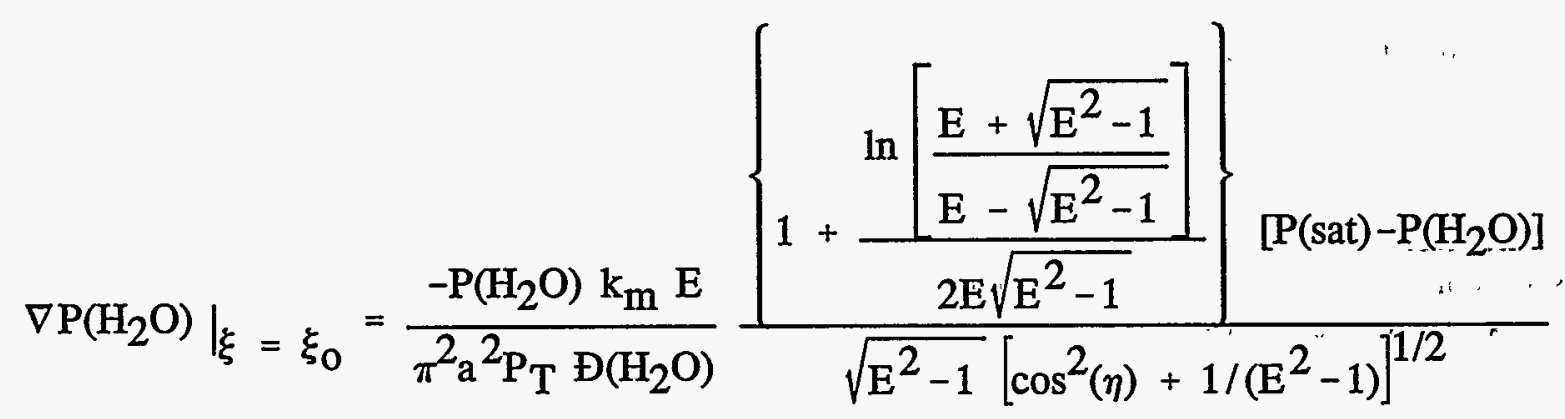


A theoretical expression for the external mass transport in potential flow over an oblate ellipsoid is [267]:

$$
S h=\frac{k_{m} D_{B}}{Ð}=\frac{2 \pi D_{B}^{2} P e^{1 / 2}}{\sqrt{\pi} A}\left\{\frac{2\left(E^{2}-1\right)^{3 / 2}}{3\left[E^{2} \tan ^{-1}\left(\sqrt{E^{2}-1}\right)-\sqrt{E^{2}-1}\right]}\right\}^{1 / 2}
$$

Taking this expression as approximately applicable also for the interior, rotational flow yields:

$$
\left.\nabla \mathrm{P}\left(\mathrm{H}_{2} \mathrm{O}\right)\right|_{\xi=\xi_{0}}=-\frac{8}{\pi^{3 / 2}} \frac{\mathrm{Pe}^{1 / 2}}{\mathrm{D}_{\mathrm{B}}} \frac{\mathrm{P}\left(\mathrm{H}_{2} \mathrm{O}\right)}{\mathrm{P}_{\mathrm{T}}} \frac{\mathrm{E}^{1 / 3}\left[\mathrm{P}(\mathrm{sat})-\mathrm{P}\left(\mathrm{H}_{2} \mathrm{O}\right)\right]}{\left[\cos ^{2}(\eta)+1 /\left(\mathrm{E}^{2}-1\right)\right]^{1 / 2}}\left[\frac{2\left(\mathrm{E}^{2}-1\right)}{3\left\{\left(\mathrm{E}^{2} \tan ^{-1}\left(\sqrt{\mathrm{E}^{2}-1}\right)-\sqrt{\mathrm{E}^{2}-1}\right\}\right.}\right]^{1 / 2}
$$

where

$$
\begin{aligned}
& \mathrm{Pe}=\mathrm{U}_{\mathrm{B}} \mathrm{D}_{\mathrm{B}} / \mathrm{D}\left(\mathrm{H}_{2} \mathrm{O}\right) \text {, and } \\
& \mathrm{D}_{\mathrm{B}}=\text { diameter of the volume equivalent sphere. }
\end{aligned}
$$

A plot of the relative variation of the partial pressure gradient and consequently the diffusiophoretic flux of particles around the surface of the bubble is shown in Figure 95. Since, in general, the saturation partial pressure at the bubble surface will be greater than the partial pressure of water vapor in the bubble, the gradient is negative. That is, the flow of evaporating water will force particles away from the surface.

\section{e. Thermophoresis}

A particle in a thermal gradient will migrate toward lower temperature due to the thermophoretic force. This effect, which is so difficult to accurately measure, has prompted a remarkable amount of intemperate language in the specialized literature (see for examples References 225 and 226). Bakanov (225) provides a readable review of the topic. Thermophoresis literature is challenging because nomenclature is not standardized.

By far, the most widely used expressions for predicting the thermophoretic motions of particles is that derived by Talbot et al. [154]:

$$
V_{D}=\frac{\frac{2 C_{s} \mu_{g}}{\chi \rho_{g}}\left[\frac{k_{g}}{k_{p}}+C_{t} K n\right] C \nabla \ln T}{\left[1+3 C_{m} K n\right]\left[1+2 k_{g} / k_{p}+2 C_{t} K n\right]}
$$


Physical Phenomena

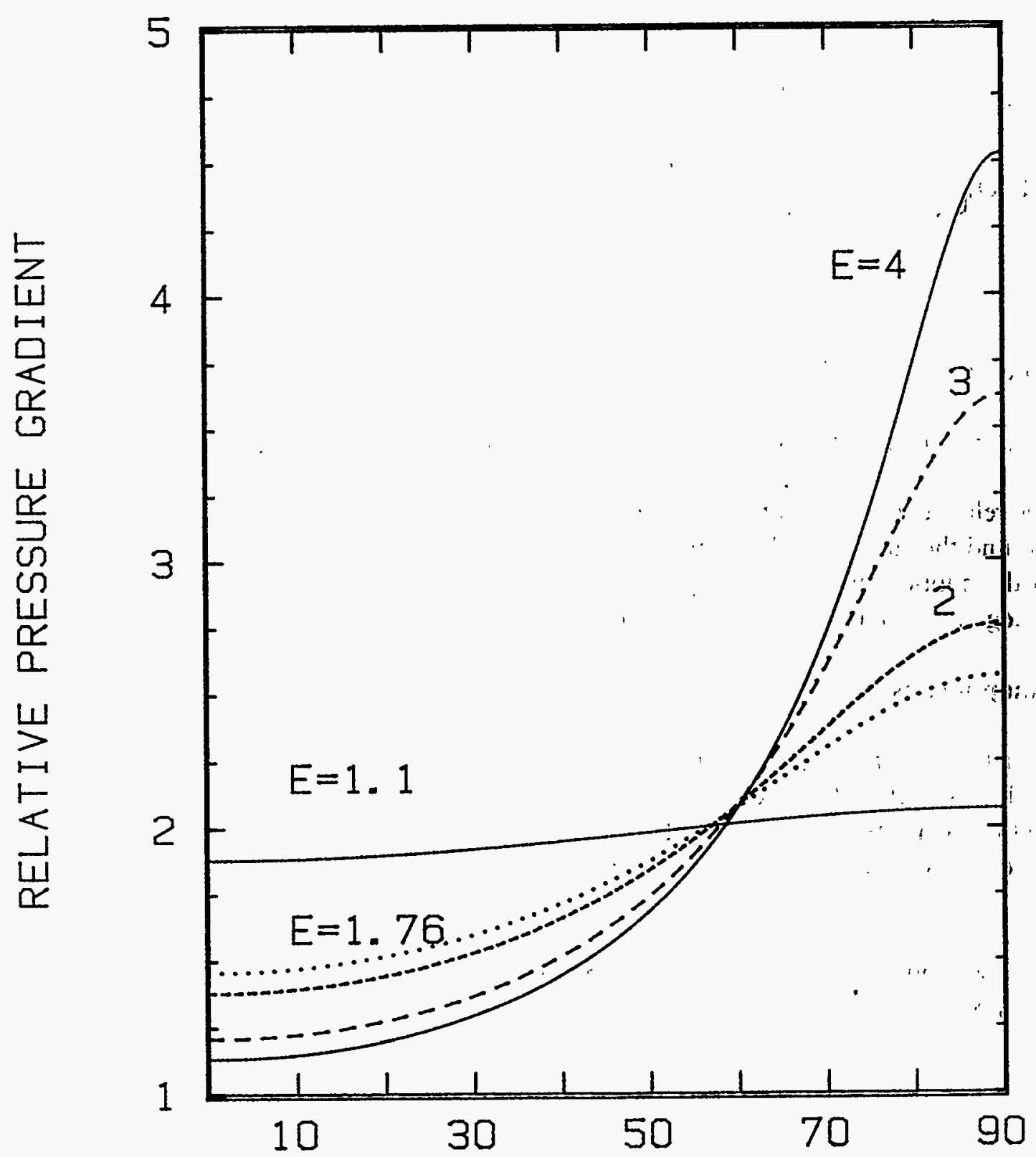

ANGLE (DEGREES)

Figure 95. Relative variation in the water vapor pressure gradient at the surfaces of ellipsoidal bubbles of various eccentricities. Note that variations are symmetrical about polar angles of 90 and $180^{\circ}$. 


$$
\mathrm{F}_{T}=\frac{\frac{-6 \pi \mu_{g} d_{p} C_{s}}{\rho_{g}}\left[\frac{k_{g}}{k_{p}}+C_{t} K n\right] \nabla \ln T}{\left[1+3 C_{m} K n\right]\left[1+2 k_{g} / k_{p}+2 C_{t} K n\right]}
$$

where

$$
\begin{aligned}
& F_{T}=\text { thermophoretic force } \\
& V_{D}=\text { thermophoretic deposition velocity } \\
& C_{s}=1.128 \\
& C_{m}=\frac{2-\alpha_{m}}{\alpha_{m}} \\
& C_{t}=\frac{15}{8} \frac{\left(2-\alpha_{t}\right)}{\alpha_{t}}
\end{aligned}
$$

Loyalka [227] has suggested some alternate expressions for parametric quantities that depend on the intermolecular force law

$$
\begin{aligned}
\mathrm{C}_{\mathrm{s}} & =0.75\left(1-\alpha_{\mathrm{m}}\right)+3 \alpha_{\mathrm{m}} \xi(\mathrm{s}) \\
\mathrm{C}_{\mathrm{t}} & =\frac{15}{8} \frac{\left(2-\alpha_{\mathrm{t}}\right)}{\alpha_{\mathrm{t}}}\left[\left(1-\alpha_{\mathrm{t}}\right) \frac{5}{8} \sqrt{\pi}+\alpha_{\mathrm{t}} \xi(\mathrm{t})\right] \\
\mathrm{C}_{\mathrm{m}} & =\left(\frac{2-\alpha_{\mathrm{m}}}{\alpha_{\mathrm{m}}}\right)\left[\left(1-\alpha_{\mathrm{m}}\right) \frac{\sqrt{\pi}}{2}+\alpha_{\mathrm{m}} \xi(\mathrm{m})\right] \\
\xi(\mathrm{s}) & =0.35 \text { to } 0.383 \\
\xi(\mathrm{t}) & =1.263 \text { to } 1.296 \\
\xi(\mathrm{m}) & =0.996 \text { to } 1.02
\end{aligned}
$$

Derjaquin and Yalamov [161] have used arguments based on irreversible thermodynamics to derive:

$$
\frac{V_{D}=\frac{-3.0 \mu_{g}}{\rho_{g}}\left[\frac{k_{g}}{k_{p}}+C_{t} K n\right] \nabla \ln T}{\left[1+2 C_{m} K n\right]\left[1+2 k_{g} / k_{p}+2 C_{t} K n\right]}
$$

which differs from that found by Talbot et al. by a factor of $2 C_{s} / 3 \cong 0.75$. 
Physical Phenomena

Fulford et al. [159] have correlated experimental data to obtain.-

$$
\begin{aligned}
\log _{10}\left[\frac{\mathrm{F}_{\mathrm{T}}}{\nabla \mathrm{T}}\right]= & -11.418-0.7525 \log _{10} \mathrm{Kn}-0.2231\left(\log _{10} \mathrm{Kn}\right)^{2} \\
& -0.2695\left(\log _{10} \mathrm{Kn}\right)^{3}
\end{aligned}
$$

and

$$
V_{D}=-F_{T} C / 3 \pi \mu_{g} d_{p}
$$

Phillips [244] has produced what is the most heroic expression for thermophoretic force:

$$
\mathrm{F}_{\mathrm{T}}=\frac{-27}{2} \pi \beta_{\mathrm{t}}\left(\frac{\mathrm{k}_{\mathrm{g}}}{2 \mathrm{k}_{\mathrm{g}}+\mathrm{k}_{\mathrm{p}}}\right) \frac{\mu_{\mathrm{g}}^{2}}{\rho_{\mathrm{g}}} \nabla \ln \mathrm{T}
$$

where

$$
\begin{aligned}
& \beta_{\mathrm{t}}=\frac{1+\mathrm{N}(1) \mathrm{Kn}+\mathrm{N}(2) \mathrm{Kn}}{1+\mathrm{D}(1) \mathrm{Kn}+\mathrm{D}(2) \mathrm{Kn}{ }^{2}+\mathrm{D}(3) \mathrm{Kn}^{3}} \\
& \mathrm{~N}(1)=\frac{\mathrm{k}_{\mathrm{p}} \mathrm{C}_{\mathrm{t}}}{\mathrm{k}_{\mathrm{g}}}-\frac{15}{4} \frac{\left(\mathrm{k}_{\mathrm{p}}-\mathrm{k}_{\mathrm{g}}\right)}{\mathrm{k}_{\mathrm{g}}} \mathrm{C}_{\mathrm{m}} \\
& \mathrm{N}(2)=\frac{15}{4} \frac{\mathrm{k}_{\mathrm{p}}}{\mathrm{k}_{\mathrm{g}}} \mathrm{C}_{\mathrm{t}} \mathrm{C}_{\mathrm{m}} \\
& \mathrm{D}(1)=\frac{9}{2}\left[\frac{\mathrm{k}_{\mathrm{g}}}{2 \mathrm{k}_{\mathrm{g}}+\mathrm{k}_{\mathrm{p}}}\right]+\left[\frac{2 \mathrm{k}_{\mathrm{p}}}{2 \mathrm{k}_{\mathrm{g}}+\mathrm{k}_{\mathrm{p}}}\right] \mathrm{C}_{\mathrm{t}}+3 \mathrm{C}_{\mathrm{m}} \\
& D(2)=\frac{9}{2}\left[\frac{k_{p}}{2 k_{g}+k_{p}}\right] C_{t}-\frac{135}{8} \frac{\left(k_{p}-k_{g}\right)}{\left(2 k_{g}+k_{\ddot{p}}\right)} C_{m}+\frac{6 k_{p}}{\left(2 k_{g}+k_{p}\right)} C_{t}+C_{m} \\
& D(3)=\frac{135}{8}\left[\frac{k_{p}}{2 k_{g}+k_{p}}\right] C_{t} C_{m}
\end{aligned}
$$

Phillips, however, has argued that the particle moving in a thermal gradient distorts the gradient so that the deposition velocity is 


$$
\mathrm{V}_{\mathrm{D}}=\frac{-9}{4} \beta_{\mathrm{t}} \mathrm{C}\left[\frac{\mathrm{k}_{\mathrm{g}}}{2 \mathrm{k}_{\mathrm{g}}+\mathrm{k}_{\mathrm{p}}}\right] \frac{\mu_{\mathrm{g}}}{\rho_{\mathrm{g}}}\left[\frac{1-\sqrt{1-2 \gamma}}{\gamma}\right] \nabla \ln \mathrm{T}
$$

where

$$
\begin{aligned}
\gamma & =\beta_{\mathrm{u}} \frac{\mathrm{k}_{\mathrm{g}} \mathrm{k}_{\mathrm{p}}}{\left(2 \mathrm{k}_{\mathrm{g}}+\mathrm{k}_{\mathrm{p}}\right)^{2}}\left(\beta_{\mathrm{t}} \mathrm{C}\right)^{2} \mathrm{Kn} \\
\beta_{\mathrm{u}} & =\frac{\mathrm{N}_{\mathrm{p}} / 16+\mathrm{BKn} \exp \left(-\mathrm{C}^{\prime} \mathrm{Kn}\right)}{1+\mathrm{DKn}} \\
\mathrm{B} & =46900 \\
\mathrm{C}^{\prime} & =31.8 \\
\mathrm{D} & =18 \\
\mathrm{~N}_{\mathrm{p}} & =\left[\frac{8 \mathrm{RT}}{\pi \mathrm{MW}}\right]^{1 / 2} \frac{\mathrm{d}_{\mathrm{p}}{ }^{3}}{8} \frac{(\nabla \ln \mathrm{T})^{2}}{\alpha_{\mathrm{p}}} \\
\mathrm{MW} & =\text { molecular weight of the gas, and } \\
\alpha_{\mathrm{p}} & =\text { thermal diffusivity of the particle. }
\end{aligned}
$$

This distortion of the thermal gradient can accentuate the thermophoretic settling of particles by the factor $(1-\sqrt{1-2 \gamma}) / \gamma$.

Phillips' model predicts somewhat lower deposition velocities when the thermal gradient correction is not made than does the model developed by Talbot et al. Parametric variations that are part of this work can cause Phillips' model to predict particle motions up the thermal gradient. Consequently, Phillips' model is not used here.

Some comparisons of the predictions for the dimensionless deposition velocity

$$
\frac{\mathrm{V}_{\mathrm{D}} \rho_{\mathrm{g}}}{\mu_{\mathrm{g}} \nabla \ln \mathrm{T}}
$$

to data for oil drops in hydrogen and carbon dioxide are shown in Figures 96 and 97 . Thermophoretic deposition velocities seem fairly well predicted for values of the Knudsen numbers greater than about 0.5. Some comparisons for inorganic species are listed in Table 18. The empirical model matches these data closely since the data were used to make the empirical fit. 


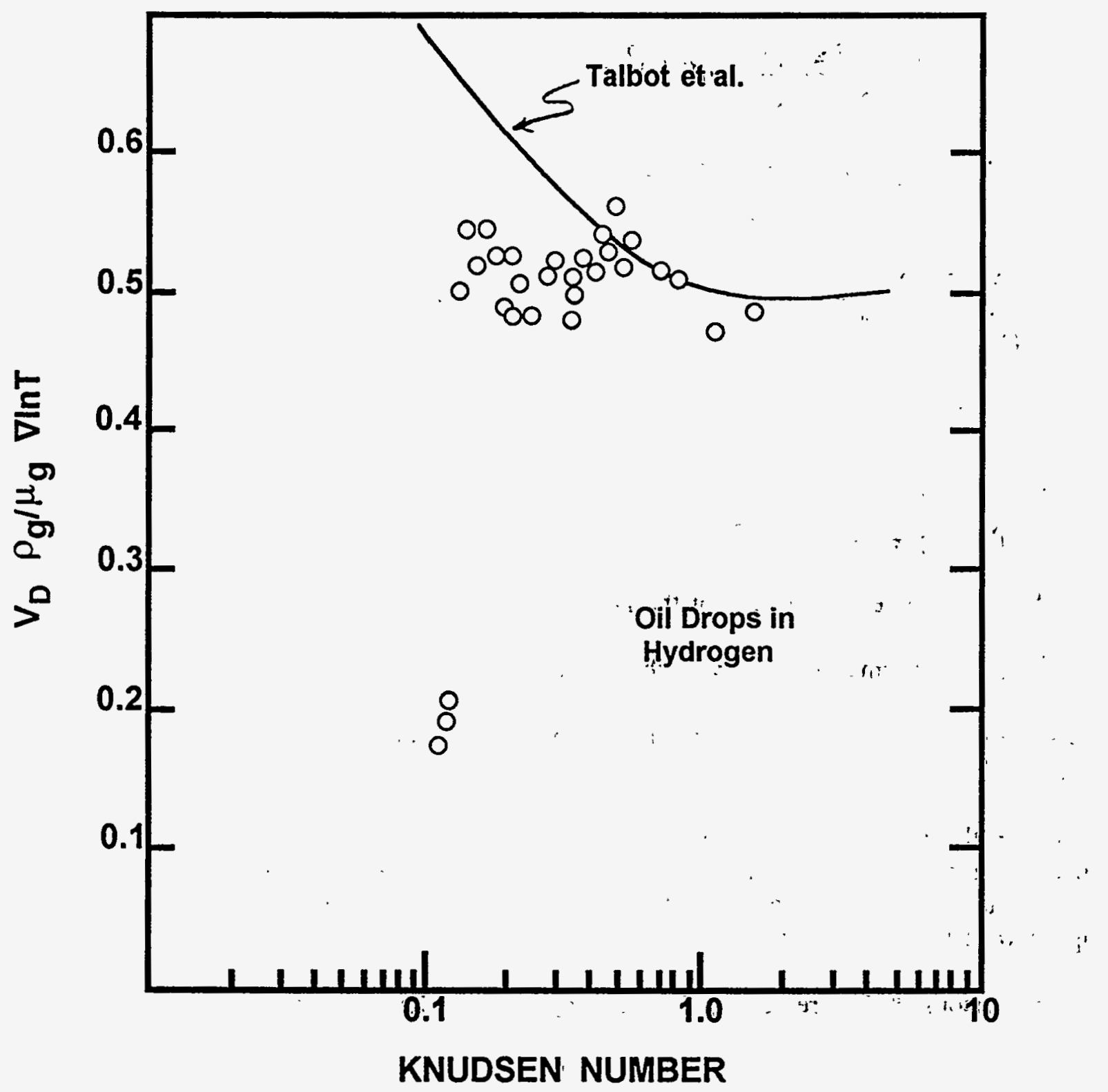

Figure 96. Comparison of dimensionless thermophoretic velocity predicted by the Talbot et al. model to data [229] for oil drops in hydrogen 


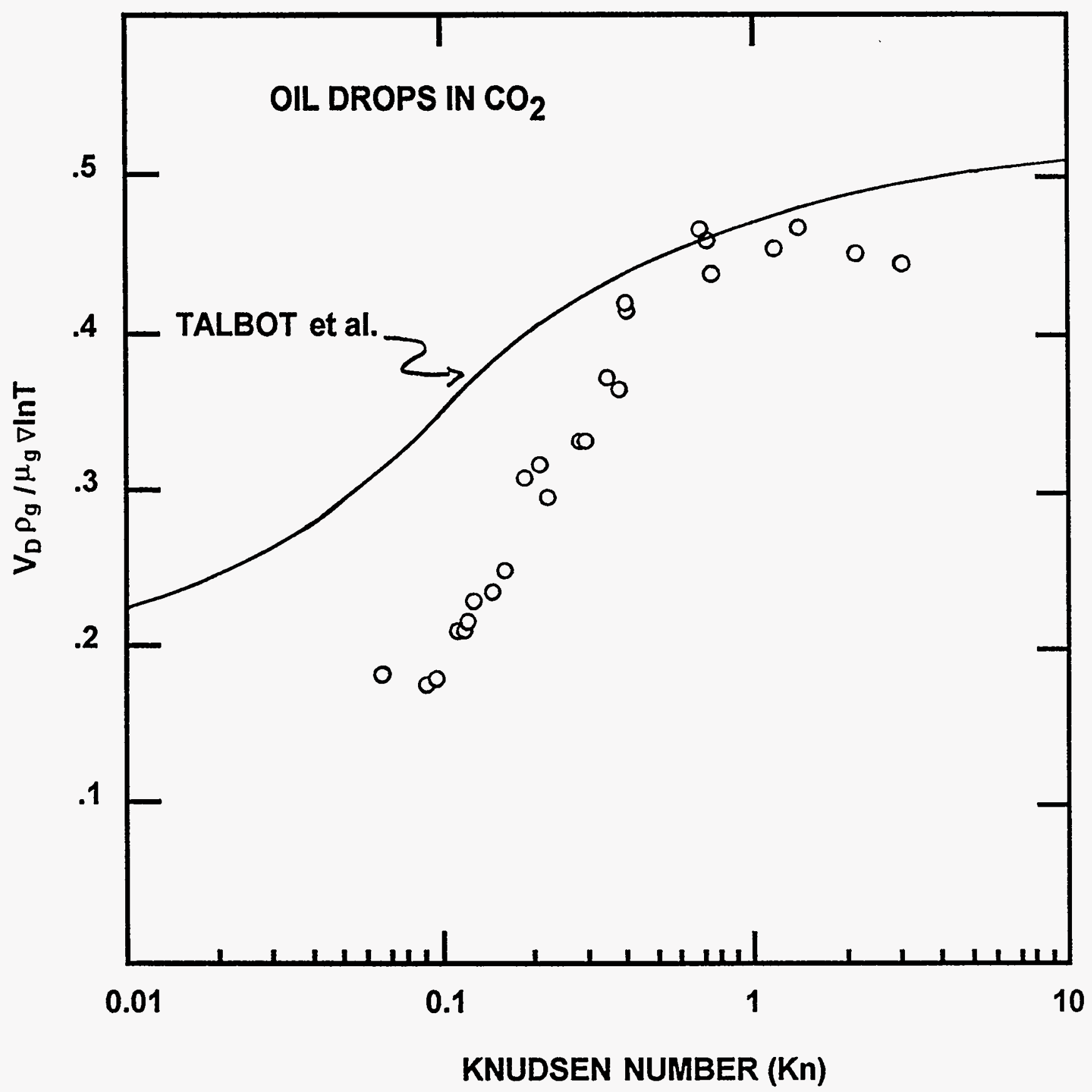

Figure 97. Comparison of dimensionless thermophoretic velocity predicted by the Talbot et al. model to data [229] for oil drops in carbon dioxide 
Table 18. Comparison of observed and predicted thermophoretic deposition velocities

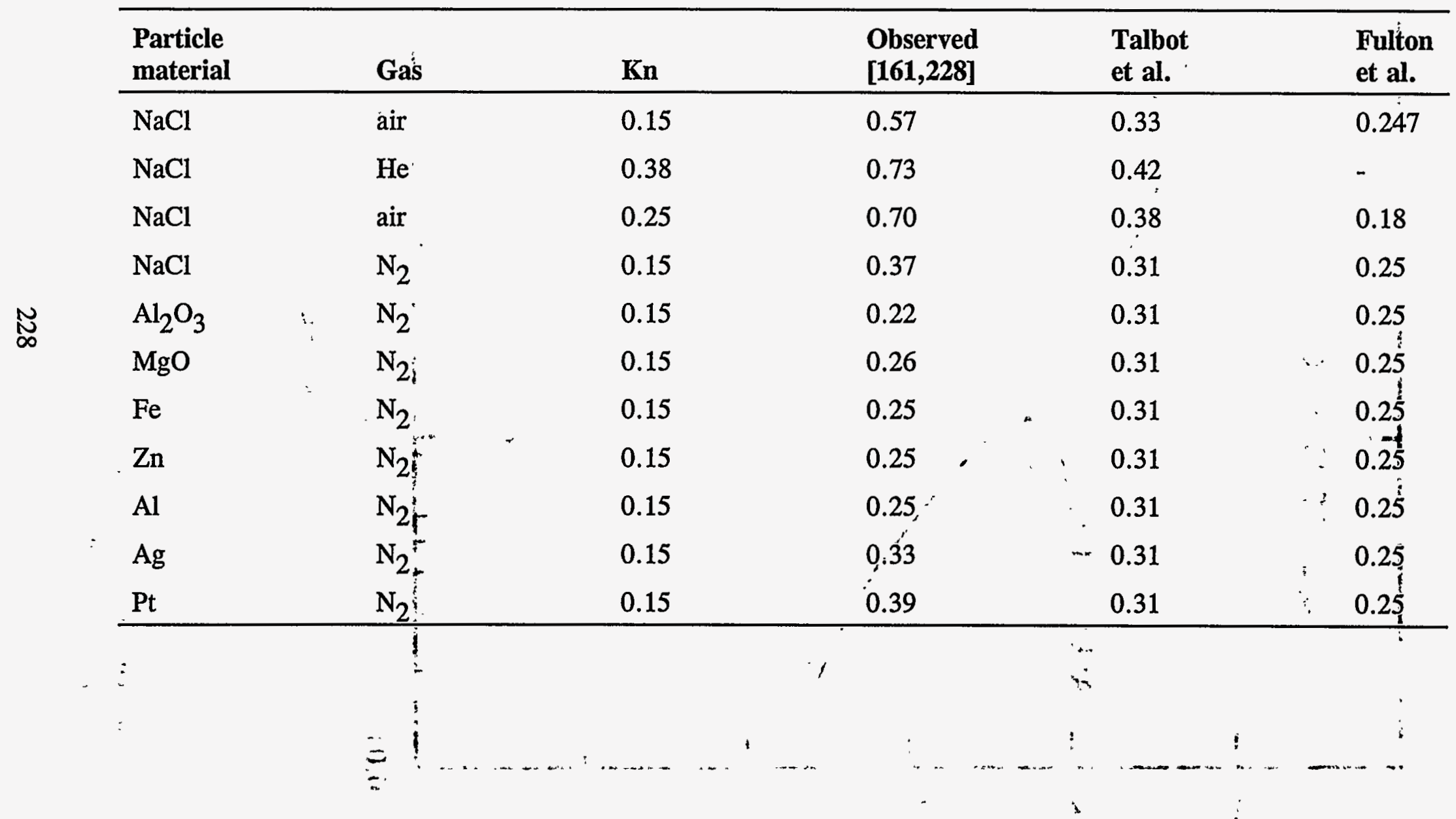


There has been a continued controversy over thermophoresis. Some theoretical models predict thermophoretic flow would be in the direction of increasing temperature [225, 232, 233]. This has not been observed in experiments. Balakov [225] accepts the theoretical prediction and terms the phenomenon "second-order slip." Other authors have not been so generous [226]. We ignore this possibility here in the suspicion that the predicted flow up the temperature gradient may be a deficiency of the models and not a real phenomenon.

Arguments have also been made that particles can rotate in the boundary layers [230]. It appears, however, that this can occur only for particles larger than those of interest here [231].

Following the same procedure used for the analysis of diffusiophoresis, the thermal gradient is:

$$
\nabla \mathrm{T}=\frac{-\mathrm{h} \Delta \mathrm{TE}}{\mathrm{a}^{2} \pi^{2} \mathrm{k}_{\mathrm{th}} \sqrt{\mathrm{E}^{2}-1}}\left[1+\frac{\ln \left[\frac{\mathrm{E}+\sqrt{\mathrm{E}^{2}-1}}{\mathrm{E}-\sqrt{\mathrm{E}^{2}-1}}\right]}{2 \mathrm{E} \sqrt{\mathrm{E}^{2}-1}}\right] /\left(\cos ^{2}(\eta)+\frac{1}{\mathrm{E}^{2}-1}\right]^{1 / 2}
$$

where $\mathrm{h}$ is the heat transfer coefficient. Then,

$$
\begin{gathered}
\left.\nabla T=\frac{-8 \Delta \mathrm{TE}^{1 / 3}}{\mathrm{D}_{\mathrm{B}} \pi^{3 / 2}} \frac{1}{\sqrt{\mathrm{E}^{2}-1}}\left[\frac{\mathrm{U}_{\text {slip }} \mathrm{D}_{\mathrm{B}} \mathrm{C}_{\mathrm{p}}(\mathrm{g}) \rho(\mathrm{g})}{\mathrm{k}_{\mathrm{th}}(\mathrm{g})}\right] \frac{\mathrm{f}(\mathrm{E})}{\left[\cos ^{2}(\eta)+\frac{1}{\mathrm{E}^{2}-1}\right]^{1 / 2}}\right]^{1 / 2} \\
\mathrm{f}(\mathrm{E})=\left\{\frac{2\left(\mathrm{E}^{2}-1\right)^{3 / 2}}{3\left[\mathrm{E}^{2} \tan ^{-1}\left(\sqrt{\mathrm{E}^{2}-1}\right)-\sqrt{\mathrm{E}^{2}-1}\right]}\right\}^{1}
\end{gathered}
$$

\section{f. Particle Growth by Water Condensation}

The discussions in the preceding subsections have shown that the rate at which particles are removed from a bubble rising through a suppression pool is a strong function of the aerosol particle size. In the water-rich environment of a steam suppression pool, the possibility that aerosol particles might grow as a result of water vapor condensation on their surfaces needs to be considered. Such particle growth could significantly affect the decontamination that could be achieved by a suppression pool.

Condensation that affects particle size has to be on the external surfaces of the particles. (Condensation of water in voids within particle agglomerates and the effects this internal condensation can have on particle shape factors has been discussed above in Section IV-K.) The convex external surfaces of individual aerosol particles and particle agglomerates resist condensation because of the Kelvin effect. And, of course, in a rising bubble the partial pressure of steam in the bubble will always be slightly below saturation. Growth of aerosol particles will occur, then, only if there is some process that will 
reduce the chemical activity of water on the surfaces of aerosol particles: Solthat the vapor pressure of the deposited water is less than the partial pressure of water vapor'in the;bubble. Tihesimostiobvious mechanism for this reduction in the chemical activity of condensed water is the dissolution of some aerosol material into the water: Nearly all of the inorganic matêrials likely:to be present;in raerosols produced in nuclear reactor accidents will cause a reduction in. water activity when they dissolve. Indeed, some of the chemical species considered to make up aerosols dischargedsto thesuppression, pool are quite water soluble. Saturation solubilities of $\mathrm{CsOH}$ and $\mathrm{CsI}$ at $373 \mathrm{~K}$ exceed 3.6 and $2.6 \mathrm{moles} / \mathrm{kg}$ $\mathrm{H}_{2} \mathrm{O}$, respectively. Aerosol particles composed of these materials would; surely grow bya rwater condensation during transport in -bubbles through the suppresșion pool. IIt is not, obviousi that such highly soluble species will actually be present in the aerosol produced during severe reactor accident. Though all materials exhibit-some solubility in water, the solubility may. not be enough;torcause a sufficient reduction in the chemical activity of water to lead to aerosol growth by water condensation. The magnitude of water solubility that is needed to lead to particle growth is given by:

$$
\ln \mathrm{a}_{\mathrm{w}}=-4 \sigma_{1} \overline{\mathrm{V}} / \mathrm{d}_{\mathrm{p}} \mathrm{RT}
$$

where

$$
\begin{aligned}
& a_{w}=\text { chemical activity of water } \\
& \bar{V}=\text { molar volume of water }
\end{aligned}
$$

At $373 \mathrm{~K}$, the chemical activity of water that will just lead to particle growth fon aerosol particles of various sizes is:

$\begin{array}{ccc}\mathrm{d}_{\mathrm{p}}(\mu \mathrm{m}) & \mathrm{a}_{\mathrm{w}} & \begin{array}{c}\text { molality } \\ \left(\text { moles } / \mathrm{kg}-\mathrm{H}_{2} \mathrm{O}\right)\end{array} \\ 1.0 & 0.9986 & 0.039 \\ 0.1 & 0.9864 & 0.38 \\ 0.01 & 0.8722 & 3.8\end{array}$

The molality of a solution of an electrolyte composed of univalent ion 'necéssảry to produtuce such reductions in water activity can be estimated from:

$$
a_{W}=\exp \left[\frac{-2 m \phi}{55.51}\right]
$$

where

$$
\begin{aligned}
\mathrm{m} & =\text { molality }, \text { and } \\
\phi & =\text { osmotic coefficient }
\end{aligned}
$$


For the purposes of these estimates, the osmotic coefficient has been taken equal to 1 . A more sophisticated estimate of the osmotic coefficient can be made. ${ }^{*}$

It is apparent from the values listed above that substantial solubilities of aerosol materials in water would be needed to get growth of even $1 \mu \mathrm{m}$ particles. (Particles larger than $1 \mu \mathrm{m}$ are so efficiently removed from bubbles by physical processes that their growth by water condensation is not very important.) There are few materials so soluble in water that $0.01 \mu \mathrm{m}$ particles of these materials will grow by water condensation.

There are kinetic as well as thermodynamic factors that will inhibit aerosol growth by water condensation. Condensation of water on aerosol particles liberates heat which raises the particle temperature and the vapor pressure of condensing water. Unfortunately, there are few mechanisms available to dissipate this heat except conduction into the gas phase. In the subsections below, the heating of aerosol particles by water condensation is examined. The examination is done first for the free molecular regime $\left(\mathrm{Kn}=2 \lambda / \mathrm{d}_{\mathrm{p}}<<1\right.$ where $\lambda$ is the mean free path of the gas phase) and for the continuum regime $(\mathrm{Kn}>>1)$. Interpolation formulae and example calculations are then presented.

\section{f-1. Condensation in the Free Molecular Regime}

Assume that thermal gradients in the gas phase around a particle are small. The thermal accommodation coefficient of water onto a water surface has been measured to be 0.96 [172]. This is close enough to unity that diffuse reflection of molecules from a surface can be assumed. The molar flux of water vapor deposition on a particle surface in the free molecular regime is then given by:

*In Pitzer's formulation of the osmotic coefficient for univalent electrolytes such as CsOH and CsI [186]:

$$
\begin{aligned}
\phi-1 & =\mathrm{f}^{\phi}+\mathrm{mB}^{\phi}+\mathrm{m}^{2} \mathrm{C}^{\phi} \\
\mathrm{f}^{\phi} & =-\mathrm{A}_{\phi}\left[\mathrm{m}^{1 / 2} /\left(1+1.2 \mathrm{~m}^{1 / 2}\right)\right] \\
\mathrm{B}^{\phi} & =\beta^{0}+\beta^{1} \exp \left(-2 \mathrm{~m}^{1 / 2}\right)
\end{aligned}
$$

Near $373 \mathrm{~K}, \mathrm{~A}_{\phi}=4.48 \times 10^{-3}+1.223 \times 10^{-3} \mathrm{~T}(\mathrm{~K})$. For CsI,

$$
\begin{aligned}
\beta^{0} & =0.0244 \\
\beta^{1} & =0.0262 \\
C^{\phi} & =-0.00365
\end{aligned}
$$

For $\mathrm{CsOH}$,

$$
\begin{aligned}
& \beta^{0}=0.150 \\
& \beta^{1}=0.30 \\
& C^{\phi}=0
\end{aligned}
$$


Physical Phenomena

$$
\begin{aligned}
\left.\frac{\mathrm{dN}\left(\mathrm{H}_{2} \mathrm{O}\right)}{\mathrm{dt}}\right|_{\mathrm{fm}} & =\frac{\mathrm{S} \pi \mathrm{d}_{\mathrm{p}}^{2}}{4}\left\{\frac{\mathrm{P}(\infty)}{\mathrm{RT}(\infty)} \mathrm{T}(\infty)^{1 / 2}-\frac{\mathrm{P}(\mathrm{s})}{\mathrm{RT}(\mathrm{s})} \mathrm{T}(\mathrm{s})^{1 / 2}\right\}\left\{\frac{8 \mathrm{R}}{\pi \mathrm{MW}}\right\}^{1 / 2} \\
& \cong \mathrm{d}_{\mathrm{p}}^{2} 32.81 \mathrm{~S}\left\{\frac{\mathrm{P}(\infty)}{\mathrm{T}(\infty)^{1 / 2}}-\frac{\mathrm{P}(\mathrm{s})}{\mathrm{T}(\mathrm{s})^{1 / 2}}\right\} \text { moles/s }
\end{aligned}
$$

where

$$
\begin{aligned}
\mathrm{N}\left(\mathrm{H}_{2} \mathrm{O}\right) & =\text { moles of } \mathrm{H}_{2} \mathrm{O} \text { deposited on the particle, } \\
\mathrm{S} & =\text { probability that a water molecule striking the surface will stick to the surface, } \\
\mathrm{P}(\infty) & =\text { partial pressure (atm) of water vapor in the gas phase, } \\
\mathrm{P}(\mathrm{s}) & =\text { equilibrium partial pressure of water vapor at the particle surface (atms), } \\
\mathrm{T}(\infty) & =\text { temperature of the bulk gas }(\mathrm{K}), \\
\mathrm{T}(\mathrm{s}) & =\text { temperature of the particle surface }(\mathrm{K}) \text {, and } \\
\mathrm{d}_{\mathrm{p}} & =\text { diameter of the particle }(\mathrm{cm})
\end{aligned}
$$

The so-called sticking coefficient, $\mathrm{S}$, that appears in the kinetic equations is not especially well known. Pruppacher and Klett [176] cite several determinations. Their citations are reproduced in Table 19. They note that the determinations of $S$ can be grouped into two categories. Low values, on the order of $S=0.03$, have been determined by static methods. High values, on the order of ' $S^{\prime}{ }^{\prime \prime}=0.9$ ' to '1.0, have been determined by methods involving rapid renewal of the water surface. This would suggest that surface contamination, which has been found to profoundly affect the behivior of small bubbles (see Section IV-F), may also affect the sticking coefficient. On the other hand; Hisu and'Grahaim [178] argue that the large dipole moment of water is responsible for the low sticking coefficient. Presumably, the orientation of the molecule as it approaches the surface can lead to attractive or repulsive forces. Certainly, other molecules with large dipole moments such as $\mathrm{HCl}$ are found to have low sticking coefficients with water even when very dynamic jet methods are used for the determination.

Pruppacher and Klett recommend the use of a low sticking coefficient for work with water drops. Whether this recommendation also applies to the issue here of water condensation on particles is not entirely evident. Wagner [179] found that large values of the sticking coefficient"yielded better matches to aerosol growth data. But, a variety of other parametric assumptions were involved in deriving this result. Levine [180] used a Millikan oil drop apparatus to measure the sticking coefficient. He obtained a mean value of 0.95 from 35 measurements, but the variance in his data is enormous: As noted by Barrett and Clement [177], the issue of the sticking coefficient is unresolved. 
Table 19. Determinations of the sticking coefficient cited by Pruppacher and Klett [176]

\begin{tabular}{|c|c|c|c|}
\hline Author & Year & Temperature (K) & $\mathbf{S}$ \\
\hline Alty & 1931 & 291 to 333 & $0.006-0.016$ \\
\hline Alty and Nicole & 1931 & 291 to 333 & $0.01-0.02$ \\
\hline Alty & 1933 & 265 to 277 & 0.04 \\
\hline Alty and Mackay & 1935 & 288 & 0.036 \\
\hline Baramaer & 1939 & - & 0.033 \\
\hline Pruger & 1940 & 373 & 0.02 \\
\hline Yamamoto \& Miura & 1949 & - & 0.023 \\
\hline Hammeke \& Kappler & 1953 & 293 & 0.045 \\
\hline Delaney et al. & 1964 & 273 to 313 & 0.0415 \\
\hline Kiriukhin \& Plaude & 1965 & 280 & 0.019 \\
\hline Chodes et al. & 1974 & 293 & 0.033 \\
\hline Rogers \& Squires & 1974 & - & 0.065 \\
\hline Narusawa \& Springer & 1975 & 291 to 300 & 0.038 \\
\hline Sinarwalla et al. & 1975 & 295.6 to 298.8 & 0.026 \\
\hline Hickman & 1954 & 273 & 0.42 \\
\hline Berman & 1961 & - & 1.0 \\
\hline Nabavian \& Bromley & 1963 & 283 to 323 & $0.35-1.0$ \\
\hline Jamieson & 1965 & 273 to 343 & 0.35 \\
\hline Mills \& Seban & 1967 & 280 to 283 & $0.45-1.0$ \\
\hline Tamir \& Hasson & 1974 & 323 & 0.20 \\
\hline Narusawa \& Springer & 1975 & 291 to 300 & 0.18 \\
\hline
\end{tabular}




\section{Physical Phénomena}

To understand the particle surface temperature, the heat imparted to the particle byycondensation and the heat losses must be considered. Decay heating is neglected here because of the time scales. Heat losses are considered to be by conduction. The relative movement of particles-with-respect to the ambient gas is small enough that convection is negligible. Radiant heat losses are'also'neglected.

In the free molecular regime the rate of heat input to the particle due to water condensation is [177]:

$$
L-\left.\frac{\mathrm{RT}(\mathrm{s})}{2} \frac{\mathrm{dN}\left(\mathrm{H}_{2} \mathrm{O}\right)}{\mathrm{dt}}\right|_{\mathrm{fm}}
$$

Then,

$$
\left.\frac{\mathrm{dQ}}{\mathrm{dt}}\right|_{\mathrm{fm}}=\left.\frac{-\mathrm{dq}}{\mathrm{dt}}\right|_{\mathrm{fm}}+\left.[\mathrm{L}-0.5 \mathrm{RT}(\mathrm{s})] \frac{\mathrm{dN}\left(\mathrm{H}_{2} \mathrm{O}\right)}{\mathrm{dt}}\right|_{\mathrm{fm}}
$$

where

$$
\begin{aligned}
& \left.\frac{\mathrm{dQ}}{\mathrm{dt}}\right|_{\mathrm{fm}}=\text { net heat input in the free molecular regime, and } \\
& \left.\frac{\mathrm{dq}}{\mathrm{dt}}\right|_{\mathrm{fm}}=\text { heat loss due to conduction. }
\end{aligned}
$$

If average molecular properties are assumed:

$$
\left.\frac{\mathrm{dq}}{\mathrm{dt}}\right|_{\mathrm{fm}}=553.5 \mathrm{~d}_{\mathrm{p}}(\mathrm{cm}) \mathrm{P}_{\mathrm{T}}(\mathrm{atm}) \frac{\mathrm{T}(\mathrm{s})-\mathrm{T}(\infty)}{\sqrt{\mathrm{T}(-\infty) \mathrm{MW}}} \mathrm{cal} / \mathrm{s}
$$

where

$$
\begin{aligned}
\mathbf{P}_{\mathrm{T}} & =\text { total pressure of the gas, and } \\
\mathrm{MW} & =\text { average molecular weight of the gas. }
\end{aligned}
$$

A closure equation for the water condensation is:

$$
\mathrm{Q}=\mathrm{C}_{\mathrm{p}}(\mathrm{p}) \frac{\pi}{6} \mathrm{~d}_{\mathrm{p}}{ }^{3} \rho_{\mathrm{p}}(\mathrm{T}(\mathrm{s})-\mathrm{T}(\infty))+\mathrm{C}_{\mathrm{p}}\left(\mathrm{H}_{2} \mathrm{O}\right) \mathrm{N}\left(\mathrm{H}_{2} \mathrm{O}\right)(\mathrm{T}(\mathrm{s})-\mathrm{T}(\infty))
$$


where

$$
\begin{aligned}
\mathrm{C}_{\mathrm{p}}(\mathrm{p}) & =\text { heat capacity of the particle material (cal/g-K), and } \\
\mathrm{C}_{\mathrm{p}}\left(\mathrm{H}_{2} \mathrm{O}\right) & =\text { heat capacity of water condensed on the external surface of the particle (cal/g-K). }
\end{aligned}
$$

This closure equation has been derived assuming that the thermal conductivity of water and the material making up the aerosol particle are infinite. The entire particle and condensed water system is then at the surface temperature. The assumptions behind this closure equation will lead to lower surface temperatures than would be predicted if thermal conductivities of the condensed materials were taken to be finite.

\section{f-2. Condensation in the Continuum Regime}

The possibility of there being a thermodynamic driving force for condensation on particles is higher for particles that are large relative to the mean free path of gas molecules. Still, even for these larger particles, during bubble rise through the suppression pool there must be some reduction in the chemical activity of condensed water for there to be condensation.

Kulmala and Vesala [181] have built upon earlier work by Barrett and Clement [177] to describe particle growth in the continuum regime $(\mathrm{Kn}<<1$ ). Again, convection in the gas phase is neglected (but, see Reference 182). Radiation heat transfer is also neglected (see Reference 183). The pseudobinary diffusion coefficient of steam in the gas phase is taken to have the temperature dependence:

$$
Đ(T)=Đ(0)\left[\frac{T}{T(\infty)}\right]^{n}
$$

where

$$
\begin{aligned}
\boxplus(0) & =\text { diffusion coefficient at } \mathrm{T}(\infty), \text { and } \\
\mathrm{n} & \neq 2 .
\end{aligned}
$$

For a hard sphere gas, $n=1.5$. The temperature profile in the vicinity of the particle is taken to be linear:

$$
T(r)=T(\infty)+[T(s)-T(\infty)] d_{p} / 2 r
$$

where $r$ is the distance from the center of the particle and $r>d_{p} / 2$. The variation in the partial pressure of steam in the gas phase surrounding the particle is also taken to be linear:

$$
\mathrm{P}\left(\mathrm{H}_{2} \mathrm{O}, \mathrm{r}\right)=\mathrm{P}\left(\mathrm{H}_{2} \mathrm{O}, \infty\right)+\left[\mathrm{P}\left(\mathrm{H}_{2} \mathrm{O}, \mathrm{s}\right)-\mathrm{P}\left(\mathrm{H}_{2} \mathrm{O}, \infty\right)\right] \mathrm{d}_{\mathrm{p}} / 2 \mathrm{r}
$$


Composition dependencies of the gas phase thermal conductivity are neglected. Thermal diffusion it included, but the Dufour effect is neglected. Then,

$$
\frac{\mathrm{dN}\left(\mathrm{H}_{2} \mathrm{O}\right)}{\mathrm{dt}}=\frac{2 \pi \mathrm{d}_{\mathrm{p}} \mathrm{P}_{\mathrm{T}} \mathrm{D}(\mathrm{o})}{\mathrm{RT}(\infty)}\left\{\mathrm{C}(1) \ln \left[\frac{\mathrm{P}_{\mathrm{T}}-\mathrm{P}(\mathrm{s})}{\mathrm{P}_{\mathrm{T}}-\mathrm{P}(\infty)}\right]+\frac{\mathrm{C}(2)}{4} \alpha[\mathrm{P}(\mathrm{s})+\mathrm{P}(\infty)]\right\}
$$

where

$$
\begin{aligned}
\mathrm{C}(1) & =\left[\frac{\mathrm{T}(\mathrm{s})-\mathrm{T}(\infty)}{\mathrm{T}_{(\infty)}^{\mathrm{n}-1}}\right]\left[\frac{2-\mathrm{n}}{\mathrm{T}_{(\mathrm{s})}^{2-\mathrm{n}}-\mathrm{T}_{(\infty)}^{2-\mathrm{n}}}\right], \\
\mathrm{C}(2) & =\left[\frac{\mathrm{T}(\mathrm{s})-\mathrm{T}(\infty)}{\mathrm{T}_{(\infty)}^{\mathrm{n}-1}}\right]\left[\frac{3-\mathrm{n}}{\mathrm{T}_{(\mathrm{s})}^{3-\mathrm{n}}-\mathrm{T}_{(\infty)}^{3-\mathrm{n}}}\right], \\
\mathrm{P}(\infty) & =\mathrm{P}\left(\mathrm{H}_{2} \mathrm{O}, \infty\right), \text { and } \\
\alpha & =\text { thermal diffusion coefficient. }
\end{aligned}
$$

The heat imparted to the particle is:

$$
\left.\frac{\mathrm{dQ}}{\mathrm{dt}}\right|_{\text {cont }}=\left.\frac{-\mathrm{dq}}{\mathrm{dt}}\right|_{\text {cont }}+\left.\frac{\mathrm{L} \mathrm{dN( \textrm {H } _ { 2 } \mathrm { O } )}}{\mathrm{dt}}\right|_{\text {cont }}
$$

where

$$
\begin{aligned}
\left.\frac{\mathrm{dq}}{\mathrm{dt}}\right|_{\text {cont }} & =2 \pi \mathrm{k}_{\mathrm{th}} \mathrm{d}_{\mathrm{p}}[\mathrm{T}(\mathrm{s})-\mathrm{T}(\infty)] \text {, and } \\
\mathrm{k}_{\mathrm{th}} & =\text { thermal conductivity of the gas. }
\end{aligned}
$$

The temperature of the particle surface is:

$$
\mathrm{T}(\mathrm{s})=\mathrm{T}(\infty)+\left.\frac{\mathrm{L}}{2 \pi \mathrm{d}_{\mathrm{p}} \mathrm{k}_{\mathrm{th}}} \frac{\mathrm{dN}\left(\mathrm{H}_{2} \mathrm{O}\right)}{\mathrm{dt}}\right|_{\text {cont }}
$$




\section{f-3. Condensation in the Transition Regime}

There is no solution for the condensation of water vapors in the transition regime where $\mathrm{Kn} \sim 1$. Williams and Loyalka [184] have suggested some interpolation formulae to predict processes in this transition regime from expressions for the limiting cases of the free molecular regime and the continuum regime. These interpolation formulae are modified for use here:

$$
\begin{gathered}
\left.\frac{\mathrm{dq}}{\mathrm{dt}}\right|_{\text {trans }}=\left.\frac{\mathrm{dq}}{\mathrm{dt}}\right|_{\text {cont }} \mathrm{f}(\mathrm{Kn}(\mathrm{h}))^{-1} \\
\left.\frac{\mathrm{dN}\left(\mathrm{H}_{2} \mathrm{O}\right)}{\mathrm{dt}}\right|_{\text {trans }}=\left.\frac{\mathrm{dN}\left(\mathrm{H}_{2} \mathrm{O}\right)}{\mathrm{dt}}\right|_{\text {cont }} \mathrm{h}(\mathrm{Kn}(\mathrm{c}))^{-1}
\end{gathered}
$$

where

$$
\begin{aligned}
& f(K n(h))=1+\left[\frac{\Omega E(h)+J(h)}{K n(h) E(h)+1}\right] K n(h) \\
& \mathrm{g}(\mathrm{Kn}(\mathrm{c}))=1+\left[\frac{\theta \mathrm{E}(\mathrm{c})+\mathrm{J}(\mathrm{c})}{\mathrm{Kn}(\mathrm{c}) \mathrm{E}(\mathrm{c})+1}\right] \mathrm{Kn}(\mathrm{c}) \\
& \mathrm{h}(\mathrm{Kn}(\mathrm{c}))=\mathrm{g}(\operatorname{Kn}(\mathrm{c})) /\left\{1+\left[\frac{1-\mathrm{s}}{\mathrm{s}}\right] \frac{\sqrt{\pi} \mathrm{Kn}(\mathrm{c})}{\mathrm{g}(\operatorname{Kn}(\mathrm{c}))}\right\} \\
& \Omega=\left.\frac{\mathrm{dq}}{\mathrm{dt}}\right|_{\text {cont }} /\left.\frac{\mathrm{dq}}{\mathrm{dt}}\right|_{\mathrm{fm}} \\
& \theta=\left.\frac{\mathrm{dN}\left(\mathrm{H}_{2} \mathrm{O}\right)}{\mathrm{dt}}\right|_{\text {cont }} /\left.\frac{\mathrm{dN}\left(\mathrm{H}_{2} \mathrm{O}\right)}{\mathrm{dt}}\right|_{\mathrm{fm}} \\
& \mathrm{Kn}(\mathrm{h})=2 \lambda(\mathrm{h}) / \mathrm{d}_{\mathrm{p}} \\
& \mathrm{Kn}(\mathrm{c})=2 \lambda(\mathrm{c}) / \mathrm{d}_{\mathrm{p}} \\
& \lambda(\mathrm{h})=0.8 \mathrm{k}_{\text {th }} \frac{\mathrm{T}(\infty)}{\mathrm{P}_{\mathrm{T}}}\left[\frac{\mathrm{MW}}{2 \mathrm{RT}(\infty)}\right]^{1 / 2} \\
& \cong \frac{2.562 \times 10^{-3} \mathrm{k}_{\mathrm{th}}(\mathrm{cal} / \mathrm{s}-\mathrm{cm}-\mathrm{K}) \mathrm{T}(\infty)^{1 / 2} \mathrm{MW}^{1 / 2}}{\mathrm{P}_{\left.\mathrm{T}^{(} \mathrm{atms}\right)}}
\end{aligned}
$$


Physical Phenomena

$$
\begin{aligned}
& \lambda(\mathrm{c})=2 \mathrm{D}_{\mathrm{AB}}^{(0)}\left[\frac{18.016}{\mathrm{RT}(\infty)}\right]^{1 / 2} \cong \frac{6.58 \times 10^{-4} \mathrm{D}_{\mathrm{AB}}\left(\mathrm{cm}^{2} / \mathrm{s}\right)}{\mathrm{T}(\infty)^{1 / 2}}(\mathrm{~cm}) \\
& \mathrm{E}(\mathrm{h})=1.9234 \\
& \mathrm{E}(\mathrm{c})=4 / 3 \\
& \mathrm{~J}(\mathrm{~h})=5 / 8 \sqrt{\pi} \mathrm{p}
\end{aligned}
$$

Loyalka and Ferziger [290] suggest values of $\mathrm{p}$ varying from 1.1136 to 1.1759 . Williams and Loyalka [184] suggest $J(c)$ depends on the composition of the gas phase:

$$
\begin{gathered}
\mathrm{J}(\mathrm{c})=0.9769-0.0518 \mathrm{z}+0.018 \mathrm{z}^{2}+0.0196 \mathrm{z}^{3} \\
\mathrm{z}=\log _{10} \frac{\mathrm{MW}(\mathrm{nc})}{\mathrm{MW}\left(\mathrm{H}_{2} \mathrm{O}\right)}
\end{gathered}
$$

where $M W(i)$ is the molecular weight of the $i^{\text {th }}$ gas species.

\section{g. Aerosol Capture by Bubble Oscillations}

Ellipsoidal bubbles with Reynolds numbers in excess of 200 to 800 (Sée (Section IV-f) can undergo shape oscillations. In principle, it might be possible for the oscillating bubble walls to sweep out any aerosols within the amplitude of the motion. The critical issue is whether the aerosol particles can respond to the motions of the bubble walls.

To estimate the possible magnitude of aerosol sweep out by the shape oscillations of bubbles, the oscillations are approximated as a sinusoidal motion. The velocity of the gas within the bubble is, then, given by:

$$
\mathrm{U}_{\mathrm{g}}=\mathrm{A} \omega \cos \omega \mathrm{t}
$$

where

$$
\begin{aligned}
& A=\text { amplitude of the motion, } \\
& \omega=2 \pi f, \text { and } \\
& f=\text { frequency of the shape oscillation }
\end{aligned}
$$

The motions of aerosol particles will be, in general, out of phase with the gas motion. The amplitude of particle motion may also be different than that of the gas. Following arguments by Clift et al. [82], the velocity of an aerosol particle is taken to be:

$$
\mathrm{U}_{\mathrm{p}}=\mathrm{A} \eta \omega \cos (\omega \mathrm{t}+\beta)
$$


where

$$
\begin{aligned}
& \beta=\text { phase shift, and } \\
& \eta=\text { amplitude magnification factor. }
\end{aligned}
$$

Clift et al. find:

$$
\begin{aligned}
& \beta=\tan ^{-1}[\mathrm{~h}(2) /(1+\mathrm{h}(1))] \\
& \eta=\left\{[1+\mathrm{h}(1)]^{2}+\mathrm{h}(2)^{2}\right\}^{1 / 2}
\end{aligned}
$$

where

$$
\begin{aligned}
\mathrm{h}(1) & =\mathrm{H}(1)(1+\mathrm{H}(2)) \\
\mathrm{h}(2) & =\mathrm{H}(1) \mathrm{H}(2)\left(1+2 \tau_{\mathrm{o}}\right) \\
\tau_{\mathrm{o}} & =4 \mu_{\mathrm{g}} / \rho_{\mathrm{g}} \omega \mathrm{d}_{\mathrm{p}}{ }^{2} \\
\mathrm{H}(1) & =2(1-\gamma) /(2 \gamma+1) /\left[\mathrm{H}(2)^{2}\left(1+\sqrt{2 \tau_{\mathrm{o}}}\right)^{2}+(1+\mathrm{H}(2))^{2}\right] \\
\mathrm{H}(2) & =9\left(\sqrt{\tau_{\mathrm{o}} / 2}\right) /(2 \gamma+1) \\
\gamma & =\rho_{\mathrm{p}} / \rho_{\mathrm{g}}
\end{aligned}
$$

Plots of $\beta$ and $\eta$ for particles of various sizes are shown as functions of frequency in Figures 98 and 99. It is evident from these figures that the motions of the particles are delayed relative to the gas. For very small particles $\left(\mathrm{d}_{\mathrm{p}}<0.1 \mu \mathrm{m}\right)$ very high frequencies must be reached before the phase shift of particle motion is significant. For particles with diameters on the order of $1.0 \mu \mathrm{m}$, the phase shift is large even at frequencies of only $10 \mathrm{~Hz}$. Once the particle is set in motion, it is slow to stop. The amplification factors for the sinusoidal motions of very small particles do not become significant until very high frequencies are reached. Amplitude magnification factors are large for larger particles even at low frequencies.

It is not immediately obvious what oscillation frequencies will occur in bubbles. It seems likely that oscillations would be at harmonic frequencies. For spherical bubbles the harmonic frequencies are given by

$$
(2 \pi)^{2}=\frac{8 \mathrm{n}(\mathrm{n}-1)(\mathrm{n}+1)(\mathrm{n}+2) \sigma_{1}}{\mathrm{D}_{\mathrm{B}}^{3}\left[(\mathrm{n}+1) \rho_{1}+\mathrm{n} \rho_{\mathrm{g}}\right]}
$$




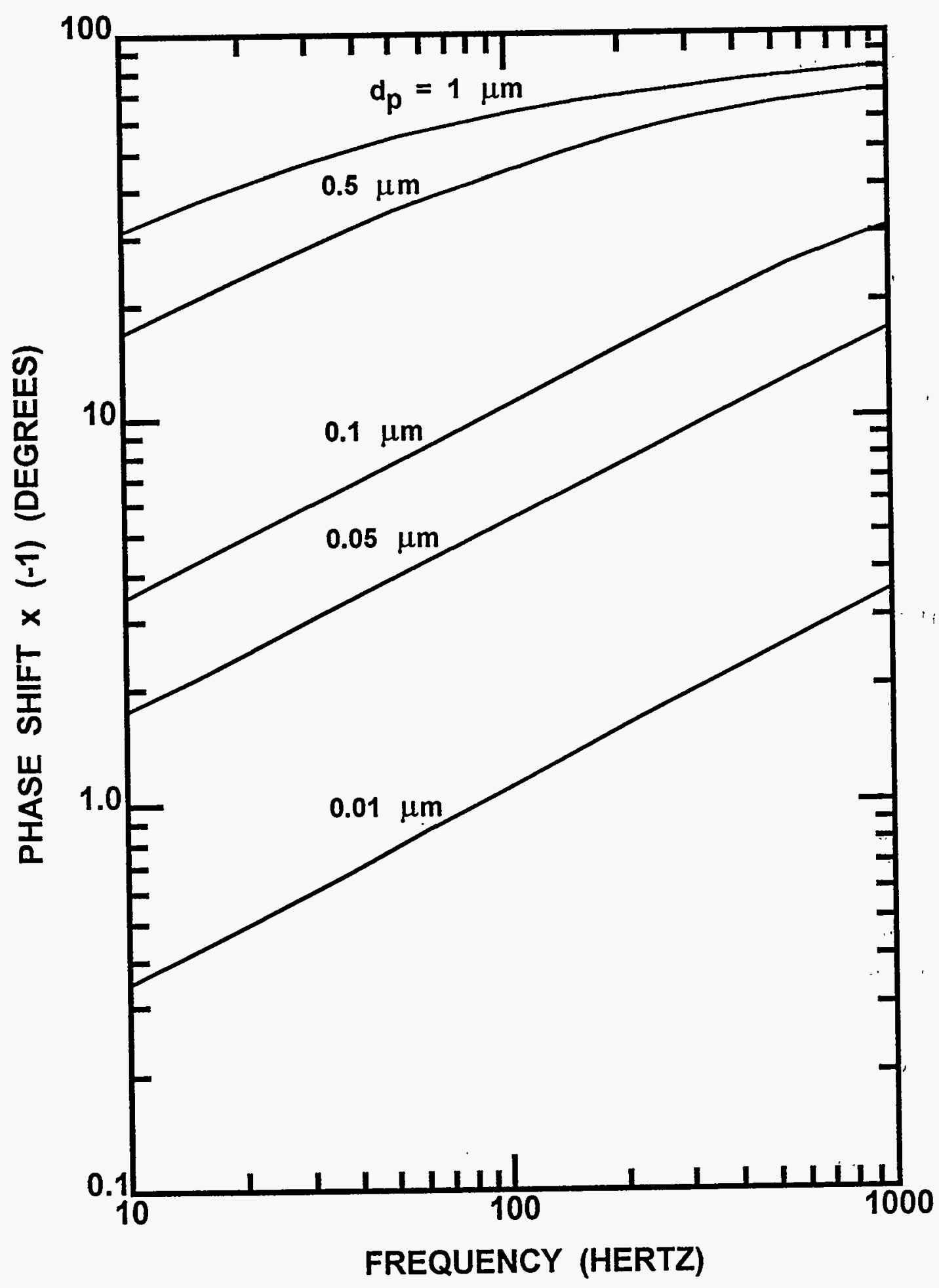

Figure 98. Phase shift for motions of particles $\left(\rho_{p}=2 \mathrm{~g} / \mathrm{cm}^{3}\right)$ of various sizes in bubbles undergoing sinusoidal oscillations 


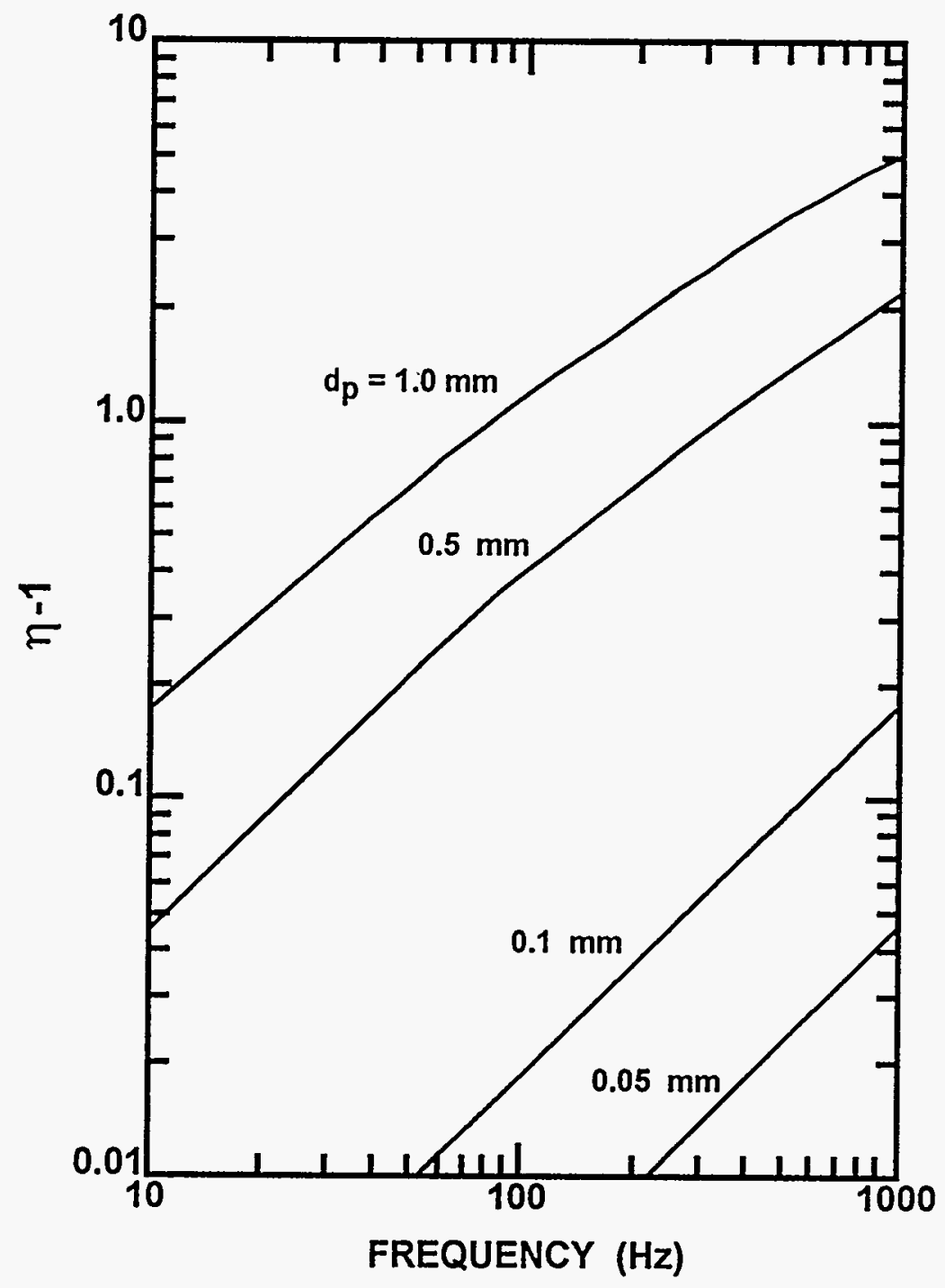

Figure 99. Amplitude magnification factors for motions of particles $\left(\rho_{\mathrm{p}}=2 \mathrm{~g} / \mathrm{cm}^{3}\right)$ of various sizes in bubbles undergoing sinusoidal oscillations 
where $\mathrm{n}$ is the mode number. These resonant frequencies are shown in Figure 100 as functions of the bubble diameter in water at $373 \mathrm{~K}$.

It is evident that particle capture by oscillation of the bubbles can occur. The rate of capture depends on particle size, bubble size, and the amplitude of oscillation. The authors are not aware of detailed theory of particle capture by this type of process. On strictly intuitive grounds, the mass transport rate is taken here to be:

$$
\mathrm{k}_{\mathrm{m}}=-2 \psi \frac{(\eta-1) \beta}{\pi} \sqrt{\mathrm{f} \oplus_{\mathrm{p}}}
$$

where $\boxplus_{p}$ is the diffusion coefficient for the particles in the bubble and $\psi$ is an uncertain, dimensionless parameter with a nominal value of 1.2 . In principle, all resonant modes of bubble oscillation ought to be considered $(n=2$ to $\infty)$. The understanding of oscillations and particle behavior is, however, too crude to justify this level of sophistication, so only the first nonzero vibration mode $(n=2)$ is considered.

\section{Aerosol Trapping During Bubble Collapse}

Once bubbles detach from orifices and begin to rise through the suppression pool they can collapse and disintegrate as discussed above (see Section IV B). The collapse process is very. rapid. Experimental observations suggest that it is complete after bubble rise of 2 to 10 initial bubble diameters [30]. Behaviors of both the bubbles and the aerosol must be very complex during this period. No attempt is made here to model these complicated behaviors in detail. Instead, it is assumed that:

- $\quad$ simple disintegration of bubbles because they are unstable does not in itself lead to a significant amount of aerosol capture, and

- condensation of steam removes aerosols in proportion to the volume change of the bubble regardless of aerosol size.

As can be seen from the discussions above, the most profound effect on aerosol trapping caused by the collapse and disintegration of bubbles following detachment is the substantial reduction in bubble size. As shown above (Section IV-L-1), aerosol deposition processes become more efficient with decreasing bubble size. Paul et al. [30] speculate that disintegration of the bubbles.released to the pool produces very small bubbles that subsequently coalesce to form. larger bubbles observed to rise through the pool. During the period that aerosols are present in the very small bubbles, aerosol deposition processes could be very efficient indeed. No attempt is made to model or qualitatively describe this very transient period. Its duration is not long, so the extent of decontamination, despite the efficiency of the deposition processes, may not be great. Some partial remediation for neglect of decontamination during the transient period is realized because particle concentrations in bubbles rising through the pool will be somewhat higher than in reality. 


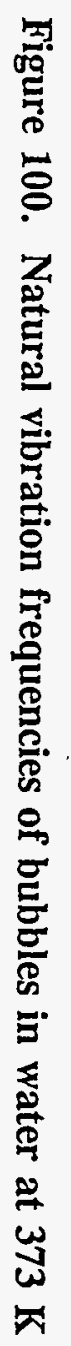

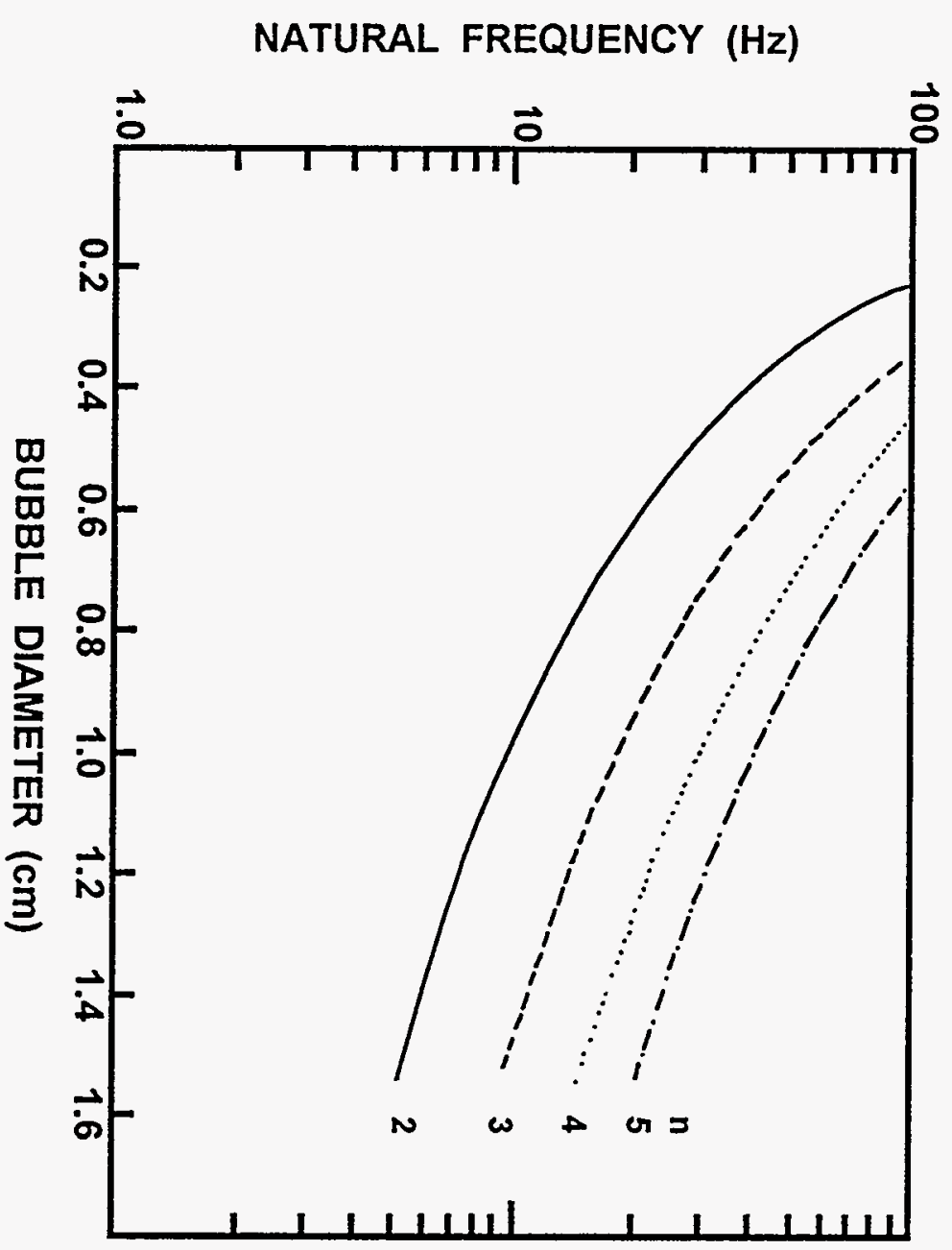




\section{Physical Phenomena}

\section{Aerosol Capture During Bubble Formation}

Bubble formation at orifices and vents in the suppression pool has been discussed at length above (see Section IV-A). The process is not entirely simple. There would appear to be opportunities for substantial aerosol capture as the bubbles form and before they detach and rise through the suppression pool. Among the possible mechanisms of aerosol capture during bubble formation are:

- impaction of particles from the jet of gas passing through the orifice stagnating at the bubble wall,

- diffusiophoretic deposition of particles as steam entering the bubble condenses on the bubble walls, and

- inertial deposition of particles from recirculating flows within the bubble.

Of course, diffusion and-gravitational sedimentation are omnipresent processes that can contribute to the trapping of aerosols during bubble formation.

Systematic studies of aerossol capture during bubble formation have, apparently, not been undertaken. Approximate descriptions of the aerosol trapping processes are provided in the SUPRA code $[7,8]$ and in the SPARC code [6]. ", The BUSCA code [9], apparently, is constructed to allow users to select between these two approximate descriptions.

The SUPRA code $[7,8]$ considers aerosol capture during bubble formation to be predominantly the result of:

- impaction of particles from the decelerating jet emerging from the orifice, and

- inertial impaction from gases circulating within a growing bubble.

Documentation available to the authors concerning these models in the SUPRA code does not provide a great deal of detail. Fortunately, Ramsdale [9] provides more information. The impaction model is based on curve fits for particle impaction on a fixed flat plate from a round gas jet. Two parameters are considered. A geometric parameter is defined by:

$$
\delta=\frac{\left(\frac{6}{\pi} \mathrm{V}_{\mathrm{B}}\right]^{1 / 3}}{\mathrm{D}_{\mathrm{jet}}}
$$

where $D_{\text {jet }}$ is the diameter of the gas jet which, presumably, is the same as the diameter of the orifice. Also, a Stokes number is defined as: 


$$
\begin{aligned}
\mathrm{Stk}(\mathrm{i}) & =\rho_{\mathrm{p}} \mathrm{d}_{\mathrm{p}}(\mathrm{i})^{2} \mathrm{~V}_{\mathrm{jet}} \mathrm{C} / \mu_{\mathrm{g}} \mathrm{D}_{\mathrm{jet}} \\
\mathrm{V}_{\mathrm{jet}} & =4 \dot{\mathrm{m}}_{\mathrm{g}} / \pi \rho_{\mathrm{g}} \mathrm{D}_{\mathrm{jet}}^{2} \mathrm{C}_{\mathrm{V}}
\end{aligned}
$$

where

$$
\begin{aligned}
& \dot{\mathrm{m}}_{\mathrm{g}}=\text { mass flow rate of gas through the orifice } \\
& \mathrm{C}_{\mathrm{v}}=\text { the velocity coefficient of the orifice }
\end{aligned}
$$

The efficiency with which a particle of size $\mathrm{d}_{\mathrm{p}}(\mathrm{i})$ is captured is a function of both Stk(i) and $\delta$ :

$\begin{array}{ll}\text { (1) } \epsilon(\mathrm{i})=0 & \text { for Stk(i) } \leq 0.090\end{array}$

(2) for $\delta \leq 0.75$; Stk(i) $\leq 0.3364$

$$
\epsilon(\mathbf{i})= \begin{cases}\text { Stk(i) })^{1 / 2}-0.3 & \text { for Stk(i) } \leq 0.16 \\ 16(\operatorname{Stk}(\mathbf{i}))^{1 / 2}-6.3 & \text { for } 0.16<\operatorname{Stk}(\mathbf{i}) \leq 0.2025 \\ 0.7(\operatorname{Stk}(\mathbf{i}))^{1 / 2}+0.59 & \text { for } 0.2025<\operatorname{Stk}(\mathbf{i}) \leq 0.3025 \\ 0.98 & \text { for } 0.3025<\operatorname{Stk}(\mathbf{i}) \leq 0.3364\end{cases}
$$

$0.75<\delta \leq 1.5$

$$
\epsilon(\mathbf{i})= \begin{cases}0 & \text { for Stk(i) } \leq 0.1024 \\ 1.25(\operatorname{Stk}(\mathbf{i}))^{1 / 2}-0.4 & \text { for } 0.1024<\operatorname{Stk}(\mathbf{i}) \leq 0.16 \\ 8(\operatorname{Stk}(\mathbf{i}))^{1 / 2}-3.1 & \text { for } 0.16<\operatorname{Stk}(\mathbf{i}) \leq 0.25 \\ 1.6(\operatorname{Stk}(\mathbf{i}))^{1 / 2}+0.1 & \text { for } 0.25<\operatorname{Stk}(\mathbf{i}) \leq 0.3025 \\ 0.98 & \text { for } 0.3025<\operatorname{Stk}(\mathbf{i}) \leq 0.3364\end{cases}
$$


Physical Phenomena

$1.5<\delta \leq 4$

$$
\epsilon(\mathrm{i})= \begin{cases}0 & \text { for } \operatorname{Stk}(\mathrm{i}) \leq 0.1296 \\ 1.43(\operatorname{Stk}(\mathrm{i}))^{1 / 2}-0.51 & \text { for } 0.1296<\operatorname{Stk}(\mathrm{i}) \leq 0.1849 \\ 11.43(\operatorname{Stk}(\mathrm{i}))^{1 / 2}-4.81 & \text { for } 0.1849<\operatorname{Stk}(\mathrm{i}) \leq 0.25 \\ 1.6(\operatorname{Stk}(\mathrm{i}))^{1 / 2}+0.1 & \text { for } 0.25<\operatorname{Stk}(\mathrm{i}) \leq 0.3025 \\ 0.98 & \text { for } 0.3025<\operatorname{Stk}(\mathrm{i}) \leq 0.3364\end{cases}
$$

$\delta>4$

$$
\epsilon(\mathrm{i})= \begin{cases}0 & \text { for } \operatorname{Stk}(\mathrm{i}) \leq 0.1296 \\ 1.67(\operatorname{Stk}(\mathrm{i}))^{1 / 2}-0.6 & \text { for } 0.1296 \leq \operatorname{Stk}(\mathrm{i}) \leq 0.2025 \\ 9.38(\operatorname{Stk}(\mathrm{i}))^{1 / 2}-4.07 & \text { for } 0.2025<\operatorname{Stk}(\mathrm{i}) \leq 0.2809 \\ 1.6(\operatorname{Stk}(\mathrm{i}))^{1 / 2}+0.05 & \text { for } 0.2809<\operatorname{Stk}(\mathrm{i}) \leq 0.3364\end{cases}
$$

(3) $\epsilon(\mathrm{i})=0.98 \quad$ for $\operatorname{Stk}(\mathrm{i})>0.3364$

The numerous linear expressions are simply the results of attempts to fit thel classic "S"-shaped curve of impaction efficiency as a function of the square root of the Stokes number for various orifice-to-plate separation distances. Certainly, there are more succinct expressions available for the impaction efficiency. The real issue is whether impaction on a fixed, infinite wall is an appropriate approximation. A more obvious approximation is to recognize that there is a boundary layer at the bubble wall opposite the orifice. This boundary layer should have a diameter on the order of $\mathrm{D}_{b} / \operatorname{Re}^{1 / 6}$ [195]. Then, deposition of aerosol particles can be treated as impaction on a disk of this diameter. The Stokes number is defined to be [194]:

$$
\operatorname{Stk}(\mathrm{i})=\operatorname{Re}^{1 / 6} \rho_{\mathrm{p}} \mathrm{V}_{\mathrm{jet}} \mathrm{d}_{\mathrm{p}}(\mathrm{i})^{2} \mathrm{C} / 18 \mu_{\mathrm{g}} \chi \stackrel{A}{\mathrm{D}} \mathrm{b}
$$

where $\operatorname{Re}=\mathrm{D}_{\mathrm{o}} \mathrm{V}_{\mathrm{jet}} \rho_{\mathrm{p}} / \mu_{\mathrm{g}}$ and $\mathrm{D}_{\mathrm{o}}$ is the diameter of the orifice. The particle collection efficiency for this approximation is compared to those for a flat plate in Figure 101. The infinite plate model predicts a transition from nearly complete capture to essentially negligible particle capture over a narrow range of particle sizes. The boundary layer disk model predicts that this transition takes place over a much broader range of particle sizes. Capture efficiencies at given jet velocities and particle sizes are lower for the disk model than the plate model.

Also shown in Figure 101 are predictions from a correlation for scrubbers suggested by Taheri and Calvert [221]: 


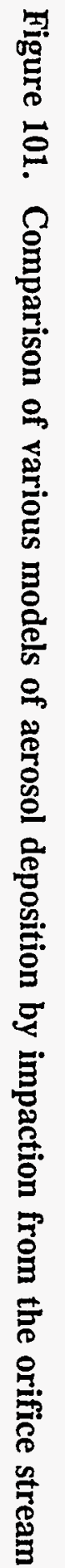

\section{CAPTURE EFFICIENCY}

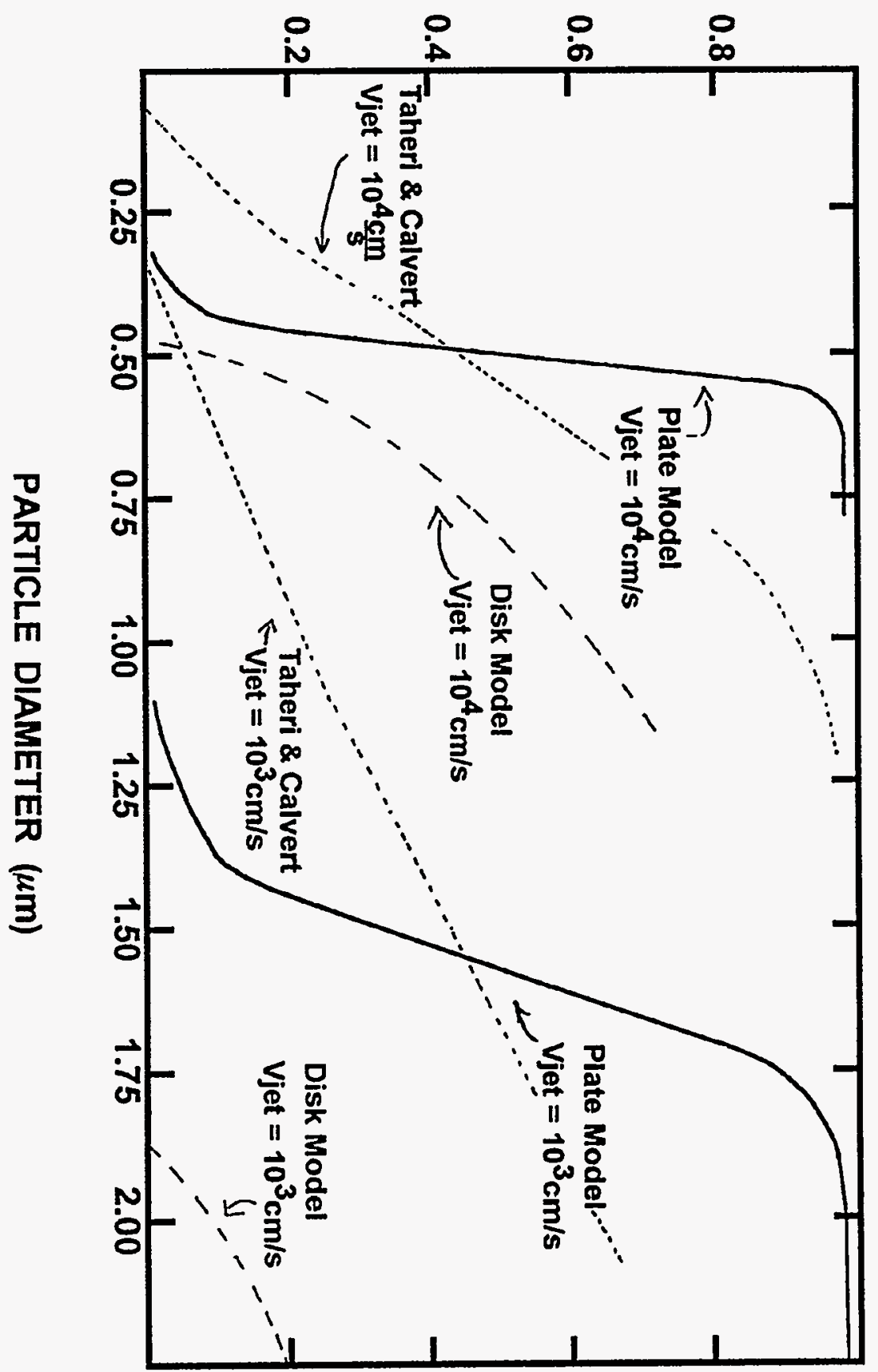


Physical Phenomena

$$
\epsilon(\mathrm{i})=1-\exp [-40 \operatorname{Stk}(\mathbf{i})]
$$

where

$$
\begin{aligned}
\epsilon(i) & =\text { efficiency of capture of particles of diameter } d_{p}(i) \text {, and } \\
\text { Stk(i) } & ={ }_{\mathrm{p}}(\mathrm{i})^{2} \rho_{\mathrm{p}} \mathrm{V}_{\text {jet }} \mathrm{C} / 9 \mu_{\mathrm{g}} \mathrm{D}_{\mathrm{o}}
\end{aligned}
$$

This correlation indicates an even broader size range of particle cap̣turite than the disk moddel. That is, the transition from very inefficient particle capture to essentially complete particle capture occurs over a larger range of particle sizes than is predicted by the plate model.

The SUPRA model describes particle capture within the forming bubble due to inertial impaction from circulating gases by:

$$
\mathrm{DF}(\mathrm{i})=\frac{1}{1-\epsilon(\mathbf{i})}=\exp \left[\alpha^{*} \mathrm{t}_{\mathrm{d}}\right]
$$

where

$$
\begin{aligned}
\alpha^{*} & =\mathrm{V}_{\mathrm{jet}}^{2} \tau / \mathrm{D}_{\mathrm{b}}(\mathrm{d}), \\
\tau & =\rho_{\mathrm{p}} \mathrm{d}_{\mathrm{p}}(\mathrm{i})^{2} \mathrm{C} / 18 \mu_{\mathrm{g}} \\
\mathrm{D}_{\mathrm{b}}(\mathrm{d}) & =\text { spherical equivalent bubble diameter at the time of detachment, and } \\
\mathrm{t}_{\mathrm{d}} & =\text { time required for a bubble to grow and detach from the orifice. }
\end{aligned}
$$

Less attention has been given to the capture of aerosol particles during the convective mass transfer associated with bubble formation. Skelland and Minhas [222] suggest the mass transport coefficient, averaged over the period of bubble formation, can be obtained from:

$$
\mathrm{k}_{\mathrm{m}}=\frac{0.0432}{\mathrm{t}_{\mathrm{f}}} \mathrm{D}_{\mathrm{B}}\left[\frac{\mathrm{v}_{\mathrm{jet}}^{2}}{\mathrm{D}_{\mathrm{B}} \mathrm{g}}\right]^{0.089}\left[\frac{\mathrm{D}_{\mathrm{B}}^{2}}{\mathrm{t}_{\mathrm{f}} \mathrm{D}^{2}}\right]^{-0.334}\left[\frac{\mu_{\mathrm{g}}}{\sqrt{\rho_{\mathrm{g}} \mathrm{D}_{\mathrm{B}} \sigma_{\mathrm{l}}}}\right]_{-\cdots}^{-0.601}
$$

where $D_{B}$ is the diameter of the bubble at the time it detaches and $t_{f}$ is the time required for the bubble to grow to this size. Particle capture efficiencies, calculated with this-model are shôn as functions of particle size in Figure 102. Very small particles $(<0.1 \mu \mathrm{m})$ àre predicted to be remoyed quite efficiently. Efficiency drops quite rapidly with increasing particle size because of the small diffusion coefficients of larger particles. Particle removal efficiency decreases slowly for particles larger than $0.3 \mu \mathrm{m}$. This slow decrease reflects particle capture during the period when the bubble was quite small. Capture efficiencies for the larger particles decrease with increasing jet velocity because the bubble grows large. 

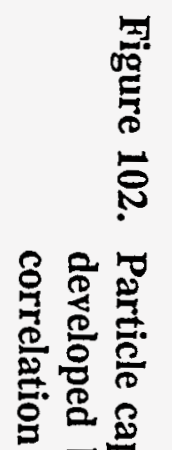

PARTICLE CAPTURE EFFICIENCY

월롤

율 웅

\&

\&

옹

居范

里

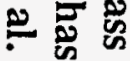

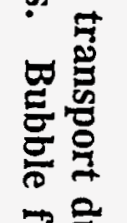

윸를.

\%

흥 몰

可. 亭

尺े

$\cong$

를

콩 웅

¿

용

듬 을

공 8

\&

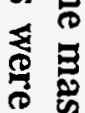

है

昰

을

蛋

들.

化

훙 응

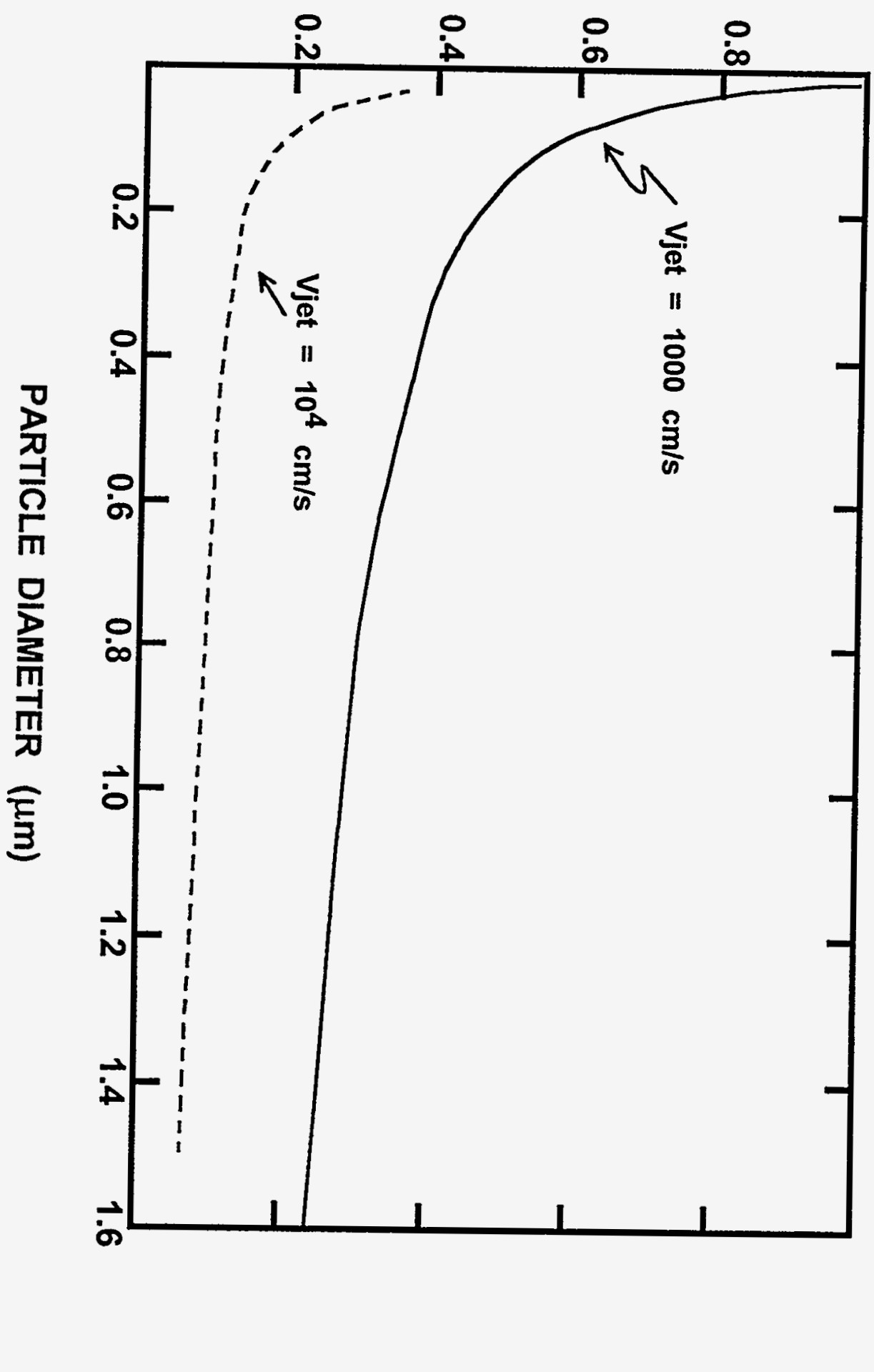

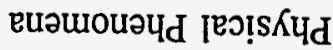


The SPARC 90 code [6] has a much more involved description of aerosol removal during bubble formation. This code attempts to account for impaction, diffusion, gravitational settling and the circulation of gases within the bubble. Like the SUPRA code, impaction is treated in SPARC 90 in analogy to impaction on fixed plates. The efficiency expressions are similari: ... . ...

$\ln \epsilon(\mathrm{i})= \begin{cases}0.58323+\left(5.9244 \times 10^{-3}\right)^{\xi} \ln \left(3.3437 \times 10^{-11}\right) & \text { for } 0 \leq \operatorname{Stk}(\mathrm{i}) \leq 0.811595 \\ 0.050532+\left(4.2597 \times 10^{-3}\right)^{\xi} \ln \left(1.4173 \times 10^{-6}\right) & \text { for } 0.811595 \leq \operatorname{Stk}(\mathbf{i}) \leq 0.3365 \\ -0.01005 & \text { for Stk(i) }>0.3365\end{cases}$

where

$$
\xi=[\operatorname{Stk}(\mathrm{i})]^{1 / 2}
$$

Diffusion is treated by:

$$
\mathrm{DF}(\mathrm{i})=\exp \left[\frac{16}{3 \mathrm{D}_{\mathrm{o}}}\left[\frac{\boxplus(\mathrm{i}) \mathrm{t}_{\mathrm{f}}}{\pi}\right]^{1 / 2}\right]
$$

where

$$
\begin{aligned}
D_{0} & =\text { orifice diameter } \\
Ð(i) & =\text { particle diffusion coefficient } \\
t_{f} & =\text { time of bubble formation }
\end{aligned}
$$

Gravitational settling is treated by:

$$
\mathrm{DF}(\mathrm{i})=\exp \left[\frac{\mathrm{A}_{\mathrm{s}} \mathrm{V}_{\mathrm{g}}(\mathrm{i}) \mathrm{t}_{\mathrm{f}}}{\mathrm{V} \text { (glob) }}\right]
$$

where

$$
\begin{aligned}
\mathrm{A}_{\mathrm{s}} & =2 \mathrm{~V}(\mathrm{glob}) / \pi \mathrm{D}_{\mathrm{o}}+\mathrm{D}_{\mathrm{o}}^{2}(\pi / 8-1 / 6) \\
\mathrm{V}(\mathrm{glob}) & =\text { gas bubble volume, and } \\
\mathrm{V}_{\mathrm{g}}(\mathrm{i}) & =\text { particle settling velocity. }
\end{aligned}
$$


Aerosol trapping by gases circulating within a bubble is treated by:

$$
\mathrm{DF}(\mathbf{i})=\exp \left[\mathrm{V}_{\mathrm{c}}(\mathbf{i}) / \dot{\mathrm{R}}\right]
$$

where

$$
\begin{aligned}
\mathrm{V}_{\mathrm{c}}(\mathrm{i}) & =\mathrm{V}_{\mathrm{s}}^{2} \mathrm{~V}_{\mathrm{g}}(\mathrm{i}) / \mathrm{r}_{\mathrm{c}} \mathrm{g} \\
\mathrm{r}_{\mathrm{c}} & =\text { curvature of the surface of the bubble } \\
\dot{\mathrm{R}} & =\text { growth rate of the bubble }
\end{aligned}
$$

$\mathrm{V}_{\mathrm{S}}$ in the above expression is a complicated expression for the gas flows in a prolate ellipsoidal bubble. Bubble rise velocity appears in the expression. It is not immediately obvious how this value of the rise velocity is determined for a bubble attached to the orifice.

It is evident that there is substantial uncertainty about decontamination that occurs during bubble formation. There is no data base to clarify hypotheses about aerosol trapping during bubble formation. Considering the general difficulty that has been encountered in obtaining data on mass transport during bubble formation, it appears unlikely that a data base will soon be available to resolve the several issues that arise concerning bubble formation and the associated aerosol removal. These issues include:

- the appropriate description of the removal of large particles by inertial impaction from the input gas jet, and

- the removal of small particles by diffusion and convective mass transport to the growing bubble surface.

There are also the issues of the thermophysical state of the carrier gas and the importance of condensation or evaporation as an aerosol removal mechanism during bubble formation. If, as discussed above (Section IVA-3), the carrier gas equilibrates during transport to the pool, then condensation and evaporation processes will not be significant during bubble formation. On the other hand, aerosol removal over the period during which equilibrium is achieved may be quite significant. 

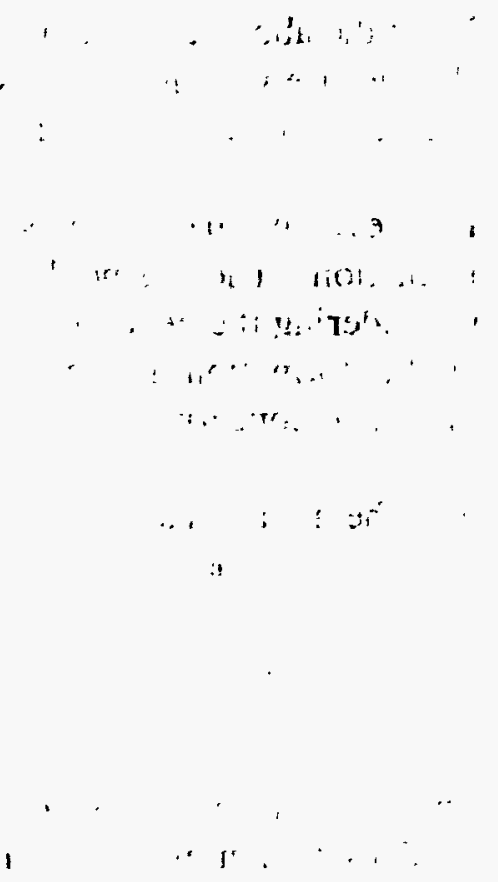


\section{Uncertainty in Predictions of Aerosol Removal by Steam Suppression Pools}

In both Chapters III and IV uncertainties that will affect the predictions of aerosol removal by steam suppression pools have been identified and discussed. To determine the cumulative effect of these several uncertainties, a mechanistic model of aerosol removal by steam suppression pools is formulated and used in a Monte Carlo uncertainty analysis. The mechanistic model is described in the subsection immediately below.

The Monte Carlo uncertainty analysis is begun by defining parameters that describe each of the uncertainties identified above. The range of possible values each parameter can assume is defined. These ranges are defined from examination of accident analyses, experimental studies, bounding analyses or, as a last resort, engineering judgement. Subjective probability distributions for values of the parameters within their respective ranges are defined. The Monte Carlo uncertainty analysis is carried out by randomly sampling values of the parameters, according to their respective probability distributions, and using these sampled values in a calculation with the mechanistic model. Results of the calculation are accumulated and the process repeated until a satisfactorily representative sample of the distribution of results obtained with the mechanistic model has been acquired. Sampling and calculations were repeated in this work until there is a 99 percent confidence that 95 percent of the range of predictions by the mechanistic model has been sampled. Results of the many calculations are then ordered and subjected to a nonparametric statistical analysis [see Appendix A of Reference 3] to obtain estimates of the probability distributions for the predictions of aerosol removal by steam suppression pools.

\section{A. Mechanistic Model}

The essential elements of the mechanistic model of aerosol removal by steam suppression pools are shown in Figure 103. Most steps in the calculational sequence involve significant phenomenological uncertainty. The phenomenological models are outlined in later sections of this chapter in connection with the discussion of uncertainties. The mechanical features of the model are described in this subsection.

\section{Input}

Because the model is used in a generic uncertainty analysis that includes uncertainties in the initial and boundary conditions, the fixed input to the model is quite restricted. Only inputs that are likely to be known with some certainty are supplied. These are the depth of the suppression pool and the phase of a severe accident that is of interest. The accident phases are those defined in the revised severe accident source term [3]:

- gap release phase

- in-vessel release phase

- ex-vessel release phase

- late in-vessel release phase 


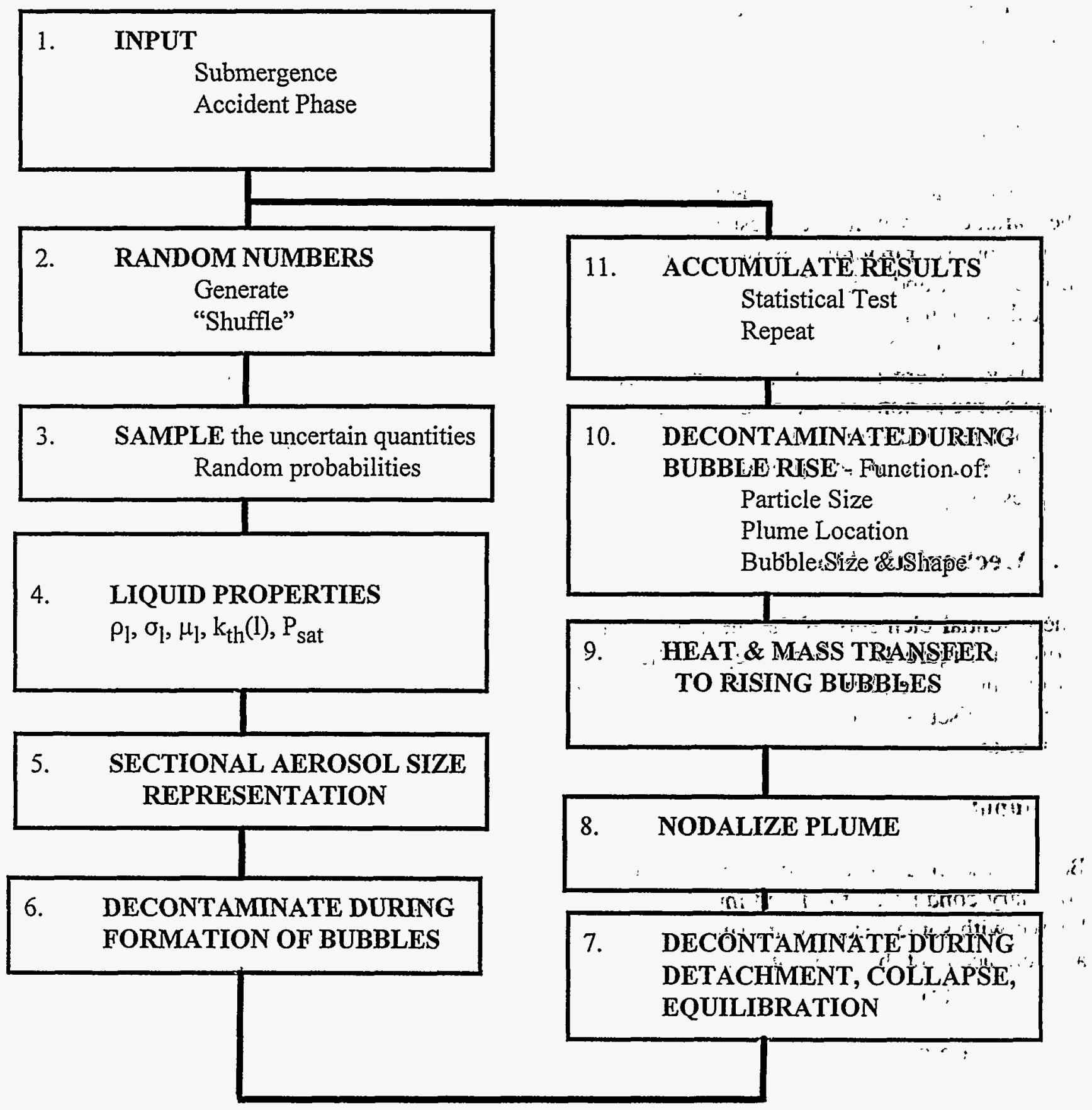

Figure 103. Essential elements of the mechanistic model of aerosol removal by steam suppression pools 
Other expected inputs to such a mechanistic model of aerosol removal by suppression pools such as aerosol size distribution, gas flow rate and gas composition are uncertain quantities whose distributed values are sampled by the computer code.

\section{Generation of Random Numbers}

Random numbers are generated by a linear congruential random number generator. Such generators are known to produce cyclical sequences of pseudorandom numbers. To avoid this problem, the random numbers are "shuffled" using an algorithm suggested by Knuth [269]. A subtle point about linear congruential random number generators is that they can yield zero as a random number, but they can never produce exactly one as a random number. Thus, the random numbers are uniformly distributed over the range $[0,1)$ rather than $(0,1)$ or $[0,1]$.

\section{Sampling Uncertain Inputs and Parametric Quantities}

The random numbers defined above are used to sample the various uncertain inputs and parametric quantities. As will be discussed further below, there are four types of probability density functions that can be sampled:

- uniform,

- $\log$-uniform,

- lognormal, and

- Student's t.

These density functions are compared in Figure 104.

The random numbers are used as probabilities that the true value of some uncertain quantity is less than some critical value. Inversions of the uniform and log-uniform distributions to obtain the critical values of the uncertain quantity at a randomly selected probability are quite obvious. For uniform and loguniform distributions over the interval $[a, b]$, the critical value of the uncertain quantity, $x$, at a probability $R$ is found from:

$$
\begin{gathered}
x=a+R(b-a) \\
\text { and } \\
\ln x=\ln (a)+R[\ln (b)-\ln (a)]
\end{gathered}
$$

Implicit equations are used to invert the lognormal and the Student's $t$ distributions. The critical value of a quantity with a lognormal distribution is found from: 


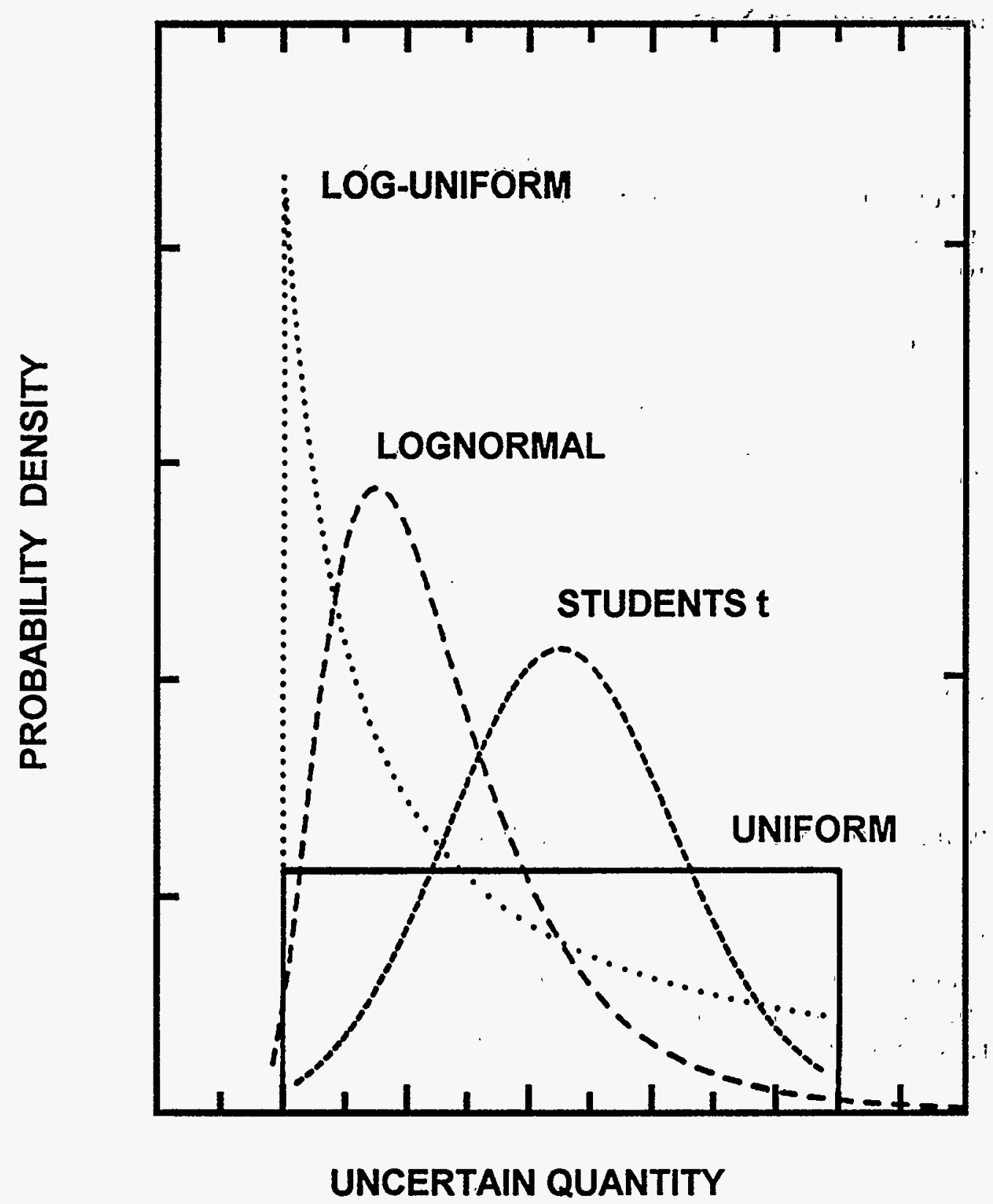

Figure 104. Comparison of uniform, log-uniform, lognormal, and Student's t probability density functions 


$$
\mathbf{R}=0.5(1+\operatorname{erf}(\mathrm{z}))
$$

where

$$
\begin{aligned}
& \mathrm{z}=\ln (\mathrm{x} / \mu) / \sqrt{(2) \ln \sigma} \\
& \mu=\text { mean of the distribution, } \\
& \sigma=\text { geometric standard deviation, and }
\end{aligned}
$$

erf(z) is the error function of $z$ defined by:

$$
\operatorname{erf}(z)=\frac{2}{\sqrt{\pi}} \int_{0}^{z} \exp \left(-y^{2}\right) d y
$$

The Student's $t$ distribution specifies the cumulative probability that the absolute value of a quantity $\xi$ where

$$
\begin{aligned}
\xi & =\left|\frac{\chi-\mu}{\sqrt{\chi^{2} / \nu}}\right| \\
\mu & =\text { mean of the distribution, } \\
\chi^{2} & =\text { chi-squared statistic, and } \\
\nu & =\text { degrees of freedom }
\end{aligned}
$$

is less than some value $t$. The cumulative probability is given by:

$$
\operatorname{Pr}(\xi<t)=1-I_{Z}(A, B)
$$

where

$$
\begin{aligned}
& \mathrm{A}=\nu / 2 \\
& \mathrm{~B}=1 / 2 \\
& \mathrm{z}=\nu /\left(\nu+\mathrm{t}^{2}\right)
\end{aligned}
$$


and $I_{z}(A, B)$ is the incomplete Beta function:

$$
I_{z}(A, B)=\frac{\Gamma(A) \Gamma(B)}{\Gamma(A+B)} \int_{0}^{t} y^{A-1}(1-y)^{B-1} d y
$$

and $\Gamma(A+B)$ is the gamma function of $A+B$.

The inversions necessary to find critical values of $\left(x-\mu / \sqrt{x^{2} / \nu}\right)$ in both the positive and negative domains are:

- $\quad$ For $\mathrm{R}<0.5$

$$
1-2 R=1-I_{Z}(A, B)
$$

- $\quad$ For $\mathrm{R} \geq 0.5$

$$
2(\mathrm{R}-0.5) \cong 1-\mathrm{I}_{\mathrm{z}}(\mathrm{A}, \mathrm{B})
$$

These implicit equations are readily solved by Newton-Raphson techniques recognizing that the derivative of $1-I_{z}(A, B)$ with respect to $z$ is:

$$
\frac{\Gamma(\mathrm{A}) \Gamma(\mathrm{B})}{\Gamma(\mathrm{A}+\mathrm{B})} \mathrm{z}^{\mathrm{A}-1}(1-\mathrm{z})^{\mathrm{B}-1}
$$

\section{Properties of the Liquid}

Thermophysical properties of the liquid are calculated using the equations described in Chapter IV for pure water. Explicit account for the effects of contamination on liquid properties is not taken. Any uncertainty in the liquid properties caused by contamination is thought to be small in comparison to other uncertainties considered here. This contrasts with the treatment of water pools overlying core debris interacting with concrete [3] where the effects of contamination on water properties were taken into account. Much of the contamination of water pools overlying core debris interacting with concrete actually comes from the action of hot water on the concrete. Water pools overlying core debris interacting with concrete become very heavily laden with dissolved and suspended materials [270] -far more so than is expected to occur in steam suppression pools. The effects of these dissolved and suspended materials on the liquid properties are then much greater than the effects of contaminants on properties of water in the suppression pool. The total aerosol mass produced during a severe reactor accident is typically about $4 \times 10^{6}$ grams. Suppression pools, typically, contain at least $2 \times 10^{9}$ grams of water. Thus, mass loadings of the suppression pool by suspended materials will be less than 0.2 percent. Molar concentrations of dissolved species would be expected to be less than $0.05 \mathrm{moles} / \mathrm{kg}$ 
$\mathrm{H}_{2} \mathrm{O}$. Such concentrations are not expected to affect substantially the physical properties of water that are of interest here.

\section{Discretization of the Aerosol Size Distribution}

The size distributions of aerosols suspended in the gas flowing to a suppression pool are very uncertain. It is assumed here that the size distributions are adequately approximated by lognormal distributions with uncertain means and geometric standard deviations.

The efficiencies of the various processes that remove aerosols from the gas are quite dependent on the aerosol particle sizes. Consequently, decontamination must be calculated as a function of particle size. To do this, the aerosol particle size distribution is segmented into size classes. The size classes are chosen such that initially each class has the same mass of aerosol particles. Decontamination of the size class is calculated based on the behavior of a particle with a diameter representative of the size class.

Experience in previous studies of source term attenuation [1,2] indicates that lognormal distributions can usually be adequately represented by 20 equal-mass size classes. Thus, the boundaries of the size classes can be found from:

$$
0.05+(i-1) 0.05=0.5\left(1+\operatorname{erf}\left(z_{i}\right)\right)
$$

where

$$
\begin{aligned}
\mathrm{z}_{\mathrm{i}} & =\ln \left[\mathrm{d}_{\mathrm{p}}(\mathrm{i}) / \mu\right] / \sqrt{(2)} \ln \sigma \\
\mathrm{d}_{\mathrm{p}}(\mathrm{i}) & =\text { upper size limit of the } \mathrm{i}^{\text {th }} \text { size class } \\
\mu & =\text { mean of the lognormal size distribution } \\
\sigma & =\text { geometric standard deviation of the lognormal size distribution. }
\end{aligned}
$$

The upper limit of the twentieth size class is, by the definition above, infinity. For practical purposes this upper limit is defined by:

$$
0.999=0.5\left(1+\operatorname{erf}\left(\mathrm{z}_{20}\right)\right)
$$

The particle diameter that is taken to be representative of the $\mathrm{i}^{\text {th }}$ size class is the mass mean particle size in the class given by:

$$
0.025+(\mathrm{i}-1) 0.05=0.5(1+\operatorname{erf}(\mathrm{z}))
$$

The nondimensional particle sizes, $\ln \left(\mathrm{d}_{\mathrm{p}}(\mathrm{i}) / \mu\right) / \sqrt{(2)} \ln \sigma$, that define and represent the size classes of the aerosol are listed in Table 20. Also shown in this table are dimensional particle sizes that define and represent size classes for some example particle size distributions. 
Table 20. Dimensionless and example dimensional discretization of the particle size distributions

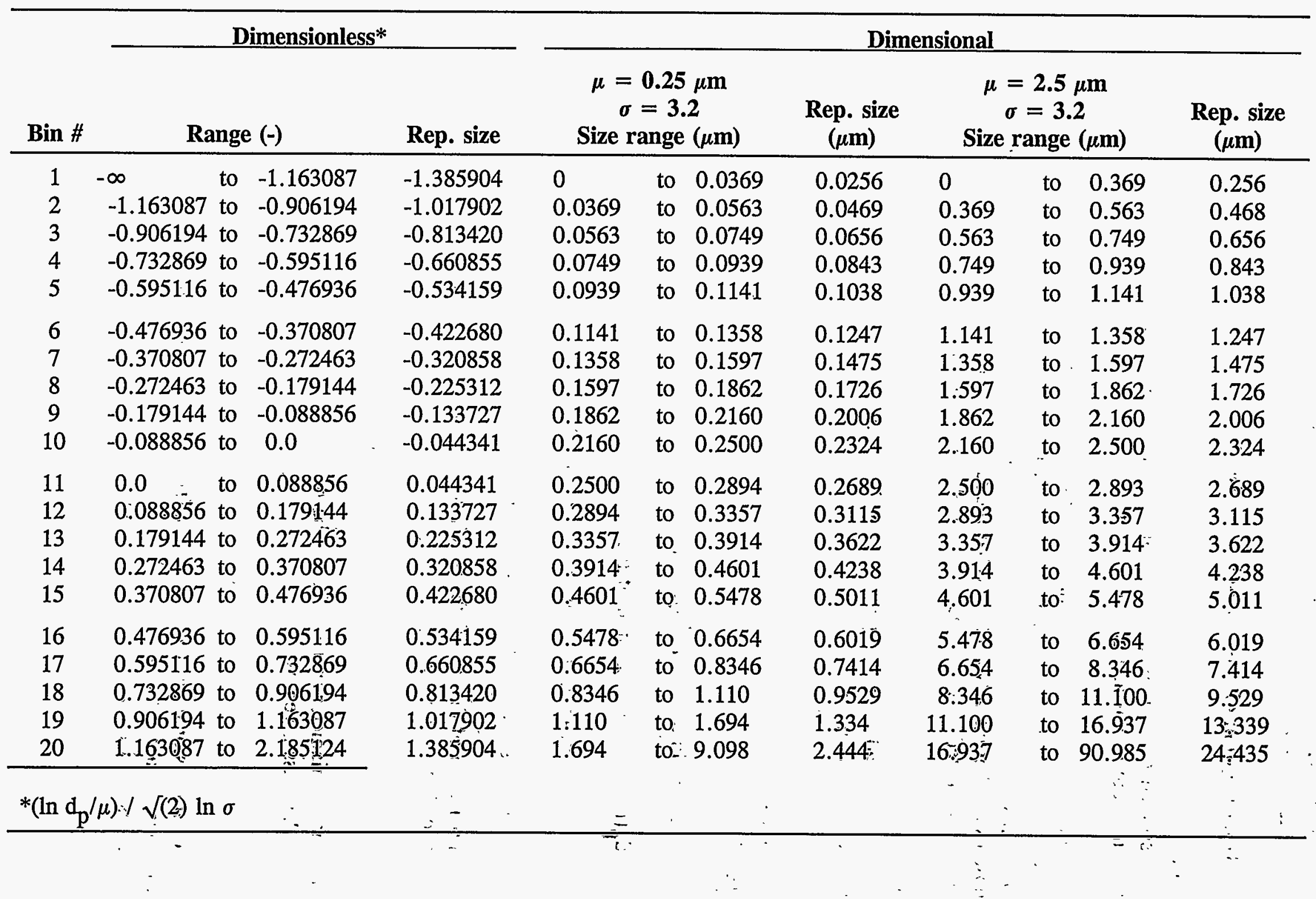




\section{Formation of Bubbles and Decontamination During Bubble Formation}

The model of bubble formation is selected depending on the accident phase. Aerosol laden gases during the gap release and in-vessel release are assumed to always go through the quenchers. This is not universally true, but seems to be the case for frequency-dominant accidents discussed in Chapter III. Aerosol-laden gases produced in the ex-vessel and the late in-vessel phases of an accident, of course, are discharged to the suppression pool through large diameter vents and downcomers.

Decontamination of the gas by inertial impaction from the gas jet and diffusion are poorly understood. In the authors' opinions, these are very important processes that have received insufficient study. They are treated in the model by uncertain, size-dependent collection efficiencies. There will, of course, be some aerosol removal as a result of steam condensation during bubble formation. This removal is neglected in the model used for uncertainty analysis. All of the effects of steam condensation during bubble formation, detachment from the orifice, collapse and equilibration with the steam suppression pool are calculated in the model of decontamination during the equilibration of the bubble with the pool.

\section{Detachment and Equilibration of the Bubble}

The events that take place immediately after a bubble detaches from an orifice or vent are very complicated. A mechanistic treatment of these processes is not attempted. Rather, it is assumed that over a distance between 2 and 10 times the initial bubble diameter, the bubble disintegrates to a stable size and that it comes into equilibrium with the pool at the local conditions of pressure and the bulk pool temperature. Collapse and disintegration of the bubble are not thought to cause any significant decontamination. Condensation of some fraction of the gas as the bubbles equilibrate with the pool is assumed to remove a proportionate amount of the aerosol independent of particle size.

\section{Plume Formation}

The modified Milgram model described in Chapter IV with many of the parameters taken to be uncertain is used to predict the behavior of bubble swarms. Each arm of a quencher is taken as a plume source. Also, each downcomer is treated as a plume source. The plume model indicates that the rise velocities of bubbles, and in some cases the slip velocities, vary both axially and radially. The rise velocities dictate, of course, how long the rising bubbles are exposed to the actions of the suppression pool. The slip velocities enter into the analyses of aerosol capture. Decontamination of bubbles should then depend on radial location within the plume.

The plume geometry and properties are calculated using a fourth order Runge-Kutta differential equation solver with an adaptive step-size controller configured to control errors to 1 part in $10^{4}$. This same differential equation solver is also used to calculate mass transfer to the bubbles.

At each axial location, the plume is nodalized in the radial direction so that there is a constant fraction of the gas flux through each ring node. That is, the total gas flux is given by:

$$
\mathrm{Q}(\mathrm{z})=\int_{0}^{\infty}\left[\mathrm{U}_{1}(\mathrm{r}, \mathrm{z})+\mathrm{U}_{\text {slip }}(\mathrm{r}, \mathrm{z})\right] \epsilon(\mathrm{r}, \mathrm{z}) 2 \pi \mathrm{rdr}
$$


where

$$
\begin{aligned}
\mathrm{U}_{\mathrm{l}}(\mathrm{r}, \mathrm{z}) & =\text { liquid velocity at radial location } \mathrm{r} \text { and axial location } \mathrm{z}= \\
& =\mathrm{U}_{1}(\mathrm{z}) \exp \left[-\mathrm{r}^{2} / \mathrm{b}(\mathrm{z})^{2}\right] \\
\mathrm{U}_{\mathrm{slip}}(\mathrm{r}, \mathrm{z}) & =\mathrm{F}(\epsilon) \mathrm{U}_{\mathrm{B}} \\
\mathrm{U}_{\mathrm{B}} & =\text { rise velocity of an isolated bubble, } \\
\epsilon(\mathrm{r}, \mathrm{z}) & =\epsilon(\mathrm{z}) \exp \left[-\mathrm{r}^{2} / \lambda^{2} \mathrm{~b}(\mathrm{z})^{2}\right] \\
\mathrm{F}(\epsilon) & =\left\{\begin{array}{c}
1-\epsilon(\mathrm{r}, \mathrm{z}) \\
\text { or } \\
1 \\
11-\epsilon(\mathrm{r}, \mathrm{z})]^{2}
\end{array}\right.
\end{aligned}
$$

Nodes are defined by the bounding radial coordinates $R(i-1)$ and $R(i)$ for $i=1$ to $N$ 'such'thát:

$$
\frac{\mathrm{Q}(\mathrm{z})}{\mathrm{N}}=\int_{\mathrm{R}(\mathrm{i}-1)}^{\mathrm{R}(\mathrm{i})}\left[\mathrm{U}_{1}(\mathrm{r}, \mathrm{z})+\mathrm{U}_{\text {slip }}(\mathrm{r} ; \mathrm{z})\right] \cdot \epsilon(\mathrm{r}, \mathrm{z}) \cdot 2 \pi \mathrm{r} d r
$$

The $\mathrm{N}^{\text {th }}$ radial coordinate is, however, taken to be such that:

$$
\frac{\mathrm{Q}(\mathrm{z})}{\mathrm{N}}-0.001=\int_{\mathrm{R}(\mathrm{N}-1)}^{\mathrm{R}(\mathrm{N})}\left[\mathrm{U}_{\mathrm{I}}(\mathrm{r}, \mathrm{z})+\mathrm{U}_{\mathrm{slip}}(\mathrm{r}, \mathrm{z})\right] \epsilon(\mathrm{r}, \mathrm{z}) 2 \pi \mathrm{r} \mathrm{dr}
$$

An example nodalization for $\mathrm{U}_{\mathrm{slip}}=\mathrm{U}_{\mathrm{B}}(1-\epsilon(\mathrm{r}, \mathrm{z}))^{2}$ at three elevations are listed in Table 21 . Some numerical tests showed that, for the purposes of the uncertainty analysis, 5 radial nodes at each axial level was sufficient to characterize the plume.

Rise and slip velocities were taken to be the averages of these quantities across the node. "These averages are: 
Table 21. Example nodalizations of a plume

\begin{tabular}{|c|c|c|c|c|c|c|c|c|c|}
\hline \multirow[b]{2}{*}{ Node \# } & \multicolumn{3}{|c|}{ for $z=60 \mathrm{~cm}$} & \multicolumn{3}{|c|}{ for $z=200 \mathrm{~cm}$} & \multicolumn{3}{|c|}{ for $\mathrm{z}=305 \mathrm{~cm}$} \\
\hline & $\begin{array}{l}\mathbf{R}(\mathbf{i}) \\
\text { (cm) }\end{array}$ & $\underset{(\mathrm{cm} / \mathrm{s})}{<\mathrm{U}_{\text {Rise }}>}$ & $\underset{(\mathrm{cm} / \mathrm{s})}{<\mathrm{U}_{\mathrm{slip}}}>$ & $\begin{array}{l}\mathbf{R}(\mathbf{i}) \\
(\mathbf{c m})\end{array}$ & $\begin{array}{c}<\mathbf{U}_{\text {Rise }}> \\
(\mathrm{cm} / \mathrm{s})\end{array}$ & $<\underset{(\mathrm{cm} / \mathrm{s})}{<\mathrm{U}_{\mathrm{slip}}}>$ & $\begin{array}{l}\mathbf{R}(\mathbf{i}) \\
(\mathbf{c m}) \\
\end{array}$ & $\begin{array}{c}<\mathbf{U}_{\text {Rise }}> \\
(\mathrm{cm} / \mathrm{s})\end{array}$ & $\begin{array}{c}<U_{\text {slip }}> \\
(\mathrm{cm} / \mathrm{s})\end{array}$ \\
\hline 1 & 1.706 & 141.0 & 7.19 & 5.721 & 116.1 & 22.02 & 8.405 & 108.1 & 23.14 \\
\hline 2 & 2.483 & 133.2 & 8.55 & 8.324 & 109.9 & 22.28 & 12.231 & 102.4 & 23.29 \\
\hline 3 & 3.138 & 125.0 & 10.02 & 10.524 & 103.4 & 22.56 & 15.463 & 96.4 & 23.44 \\
\hline 4 & 3.756 & 116.5 & 11.60 & 12.594 & 96.6 & 22.83 & 18.505 & 90.2 & 23.59 \\
\hline 5 & 4.375 & 107.5 & 13.31 & 14.670 & 89.3 & 23.10 & 21.556 & 83.6 & 23.74 \\
\hline 6 & 5.029 & 97.9 & 15.14 & 16.867 & 81.6 & 23.38 & 24.783 & 76.4 & 23.89 \\
\hline 7 & 5.765 & 87.4 & 17.08 & 19.334 & 73.1 & 23.66 & 28.408 & 68.7 & 24.04 \\
\hline 8 & 6.664 & 75.6 & 19.15 & 22.353 & 63.6 & 23.94 & 32.845 & 60.0 & 24.20 \\
\hline 9 & 7.970 & 61.3 & 21.38 & 26.734 & 52.3 & 24.23 & 39.284 & 49.0 & 24.35 \\
\hline 10 & 14.967 & 32.6 & 24.31 & 45.959 & 31.9 & 24.58 & 67.725 & 31.1 & 24.54 \\
\hline
\end{tabular}


Uncertainty

$$
\begin{aligned}
& \text { Average Rise Velocity }=\left\langle\mathrm{U}_{\text {Rise }}\right\rangle=\frac{1}{\pi\left[\mathrm{R}(\mathrm{i})^{2}-\mathrm{R}(\mathrm{i}-1)^{2}\right]} \int_{\mathrm{R}(\mathrm{i}-1)}^{\mathrm{R}(\mathrm{i})}\left[\mathrm{U}_{1}(\mathrm{r}, \mathrm{z})+\mathrm{U}_{\text {slip }}\right] 2 \pi \mathrm{rdr} \\
& \text { Average Slip Velocity }=\left\langle\mathrm{U}_{\mathrm{slip}}\right\rangle=\frac{1}{\pi\left[\mathrm{R}(\mathrm{i})^{2}-\mathrm{R}(\mathrm{i}-1)^{2}\right]} \int_{\mathrm{R}(\mathrm{i}-1)}^{\mathrm{R}(\mathrm{i})} \vdots^{\prime} \mathrm{U}_{\mathrm{slip}} 2 \pi \mathrm{rdr}
\end{aligned}
$$

The average liquid rise velocity is

$$
<\mathrm{U}_{\text {liq }}>=\mathrm{b}^{2} \mathrm{U}(\mathrm{z})\left\{\exp \left[\frac{-\mathrm{R}(\mathrm{i}-1)^{2}}{\mathrm{~b}^{2}}\right]-\exp \left[\frac{-\mathrm{R}(\mathrm{i})^{2}}{\mathrm{~b}^{2}}\right]\right\} /\left(\mathrm{r}(\mathrm{i})^{2}-\stackrel{\left.\ddot{\mathrm{R}}(\mathrm{i}-1)^{2}\right)}{-}\right.
$$

Then, the average bubble rise velocity is:

$$
\left\langle\mathrm{U}_{\text {Rise }}\right\rangle=\left\langle\mathrm{U}_{\mathrm{liq}}\right\rangle+\left\langle\mathrm{U}_{\text {slip }}\right\rangle
$$

where

$$
\begin{gathered}
<U_{\text {slip }}>=U_{B} \quad \text { for } U_{\text {slip }}(r, z)=U_{B} \\
<U_{\text {slip }}>=U_{B}\left[1-\frac{\lambda^{2} b^{2} \epsilon(z)}{R(i)^{2}-R(i-1)^{2}}\left\{\exp \left[\frac{-R(i-1)^{2}}{\lambda^{2} \dot{b}^{2}}\right]-\exp \left[\frac{-R(i)}{\lambda^{2} b^{2}}\right]\right\}\right] \\
\text { for } U_{s l i p}(r, z)=U_{B}(1-\epsilon(r, z))
\end{gathered}
$$




$$
\begin{gathered}
<\mathrm{U}_{\text {slip }}>=\mathrm{U}_{\mathrm{B}}\left[1-\frac{2 \lambda^{2} \mathrm{~b}^{2} \epsilon(\mathrm{z})}{\mathrm{R}(\mathrm{i})^{2}-\mathrm{R}(\mathrm{i}-1)^{2}}\left\{\exp \left[\frac{-\mathrm{R}(\mathrm{i}-1)^{2}}{\lambda^{2} \mathrm{~b}^{2}}\right]-\exp \left[\frac{-\mathrm{R}(\mathrm{i})^{2}}{\lambda^{2} \mathrm{~b}^{2}}\right]\right\}\right. \\
\left.+\frac{\epsilon(\mathrm{z})^{2} \lambda^{2} \mathrm{~b}^{2}}{\mathrm{R}(\mathrm{i})^{2}-\mathrm{R}(\mathrm{i}-1)^{2}}\left\{\exp \left[\frac{-2 \mathrm{R}(\mathrm{i}-1)^{2}}{\lambda^{2} \mathrm{~b}^{2}}\right]-\exp \left[\frac{-2 \mathrm{R}(\mathrm{i})^{2}}{\lambda^{2} \mathrm{~b}^{2}}\right]\right\}\right] \\
\text { for } \mathrm{U}_{\text {slip }^{(\mathrm{r}, \mathrm{z})}=\mathrm{U}_{\mathrm{B}}(1-\epsilon(\mathrm{r}, \mathrm{z}))^{2}}
\end{gathered}
$$

These average quantities for the example nodalizations are also listed in Table 21.

Note that nodalizations are fixed at the start of each spatial step and not altered in the Runge-Kutta calculations for the step.

\section{Mass Transfer to the Bubble}

Mass transfer to the bubble were calculated using the thermodynamic model described in Chapter IV (See Section IV-D). Heat transfer to and within the bubble was taken to be rapid. Numerical tests showed that thermal gradients were likely to be small enough that thermophoresis of aerosol particles could be neglected in comparison to diffusiophoresis.

\section{Decontamination During Bubble Rise}

Decontamination of bubbles in each of the 5 nodes is calculated for each of the 20 size classes. These results are summed to determine on overall decontamination factor. A mass-weighted mean particle size is calculated from:

$$
\left\langle\ln d_{p}\right\rangle=\frac{\sum_{i=1}^{20} \sum_{j=1}^{5} M(i, j) \ln d_{p}(i)}{\sum_{i=1}^{20} \sum_{j=1}^{5} M(i, j)}
$$

where $M(i, j)$ is the aerosol mass of size class $i$ remaining in node $j$. A standard deviation of the size distribution of aerosol particles emerging from the suppression pool is calculated using the expression: 


$$
\ln ^{2} \sigma=\frac{\sum_{i=1}^{20} \sum_{j=1}^{5} M(i, j)\left[\ln \left(d_{p}(i)\right)-<\operatorname{lnd} d_{p}>\right]^{2}}{\sum_{i=1}^{20} \sum_{j=1}^{5} M(i, j)}
$$

\section{Accumulation of Results}

The overall decontamination factor and the characteristics of the particle size distribution were accumulated for subsequent statistical analyses. Results are accumulated until there was at least a 99 percent confidence that 95 percent of the range of these output quantities had been sampled. The accumulated samples were ordered and used to uncertainty distributions at 50 and 90 percent confidence levels as described elsewhere [1].

\section{B. Uncertain Models, Inputs and Parametric Quantities}

Uncertainties that affect the predictions of aerosol removal by steam suppression pools include uncertainties in the boundary and initial conditions: dictated by: accident progression, ;uncertainties in the aerosol properties, and uncertainties in phenomena and processes. „.Many of these ‘uñcertaintièss arè readily expressed in terms of parameters that can assume ranges of values. :Pröbabilityrdistributions $/$ can be hypothesized to describe the distributions of the values of these parametric quantities rwithin these ranges.

Especially in connection with the phenomena and processes responsible for the removal of aerosols from gases sparging through a steam suppression pool, there is another type of uncertainty: '.This is uncertainty in the physical model used to describe the process or phenomenon. It is notrobvious how this type of uncertainty can be reduced to a parametric quantity with a range of valuesrand:a distiribution of values within this range that can be sampled in the Monte Carlo uncertainty analysis. Yet, such model uncertainty is very important to the overall uncertainty in predicting the decontamination that can be achieved by a steam suppression pool. Thus, model uncertainty cannot be neglected in the Monte Carlo uncertainty analysis.

Reduction of model uncertainty to a parametric quantity is done here in two ways. Consider two models that purport to describe the same phenomenon. The prediction of the first model is designated $\pi(\mathrm{A})$. The prediction of the second model is designated $\pi(\mathrm{B})$. If the models are quite distinct, say because they invoke different physics to describe the phenomenon, a parameter, $\delta$, is defined to be uniformly distributed over the range from zero to one. The quantity used in the mechanistic model, $\pi$, is then derived from the two models by: 


$$
\pi= \begin{cases}\pi(\mathrm{A}) & \text { if } \delta<0.5 \\ \pi(\mathrm{B}) & \text { if } \delta \geq 0.5\end{cases}
$$

On the other hand, the two models might be quite similar. They may differ only by different parameterization of a correlation for some set of data. Then, a parameter $\epsilon$ is defined to be uniformly distributed over the range of 0 to 1 . The quantity used in the mechanistic model is then found from the two alternative models from:

$$
\pi=\epsilon \pi(\mathrm{A})+(1-\epsilon) \pi(\mathrm{B})
$$

These two procedures for reducing model uncertainty to a parametric quantity are easily extended to situations involving more than two alternative models.

In the subsections below, the various parametric quantities sampled in the Monte Carlo uncertainty analysis including parameters used to represent model uncertainty are described. The emphases of the discussions are to justify credible ranges for the values of these parameters and to define subjective probability distributions for values of parameters within their respective ranges.

The authors are unaware of any algorithm for the definition of subjective probability distributions for uncertain quantities within justifiable ranges. The authors are aware that some investigators [271,272] develop fairly elaborate distributions for uncertain quantities. The very limited justifications offered for these complicated distributions do not appear persuasive to the authors. Based on criticisms levelled at these complicated distributions, it appears others in the technical community are also skeptical.

Here, simple, high-entropy probability distributions are ascribed to parametric values according to a set of rules. These rules are:

1. Values predicted by correlations derived from least-squares fits of experimental data are taken to be distributed according to a Student's t distribution.

2. Uncertain quantities whose meaningful range of values spans less than an order of magnitude are assigned a uniform distribution.

3. Uncertain quantities whose meaningful range spans more than one order of magnitude are assigned a log-uniform distribution.

4. If there is a substantial basis to believe values of a parameter are better known than would be reflected by the uniform or log-uniform distributions, this parameter is assigned a lognormal distribution.

High-entropy distributions such as the Student's $t$ distribution, the uniform distribution, and the lognormal distribution have been adopted primarily because the authors believe there is very little 


\section{Uncertainty}

knowledge about the parameter values within their respective ranges. It is more defensible to further decompose an issue into more fundamental parts than to attempt to define some highly structured probability distribution for a parameter. There is, however, another advantage associated with the use of high-entropy distributions. By restricting the distributions that can be assigned to values of a parameter to high-entropy distributions, the results of the uncertainty analyses are not very sensitive to the particular distributions assigned to the parameters. This relieves a question concerning the sensitivity of results to the parameter distributions that nags all probabilistic uncertainty analyses. Relief, from this question comes about because of the peculiar similarities of high-entropy distributions:in the vicinities of the tails of the distributions. For nearly all of the high entropy distributions:*

$$
\begin{gathered}
\mathrm{x}(5)=\mu-1.6( \pm 0.05) \sigma \\
\mathrm{x}(95)=\mu+1.6( \pm 0.05) \sigma
\end{gathered}
$$

where

$$
\begin{aligned}
\mathrm{x}(5) & =5 \text { th percentile value of the uncertain quantity } \mathrm{x}, \\
\mathrm{x}(95) & =95 \text { th percentile value of the uncertain quantity } \mathrm{x}, \\
\mu & =\text { mean of the distribution, and } \\
\sigma & =\text { standard deviation of the distribution. }
\end{aligned}
$$

Since the ranges assigned to values of a parameter essentially fix 'both the 'mean'and the standard deviation of the distribution, all of the distributions become rather similar. This is especially truènear: the "tails" of the distributions. The tails of distributions in the vicinities of the 5 and 9.5 percentilestare often of great interest in analyses of reactor safety issuesıbecause parametric values in these tail regions. can produce the hazardous circumstances of accidents. It is usually the sensitivity of results to tails of parameter distributions that cause the greatest controversies when complicated; structured distributions are employed. Though there can still be some legitimate concern about the tails, of distributions swhen high-entropy distributions are employed, this concern is much attenuated relative to the situation when other types of subjective distributions are used.

\section{Input and Boundary Condition Uncertainties}

The first class of uncertainties to be described are those that arise because of

- the variability in the designs of boiling water reactors, and

- the variability of conditions that prevail during the various types of severe accidents hypothesized to occur at boiling water reactors.

\footnotetext{
*The authors were made aware of this interesting property of high-entropy distributions by A. N. Roumiantsey of the Kurchatov Institute in Moscow, Russia.
} 
In the subsections below, ranges are defined and probability distributions are assigned to uncertainties of these types.

Discussions in Chapter III show that conditions vary so significantly over the four phases of severe accidents that it is useful to draw distinctions among the uncertainties that prevail during these accident phases. Therefore in the discussions of many of the uncertainties in the subsections below, distinct ranges are identified for the gap release phase, the in-vessel phase, the ex-vessel phase and the late invessel phase of an accident.

It is also found that especially for the ex-vessel phase of an accident that it is useful to distinguish between Mark I boiling water reactors and other types of boiling water reactors. Such a distinction is also useful during the gap and in-vessel release phases of an accident because the submergence of quenchers in the suppression pools are so different in Mark I reactors than in other types of boiling water reactors.

The various uncertainties discussed in the subsections below are summarized in Table 22. Also shown in this table are the ranges and the probability distribution functions ascribed to these uncertainties.

\section{a. Pool Depths}

The submergence of the orifices and vents in the suppression pools are assumed to be known by the analyst. Calculations are done for submergences of 100 to $700 \mathrm{~cm}$. The submergence depth is used to correlate results of the uncertainty analyses to formulate simplified models are described in Chapter VII.

\section{b. Orifice Sizes}

Orifices in quenchers are taken to have diameters uniformly distributed over the range from 0.993 to $1.27 \mathrm{~cm}$. The number of orifices was fixed at 19056 which is characteristic of Mark I suppression pools. Mark II and Mark III suppression pools have between 17952 and 23936 quenchers orifices. This range is small in comparison to the range of volumetric flows to the orifices. Consequently, it was assumed that the uncertainty in the flow through an orifice would be dominated by the uncertainty in the gas source and not very sensitive to the uncertainty concerning the number of orifices.

Downcomers vents were taken to have diameters between 59.7 to $69.8 \mathrm{~cm}$. In Mark I and Mark II suppression pools there are between 82 to 136 downcomers. It was assumed, however, that at the low gas generation rates typical of the ex-vessel phase and late in-vessel phase of reactor accidents, there would not be simultaneous flow through all these downcomers.

\section{c. Wetwell Pressures}

Boiling water reactors are susceptible to ATWS type sequences that cause pressurization of the drywells and wetwells even before gap release can begin. They are also subject to station blackout accidents in which pressure builds up, in some cases to failure, over the course of the accident. Consequently, the ranges of gas pressures that can exist over the suppression pools are the same for all phases of the accidents. This range is essentially from 1 atmosphere to the failure pressure. 
Table 22. Input uncertainties

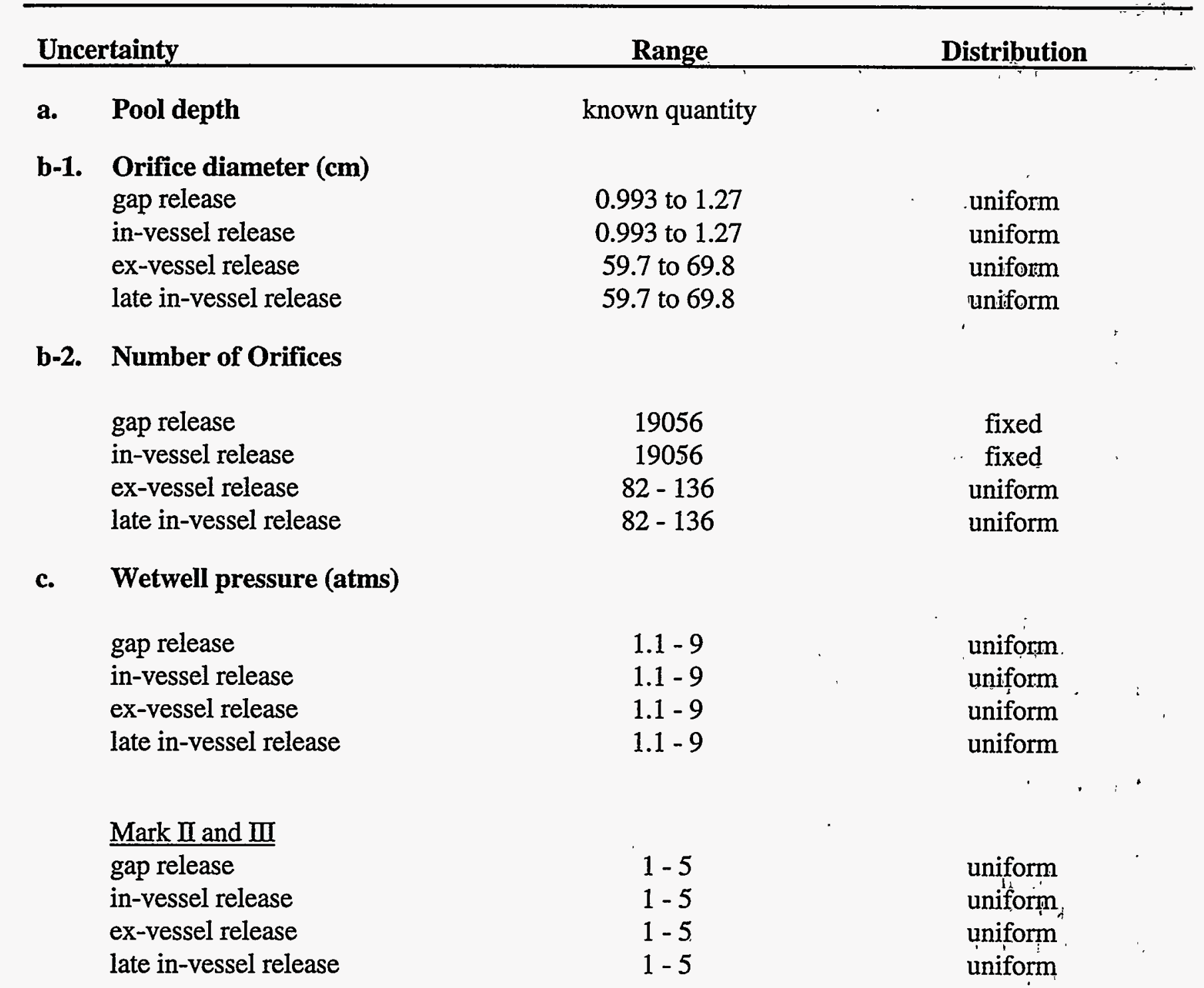

d-1. Mean aerosol particle

diameter $(\mu \mathrm{m})$

gap

in-vessel

ex-vessel

late in-vessel

$$
\begin{gathered}
\mu^{-3}=-366+0.958 \mathrm{Q} \\
0.5 \text { to } 5.0 \\
1.1 \text { to } 7.0 \\
0.19 \text { to } 3.0
\end{gathered}
$$

correlated with flow

lognormal $(\mu=1.6, \sigma=2)$ uniform

$\log$ uniform ,

\section{d-2. Geometric standard deviation \\ of aerosol size distribution}

\begin{tabular}{l} 
gap \\
in-vessel \\
ex-vessel \\
late in-vessel \\
\hline
\end{tabular}

1.2 to 1.8

1.8 to 3.8

1.6 to 3.8

1.6 to 3.8 uniform'

uniform

uniform

uniform 
Table 22. Input uncertainties (concluded)

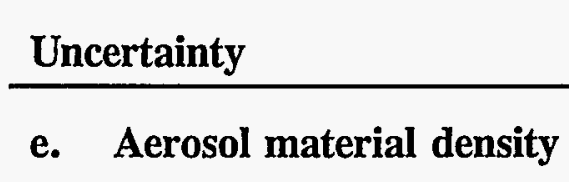

gap

in-vessel

ex-vessel

late in-vessel

f. Shape factors

- primary particle diameter

- fractal dimension

g. Steam Production Rates

(moles/s)

gap

in-vessel

ex-vessel

Mark I

Mark II/III

$\epsilon(\mathrm{x})$

late-invessel

Mark I

Mark II/III

$\epsilon(\mathrm{y})$

h. Hydrogen Production (moles/s)

gap

in-vessel

i. Total Gas Production (moles/s)

ex-vessel

Mark I

Mark II/III

late-invessel

Mark I

Mark II/III
2.8 to 6.1

3.25 to 10.96

2.9 to 5.65

3.15 to 2.65

0.001 to 0.1

1.5 to 2.2
Distribution

uniform

uniform

uniform

uniform

log-uniform

uniform
10 to $35 \%$ of total gas

correlated with gas

production

0-1 uniform

uniform

uniform

uniform

Uniform

uniform

uniform 20 to 120

uniform

100 to 300

uniform

150 to 1100

uniform

20 to 80

uniform

160 to 500 
There are radical differences in the failure pressures predicted for the various types of boiling water reactors. The Mark I steel containments have been calculated to rupture at differential pressures up to 8 atmospheres. Mark III containments are not as strong and are thought to rupture at differential pressures of about 4 atmospheres. Consequently, a distinction is drawn here between the range of wetwell pressures in Mark I containments and the range of wetwell pressures in the Mark II and Mark III containments. Wetwell pressures in the Mark I are considered to be uniformily' distributed over the range of 1.1 to 9 atmospheres. Wetwell pressures in the Mark II and Mark III reactors are taken to be uniformly distributed over the range of 1 to 5 atmospheres. Again, the ranges of wetwell pressures are taken to be the same for all phases of severe accidents.

\section{d. Aerosol Particle Size}

It is assumed for this work that aerosols reaching the steam suppression pool have a lognormal size distribution. Discussions above show that this can only be an approximation. The uncertainty in this approximation is, however, confronted only through the uncertainties in the parameters that characterize a lognormal distribution-the mean particle size and the geometric standard deviation of the distribution. That is, the Monte Carlo uncertainty analyses done here do not consider size distributions that differ from the lognormal distribution. This is probably not a serious omission. It is quite likely $y_{x}$ that all aerosols that reach the suppression pool have aged sufficiently long that coagulation and deposition processes have eliminated any features of the distribution that deviate much from lognormal such as bimodality in the distribution. The most likely discrepancy from an exactly lognormal distribution is probably a lack of aerosol mass at the larger, low-probability sizes.

The size distributions of aerosol reaching the steam suppression pool are expectedi to be different in the four phases of the severe reactor accident defined in the.U.S. Nuclear Regulatory Commission's revised severe accident source term [1]. The aerosol size distributions are, however, not expected to vary according to the type of boiling water reactor of interest.

\section{d-1. Gap Release Size Distribution}

Only small amounts of aerosol mass are introduced into large gas flows during the gap release phase of the accident. There will be little opportunity for such dilute aerosol particles to grow. Any particles that do coagulate or grow to a substantial size are very likely to be removed from the high velocity flow stream by impaction in bends and flow discontinuities in the pathway to the steam suppressision pool. For these reasons, aerosol reaching the steam suppression pool is expected to have a size distribution with a small mean particle size and a small geometric standard deviation.

For all of the interest that has been paid to gap release, there is remarkably little experimental data on particle size distributions to validate these theoretical predictions. "Further, there has been little published information on particle sizes predicted by analysis. Jordan et al. [273] have argued that aerosol particles nucleate from vapors such as those released from the fuel cladding gap to rapid̆ly form particles $0.05 \mu \mathrm{m}$ in diameter. If it is further assumed that particle concentrations arre quickly reduced to $10^{8}$ particles $/ \mathrm{cm}^{3}$ by coagulation. Then, final, mean particle sizes during gap release would be expected to range from 0.05 to $0.25 \mu \mathrm{m}$. These estimates seem consistent with results of calculations with the Source Term Code Package reported by Gieseke et al. [27] for a station blackout accident at a Mark III boiling water reactor. 
The analysis presented above suggests that the mean particle size will be correlated closely with the molar flow. Here, this correlation is take to be:

$$
\mu^{-3}=-1448+3.78 \mathrm{Q}
$$

where

$$
\begin{aligned}
& \mu=\text { mean particle size in } \mu \mathrm{m}, \text { and } \\
& \mathrm{Q}=\text { flow through the reactor coolant system in moles/s. }
\end{aligned}
$$

The material released from the fuel cladding gap may be rich in $\mathrm{CsOH}$ and CsI. These are two very hygroscopic materials. Though particles of $\mathrm{CsOH}$ and CsI may not grow by water adsorption in the reactor coolant system itself, they will surely grow as the aerosol-laden gas cools within the piping system leading to the suppression pool. Adsorption of water might be expected to continue until the particles become saturated liquids. Then, particle sizes are given by the correlation:

$$
\mu^{-3}=-366+0.958 \mathrm{Q}(\mathrm{moles} / \mathrm{s})
$$

which is the correlation adopted here.

The geometric standard deviation of the size distribution is much more difficult to predict. It depends, among other things, on the heterogeneity of processes taking place during the release and transport of the aerosol. It is expected here that the size distributions will be narrow. Geometric standard deviations observed in flame vaporization processes are as low as 1.2 [274]. Consequently, the geometric standard deviation for aerosol produced during gap release is taken to be uniformly distributed over the range from 1.2 to 1.8. The upper end of this range has been selected because for larger values of the geometric standard deviation, the aerosol would have a noticeable spread in particle sizes.

\section{d-2. In-Vessel Release Size Distributions}

In contrast to the case during the gap release phase of the accident, a very large amount of material is aerosolized during the in-vessel release phase of the accident. Most of this aerosol mass will be nonradioactive. A great amount of aerosol will come from vaporization of steel, tin from the zircaloy cladding, and vaporization of $\mathrm{UO}_{2}$. Radioactive species will constitute a relatively small portion of the total aerosol release. The aerosol that reaches the suppression pool will have a size distribution dictated by the interplay of particle growth and particle deposition processes.

There has not been much information published on the sizes of particles that are predicted to be released to the suppression pool during the in-vessel phase of an accident. Denning et al. [23] report, for an ATWS accident sequence, mean particle sizes of about $13 \mu \mathrm{m}$ at the suppression pool. On the other hand, another analysis [296] of the aerosol suddenly released to the drywell of a boiling water reactor at the time of vessel failure indicates a nearly lognormal size distribution with a mean particle diameter of $0.8 \mu \mathrm{m}$. Distributions shown in Figure 13 similarly indicate a very broad uncertainty in the size distributions of aerosols produced during the in-vessel release phase. Not all of the analyses that produce the widely ranging size distributions have considered in detail opportunities for particle deposition during transport to the suppression pool. The deposition processes are often quite dependent 
on the aerosol particle size and tend to preferentially extract-particles larger than 1 to $2 \mu \mathrm{m}$. Based on this reasoning, the mean aerosol particle size during the in-vessel phase of an accident is taken to be lognormally distributed around $1.6 \mu \mathrm{m}$ with a geometric standard deviation for the distribution of the mean taken to be 2 . Then, the 5 and 95 percentiles for the mean are at about 0.5 and $5.0 \mu \mathrm{m}$, respectively.

The geometric standard deviation of the aerosol size distribution is expected to be large. Here it is assumed to be uniformly distributed over the range of 1.8 to 3.8 .

\section{d-3. Ex-Vessel Release Size Distributions}

Considerably attention has been paid to the size distribution of aerosols produced during core debris interactions with concrete. During the vigorous phase of interactions when most of the release of radionuclides occurs, predictions derived from correlations of experimental data indicate that mean particle sizes are between 1.1 and $2.2 \mu \mathrm{m}$. These predictions apply, however,' to the aerosol immediately above the core debris and not to the aerosol that enters the suppression pool: Aerosol that is produced by core debris interactions with concrete mixes with the drywell atmosphere and has an opportunity to age. That is, the aerosol will coagulate to larger particle sizes before it passes to the suppression pool. Again, notice should be taken of the wide range of aerosol particle sizes predicted by the Source Term Code Package to be present in the drywell (See Figure 13).

Because of the aging of aerosol in the drywell, the mean particle size of aerosol produced by: coredebris concrete interactions is taken to be the lower bound on the mean size of aerosol discharged to the suppression pool during the ex-vessel release phase of a severe accident: The upper limit on this: mean size is taken to be $7.0 \mu \mathrm{m}$ based on accident calculations with the Source Term Code Package [14]:

The geometric standard deviation of the aerosol size distribution is, because of the mixing:and flow in the drywell, expected to be large. Experimental studies of aerosols produced during core debris interactions with concrete have shown geometric standard deviations that vary from about 1.6 to 3.8. Aerosol discharged to the suppression pool will probably have a similarly large range of geometria standard deviations in its size distributions.

Aerosol produced during intense core debris interactions with concrete is expected to be chemically stable and not very hygroscopic. Certainly this is what Adams [248] found when he produced aerosols from concrete and introduced them into a condensing steam atmosphere. Little particle growth by water condensation on the external surfaces of the particles is to be expected. (Internal voids are expected to be filled with water when the aerosol reaches the suppression pool as discussed above in Section IV-K.1).

\section{d-4. Late In-Vessel Release Size Distributions}

Almost nothing is known about the release by revaporization of radioactive materials. that had been deposited in the reactor coolant system during earlier phases of the accident. The materialireleased from the reactor coolant system will be relatively volatile. Cesium iodide, cesium hiydroxide and tellurium oxides are expected to be important constituents of the released material. The late in - vessel release is expected to be slow so that aerosol concentrations will be correspondingly low. Particle sizes might also, then, be small. 
When aerosol (or vapors) produced by the late in-vessel release emerge into the reactor drywell, they will encounter aerosols produced by the long-term core debris interactions with concrete. After the initial, intense aerosol production marking the ex-vessel release phase of the accident, core debris/concrete interactions settle into a quasi-steady state interaction that produces aerosols mostly from constituents of concrete at rates of 1 to 10 grams per second. Though these are small rates of aerosol production in comparison to rates of aerosol production during ex-vessel release, they are significant rates in comparison to the rates of late in-vessel aerosol production. It is likely, then, that aerosol reaching the steam suppression pool during the late in-vessel phase of the accident will have size characteristics determined by aerosols produced by the quasi-steady state core debris/concrete interactions. Model predictions of these aerosols indicate mean particle sizes of 0.19 to $0.30 \mu \mathrm{m}$. These predictions are based on an assumption concerning the nature of aerosol growth. This assumption has not been validated by experimental studies. These mean particle sizes do not account for growth of particles during residence in the drywell. Residence periods can be quite long during this late-stage of the accident when gas production rates are low. To account for this growth, the mean aerosol particle size during the late in-vessel phase of the accident is taken to be loguniformly distributed over the range from 0.19 to $3.0 \mu \mathrm{m}$.

Size distributions of aerosol produced during the late stage of core debris interactions with concrete are assumed to have geometric standard deviations of 2.3 [19]. This is an average of experimental observations that have varied from 1.6 to 3.8. Consequently, the geometric standard deviation of the size distributions of aerosol produced during the late in-vessel phase of an accident is taken to be uniformly distributed over the range from 1.6 to 3.8 .

The aerosol produced in the drywell during the late in-vessel phase of an accident might be quite hygroscopic. Certainly $\mathrm{CsOH}$ and $\mathrm{CsI}$ vaporized from the reactor coolant system are hygroscopic. Aerosols produced by core debris/concrete interactions at this late stage of the accident are rich in hygroscopic oxides of sodium and potassium. On the other hand, the atmosphere will contain quite a lot of carbon dioxide that will react with oxides and hydroxides to form decidedly less hygroscopic bicarbonates.

\section{e. Aerosol Material Density}

Material densities enter into the descriptions of aerosol removal processes. The material densities are expected to vary some among the four phases of the accident.

\section{e-1. Gap Release}

Room temperature densities of the materials expected to make up much of the gap release are shown below:

$\begin{array}{cc}\text { Material } & \text { Density }\left(\mathrm{g} / \mathrm{cm}^{3}\right) \\ & 4.510 \\ \mathrm{CsOH} & 3.675 \\ \mathrm{TeO} & 5.682 \\ \mathrm{TeO}_{3} & 5.075-6.1\end{array}$


Cesium hydroxide and cesium iodide are so hygroscopic that they may be present as saturate solutions rather than as solid particles. These densities would be reduced substantially to 2.8 to 3.2 in saturated 'sólutions. Consequently, the aerosol material densities during the gap release are taken to be uniförmly distributed over the range 2.8 to $6.1 \mathrm{~g} / \mathrm{cm}^{3}$.

\section{e-2. In-Vessel Release}

Aerosol material densities during the in-vessel release will be determined primarily by the massive amounts of nonradioactive materials released during this phase of the accident. Some typical densities of these materials are:

\begin{tabular}{cc} 
Material & Density $\left(\mathrm{g} / \mathrm{cm}^{3}\right)$ \\
\cline { 2 - 2 } $\mathrm{UO}_{2}$ & 10.96 \\
$\mathrm{U}_{3} \mathrm{O}_{8}$ & 8.30 \\
$\mathrm{UO}_{3}$ & 7.29 \\
$\mathrm{ZrO}_{2}$ & $5.6-5.89$ \\
$\mathrm{ZrO}_{2} \cdot \mathrm{z} \mathrm{H} \mathrm{H}_{2} \mathrm{O}$ & 3.25 \\
$\mathrm{Sn}$ & 5.75. to 7.28 \\
$\mathrm{SnO}$ & 6.446 \\
$\mathrm{SnO}_{2}$ & 6.95 \\
$\mathrm{Fe}_{3} \mathrm{O}_{4}$ & 5.18
\end{tabular}

Material densities during the in-vessel phase of a severe reactor accident are taken to be uniformly distributed over the range of 3.25 to 10.96 .

\section{e-3. Ex-Vessel Release}

Examination of calculated results for a variety of severe accidents [25] shows that materialidensities during the period of intense aerosol generation in core debris interaction vary from about 5.65 to $2.9 \cdot \mathrm{g} / \mathrm{cm}^{3}$.

\section{e-4. Late In-vessel Release}

Again, the aerosol properties during the late in-vessel release will actually be determinedi by the:aerosol materials generated by the long-term, quasi-steady core debris interactions swith concrete: Materialıdensities during this phase of an accident are calculated [25] to be in the range of 3.15 to $2.65 \mathrm{~g} / \mathrm{cm}^{3}$.

\section{f. Uncertainty in Shape Factors}

It is assumed here that there is enough water adsorption by aerosol particles that these particles become porous spheres. The collision shape factor, $\gamma$, and the dynamic shape factor, $x$, are equal for all particles:

$$
x=\gamma=1 / \alpha^{1 / 3}
$$


It is also assumed that shape factors are size dependent and this dependency is described by:

$$
\begin{gathered}
\alpha=\frac{\epsilon \rho_{\mathrm{p}}+(1-\epsilon) \rho_{\omega}}{\rho_{\mathrm{p}}} \\
\epsilon=\min \left[1,\left[\frac{\mathrm{z}}{\mathrm{d}_{\mathrm{p}}}\right)^{3-\mathrm{d}_{\mathrm{f}}}\right]
\end{gathered}
$$

where $\mathrm{z}$ is the diameter of primary particles that make up agglomerated particles and $\mathrm{d}_{\mathrm{f}}$ is the fractal dimension of agglomerates. This primary particle size is taken to be uncertain and has a log-uniform distribution over the interval from 0.001 to $0.1 \mu \mathrm{m}$. The fractal dimension of the agglomerates was taken to be uniformly distributed over the range from 1.5 to 2.2 .

\section{g. Gas Flow Rates}

Gas flow rates to the suppression pool are expected to be quite variable over the course of the four phases of severe accidents considered here. An assumption made in the analyses done here is that gases flow to the quenchers during the gap release and the in-vessel release phase of the accident. Gases flow to the suppression pool through downcomers and horizontal vents during the ex-vessel and late in-vessel phases of the accidents. Possible bypass of the suppression pool is neglected throughout the analyses.

\section{g-1. Gap Release Phase}

Based on the discussions of accident sequences presented in Chapter III, the gas flows to the quenchers for all types of boiling water reactors are taken to be uniformly distributed over the range of 2500 to 400 moles per second. Hydrogen generation rates are taken to be uniformly distributed over the range of 20 to 120 moles/s.

\section{g-2. In-Vessel Release Phase}

Again, from the discussions in Chapter III steam flows to the quenchers during the in-vessel phase of an accident are taken to be uniformly distributed over the range of 50 to $500 \mathrm{moles} / \mathrm{s}$. The hydrogen flows are taken to be uniformly distributed over the range 20 to $120 \mathrm{moles} / \mathrm{s}$. No attempt is made here to account for episodic eruptions of steam that accompany the relocation of core debris to the waterfilled lower plenum of the reactor vessel. 


\section{g-3. Ex-vessel Release Phase}

Gas production during the ex-vessel phase of a severe reactor accident must be treated 'differently for Mark I reactors than for Mark II and Mark III reactors. The differences arise because in the Mark II and Mark III reactors, degassing of the concrete introduces substantial quantities of water vapor into the gases being discharged to the suppression pools. Consequently, molar flows to the suppression pool in the case of Mark I reactors are taken to be uniformly distributed over the range of 100 to 300 moles/s. Molar flows to the suppression pool in the case of Mark II and Mark III reactors are taken to be uniformly distributed over the range of 150 to $1100 \mathrm{moles} / \mathrm{s}$.

The condensible portion of the gas produced during the ex-vessel phase of an accident in a Mark I boiling water reactor would be calculated to be very small ( $<1$ percent) if only core debris interactions with concrete were considered. There is not much concrete exposed to heating that will degas to add water vapor to the gas discharged to the suppression pool. The reactor pedestal is concrete that can degas and there may be some evaporation from residual water in the reactor copolant system. Consequently, gas discharged to the suppression pool in an accident at a Mark Ireactor is taken to have a water vapor content uniformly distributed over the range of 1 to 10 percent.

Much of the gas discharged to the suppression pools during the ex-vessel phases of anyaccidentingark II and Mark III reactors can be water vapor. The water vapor content is taken here to be correlated with the gas production rate:

$$
\dot{\mathrm{m}}\left(\mathrm{H}_{2} \mathrm{O}\right)= \begin{cases}\dot{\mathrm{m}}(\text { total })-0.8[100+\epsilon(\mathrm{x}) 200] & \text { for } \dot{\mathrm{m}}(\text { total })>300 \cdot \frac{\mathrm{moles}}{\mathrm{s}} \\ 0.2 \dot{\mathrm{m}} \text { (total) } & \text { for } \dot{\mathrm{m}}(\text { total }) \leq 300, \frac{\text { moles }}{\mathrm{s}}\end{cases}
$$

where

$\dot{\mathrm{m}}\left(\mathrm{H}_{2} \mathrm{O}\right)=$ moles water vapor discharged to the suppression pool per second,

min $($ total $)=$ total number of moles of water vapor discharged to the suppréšsion poôl pér second, and $\epsilon(x)=$ uncertain number uniformly distributed over the range 0 to 1 .

\section{g-4. Late In-vessel Release Phase}

Similar reasoning to that discussed above in connection with gas generation during the Ex-Vessel Release phase of an accident is used to draw a distinction between gas generation during the Late InVessel Release phases of accidents at Mark I reactors and accidents at Mark II and Mark III reactors. Gas production during the Late In-Vessel Release phase of an accident in a Mark I reactor is taken to be uniformly distributed over the range of 20 to 80 moles/s. As discussed in Chapter III, much more of this gas can be water vapor. Here the water vapor content of the gas is taken to be uniformly distributed over the range of 10 to 35 percent. 
On the other hand, during accidents at Mark II and Mark III reactors, the gas production is taken to be uniformly distributed over the range of 160 to $500 \mathrm{moles} / \mathrm{s}$. Water vapor production is taken to be:

$$
\dot{\mathrm{m}}\left(\mathrm{H}_{2} \mathrm{O}\right)=\dot{\mathrm{m}}(\text { total })-[20+60 \epsilon(\mathrm{y})]
$$

where $\epsilon(y)$ is uniformly distributed over the range of 0 to 1 .

\section{Phenomenological Uncertainties in Bubble Behavior}

In the subsections below, the phenomenological uncertainties in bubble behavior recognized in the Monte Carlo uncertainty analyses are described. The uncertain parameters, the possible ranges of values they can assume, and the distributions of values within these ranges are summarized in Table 23 .

\section{a. Uncertainty in Bubble Formation}

It is apparent from the discussions above (see Section IVA) that there is no universally applicable model of bubble formation. The two-stage model devised by Kumar and Kaloor [31] has the attractions of validation by comparison to a wide variety of data and because it has explicit dependencies on orifice geometry. The empirical correlation devised by Paul et al. [30] yields predictions that are different than those obtained from the Kumar and Kaloor model. But, the empirical correlation is attractive because it is based on data obtained from a simulated quencher orifice. Neither the Kumar and Kaloor model nor the empirical correlation seems to have been thoroughly validated for steam-rich gases entering steam suppression pools that are significantly sub-cooled.

To treat the uncertainty of bubble formation at quencher orifices, a parameter $\delta(b)$ is defined to be uniformly distributed over the range $0 \leq \delta(b)<1$. Then, the Kumar and Kaloor model is used when randomly sampled values of $\delta(b)$ are less than 0.5 . The empirical correlation developed by Paul et al. is used when $\delta(b) \geq 0.5$.

When the Kumar and Kaloor model is selected, the orifice orientation angle, $\gamma$, is randomly selected from the range $0 \leq \gamma<90^{\circ}$. When the correlation developed by Paul et al. is selected, the prediction of the model is taken to be uncertain. The uncertainty in the natural logarithm of the normalized volume is given by a Students' $t$ distribution with 15 degrees of freedom and a standard error of:

$$
\text { standard error }=0.225\left[0.0588+\frac{(\ln (\mathrm{We})-7.6562)^{2}}{145.952}\right]^{1 / 2}
$$

where

$$
\text { We }=\text { Weber number }=\mathrm{U}^{2} \rho_{1} \mathrm{D}_{\mathrm{o}} / \sigma_{1},
$$


Table 23. Uncertainties in the phenomena affecting bubbles

\section{Uncertain quantity}

Range of values

Distribution

Bubble Formation

- gap and invessel release

$\delta(\mathrm{b})$, parameter to select among models

$\theta$, orifice orientation in Kumar and Kaloor model (degrees)

$\mathrm{e}(\mathrm{P})$, uncertainty in correlation of the natural logarithm of the normalized bubble volume

$\begin{array}{cc}\begin{array}{cc}0 \text { to } 1 \\ 0 \text { to } 90\end{array} & \begin{array}{c}\text { uniform } \\ \text { uniform }\end{array} \\ \operatorname{se}=\left\{0.0588+\frac{[\ln (\mathrm{we})-7.6561]^{2}}{145.952}\right\}^{1 / 2} & \begin{array}{c}\text { Students' } \mathrm{v}=15 \\ \end{array}\end{array}$

- ex-vessel and late invessel

C, coefficient in Davidson Schular model

uniform

Initial Bubble Size

$e(b s)$, uncertainty in the correlation of the natural logarithm of the mean bubble size

$\mathrm{se}=0.0634\left[0.0833+\frac{\left(\mathrm{y}^{2}-0.4434\right)^{2}}{1.1847}\right]^{\ddot{1} / 2} \quad \begin{gathered}\text { Students' } t \\ \mathrm{v}=12\end{gathered}$

$\sigma(\beta)$, geometric standard deviation of the log-normal 1.36 to 1.61 uniform bubble size

Bubble Shape

$\delta(\mathrm{E})$, parameter to select between models.

Bubble Slip Velocity

$\delta(\mathrm{v})$; parameter to select between models of two phase flow 
Table 23. Uncertainties in the phenomena affecting bubbles (continued)

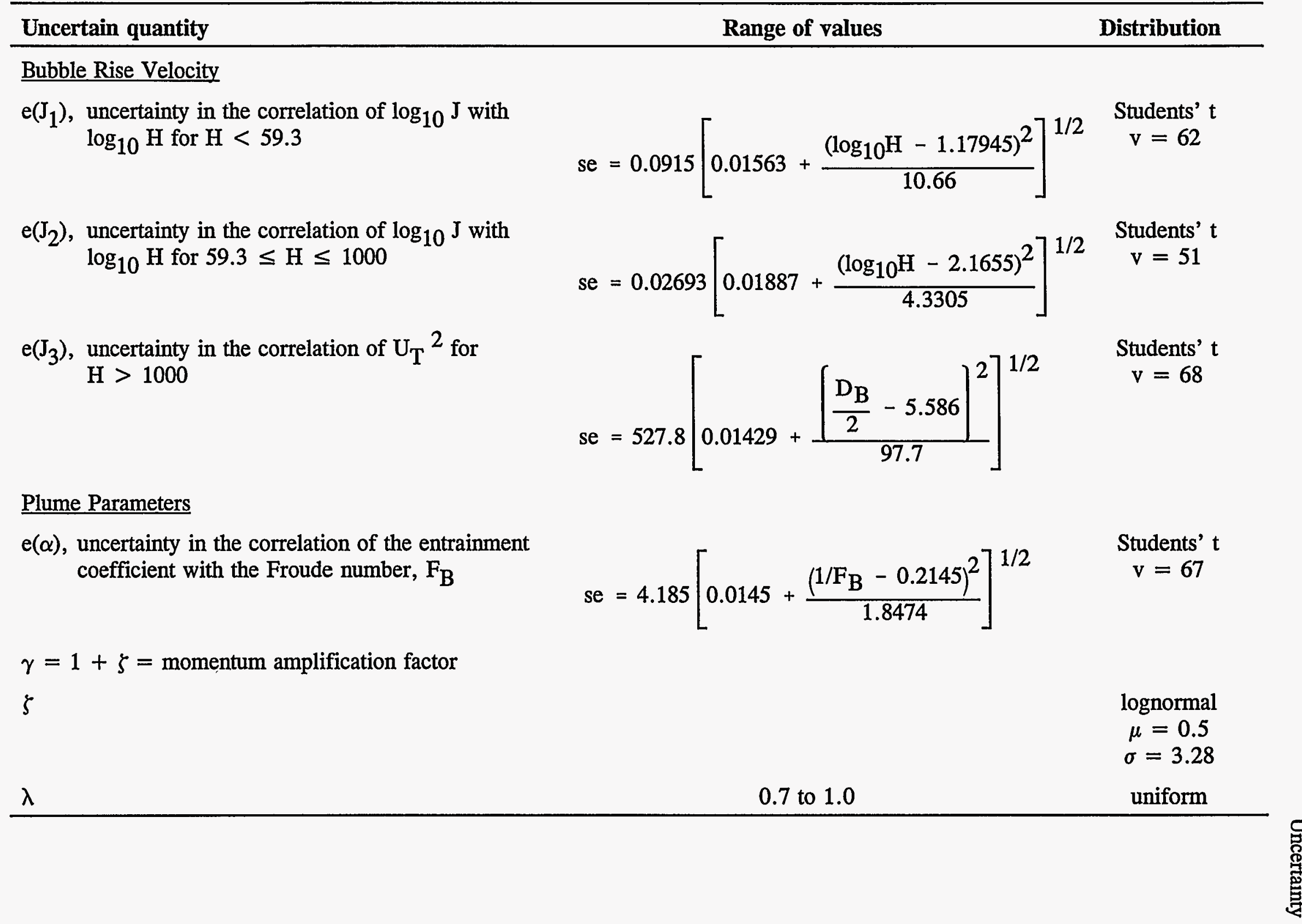




$$
\begin{aligned}
\mathrm{V}_{\mathrm{N}} & =\text { normalized volume }=\frac{4 \mathrm{~V}}{\pi \mathrm{D}_{\mathrm{o}}^{2}}\left[\frac{\left(\rho_{1}-\rho_{\mathrm{g}}\right)}{\sigma_{\mathrm{l}}} \mathrm{g}\right]^{1 / 2}, \\
\mathrm{U} & =4 \dot{\mathrm{m}} / \rho_{\mathrm{g}} \pi \mathrm{D}_{\mathrm{o}}^{2} \\
\mathrm{D}_{\mathrm{O}} & =\text { orifice diameter, } \\
\dot{\mathrm{m}} & =\text { mass flow rate, } \\
\mathrm{V} & =\text { bubble volume, } \\
\rho_{\mathrm{g}} & =\text { gas density at the orifice. }
\end{aligned}
$$

Data for bubble formation at large diameter horizontal vents and downcomers are scarce. Though it is not strictly applicable, the Davidson-Schuler model is used to predict the size of bubble formed at these large diameter vents:

$$
\mathrm{V}_{\mathrm{B}}=\frac{\pi}{6} \mathrm{D}_{\mathrm{B}}^{3}=\mathrm{CQ}^{6 / 5} \mathrm{~g}^{-3 / 5}
$$

The leading coefficient in the Davidson-Schuler model, $\mathrm{C}$, is taken to be uncertain and is assumed to be uniformly distributed over the range of 0.976 to 1.722 .

\section{b. Uncertainty in the Equilibration Distance}

Bubbles that detach from orifices are large and may be steam-rich relative to the partial pressure of water in equilibrium with the suppression pool. It was assumed that over an uncertain distance between 2 and 10 initial bubble diameters, the gas comes into compositional and thermal equilibrium with the suppression pool. The most important effect of this equilibration is, of course, to remove aerosols by the condensation of excess steam in the gas. Removal of aerosols during this equilibrâtion compensatẹs for the neglect of aerosol removal by steam condensation during bubble formation.

The equilibration of steam-rich bubbles is a fairly violent process. Undoubtably, mechanismsi other than condensation of steam may well remove aerosols from the gas during this equilibration processs. It has not been possible to identify these additional mechanisms quantitatively. It is an area meriting additional experimental attention.

\section{c. Initial Size of Bubbles in the Plume}

Experiments by Paul et al. [30] and by Hakaii et al. [69] show that bubbles rising through the pool have a distribution of sizes. The experimental evidence is for bubbles that are formed above guencher orifices. Presumably bubbles with similarly distributed sizes are formed when gas globules detach from 
downcomers and horizontal vents and then disintegrate. Experimental studies by Paul et al. [30] and by Hakaii et al. [69] showed that the bubble sizes were lognormally distributed.

The mechanistic model of source term attenuation by steam suppression pools used for the Monte Carlo analyses has been constructed for bubbles of a fixed size. Consequently, bubble size must be treated as an uncertain quantity. The uncertain bubble size is taken to be lognormally distributed. The mean of the bubble size distribution has been taken from a correlation of the experimental results obtained by Paul et al. as described in Section IV-C. The mean size, $\mu(\mathrm{B})$, is found from:

$$
\mu(\mathrm{B})=0.435\{1+\exp [-0.08789 / \mathrm{Q}]\} \exp \left[-0.5972 \mathrm{y}^{2}\right]
$$

where

$$
\begin{aligned}
\mu(\mathrm{B}) & =\text { mean of the bubble size distribution, } \\
\mathrm{Q} & =\text { volumetric flow rate through the orifice, and } \\
\mathrm{y} & =\text { mole fraction of steam in the gas flowing through the orifice. }
\end{aligned}
$$

The logarithm of the mean size is taken itself to have a Student's $t$ distribution with 10 degrees of freedom, and a standard error given by:

$$
0.0634\left[0.0833+\left(y^{2}-0.4434\right)^{2} / 1.1847\right]^{1 / 2}
$$

The geometric standard deviation for the bubble size distribution is only modestly uncertain. Based on the experimental data obtained by Paul et al. this geometric standard deviation, $\sigma(\mathrm{B})$, is taken to be uniformly distributed over the range 1.36 to 1.61 .

\section{d. Uncertainty in Bubble Shape}

The mechanistic model used here for the Monte Carlo uncertainty analyses has been constructed for ellipsoidal bubbles of eccentricity E. This eccentricity is a function of bubble size and behavior. Eccentricities are recalculated at each time step. Models for the dependencies of eccentricity on bubble properties are uncertain. The available data on eccentricities are scattered. There is at least some evidence that bubbles in swarms are less distorted than are isolated bubbles. Proof of this speculation, however, has not been found. Consequently two models for the eccentricities of bubbles are considered. One is a correlation of data for isolated bubbles [82]: 


$$
1 / \mathrm{E}(\mathrm{A})= \begin{cases}1 & \text { for } \mathrm{Ta}<1 \\ {\left[0.81+0.206 \tanh \left\{2\left(0.8-\log _{10} \mathrm{Ta}\right)\right\}\right]^{3}} & \text { for } 1 \leq \mathrm{Ta} \leq 39.8 \\ 0.24 & \text { for } \mathrm{Ta}>39.8\end{cases}
$$

where

$$
\begin{aligned}
\mathrm{Ta} & =\operatorname{Re} \mathrm{M}^{0.23}, \\
\operatorname{Re} & =\rho(1) \mathrm{U}(\text { slip }) \mathrm{D}_{\mathrm{B}} / \mu(\mathrm{l}), \\
\mathrm{U}(\mathrm{slip}) & =\text { slip velocity of the bubble, and } \\
\rho & =\text { Morton number }=\mathrm{g} \mu_{1}^{4}\left(\rho_{1}-\rho_{\mathrm{g}}\right) / \rho_{1}^{2}{\sigma_{1}}^{3} .
\end{aligned}
$$

The second model is an empirical correlation of experimental data obtained by Paul et al. [30]:

$$
1 / E(B)= \begin{cases}1 & \text { for } D_{B} \leq 0.15 \mathrm{~cm} \\ 0.68-0.57 \exp \left[-D_{B} / 0.26\right] & \text { for } D_{B}>0.15 \mathrm{~cm}\end{cases}
$$

A parameter $\delta(E)$ is defined to be uniformly distributed over the range 0 to 1 . The eccentricity model used in a particular calculation, then, is found from:

$$
E= \begin{cases}E(A) & \text { for } \delta(E)<0.5 \\ E(B) & \text { for } \delta(E) \geq 0.5\end{cases}
$$

\section{e. Bubble Slip Velocity}

The slip velocities of bubbles in a rising plume depend on the void fraction of the plumex. Antindepth treatment of this two-phase flow issues has not been attempted. ' Rather, the unceritainty in the islip velocity dependence on void fraction is reflected by the consideration of various:models! - As parameter $\delta(\epsilon)$ is defined to be uniformly distributed on the range from 0 to 1 . Then, the slip. velocity is found to be: 


$$
U(\text { slip })= \begin{cases}U_{B} & \text { for } \delta(\epsilon)<1 / 3 \\ U_{B}(1-\epsilon(r, z)) & \text { for } 1 / 3 \leq \delta(\epsilon)<2 / 3 \\ U_{B}(1-\epsilon(r, z))^{2} & \text { for } \delta(\epsilon) \geq 2 / 3\end{cases}
$$

where

$$
\begin{aligned}
\mathrm{U}_{\mathrm{B}}= & \text { rise velocity of an isolated bubble of the same size, and } \\
\epsilon(\mathrm{r}, \mathrm{z})= & \text { void fraction at axial location } \mathrm{z} \text { above the orifice and radial location } \mathrm{r} \text { away from the } \\
& \text { orifice. }
\end{aligned}
$$

The rise velocity of an isolated bubble is found from:

$$
\mathrm{U}_{\mathrm{T}}(\mathrm{cm} / \mathrm{s})= \begin{cases}0.735 \sqrt{\mathrm{gD}_{\mathrm{B}}(\mathrm{cm})} & \text { for } \mathrm{H}>1000 \\ \frac{\mu_{1}}{\rho_{1} \mathrm{D}_{\mathrm{B}}} \mathrm{M}^{-0.149}(\mathrm{~J}-0.857) & \text { for } \mathrm{H} \leq 1000\end{cases}
$$

where

$$
\begin{aligned}
M & =\text { Morton number } \\
\mathbf{J} & = \begin{cases}0.94 \mathrm{H}^{0.757} & \text { for } 2 \leq \mathrm{H} \leq 59.3 \\
3.42 \mathrm{H}^{0.441} & \text { for } 59.3<\mathrm{H} \leq 1000\end{cases} \\
H & =4 / 3 \mathrm{E}_{\mathrm{O}} \mathrm{M}^{-0.149}\left(\mu_{1} \text { (poise) } / 0.009\right)^{-0.14}
\end{aligned}
$$

The correlations of $\mathrm{J}$ in terms of $\mathrm{H}$ were found by linear least-squares fitting of $\log \mathrm{J}$ as a function of $\log \mathrm{H}$. The uncertainty in the predictions of $\log \mathrm{J}$ derived from the correlations are then given by Students $\mathrm{t}$ distributions. For the regime of $2 \leq \mathrm{H} \leq 59.3$ the parameters of the distribution are:

$$
\begin{aligned}
& \text { degrees of freedom }=62 \\
& \text { standard error }=0.0915\left[0.01563+\frac{(\log H-1.17945)^{2}}{10.66}\right]^{1 / 2}
\end{aligned}
$$


Uncertainty

For the regime $59.3<\mathrm{H} \leq 1000$, the parameters are:

degrees of freedom $=51$

standard error $=0.02693\left[0.01887+\frac{(\log \mathrm{H}-2.1655)^{2}}{4.3305}\right]^{1 / 2}$

The values of $U_{T}$ for $H>1000$ were found from linear least-squares fitting of $U_{T}{ }^{2}$ values to $D_{B}$ values. The uncertainty in the predicted values of $\mathrm{U}_{\mathrm{T}}{ }^{2}$ follows a Student's' $t$ distribuition:s:'

degrees of freedom $=68$

standard error $\left.=527.8\left[0.014286+\frac{\left(\frac{\dot{D}_{B}}{2}-5.586\right.}{97.7}\right]^{2}\right]^{1 / 2}$.

\section{f. Uncertainty in Plume.Parameters}

Three uncertain parameters are used in the description of the bubble plumes rising through the suppression pool:

- the entrainment coefficient, $\alpha$

- the momentum amplification factor, $\gamma$, and

- $\lambda$ which is the ratio of the size parameters for the void and liquid velocity distribution parameter.

Milgram [44] provides a correlation for entrainment coefficients, $\alpha$, derived from experimental values. The correlation was derived by linear least squares fitting of the experimental values. Consequently, the uncertainty in the predictions of the correlation should have a Students' $t$ distribution. Though Tacke et al. [45] argue that the uncertainty is larger than this, this prescription is adopted here.

Milgram's correlation for the momentum amplification factor proves to be computationally difficult to use. Milgram's arguments concerning the correlation of the momentum amplification factor are difficult to follow. Detailed examination of the correlation derived by fitting an expression to,datajuggests that there may be little correlation. Consequently, the momentum amplification:factor, is treated as an uncertain parameter. Theoretical arguments suggest its value is always greaternthan $1_{1}$, $0_{\text {iand }}$ perhaps greater than 1.07. Comparisons to data suggest values in the range of 1.1 to 2.8 characterize properties of bubble plumes reasonably well. Here the momentum amplification factor is taken to be: $r$ ir

$$
\gamma=1+\xi
$$


where $\xi$ is an uncertain parameter with a lognormal distribution of values around a mean of 0.5 with a geometric standard deviation of 3.28. Then, 95 percent of the values of $\gamma$ are greater than 1.07, and 94 percent of the values of $\gamma$ are less than about 4.6.

The distribution of liquid velocities with radial distance in the plume is taken to be exponential:

$$
\mathrm{U}_{1}(\mathrm{r}, \mathrm{z})=\mathrm{U}_{1}(\mathrm{z}) \exp \left(-\mathrm{r}^{2} / \mathrm{b}^{2}(\mathrm{z})\right)
$$

Void fraction is also taken to be exponentially distributed with radial distance:

$$
\epsilon(\mathrm{r}, \mathrm{z})=\epsilon(\mathrm{z}) \exp \left(-\mathrm{r}^{2} / \mathrm{b}_{\epsilon}^{2}(\mathrm{z})\right)
$$

The plume model used in the mechanistic model has been constructed under the assumption that the radial distributions of void fraction and liquid velocities are related by:

$$
\lambda=\frac{\mathrm{b}_{\epsilon}(\mathrm{z})}{\mathrm{b}(\mathrm{z})}
$$

where $\lambda$ is a constant that is independent of position, flow, etc. Milgram [44] argues that predictions of the plume model are not especially sensitive to the values of $\lambda$ that is assumed. Values of $\lambda=0.7$ to 1.0 have been used by various investigators [45]. Here it is assumed that $\lambda$ is uncertain and that its values are uniformly distributed over the range of 0.7 to 1.0 .

\section{g. Uncertainty in Bubble Growth}

As bubbles rise through a pool they will grow as a result of both the loss of pressure head and the vaporization of water into the bubble. Paul et al. [30] did not observe a significant amount of bubble growth in their tests. Certainly, the developers of the SPARC code [6] took this as the justification for treating the bubbles as though their sizes were invariant with axial distance. Certainly, the low ionic strength medium used for the tests conducted by Paul et al. would be conducive to the establishment of a dynamic equilibrium between bubble disintegration and coalescence. Dissolution of salts in the pool, which would be expected in a reactor accident, might interrupt this equilibrium. On the other hand, growth of bubbles may not have been detectable except near the very top of the pool.

The growth of bubbles as they rise through a water pool can reduce the efficiencies of processes such as diffusion, inertial impaction, and sedimentation at depositing aerosol particles on the bubble walls. A dynamic equilibrium that keeps bubble size about the same along the axial dimension of the plume would certainly keep the deposition efficiency high. The dynamic equilibrium could have another effect when the variation in the efficiency of aerosol removal with radial distance modeled here is recognized. The dynamic equilibrium of coalescing and disintegrating bubbles would move aerosol-laden gases 
between regimes of maximal and minimal attenuation. In the model used here, bubble growth is recognized and calculated following the thermodynamic model described in Chapter IV. Heat:transfer to and within the bubble is taken to be instantaneous. There are no thermal gradients near the surface of the bubble that would inhibit aerosol deposition on the surface.

\section{h. Radial Mixing in the Bubble Plume}

Bubble within a plume. There can, in fact, be a dynamic equilibrium of bubbles coalescing and disintegrating. This dynamic process has the effect of moving aerosol-laden gases from regions of low aerosol removal rates in the plume into regions where removal is more rapid. Unfortunately, there is not now an indication of how much mixing occurs. Consequently, it is assumed that at the end of each computational step a fraction of the bubbles in a radial node exchanges with bubbles in an adjacent node. This fraction is taken to be uniformly distributed over the range of 0 to 1 .

\section{Phenomenological Uncertainties in Aerosol Behavior}

Uncertainties that arise in the description of processes that remove aerosol from gas bubbles in the suppression pool are described in the subsections below. The discussions address aerosol , removal during formation of bubbles at orifices, downcomers and vents as well as aerosol removial as; bubbles rise through the suppression pool. Uncertain parameters defined in these discussions are summarized in Table 24. Also shown in this table are the ranges of possible values theses parameters can assume and subjective probability distributions for values within these ranges. Note that no uncertainties are ascribed to the transition period between the time bubbles detach from the orifice and the formation of a bubble plume. Aerosol mass removal during this period is taken to be proportional to the amount of gas removed by condensation and the aerosol removal is taken to be independent of aerosol particle size.

\section{a. Uncertainty in Aerosol Trapping by Inertial Impaction}

Inertial impaction of aerosol on the walls of rising bubbles is a very important mechanism for the attenuation of aerosol source terms in suppression pools. This mechanism depends, of course, on the circulation of gases within a rising bubble. The issue of the circulation of \&gases has been much discussed in the literature. In many of the earlier discussions, it has been assumed that there is some critical dimension at which circulation of gases within a rising bubble begins. Bubbles smaller than this critical dimension were found to rise through liquid as though they were rigid spheres. Larger bubbles rose through the liquid as though they were fluid spheres.

More recently, attentions have been directed toward the accumulation of surface active agents, as often minute impurities in the liquid, at the gas liquid interface. Immobilization of the gas-liquid interface by these impurities rather than simply the bubble-dimension is thought to be responsible for stagnation of gases within a bubble. Bubbles initially: released into a pool may have circulating gases. As they rise and accumulate impurities gas circulation is damped.

Arguments concerning the surface activity of liquid phase impurities are quite significant with respect to discussions of steam suppression pools. Though it might be argued waters in these pools are quite pure at the start of an accident, these waters will surely become contaminated: as a seivere accident progresses. The possibility that the contamination will immobilize the gas-liquid interface of rising bubbles and, consequently, inhibit circulation of gases within the bubble must be recognized. 
Table 24. Uncertainties in the phenomena affecting aerosol behavior

\begin{tabular}{|c|c|c|}
\hline Uncertain quantity & Range of values & Distribution \\
\hline \multicolumn{3}{|l|}{ Efficiency of Inertial Impaction } \\
\hline $\begin{array}{l}\mathrm{V}_{\mathrm{m}}\left(\mathrm{cm}^{3} / \text { mole }\right), \text { molar volume of } \\
\text { surface-active agents }\end{array}$ & 40 to 1,000 & log-uniform \\
\hline $\begin{array}{l}\mathrm{C} \text { (surf)(moles per liter), surface-active } \\
\text { agent concentration }\end{array}$ & $10^{-10}$ to $10^{-4}$ & log-uniform \\
\hline \multicolumn{3}{|l|}{ Diffusive Deposition } \\
\hline $\begin{array}{l}S^{*}, \text { Sherwood number for particle mass } \\
\text { transfer from Hill's vortex }\end{array}$ & 14.6 to 17.66 & uniform \\
\hline \multicolumn{3}{|l|}{ Momentum Accommodation Coefficient } \\
\hline $\begin{array}{l}\alpha_{\mathrm{m}}=1-\mathrm{A} \exp (-300 / \mathrm{T}), \mathrm{A} \\
\text { Temperature Accommodation Coefficient }\end{array}$ & 0 to 0.6 & uniform \\
\hline $\begin{array}{l}\alpha_{t}=\alpha_{\mathrm{m}}\left[1-\mathrm{A}^{\prime} \exp (-300 / \mathrm{T})\right], \mathrm{A}^{\prime} \\
\text { Oscillation Capture }\end{array}$ & 0 to 1 & uniform \\
\hline $\begin{array}{l}C(0) \text {, criterion for the onset of } \\
\text { oscillations }\end{array}$ & 2.96 to 4.24 & uniform \\
\hline $\begin{array}{l}\delta(\mathrm{osc}), \text { parameter for evaluation of } \\
\text { oscillation frequency }\end{array}$ & 0 to 1 & uniform \\
\hline \multicolumn{3}{|l|}{ Capture During Bubble Formation } \\
\hline $\begin{array}{l}\epsilon(\mathrm{f}), \text { parameter to interpolate between } \\
\text { models of inertial impaction }\end{array}$ & 0 to 1 & uniform \\
\hline $\begin{array}{l}\delta(f) \text {, parameter to select model of } \\
\text { particle mass transport within the } \\
\text { forming bubble }\end{array}$ & 0 to 1 & uniform \\
\hline
\end{tabular}


It is hypothesized here that bubbles are formed with entirely mobile interfaces. As: they rise through the pool, surface active contaminants accumulate at the interface and progressive immobilize this interface beginning at the trailing boundary of the bubble and progressing, perhaps, to eventually immobilize the entire bubble interface. Thus, at an arbitrary position in the pool, a bubble,will have its interface immobilized over polar angles from 0 to $\phi$. For analysis purposes, the interface over polar angles from $\phi$ to $\pi$ radians is assumed to be entirely free of surface active agents. 'Experitimental: data suggest that this may be only an approximate description of the actual nature of bubble surfaces [237]. Though accumulations of surface active agents necessary to immobilize the gas bubble interface may first develop at the trailing surface of rising bubbles, all surfaces may quickly be partially contaminated with surface active agents at concentrations that at least affect interface mobility.

Sadhal and Johnson [238] have analyzed the circulation of gases within spherical bubbles with partially immobilized interfaces. It is assumed here that the proportionate reduction in particle deposition

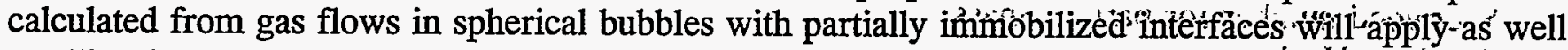
to ellipsoidal bubbles with partially immobilized interfaces considered in the mechanistic mo ódel: The non-dimensional stream function found by Sadhal and Johnson for gas flows in spherical bubbles with partially immobilized interfaces is:

$$
\psi=1.5\left(\xi^{4}-\xi^{2}\right) \int_{\cos \theta}^{1} \mathrm{P}_{1}^{\mathrm{o}}(\mathrm{x}) \mathrm{dx}+\sum_{\mathrm{k}=1}^{\infty} \mathrm{C}_{\mathrm{k}}\left[\xi^{\mathrm{k}+3}-\xi^{\mathrm{k}+1}\right] \int_{\cos \theta}^{1} \mathrm{P}_{\mathrm{k}}^{\mathrm{o}}(\mathrm{x}) \mathrm{dx}
$$

where

$$
\begin{aligned}
\xi & =2 \mathrm{r} / \mathrm{D}_{\mathrm{B}}, \\
\theta & =\text { polar angle, } \\
\mathrm{P}_{\mathrm{k}}^{\mathrm{O}}(\mathrm{x}) & =\mathrm{k} \underline{\text { th }} \text { degree Legendre polynomial, }
\end{aligned}
$$

*The integral $\int_{\cos \theta}^{1} \mathrm{P}_{\mathrm{k}}^{\mathrm{o}}(\mathrm{x}) \mathrm{dx}=\sin \theta \mathrm{T}_{\mathrm{k}}^{-1}(\cos \theta)$ where $\mathrm{T}_{\mathrm{k}}^{-1}(\cos \theta)$ s an associate Legendre function. Associated Legendre functions, which are integrals of classic Legendre polynomials, are not discussed as frequently as are the derivatives of Legendre polynomials. The recurrence relationship for the first integrals is:

$$
(n+1) T_{n}^{-1}(\cos \theta)=(2 n-1) T_{n-1}^{-1}(\cos \theta)-(n-2) T_{n-2}^{-1}(\cos \theta) \text {. }
$$

Note that $\mathrm{T}_{1}^{-1}(\cos \theta)=0.5 \sin (\theta)$ and $\mathrm{T}_{2}^{-1}(\cos \theta)=0.5 \sin (\theta) \cos \theta$. 


$$
\begin{aligned}
\mathrm{C}_{1}= & -\left\{\frac{1}{4 \pi}\left[2 \phi+\sin \phi-\sin 2 \phi-\frac{1}{3} 3 \phi\right]+1\right\} \\
\mathrm{C}_{\mathrm{k}}= & \frac{1}{4 \pi}\{\sin (\mathrm{k}+2) \phi-\sin \mathrm{k} \phi+\sin (\mathrm{k}+1) \phi-\sin (\mathrm{k}-1) \phi \\
& \left.-2\left[\frac{\sin (\mathrm{k}+2) \phi}{\mathrm{k}+2}+\frac{\sin (\mathrm{k}-1) \phi}{\mathrm{k}-1}\right]\right\}
\end{aligned}
$$

The velocity of the gas tangential to the gas-liquid interface is found from:

$$
\mathrm{V}(\text { tangential })=\left.\frac{-1}{\xi \sin \theta} \frac{\partial \psi}{\partial \xi}\right|_{\xi=1}
$$

Normalized tangential velocities are shown in Figure 105 as functions of polar angle for various values of $\phi$. As immobilization of the interface progresses, the circulation of gases within the bubble becomes confined into a smaller region near the leading front of the rising bubble. Particle deposition is proportional to the angular acceleration:

$$
{ }^{a_{\theta}}=K \frac{V\left(\text { tangential }^{2}\right.}{D_{B}}
$$

where $\mathrm{K}$ is the proportionality constant. Total deposition of particles by inertial impaction over the gasliquid interface is given by:

$$
\text { Deposition } \propto \int_{0}^{\pi} \frac{\pi \mathrm{D}_{\mathrm{B}}}{2} \sin \theta \mathrm{a}_{\theta} \mathrm{d} \theta
$$

The variation in the deposition with $\phi$ is shown in Figure 106. There is a sharp reduction in the amount of deposition as $\phi$ exceeds $30^{\circ}$. As $\phi$ exceeds $125^{\circ}$ particle deposition approaches 0 . This variation in particle disposition by inertial impaction is given, approximately, by:

$$
[1-\mathrm{m}(\phi)] /[1+\mathrm{m}(\phi)]=\mathrm{z}(\phi)
$$

where $\mathrm{m}(\phi)=(1 / 2 \pi)[2 \phi+\sin \phi-\sin 2 \phi-1 / 3 \sin 3 \phi]$. 


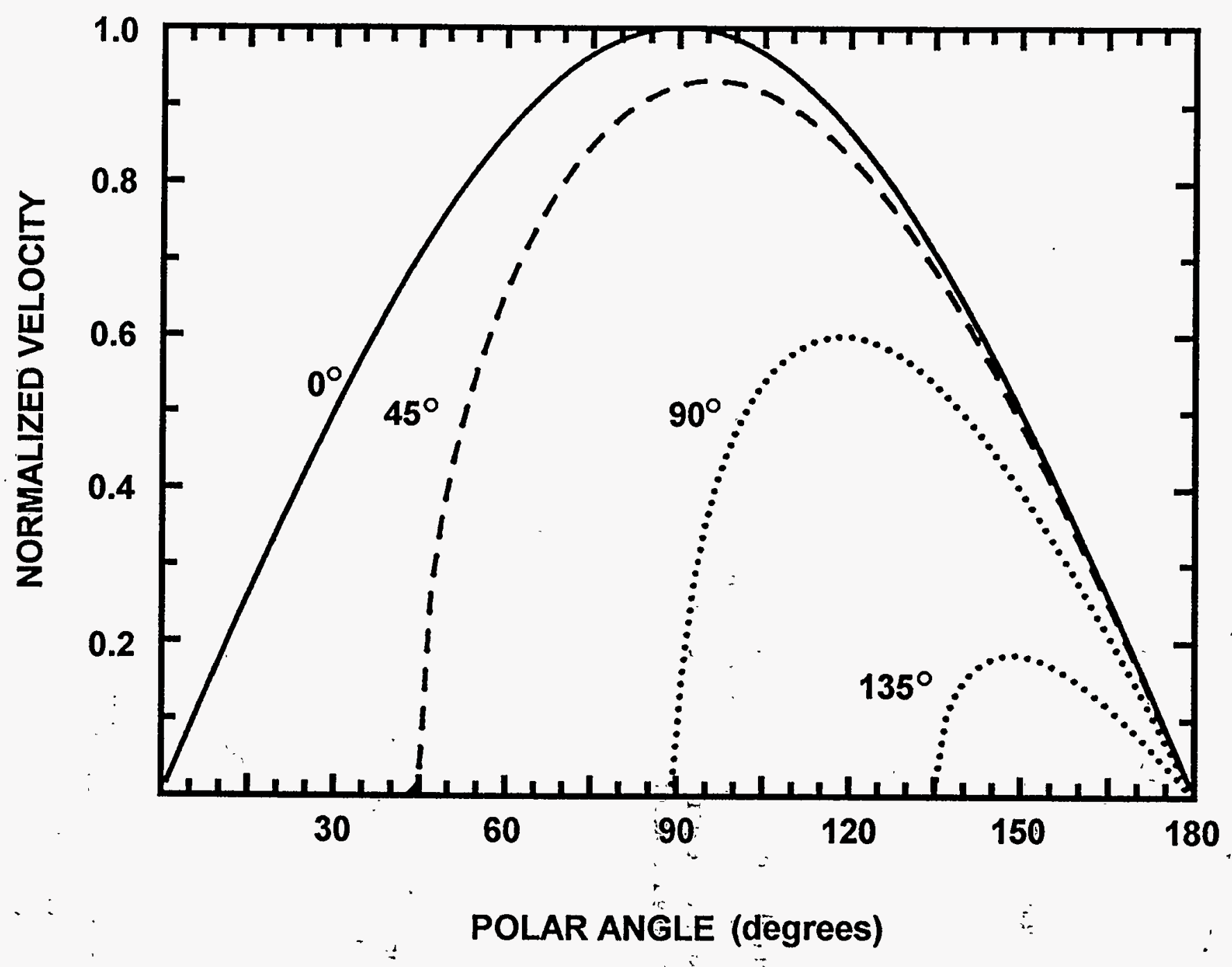

Figure 105. Variation of the normalized tangential velocities about spherical bubble with various amounts of surface immobilization. Curves are labelled by values of $\phi$ in dêgrees: 


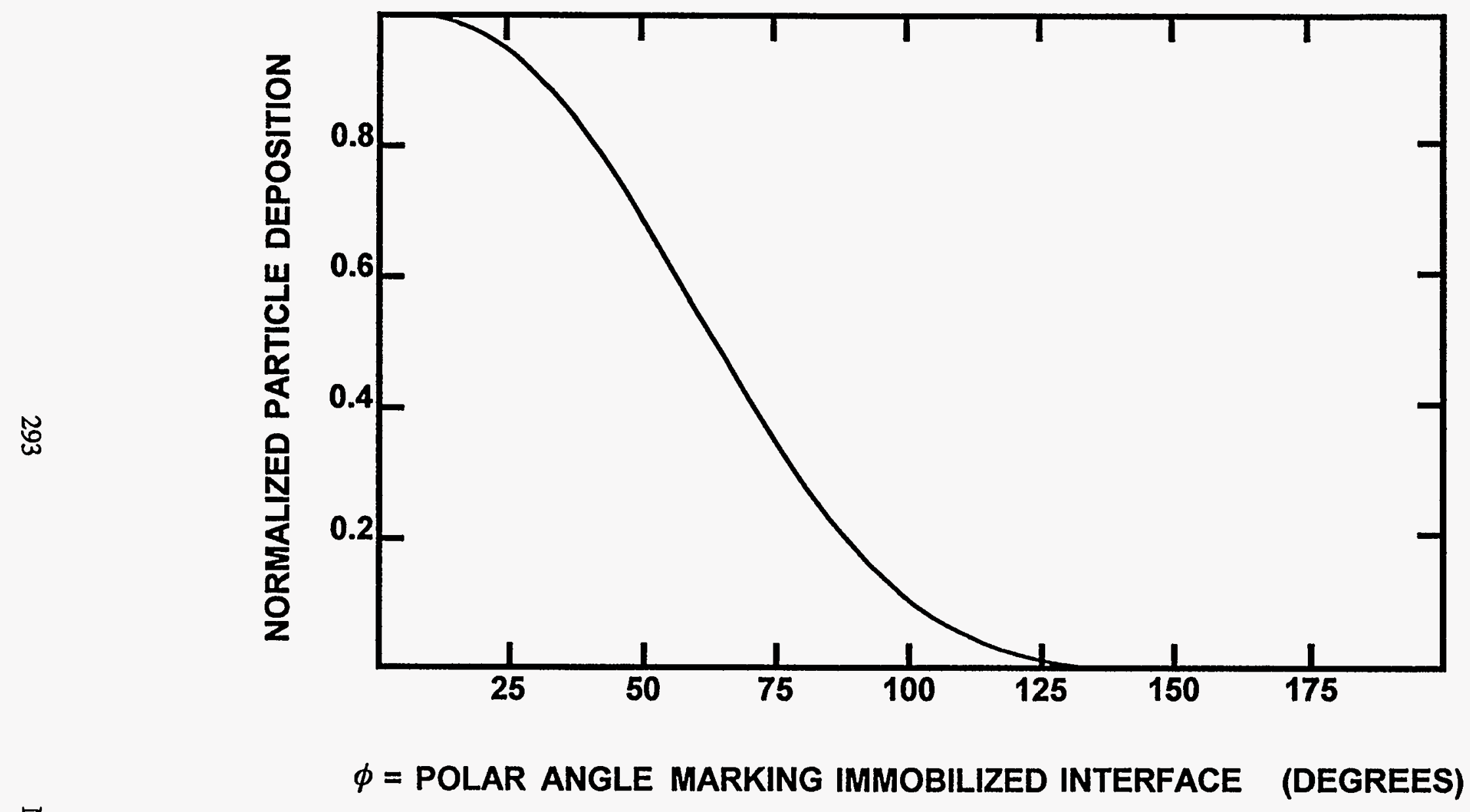

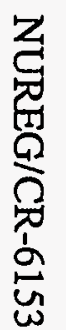

Figure 106. Variation of the normalized, integrated particle deposition by inertial impaction as a function of the extent of surface immobilization 
Sadhal and Johnson find the angle of surface immobilization, $\phi$, to be related to the molar amount of surface active agent, $\mathrm{N}$ (surf), by:

$$
\mathrm{N}\left(\text { surf) }=\mathrm{U}_{\text {slip }} \frac{\pi \mathrm{D}_{\mathrm{B}^{-\cdots}}^{2}}{2 \mathrm{RT}} \mu(\mathrm{l})[2 \phi-4 \dot{\phi} \cos \phi-\sin 2 \phi+4 \sin \phi]\right.
$$

Assume the surface active agent is present in the liquid at a molar concentration of $\mathrm{C}$ (sứrf). Then,

$$
\frac{\mathrm{dN}(\text { surf })}{\mathrm{dx}}=\pi \mathrm{D}_{\mathrm{B}} \frac{Ð \text { Sh C(surf) }}{1000 \mathrm{U}_{\mathrm{slip}}}
$$

where

$$
\begin{aligned}
\mathrm{C}(\text { surf }) & =\text { concentration of surface active agent (moles/liter), } \\
\mathrm{Sh}= & \text { Sherwood number for mass transport to the bubble, } \\
\mathrm{\Xi}= & \text { diffusion coefficient of the surface active agent in water }\left(\mathrm{cm}^{2} / \mathrm{s}\right), \\
\mathrm{x}= & \text { distance the bubble has risen in the pool }(\mathrm{cm}), \text { and } \\
\mathrm{U}_{\mathrm{slip}}= & \begin{array}{l}
\text { slip velocity of the bubble in the bubble plume rising through the suppression pool } \\
\end{array}
\end{aligned}
$$

Then, to a satisfactory level of approximation

$$
\mathrm{N}(\text { surf })=\chi \pi \mathrm{D}_{\mathrm{B}} \boxplus \mathrm{Sh} \mathrm{C}(\text { surf }) / \mathrm{U}_{\text {slip }} 1000
$$

There is no information on what types of agents might be responsible for immobilization of bubble interfaces in a suppression pool:' Trace concentration organic species are, of course, often quite potent surface active agents. The Wilke-Change method for the estimation of diffusion coefficients of such species in water yields:

$$
\boxplus=\frac{5 \times 10^{-9} \mathrm{~T}}{\mu(1) \mathrm{V}_{\mathrm{m}}^{0.6}} \mathrm{~cm}^{2} / \mathrm{s}
$$

where $\mathrm{V}_{\mathrm{m}}$ is the molar volume of the surface active agent at its normal boiling point. Such molar volumes might vary from 40 to $1000 \mathrm{~cm}^{3} / \mathrm{mole}$. Similarly, the concentrations of the surface active agents are unknown, but can be imagined to be in the range of $10^{-10}$ to $10^{-4}$ moles per liter of water. 
Solution of the above equations for $\phi$ allows $\mathrm{m}(\phi)$ to be found. Then, the deposition velocities of aerosol particles by inertial impaction are found from:

$$
\mathrm{V}_{\mathrm{D}}(\phi)=\frac{2 \mathrm{U}_{\mathrm{B}}^{2} \sin ^{2}(\eta) \sqrt{\mathrm{E}^{2}-1} \mathrm{E}^{5 / 3} \mathrm{z}(\phi) \tau}{\mathrm{D}_{\mathrm{B}}\left\{\cos ^{2}(\eta)+\frac{1}{\mathrm{E}^{2}-1}\right\}^{5 / 2}\left\{\sqrt{\mathrm{E}^{2}-1}-\mathrm{E}^{2} \tan ^{-1}\left[\sqrt{\mathrm{E}^{2}-1}\right]\right\}^{2}}
$$

\section{b. Uncertainty in Aerosol Trapping by Diffusion}

Controversies concerning the proper description of aerosol trapping by diffusion of particles to the bubble walls have been discussed above in Section IV-L.1.a. There are three models available. Fuchs [148] has derived a model that is widely used. The derivation is based on vortex flows within the bubble. But, Mills and Hoseyni [204] point out that the result of the derivation is more appropriate for conditions in which the gas making up the bubble is well-mixed. They correctly note that for vortex flows the Kronig-Brink model [88] of mass transfer is more appropriate. They also point to Calderbank-Korchinski model [206] as being applicable. As noted above, vortex flows may be substantially damped in a bubble due to contamination. As the gas in the bubble becomes stagnant there is no convective enhancement of the diffusion of particles to the bubble walls. A complicated situation can be imagined in which a substantial volume of the bubble is stagnant and the rest is involved in a vortex flow or is well-mixed. But, for bigger bubbles shape oscillations (see below) may produce mixing--even when otherwise the gas would be stagnant within a bubble.

The analyses presented above provide a definition for the region of a bubble that is involved in vortex flows. Diffusive deposition in this region is calculated from:

$$
\mathrm{Sh}=\mathrm{S}^{*}
$$

where $S^{*}$ is uncertain and is taken to be uniformly distributed over the range from 14.6 (the long time limit of the Calderbank-Korchinski model) and 17.66 (the long time limit of the Kronig-Brink model). The diffusive deposition of particles from stagnated gases in small bubbles that do not undergo shape oscillations is found from:

$$
\mathrm{Sh}=6.58
$$

which is the long time limit of Newman's solution for diffusion in a sphere. When shape oscillations are predicted to occur are assumed here to mix well all regions of the bubble. The diffusive deposition is calculated from Fuchs' model:

$$
S h=f(E) P e^{1 / 2}
$$




\section{Uncertainty}

\section{c. Uncertainty in Slip Correction Factors}

There have been a variety of empirical, slip correction factors used by various authors. Several of these are described in Section IV-K.2. Despite the differences in the parametric values of the different impressions, there are not great differences among the predietions derived from the expressions. With the exception of the expression obtained by Allen and Raabe [143] these various expressionis have been obtained by fitting to the same or at least similar database. The functional form of the slip correction factor expression is such that there is a great deal of correlation among the three adjustable parameters. Small differences in the procedure used to obtain parametric values produce fairly significant changes in parametric values. But, because of the correlation the three adjustable parameters do not vary arbitrarily. There is a compensation in the variations so that large variations in the predictions of the expressions within the range of the database are not produced.

The empirical expressions are, however, based on a rather narrow database that does not seem closely related to the conditions of interest here. Most of the data used in the fitting processitwas obtained for oil droplets at room temperature. The theoretical expression obtained 'by Phillips [145]' is more attractive for the substantial extrapolation to be done in this work:

$$
\mathrm{C}=\frac{15+12 \mathrm{C}_{1} \mathrm{Kn}+9\left(\mathrm{C}_{1}{ }^{2}+1\right) \mathrm{Kn}^{2}+18 \mathrm{C}_{2}\left(\mathrm{C}_{1}{ }^{2}+2\right) \mathrm{Kn}^{3} \mathrm{x}_{\mathrm{s}}}{15-3 \mathrm{C}_{1} \mathrm{Kn}+\mathrm{C}_{2}\left(8+\pi \alpha_{t}\right)\left(\mathrm{C}_{1}^{2}+2\right) \mathrm{Kn}^{2}}
$$

where

$$
\begin{aligned}
& \mathrm{C}_{1}=\left(2-\alpha_{\mathrm{m}}\right) / \alpha_{\mathrm{m}}, \\
& \mathrm{C}_{2}=1 /\left(2-\alpha_{\mathrm{m}}\right), \\
& \alpha_{\mathrm{m}}=\text { momentum accommodation coefficient, and } \\
& \alpha_{\mathrm{t}}=\text { thermal accommodation coefficient. }
\end{aligned}
$$

This theoretical expression was derived, of course, based on a variety of questionable 'assumpiptions: 'It' does seem to predict well the slip correction factors in the regimes where the many empirical expressions are applicable. Consequently, the Phillips model is taken here to be accurate (no uncertainty). Uncertainty in the slip correction factors arises from uncertainty in the accommodation coefficient to use in the theoretical expression. It is assumed here that this uncertainty is'a muich bigger effect than uncertainty that can arise because particles are slightly distorted from 'perfect spheres.'

\section{d. Uncertainty in Accommodation Coefficients}

All available data seem to suggest that momentum accommodation coefficients vary from perhaps as low as 0.74 to 1.0. Most measured values are around 0.9. But, the available data are quite limited. In particular, few measurements have been made at elevated temperatures in steam-rich atmospheres. 
Intuition suggests that the momentum accommodation coefficient should decrease with temperature. Here, the momentum accommodation coefficient is taken to be

$$
\alpha_{\mathrm{m}}=1.0-\mathrm{A} \exp (-300 / \mathrm{T})
$$

where $\mathrm{A}$ is an uncertain parameter uniformly distributed over the range from 0 to 0.6 .

What data are available suggest that the temperature accommodation coefficient is no greater than the momentum accommodation coefficient. Consequently, the temperature accommodation coefficient is taken to be:

$$
\alpha_{\mathrm{t}}=\alpha_{\mathrm{m}}\left[1-\mathrm{A}^{\prime} \exp (-300 / \mathrm{T})\right]
$$

where $\mathrm{A}^{\prime}$ is an uncertain parameter uniformly distributed over the range of 0 to 1.

\section{e. Uncertainty in Aerosol Capture by Bubble Oscillations}

Bubbles rising through the pool can be big-enough that they do not rise smoothly. Rather, there are sharp oscillations of the bubbles. These oscillations are assumed to sweep out aerosol particles. The uncertainties that arise concerning this mechanism of aerosol capture deal with the onset of bubble oscillations as well as the effectiveness of oscillations at aerosol capture.

Available information concerning the onset of oscillations of bubbles is really for isolated bubbles. It is not clear such information is actually applicable to bubbles in swarms, but this is assumed to be the case here. Oscillations are then assumed to occur when:

$$
\frac{\rho_{1}}{\sigma_{1}} \mathrm{U}_{\text {slip }}^{3} \mathrm{D}_{\mathrm{B}}>\mathrm{C}(\mathrm{o})
$$

where $C(0)$ is uniformly distributed over the interval from 2.96 to 4.24 (see Section IV-F).

The removal of particles by oscillations is described by:

$$
\frac{1}{A} \frac{\mathrm{dn}\left(\mathrm{d}_{\mathrm{p}}\right)}{\mathrm{dt}}=\frac{-\mathrm{k}_{\mathrm{m}}(\mathrm{osc})}{\mathrm{V}_{\mathrm{B}}} \mathrm{n}\left(\mathrm{d}_{\mathrm{p}}\right)
$$


or

$$
\frac{1}{A} \frac{d n\left(d_{p}\right)}{d x}=\frac{-k_{m}(o s c)}{U_{\text {slip }} V_{B}} n\left(d_{p}\right)
$$

where

$$
\begin{aligned}
\mathrm{n}\left(\mathrm{d}_{\mathrm{p}}\right) & =\text { number of particles of diameter } \mathrm{d}_{\mathrm{p}} \text { in the bubble, } \\
\mathrm{x} & =\text { rise distance of the bubble, } \\
\mathrm{k}_{\mathrm{m}}(\mathrm{osc}) & =\text { mass transfer coefficient }=\frac{2 \psi(\eta-1) \beta}{\pi} \sqrt{\mathrm{f} \oplus\left(\mathrm{d}_{\mathrm{p}}\right)}, \text { and } \\
\psi & =\text { uncertain parameter uniformly distributed over the interval } 0 \text { to } 2,4 .
\end{aligned}
$$

Other quantities in these equations are defined in Section IV-L.1,g. The frequency, of bubble os osiliation is calculated from

$$
(2 \pi f)^{2}=\frac{8 \mathrm{n}(\mathrm{n}-1)(\mathrm{n}+1) \cdot(\mathrm{n}+2) \sigma_{1}}{\mathrm{D}_{\mathrm{B}}^{3}\left[(\mathrm{n}+1) \rho_{1}+\mathrm{n} \rho_{\mathrm{g}}\right]}
$$

where $\mathrm{n}=2$.

\section{f. Uncertainty in the Summation of Aerosol Capture Processes}

The discussions of mechanisms of aerosol capture processes, were presented as though each of the mechanisms was independent of the others. This, of course, is not the case. Treatment of the processes as though they were independent is certainly a common approximation. The next level of approximation is a vector addition of the deposition velocities. That is, the net deposition velocity, V(net), is given in the BUSCA code [9] by:

$$
\begin{aligned}
\mathrm{V}(\text { net })= & \mathrm{V}(\text { impaction })+\mathrm{V}(\text { thermophoresis })+\mathrm{V}(\text { diffusiophoresis }) \\
& -\mathrm{V}(\text { settling }) \cos \theta+\mathrm{V}(\text { impaction })+\mathrm{V}(\text { diffusion })
\end{aligned}
$$

and this is integrated over the surface of the bubble. In the SPARC code [6],

$$
\mathrm{V}(\text { net })=\mathrm{V}(\text { impaction })+\mathrm{V}(\text { diffusion })-\mathrm{V}(\text { settling }) \cos \phi-\mathrm{V}(\text { vapor })
$$


where $V$ (vapor) is the velocity of the vapor evaporating from the bubble surface.

Vector addition, appealing as it is, still does not fully correct for the full effects of coupling among mechanisms. Physically, the additional coupling comes about because the various mechanisms affect the concentration gradients in the boundary layers which has a strong effect on the diffusive mechanisms. Derevich and Zaichik [251] formulate the net flux to the wall using the Fokker-Plank equation to be:

$$
J=\left.\left[\left[\frac{\boxplus}{2 \pi \tau}\right]^{1 / 2} n+\frac{1}{2} \frac{d \boxplus n}{d y}-\left(U_{y}+\tau a_{y}\right) \frac{n}{2}\right]\right|_{y=0}
$$

where

$$
\begin{aligned}
J & =\text { particle flux to the surface, } \\
\mathrm{y} & =\text { distance from the wall, } \\
\boxplus & =\text { diffusion coefficient, } \\
\tau & =\rho_{\mathrm{p}} \mathrm{d}_{\mathrm{p}}^{2} / 18 \mu_{\mathrm{g}} \\
\mathrm{U}_{\mathrm{y}} & =\text { gas velocity perpendicular to surface, } \\
\mathrm{a}_{\mathrm{y}} & =\text { accelerations on particle, and } \\
\mathrm{n} & =\text { particle concentration. }
\end{aligned}
$$

The gradient in the term Đn is the source of complicated coupling. Goldberg [251] has solved the Fokker-Plank equation for simultaneous gravitational settling and diffusive deposition of particles. The fraction of particles that would be deposited by the coupled gravitational settling and diffusive deposition mechanisms are shown in Table 25 for dimensionless times of $\xi=2 V_{s} t / D_{B}$ and various values of $2 \boxplus / V_{S} D_{B}$. also shown in the table are the fraction of particles that would deposit by pure diffusive deposition and pure gravitational settling. Simply summing these pure deposition processes does, of course, overpredict deposition (it even yields physically impossible values greater than 1).

Rosner and coworkers [252-5] have discussed the complicated coupling between thermophoresis and other deposition processes. They find a complicated correlation of the deposition flux with thermophoresis, and without thermophoresis that depend in complicated ways on the specifics of the situation.

Here the vector addition procedure is utilized in the form:

$$
\begin{aligned}
\mathrm{V}= & \mathrm{V}(\text { impaction })+\mathrm{V} \text { (thermophoresis) }+\mathrm{V} \text { (diffusiophoresis) }-\mathrm{V} \text { (settling) } \cos \phi \\
& +\mathrm{V} \text { (impaction) }+\alpha_{\mathrm{s}} \mathrm{V} \text { (diffusion) }-\mathrm{V} \text { (vapor) }
\end{aligned}
$$




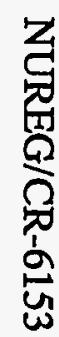

Table 25. Effects of coupling between diffusion and gravitational settling

\begin{tabular}{|c|c|c|c|c|c|c|}
\hline \multirow[b]{2}{*}{$\alpha=2 \mathbf{D} / \mathbf{V}_{\mathbf{S}} \mathbf{D}_{\mathbf{B}}$} & \multirow[b]{2}{*}{$\xi=2 V_{s} t / D_{B}$} & \multicolumn{5}{|c|}{ Fraction of particles deposited by } \\
\hline & & $\begin{array}{c}\text { pure } \\
\text { gravitational } \\
\text { settling } \mathrm{f}_{\mathrm{s}} \\
\end{array}$ & 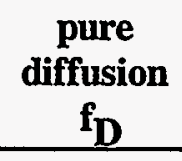 & $\begin{array}{c}\text { sum } \\
\mathbf{f}_{\mathbf{D}}+\mathbf{f}_{\mathbf{S}}\end{array}$ & 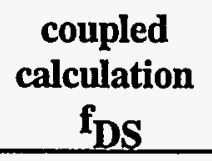 & $\begin{array}{c}\epsilon^{*} \text { for } \mathbf{f}_{\mathbf{D S}}= \\
\mathbf{f}_{\mathbf{S}}+\epsilon^{*} \mathbf{f}_{\mathrm{D}}\end{array}$ \\
\hline 0.05 & \multirow[t]{5}{*}{0.1} & 0.075 & 0.224 & 0.299 & 0.223 & 0.661 \\
\hline 0.10 & & 0.075 & 0.308 & 0.384 & 0.310 & 0.763 \\
\hline 0.20 & & 0.075 & 0.419 & 0.454 & 0.645 & 1.360 \\
\hline 0.50 & & 0.075 & 0.607 & 0.682 & 0.705 & 1.036 \\
\hline 1.00 & & 0.075 & 0.770 & 0.845 & 0.744 & 0.869 \\
\hline 0.05 & \multirow[t]{5}{*}{0.2} & 0.150 & 0.308 & 0.458 & 0.333 & 0.594 \\
\hline 0.10 & & 0.150 & 0.419 & 0.568 & 0.437 & 0.685 \\
\hline 0.20 & & 0.150 & 0.557 & 0.706 & 0.561 & 0.738 \\
\hline 0.50 & & 0.150 & 0.770 & 0.920 & 0.769 & 0.804 \\
\hline 1.00 & & 0.150 & 0.916 & (1.065) & 0.906 & 0.825 \\
\hline 0.05 & \multirow[t]{5}{*}{0.4} & 0.296 & 0.419 & 0.715 & 0.499 & 0.484 \\
\hline 0.10 & & 0.296 & 0.557 & 0.853 & 0.603 & 0.551 \\
\hline 0.20 & & 0.296 & 0.718 & $(1.014)$ & 0.740 & 0.618 \\
\hline 0.50 & & 0.296 & 0.916 & $(1: 212)$ & 0.911 & 0.671 \\
\hline 1.00 & & 0.296 & 0.988 & (1:284) & 0.993 & 0.705 \\
\hline 0.05 & \multirow[t]{4}{*}{0.7} & 0.504 & 0.528 & $(1.032)$ & 0.675 & 0.324 \\
\hline 0.10 & & 0.504 & 0.686 & (1.189) & 0.774 & $0: 394$ \\
\hline 0.20 & & 0.504 & 0.847 & $(1.350)$ & 0.901 & 0.469 \\
\hline 0.50 & & 0.504 & 0.981 & (1.484) & 0.978 & 0.483 \\
\hline 0.05 & 1.0 & 0.688 & 0.607 & (1.294) & 0.799 & 0.183 \\
\hline 0.10 & \multirow[b]{2}{*}{$\therefore$} & 0.688 & 0.770 & $(1.458)$ & 0.903 & 0.279 \\
\hline 0.20 & & 0.688 & 0.916 & (1.603) & 0.945 & 0.280 \\
\hline
\end{tabular}


where $\alpha_{\mathrm{s}}$ is an uncertain parameter uniformly distributed over the range from 0.5 to 1.5 . When oscillations of the bubble become important, the mechanisms of aerosol deposition are taken to be diffusion, oscillations, and gravitational settling and they are taken to be independent.

\section{g. Uncertainty in Aerosol Capture During Bubble Formation}

Three mechanisms of aerosol capture during bubble formation are consider here:

- inertial impaction from the jet,

- convective deposition from circulating gases, and

- diffusiophoretic deposition due to the condensation of steam.

Uncertainty in the diffusiophoretic deposition of aerosol particles is assumed here to be dominated by the uncertainty in heat transfer from the forming bubble and uncertainty in the gas composition. These uncertainties have been discussed above. Uncertainty in the other two mechanisms are discussed here.

Most computer codes used as a model for inertial impaction from the gas jet a model appropriate for stagnation flow against a fixed plate. This model predicts a rather abrupt variation in the efficiency of particle capture with variations in particle size. Above, an alternative model is described. This model shows much less variation in particle capture efficiency with particle size. Since there are not data to guide selection between these models, a parameter $\epsilon(f)$ is defined to be distributed uniformly over the range from 0 to 1 , and the particle capture efficiency as a function of particle size is found from

$$
. \epsilon\left(\mathrm{d}_{\mathrm{p}}\right)=\epsilon(\mathrm{f}) \mathrm{E}(\text { plate })+[1-\mathrm{E}(\mathrm{f})] \mathrm{E}(\text { disk })
$$

where

$$
\epsilon\left(d_{p}\right)=\text { fraction of particles of diameter } d_{p} \text { captured, }
$$

$\mathrm{E}($ plate $)=$ fraction of particles of diameter $\mathrm{d}_{\mathrm{p}}$ captured according to the fixed plate model, and

$\mathrm{E}\left(\right.$ disk) $=$ fraction of particles of diameter $\mathrm{d}_{\mathrm{p}}$ captured according to the alternative (disk) model.

The capture of particles from convective motion of gases within the bubble can be described in terms of inertial impaction or, in terms of convective mass transport. These are qualitatively different hypotheses and it is not clear which best describes what takes place within the bubbles. Consequently, a parameter $\delta(f)$ is defined to be uniformly distributed over the range 0 to 1 . The convective deposition efficiency of particles is determined from: 
Uncertainty

$$
\epsilon= \begin{cases}\epsilon(\text { inertial }) & \text { for } \delta(f)<0.5 \\ \epsilon(\text { convection }) & \text { for } \delta(f) \geq 0.5\end{cases}
$$

\section{Summary of Uncertainties}

The uncertainty analyses described in Chapter VI consider 38 uncertainty quantities. Nine of these uncertain quantities (described in Table 22) deal with the boundary, conditions dictated by , plant geometry and accident progress. Nineteen of the uncertain quantities deal with the behaviors of gas bubbles forming and rising in the steam suppression pool (see Table 23). Ten uncertain quantities deal with the behavior of aerosol particles in bubbles in the suppression pool (see Table 24). 


\section{Results of the Uncertainty Analyses}

Results of the Monte Carlo uncertainty analyses are described in this chapter. Uncertain quantities predicted by the mechanistic model of decontamination by a steam suppression pool and of interest here are:

- the extent of decontamination, and

- the sizes of aerosol particles that emerge from the pool.

The extent of decontamination of gases that sparge through suppression pools is of interest because this represents an attenuation of the severe accident source term. Particle size information for aerosol materials that do emerge from the suppression pool is of interest for prediction of the subsequent behavior of these aerosols.

Decontamination of aerosol-laden gases sparging through suppression pools is characterized here by decontamination factors. These decontamination factors are defined as the aerosol mass input to a process divided by the aerosol mass that emerges from the process.

The calculations done for the Monte Carlo uncertainty analysis were organized so that distinct decontamination factors were accumulated for the processes:

- bubble formation, $\mathrm{DF}$ (form)

- bubble detachment, collapse and equilibration with the suppression pool, DF(equil), and

- bubble rise through the pool, $\mathrm{DF}$ (rise).

The product of these three decontamination factors in a particular calculation yields the total decontamination factor, DF(total), predicted for the particular set of values of uncertain quantities of the calculation. Some correlation among the three decontamination factors is to be expected. Consequently, accumulated values of $\mathrm{DF}$ (form), $\mathrm{DF}$ (equil), and $\mathrm{DF}$ (rise) ought not be separately analyzed and the results multiplied to form an estimate of $\mathrm{DF}$ (total).

Condensation of excess steam is an important decontamination process during both bubble formation and bubble equilibration. The mechanistic calculations treat decontamination by considering it to occur only during equilibration. The product, $\mathrm{DF}(\mathrm{FE})=\mathrm{DF}($ form $) \mathrm{DF}$ (equil) is more physically meaningful than the component decontamination factors.

In this chapter, uncertainty distributions are discussed for:

- $\mathrm{DF}(\mathrm{FE})$

- $\mathrm{DF}$ (rise)

- $\mathrm{DF}($ total)

- the mean size of aerosol particles that emerge from a suppression pool, $\mathrm{d}_{\mathrm{p}}$ (mean) and 
- the standard deviation of the distribution of particle sizes, $\sigma$, of aerosol that emerges from the pool.

Example uncertainty distribution for $\mathrm{DF}$ (total), $\mathrm{d}_{\mathrm{p}}$ (mean), and $\sigma$ are shown in Tables 26, 27, and 28, respectively. Other distributions calculated in this work is collected in tabulated form in Appendix A.

Each uncertainty distribution is derived from a finite sample obtained in the Monte Carlo calculations. Consequently, the uncertainty distributions can be determined only to a specified confidence interval.

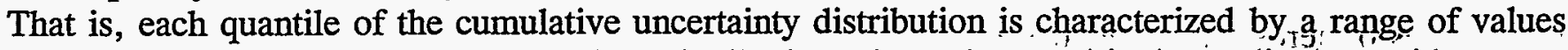
of the uncertain quantity. The uncertainty distributions shown here and in Appendix A provide ranges for quantiles at 5 percent intervals between 5 and 95 percent. The ranges are shown for confidence levels of 50 and 90 percent. At a confidence level of $100(1-\alpha)$ percent, there is a confidence of $100(1-\alpha)$ percent that the value of the uncertain quantity corresponding to the specified quantile of the "true" uncertainty distribution lies within the specified range. There is a $100 \alpha$ percent probability that this true value is actually above of below the specified range. The widths of the ranges increase as higher levels of confidence that the range include the true value are demanded. The widths of the ranges shrink with increasing sample size. Unfortunately, the ranges decrease in size only with the square root of the number of samples taken in the Monte Carlo analyses. There is, then, a rapidly diminishing return obtained by increasing the sample size.

As noted in the introduction to this document, sample sizes were selected so that there was a 9 percent confidence that 95 percent of the ranges of uncertain values were sampled. In general, the ranges of values of the uncertain quantities associated with quantiles of the uncertainty distributions are small, compared to the 10 to 90 percent range of uncertain values spanned by the distribution. However, especially for the decontamination coefficients, ranges at the 90 and 95 percent quantiles do become. quite large.

In the remainder of the discussion here only selected features of the uncertainty distributions are described in detail. These selected features are:

- the medians or 50 percentiles of the distributions which are considered here to be the best estimates of the uncertain quantities,

- the 90 percentiles of the distributions which are considered here to be reasonable upper bound values of the uncertain quantities,

- the 10 percentiles of the distributions which are considered here to be reasonable lower, bound values of the uncertain quantities, and

- the means of the distributions which may be of interest to some but have no particular statistical significance for the uncertainty distributions developed here.

\section{A. Decontamination During Release Through ' $T$ ' Quenchers}

Uncertainty distributions for the decontamination factors and size characteristics of particles that emerge from a suppression pool were calculated for materials discharged to the pool through ' $\mathrm{T}$ ', quenchers during the gap release and the invessel release phases of an accident. The quenchers were assumed to 
Table 26. Uncertainty distribution for the total decontamination of invessel release material after passing through a ' $T$ ' quencher $500 \mathrm{~cm}$ deep

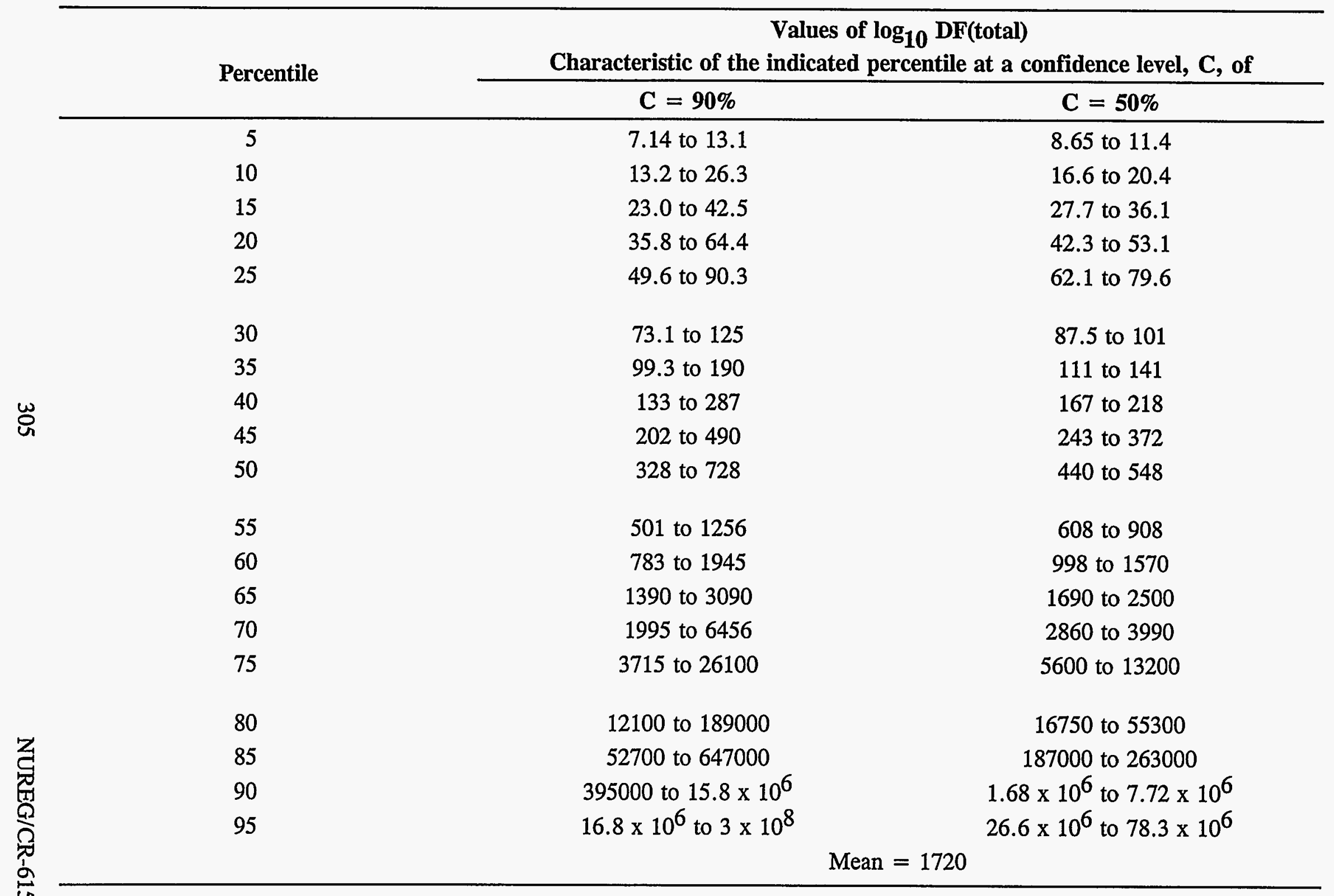




\begin{tabular}{|c|c|c|}
\hline \multirow{2}{*}{ Percentile } & \multicolumn{2}{|c|}{$\begin{array}{l}\text { Values of } d_{p}(\mu \mathrm{m}) \\
\text { Characteristic of the indicated percentile at a confidence level, } C \text {, of }\end{array}$} \\
\hline & $\mathrm{C}=90 \%$ & $\mathrm{C}=\mathbf{5 0 \%}$ \\
\hline 5 & 0.114 to 0.138 & 0.122 to 0.130 \\
\hline 10 & 0.138 to 0.154 & 0.144 to 0.150 \\
\hline 15 & 0.150 to 0.169 & 0.155 to 0.159 \\
\hline 20 & 0.159 to 0.185 & 0.169 to 0.179 \\
\hline 25 & 0.176 to 0.207 & 0.182 to 0.193 \\
\hline 30 & 0.188 to 0.221 & 0.198 to 0.212 \\
\hline 35 & 0.210 to 0.231 & 0.216 to 0.226 \\
\hline 40 & 0.222 to 0.243 & 0.228 to 0.238 \\
\hline 45 & 0.231 to 0.256 & 0.242 to 0.248 \\
\hline 50 & 0.244 to 0.27 .6 & 0.251 to 0.265 \\
\hline 55 & 0.257 to 0.291 & 0.267 to 0.283 \\
\hline 60 & 0.279 to 0.314 & 0.287 to 0.302 \\
\hline 65 & 0.293 to 0.339 & 0.307 to 0.325 \\
\hline 70 & 0.321 to 0.375 & 0.330 to 0.358 \\
\hline 75 & 0.353 to 0.409 & 0.366 to 0.394 \\
\hline 80 & 0.393 to 0.452 & 0.408 to 0.433 \\
\hline 85. & 0.433 to 0.494 & 0.452 to 0.478 \\
\hline 90 & 0.482 to 0.569 & 0.500 to 0.539 \\
\hline 95 . & 0.571 to 1.293 & 0.627 to 0.700 \\
\hline & & \\
\hline
\end{tabular}


Table 28. Uncertainty distribution for the standard deviation invessel release after passing through a ' $T$ ' quencher $500 \mathrm{~cm}$ deep

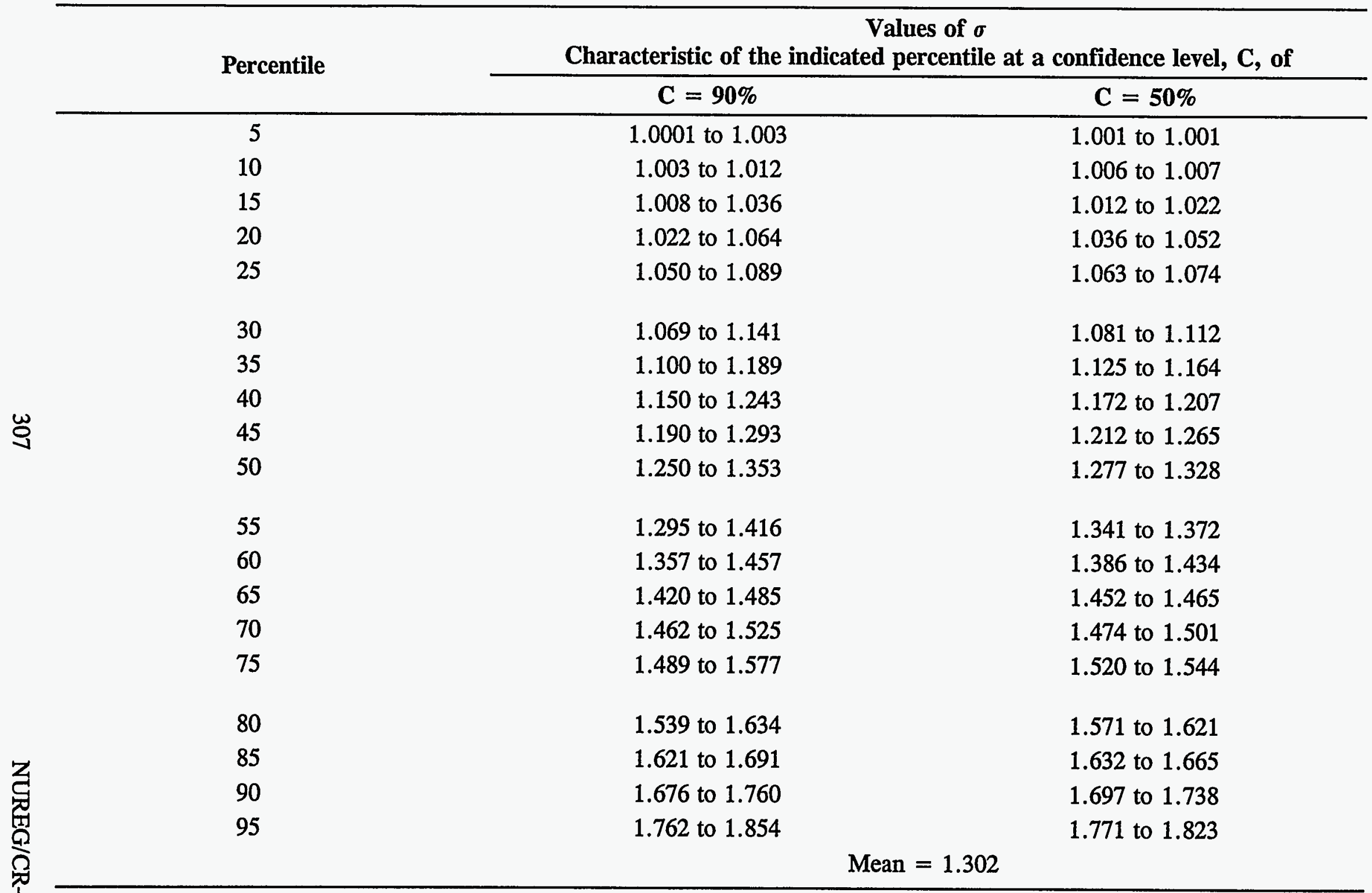




\section{Results}

be submerged to depths of $100,200,300,500$, and $700 \mathrm{~cm}$. Selected features of these uncertainty distributions are summarized in Tables 29 through 33. Note that the uncertainty distributions were developed for logarithms of uncertain quantities. Actual values rather than logarithms are listed here to facilitate discussion.

The median, 10 percentile, and 90 percentile values of the decontamination factor associated with bubble formation at a ' $T$ ' quencher during gap release are shown as functions of quencher, submergence in Figure 107. A similar plot of these decontamination factors for aerósol'ladên gases, released through a ' $\mathrm{T}$ ' quencher duritig the invessel release phase of an accident is shown in Figure 108. In both of these figures, the bars indicate the limits of the 50 percent confidence level for medianvalues and the 90 percent confidence level for the 10 and 90 percentile values.

Decontamination during formation and equilibration is rather insensitive to the depth of quencher submergence. There is much less than a factor of 10 change in the decontamination by bubble formation and equilibration as the assumed submergence of the ' $T$ ' quencher is varied from 100 to 700 $\mathrm{cm}$.

Decontamination during the gap release is consistently, but modestly, less than decontamination during the invessel release phase. Decontamination by bubble formation during the gap release phase is much less than during the invessel release phase because gas flow velocities are so much higher during the gap release phase of a severe reactor accident. On the other hand, gas flowing to the suppression pool during the gap release phase is mostly steam. Consequently, equilibration of the gas with the suppression pool during gap removes a very large amount of aerọsol mẩterial relative to the amount removed by the equilibration process during invessel release when a signifịcant amount of noncondensible hydrogen is present in the gas.

The predicted decontamination factors during bubble formation and equilibration with the suppression pool can be correlated simply as constants for particular percentiles and phases of an accident. For gäp release through a ' $T$ ' quencher:

- Median (50 percentile)

$\log _{10} \mathrm{DF}(\mathrm{FE})=1.313$

$\mathrm{DF}(\mathrm{FE})=20.6$

- Lower Bound (10 percentile)

$\log _{10} \mathrm{DF}(\mathrm{FE})=0.905$

$\mathrm{DF}(\mathrm{FE})=8.0$

- Upper Bound (90 percentile)

$\log _{10} \mathrm{DF}(\mathrm{FE})=1.786$

$\mathrm{DF}(\mathrm{FE})=61.0$ 
Table 29. Summary of the uncertainty distributions for the decontamination factor associated with formation and equilibration of bubbles, $\mathrm{DF}(\mathrm{FE})$, during gap release and invessel release through ' $\mathrm{T}$ ' quenchers

\begin{tabular}{|c|c|c|c|c|}
\hline \multirow[b]{2}{*}{$\begin{array}{c}\text { Quencher } \\
\text { submergence (cm) }\end{array}$} & \multicolumn{4}{|c|}{ Decontamination factor, $\mathrm{DF}(\mathrm{FE})$} \\
\hline & $\begin{array}{c}\text { Upper bound } \\
\left.\text { (90 percentile }{ }^{*}\right)\end{array}$ & $\left.\begin{array}{c}\text { Median } \\
(50 \text { percentile }\end{array}{ }^{* *}\right)$ & $\begin{array}{l}\text { Lower bound } \\
\text { (10 percentile }\end{array}$ & Mean \\
\hline \multicolumn{5}{|l|}{ Gap release } \\
\hline 100 & 57.5 to 83.8 & 20.2 to 22.0 & 6.87 to 9.14 & 22.0 \\
\hline 200 & 48.3 to 78.9 & 19.5 to 21.3 & 5.48 to 9.84 & 21.0 \\
\hline 300 & 49.6 to 68.5 & 20.2 to 21.6 & 7.33 to 9.68 & 21.1 \\
\hline 500 & 43.6 to 60.7 & 18.7 to 20.9 & 6.47 to 8.53 & 19.7 \\
\hline 700 & 55.7 to 77.3 & 19.9 to 21.5 & 8.11 to 10.5 & 22.2 \\
\hline \multicolumn{5}{|l|}{ Invessel release } \\
\hline 100 & 368 to 783 & 28.9 to 33.5 & 4.92 to 7.33 & 47.1 \\
\hline 200 & 406 to 1387 & 27.3 to 34.5 & 4.46 to 8.93 & 54.7 \\
\hline 300 & 570 to 1871 & 25.9 to 31.3 & 4.93 to 7.24 & 51.0 \\
\hline 500 & 197 to 413 & 24.7 to 29.0 & 4.08 to 5.16 & 36.1 \\
\hline 700 & 189 to 333 & 28.6 to 30.4 & 5.08 to 7.34 & 34.0 \\
\hline \multicolumn{5}{|c|}{$\begin{array}{l}{ }^{*} 90 \text { percent confidence level. } \\
* * 0 \text { percent confidence level. }\end{array}$} \\
\hline
\end{tabular}




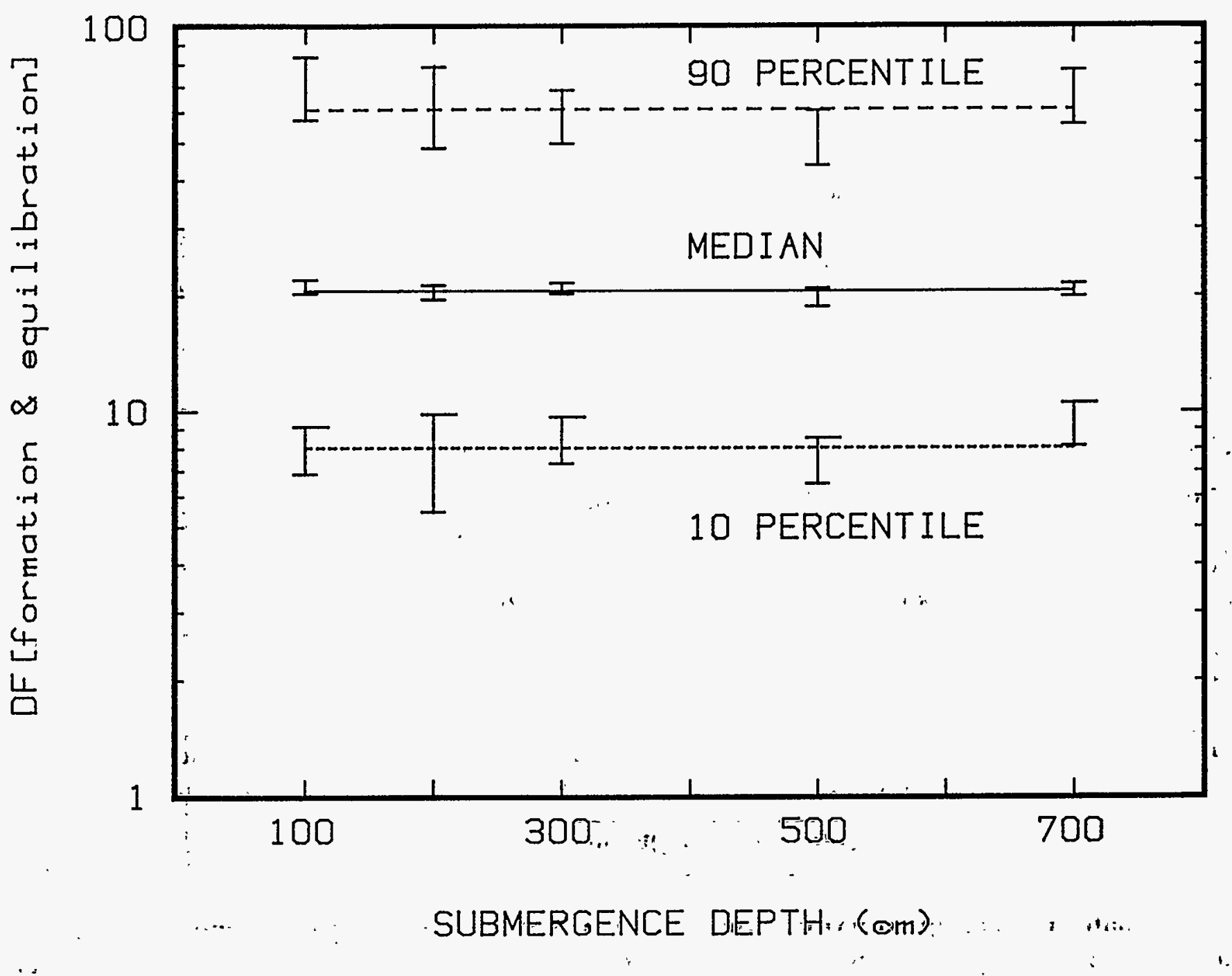

Figure 107. Variation of $\mathrm{DF}(\mathrm{FE})$ during gap release through a ' $\mathrm{T}$ ' quencher with quencher submergence 


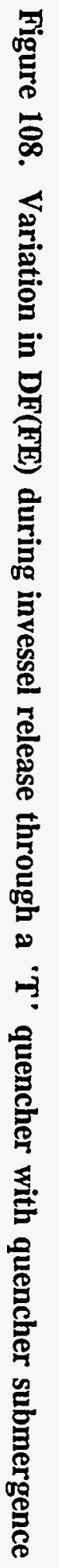

DF [formation \& equilibration]

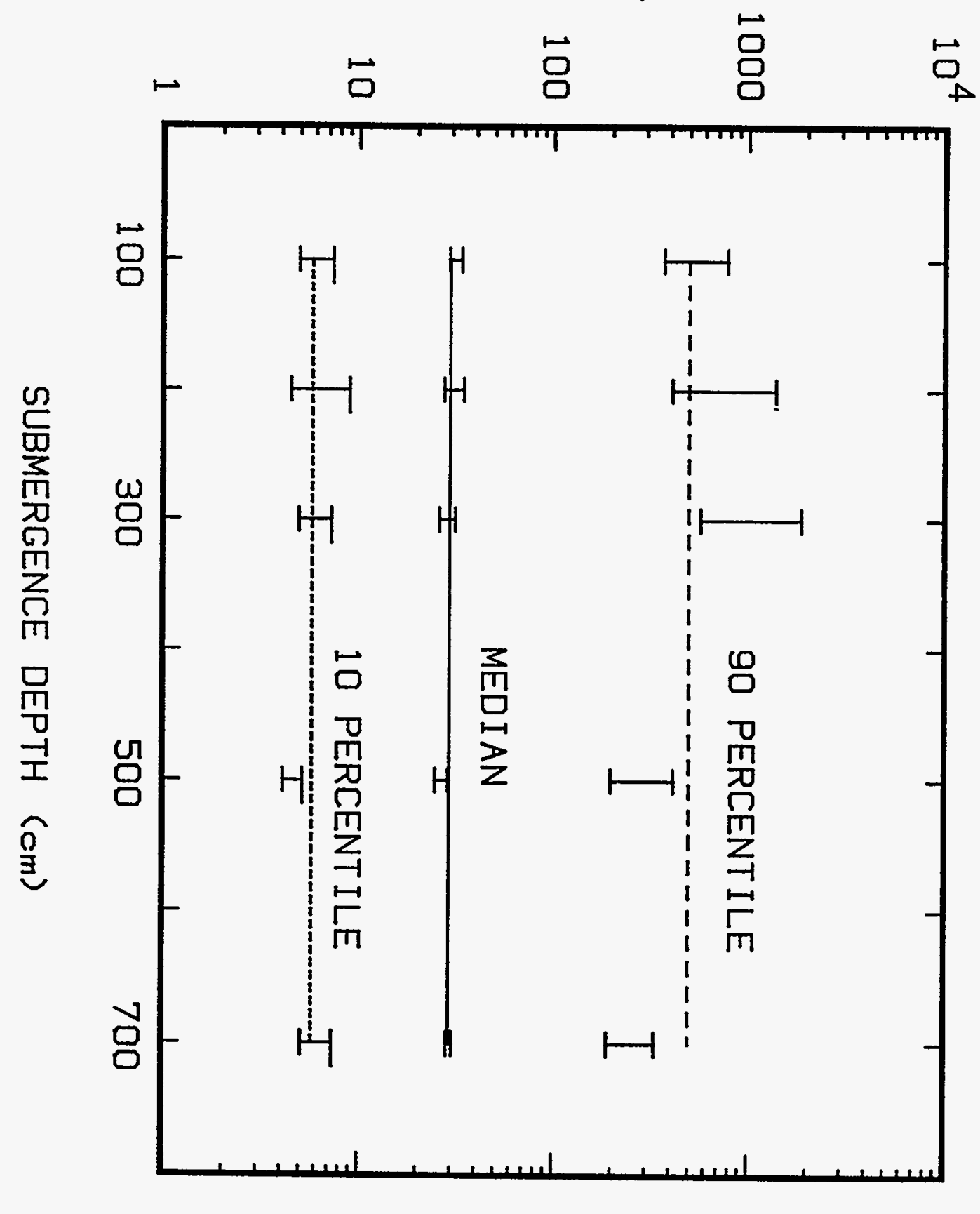


Results

- Mean

$\log _{10} \mathrm{DF}(\mathrm{FE})=1.326$

$\mathrm{DF}(\mathrm{FE})=21.2$

During invessel release through a ' $T$ ' quencher:

- Median (50 percentile)

$\log _{10} \mathrm{DF}(\mathrm{FE})=1.466$

$\mathrm{DF}(\mathrm{FE})=29.3$

- Lower Bound (10 percentile)

$\log _{10} \mathrm{DF}(\mathrm{FE})=0.760$

$\mathrm{DF}(\mathrm{FE})=5.8$

- Upper Bound (90 percéntile)

$\log _{10} \mathrm{DF}(\mathrm{FE})=2.695$

$\mathrm{DF}(\mathrm{FE})=495$

- Mean

$\log _{10} \mathrm{DF}(\mathrm{FE})=1.642$

$\mathrm{DF}(\mathrm{FE})=43.8$

Note that no statistical significance is ascribed here to the means of the samples taken to construct the uncertainty distributions for decontamination by bubble formation and equilibration. It is, however, interesting that the mean values are rather similar to the median values. It appears that theluncertainty distributions for the decontamination factors associated with bubble formation and equilibration âpproximate lognormal distributions.

The decontamination associated with bubble formation and equilibration is most significant since historically this decontamination has not been considered in analyses of bubble rise through water pools

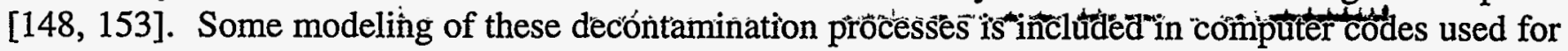
analyses of reactor accidents [6-9]. Systematic experimental studies of decontamination during the processes of bubble formation and equilibration have not been conducted. Rèesults obtained hiere, then are strictly the products of modeling described in Chapter IV of this report. It would be uisefuil to have some experimental validation of this modeling. Of panticular interest would be studies offethereffects of flow within the inflating bubble and the effects of bubble disintegration and coalescence on decontamination.

Much more attention has been devoted to decontamination of aerosol-laden gas bubbles as they rise through water pools. Results obtained here for decontamination as bubbles rise through suppression pools after emerging from ' $T$ ' quenchers are summarized in Table 30. Decontamination factors associated with bubble rise, $\mathrm{DF}$ (rise), are dependent on the submergences of the quenchers within the pools as is evident 
Table 30. Summary of the uncertainty distributions for the decontamination factor associated with bubble rise through a suppression pool during gap release and invessel release through a ' $T$ ' quencher

\begin{tabular}{|c|c|c|c|c|}
\hline \multirow{2}{*}{$\begin{array}{c}\text { Quencher } \\
\text { submergence } \\
\text { (cm) }\end{array}$} & \multicolumn{3}{|c|}{ Decontamination Factor, DF (rise) } & \multirow[b]{2}{*}{ Mean } \\
\hline & $\begin{array}{l}\text { Upper bound } \\
\text { (90 percentile*) }\end{array}$ & $\begin{array}{c}\text { Median } \\
\text { (50 percentile**) }\end{array}$ & $\begin{array}{l}\text { Lower bound } \\
\text { (10 percentile*) }\end{array}$ & \\
\hline \multicolumn{5}{|l|}{ Gap release } \\
\hline $\begin{array}{l}100 \\
200 \\
300 \\
500 \\
700\end{array}$ & $\begin{array}{c}2.56 \text { to } 3.93 \\
8.01 \text { to } 16.6 \\
44.8 \text { to } 120 \\
118 \text { to } 762 \\
4900 \text { to } 37800\end{array}$ & $\begin{array}{l}1.33 \text { to } 1.43 \\
2.44 \text { to } 2.70 \\
3.35 \text { to } 3.76 \\
5.52 \text { to } 7.14 \\
19.7 \text { to } 26.5\end{array}$ & $\begin{array}{l}1.10 \text { to } 1.13 \\
1.27 \text { to } 1.44 \\
1.54 \text { to } 1.66 \\
1.96 \text { to } 2.24 \\
2.88 \text { to } 3.65\end{array}$ & $\begin{array}{l}1.66 \\
3.24 \\
6.71 \\
13.6 \\
82.4\end{array}$ \\
\hline \multicolumn{5}{|l|}{ Invessel release } \\
\hline $\begin{array}{l}100 \\
200 \\
300 \\
500 \\
700\end{array}$ & $\begin{array}{c}5.70 \text { to } 11.4 \\
78.7 \text { to } 447 \\
320 \text { to } 1570 \\
2900 \text { to } 3100 \\
11900 \text { to } 292000\end{array}$ & $\begin{array}{l}1.72 \text { to } 2.12 \\
3.42 \text { to } 3.94 \\
5.42 \text { to } 6.22 \\
12.4 \text { to } 17.1 \\
24.4 \text { to } 39.9\end{array}$ & $\begin{array}{l}1.10 \text { to } 1.16 \\
1.30 \text { to } 1.53 \\
1.51 \text { to } 1.89 \\
2.08 \text { to } 2.54 \\
2.94 \text { to } 3.74\end{array}$ & $\begin{array}{c}2.69 \\
8.55 \\
16.0 \\
47.6 \\
153\end{array}$ \\
\hline
\end{tabular}


from plots of $\mathrm{DF}$ (rise) against submergence shown in Figures 109 and 110 for the gap release and invessel release phases of an accident, respectively.

The first notable feature of the uncertainty distributions for decontamination during bubible rise is that these distributions are much wider as measured by the range from the 10 percentile to the 90 percentile. Much of this breadth is actually between the medians and the 90 percentiles. Combinations of small bubble size and large aerosol particles can lead to very extensive decontamination.

The next noticeable feature of results obtained here for $\mathrm{DF}$ (rise) is that values of the decontamination factor at the medians and 10 percentiles of the distributions are not large relative to décontamination produced by formation and equilibration of bubbles. Restricting attentions to median values, $\mathrm{DF}$ (rise) becomes comparable to $\mathrm{DF}(\mathrm{FE})$ only at the deepest submergences considered here.

Decontamination of aerosol-laden bubbles as they rise through the suppression! pool iș: suppressed by the evaporation of water into the bubble as hydrostatic head is lost. (Note that this ev been overlooked in many classic treatments of bubble decontamination $[148,153]$ thoügh it has been included in models used for reactor accident analyses [6-9]). Plume effects shorten the:opportunity for decontamination before the bubble reaches the pool surface.

The analyses here have included an effect that does produce decontamination dưring bubble rise. Bubbles that are large-enough will oscillate and undergo shape deformations as they rise. The movements of the bubble walls will sweep out particles too large to respond to the gas imotions within the bubbles induced by bubble deformations. The authors are uñaware of experimê̆̀ntal studies of decontamination by shape oscillations that would validate the model of this process:adopted here.

The results obtained for decontamination during bubble rise can be correlated lineatily=with quencher submergence, H. During the gap release phase:

- Median (50 percentile)

$\log _{10} \mathrm{DF}($ rise $)=-0.03007+1.892 \times 10^{-3} \mathrm{H}(\mathrm{cm})$
$\mathrm{DF}($ rise $)=10$

- Lower Bound (10 percentile)

$\log _{10} \mathrm{DF}$ (rise) $=-0.02609+0.746 \times 10^{-3} \mathrm{H}(\mathrm{cm})$
$\mathrm{DF}($ rise $)=10$

- Upper Bound (90 percentile)

$\log _{10} \mathrm{DF}$ (rise) $=-0.07191+5.777 \times 10^{-3} \mathrm{H}(\mathrm{cm})$
$\mathrm{DF}($ rise $)=10[(\mathrm{H}-12.4) / 173]$

- Mean

$\log _{10} \mathrm{DF}($ rise $)=-0.04374+2.681 \times 10^{-3} \mathrm{H}(\mathrm{cm})$
$\mathrm{DF}($ rise $)=10(\mathrm{H}-16.3) / 373]$ 


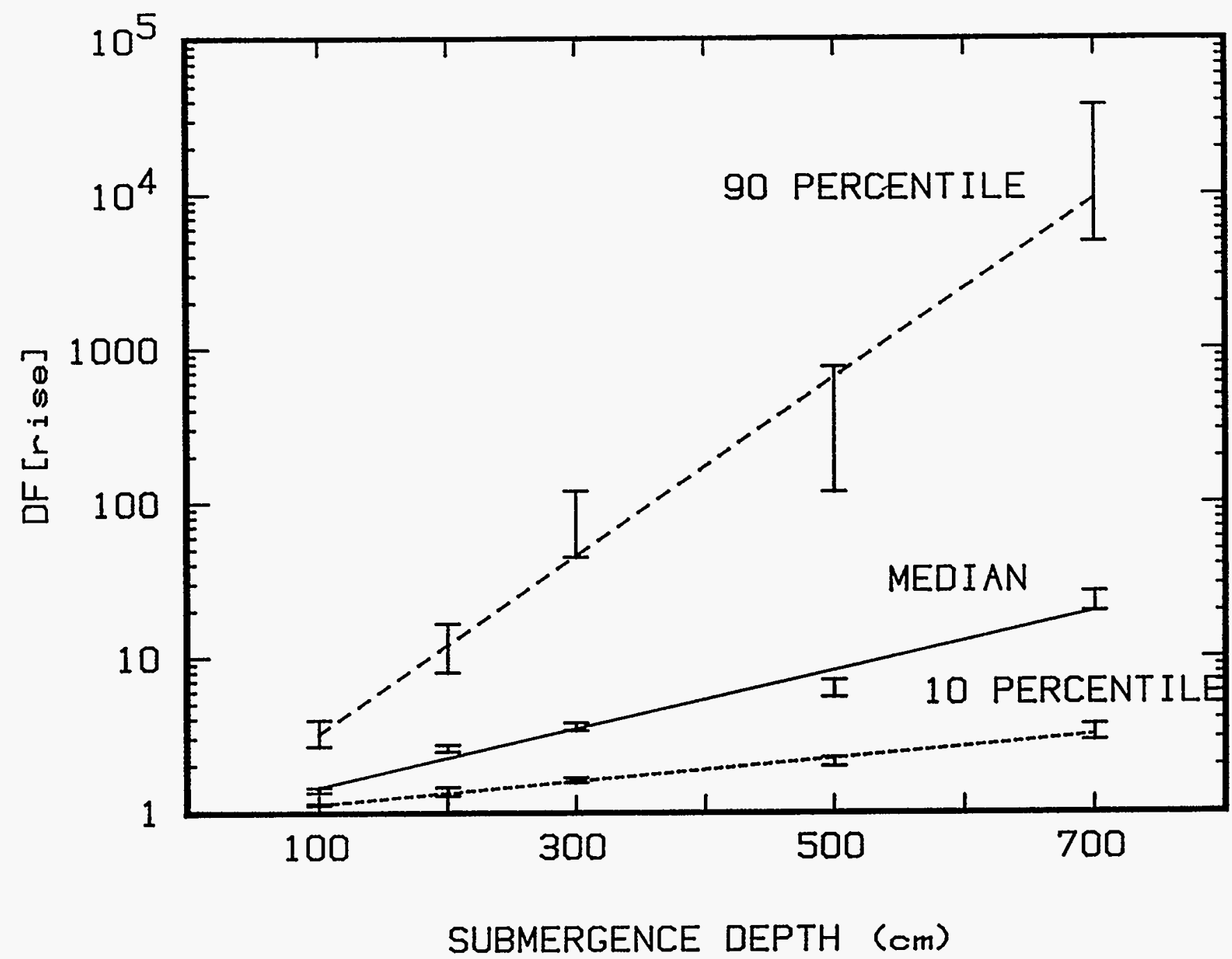

Figure 109. Variation in $\mathrm{DF}$ (rise) for gap release through a ' $\mathrm{T}$ ' quencher with quencher submergence. The solid line are fits to medians of the uncertainty distributions. Dashed lines are fits to the midpoints of ranges for the $\mathbf{1 0}$ and $\mathbf{9 0}$ percentiles of the distributions. 
$\stackrel{w}{\sigma}$

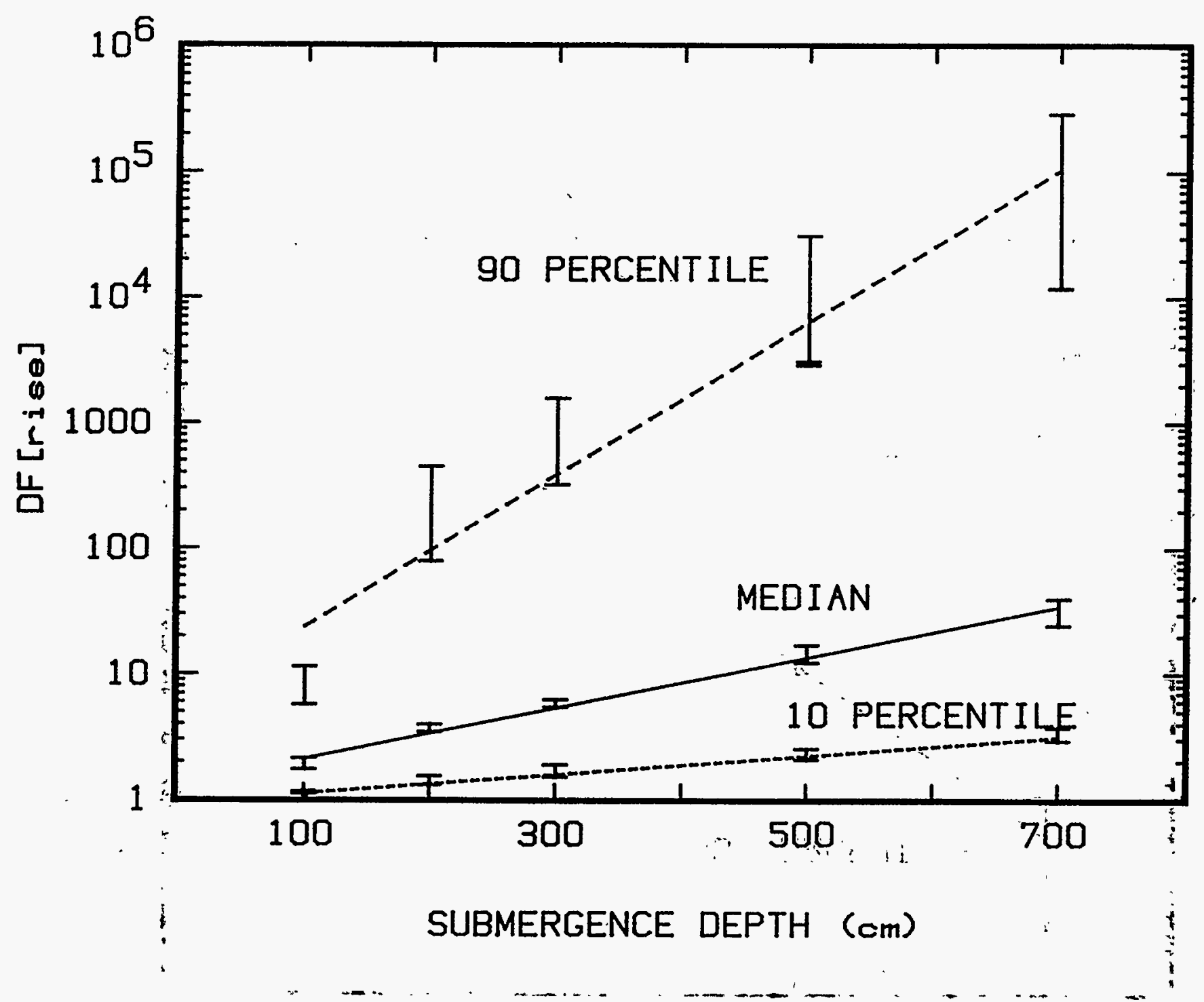

Figure 110. Variation in $\mathrm{DF}$ (rise) for invessel release through a ' $\mathrm{T}$ ' quencher with quencher submergence 
The correlations do not extrapolate to $\mathrm{DF}$ (rise) $=1$ (no decontamination) at zero submergence. This is because the decontamination processes considered in the definition of $\mathrm{DF}$ (rise) were assumed inoperative in the injection zone between the quencher orifice and the point at which bubbles had equilibrated with the suppression pool.

Similar correlations of $\mathrm{DF}($ rise) with quencher submergence during the invessel release phase are:

- Median (50 percentile)

$\log _{10} \mathrm{DF}$ (rise) $=0.1204+2: 021 \times 10^{-3} \mathrm{H}(\mathrm{cm})$

$\mathrm{DF}($ rise $)=10^{[(\mathrm{H}+59.6) / 495]}$

- Lower Bound (10 percentile)

$\log _{10} \mathrm{DF}$ (rise) $=-0.0261+0.746 \times 10^{-3} \mathrm{H}(\mathrm{cm})$

$\mathrm{DF}$ (rise) $=10^{[\mathrm{H}-35) / 1340]}$

- Upper Bound (90 percentile)

$\log _{10} \mathrm{DF}$ (rise) $=0.770+6.07 \times 10^{-3} \mathrm{H}(\mathrm{cm})$

$\mathrm{DF}$ (rise) $=10^{[(\mathrm{H}+127) / 165]}$

- Mean

$\log _{10} \mathrm{DF}($ rise $)=0.286+2.78 \times 10^{-3} \mathrm{H}(\mathrm{cm})$

$\mathrm{DF}($ rise $)=10^{[\mathrm{H}+103) / 360]}$

Note that at the high levels of decontamination characteristic of deeper submergences, the logarithm of $\mathrm{DF}$ (rise) does not vary linearly with depth. This is because of changes in the size distribution caused by decontamination during bubble rise which is discussed further below. More complicated correlations would have to be developed to account for the decreasing efficiency of decontamination with depth and the effects of the injection zone described above. Suffice it to say here that these correlations ought not be extrapolated to deeper or shallower submergences than those considered in developing the correlations.

The total decontamination of aerosol-laden gases is, of course, the product of the effects of bubble formation and equilibration and the effects of bubble rise. Because there is some correlation of these effects in any of the samples used to construct the uncertainty distributions, the distributions for the decontamination by formation and equilibration cannot be simply combined with distributions for decontamination during bubble rise to produce a distribution for the total decontamination, DF(total). Instead, distributions for $\mathrm{DF}$ (total) have to be constructed from sampled results. The distributions for $\mathrm{DF}$ (total) during the gap release and invessel release phases of the accident are summarized in Table 31 . These results are also shown as plots of $\mathrm{DF}$ (total) against the assumed submergence of the ' $\mathrm{T}$ ' quencher in Figures 111and 112.

Note that the upper bound or 90 percentile values of the total decontamination factor exceed $10^{6}$ for the deeper submergences of the quencher. The authors are not persuaded that the models they have 
Table 31. Summary of the uncertainty distributions for the total decontamination factor for material released to a suppression pool during gap release and invessel release through a ' $T$ ' quencher

\begin{tabular}{|c|c|c|c|c|}
\hline \multirow{2}{*}{$\begin{array}{l}\text { Quencher } \\
\text { submergence } \\
\text { (cm) }\end{array}$} & \multicolumn{3}{|c|}{ Decontamination factor } & \multirow[b]{2}{*}{ Mean } \\
\hline & $\begin{array}{l}\text { Upper bound } \\
\text { (90 percentile*) }\end{array}$ & $\begin{array}{c}\text { Median } \\
\text { (50 percentile**) }\end{array}$ & $\begin{array}{l}\text { Lower bound } \\
\text { (10 percentile*) }\end{array}$ & \\
\hline \multicolumn{5}{|l|}{ Gap release } \\
\hline $\begin{array}{l}100 \\
200 \\
300 \\
500 \\
700\end{array}$ & $\begin{array}{c}115 \text { to } 146 \\
257 \text { to } 557 \\
1190 \text { to } 3400 \\
2450 \text { to } 15600 \\
146000 \text { to } 1.3 \times 10^{6}\end{array}$ & $\begin{array}{l}31.8 \text { to } 36.2 \\
58.6 \text { to } 64.3 \\
85.5 \text { to } 93.8 \\
142 \text { to } 163 \\
497 \text { to } 721\end{array}$ & $\begin{array}{l}9.59 \text { to } 13.0 \\
13.7 \text { to } 20.5 \\
17.7 \text { to } 24.0 \\
18.8 \text { to } 36.0 \\
42.2 \text { to } 63.0\end{array}$ & $\begin{array}{c}36.5 \\
67.9 \\
142 \\
269 \\
1840\end{array}$ \\
\hline \multicolumn{5}{|l|}{ Invessel release } \\
\hline $\begin{array}{l}100 \\
200 \\
300 \\
500 \\
700\end{array}$ & $\begin{array}{c}1020 \text { to } 7130 \\
11900 \text { to } 244000 \\
73500 \text { to } 1.3 \times 10^{6} \\
395000 \text { to } 15 \times 10^{6} \\
2.3 \times 10^{6} \text { to } 22 \times 10^{6}\end{array}$ & $\begin{array}{l}64.4 \text { to } 71.6 \\
147 \text { to } 200 \\
214 \text { to } 275 \\
440 \text { to } 548 \\
895 \text { to } 1580\end{array}$ & $\begin{array}{l}7.11 \text { to } 11.4 \\
10.8 \text { to } 19.8 \\
14.6 \text { to } 22.2 \\
13.2 \text { to } 26.3 \\
28.0 \text { to } 49.5\end{array}$ & $\begin{array}{c}127 \\
468 \\
820 \\
1720 \\
52000\end{array}$ \\
\hline $\begin{array}{l}* 90 \text { percent confid } \\
* * 50 \text { percent confic }\end{array}$ & $\begin{array}{l}\text { vel.: } \\
\text { vel. }\end{array}$ & & & \\
\hline
\end{tabular}

*90 percent confidence level. 
Results

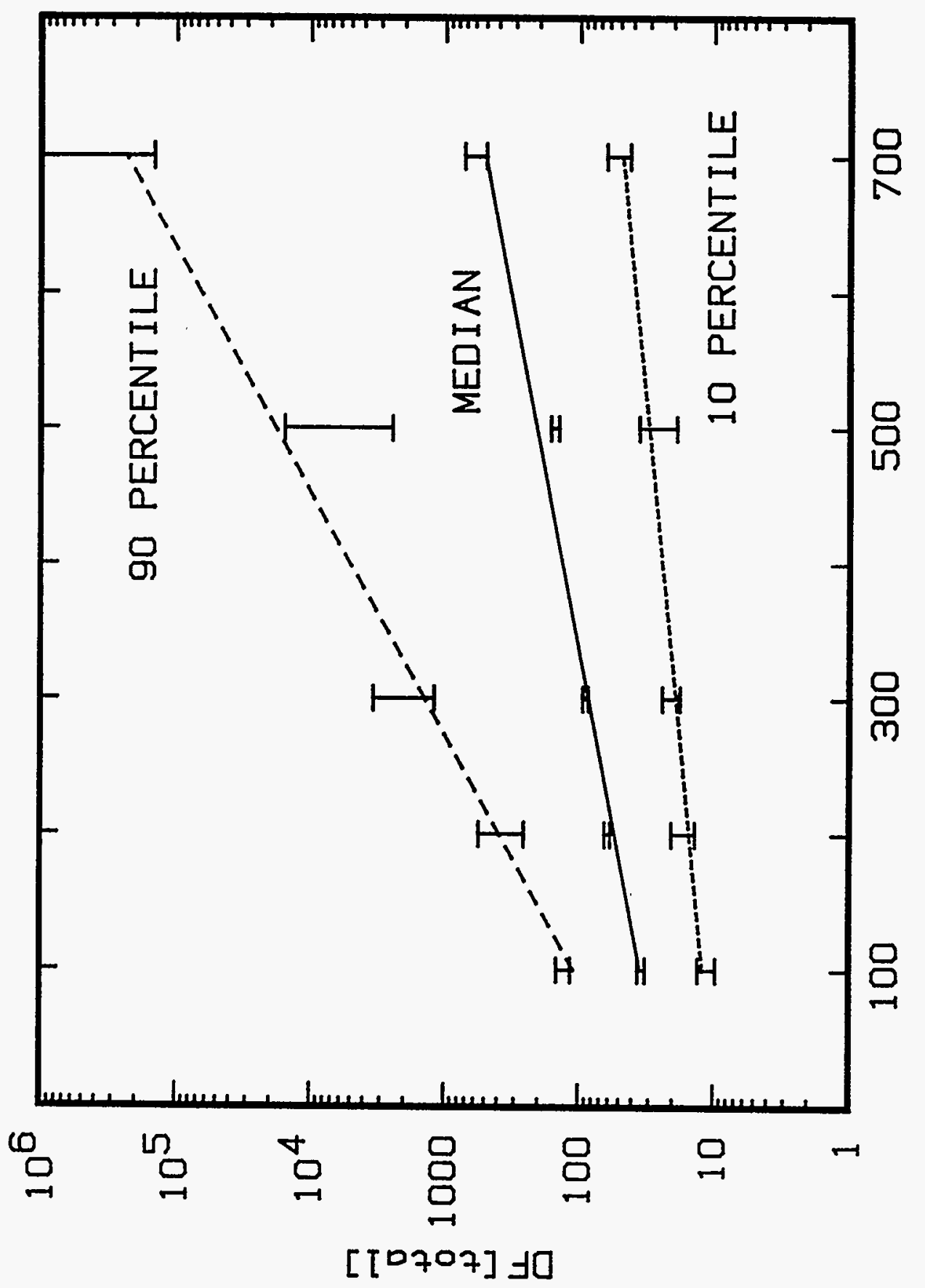

䓪 


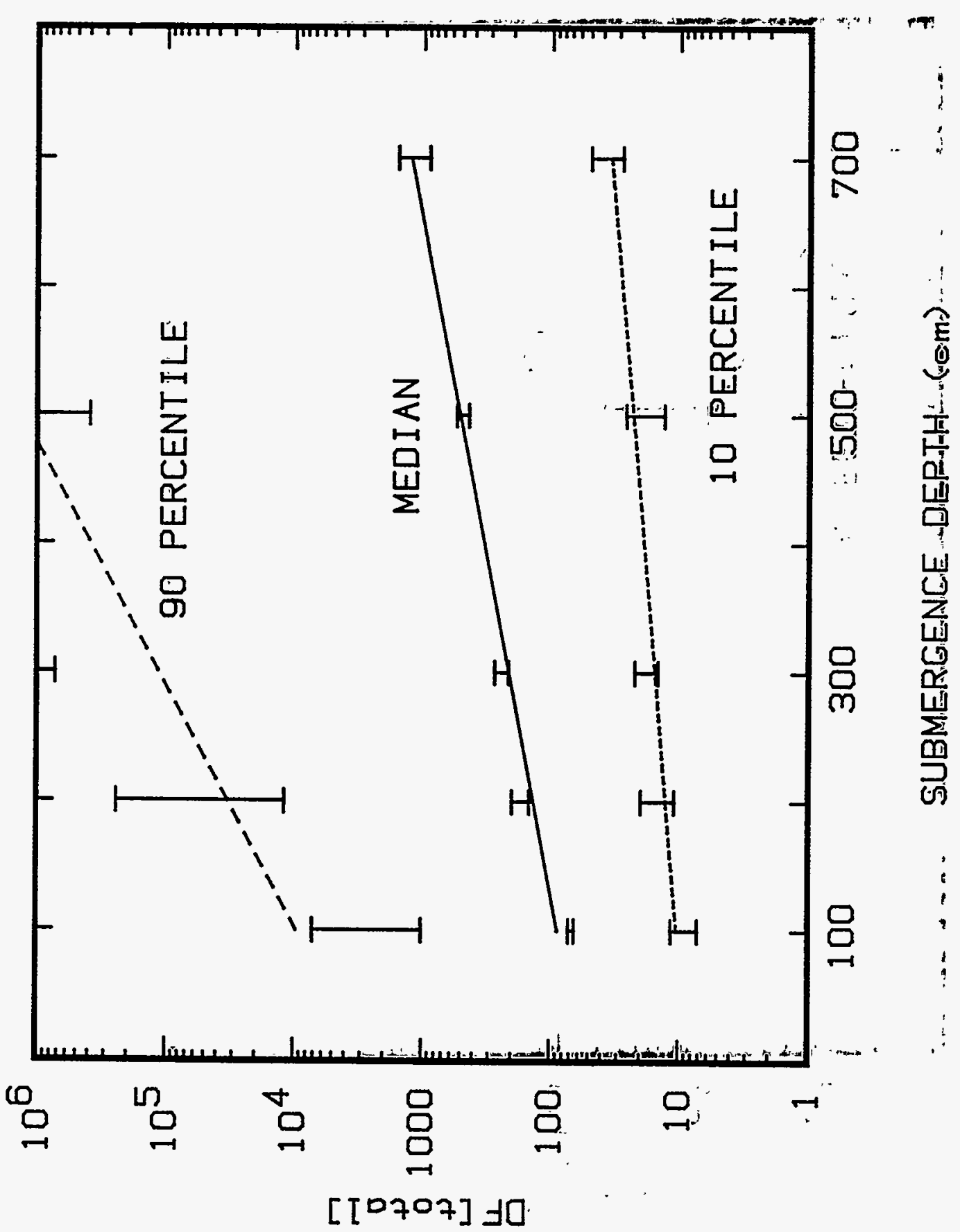

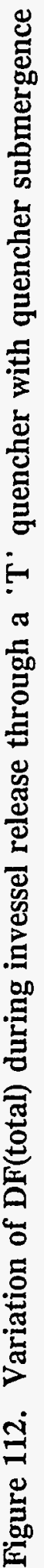


used are sufficiently accurate to place much faith in such nearly quantitative decontamination. To be sure, the models used here have neglected re-entrainment of contaminated liquids when bubbles break at the pool surface. Such re-entrainment, especially later in an accident, will limit the apparent decontamination based on the radioactivity of gases above a water pool to values of about $10^{6}$. Consequently, the authors recommend that decontamination factors calculated to be greater than $10^{6}$ be interpreted as $10^{6}$.

The efficiencies of many of the processes that lead to decontamination are dependent on the aerosol particle size. Certainly, this is true for decontamination during bubble formation and during bubble rise. Particle-size dependence of decontamination during bubble equilibration is expected to be small and has been neglected here.

Because of the particle-size dependencies of the decontamination processes, the size distribution of aerosols that do emerge from the suppression pool can be quite different than the size distributions of the aerosols that enter the suppression pool. Typically, it is found that the decontamination processes are very efficient for very large and very small aerosol particles, but there is an intermediate particle size for which the combination of all aerosol removal processes has minimal efficiency. As discussed at some length in Chapter IV, the size of minimal removal efficiency is sensitive to details of the modeling. Notably, it is sensitive to removal by inertial impaction modeling both during bubble formation and bubble rise.

Because of the size dependence of aerosol removal processes, the aerosol that emerges from the suppression pool will have a size distribution that is narrower than the size distribution injected into the pool. The mean of the size distribution of aerosol emerging from the pool will be shifted toward the size of minimal aerosol removal efficiency. As decontamination progresses the aerosol size distribution will become very sharply peaked at this size of minimum removal efficiency. The rate of decontamination drops from high values when large or small particles were being rapidly removed to the minimal rate.

These expectations concerning the changes of the aerosol size distribution caused by passage through the suppression pool are reflected in the results obtained here. The size distribution of aerosol emerging from the pool was characterized by a mass weighted mean $\mathrm{d}_{\mathrm{p}}(\mu \mathrm{m})$, and a standard deviation, $\sigma$. Uncertainty distributions for $d_{p}(\mu \mathrm{m})$ and $\sigma$ are summarily described in Tables 32 and 33. Values of $\mathrm{d}_{\mathrm{p}}(\mu \mathrm{m})$ and $\sigma$ are plotted against the assumed submergence of the ' $\mathrm{T}$ ' quencher in Figures 113 to 116.

The characteristic features of the mean particle size decrease modestly with increasing submergence of the ' $T$ ' quencher. Much of the change in the size distribution occurs by very rapid removal of large and small particles during bubble formation and over rise distances of less that one meter. Continued change in the size distribution is not rapid because particles that remain in bubbles are difficult to remove. Some removal does still occur preferentially at the tails of the distributions since the standard deviations decrease with increasing submergence of the ' $T$ ' quencher.

Interestingly, the mean size of aerosol emerging from the suppression pool is consistently smaller during the gap release phase of the accident than during the invessel release phase. This is largely due to:

- somewhat smaller bubbles are, on average, expected to be present during the gap release phase, and 
Table 32. Summary of the uncertainty distributions for the mean size of aerosol particles emerging from a suppression pool during gap release and invessel release through a ' $T$ ' quencher

\begin{tabular}{|c|c|c|c|c|}
\hline \multirow{2}{*}{$\begin{array}{l}\text { Quencher } \\
\text { submergence } \\
\text { (cm) }\end{array}$} & \multicolumn{3}{|c|}{ Mean particle size $(\mu \mathrm{m})$} & \multirow[b]{2}{*}{ Mean } \\
\hline & $\begin{array}{l}\text { Upper bound } \\
(90 \text { percentile*) }\end{array}$ & $\begin{array}{c}\text { Median } \\
\left(50 \text { percentile }{ }^{* *}\right)\end{array}$ & $\begin{array}{l}\text { Lower bound } \\
\text { (10 percentile*) }\end{array}$ & \\
\hline \multicolumn{5}{|l|}{ Gap release } \\
\hline $\begin{array}{l}100 \\
200 \\
300 \\
500 \\
700\end{array}$ & $\begin{array}{l}0.143 \text { to } 0.166 \\
0.139 \text { to } 0.159 \\
0.137 \text { to } 0.149 \\
0.139 \text { to } 0.160 \\
0.143 \text { to } 0.154\end{array}$ & $\begin{array}{l}0.094 \text { to } 0.097 \\
0.097 \text { to } 0.101 \\
0.100 \text { to } 0.103 \\
0.102 \text { to } 0.105 \\
0.109 \text { to } 0.1 \overline{1} 1\end{array}$ & $\begin{array}{l}0.079 \text { to } 0.081 \\
0.081 \text { to } 0.084 \\
0.082 \text { to } 0.085 \\
0.084 \text { to } 0.089 \\
0.088 \text { to } 0.093\end{array}$ & $\begin{array}{l}0.105 \\
0.104 \\
0.106 \\
0.108 \\
0.113\end{array}$ \\
\hline$\frac{\text { Invessel release }}{-}$ & $\vdots$ & & & \\
\hline $\begin{array}{r}100 \\
2000 \\
3,00 \\
5.00 \\
7.00 \\
\end{array}$ & $\begin{array}{l}0.508 \text { to } 0.573 \\
0.634 \text { to } 0.771 \\
0.517 \text { to } 0.655 \\
0.482 \text { to } 0.569 \\
0.464 \text { to } 0.617\end{array}$ & $\begin{array}{l}0.302 \text { to } 0.319 \\
0.313 \text { to } 0.331 \\
0.268 \text { to } 0.281 \\
0.251 \text { to } 0.265 \\
0.245 \text { to } 0.251\end{array}$ & $\begin{array}{l}0.174 \text { to } 0.195 \\
0.147 \text { to } 0.180 \\
0.147 \text { to } 0.166 \\
0.138 \text { to } 0.154 \\
0.127 \text { to } 0.143\end{array}$ & $\begin{array}{l}0.331 \\
0.330 \\
0.289 \\
0.270 \\
0.258\end{array}$ \\
\hline \multicolumn{2}{|c|}{$\begin{array}{l}* 90 \text { percent confidence level. } \\
* * 50 \text { percent confidence level. }\end{array}$} & . & & $\cdots$ \\
\hline
\end{tabular}

**50 percént confidence level 
Table 33. Summary of the uncertainty distributions for the standard deviation of the size distribution of aerosol particles emerging from a suppression pool during gap release and invessel release through a ' $T$ ' quencher

\begin{tabular}{|c|c|c|c|c|}
\hline \multirow{2}{*}{$\begin{array}{l}\text { Quencher } \\
\text { submergence } \\
\text { (cm) }\end{array}$} & \multicolumn{3}{|c|}{ Decontamination factor } & \multirow[b]{2}{*}{ Mean } \\
\hline & $\begin{array}{c}\text { Upper bound } \\
\text { (90 percentile*) }\end{array}$ & $\begin{array}{c}\text { Median } \\
\text { (50 percentile**) }\end{array}$ & $\begin{array}{l}\text { Lower bound } \\
\text { (10 percentile*) }\end{array}$ & \\
\hline \multicolumn{5}{|l|}{ Gap release } \\
\hline $\begin{array}{l}100 \\
200 \\
300 \\
500 \\
700\end{array}$ & $\begin{array}{l}1.604 \text { to } 1.644 \\
1.573 \text { to } 1.621 \\
1.562 \text { to } 1.594 \\
1.522 \text { to } 1.593 \\
1.474 \text { to } 1.531\end{array}$ & $\begin{array}{l}1.429 \text { to } 1.456 \\
1.409 \text { to } 1.436 \\
1.385 \text { to } 1.405 \\
1.370 \text { to } 1.379 \\
1.333 \text { to } 1.348\end{array}$ & $\begin{array}{l}1.221 \text { to } 1.261 \\
1.224 \text { to } 1.265 \\
1.211 \text { to } 1.241 \\
1.240 \text { to } 1.272 \\
1.203 \text { to } 1.222\end{array}$ & $\begin{array}{l}1.430 \\
1.415 \\
1.394 \\
1.388 \\
1.348\end{array}$ \\
\hline \multicolumn{5}{|l|}{ Invessel release } \\
\hline $\begin{array}{l}100 \\
200 \\
300 \\
500 \\
700\end{array}$ & $\begin{array}{l}1.801 \text { to } 1.921 \\
1.709 \text { to } 1.774 \\
1.678 \text { to } 1.744 \\
1.676 \text { to } 1.760 \\
1.540 \text { to } 1.661\end{array}$ & $\begin{array}{l}1.446 \text { to } 1.470 \\
1.311 \text { to } 1.370 \\
1.322 \text { to } 1.348 \\
1.277 \text { to } 1.328 \\
1.204 \text { to } 1.245\end{array}$ & $\begin{array}{l}1.030 \text { to } 1.090 \\
1.010 \text { to } 1.034 \\
1.007 \text { to } 1.026 \\
1.003 \text { to } 1.012 \\
1.002 \text { to } 1.012\end{array}$ & $\begin{array}{l}1.431 \\
1.333 \\
1.324 \\
1.302 \\
1.254\end{array}$ \\
\hline $\begin{array}{l}* 90 \text { percent confid } \\
* * 50 \text { percent confic }\end{array}$ & & & & \\
\hline
\end{tabular}




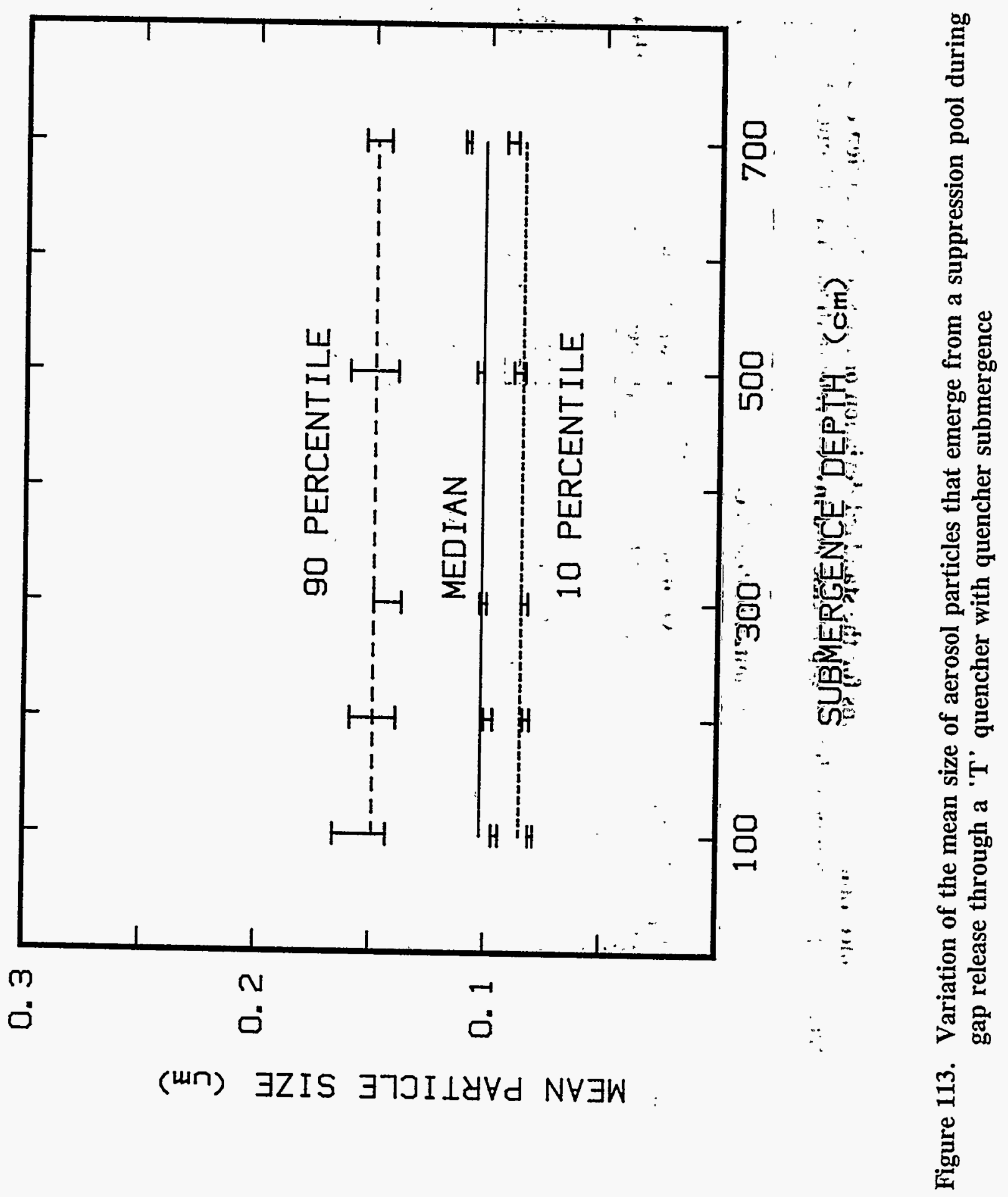




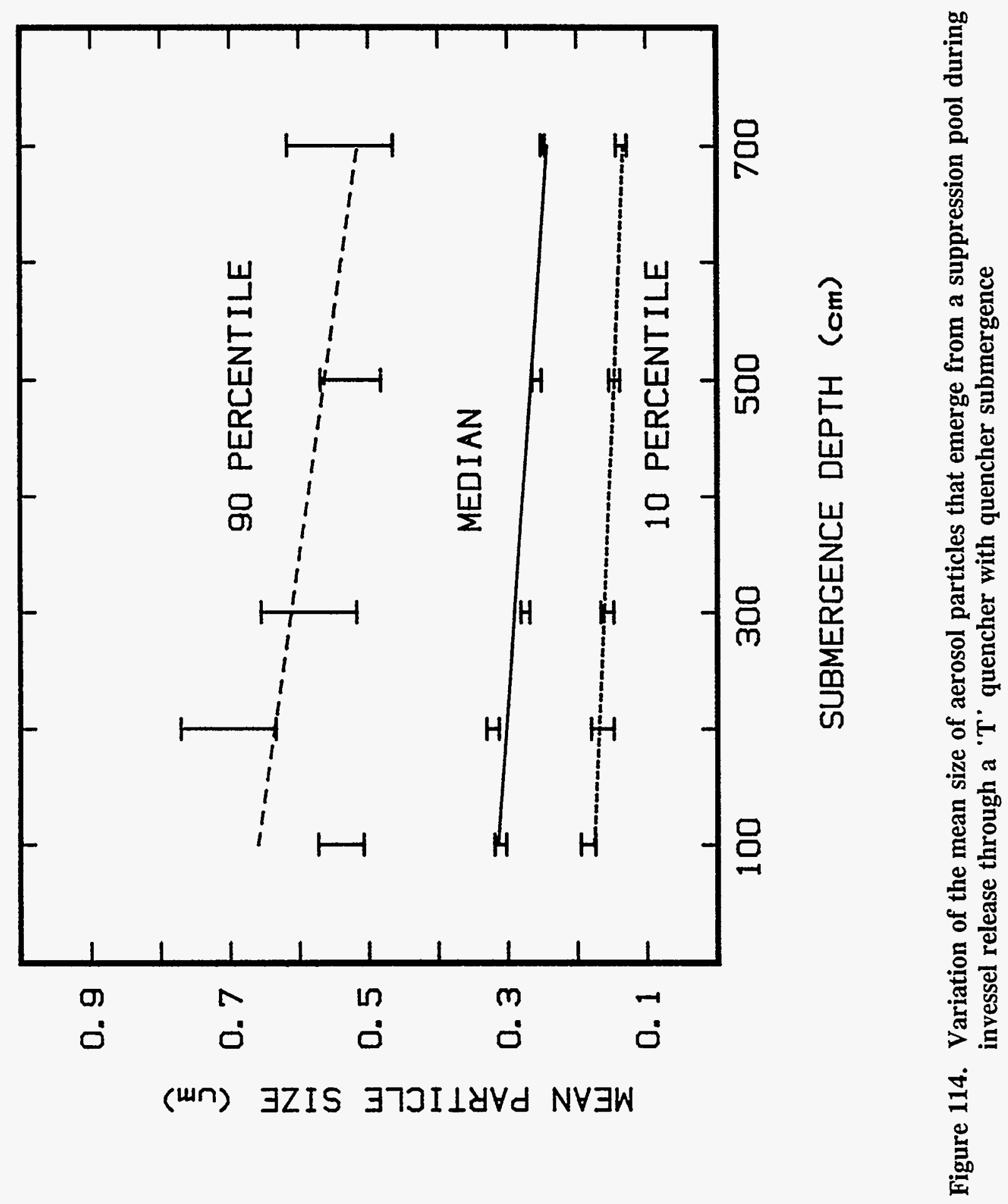




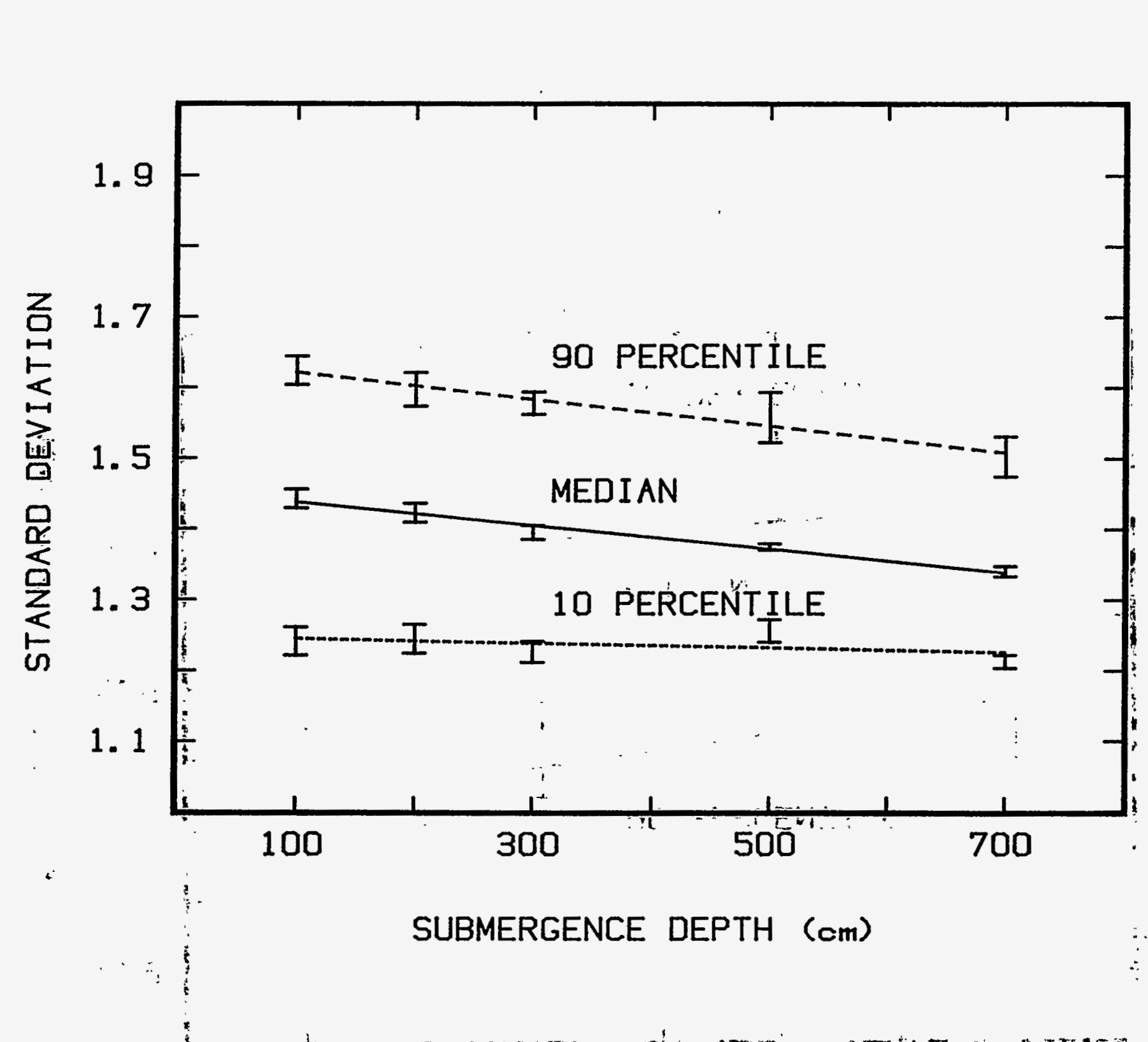

Figure 115. Variation of the standard deviation of the size distribution of aerosol particles that emerge from a suppression pool during gap release through a ' $T$ ' quencher with quencher submergence 


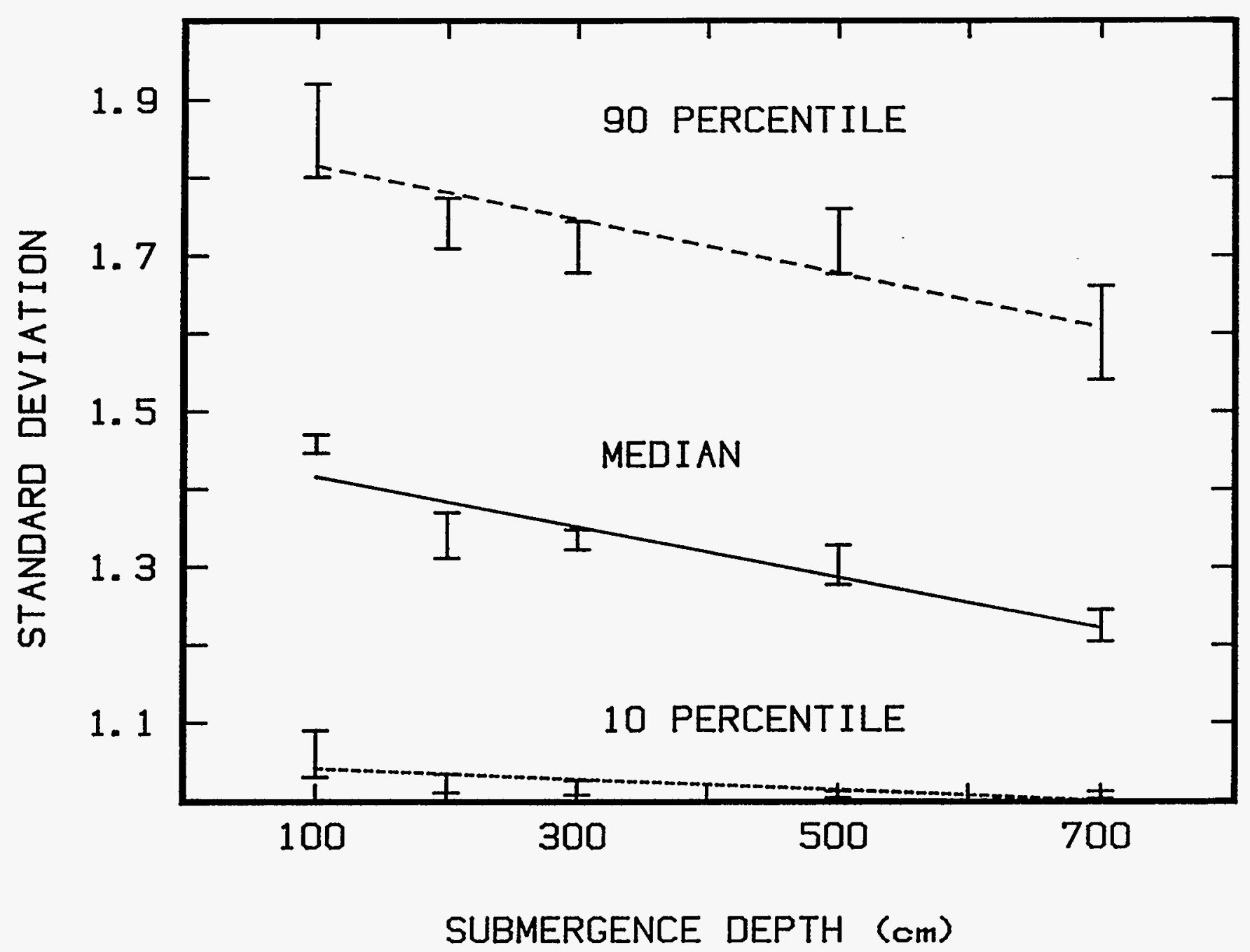

Figure 116. Variation of the standard deviation of the size distribution of aerosol particles that emerge from a suppression pool during invessel release through a ' $T$ ' quencher with quencher submergence 
- because much of the gas entering the suppression pool during the gap release phase is condensed, plume effects on the rise velocities of gas bubbles are smaller than during the invessel release phase.

It is noteworthy that the uncertainty distributions for the mean particle size of aerosol emerging from the pool are not especially large. Accurate measurements of the mean particle size.could be useful for validating the modeling used for this work, but would not be useful for identifying the causes of discrepancies between predictions and observations. Unfortunately, accurately measuring size distributions in the predicted range is challenging.

It should be noted also that the standard deviations of the size distributions found here are small, even at high percentiles of the uncertainty distributions, relative to standard deviations of size distributions measured for aerosols directly from the generation processes. To a defensible level of approximation, certainly at the 50 percentile range, aerosols that emerge from suppression pools are nearly monodisperse. (It was, in fact, for the purposes of generating monodisperse aeriosols that decontamination by bubble rises through water pools was first studied [148]). The_emerging particles from pools are narrowly distributed around size that are slow to be removed by the pool and often found to be only slowly removed by other processes including filtration and the actions of water sprays.

\section{B. Decontamination During Release Through ' $\mathbf{X}$ ' Quenchers}

Exploratory calculations suggested results obtained for decontamination of gap release material discharged through an ' $X$ ' quencher would be little different than results obtained for gap release through a ' $T$ ' quencher. Certainly, gap release is only a small fraction of the radioactivity released during a severe accident so whatever small differences arise between discharge to a pool thrọgh a ' $T$ ' quencher and discharge through an ' $\mathrm{X}$ ' quencher ought to be negligible.

Calculations were done for invessel release through an ' $\mathrm{X}$ ' quencher. Qualitatively, results were entirely analogous to results obtained for invessel release through a ' $T$ ' quencher. These-rresults for invessel release through ' $X$ ' quenchers are summarized in Tables 34 through 38 and are plotted against quencher submergence in Figures 117 through 121.

Correlations of the results obtained for decontamination by bubble formation and equilibrátion at an ' $\mathrm{X}$ ' quencher are:

- Median (50 percentile)

$\log _{10} \mathrm{DF}(\mathrm{FE})=1.640$

$\mathrm{DF}(\mathrm{FE})=43.6$

- Lower Bound (10 percentile)

$\log _{10} \mathrm{DF}(\mathrm{FE})=0.852$

$\mathrm{DF}(\mathrm{FE})=7.12$ 
Table 34. Summary of the uncertainty distributions for the decontamination factor associated with formation and equilibration of bubbles, $\mathrm{DF}(\mathrm{FE})$, during invessel release through an ' $X$ ' quencher

\begin{tabular}{ccccc}
\hline $\begin{array}{c}\text { Quencher } \\
\text { submergence } \\
\text { (cm) }\end{array}$ & $\begin{array}{c}\text { Decontamination factor, DF(FE) } \\
\text { Upper bound } \\
\text { (90 percentile*) }\end{array}$ & $\begin{array}{c}\text { Median } \\
\text { (50 percentile**) }\end{array}$ & $\begin{array}{c}\text { Lower bound } \\
\text { (10 percentile*) }\end{array}$ & Mean \\
\hline Invessel release & & & & \\
100 & 723 to 2930 & 49.4 to 62.2 & 7.11 to 8.89 & 91.4 \\
200 & 908 to 3910 & 43.4 to 51.3 & 6.65 to 8.79 & 63.8 \\
300 & 562 to 2170 & 36.1 to 40.0 & 6.10 to 7.89 & 55.1 \\
500 & 450 to 1770 & 35.6 to 44.6 & 6.22 to 8.32 & 61.9 \\
700 & 613 to 1900 & 34.7 to 46.6 & 4.53 to 7.98 & \\
\hline *90 percent confidence level. & & & \\
$*$ *50 percent confidence level. & & & \\
\hline
\end{tabular}


Table 35. Summary of the uncertainty distributions for the decontamination factor associated with bubble rise through a suppression pool, DF(rise), during invessel release through an ' $X$ ' quencher

\begin{tabular}{|c|c|c|c|c|}
\hline \multirow{2}{*}{$\begin{array}{c}\text { Quencher } \\
\text { submergence } \\
\text { (cm) }\end{array}$} & \multicolumn{3}{|c|}{ Decontamination factor, DF(rise) } & \multirow[b]{2}{*}{ Mean } \\
\hline & $\begin{array}{c}\text { Upper bound } \\
\text { (90 percentile*) }\end{array}$ & $\begin{array}{c}\text { Median } \\
(50 \text { percentile**) }\end{array}$ & $\begin{array}{l}\text { Lower bound } \\
\text { (10 percentile*) }\end{array}$ & \\
\hline \multicolumn{5}{|l|}{ Invessel release } \\
\hline $\begin{array}{l}100 \\
200 \\
300 \\
500 \\
700\end{array}$ & $\begin{array}{c}10.6 \text { to } 18.2 \\
56.0 \text { to } 180 \\
453 \text { to } 9910 \\
339000 \text { to } 6.2 \times 10^{6} \\
13000 \text { to } 828000\end{array}$ & $\begin{array}{l}1.86 \text { to } 2.01 \\
3.30 \text { to } 3.52 \\
5.75 \text { to } 16.87 \\
17.5 \text { to } 25.3 \\
36.1 \text { to } 54.0\end{array}$ & $\begin{array}{l}1.14 \text { to } 1.20 \\
1.28 \text { to } 1.44 \\
1.44 \text { to } 1.71 \\
1.88 \text { to } 3.30 \\
2.22 \text { to } 3.84\end{array}$ & $\begin{array}{l}2.94 \\
7.59 \\
18.0 \\
157 \\
162\end{array}$ \\
\hline
\end{tabular}


Table 36. Summary of the uncertainty distributions for the total decontamination factor, $\mathrm{DF}$ (total), for material released to a suppression pool during invessel release through an ' $X$ ' quencher

\begin{tabular}{ccccc}
\hline $\begin{array}{c}\text { Quencher } \\
\text { submergence } \\
\text { (cm) }\end{array}$ & $\begin{array}{c}\text { Upper bound } \\
\text { (90 percentile*) }\end{array}$ & $\begin{array}{c}\text { Median } \\
\text { (50 percentile*) }\end{array}$ & $\begin{array}{c}\text { Lower bound } \\
\text { (10 percentile*) }\end{array}$ & Mean \\
\hline Invessel Release & & & & \\
100 & 3890 to 27800 & 57.3 to 123 & 9.55 to 17.6 & 268 \\
200 & 7670 to 98400 & 179 to 223 & 13.4 to 21.1 & 679 \\
300 & 458000 to $3.3 \times 10^{6}$ & 232 to 360 & 13.8 to 27.2 & 1150 \\
500 & $3.3 \times 10^{6}$ to $656 \times 10^{6}$ & 1050 to 1860 & 19.8 to 45.2 & 8670 \\
700 & $2.8 \times 10^{6}$ to $1.5 \times 10^{9}$ & 2275 to 3860 & 27.7 to 70.3 & 9890 \\
\hline$* 90$ percent confidence level. & & & \\
$* * 50$ percent confidence level. & & & \\
\hline
\end{tabular}


Table 37. Summary of the uncertainty distributions for the mean size of aerosol particles emerging from a suppression pool during invessel release through an ' $\mathrm{X}$ ' quencher

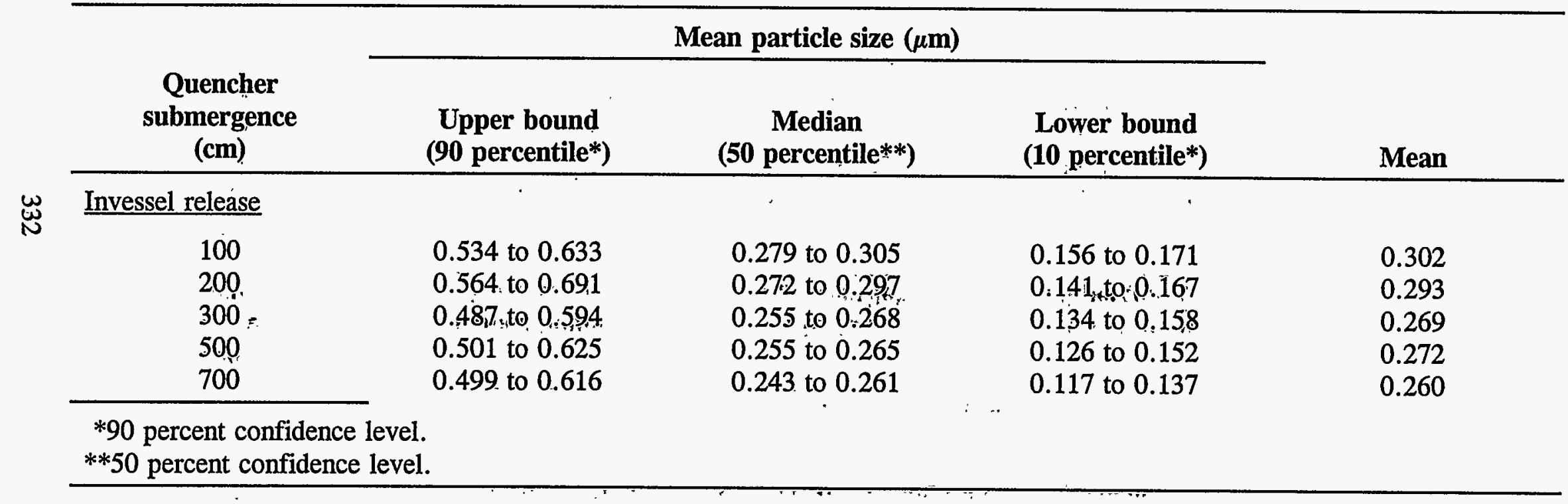


Table 38. Summary of the uncertainty distributions for the standard deviation of the size distributions of aerosol particles emerging from a suppression pool during invessel release through an ' $X$ ' quencher

\begin{tabular}{ccccc}
\hline $\begin{array}{c}\text { Quencher } \\
\text { submergence } \\
\text { (cm) }\end{array}$ & $\begin{array}{c}\text { Upper bound } \\
\text { (90 percentile*) }\end{array}$ & $\begin{array}{c}\text { Standard deviation, } \boldsymbol{~} \\
\text { (50 percentile**) }\end{array}$ & $\begin{array}{c}\text { Lower bound } \\
\text { (10 percentile*) }\end{array}$ & Mean \\
\hline Invessel Release & & & & \\
100 & 1.745 to 1.849 & 1.380 to 1.412 & 1.007 to 1.055 & 1.376 \\
200 & 1.688 to 1.776 & 1.329 to 1.362 & 1.002 to 1.019 & 1.330 \\
300 & 1.703 to 1.786 & 1.312 to 1.376 & 1.007 to 1.013 & 1.327 \\
500 & 1.613 to 1.701 & 1.191 to 1.244 & 1.0007 to 1.004 & 1.260 \\
700 & 1.523 to 1.641 & 1.127 to 1.175 & 1.0004 to 1.006 & 1.216 \\
\hline$* 90$ percent confidence level. & & & \\
$* * 50$ percent confidence level. & & & & \\
\hline
\end{tabular}




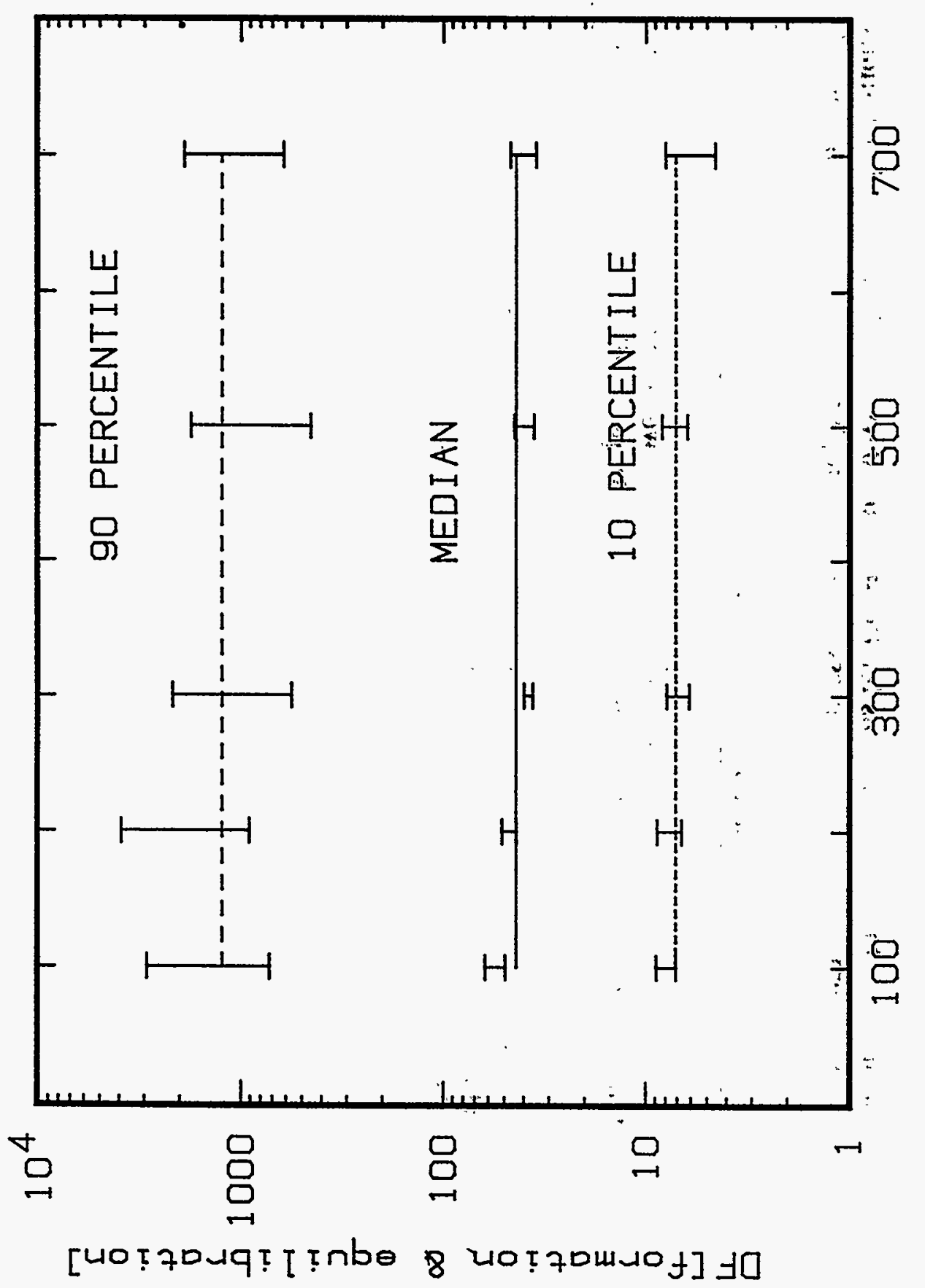

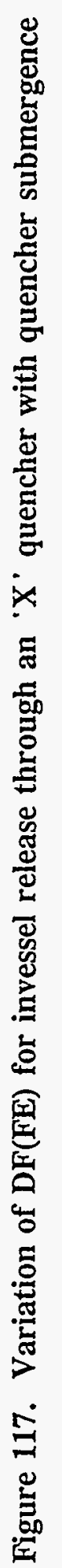




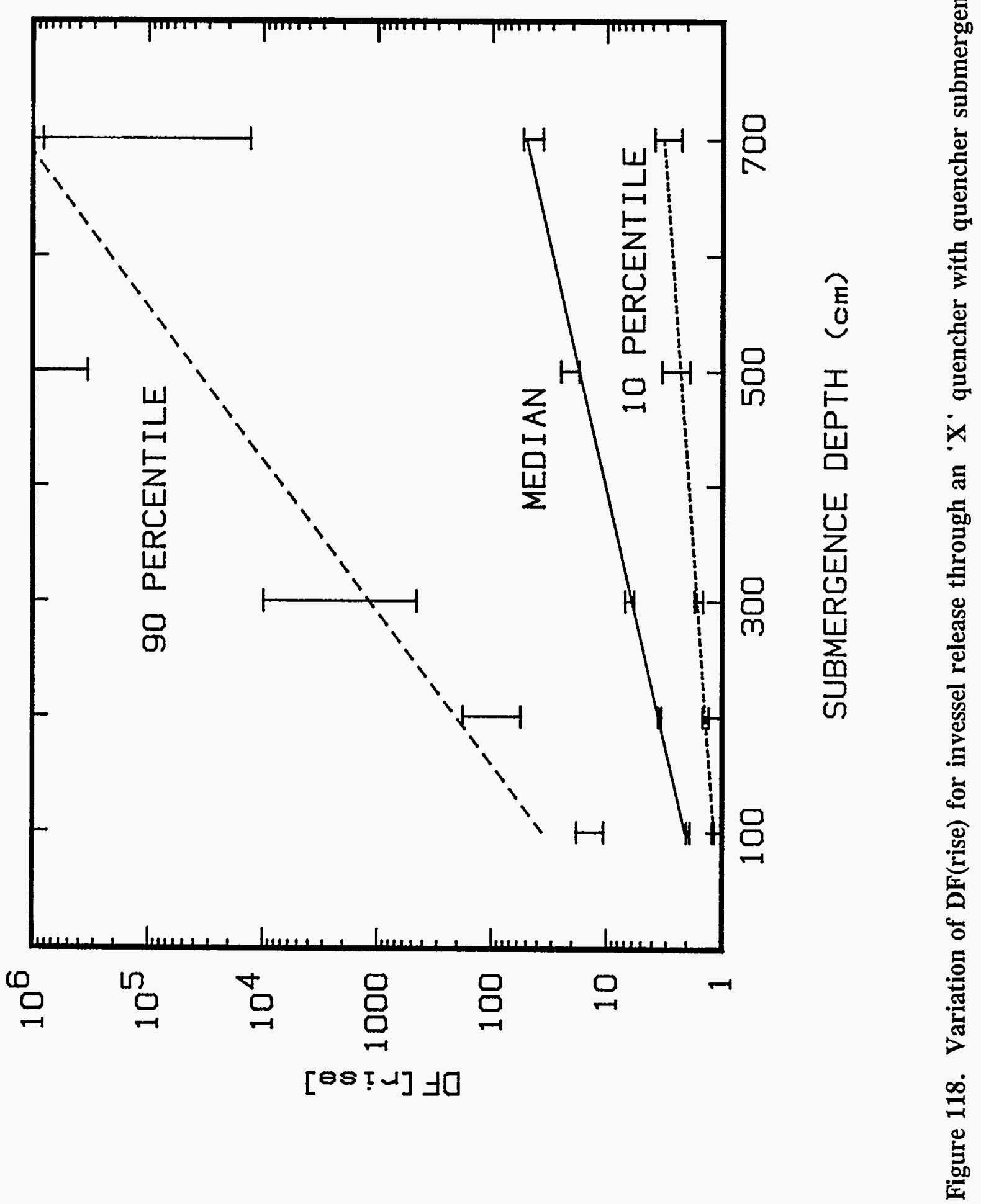




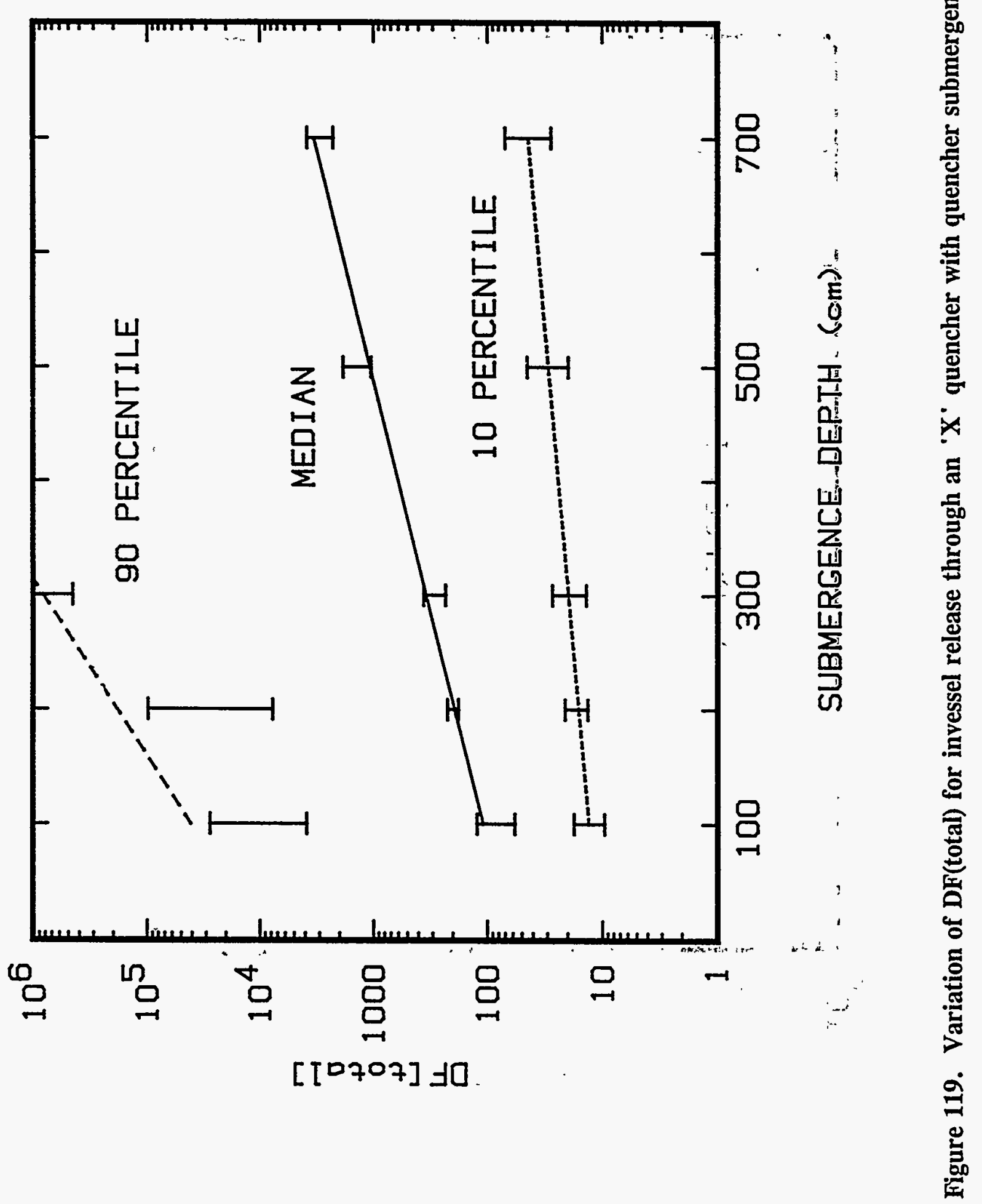



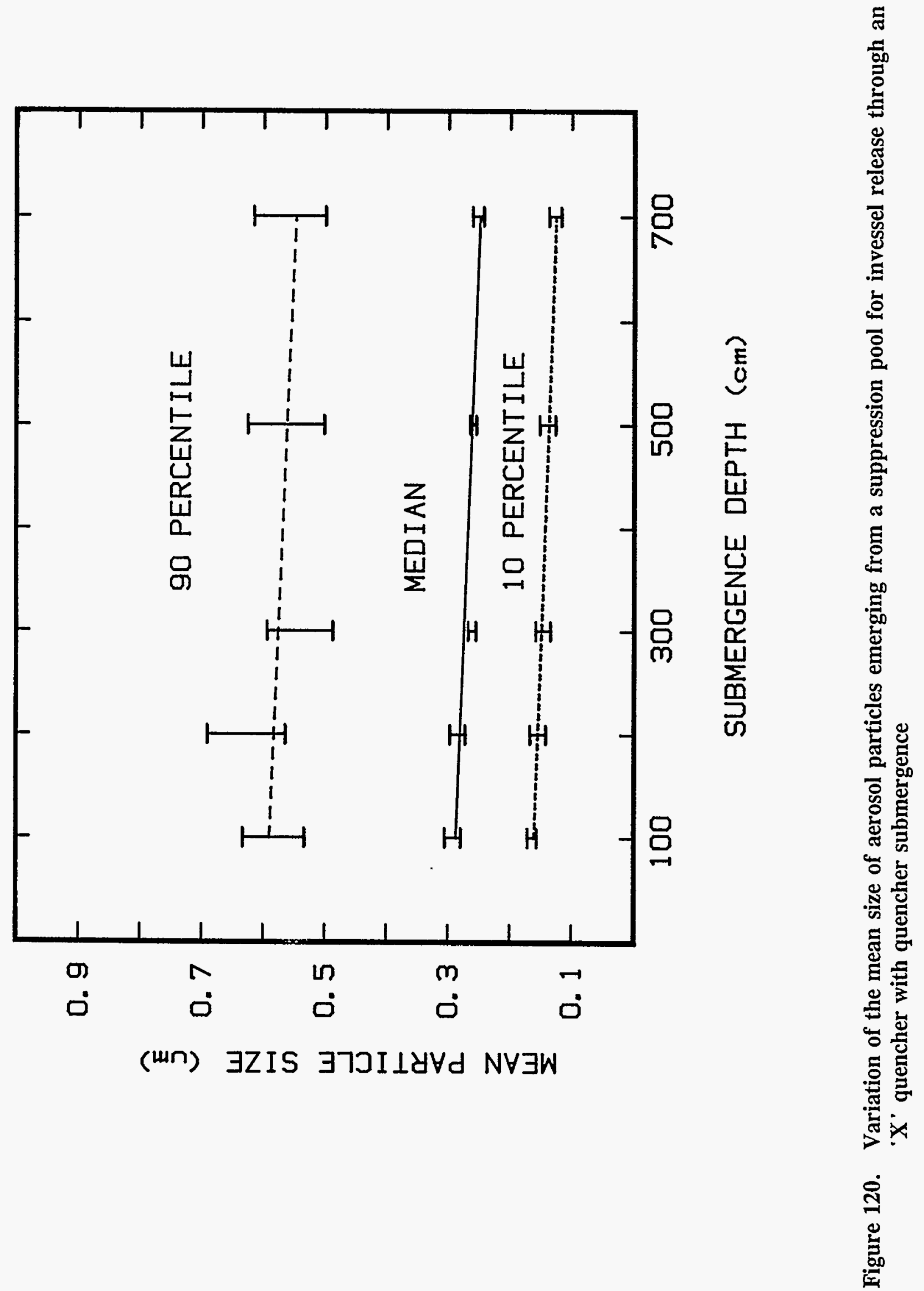


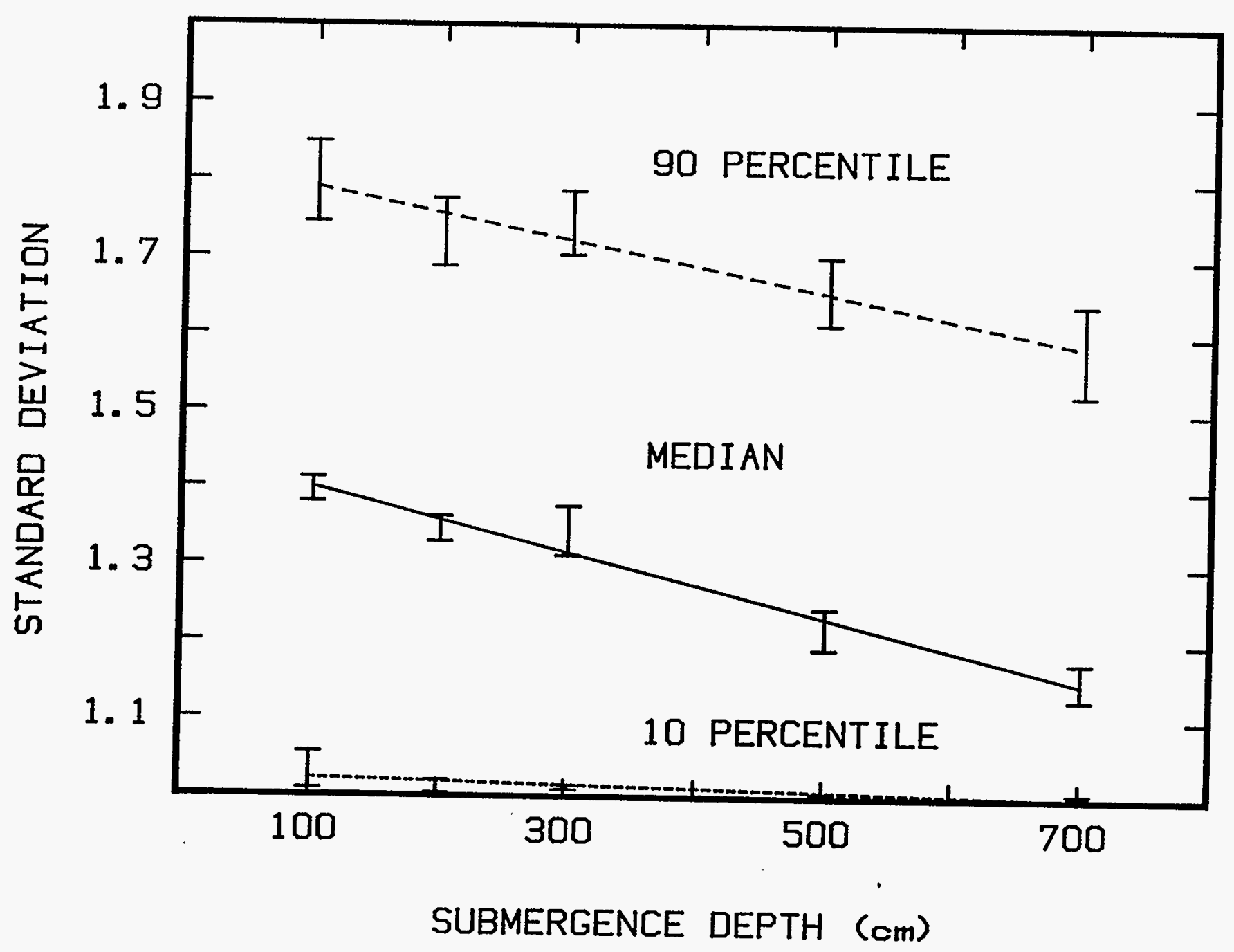

Figure 121. Variation in the standard deviation of the size distribution of aerosols emerging from a suppression pool for invessel release through an ' $X$ ' quencher with quencher submergence 
- Upper Bound (90 percentile)

$\log _{10} \mathrm{DF}(\mathrm{FE})=3.093$

$\mathrm{DF}(\mathrm{FE})=1240$

- Mean

$\log _{10} \mathrm{DF}(\mathrm{FE})=1.849$

$\mathrm{DF}(\mathrm{FE})=70.6$

Correlations of decontamination during bubble rise with the depth of submergence, $\mathrm{H}(\mathrm{cm})$, of an ' $\mathrm{X}$ ' quencher are:

- Median (5 percentile)

$$
\log _{10} \mathrm{DF} \text { (rise) }=0.0836+2.315 \times 10^{-3} \mathrm{H}(\mathrm{cm})
$$

- Lower Bound (10 percentile)

$$
\log _{10} \mathrm{DF}(\text { rise })=-0.0078+0.731 \times 10^{-3} \mathrm{H}(\mathrm{cm})
$$

- Upper Bound (90 percentile)

$$
\log _{10} \mathrm{DF} \text { (rise) }=0.812+7.548 \times 10^{-3} \mathrm{H}(\mathrm{cm})
$$

- Mean

$$
\log _{10} \mathrm{DF} \text { (rise) }=0.283+3.107 \times 10^{-3} \mathrm{H}(\mathrm{cm})
$$

Decontamination by discharge through an ' $X$ ' quencher differs by a small amount from decontamination by discharge through a ' $T$ ' quencher. Most of the difference is due to differences in the decontamination during bubble formation and equilibration. A detailed examination of the results to identify the exact cause of the difference has not been undertaken. It appears, however, that the narrower range of wetwell pressures considered for the ' $\mathrm{X}$ ' quencher case in comparison to the range for ' $\mathrm{T}$ ' quenchers is responsible. Wetwell pressure will affect both the rate of bubble formation and consequently the bubble size at the point bubbles detach from orifices. This, in turn, will affect predictions of particle capture by impaction and by diffusion. 


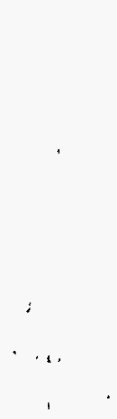

- 


\section{Simplified Model}

A simplified model of decontamination by steam suppression pools is constructed by correlation of the results obtained in the Monte Carlo uncertainty analysis. The critical features of decontamination by suppression pools that need to be predicted by a simplified model are:

- total decontamination, and

- size distribution of the emerging aerosol

It is assumed for the development of this model that the decontamination processes are strictly physical so the composition of the aerosol that emerges from a suppression pool is exactly the same as the composition of aerosol discharged to the pool. That is, mechanisms to preferentially deplete or enrich the emerging aerosol in radionuclides are not known.

It is further assumed that the emerging aerosol has a lognormal size distribution so that the fraction of the aerosol mass with particle sizes less than $D_{p}$ is given by:

$$
f\left(D_{p}\right)=\frac{1}{\ln \sigma \sqrt{2 \pi}} \int_{-\infty}^{\ln D_{p}} \exp \left\{-\left(\frac{\ln D_{p} / d_{p}}{\sqrt{2} \ln \sigma}\right)^{2}\right\} \ln D_{p}
$$

It is assumed that the important parameters DF(total), $d_{p}$, and $\sigma$ will depend on the phase of the accident and the type of quencher used in the suppression pool.

Best estimate values of the important parameters are obtained by correlation of the median values of uncertainty distributions obtained in the Monte Carlo analyses. There is an apparent dichotomy of opinion within the technical community concerning whether medians of uncertainty distributions are best-estimates (as is believed by the authors of this report) or means of the distributions are best-estimates. (Some refer to means by the regrettable term "conservative best-estimate" - whatever that is.) The authors do not propose to resolve this debate, but do provide correlations of the means of the samples used to construct uncertainty distributions from the Monte Carlo uncertainty analyses.

Whatever convention is adopted for the best estimate of uncertainty distributions, it is important to know the width of the distributions. For the simplified model adopted here, the 10 percentile and 90 percentile values are considered reasonable lower bounds and reasonable upper bounds on the distributions. Correlations for these lower and upper bounds are provided.

The important parameters, $D F$ (total), $d_{p}$, and $\sigma$, in principle, are not entirely independent of one another. results of the Monte Carlo samples were examined for correlations among these quantities. The search for correlations was based on the conventional linear correlation coefficient, $r$, between sets of values $X(i)$ and Y(i): 


$$
r=\frac{N \sum_{i=1}^{N} X(i) Y(i)-\sum_{i=1}^{N} X(i) \sum_{j=1}^{N} Y(j)}{\left[N \sum_{i=1}^{N} X(i)^{2}-\left(\sum_{i=1}^{N} X(i)\right)^{2}\right]^{\frac{1}{2}}\left[N \sum_{j=1}^{N} Y(j)^{2}-\left(\sum_{j=1}^{N} Y(j)\right)^{2 / \frac{1}{2}}\right]}
$$

where $\mathrm{N}$ is the number of samples and $\mathrm{X}(\mathrm{i}), \mathrm{Y}(\mathrm{i})$ were sampled values of $\log _{10} \mathrm{DF}$ (total), $\mathrm{d}_{\mathrm{p}_{1}}$, or $\mathrm{o}$.

Significant (99 percent confidence) negative correlation of $\mathrm{d}_{\mathrm{p}}$ with $\log _{10} \mathrm{DF}$ (total) was found in all' cásés.

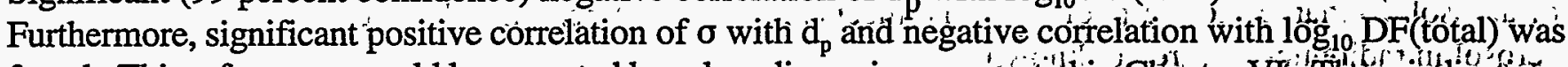
found. This, of course, would be expected based on discussions presented in 'Châpter VI: 'These indications of correlation among the important predictions of the simplified models means that correlations for the important predictions cannot be selected independently. That is, the best-estimate of thé décóntatamination factor cannot be used in conjunction with the lower bound particle size of aerosol 'emerging from the suppression pool. Such a combination would be inconsistent with the predictions of detailed mechanistic models.

The acceptable combinations of correlations for important predictions of the simplified model are:

1. Gap release through either ' $X$ ' or ' $T$ ' quenchers submerged to a depth $H(\mathrm{~cm})$ :

- Median (Best Estimate)

$$
\begin{aligned}
\log _{10} \mathrm{DF}(\text { total }) & =1.350+1.933 \times 10^{-3} \mathrm{H}(\mathrm{cm}) \\
\mathrm{d}_{\mathrm{p}} & =0.102 \mu \mathrm{m} \\
\sigma & =1.454-0.166 \times 10^{-3} \mathrm{H}(\mathrm{cm})
\end{aligned}
$$

- Mean

$$
\begin{aligned}
\log _{10} \mathrm{DF}(\text { total }) & =1.283+2.68 \times 10^{-3} \mathrm{H}(\mathrm{cm}) \\
\mathrm{d}_{\mathrm{p}} & =0.107 \mu \mathrm{m} \\
\sigma & =1.440-0.126 \times 10^{-3} \mathrm{H}(\mathrm{cm})
\end{aligned}
$$

- Lower Bound (10 percentile)

$$
\begin{aligned}
\log _{10} \mathrm{DF}(\text { total }) & =0.980+1.006 \times 10^{-3} \mathrm{H}(\mathrm{cm}) \\
\mathrm{d}_{\mathrm{p}} & =0.149 \mu \mathrm{m} \\
\sigma & =1.640-0.189 \times 10^{-3} \mathrm{H}(\mathrm{cm})
\end{aligned}
$$

- Upper Bound (90 percentile)

$$
\begin{aligned}
\log _{10} \mathrm{DF}(\text { total }) & =1.485+5.554 \times 10^{-3} \mathrm{H}(\mathrm{cm}) \\
\mathrm{d}_{\mathrm{p}} & =0.085 \mu \mathrm{m} \\
\sigma & =1.248-0.032 \times 10^{-3} \mathrm{H}(\mathrm{cm})
\end{aligned}
$$


2. Invessel release through a ' $T$ ' quencher submerged to a depth $\mathrm{H}(\mathrm{cm})$ with a wetwell that can sustain pressures in excess of 5 atms:

- Median (Best Estimate)

$$
\begin{aligned}
\log _{10} \mathrm{DF}(\text { total }) & =1.752+1.92 \times 10^{-3} \mathrm{H}(\mathrm{cm}) \\
\mathrm{d}_{\mathrm{p}}(\mu \mathrm{m}) & =0.326-0.121 \times 10^{-3} \mathrm{H}(\mathrm{cm}) \\
\sigma & =1.448-0.324 \times 10^{-3} \mathrm{H}(\mathrm{cm})
\end{aligned}
$$

- Mean

$$
\begin{aligned}
\log _{10} \mathrm{DF}(\text { total }) & =2.047+2.45 \times 10^{-3} \mathrm{H}(\mathrm{cm}) \\
\mathrm{d}_{\mathrm{p}}(\mu \mathrm{m}) & =0.343-0.132 \times 10^{-3} \mathrm{H}(\mathrm{cm}) \\
\sigma & =1.416-0.242 \times 10^{-3} \mathrm{H}(\mathrm{cm})
\end{aligned}
$$

- Lower Bound (10 percentile)

$$
\begin{aligned}
\log _{10} \mathrm{DF}(\text { total }) & =0.930+0.870 \times 10^{-3} \mathrm{H}(\mathrm{cm}) \\
\mathrm{d}_{\mathrm{p}}(\mu \mathrm{m}) & =0.684-0.242 \times 10^{-3} \mathrm{H}(\mathrm{cm}) \\
\sigma & =1.850-0.346 \times 10^{-3} \mathrm{H}(\mathrm{cm})
\end{aligned}
$$

- Upper Bound (90 percentile)

$$
\begin{aligned}
\log _{10} \mathrm{DF}(\text { total }) & =3.444+5.38 \times 10^{-3} \mathrm{H}(\mathrm{cm}) \\
\mathrm{d}_{\mathrm{p}}(\mu \mathrm{m}) & =0.183-0.073 \times 10^{-3} \mathrm{H}(\mathrm{cm})
\end{aligned}
$$

3. Invessel release through a ' $T$ ' or an ' $\mathrm{X}$ ' quencher at a submergence $\mathrm{H}(\mathrm{cm})$ and wetwell that can only sustain pressures less than 5 atms:

- Median (Best Estimate)

$$
\begin{aligned}
\log _{10} \mathrm{DF}(\text { total }) & =1.791+2.477 \times 10^{-3} \mathrm{H}(\mathrm{cm}) \\
\mathrm{d}_{\mathrm{p}}(\mu \mathrm{m}) & =0.293-0.064 \times 10^{-3} \mathrm{H}(\mathrm{cm}) \\
\sigma & =1.441-0.420 \times 10^{-3} \mathrm{H}(\mathrm{cm})
\end{aligned}
$$

- Mean

$$
\begin{aligned}
\log _{10} \mathrm{DF}(\text { total }) & =2.256+2.764 \times 10^{-3} \mathrm{H}(\mathrm{cm}) \\
\mathrm{d}_{\mathrm{p}}(\mu \mathrm{m}) & =0.303-0.065 \times 10^{-3} \mathrm{H}(\mathrm{cm}) \\
\sigma & =1.395-0.260 \times 10^{-3} \mathrm{H}(\mathrm{cm})
\end{aligned}
$$

- Lower Bound (10 percentile)

$$
\begin{aligned}
\log _{10} \mathrm{DF}(\text { total }) & =1.034+0.875 \times 10^{-3} \mathrm{H}(\mathrm{cm}) \\
\mathrm{d}_{\mathrm{p}}(\mu \mathrm{m}) & =0.597-0.071 \times 10^{-3} \mathrm{H}(\mathrm{cm}) \\
\sigma & =1.824-0.341 \times 10^{-3} \mathrm{H}(\mathrm{cm})
\end{aligned}
$$


- Upper Bound (90 percentile)

$$
\begin{aligned}
\log _{10} \mathrm{DF}(\text { total }) & =3.964+6.528 \times 10^{-3} \mathrm{H}(\mathrm{cm}) \\
\mathrm{d}_{\mathrm{p}}(\mu \mathrm{m}) & =0.166-0.058 \times 10^{-3} \mathrm{H}(\mathrm{cm}) \\
\sigma & =1.025-0.038 \times 10^{-3} \mathrm{H}(\mathrm{cm})
\end{aligned}
$$

Two additional points concerning the simplified model are:

- 1 percent of the discharge to suppression pool may leak into the wetwell space and thus bypass the actions of the pool, and

- calculated decontamination factors in excess of $10^{6}$ should be reduced to $10^{6}$. ..i . .

To illustrate the application of the simplified model consider the concentration of iodine in the wetwell space in the absence of any attenuation mechanisms other than the suppression pool. From NUREG-1465 [3], 5 percent of the initial core inventory is discharged, to the suppression pool during the gap release phase of an accident and 35 percent of the initial core inventory is discharged during the invessel release phase. Assume 1 percent of the discharge-leaks inț the wetwell without.passing through the suppression pool. This leakage puts 0.4 percent of the initial core inventory of iodine into the wetwell space.

To calculate the additional iodine passing through the suppression pool assume that the discharge, to the pool is through ' $T$ ' quenchers submerged to a depth of $150 \mathrm{~cm}$ and the wetwell space is always less than 5 atmospheres. The best estimate decontamination factor during gap release is:., i:

$$
\mathrm{DF}(\text { total })=43.6
$$

Then, the amount of iodine entering the wetwell space is 4.95 percent of the initial core inventory. (5 percent less the amount leaked) times $1 / 43.6$ or 0.11 percent of the initial corre inventory. Lower bound and upper bounds are 0.37 percent and 0.024 percent of the initial core inventory. The best estimate of the mean particle size of the iodine bearing material is $0.102 \mu \mathrm{m}$. The reasonable range, for this mean size is 0.085 to $0.149 \mu \mathrm{m}$.

The best estimate of iodine reaching the wetwell space during invessel release is:

$$
34.65 / 145.4=0.24 \text { percent }
$$

The upper and lower bounds on this range are 2.37 percent and 0.0004 percent.

Then, the best estimate of the total iodine released to the wetwell by the discharge that the suppression pool is 0.11 percent +0.24 percent $=0.35$ percent which is slightly less than reaches the wetwell space by leakage. The reasonable range for the concentration of iodine in the wetwell space is:

- Upper Bound $=0.4+0.37+2.37$ percent $=3.14$ percent of the initial core inyêntory

- Lower Bound $=0.4+0.024+0.0004$ percent $=0.42$ percent of the initial core inventory 


\section{Conclusions}

Monte Carlo uncertainty analyses of decontamination of aerosol-laden gases sparging through a suppression pool show that decontamination by bubble formation and equilibration with the suppression pool can be significant. For shallow pools, the decontamination by the bubble formation and equilibration processes can be larger than decontamination by bubble rise through the pool. Much less experimental and analytic attention has been given to decontamination during the formation of bubbles and the subsequent processes of disintegration and coalescence than has been given to decontamination during bubble rise through a pool. Decontamination by bubble formation and equilibration found to be relatively insensitive to pool depth but is sensitive to the flow and steam content of gas discharged lot.

Decontamination of aerosol-laden bubbles rising through a water pool is resisted by the evaporation of water from the bubble surface as the hydrostatic head is released. Bubble plumes that entrain water in the upward flow of gases reduce the opportunity for decontamination during bubble rise. On the other hand, bubble oscillations and shape deformations may cause decontamination not considered in some models.

Decontamination is predicted to narrow the size distribution of aerosol discharged to a pool and to shift the mass mean of the size distribution toward values where decontamination processes are minimally effective. This size of minimal effectiveness of removal processes is relatively insensitive to pool depth. It is sensitive to the flow rate of gases to the pool.

Uncertainties in the predicted decontamination that can be achieved by steam suppression pools arise from:

- uncertainties in boundary conditions dictated by the nature of accident progression such as pool temperature and wetwell pressure,

- uncertainties in the sizes of aerosol particles discharged to the suppression pools,

- uncertainties in bubble behavior, is

- uncertainties in aerosol behavior in forming and rising bubbles.

The means, medians, and the 10 percentile and 90 percentile values of uncertainty distributions for total decontamination of gases sparging through suppression pools and the parameters of the size distribution of aerosol emerging from pools can be correlated with pool depth. Parameters of the correlations depend on the phase of the accident and the nature of the discharge to the pool. 


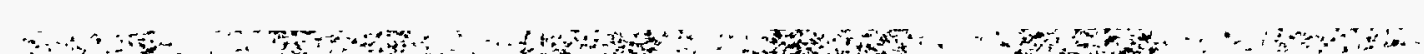




\section{References}

1. D. A. Powers and J. L. Sprung, A Simplified Model of Aerosol Scrubbing by a Water Pool Overlying Core Debris Interacting with Concrete, NUREG/CR-5901, SAND92-1422, Sandia National Laboratories, Albuquerque, NM, October 1992.

2. D. A. Powers and S. B. Burson, A Simplified Model of Aerosol Removal by Containment Sprays, NUREG/CR-5966, SAND92-2689, Sandia National Laboratories, Albuquerque, NM, June 1993.

3. L. Soffer, S. B. Burson, C. M. Ferrell, R. Y. Lee, and J. N. Ridgely, Accident Source Terms for Light Water Nuclear Power Plants, NUREG/CR-1465, U.S. Nuclear Regulatory Commission, Washington, D.C., February 1995.

4. K. E. Washington, K. K. Murata, R. G. Gido, F. Gelbard, N. A. Rusell, S. C. Billups, D. C. Carroll, R. O. Griffith, and D. L. Y. Louie, Reference Manual for the CONTAIN 1.1 Code for Containment Severe Accident Analysis, NUREG/CR-5715, SAND91-0835, Sandia National Laboratories, Albuquerque, NM, July 1991.

5. R. M. Summers et al., MELCOR 1.8.0: A Computer Code for Nuclear Reactor Severe Accident Source Term and Risk Assessment Analysis, NUREG/CR-5531, SAND90-0364, Sandia National Laboratories, Albuquerque, NM, January 1991.

6. P. C. Owczarski, and K. W. Burk, SPARC-90: A Code for Calculating Fission Product Capture in Suppression Pools, NUREG/CR-5765, PNL-7723, Pacific Northwest Laboratory, Richland, WA, October 1991.

7. A. T. Wassel, A. F. Mills, D. C. Bugby, and R. N. Oehlberg, Nuclear Engineering and Design 90 (1985) 87.

8. A. T. Wassel, J. L. Farr, Jr., and M. S. Hoseyni, SUPRA: A Code for Simulating Removal of Radionuclides by Water Pools Under Severe Accident Conditions, NP-3886-CCMP, Science Applications, Inc., Hermosa Beach, CA, 1985.

9. S. A. Ramsdale, BUSCA-JUN90 Reference Manual, SRD R542, Safety and Reliability Directorate, United Kingdom, 1991.

10. V. F. Ubanic, and T. R. Heidrich, J. Nuclear Materials, 75 (1978) 251.

11. M. R. Kuhlman, J. A. Gieseke, M. Merilo, and R. Oehlberg, "Scrubbing of Fission Product Aerosols in LWR Water Pools Under Severe Accident Conditions," p. 633 Paper IAEA-SM-281/47, Source Term Evaluation for Accident Conditions, International Atomic Energy Agency, Vienna, Austria, 1986.

12. S. R. Greene, A. E. Levin, C. R. Hyman, A. Sozer, and R. P. Taleyarkhan, BWR Mark II Ex-Vessel Corium Interaction Analyses, NUREG/CR-5623, ORNL/TM-11644, Oak Ridge National Laboratory, Oak Ridge, TN, November 1991.

13. GESAR II BWR/6 Nuclear Island Design, General Electric Co., San Jose, CA, undated. 
References

14. J. A. Gieseke, et al., Source Term Code Package: A User's Guide, NUREG/CR-4587, Battelle Columbus Laboratory, Columbus, OH, July 1886.

15. I. K. Madni, Analysis of Long Term Station Blackout Without Automatic Depressurization at Peach Bottom Using MELCOR (Version 1.8), NUREG/CR-5850, BNL-NUREG-52319, Brookhaven National Laboratory, Upton, NY, May 1994.

16. S. A. Hodge and L. J. Ott, Boiling Water Reactor Severe Accident Response (BWRSAR) Code Description and Assessment, Oak Ridge National Laboratory, Oak Ridge, TN, Fepruary 1989.

17. Final Safety Analysis Report Peach Bottom Atomic Power Station Units 2 and 3 , Volume 2, Philadelphia Electric Co., undated.

18. IDCOR Technical Report 16.2-3, MAAP Modular Accident Analysis Program 'User's Manual, Atomic Industrial Forum, Bethesda, MD, August 1983.

19. D. A. Powers, J. E. Brockmann, and A. W. Shiver, VANESA: A Mechanistic Model of Radionuclide Release and Aerosol Generation During Core Debris Interactions with Concrete, NUREG/CR-4308, SAND85-1370, Sandia National Laboratories, Albuquérque, NM; Julý 1986.

20. D. R. Bradley, et al., CORCON-MOD 3: An Integrated Computer Model for Analysis of Molten Core-Concrete Interactions: User's Manual, NUREG/CR-5843, Sandia 'National Laboratories, Albuquerque, NM, April 1993.

21. Industry Degraded Core Rulemaking Project, Peach Bottom Atomic Power Station, IDCORTask 23.1. Integrated Containment Analysis, Atomic Industrial Forum, Béthésda, M̀', 1984.'

22. Office of Nuclear Regulatory Research, Severe Accident Risks: An Assessment for Five U.S. Nuclear Power Plants, NUREG-1150 Volımes 1-3, U.S. Nuclear Regulatory 'Commíssion, Washington, D.C., June 1989.

23. R. S. Denning et al., Radionuclide Release Calculations for Selected Severe Accident Scenarios, NUREG/CR-4624, BMJ-2139, Volume 1, Battelle Columbus Laboratory, Columbiừí Ohío, July 1986.

24. D. A. Powers and F. E. Arellano, Large-scale, Transient Tests of thè IntèräctionnofofiMóltèn Steel with Concrete, NUREG/CR-2282, SAND81-1753, Sandia National Laboratories, Albuquerque, NM, January 1982.

25. P. K. Mast, D. R. Bradley, J. E. Brockmann, R. J. Lipinski, and'D: A. Powiers; Uncertainty in Radionuclide Release Under Specific LWR Accident Conditions, Volume IV, TC Analysis, Sandia National Laboratories, Albuquerque, NM, December 1985.

26. J. E. Brockmann, Progress in Nuclear Energy, 19 (1987) 7. 
27. J. A. Gieseke, P. Cybulskis, R. S. Denning, M. R. Kuhlman, K. W. Lee, and H. Chen, Radionuclide Release Under Specific LWR Accident Conditions, Volume III. BWR Mark III Design, BMI-2104, Vol. III, Battelle Columbus Laboratory, Columbus, OH, July 1984.

28. N. M. Chown and D. A. Williams, A Limited Investigation of the Sensitivity of the Containment Source Term to Certain Primary Circuit Parameters Under PWR Severe Accident Conditions, AEEW-R2429, Winfrith Technology Centre, Winfrith, UK, 1989.

29. U.S. Nuclear Regulatory Commission, Reactor Safety Study - An Assessment of Accident Risks in U.S. Commercial Nuclear Power Plants, WASH-1400, NUREG-75/04, Washington, D.C., October 1975.

30. D. D. Paul, L. J. Flanigan, R. A. Cudnik, J. C. Cunnane, and R. P. Collier, Radionuclide Scrubbing in Water Pools, Volume 1: Gas-Liquid Hydrodynamics, NP-4154, Volume 1, Battelle Columbus Laboratory, Columbus, OH, August 1985.

31. R. Kumar and N. R. Kuloor, "The Formation of Bubbles and Drops," in Advances in Chemical Engineering Volume 8, 1970, pp. 256ff.

32. J. F. Davidson and B. O. G. Schuler, Trans. Instit. Chem. Engrs., (London) 38 (1960) 335.

33. D. W. Van Krevelen and P. J. Hoftijzer, Chem. Eng. Prog., 46 (1950) 29.

34. J. F. Davidson and H. Harrison, Fluidized Particles, Cambridge University Press, 1963.

35. K. Ruff, Chemie-Ingenieur Technik, 44 (1972) 1360.

36. D. L. Datta, D. H. Napier, D. M. Newitt, Trans. Instit. Chem. Engrs., (London) 28 (1950) 14.

37. P. D. Coppock and G. T. Meiklejohn, Trans. Instit. Chem Engrs., (London) 29 (1951) 75.

38. L. Davidson and E. H. Amick, Jr., AIChE J., 2 (1956) 337.

39. W. Siemes, Chemie Inq. Tech., 26 (1954) 479.

40. C. K. B. Lee and C. K. Chan, Steam Chugging in Pressure Suppression Containment, NUREG/CR-1562, University of California at Los Angeles, Los Angeles, CA, July 1980.

41. W. Kowakchuk and A. A. Sonin, A Model for Condensation Oscillations in a Vertical Pipe Discharging Steam Into a Subcooled Water Pool, NUREG/CR-0221, Massachusetts Institute of Technology, Cambridge, MA, June 1978.

42. D. D. Paul, D. C. Newman, and R. A. Cudnik, Gas-Liquid Hydrodynamics of Large Vent/Suppression Pool Systems of Nuclear Power Plants During Some Accident Conditions, 
References

43. D. A. Sargis, J. H. Stuhmiller, and S. S. Wang, Analysis of Steam Chúğgịing P̂henomena Volume 2: User's Manual for the CHUG1 Computer Program, EPRI NP1962, Volume 2, Jaycor, Del Mar, CA, January, 1979.

44. J. H. Milgram, J. Fluid Mechanics, 133 (1983) 345.

45. K. H. Tacke, H. G. Schubert, D. J. Weber, and K. Schwerdtfeger, Metallurgical'Trinsactions $B, 16 B(1985) 263$.

46. T. Y. Sun and G. M. Faeth, Int. J. Multiphase Flow, 12 (1986) 99.

47. T. Y. Sun and G. M. Faeth, Int. J. Multiphase Flow, 12 (1986) 115.

48. J. S. Shuen, A. S. P. Solomon, Q. F. Zhang, and G. M. Faeth, AIAA Journal, $123^{\prime}(1985) 396$.

49. J. S. Shuen, L. D. Chen, and G. M. Faeth, AIAA Journal, 21 (1983) 1483.

50. J. S. Shuen, L. D. Chen, and G. M. Faeth, AIChE Journal, 29 (1983) 167.

51. G. B. Wallis, One-Dimensional Two-Phase Flow, McGraw-Hill, 1969:

52. J. F. Davidson and D. Harrison, Chem. Eng. Sci., 21 (1966) 731.

53. W. K. George, R. L. Alpert, and F. Tamanini, Intl. J: Heat Mass Träsfer,-20 (1977) 1.145.

54. T. J. McDougall, J. Fluid Mechanics, 85 (1978) 655.

55. J. V. Sengers and J. T. R. Watson, J. Phys. Chem Ref. Data, 15 (1986) 1291.

56. J. Kestin, J.V. Sengers, B. Kamgar-Parsi, and J. M. H. Levelt Sengers, J: Phys. Ćhem. Ref: Data, 13 (1984) 175.

57. W. N. Bond and D. A. Newton, Philosophical Magazine, 5 (1928) 794.

58. F. N. Peebles and H. J. Garber, Chem. Eng. Progress, 49 (1953) 88.

59. E. Coester, Z. Angew. Phys., 13 (1961) 254.

60. S. Winnikow, Chem. Eng. Sci., 22 (1967) 477.

61. H. Lamb, Hydrodynamics, Cambridge University Press, 1932.

62. M. E. Weber, Chem. Eng. Sci., 30 (1975) 1507.

63. J. T. Lindt and R. G. De Groot, Chem. Eng. Sci., 29 (1974) 957.

64. P. H. Calderbank and M. B. Moo-Young, Chem. Eng. Sci., 16 (1961) 39. 
65. B. F. Le Clair and A. E. Hamielec, Canadian J. Chem. Eng., 49 (1971) 713.

66. J. R. Grace, T. Wairegi, and T. H. Nguyen, Trans. Inst. Chem Eng., 54 (1976) 167.

67. A. E. Hamielec, J. H. Storey, and J. H. Whitehead, Canadian J. Chem. Eng., 41 (1963) 246.

68. R. M. Davies and G. I. Taylor, Proc. R. Soc, A200 (1950) 375.

69. J. Hakii, H. Kaneko, M. Fikasawa, Y. Masahiro, and M. Matsumoto, "Experimental Study of Aerosol Removal Effect by Pool Scrubbing," 2nd Workshop on LWR Severe Accident Research at JAERI, Tokyo, Japan, 1991.

70. C. N. Amos, "Evaluation of the Contact Time for Pool Scrubbing," Proceedings American Nuclear Society Meeting on Fission Product Behavior and Source Term Research, NP-4113-SR, p. 33-1, M. F. Huebner, editor, Electric Power Research Institute, Palo Alto, CA, July, 1985.

71. C. K. B. Lee, Int. Comm. Heat Mass Transfer, 10 (1983) 25.

72. T. O. Oolman and H. W. Blanch, Chem. Eng. Communciations, 43 (1986) 237.

73. A. K. Chesters and G. Hoffman, Appl. Sci. Res., 38 (1982) 353.

74. P. H. Calderbank, Chemical Engineering (London) 212 (1967) CE209-CE233.

75. G. Marucci and L. Nicodemo, Chem. Eng. Sci., 22 (1967) 1257.

76. R. L. Lessard and D. A. Zieminski, Ind. Eng. Chem. Fundamentals, 10 (1971) 260.

77. H. S. Allen, Philos. Magazine, 54 (1900) 323.

78. A. V. Gorodetskaya, Russ. J. Phys. Chem., 23 (1949) 71.

79. W. L. Haberman and R. K. Morton, An Experimental Investigation of the Drag and Shape of Air Bubbles Rising in Various Liquids, David W. Taylor Model Basin Report 802, September, 1953.

80. B. Rosenberg, The Drag and Shape of Air Bubbles Moving in Liquids, David W. Taylor Model Basin Report 727, September 1950.

81. C. Bachhuber and C. Sanford, J. Appl. Phys., 45 (1974) 2567.

82. R. Clift, J. R. Grace, and M. E. Weber, Bubbles, Drops and Particles, Academic Press, 1978.

83. h. c. J. M. H. Levelt Sengers and B. Dooley, J. Phys. Chem. Ref. Data, 22 (1993) 785.

84. D. Bhaga and M. E. Weber, J. Fluid Mechanics, 105 (1981) 61. 
References

85. G. B. Wallis, One Dimensional Two Phase Flow, McGraw-Hill, 1969:

86. A. I. Johnson, F. Besik, and A. E. Hamielec, Canadian J. Chem. Eng., 47 (1969) 559.

87. D. R. Raymond and S. A. Zieminski, AIChE Journal, 17 (1971) 57.

88. R. Kronig and J. C. Brink, Appl. Sci. Res., A2 (1950) 142.

89. A. B. Newman, Am. Inst. Chem. Engrs., 27 (1931) 310.

90. R. Hickling and M. S. Plesset, Physics of Fluids, 7 (1964) 7.

91. K. Vokurka, Acustica, 59 (1986) 214.

92. J. W. Rayleigh, Philos. Magazine, 34 (1917) 94.

93. M. S. Plesset and T. P. Mitchell, Quarterly Applied Mathematics, 13 (1955) 419.

94. W. Florshuetz and B. T. Chao, Trans ASME 87C, J. Heat Transfer, (1965) 209.

95. V. F. Prisnyakov, Int. J. Heat Mass Transfer, 14 (1971) 353.

96. D. D. Wittke and B. T. Chao, J. Heat Transfer, (1967) 17.

97. D. Moalem and S. Sideman, Int'l. J. Heat Mass Transfer, 16 (1973) 2321!.

98. O. Levenspiel, Ind. Eng. Chem., 51 (1959) 787.

99. V. G. Levich, Physicochemical Hydrodynamics, Prentice-Hall Publ. Co., 1962.

100. J. Loertscher, B. Covelli, and R. Gubler, Chemi-Ingenieur Technik, 57 (1985) 863.

101. J. R. Grace, T. Wairegi, and B. Brophy, Canadian J. Chem Eng.'; 56 (197:8) 3.

102. E. R. Elzinga and J. T. Banchero, Chem. Eng. Progr. Symp. Ser., 55 (1959) 149.

103. N. B. Vargaftik, Tables on the Thermophysical Properties of Liquids: and:Gàses; SSecondEđition,, Hemisphere, 1975.

104. M. W. Chase et al., J. Phys. Chem. Ref. Data, 11 (1982) 695.

105. D. R. Stull and H. Prophet, JANAF Thermochemical Tables, SecondiEdition, National Bureau of Standards, June 1971.

106. Y. S. Touloukian, S. C. Saxena, and P. Hestermans, Thermophysical Properties of Matter Volume II Viscosity, IFI Plenum, 1975. 
107. F. J. Uribe, E. A. Mason, and J. Kestin, J. Phys. Chem. Ref. Data, 19 (1990) 1123.

108. J. Millat et al., Physica, 145A (1987) 461.

109. A. A. Clifford, J. Kestin, and W. A. Wakenham, Physica, $97 A$ (1979) 287.

110. L. B. Thomas and R. C. Golike, J. Chem. Phys., 22 (1954) 300.

111. A. C. Scott, A. I. Johns, J. T. R. Wats, and A. A. Clifford, J. Chem. Soc. Faraday Transactions I, 79 (1983) 733.

112. H. L. Johnston and E. R. Grilly, J. Chem. Phys., 14 (1946) 233.

113. N. Imaishi, J. Kestin, and W.A. Wakeham, Physica, 123A (1984) 50.

114. H. M. Roder, J. Research NBS, 87 (1982) 279.

115. M. J. Assael and W. A. Wakeham, J. Chem. Soc. Faraday Trans. I, 77 (1981) 697.

116. A. I. Johns et al., Int'l J. Thermophysics, 9 (1988) 3.

117. A. A. Clifford, J. Kestin, and W. A. Wakeham, Ber. Bunsenges. Phys. Chem., 84 (1980) 9.

118. J. Kestin, Y. Nagasaka, and W. A. Wakeham Ber. Bunsenges. Phys. Chem.,

119. E. N. Haran et al., Ber. Bunsenges. Phys. Chem., 87 (1983) 657.

120. E. A. Mason and S. C. Saxena, Physics of Fluids, 1 (1958) 361.

121. P. K. Tondon and S. C. Saxena, Appl. Sci. Res., 19 (1968) 163.

122. Solubility Data Series, Volume 43, Carbon Monoxide, R. W. Cargill, editor, Pergamon Press.

123. J. J. Carroll, J. D. Slupsky, and A. E. Mather, J. Phys. Chem. Ref. Data, 20 (1991) 1201.

124. Solubility Data Series, Volume 5/6, Hydrogen and Deuterium, C. L. Young, editor, Pergamon Press.

125. Solubility Data Series, Volume 7, Oxygen and Ozone, R. Battino, editor, Pergamon Press.

126. Solubility Data Series, Volume 10, Nitrogen and Air, R. Battino, editor, Pergamon Press.

127. R. C. Reid, J. M. Prausnitz, and B. E. Poling, The Properties of Gases and Liquids, 4th Edition, McGraw-Hill Book Co., 1987.

128. E. N. Fuller, K. Ensley, and J. C. Giddings, J. Phys. Chem., 75 (1969) 3679. 
References

129. E. N. Fuller, P. D. Schettler, and J. C. Giddings, Ind. Eng. Chem., 58 (1966) 18.

130. C. R. Wilke and C. Y. Lee, Ind. Eng. Chem., 47 (1955) 1253.

131. R. W. Elliott and H. Watts, Canad. J. Chem., 50 (1972) 31.

132. S. Gotoh, M. Manner, J. P. Sorensen, and W. E. Stewart, Ind. Eng. Chem.; 12 (1973) 119."

133. S. Gotoh, M. Manner, J. P. Sorensen, and W. E. Stewart, J. Chem. Eng. Data; 19:(1974) 169.

134. G. A. Lugg, Anal. Chem., 40 (1968) 1072.

135. B. K. Pathak, V. N. Singh, and P. C. Singh, Canad. J. Chem. Eng., 59 (1981) 362.

136. P. D. Neufeld, A. R. Janzen, and R. A. Aziz, J. Chem. Phys., 57 (1972) 1100.

137. D. M. Himmelblau, Chem. Rev., 64 (1964) 527.

138. C. R. Wilke and P. Chang, AIChE J., 1 (1955) 264.

139. W. Hayduk and B. S. Minhas, Canad. J. Chem. Eng., 60 (1982) 295.

140. E. G. Scheibel, Ind. Eng. Chem., 46 (1954) 2007.

141. D. F. Othmer and M. S. Thakar, Ind. Eng. Chem., 45 (1953) 589.

142. D. G. Leaist, J. Phys. Chem., 91 (1987) 4635.

143. M. D. Allen and O. G. Raabe, Aerosol Science and Technology, 4 (1985) 269.

144. C. N. Davies, Proc. Phys. Soc., 57 (1945) 259.

145. W. F. Phillips, Physics of Fluids, 18 (1975) 1069.

146. R. A. Millikan, Phys. Rev., 32 (1911) 349.

147. R. A. Millikan, Phys. Rev., 22 (1923) 1.

148. N. A. Fuchs, Mechanics of Aerosols, Pergamon' Press, 1964.

149. T. Demitrack and F. J. Moody, Trans. Amer. Nucl. Soc., 45 (1983) 483.

150. D. A. Powers, An Analysis of Radionuclide Behavior tin' 'Water Pools Dúning'A'ccidents at the Annular Core Research Reactor, SAND91-1222, Sandia National Laborảtóríès;' 'Albưưưuerque, NM, May 1992.

151. I. S. Goldberg, J. Aerosol Sci., 12 (1981) 11. 
152. I. V. Derevich and L. I. Zaichik, High Temperature, 26 (1986) 120.

153. J. Pich and W. Schuetz, J. Aerosol Sci., 22 (1991) 27.

154. L. Talbot, R. K. Cheng, R. W. Schefer, and D. R. Willis, J. Fluid Mech., 101 (1980) 737.

155. S. K. Loyalka and J. H. Ferziger, Phys. Fluids, 10 (1967) 1833.

156. I. N. Ivchenko and Yu. I. Yalamov, Russ. J. Phys. Chem., 45 (1971) 317.

157. S. K. Loyalka, J. Chem. Phys., 48 (1968) 5432.

158. B. K. Annis, J. Chem. Phys., 57 (1972) 2898.

159. B. V. Derjaquin, Ya. I. Rabinovich, A. I. Storozhilov, and G. I Shcherbina, J. Coll. Int. Sci., 57 (1976) 451.

160. D. J. Rader, J. Aerosol Science, 21 (1990) 161.

161. B. V. Derjaquin and Yu. I. Yalamov, "The Theory of Thermophoresis and Diffusiophoresis of Aerosol Particles and Their Experimental Testing," in Topics in Current Aerosol Research, Part 2, G. M. Hidy and J. R. Brook, editors, Pergamon Press, 1972.

162. G. M. Rossenblatt, Accounts of Chemical Research, 14 (1981) 4.

163. M. E. Riley and D. J. Diestler, Surface Science, 175 (1986) 579.

164. J. E. Brockmann, "Rage of Possible Dymanic and Collision Shape Factors," Appendix F, R. J. Lipinski et al., Uncertainty in Radionuclide Release Under Specific LWR Accident Conditions, Volume II, TMBL' Analyses, SAND84-0410 Vol. 2, Sandia National Laboratories, Albuquerque, NM, February 1985.

165. M. M. R. Williams and S. K. Loyalka, Aerosol Science Theory and Practice, Pergamon Press, 1991.

166. L. Waldmann and K. H. Schmitt, "Thermophoresis and Diffusiophoresis of Aerosols," Chapter VI in Aerosol Science, C. N. Davies, editor, Academic Press, 1966.

167. P. Goldsmith and F. G. May, "Diffusionphoresis and Thermophoresis in Water Vapour Systems," Chapter VII in Aerosol Science, C. N. Davies, editor, Academic Press, 1966.

168. H-C. Hansson and M. S. Ahlberg, J. Aerosol Science, 16 (1985) 69.

169. B. E. Dahneke, Aerosol Science, 4 (1973) 147.

170. B. E. Dahneke, Aerosol Science, 4 (1973) 139. 
References

171. B. E. Dahneke, Aerosol Science, 4 (1973) 163.

172. T. Alty and C. A. Mackay, Proc. Roy. Soc. London, A149 (1935) 104.

173. S. K. Loyalka and J. H. Ferziger, Phys. of Fluids, 11 (1968) 1668.

174. J. M. Thomas, Introduction to the Principles of Heterogeneous Catalysis, Academic Press; 1967 :

175. R. M. Barrer, N. McKenzie, and J. S. S. Reay, J. Colloid Sci., 11'(1956) 479:

176. H. R. Pruppacher and J. D. Klett, Microphysics of Cloúds and Precipitation, D. Reidel Publishing Co.

177. J. C. Barrett and C. F. Clement, J. Aerosol Science, 19 (1988) 223.

178. Y. Y. Hsu and R. W. Graham, Transport Processes in Boiling and Tẃo-Pháse Sýstems, Hemispher, 1976.

179. P. E. Wagner, "Aerosol Growth by Condensation," Chapter 5 in Aerosol Microphysics II Chemical Physics of Microparticles, W. H. Marlow, editor; Springer Verläg', 11982.

180. N. E. Levine, J. Geophys. Res., 78 (1973) 6266.

181. M. Kulmala and T. Vesala, J. Aerosol Sci., 22 (1991) 337:

182. J. Kukkonen, T. Vesala, and M. Kulmala, J. Aerosol Sci., 20 (1989) 749.'

183. J. C. Barrett and C. F. Clement, J. Aerosol Sci., 21 (1990) 761.

184. S. K. Loyalka and J. W. Park, J. Colloid and Interfacial Science, 125 (1988) 7i2:

185. S. G. Jennings, J. Aerosol Sci., 19 (1988) 159.

186. K. S. Pitzer, "Theory: Ion Interaction Approach," Chapter 7 in Activity Coeffičients in Electrolyte Solutions, Volume 1, R. M. Pytkowicz, editor, CRC Press.

187. S. C. Cho and W. K. Lee, Chem. Eng. Sci., 46 (1991) 789. 188. Chemical Engineer's Handbook, 47th Edition, R: H. Perry; C. H. Chilton'? ánd :S. 'D.'

189. A. Jeje and B. Ross, Chem. Eng. Sci., 43 (1988) 2817.

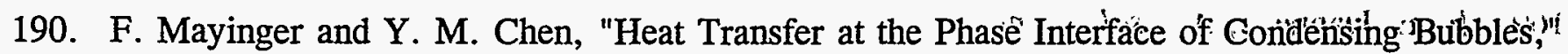
Proc. 8th Int'l Heat Transfer Conf., Vol. 4, p. 1913, C. L. Tien, V. P. Carey, and J. K. Ferrell, editors, 1986. 
191. W. V. Pinczewski, Chem Eng. Sci., 36 (1981) 405.

192. T. B. Guy and T. J. Ledwidge, Int'l J. Heat Mass Transf., 16 (1973) 2393.

193. R. B. H. Tan and I. J. Harris, Chem. Eng. Sci., 41 (1986) 3175.

194. W. E. Ranz, "Principles of Inertial Impaction," Bulletin 66, Department of Engineering Research, Pennsylvania State University, University Park, PA, December 1956.

195. D. W. Moore J. Fluid Mechanics, 16 (1963) 161.

196. H. Tsuge, Y. Tanaka, and S. Hibino, Canad. J. Chem. Eng., 59 (1981) 569.

197. W. L. McCabe and J. C. Smith, Unit Operations of Chemical Enginearing, McGraw-Hill, 1954.

198. P. A. Kolodzie, Jr. and M. Van Winkle, AIChE Journal, 3 (1957) 305.

199. P. L. Smith, Jr. and M. Van Winkle, AIChE Journal, 4 (1958) 266.

200. D. Azbel et al., "Acoustic Resonance Theory for the Rupture of Film Cap of a Gas Bubble at a Horizontal Gas-Liquid Interface, " pp. 159-170, Two-Phase Momentum Heat and Mass Transfer in Chemical Process and Energy Engineering Systems, Volume 1, Hemisphere Publishing Company, 1978.

201. I. Kataoka and M. Ishii, Int. J. Heat Mass Transfer, 27 (1984) 1999.

202. A. M. Rozen, S. I. Golub, and T. I. Votintseva, Teploenergetika, 23 (1976) 59.

203. C. Pozrikidis, J. Fluid Mechanics, 168 (1986) 337.

204. A. F. Mills and M. S. Hoseyni, Aerosol Science and Technology, 8 (1988) 103.

205. P. H. Calderbank and I. J. O. Korchinski, Chem. Eng. Sci., 6 (1956) 65.

206. R. J. Bunson and R. M. Wellek, Canad. J. Chem. Eng., 48 (1970) 267.

207. H. Tsuge and S-I. Hibino, Chem. Eng. Comm., 22 (1983) 63.

208. J. Besset, Contribution to the Thermalhydraulic Study of Vapor Bubble Injection into a Subsaturated Liquid, Doctoral Thesis, The Claude Bernard University, Central School of Lyon, Institute of Applied Science, 1980.

209. M. J. Prince and H. W. Blanch, AIChE J, 36 (1990) 1425.

210. J. H. Pitts, Int'l J. Multiphase Flow, 6 (1980) 329.

211. G. G. Brucker and E. M. Sparrow, Int'l J. Heat and Mass Transfer, 26 (1977) 371. 
References

212. D. Moalem and S. Sideman, Int'l J. Heat Mass Transfer, 16 (1973) 2321.

213. A. Jeje, B. Asante, and B. Ross, Chem. Eng. Sci., 45 (1990) 639.

214. A. E. Wraith, Proc. Int'l Symp. Mining and Metallurgy, 'p. 303, 1972.

215. H. Tsuge, P. Rudin, and R. Kannel, J. Chem. Eng. Japan, 19 (19.86) 326.

216. G. K. Batchelor, J. Fluid Mechanics, 184 (1987) 399.

217. J. Kitscha and G. Kocamustafaogullari, Int'l J. Multiphase Flow, 15 (1989) 573.

218. P. H. Calderbank, "Mass Transfer," Chapter $\sigma$ in Mixing Theory and Practice, Volume II, V. W. Uhl and J. B. Gray, editors, Academic Press, 1967.

219. R. M. Ladyzhensky, J. Appl. Chem USSR; 27 (1954) 17.

220. C-H. Lee, L. E. Erickson, and L. A. Glasgow, Chemical Eng. Comm., 59 (1987)'65.

221. M. Taheri and S. Calvert, J. Air Poll. Control Assoc.; 3 (1960) 129.

222. A. H. P. Skelland and S. S. Minhas, AIChE J., 17 (1971) 1316.

223. N. B. Vargaftik, Tables on the Thermophysical Properties of Liquids and Gases, Second Edition, Hemisphere Publishing Co., 1975.

224. V. B. Okhotskii, Inzhenerno-Fizicheskoi Zhurnal, 59 (1990) 109.

225. S. P. Bakanov, Aerosol Science and Technology, 15 (1991) 77.

226. N. A. Fuchs J. Aerosol Science, 13 (1982) 327.

227. S. K. Loyalka, Physica A, 163 (1990) 813.

228. E. Y. H. Keng and C. Orr, Jr., J. Colloid and Interface Science, 22 (1966) 107.

229. K. H. Schmidt, Z. Natf., $14 a$ (1959) 870.

230. J. Chomiak and A. K. Gupta, J. Aerosol Sci., 20 (1989) 1.

231. W. W. Nazaroff, J. Aerosol Sci., 21 (1990) 827.

232. Y. Sone, Physics of Fluids, 15 (1972) 1418.

233. H. A. Dwyer, Physics of Fluids, 10 (1968) 976, 11 (1968) 923. 
234. S. R. Greene, S. A. Hodge, C. R. Hyman, B. W. Patton, and M. L. Tobias, The Response of BWR Mark III Containments to Short-Term Station Blackout Severe Accident Sequences, NUREG/CR-5571, ORNL/TM-11549, Oak Ridge National Laboratory, Oak Ridge, TN, June 1991.

235. C. J. Shaffer, L. A. Miller, and A. C. Payne, Jr., Intergrated Risk Assessment for the LaSalle Unit 2 Nuclear Power Plant. Phenomenological and Risk Uncertainty Evaluation Program (PRUEP) MELCOR Code Calculations, NUREG/CR-5305, SAND90-2765, Volume 3, Sandia National Laboratories, Albuquerque, NM, October 1992.

236. S. E. Dingman, C. J. Shaffer, A. C. Payne, and M. K. Carmel, MELCOR Analyses for Accident Progression Issues, NUREG/CR-5331, SAND89-0072, Sandia National Laboratories, Albuquerque, NM, January 1991.

237. F. Durst, B. Schonung, K. Selanger, and M. Winter, J. Fluid Mechanics, 170 (1986) 53.

238. S. S. Sadhal and Robert E. Johnson, J. Fluid Mechanics, 126 (1983) 237.

239. A. C. Payne, Jr., Analysis of the LaSalle Unit 2 Nuclear Power Plant: Risk Methods Integration and Evaluation Program (RMIEP), Volume 1, NUREG/CR-4832, SAND90-0537, Sandia National Laboratories, Albuquerque, NM, July 1992.

240. J. A. Gieseke, P. Cybulskis, R. S. Denning, M. R. Kuhlman, K. W. Lee, and H. Chen, Radionuclide Release Under Specific LWR Accident Conditions, Volume II, BWR, MARK I Design, BMI-2104, Volume II, Battelle Columbus Laboratory, Columbus, OH, July 1984.

241. R. A. Lorenz, J. L. Collins, and A. P. Malinauskas, Nuclear Technology, 46 (1979) 404.

242. S. C. Saxena and R. K. Joshi, Thermal Accommodation and Adsorption Coefficients of Gases, Hemisphere Publishing Company, 1991.

243. F. O. Goodman and H. Y. Wachman, J. Chem. Phys., 46 (1967) 2376.

244. W. F. Phillips, The Physics of Fluids, 18 (1975) 144.

245. B. R. Bowsher and S. Dickinson The Interaction of Caesium Iodide with Boric Acid: Vapour Phase and Vapour-Condensed Phase Reactions, AEEW-R 2102, AEE Winfrith, United Kingdom, May 1986.

246. R. M. Elrick, R. A. Sallach, A. L. Ouellette, S. C. Douglas, Boron Carbide-Steam Reactions with Cesium Hydroxide and with Cesium Iodide at $1270 \mathrm{~K}$ in an Inconel System, NUREG/CR4962, SAND87-1491, Sandia National Laboratories, Albuquerque, NM, September 1987.

247. R. G. Bock, J. D. Duncan, and J. E. Leonard, Nuclear Technology, 11 (1971) 532. 
References

248. R. E. Adams and M. L. Tobias, Uranium Oxide AAerosolrExperiments in Steam-Ain Atmosphe'res: NSPP Tests 401-407 Data Record Report, NUREG/CR-4716, ORNL/TM-10165, Oak/Riáge National Laboratory, Oak Ridge, TN, September 1986.

249. M. L. Tobias and R. E. Adams, Limestone Concrete Aerosol Experiments in Steam-Air Atmospheres: NSPP Tests 521, 522, and 531, Data Record Report, NUREG/CR-5017, ORNU/ATM-10587, Oak Ridge National Laboratory, Oak Ridge, TN, October 1987.

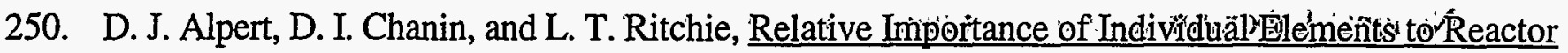
Accident Consequences Assuming Equal Releases Fractions, NUREG/CR-4467, SAND85-2575, Sandia National Laboratories, Albuquerque, NM, March 1986.

251. I. V. Derevich and L. I. Zaichik, High Temperature, 26 (1988) 120.

252. I. S. Goldberg, J. Aerosol Sci., 12 (1981) 11.

253. S. A. Gokaglu and D. E. Rosner, AIAA Journal, 24 (1986) 172.

254. H. M. Park and D. E. Rosner, Chem. Eng. Sci., 44 (1989)' 2233'.

254a. D. E. Rosner and H. M. Park, Chem. Eng. Sci., 43 (1988) 2689.

255. S. A. Gokoglu and D. E. Rosner, Chem. Eng. Commun., 44 (1986) 107.

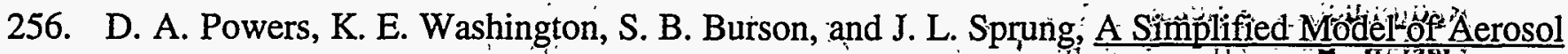
Removed by Natural Processes in Reactor Containments, NUREG/CR-6189;'SAND=9407,'Sandia National Laboratories, Albuquerque, NM, July 1996.

257. P. von der Hardt and A. Tattegrain, J. Nuclear Materials, 188 (1992) 115.

258. A. Kupferberg and G. J. Jameson, Trans. Instu. Chem. Engrs., 47 (1969) 241.

259. T. B. Guy and T. J. Ledwidge, Int. J. Heat Mass Transfer, 16 (1973) 2393.

260. W. V. Pinczewski, Chemical Engineering Science, 36 (1981) 405.

261. R. B. H. Tan and I. J. Harris Chemical Engineering Science, 41 (1986) 3175.

262. J. Singh and D. K. Gupta Indian J. Technology, 25 (1987) 457.

263. A. Jeje and B. Ross, Chemical Engineering Science, 43 (1988) 2817.

264. S. C. Cho and W. K. Lee, Chemical Engineering Science, 46 (1991) 789.

265. A. K. Chesters, M. van Doorn, and L. H. J. Goosens, Int'l J. Multiphase Flow, 6 (1980) 499.

266. Y. Sahai and R. I. L. Guthrie, Metallurgical Transactions B, $13 B$ (1982) 193. 
267. A. C. Lochiel and P. H. Calderbank, Chemical Engineering Science, 19 (1964) 471.

268. T. J. Heames et al., VICTORIA: A Mechanistic Model of Radionuclide Behavior in the Reactor Coolant System Under Severe Accident Conditions, NUREG/CR-5545, SAND90-0756, Rev. 1, Sandia National Laboratories, Albuquerque, NM, December 1992.

269. D. E. Knuth, Seminumerical Algorithms, second edition, Addison-Wesley Publishing Co., 1981.

270. R. E. Blose et al., SWISS 1 and 2: Sustained Interactions of Molten Steel and Concrete in the Presence of Water, NUREG/CR-4727, SAND85-1546, Sandia National Laboratories, Albuquerque, NM, July 1987.

271. T. G. Theofanous, W. H. Amarasooriya, H. Yan, and U. Ratman, The Probability of Liner Failure in a Mark I Containment, NUREG/CR-5423, University of California, Santa Barbara, CA, July 1989.

272. I. Cook and S. Unwin, Nuclear Science and Engineering, 94 (1986) 107.

273. H. Jordan and M. R. Kuhlman, Trapmelt 2 User's Manual, NUREG/CR-4205, BMI-2621, Battelle Columbus Laboratory, Columbus, OH, 1985.

274. C. G. Granquist and R. A. Buhrman, Solid State Communications, 18 (1976) 123.

275. S. R. Forrest and T. A. Witten, J. Phys. A, 12 (1979) L109.

276. P. Meakin, J. Chem. Phys., 81 (1984) 4637.

277. R. Richter, L. M. Sanders, and Z. Cheng, J. Colloid Interface Science, 100 (1984) 203.

278. J. Feder, T. Jossang, and E. Rosenquist, Phys. Rev. Letters, 53 (1984) 1403.

279. J. E. Martin, D. W. Schaefer, and A. Hurd, Phys. Rev., A33 (1986) 3540.

280. R. D. Mountain, G. W. Mulholland, and H. Baum, J. Colloid Interface Science, 114 (1986) 67.

281. R. J. Samson, G. W. Mulholland, and J. W. Gentry, Langmuir, 3 (1987) 272.

282. A. J. Hurd and W. L. Fowler, J. Colloid Interface Science, 122 (1988) 178.

283. H. X. Zhang, C. M. Sorensen, E. R. Ramer, B. J. Olivier, and J. F. Merkin, Langmuir, 4 (1988) 867.

284. G. W. Mulholland, R. J. Samson, R. D. Mountain, and M. H. Ernst, Energy and Fuels, 2 (1988) 481.

285. F. Lesaffre, J. Aerosol Science, 20 (1989) 857. 
286. P. Meakin, B. Donn, and G. W. Mullholand, Langmuir, 5 (1989) 510.

287. C. M. Megaridis and R. A. Dobbins, Combustion Science and Technology. 71 (1990) 95.

288. T. T. Charalampopoulos and H. Chang, Combustion and Flame, 87.(199,1) 89.

289. F. Herning and L. Zipperer, Gas Wasserfach., 79 (1936) 49.

290. S. K. Loyalka and J. H. Ferziger, Physics of Fluids, 11 (1968) 1668.

291. P. J. Kerney, G. M. Faeth, and D. R. Olson, AIChE J., 18 (1972) 548.

292. K. Fischer and W. Häfner, Retention of Aerosols in Water Pools, BF $-V_{T} 38,070-01$, Battelle Engineering Corp., Frankfurt am Main, Germany, March 1994 [in German].

293. H. Schmidt, Int. J. Heat Mass Transport, 20 (177) 635.

294. A. Boushehni, J. Bzowski, J. Kestin, and E. A. Mason, J. Phys. Chem. Ref. Data, 16 (1987) 445 .

295. B. K. Annis, A. P. Malinauskus, and E. A. Mason, J. Aerosol Science, 3 (1972) 55. 


\section{Appendix A \\ Tabulations of Uncertainty Distributions}

Uncertainty distributions calculated in this work for:

- $\log _{10}$ DF (FE): logarithm of the decontamination factor for bubble formation and equilibration,

- $\log _{10} \mathrm{DF}$ (rise): logarithm of the decontamination factor associated with the bubble rise through the suppression pool,

- $\log _{10}$ DF (total): logarithm of the total decontamination of aerosol-laden gases passing through the steam suppression pool,

- $d_{p}(\mu m)$ : mean particle size of aerosol that emerges from the suppression pool, and

- $\sigma_{\mathrm{g}}$ : standard deviation of the particle size distribution that emerges from the suppression pool

are tabulated in Tables A-1 to A-75. Tabulations show the ranges of values at confidence levels of 90 percent and 50 percent for percentiles of the cumulative distribution from 5 to 95 percentiles at 5 percent intervals. Distributions are shown for pool depths of $100,200,300,500$, and $700 \mathrm{~cm}$. The mean of the sample used to construct each uncertainty distribution is also listed, but it should be noted that the mean has no particular statistical significance for the distributions listed here. 
Table A-1. Uncertainty distribution for decontamination during bubble formation and equilibration of gap release through a ' $T$ ' quencher $100 \mathrm{~cm}$ deep

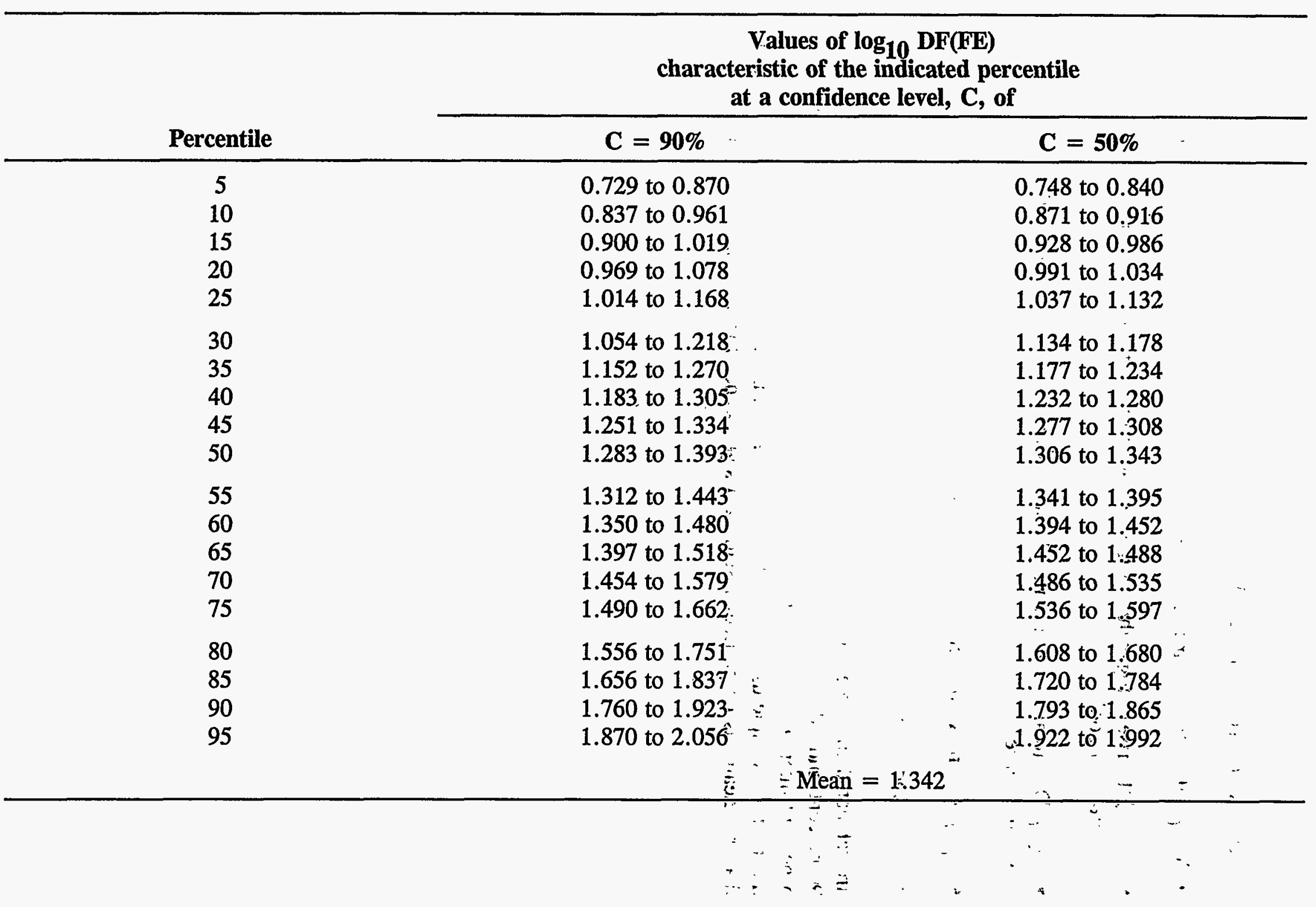


Table A-2. Uncertainty distribution for decontamination of gap release during bubble rise from a ' $T$ ' quencher $100 \mathrm{~cm}$ deep

\begin{tabular}{|c|c|c|}
\hline \multirow[b]{2}{*}{ Percentile } & \multicolumn{2}{|c|}{$\begin{array}{l}\text { Values of } \log _{10} \mathrm{DF} \text { (rise) } \\
\text { characteristic of the indicated percentile } \\
\text { at a confidence level, } \mathrm{C} \text {, of }\end{array}$} \\
\hline & $\mathrm{C}=90 \%$ & $\mathrm{C}=\mathbf{5 0 \%}$ \\
\hline $\begin{array}{c}5 \\
10 \\
15 \\
20 \\
25\end{array}$ & $\begin{array}{l}0.0308 \text { to } 0.0450 \\
0.0399 \text { to } 0.0548 \\
0.0478 \text { to } 0.0673 \\
0.0549 \text { to } 0.0798 \\
0.0656 \text { to } 0.0851\end{array}$ & $\begin{array}{l}0.0345 \text { to } 0.0400 \\
0.0456 \text { to } 0.0507 \\
0.0544 \text { to } 0.0604 \\
0.0617 \text { to } 0.0701 \\
0.0704 \text { to } 0.0825\end{array}$ \\
\hline $\begin{array}{l}30 \\
35 \\
40 \\
45 \\
50\end{array}$ & $\begin{array}{r}0.0733 \text { to } 0.106 \\
0.0836 \text { to } 0.114 \\
0.0963 \text { to } 0.123 \\
0.110 \text { to } 0.143 \\
0.118 \text { to } 0.172\end{array}$ & $\begin{array}{c}0.0827 \text { to } 0.0914 \\
0.0902 \text { to } 0.108 \\
0.108 \text { to } 0.116 \\
0.116 \text { to } 0.125 \\
0.124 \text { to } 0.155\end{array}$ \\
\hline $\begin{array}{l}55 \\
60 \\
65 \\
70 \\
75\end{array}$ & $\begin{array}{l}0.126 \text { to } 0.205 \\
0.160 \text { to } 0.237 \\
0.177 \text { to } 0.263 \\
0.225 \text { to } 0.314 \\
0.248 \text { to } 0.361\end{array}$ & $\begin{array}{l}0.145 \text { to } 0.173 \\
0.173 \text { to } 0.218 \\
0.217 \text { to } 0.242 \\
0.241 \text { to } 0.273 \\
0.273 \text { to } 0.332\end{array}$ \\
\hline $\begin{array}{l}80 \\
85 \\
90 \\
95\end{array}$ & $\begin{array}{l}0.291 \text { to } 0.406 \\
0.350 \text { to } 0.446 \\
0.409 \text { to } 0.594 \\
0.579 \text { to } 0.860\end{array}$ & $\begin{array}{l}0.335 \text { to } 0.371 \\
0.380 \text { to } 0.419 \\
0.425 \text { to } 0.577 \\
0.592 \text { to } 0.727\end{array}$ \\
\hline
\end{tabular}


Table A-3. Uncertainty distribution for the total gap release decontamination after passing through a ' $T$ ' quencher $100 \mathrm{~cm}$ deep

Values of $\log _{10} \mathrm{DF}$ (total)

characteristic of the indicated percentile

at a confidence level, $\mathrm{C}$, of

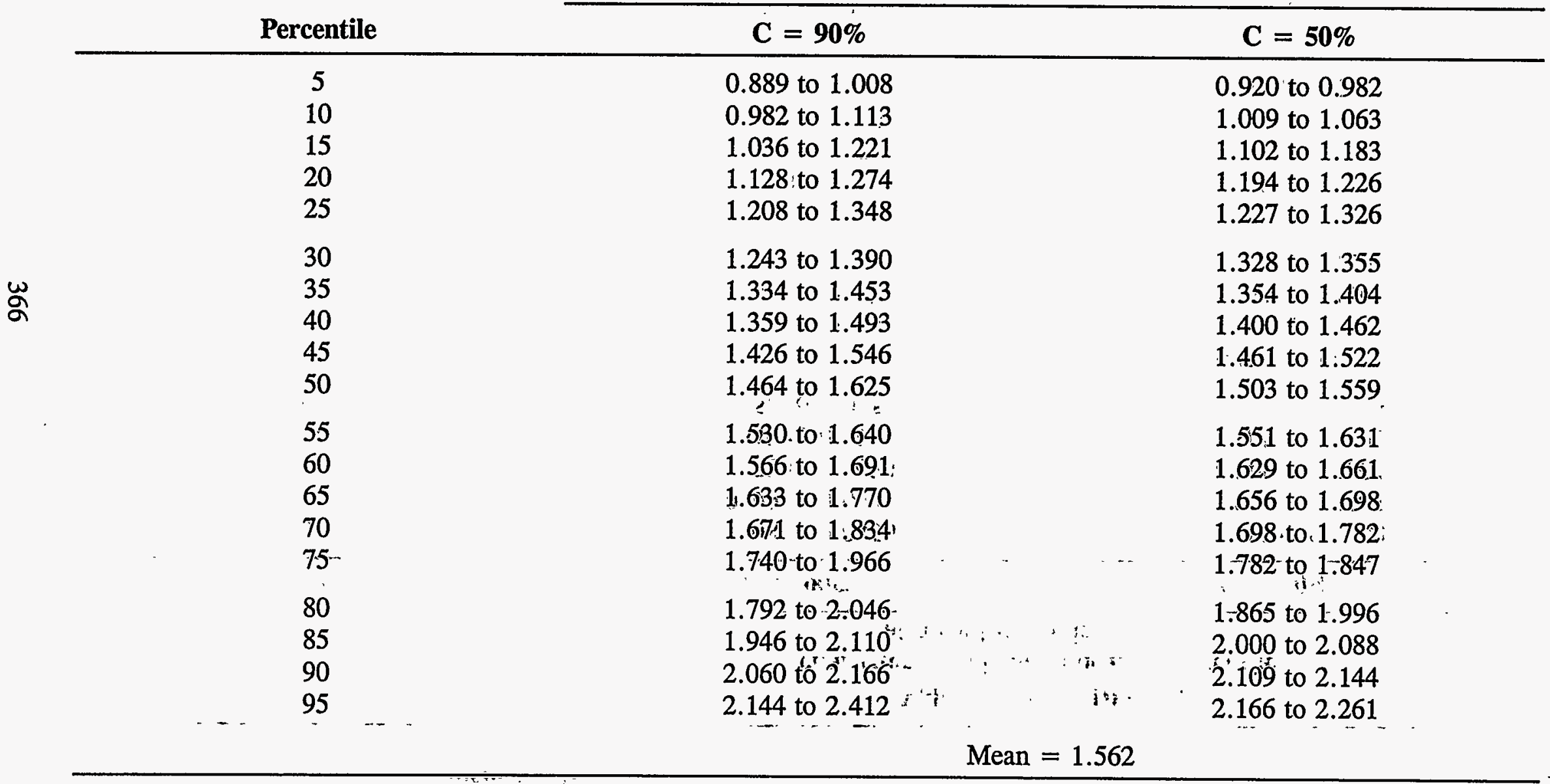


Table A-4. Uncertainty distribution for the mean particle size of gap release after passing through a ' $T$ ' quencher $100 \mathrm{~cm}$ deep

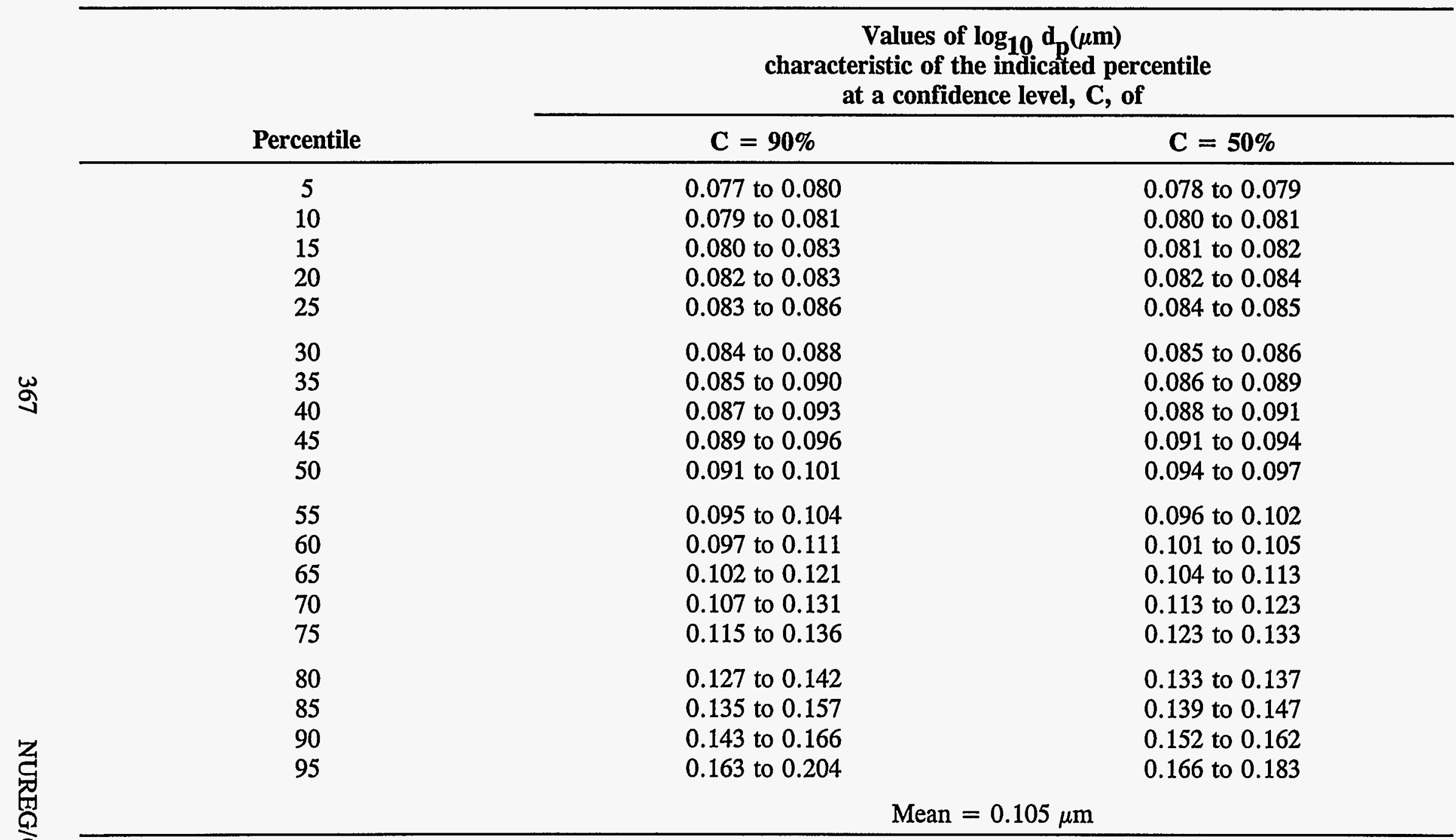


Table A-5. Uncertainty distribution for the standard deviation of gap release after passing through a ' $T$ ' quencher $100 \mathrm{~cm}$ deep

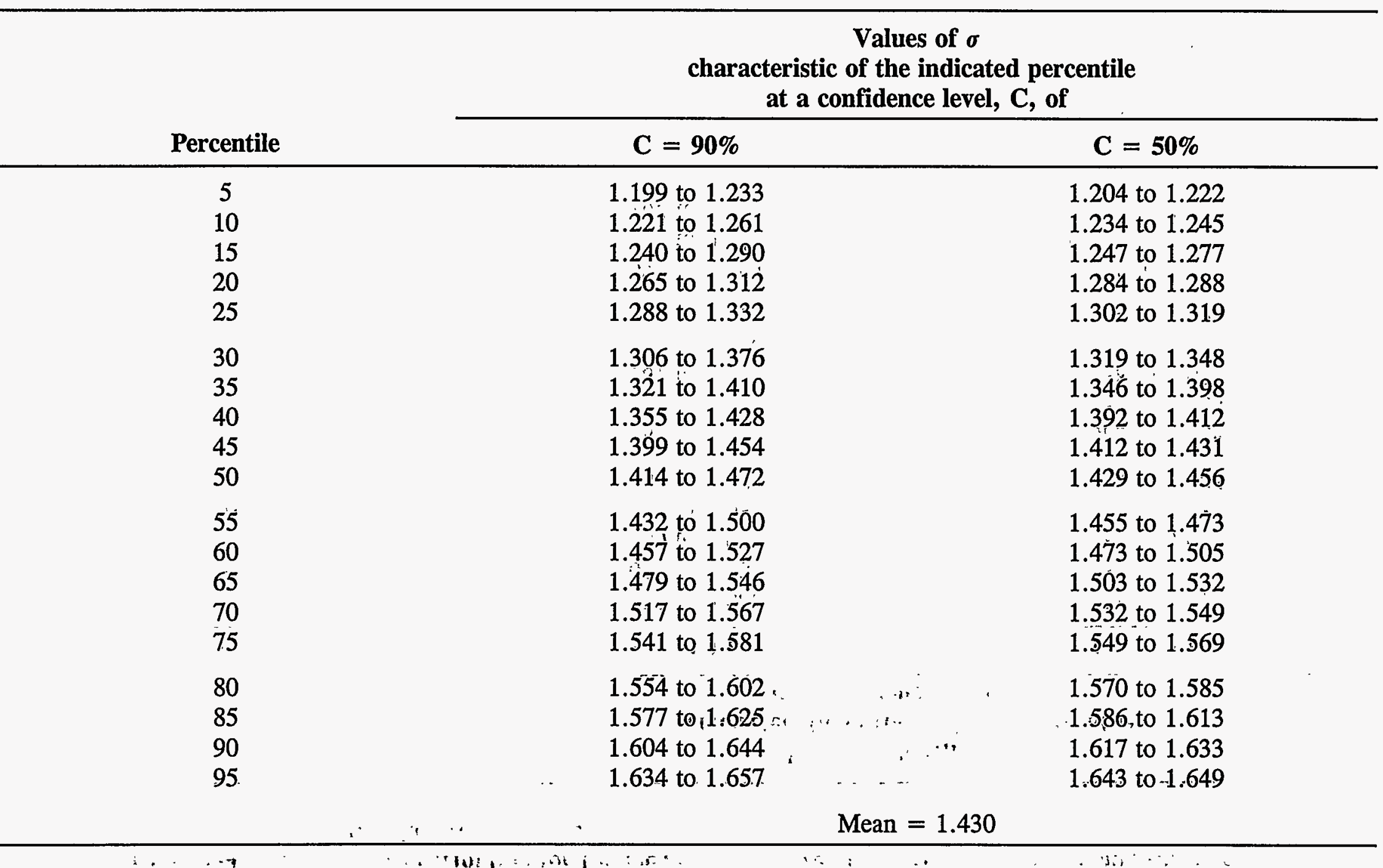


Table A-6. Uncertainty distribution for decontamination during bubble formation and equilibration of gap release through a ' $T$ ' quencher $200 \mathrm{~cm}$ deep

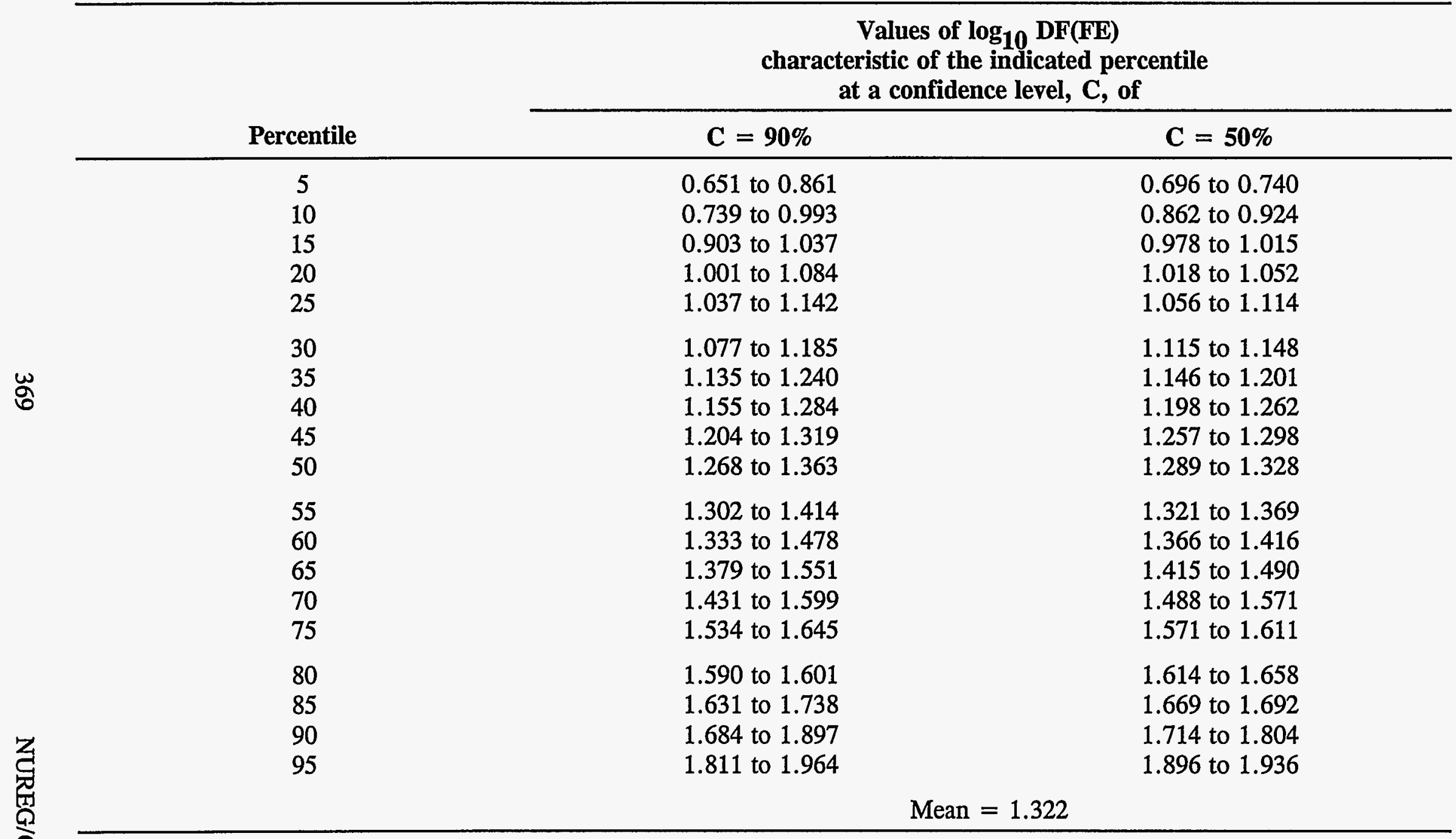


Table A-7. Uncertainty distribution for decontamination of gap release during bubble rise from a ' $T$ ' quencher $200 \mathrm{~cm}$ deep

\begin{tabular}{|c|c|c|}
\hline \multirow[b]{2}{*}{ Percentile } & \multicolumn{2}{|c|}{$\begin{array}{c}\text { Values of } \log _{10} \mathrm{DF} \text { (rise) } \\
\text { characteristic of the indicated percentile } \\
\text { at a confidence level, } \mathrm{C} \text {, of }\end{array}$} \\
\hline & $\mathrm{C}=90 \%$ & $\mathrm{C}=\mathbf{5 0 \%}$ \\
\hline $\begin{array}{c}5 \\
10 \\
15 \\
20 \\
25\end{array}$ & $\begin{array}{l}0.0870 \text { to } 0.122 \\
0.105 \text { to } 0.157 \\
0.135 \text { to } 0.173 \\
0.159 \text { to } 0.182 \\
0.172 \text { to } 0.220\end{array}$ & $\begin{array}{r}0.0911 \text { to } 0.105 \\
0.124 \text { to } 0.139 \\
0.155 \text { to } 0.163 \\
0.166 \text { to } 0.176 \\
0.177 \text { to } 0.189\end{array}$ \\
\hline $\begin{array}{l}30 \\
35 \\
40 \\
45 \\
50\end{array}$ & $\begin{array}{l}0.179 \text { to } 0.248 \\
0.196 \text { to } 0.320 \\
0.235 \text { to } 0.378 \\
0.272 \text { to } 0.417 \\
0.332 \text { to } 0.491\end{array}$ & $\begin{array}{l}0.190 \text { to } 0.227 \\
0.227 \text { to } 0.265 \\
0.259 \text { to } 0.331 \\
0.329 \text { to } 0.398 \\
0.388 \text { to } 0.431\end{array}$ \\
\hline $\begin{array}{l}55 \\
60 \\
65 \\
70 \\
75\end{array}$ & $\begin{array}{l}0.399 \text { to } 0.520 \\
0.446 \text { to } 0.590 \\
0.502 \text { to } 0.678 \\
0.550 \text { to } 0.7 .16 \\
0.637 \text { to } 0.794\end{array}$ & $\begin{array}{l}0.422 \text { to } 0.499 \\
0.496 \text { to } 0.531 \\
0.530 \text { to } 0.603 \\
0.603 \text { to } 0.692 \\
0.692 \text { to } 0.733\end{array}$ \\
\hline $\begin{array}{l}80 \\
85 \\
90 \\
95\end{array}$ & $\begin{array}{l}0.705 \text { to } 0.884 \\
0.785 \text { to } 1.010^{*} \\
0.904 \text { to }: 1.220 \\
1.114 \text { to } 1.677\end{array}$ & $\begin{array}{l}0.741 \text { to } 0.820 \\
0.828 \text { to } 0.918 \\
0.985 \text { to } 1.100 \\
1.021 \text { to } 1.423\end{array}$ \\
\hline
\end{tabular}


Table A-8. Uncertainty distribution for the total gap release decontamination after passing through a ' $T$ ' quencher $200 \mathrm{~cm}$ deep

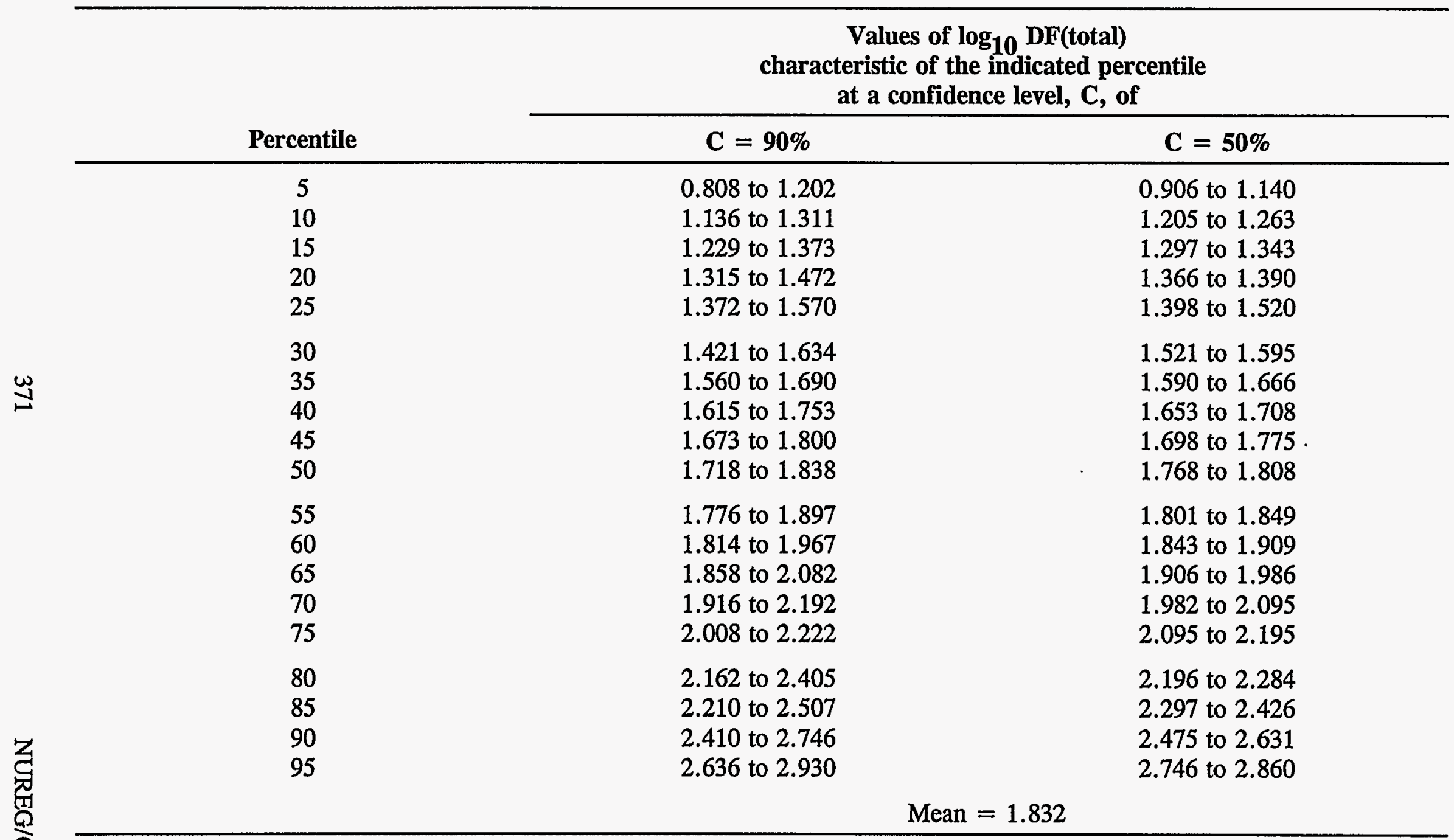


Table A-9. Uncertainty distribution for mean particle size of gap release after flow through a ' $T$ ' quencher $200 \mathrm{~cm}$ deep

Values of $\mathbf{d}_{\mathrm{p}}(\mu \mathrm{m})$

characteristic of the indicated percentile

at a confidence level, $C$, of

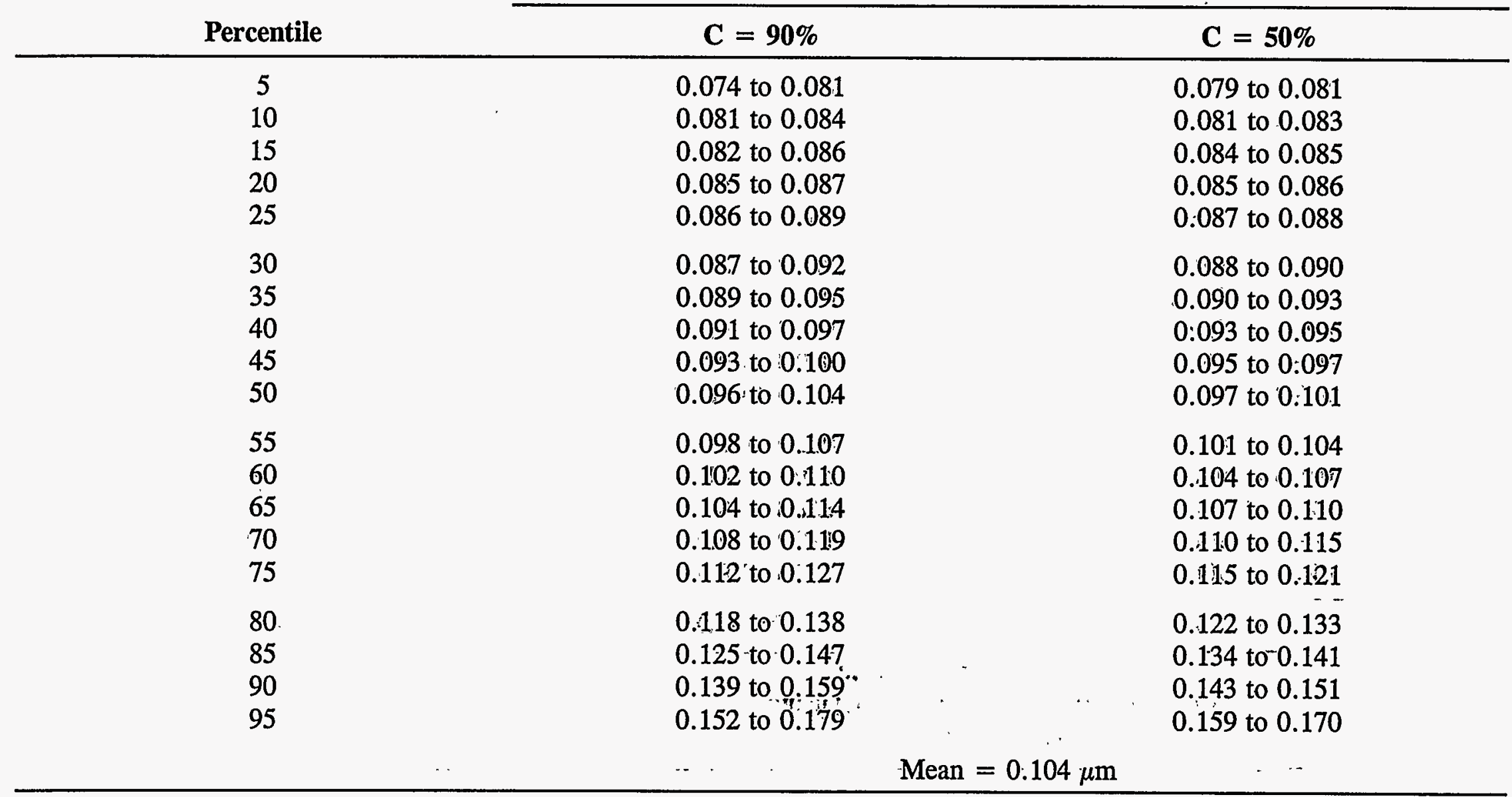


Table A-10. Uncertainty distribution for standard deviation of gap release after passing through a ' $T$ ' quencher $200 \mathrm{~cm}$ deep

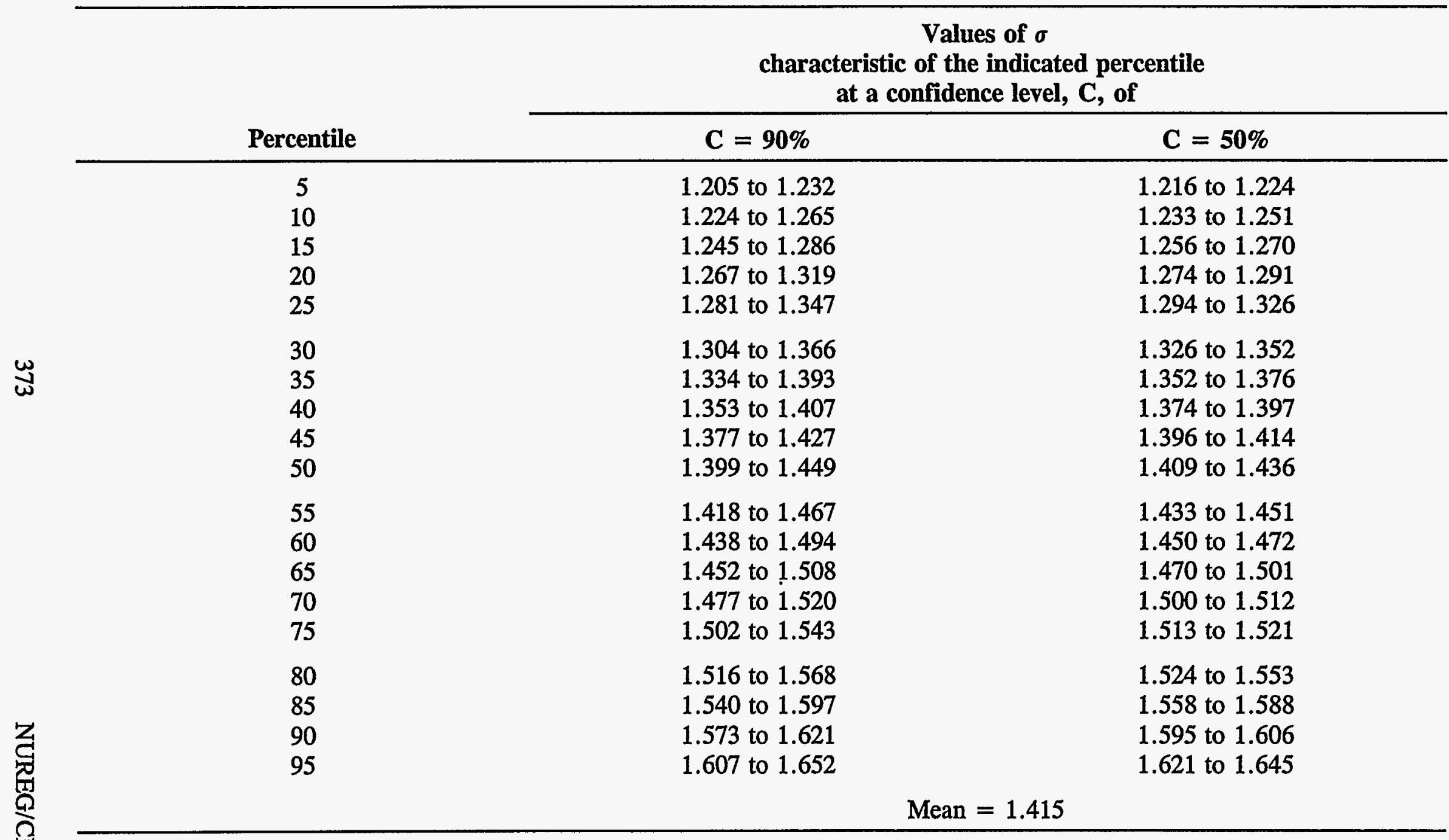


Table A-11. Uncertainty distribution for the decontamination of gap release material during bubble formation and equilibration at a ' $T$ ' quencher $300 \mathrm{~cm}$ deep

\begin{tabular}{|c|c|c|}
\hline \multirow[b]{2}{*}{ Percentile } & \multicolumn{2}{|c|}{$\begin{array}{l}\text { Values of } \log _{10} \mathrm{DF}(\mathrm{FE}) \\
\text { characteristic of the indicated percentile } \\
\text { at a confidence level, } C \text {, of }\end{array}$} \\
\hline & $\mathrm{C}=90 \%$ & $C=50 \%$ \\
\hline $\begin{array}{c}5 \\
10 \\
15 \\
20 \\
25\end{array}$ & $\begin{array}{l}0.729 \text { to } 0.864 \\
0.865 \text { to } 0.986 \\
0.962 \text { to } 1.060 \\
1.036 \text { to } 1.095 \\
1.080 \text { to } 1.132\end{array}$ & $\begin{array}{l}0.780 \text { to } 0.835 \\
0.916 \text { to } 0.950 \\
0.992 \text { to } 1.037 \\
1.060 \text { to } 1.081 \\
1.091 \text { to } 1.112\end{array}$ \\
\hline $\begin{array}{l}30 \\
35 \\
40 \\
45 \\
50\end{array}$ & $\begin{array}{l}1.105 \text { to } 1.173 \\
1.148 \text { to } 1.232 \\
1.190 \text { to } 1.282 \\
1.234 \text { to } 1.318 \\
1.291 \text { to } 1.348\end{array}$ & $\begin{array}{l}1.127 \text { to } 1.158 \\
1.167 \text { to } 1.197 \\
1.215 \text { to } 1.254 \\
1.264 \text { to } 1.299 \\
1.305 \text { to } 1.334\end{array}$ \\
\hline $\begin{array}{l}55 \\
60 \\
65 \\
70 \\
75:\end{array}$ & $\begin{array}{l}1.323 \text { to } 1.375 \\
1.35^{2} \text { to } 1.424 \\
1.381 \text { to } 1.480 \\
1.432 \text { to } 1.526 \\
1.484 \text { to } 1.586\end{array}$ & $\begin{array}{l}1.337 \text { to } 1.363 \\
1.370 \text { to } 1.396 \\
1.412 \text { to } 1.444 \\
1.457 \text { to } 1.502 \\
1.518 \text { to } 1.553\end{array}$ \\
\hline $\begin{array}{l}80 \\
85 \\
90 \\
95\end{array}$ & $\begin{array}{l}1.550 \text { to } 1.669 \\
1.633 \text { to } 1 ! 731 \\
1.696 \text { to } 1.836 \\
1.838 \text { to } 1.945\end{array}$ & $\begin{array}{l}1.573 \text { to } 1.633 \\
1.665 \text { to } 1.692 \\
1.736 \text { to } 1.792 \\
1.876 \text { to } 1.921\end{array}$ \\
\hline & \multicolumn{2}{|c|}{ Mean $=1.324$} \\
\hline
\end{tabular}


Table A-12. Uncertainty distribution for the decontamination of gap release material during bubble rise from a ' $T$ ' quencher $300 \mathrm{~cm}$ deep

\begin{tabular}{|c|c|c|c|}
\hline & \multirow[b]{2}{*}{ Percentile } & \multicolumn{2}{|c|}{$\begin{array}{l}\text { Values of } \log _{10} \mathrm{DF}(\mathrm{rise}) \\
\text { characteristic of the indicated percentile } \\
\text { at a confidence level, } \mathrm{C} \text {, of }\end{array}$} \\
\hline & & $\mathrm{C}=90 \%$ & $C=50 \%$ \\
\hline & $\begin{array}{c}5 \\
10 \\
15 \\
20 \\
25\end{array}$ & $\begin{array}{l}0.147 \text { to } 0.185 \\
0.186 \text { to } 0.219 \\
0.214 \text { to } 0.263 \\
0.245 \text { to } 0.305 \\
0.278 \text { to } 0.352\end{array}$ & $\begin{array}{l}0.168 \text { to } 0.179 \\
0.197 \text { to } 0.213 \\
0.227 \text { to } 0.245 \\
0.262 \text { to } 0.283 \\
0.300 \text { to } 0.326\end{array}$ \\
\hline W్ & $\begin{array}{l}30 \\
35 \\
40 \\
45 \\
50\end{array}$ & $\begin{array}{l}0.318 \text { to } 0.387 \\
0.360 \text { to } 0.434 \\
0.398 \text { to } 0.491 \\
0.438 \text { to } 0.548 \\
0.498 \text { to } 0.602\end{array}$ & $\begin{array}{l}0.340 \text { to } 0.372 \\
0.383 \text { to } 0.411 \\
0.423 \text { to } 0.456 \\
0.473 \text { to } 0.520 \\
0.525 \text { to } 0.575\end{array}$ \\
\hline & $\begin{array}{l}55 \\
60 \\
65 \\
70 \\
75\end{array}$ & $\begin{array}{l}0.552 \text { to } 0.674 \\
0.605 \text { to } 0.758 \\
0.698 \text { to } 0.848 \\
0.780 \text { to } 0.984 \\
0.903 \text { to } 1.165\end{array}$ & $\begin{array}{l}0.590 \text { to } 0.622 \\
0.660 \text { to } 0.718 \\
0.740 \text { to } 0.798 \\
0.837 \text { to } 0.909 \\
0.967 \text { to } 1.117\end{array}$ \\
\hline & $\begin{array}{l}80 \\
85 \\
90 \\
95\end{array}$ & $\begin{array}{l}1.050 \text { to } 1.359 \\
1.247 \text { to } 1.750 \\
1.651 \text { to } 2.078 \\
2.092 \text { to } 2.878\end{array}$ & $\begin{array}{l}1.156 \text { to } 1.248 \\
1.353 \text { to } 1.554 \\
1.785 \text { to } 1.952 \\
2.185 \text { to } 2.538\end{array}$ \\
\hline & \multicolumn{3}{|c|}{ Mean $=0.8265$} \\
\hline
\end{tabular}




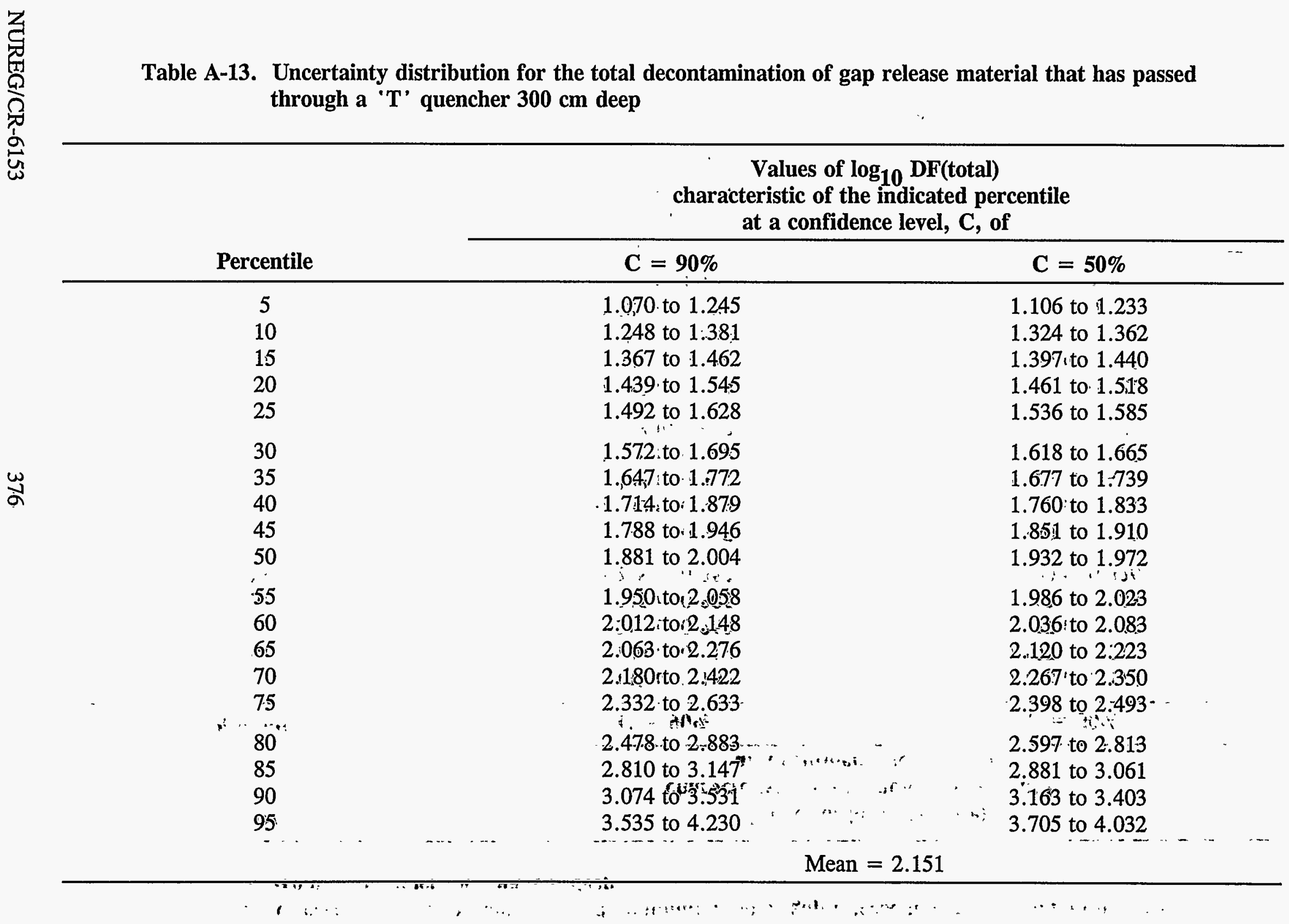


Table A-14. Uncertainty distribution for the mean particle size of gap release material after passing through a ' $T$ ' quencher $300 \mathrm{~cm}$ deep

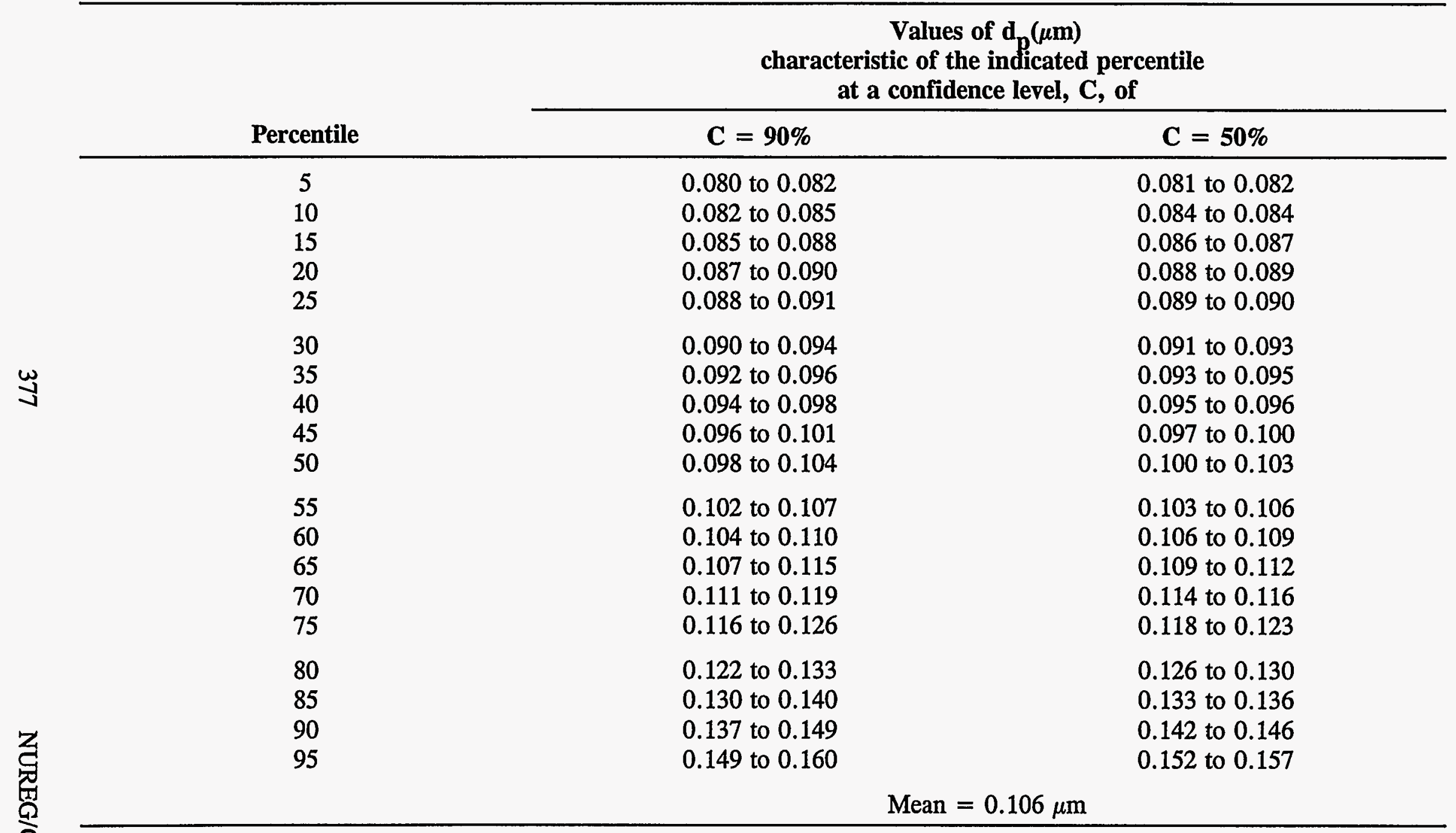


Table A-15. Uncertainty distribution for the standard deviation of gap release material after passing through a ' $T$ ' quencher $300 \mathrm{~cm}$ deep

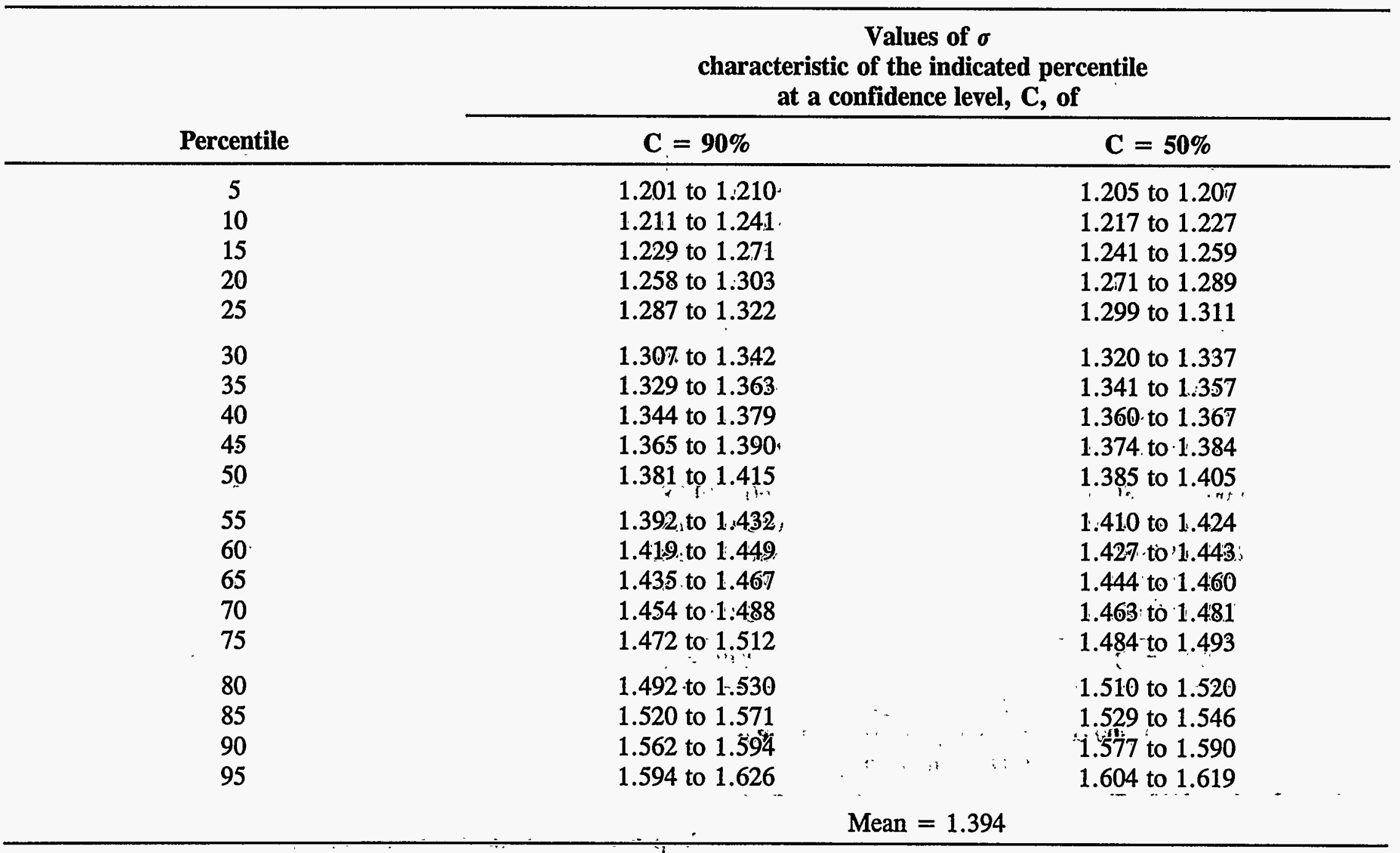


Table A-16. Uncertainty distribution for decontamination during bubble formation and equilibration for gap release through a ' $T$ ' quencher $300 \mathrm{~cm}$ deep

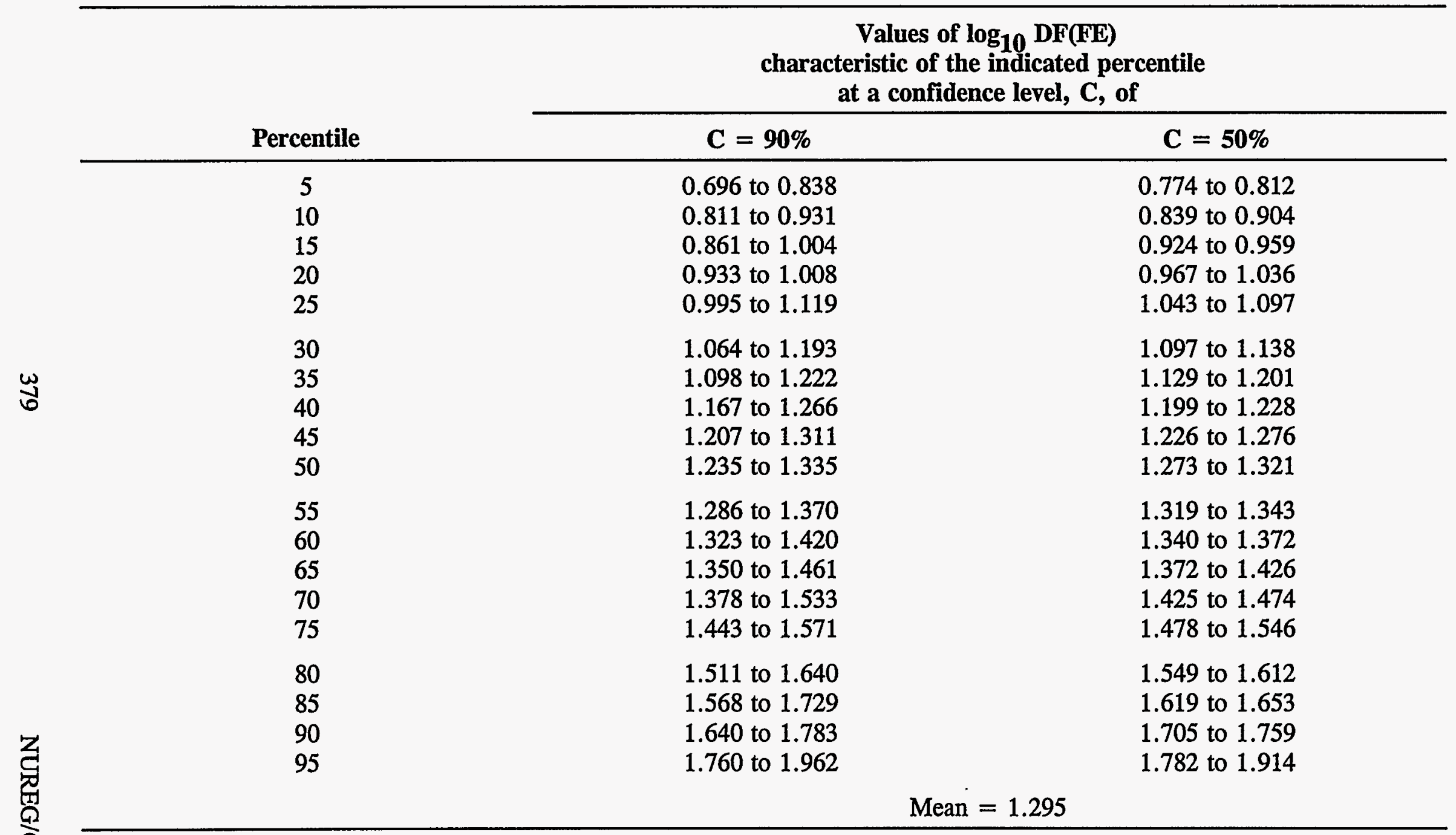


Table A-17. Uncertainty distribution for decontamination of gap release during bubble rise from a ' $T$ ' quencher $500 \mathrm{~cm}$ deep

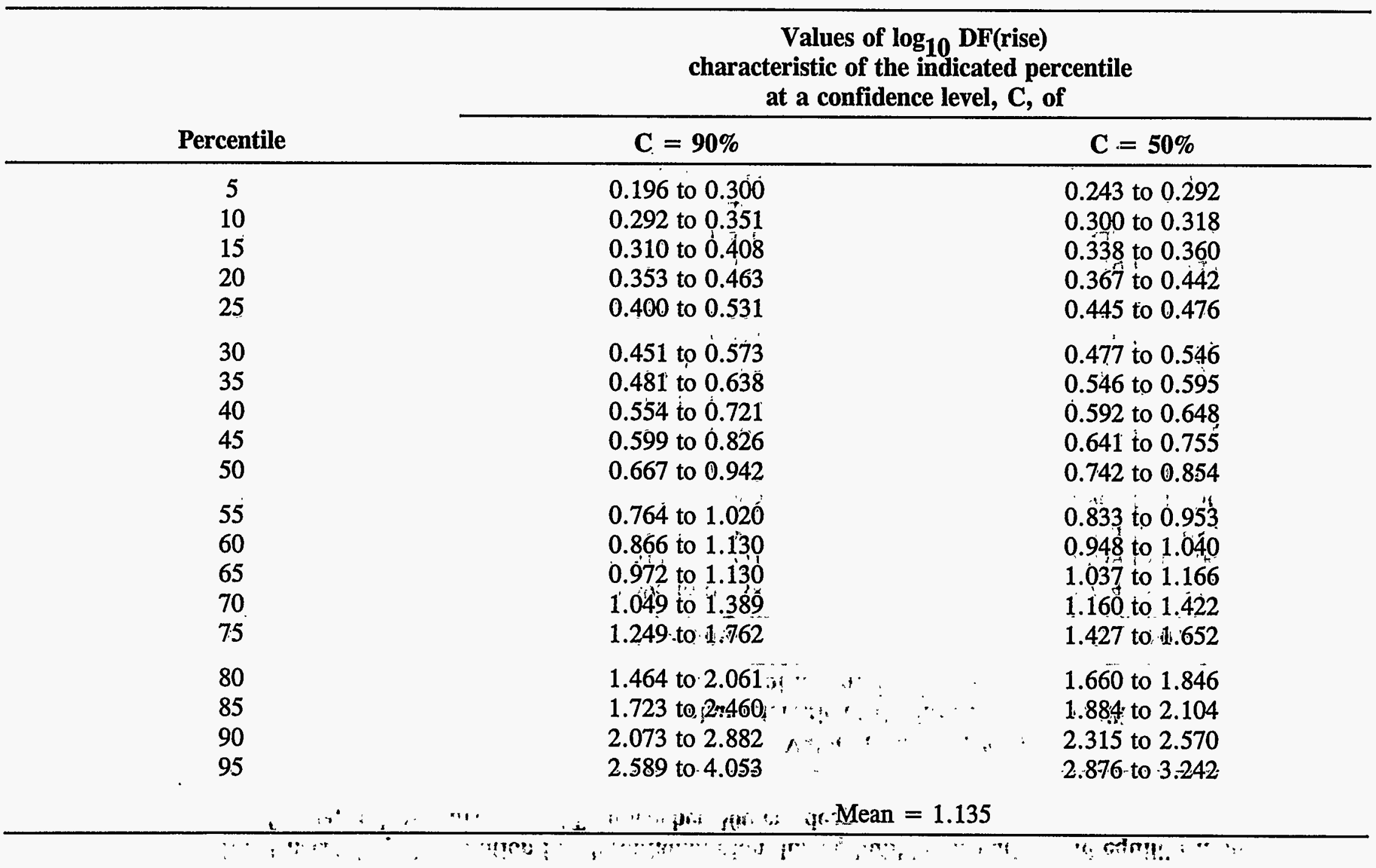


Table A-18. Uncertainty distribution for total gap release decontamination after passing through a ' $T$ ' quencher $500 \mathrm{~cm}$ deep

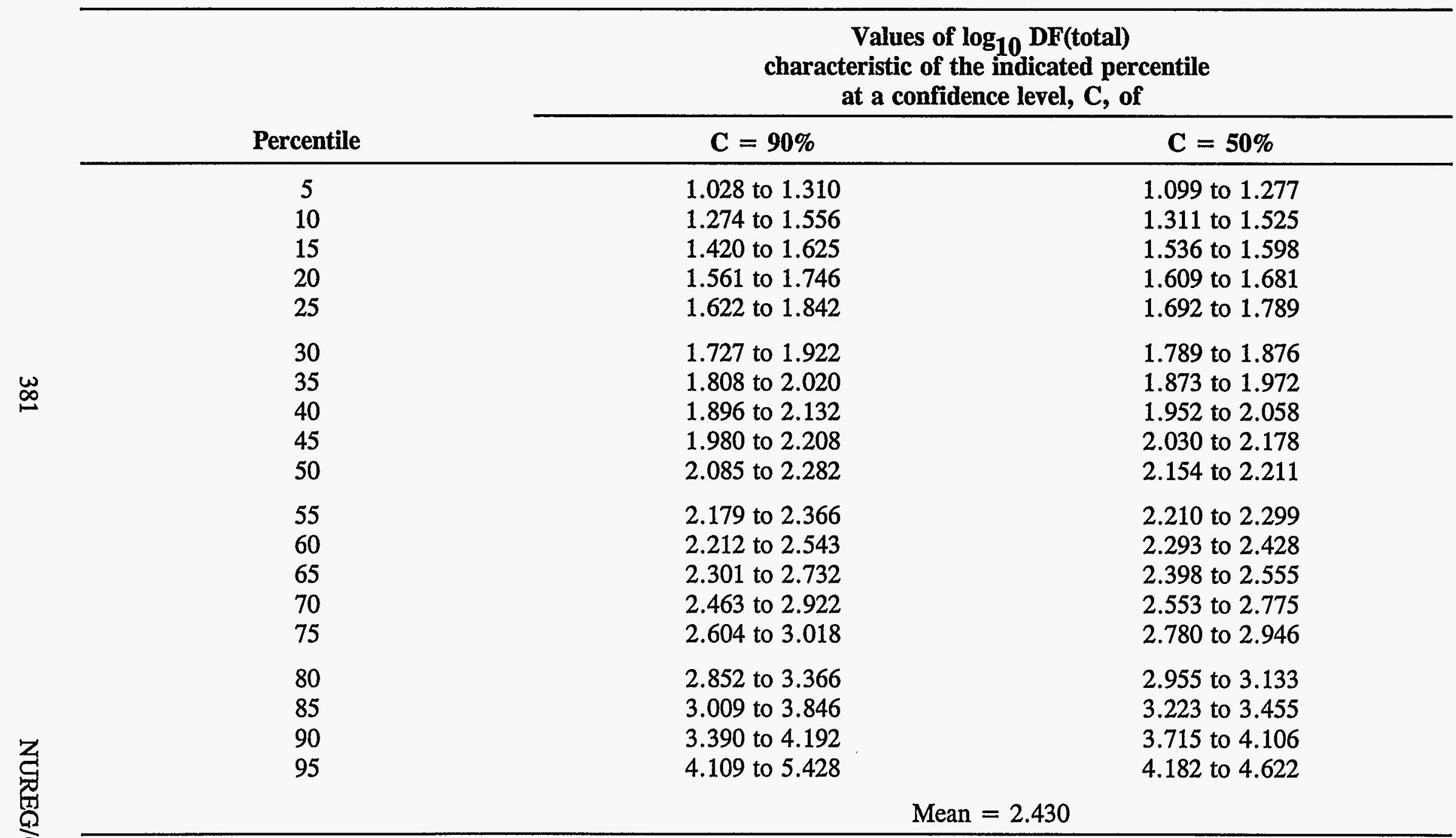


Table A-19. Uncertainty distribution for the mean particle size of gap release material after passing through a ' $T$ ' quencher $500 \mathrm{~cm}$ deep

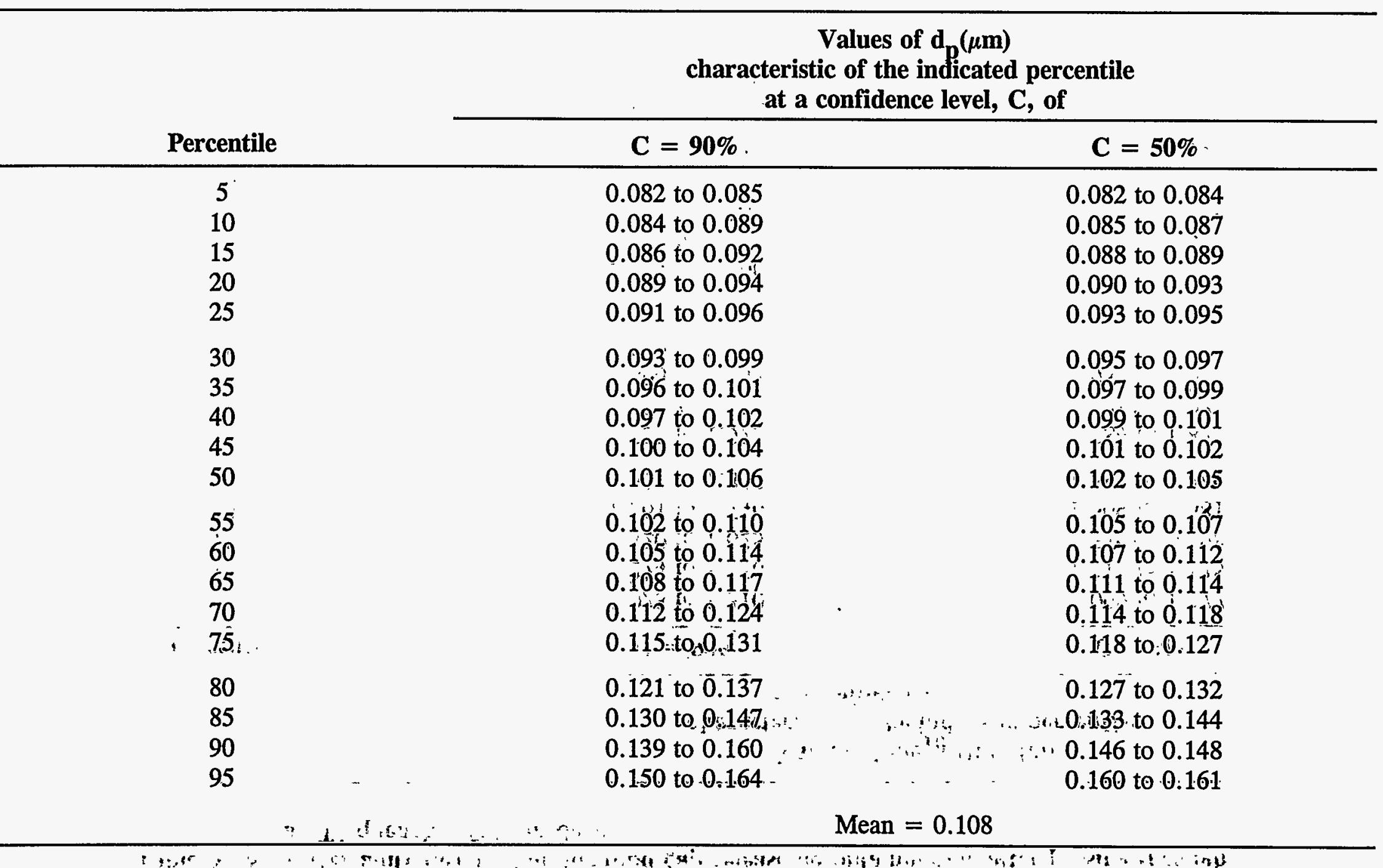


Table A-20. Uncertainty distribution for the geometric standard deviation of release material after passing through a ' $T$ ' quencher $500 \mathrm{~cm}$ deep

\begin{tabular}{|c|c|c|c|}
\hline & \multirow[b]{2}{*}{ Percentile } & \multicolumn{2}{|c|}{$\begin{array}{l}\text { Values of } \sigma \\
\text { characteristic of the indicated percentile } \\
\text { at a confidence level, } C \text {, of }\end{array}$} \\
\hline & & $C=90 \%$ & $\mathrm{C}=\mathbf{5 0 \%}$ \\
\hline & $\begin{array}{c}5 \\
10 \\
15 \\
20 \\
25\end{array}$ & $\begin{array}{l}1.198 \text { to } 1.248 \\
1.240 \text { to } 1.272 \\
1.260 \text { to } 1.292 \\
1.273 \text { to } 1.304 \\
1.290 \text { to } 1.329\end{array}$ & $\begin{array}{l}1.217 \text { to } 1.240 \\
1.248 \text { to } 1.261 \\
1.271 \text { to } 1.283 \\
1.287 \text { to } 1.298 \\
1.299 \text { to } 1.317\end{array}$ \\
\hline & $\begin{array}{l}30 \\
35 \\
40 \\
45 \\
50\end{array}$ & $\begin{array}{l}1.302 \text { to } 1.342 \\
1.323 \text { to } 1.355 \\
1.335 \text { to } 1.369 \\
1.346 \text { to } 1.379 \\
1.359 \text { to } 1.391\end{array}$ & $\begin{array}{l}1.317 \text { to } 1.335 \\
1.334 \text { to } 1.346 \\
1.344 \text { to } 1.357 \\
1.357 \text { to } 1.370 \\
1.370 \text { to } 1.379\end{array}$ \\
\hline & $\begin{array}{l}55 \\
60 \\
65 \\
70 \\
75\end{array}$ & $\begin{array}{l}1.370 \text { to } 1.415 \\
1.381 \text { to } 1.444 \\
1.397 \text { to } 1.455 \\
1.423 \text { to } 1.478 \\
1.450 \text { to } 1.501\end{array}$ & $\begin{array}{l}1.379 \text { to } 1.395 \\
1.393 \text { to } 1.420 \\
1.418 \text { to } 1.449 \\
1.449 \text { to } 1.458 \\
1.458 \text { to } 1.483\end{array}$ \\
\hline & $\begin{array}{l}80 \\
85 \\
90 \\
95\end{array}$ & $\begin{array}{l}1.477 \text { to } 1.521 \\
1.490 \text { to } 1.548 \\
1.522 \text { to } 1.593 \\
1.557 \text { to } 1.637\end{array}$ & $\begin{array}{l}1.483 \text { to } 1.512 \\
1.514 \text { to } 1.528 \\
1.532 \text { to } 1.557 \\
1.593 \text { to } 1.611\end{array}$ \\
\hline
\end{tabular}


Table A-21. Uncertainty distribution for decontamination of gap release by bubble formation and equilibration at a ' $T$ ' quencher $700 \mathrm{~cm}$ deep

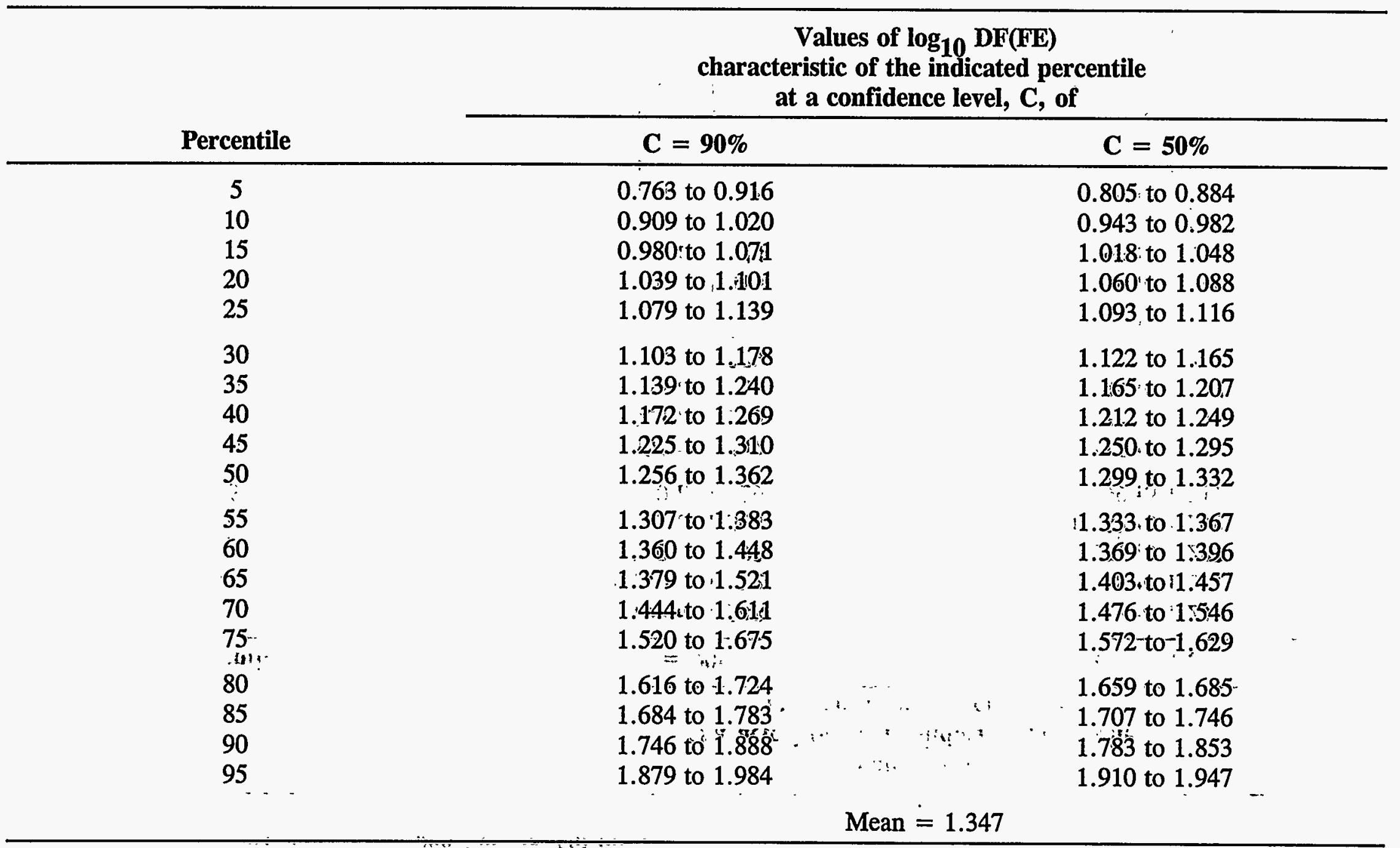


Table A-22. Uncertainty distribution for decontamination of gap release during bubble rise from a ' $T$ ' quencher $700 \mathrm{~cm}$ deep

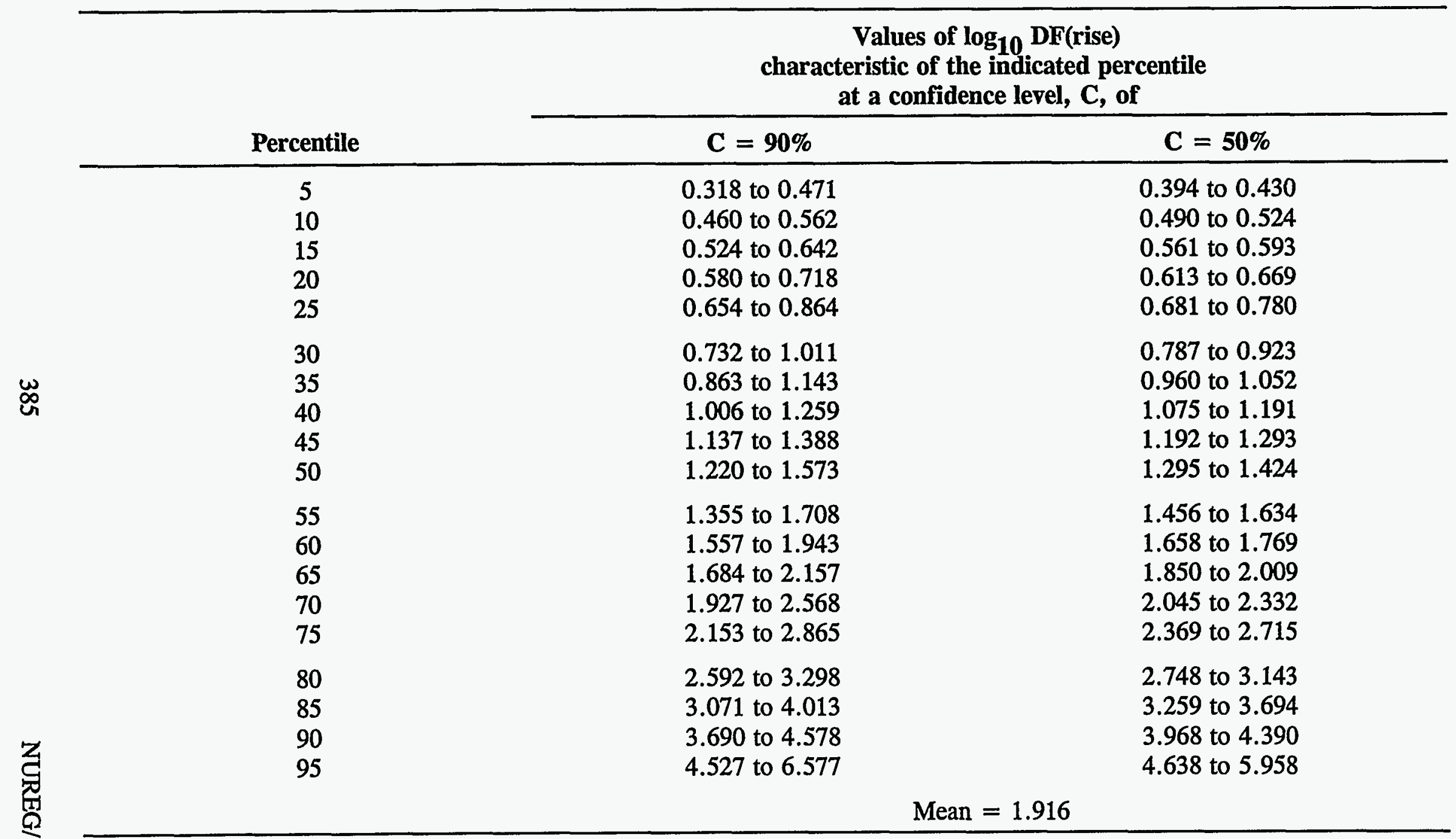


Table A-23. Uncertainty distribution for total decontamination of gap release after passing through $a^{\prime} T$ ' quencher $700 \mathrm{~cm}$ deep

\begin{tabular}{|c|c|c|c|}
\hline \multirow[b]{2}{*}{ Percentile } & \multicolumn{3}{|c|}{$\begin{array}{l}\text { Values of } \log _{10} \mathrm{DF}(\text { total) } \\
\text { characteristic of the indicated percentile } \\
\text { at a confidence level, } \mathrm{C} \text {, of }\end{array}$} \\
\hline & $\mathrm{C}=90 \%$ & & $\mathrm{C}=\mathbf{5 0 \%}$ \\
\hline $\begin{array}{c}5 \\
10 \\
15 \\
20 \\
25\end{array}$ & $\begin{array}{l}1.405 \text { to } 1.653 \\
1.625 \text { to } 1.799 \\
1.740 \text { to } 2.003 \\
1.896 \text { to } 2.152 \\
2.034 \text { to } 2.254\end{array}$ & & $\begin{array}{l}1.500 \text { to } 1.606 \\
1.667 \text { to } 1.741 \\
1.799 \text { to } 1.914 \\
1.955 \text { to } 2.061 \\
2.091 \text { to } 2.209\end{array}$ \\
\hline $\begin{array}{l}30 \\
35 \\
40 \\
45 \\
50\end{array}$ & $\begin{array}{l}2.156 \text { to } 2.372 \\
2.254 \text { to } 2.455 \\
2.361 \text { to } 2.637 \\
2.445 \text { to } 2.787 \\
2.587 \text { to } 2.917\end{array}$ & & $\begin{array}{l}2.222 \text { to } 2.306 \\
2.319 \text { to } 2.397 \\
2.412 \text { to } 2.513 \\
2.549 \text { to } 2.693 \\
2.69 .6 \text { to } 2.858\end{array}$ \\
\hline $\begin{array}{l}55 \\
60 \\
65 \\
70 \\
75\end{array}$ & $\begin{array}{l}2.740 \text { to } 3.097 \\
2.910 \text { to } 3.306 \\
3.082 \text { to } 3.542 \\
3.298 \text { to } 3.849 \\
3.542 \text { tor } 4.360\end{array}$ & & $\begin{array}{l}2.861 \text { to } 2.982 \\
2.999 \text { to } 3.170 \\
3.179 \text { to } 3.422 \\
3.428 \text { to } 3.575 \\
3.599 \text { to } 3.947\end{array}$ \\
\hline $\begin{array}{l}80 \\
85 \\
90 \\
95\end{array}$ & $\begin{array}{l}3.896 \text { to } 4.716 \\
4.529 \text { to } 5.493 \\
5.167 \text { to } 6.114 \\
5.947 \text { to } 8.018\end{array}$ & $\begin{array}{c}\because \cdots, \cdot \\
\cdots \cdot \\
\cdots\end{array}$ & $\begin{array}{l}4.171 \text { to } 4.532 \\
4.646 \text { to } 5.170 \\
5.450 \text { to } 5.742 \\
6.384 \text { to } 7.506\end{array}$ \\
\hline \multicolumn{4}{|c|}{ Mean $=3.264$} \\
\hline
\end{tabular}


Table A-24. Uncertainty distribution for the mean particle size of gap release after passing through a ' $T$ ' quencher $700 \mathrm{~cm}$ deep

\begin{tabular}{|c|c|c|}
\hline \multirow[b]{2}{*}{ Percentile } & \multicolumn{2}{|c|}{$\begin{array}{l}\text { Values of } d_{p}(\mu \mathrm{m}) \\
\text { characteristic of the indicated percentile } \\
\text { at a confidence level, } C \text {, of }\end{array}$} \\
\hline & $\mathrm{C}=90 \%$ & $\mathrm{C}=\mathbf{5 0 \%}$ \\
\hline $\begin{array}{c}5 \\
10 \\
15 \\
20 \\
25\end{array}$ & $\begin{array}{l}0.085 \text { to } 0.089 \\
0.088 \text { to } 0.093 \\
0.091 \text { to } 0.095 \\
0.094 \text { to } 0.098 \\
0.096 \text { to } 0.101\end{array}$ & $\begin{array}{l}0.086 \text { to } 0.087 \\
0.090 \text { to } 0.091 \\
0.093 \text { to } 0.094 \\
0.095 \text { to } 0.096 \\
0.097 \text { to } 0.099\end{array}$ \\
\hline $\begin{array}{l}30 \\
35 \\
40 \\
45 \\
50\end{array}$ & $\begin{array}{l}0.098 \text { to } 0.103 \\
0.101 \text { to } 0.104 \\
0.102 \text { to } 0.106 \\
0.104 \text { to } 0.110 \\
0.106 \text { to } 0.112\end{array}$ & $\begin{array}{l}0.100 \text { to } 0.101 \\
0.102 \text { to } 0.103 \\
0.104 \text { to } 0.105 \\
0.105 \text { to } 0.109 \\
0.109 \text { to } 0.111\end{array}$ \\
\hline $\begin{array}{l}55 \\
60 \\
65 \\
70 \\
75\end{array}$ & $\begin{array}{l}0.110 \text { to } 0.115 \\
0.112 \text { to } 0.117 \\
0.115 \text { to } 0.121 \\
0.117 \text { to } 0.125 \\
0.121 \text { to } 0.132\end{array}$ & $\begin{array}{l}0.111 \text { to } 0.113 \\
0.114 \text { to } 0.116 \\
0.117 \text { to } 0.119 \\
0.119 \text { to } 0.123 \\
0.124 \text { to } 0.128\end{array}$ \\
\hline $\begin{array}{l}80 \\
85 \\
90 \\
95\end{array}$ & $\begin{array}{l}0.126 \text { to } 0.137 \\
0.133 \text { to } 0.146 \\
0.143 \text { to } 0.154 \\
0.152 \text { to } 0.172\end{array}$ & $\begin{array}{l}0.130 \text { to } 0.133 \\
0.135 \text { to } 0.143 \\
0.146 \text { to } 0.151 \\
0.155 \text { to } 0.164\end{array}$ \\
\hline
\end{tabular}


Table A-25. Uncertainty distribution for the standard deviation of gap release after passing through a ' $T$ ' quencher $700 \mathrm{~cm}$ deep

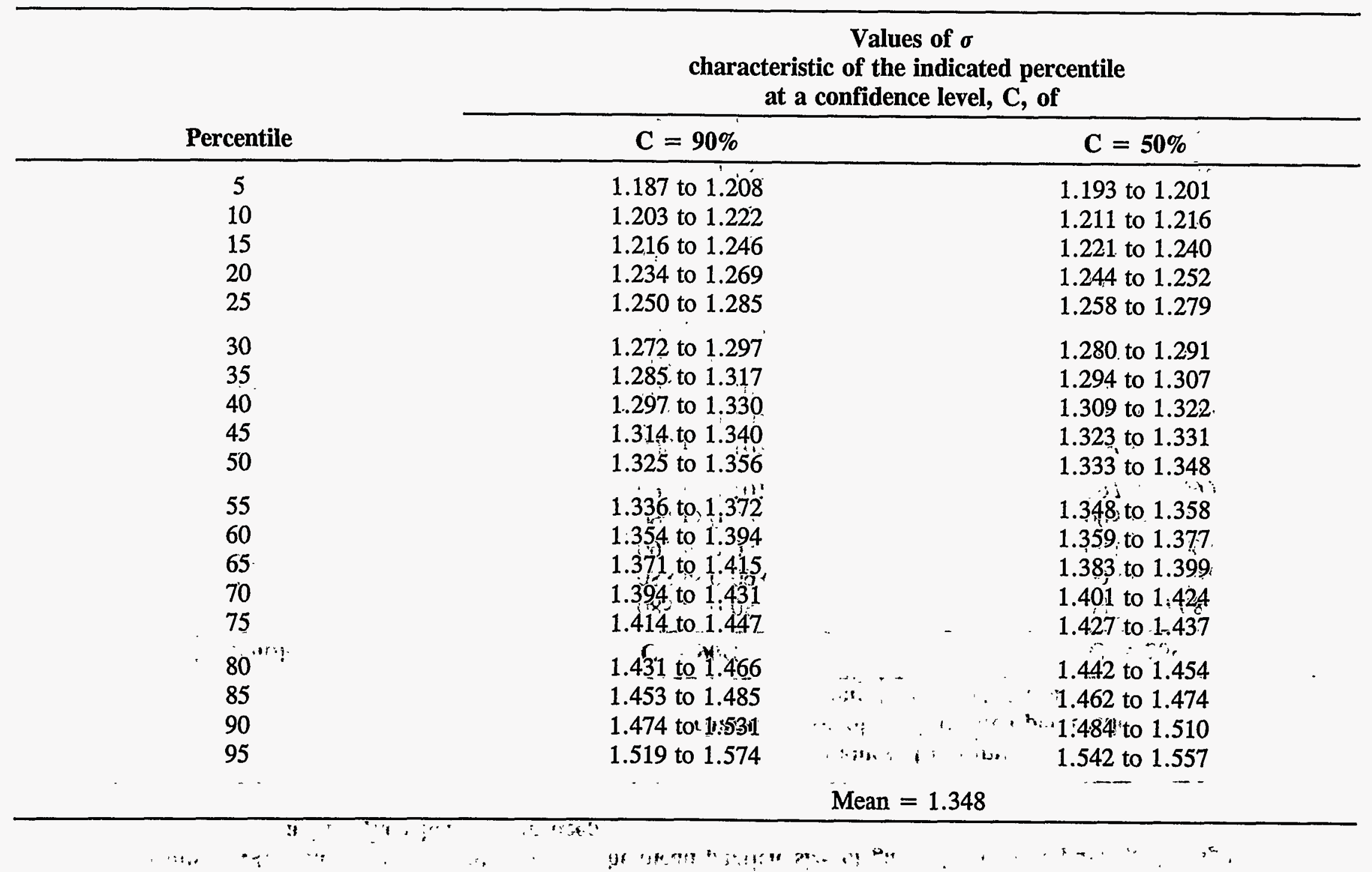


Table A-26. Uncertainty distribution for decontamination of invessel release by bubble formation and equilibration at a ' $T$ ' quencher $100 \mathrm{~cm}$ deep

\begin{tabular}{|c|c|c|}
\hline \multirow[b]{2}{*}{ Percentile } & \multicolumn{2}{|c|}{$\begin{array}{l}\text { Values of } \log _{10} \mathrm{DF}(\mathrm{FE}) \\
\text { characteristic of the indicated percentile } \\
\text { at a confidence level, } \mathrm{C} \text {, of }\end{array}$} \\
\hline & $\mathrm{C}=90 \%$ & $\mathrm{C}=50 \%$ \\
\hline $\begin{array}{c}5 \\
10 \\
15 \\
20 \\
25\end{array}$ & $\begin{array}{l}0.545 \text { to } 0.693 \\
0.692 \text { to } 0.865 \\
0.820 \text { to } 1.017 \\
0.933 \text { to } 1.075 \\
1.042 \text { to } 1.146\end{array}$ & $\begin{array}{l}0.620 \text { to } 0.653 \\
0.739 \text { to } 0.811 \\
0.878 \text { to } 0.969 \\
1.015 \text { to } 1.055 \\
1.073 \text { to } 1.110\end{array}$ \\
\hline $\begin{array}{l}30 \\
35 \\
40 \\
45 \\
50\end{array}$ & $\begin{array}{l}1.096 \text { to } 1.238 \\
1.155 \text { to } 1.353 \\
1.257 \text { to } 1.422 \\
1.364 \text { to } 1.496 \\
1.425 \text { to } 1.596\end{array}$ & $\begin{array}{l}1.125 \text { to } 1.173 \\
1.210 \text { to } 1.309 \\
1.321 \text { to } 1.393 \\
1.400 \text { to } 1.459 \\
1.461 \text { to } 1.525\end{array}$ \\
\hline $\begin{array}{l}55 \\
60 \\
65 \\
70 \\
75\end{array}$ & $\begin{array}{l}1.499 \text { to } 1.680 \\
1.599 \text { to } 1.798 \\
1.686 \text { to } 1.920 \\
1.817 \text { to } 2.018 \\
1.934 \text { to } 2.189\end{array}$ & $\begin{array}{l}1.534 \text { to } 1.626 \\
1.648 \text { to } 1.723 \\
1.763 \text { to } 1.859 \\
1.876 \text { to } 1.950 \\
1.993 \text { to } 2.112\end{array}$ \\
\hline $\begin{array}{l}80 \\
85 \\
90 \\
95\end{array}$ & $\begin{array}{l}2.066 \text { to } 2.339 \\
2.261 \text { to } 2.679 \\
2.566 \text { to } 2.894 \\
2.891 \text { to } 3.944\end{array}$ & $\begin{array}{l}2.173 \text { to } 2.267 \\
2.330 \text { to } 2.530 \\
2.698 \text { to } 2.837 \\
3.079 \text { to } 3.462\end{array}$ \\
\hline
\end{tabular}


Table A-27. Uncertainty distribution for decontamination of invessel release during bubble rise from a ' $T$ ' quencher $100 \mathrm{~cm}$ deep

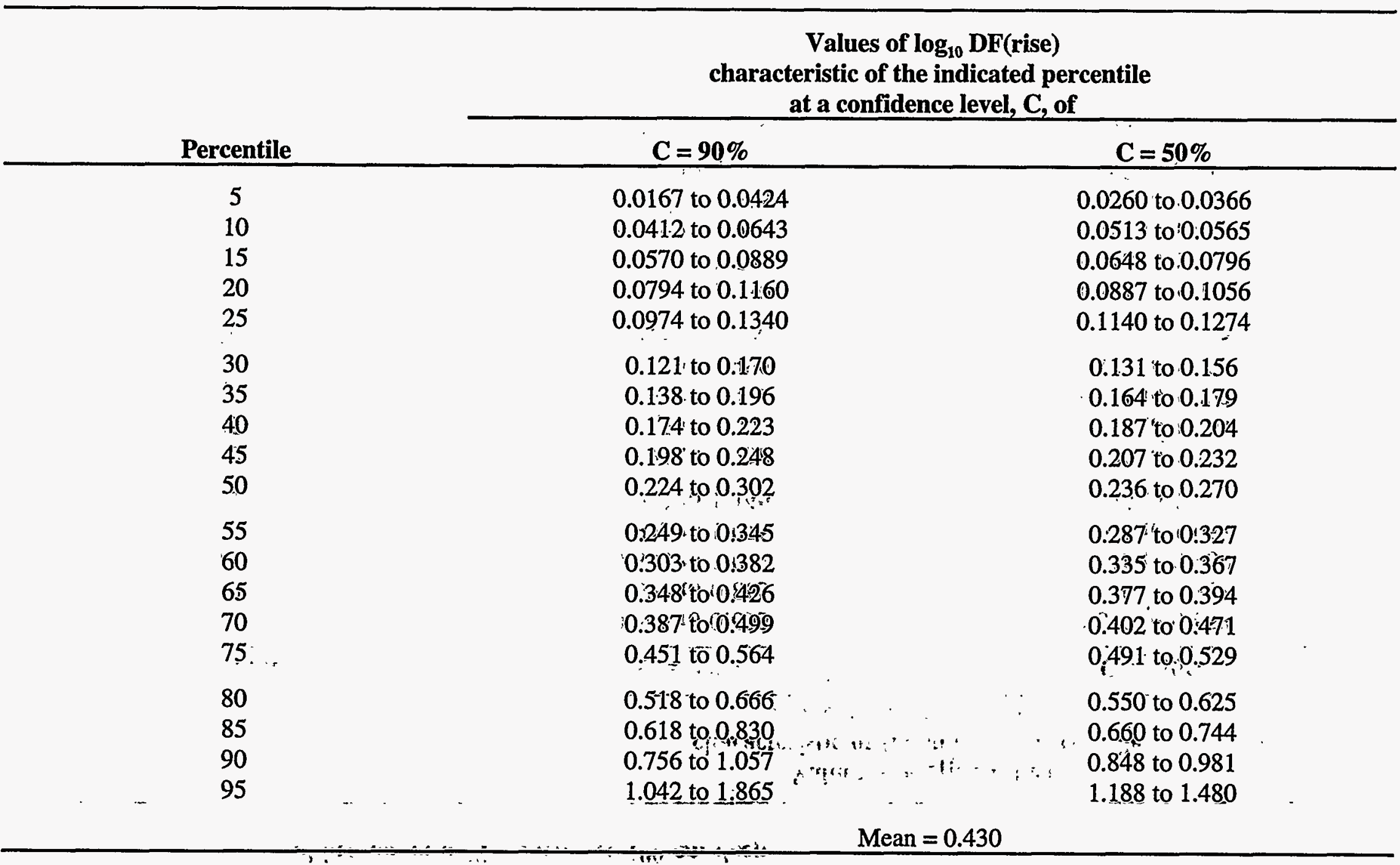


Table A-28. Uncertainty distribution for total decontamination of invessel release after passing through a ' $T$ ' quencher $100 \mathrm{~cm}$ deep

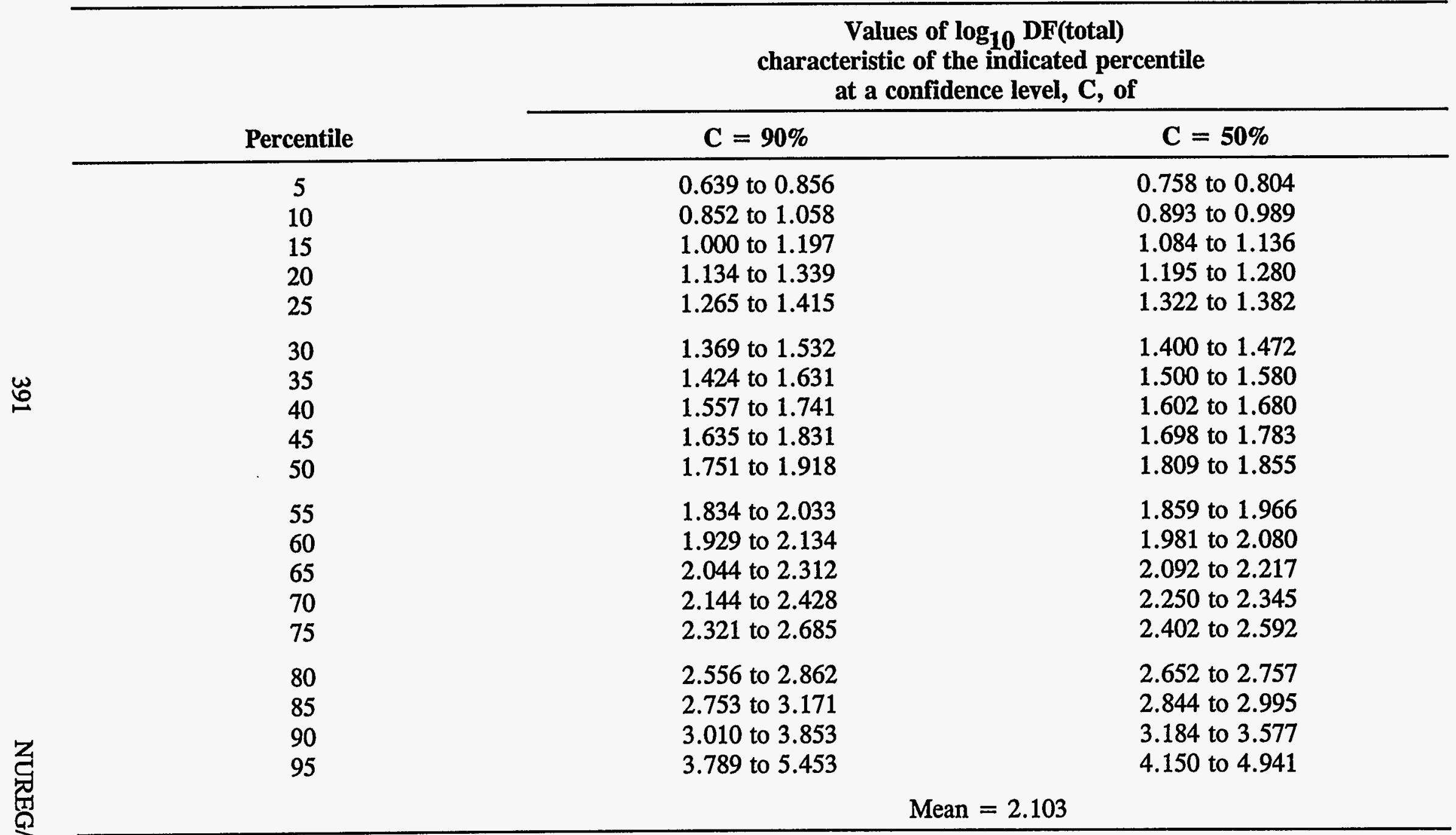


Table A-29. Uncertainty distribution for the mean particle size of invessel release after passing through a ' $T$ ' quencher $100 \mathrm{~cm}$ deep

\begin{tabular}{|c|c|c|}
\hline \multirow[b]{2}{*}{ Percentile } & \multicolumn{2}{|c|}{$\begin{array}{l}\text { Values of } d_{p}(\mu \mathrm{m}) \\
\text { characteristic of the indicated percentile } \\
\text { at a confidence level, } C \text {, of }\end{array}$} \\
\hline & $\mathrm{C}=.90 \%$ & $\mathrm{C}=\mathbf{5 0 \%}$ \\
\hline $\begin{array}{c}5 \\
10 \\
15 \\
20 \\
25\end{array}$ & $\begin{array}{l}0.144 \text { to } 0.174 \\
0.174 \text { to } 0.195 \\
0.187 \text { to } 0.222 \\
0.209 \text { to } 0.237 \\
0.230 \text {, to } 0.251\end{array}$ & $\begin{array}{l}0.156 \text { to } 0.167 \\
0.179 \text { to } 0.186 \\
0.197 \text { to } 0.210 \\
0.220 \text { to } 0.233 \\
0.235 \text { to } 0.241\end{array}$ \\
\hline $\begin{array}{l}30 \\
35 \\
40 \\
45 \\
50\end{array}$ & $\begin{array}{l}0.239 \text { to } 0.261 \\
0.253 \text { to } 0.277 \\
0.263 \text { to } 0.293 \\
0.278 \text { to } 0.309 \\
0.294 \text { to } 0.334\end{array}$ & $\begin{array}{l}0.247 \text { to } 0.257 \\
0.259 \text { to } 0.270 \\
0.272 \text { to } 0.286 \\
0.288 \text { to } 0.299 \\
0.302 \text { to } 0.319\end{array}$ \\
\hline $\begin{array}{l}55 \\
60 \\
65 \\
70 \\
75\end{array}$ & $\begin{array}{l}0.309 \text { to } 0.356 \\
0.335 \text { to } 0.384 \\
0.357 \text { to } 0.411^{*} \\
0.385 \text { to } 0.449 \\
0.419 \text { to } 0.481\end{array}$ & $\begin{array}{l}0.320 \text { to } 0.345 \\
0.349 \text { to } 0.361 \\
0.364 \text { to } 0.394 \\
0.404 \text { to } 0.424 \\
0.440 \text { to } 0.468\end{array}$ \\
\hline $\begin{array}{l}80 \\
85 \\
90 \\
95\end{array}$ & $\begin{array}{l}0.459 \text { to } 0.535 \\
0.508 \text { to } 0.573 \\
0.554 \text { to } 0.740 \\
0.732 \text { to } 0.973\end{array}$ & $\begin{array}{l}0.478 \text { to } 0.516 \\
0.533 \text {; to } 0.551 \\
0.579 \text { to } 0.679 \\
0.770 \text { to } 0.901\end{array}$ \\
\hline 95 & \multicolumn{2}{|c|}{ Mean $=0.331 \mu \mathrm{m}$} \\
\hline
\end{tabular}


Table A-30. Uncertainty distribution for the geometric standard deviation of invessel release after passing through a ' $T$ ' quencher $100 \mathrm{~cm}$ deep

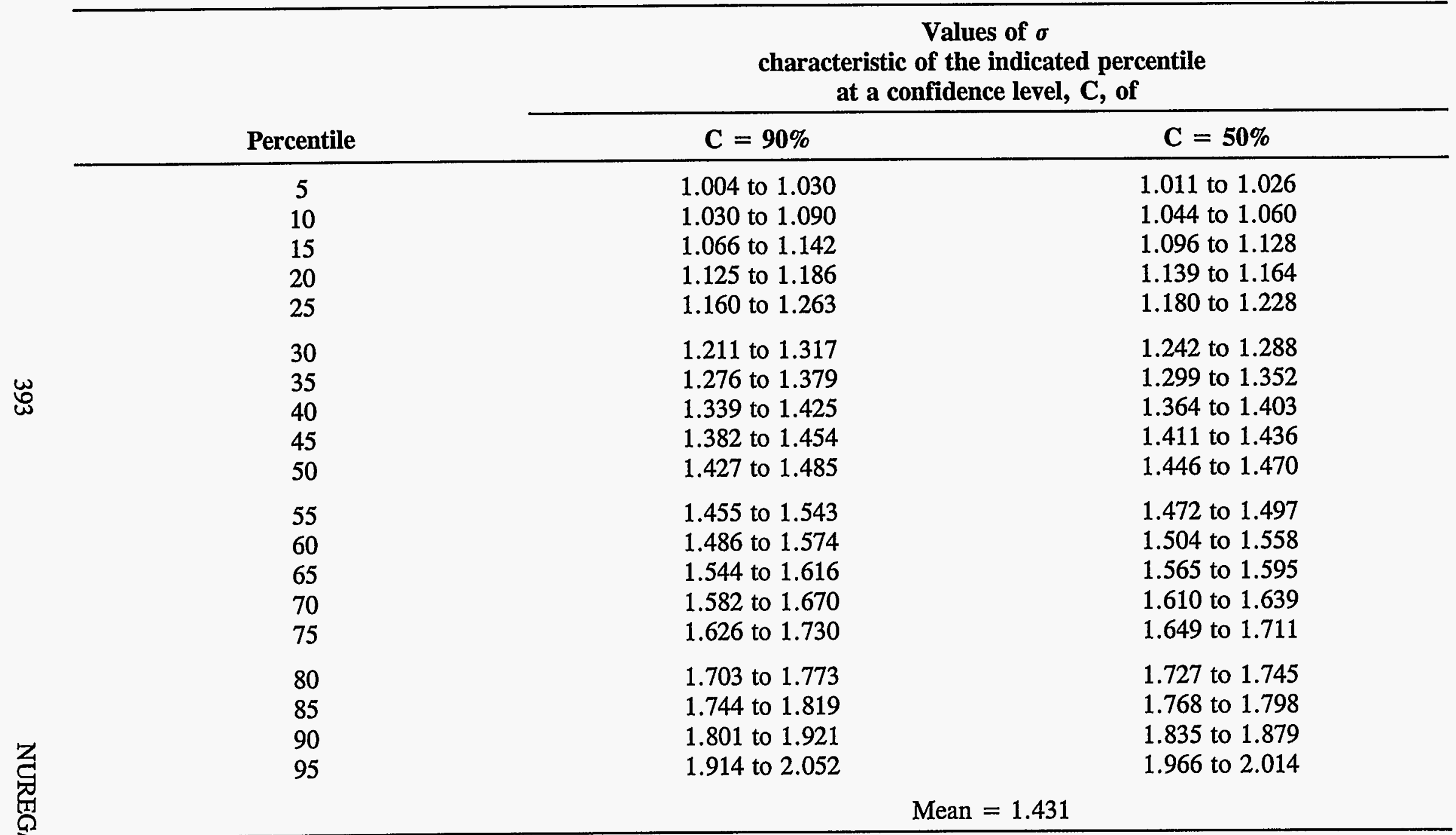


Table A-31. Uncertainty distribution for decontamination during bubble formation and equilibration for invessel release through a ' $T$ ' quencher $200 \mathrm{~cm}$ deep

\begin{tabular}{|c|c|c|}
\hline \multirow[b]{2}{*}{ Percentile } & \multicolumn{2}{|c|}{$\begin{array}{c}\text { Values of } \log _{10} \mathrm{DF}(\mathrm{FE}) \\
\text { characteristic of the indicated percentile } \\
\text { at a confidence level, } \mathrm{C} \text {, of }\end{array}$} \\
\hline & $C=90 \%$ & $\mathrm{C}=\mathbf{5 0 \%}$ \\
\hline $\begin{array}{c}5 \\
10 \\
15 \\
20 \\
25\end{array}$ & $\begin{array}{l}0.496 \text { to } 0.742 \\
0.649 \text { to } 0.951 \\
0.838 \text { to } 1.035 \\
0.972 \text { to } 1.126 \\
1.037 \text { to } 1.232\end{array}$ & $\begin{array}{l}0.584 \text { to } 0.648 \\
0.751 \text { to } 0.855 \\
0.948 \text { to } 1.002 \\
1.022 \text { to } 1.081 \\
1.094 \text { to } 1.17 .9\end{array}$ \\
\hline $\begin{array}{l}30 \\
35 \\
40 \\
45 \\
50\end{array}$ & $\begin{array}{l}1.123 \text { to } 1.296 \\
1.220 \text { to } 1.354 \\
1.289 \text { to } 1.415 \\
1.335 \text { to } 1.515 \\
1.395 \text { to } 1.620\end{array}$ & $\begin{array}{l}1.201 \text { to } 1.264 \\
1.276 \text { to } 1.310 \\
1.311 \text { to } 1.372 \\
1.373 \text { to } 1.435 \\
1.436 \text { to } 1.538\end{array}$ \\
\hline $\begin{array}{l}55 \\
60 \\
65 \\
70 \\
75\end{array}$ & $\begin{array}{l}1.448 \text { to } 1.731 \\
1.556 \text { to } 1.865 \\
1.710 \text { to } 2.061 \\
1.813 \text { to } 2.155 \\
2.039 \text { to } 2.372\end{array}$ & $\begin{array}{l}1.540 \text { to } 1.676 \\
1.679 \text { to } 1.763 \\
1.765 \text { to } 1.927 \\
1.953 \text { to } 2.086 \\
2.114 \text { to } 2.215\end{array}$ \\
\hline $\begin{array}{l}80 \\
85 \\
90 \\
95\end{array}$ & $\begin{array}{l}2.154 \text { to } 2.568 \\
2.388 \text { to } 2.708 \\
2.608 \text { to } 3.142 \\
2.911 \text { to } 4.329\end{array}$ & $\begin{array}{l}2.227 \text { to } 2.420 \\
2.498 \text { to } 2.625 \\
2.685 \text { to } 2.783 \\
3.422 \text { to } 3.651\end{array}$ \\
\hline \multicolumn{3}{|c|}{ Mean $=1.738$} \\
\hline
\end{tabular}


Table A-32. Uncertainty distribution for decontamination for invessel release during bubble rise from a ' $T$ ' quencher $200 \mathrm{~cm}$ deep

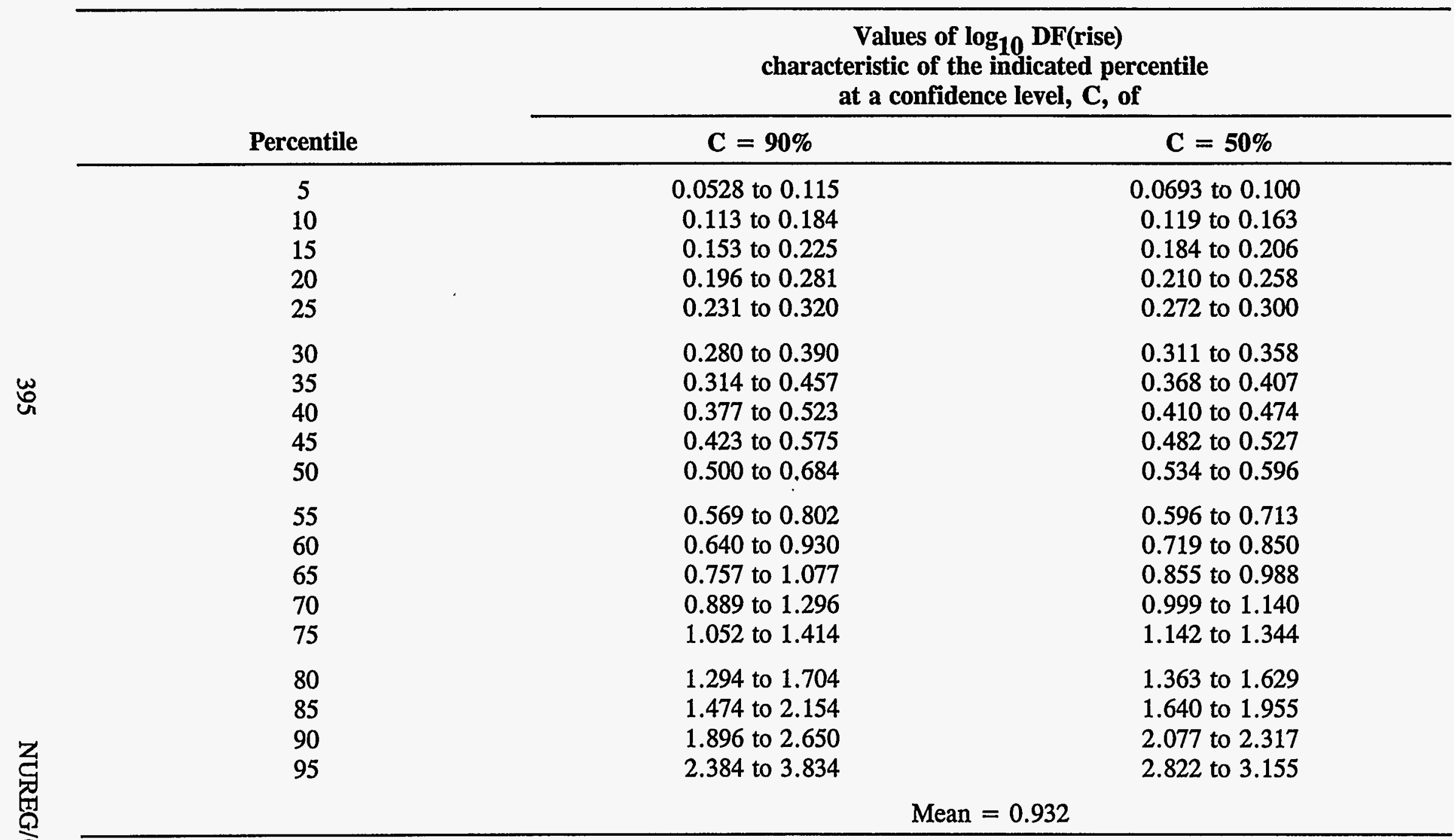


Table A-33. Uncertainty distribution for total invessel release decontamination after passing through a ' $T$ ' quencher $200 \mathrm{~cm}$ deep

\begin{tabular}{|c|c|c|}
\hline \multirow[b]{2}{*}{ Percentile } & \multicolumn{2}{|c|}{$\begin{array}{c}\text { Values of } \log _{10} \mathrm{DF}(\text { total) } \\
\text { characteristic of the indicated percentile } \\
\text { at a confidence level, } \mathrm{C} \text {, of }\end{array}$} \\
\hline & $\mathrm{C}=90 \%$ & $C=50 \%$ \\
\hline $\begin{array}{c}5 \\
10 \\
15 \\
20 \\
25\end{array}$ & $\begin{array}{l}0.707 \text { to } 1.055 \\
1.034 \text { to } 1.296 \\
1.173 \text { to } 1.417 \\
1.346 \text { to } 1.536 \\
1.424 \text { to } 1.648\end{array}$ & $\begin{array}{l}0.915 \text { to } 1.021 \\
1.107 \text { to } 1.177 \\
1.279 \text { to } 1.384 \\
1.405 \text { to } 1.500 \\
1.516 \text { to } 1.581\end{array}$ \\
\hline $\begin{array}{l}30 \\
35 \\
40 \\
45 \\
50\end{array}$ & $\begin{array}{l}1.534 \text { to } 1.854 \\
1.624 \text { to } 1.972 \\
1.840 \text { to } 2.099 \\
1.944 \text { to } 2.2528 \\
2.031 \text { to } 2.432\end{array}$ & $\begin{array}{l}1.595 \text { to } 1.766 \\
1.793 \text { to } 1.885 \\
1.900 \text { to } 1.997 \\
2.004 \text { to } 2.164 \\
2.167 \text { to } 2.302\end{array}$ \\
\hline $\begin{array}{l}55 \\
60 \\
65 \\
70 \\
75\end{array}$ & $\begin{array}{l}2.213 \text { to } 2.636 \\
2.371 \text { to } 2.846 \\
2.603 \text { to } 3.127 \\
2.816 \text { to } 3.336 \\
3.116 \text { to } 3.510\end{array}$ & $\begin{array}{l}2.302 \text { to } 2.587 \\
2.589 \text { to } 2.708 \\
2.709 \text { to } 2.876 \\
2.878 \text { to } 3.181 \\
3.230 \text { to } 3.367\end{array}$ \\
\hline $\begin{array}{l}80 \\
85 \\
90 \\
95\end{array}$ & $\begin{array}{l}3.328 \text { to } 4.041 \\
3.556 \text { to } 4.613 \\
4.077 \text { tô } 5.388 \\
5.250 \text { to } 7.532, \ldots\end{array}$ & $\begin{array}{l}3.400 \text { to } 3.769 \\
3.964 \text { to } 4.122 \\
4.425 \text { to } 5.105 \\
5.787 \text { to } 6.524\end{array}$ \\
\hline
\end{tabular}

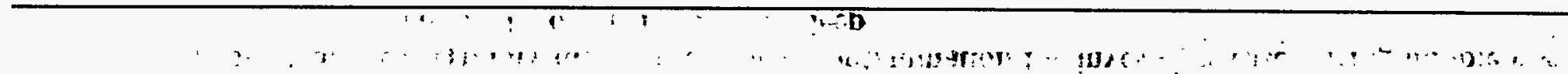


Table A-34. Uncertainty distribution for mean particle size of invessel release after flow through a ' $T$ ' quencher $200 \mathrm{~cm}$ deep

\begin{tabular}{|c|c|c|}
\hline \multirow[b]{2}{*}{ Percentile } & \multicolumn{2}{|c|}{$\begin{array}{l}\text { Values of } d_{p}(\mu \mathrm{m}) \\
\text { characteristic of the indicated percentile } \\
\text { at a confidence level, } C \text {, of }\end{array}$} \\
\hline & $\mathrm{C}=90 \%$ & $\mathrm{C}=\mathbf{5 0 \%}$ \\
\hline $\begin{array}{c}5 \\
10 \\
15 \\
20 \\
25\end{array}$ & $\begin{array}{l}0.124 \text { to } 0.153 \\
0.147 \text { to } 0.180 \\
0.166 \text { to } 0.196 \\
0.183 \text { to } 0.220 \\
0.198 \text { to } 0.239\end{array}$ & $\begin{array}{l}0.132 \text { to } 0.144 \\
0.157 \text { to } 0.168 \\
0.180 \text { to } 0.185 \\
0.190 \text { to } 0.204 \\
0.207 \text { to } 0.227\end{array}$ \\
\hline $\begin{array}{l}30 \\
35 \\
40 \\
45 \\
50\end{array}$ & $\begin{array}{l}0.216 \text { to } 0.255 \\
0.237 \text { to } 0.276 \\
0.250 \text { to } 0.306 \\
0.266 \text { to } 0.325 \\
0.291 \text { to } 0.363\end{array}$ & $\begin{array}{l}0.230 \text { to } 0.243 \\
0.245 \text { to } 0.262 \\
0.262 \text { to } 0.282 \\
0.285 \text { to } 0.313 \\
0.313 \text { to } 0.331\end{array}$ \\
\hline $\begin{array}{l}55 \\
60 \\
65 \\
70 \\
75\end{array}$ & $\begin{array}{l}0.321 \text { to } 0.378 \\
0.349 \text { to } 0.393 \\
0.372 \text { to } 0.437 \\
0.387 \text { to } 0.495 \\
0.424 \text { to } 0.545\end{array}$ & $\begin{array}{l}0.332 \text { to } 0.367 \\
0.367 \text { to } 0.382 \\
0.382 \text { to } 0.405 \\
0.409 \text { to } 0.447 \\
0.454 \text { to } 0.507\end{array}$ \\
\hline $\begin{array}{l}80 \\
85 \\
90 \\
95\end{array}$ & $\begin{array}{l}0.489 \text { to } 0.617 \\
0.552 \text { to } 0.695 \\
0.634 \text { to } 0.771 \\
0.740 \text { to } 1.100\end{array}$ & $\begin{array}{l}0.518 \text { to } 0.571 \\
0.591 \text { to } 0.646 \\
0.689 \text { to } 0.734 \\
0.826 \text { to } 0.983\end{array}$ \\
\hline \multicolumn{3}{|c|}{ Mean $=0.330 \mu \mathrm{m}$} \\
\hline
\end{tabular}


Table A-35. Uncertainty distribution for the geometric standard deviation of invessel release after passing through a ' $T$ ' quencher $200 \mathrm{~cm}$ deep

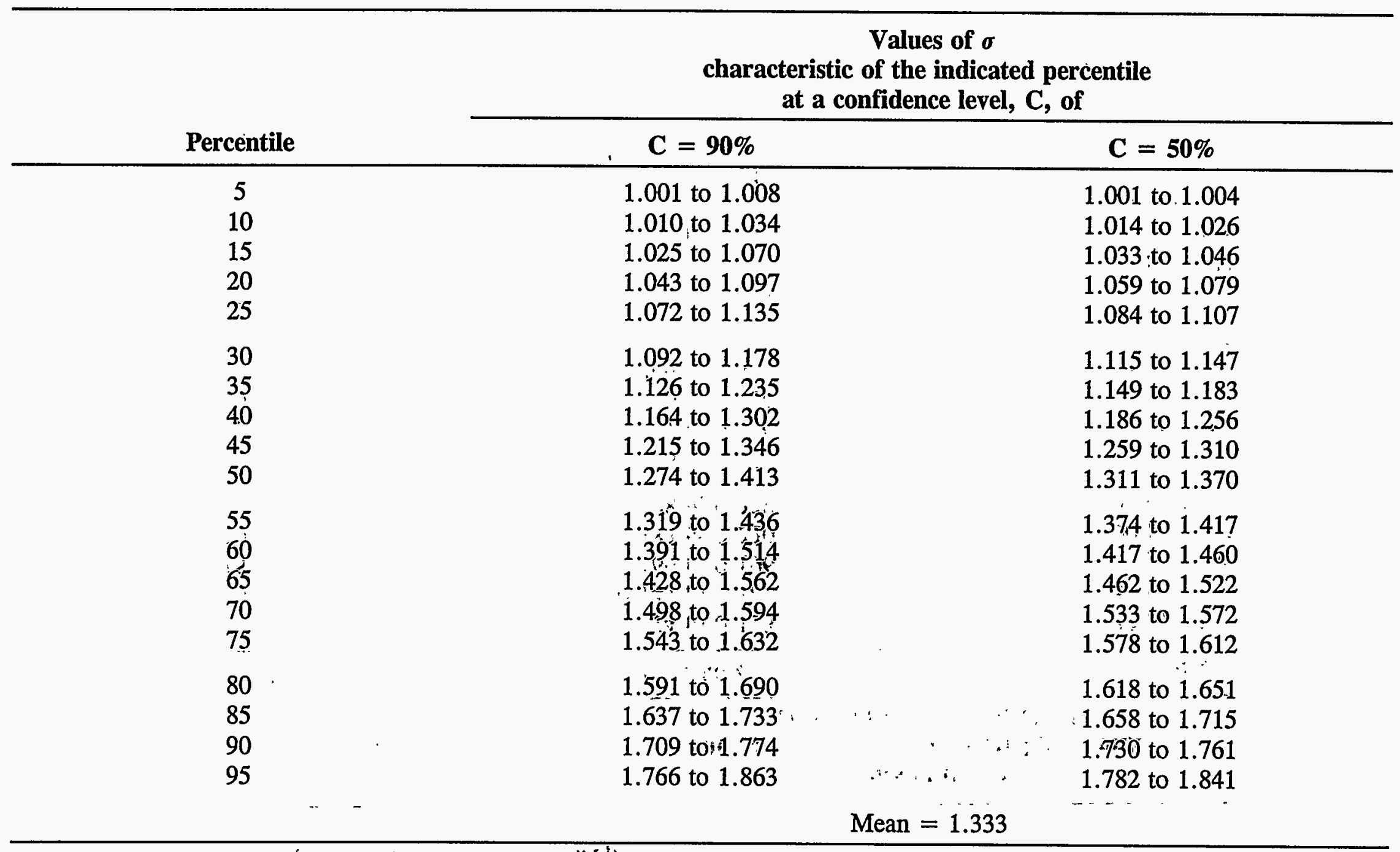


Table A-36. Uncertainty distribution for decontamination of invessel release material by bubble formation and equilibration at a ' $T$ ' quencher $300 \mathrm{~cm}$ deep

\begin{tabular}{|c|c|c|c|}
\hline & \multirow[b]{2}{*}{ Percentile } & \multicolumn{2}{|c|}{$\begin{array}{l}\text { Values of } \log _{10} \mathrm{DF}(\mathrm{FE}) \\
\text { characteristic of the indicated percentile } \\
\text { at a confidence level, } C \text {, of }\end{array}$} \\
\hline & & $\mathrm{C}=90 \%$ & $\mathrm{C}=\mathbf{5 0 \%}$ \\
\hline & $\begin{array}{c}5 \\
10 \\
15 \\
20 \\
25\end{array}$ & $\begin{array}{l}0.442 \text { to } 0.691 \\
0.693 \text { to } 0.860 \\
0.847 \text { to } 0.982 \\
0.924 \text { to } 1.089 \\
1.019 \text { to } 1.226\end{array}$ & $\begin{array}{l}0.533 \text { to } 0.611 \\
0.779 \text { to } 0.831 \\
0.882 \text { to } 0.927 \\
0.980 \text { to } 1.031 \\
1.082 \text { to } 1.158\end{array}$ \\
\hline జ̈ & $\begin{array}{l}30 \\
35 \\
40 \\
45 \\
50\end{array}$ & $\begin{array}{l}1.133 \text { to } 1.254 \\
1.230 \text { to } 1.343 \\
1.273 \text { to } 1.381 \\
1.345 \text { to } 1.472 \\
1.385 \text { to } 1.524\end{array}$ & $\begin{array}{l}1.194 \text { to } 1.238 \\
1.246 \text { to } 1.304 \\
1.312 \text { to } 1.351 \\
1.362 \text { to } 1.401 \\
1.414 \text { to } 1.496\end{array}$ \\
\hline & $\begin{array}{l}55 \\
60 \\
65 \\
70 \\
75\end{array}$ & $\begin{array}{l}1.477 \text { to } 1.606 \\
1.528 \text { to } 1.714 \\
1.637 \text { to } 1.857 \\
1.742 \text { to } 1.983 \\
1.906 \text { to } 2.183\end{array}$ & $\begin{array}{l}1.509 \text { to } 1.548 \\
1.572 \text { to } 1.690 \\
1.699 \text { to } 1.764 \\
1.807 \text { to } 1.915 \\
1.946 \text { to } 2.059\end{array}$ \\
\hline 叴 & $\begin{array}{l}80 \\
85 \\
90 \\
95\end{array}$ & $\begin{array}{l}2.056 \text { to } 2.433 \\
2.292 \text { to } 2.821 \\
2.756 \text { to } 3.272 \\
3.285 \text { to } 4.083\end{array}$ & $\begin{array}{l}2.115 \text { to } 2.292 \\
2.406 \text { to } 2.692 \\
2.876 \text { to } 3.072 \\
3.478 \text { to } 3.698\end{array}$ \\
\hline & \multicolumn{3}{|c|}{ Mean $=1.708$} \\
\hline
\end{tabular}


Table A-37. Uncertainty distribution for decontamination of invessel release during bubble rise from a ' $T$ ' quencher $300 \mathrm{~cm}$ deep

\begin{tabular}{|c|c|c|}
\hline \multirow[b]{2}{*}{ Percentile } & \multicolumn{2}{|c|}{$\begin{array}{l}\text { Values of } \log _{10} \mathrm{DF} \text { (rise) } \\
\text { characteristic of the indicated percentile } \\
\text { at a confidence level, } C \text {, of }\end{array}$} \\
\hline & $\mathrm{C}=90 \%$ & $\mathrm{C}=\mathbf{5 0 \%}$ \\
\hline $\begin{array}{c}5 \\
10 \\
15 \\
20 \\
25\end{array}$ & $\begin{array}{l}0.110 \text { to } 0.178 \\
0.179 \text { to } 0.276 \\
0.269 \text { to } 0.330 \\
0.308 \text { to } 0.405 \\
0.370 \text { to } 0.454\end{array}$ & $\begin{array}{l}0.121 \text { to } 0.160 \\
0.225 \text { to } 0.257 \\
0.281 \text { to } 0.310 \\
0.330 \text { to } 0.377 \\
0.396 \text { to } 0.432\end{array}$ \\
\hline $\begin{array}{l}30 \\
35 \\
40 \\
45 \\
50\end{array}$ & $\begin{array}{l}0.419 \text { to } 0.487 \\
0.465 \text { to } 0.572 \\
0.504 \text { to } 0.676 \\
0.582 \text { to } 0.759 \\
0.682 \text { to } 0.849\end{array}$ & $\begin{array}{l}0.448 \text { to } 0.469 \\
0.481 \text { to } 0.550 \\
0.554 \text { to } 0.620 \\
0.643 \text { to } 0.715 \\
0.734 \text { to } 0.794\end{array}$ \\
\hline $\begin{array}{l}55 \\
60 \\
65 \\
70 \\
75\end{array}$ & $\begin{array}{l}0.764 \text { to } 0.945 \\
0.860 \text { to } 1.046 \\
0.960 \text { to } 1.263 \\
1.070 \text { to } 1.482 \\
1.294 \text { to } 1.794\end{array}$ & $\begin{array}{l}0.821 \text { to } 0.885 \\
0.900 \text { to } 0.975 \\
0.990 \text { to } 1.126 \\
1.240 \text { to } 1.328 \\
1.444 \text { to } 1.620\end{array}$ \\
\hline $\begin{array}{l}80 \\
85 \\
90 \\
95\end{array}$ & $\begin{array}{l}1.581 \text { to } 2.289 \\
1.998 \text { to } 2.648 \\
2.505 \text { to } 3.197 \\
3.209 \text { to } 4.813\end{array}$ & $\begin{array}{l}1.742 \text { to } 2.002 \\
2.256 \text { to } 2.469 \\
2.658 \text { to } 2.936 \\
3.438 \text { to } 4.409\end{array}$ \\
\hline \multicolumn{3}{|c|}{ Mean $=1.205$} \\
\hline
\end{tabular}


Table A-38. Uncertainty distribution for total decontamination of invessel release material after passing through a ' $T$ ' quencher $300 \mathrm{~cm}$ deep

\begin{tabular}{|c|c|c|}
\hline \multirow[b]{2}{*}{ Percentile } & \multicolumn{2}{|c|}{$\begin{array}{l}\text { Values of } \log _{10} \mathrm{DF} \text { (total) } \\
\text { characteristic of the indicated percentile } \\
\text { at a confidence level, } \mathrm{C} \text {, of }\end{array}$} \\
\hline & $\mathrm{C}=90 \%$ & $\mathrm{C}=\mathbf{5 0} \%$ \\
\hline $\begin{array}{c}5 \\
10 \\
15 \\
20 \\
25\end{array}$ & $\begin{array}{l}0.805 \text { to } 1.160 \\
1.163 \text { to } 1.346 \\
1.305 \text { to } 1.473 \\
1.435 \text { to } 1.620 \\
1.524 \text { to } 1.809\end{array}$ & $\begin{array}{l}0.892 \text { to } 1.097 \\
1.219 \text { to } 1.294 \\
1.354 \text { to } 1.438 \\
1.473 \text { to } 1.544 \\
1.610 \text { to } 1.700\end{array}$ \\
\hline $\begin{array}{l}30 \\
35 \\
40 \\
45 \\
50\end{array}$ & $\begin{array}{l}1.685 \text { to } 1.957 \\
1.841 \text { to } 2.087 \\
1.988 \text { to } 2.216 \\
2.092 \text { to } 2.381 \\
2.264 \text { to } 2.492\end{array}$ & $\begin{array}{l}1.727 \text { to } 1.885 \\
1.894 \text { to } 2.021 \\
2.052 \text { to } 2.123 \\
2.162 \text { to } 2.300 \\
2.331 \text { to } 2.440\end{array}$ \\
\hline $\begin{array}{l}55 \\
60 \\
65 \\
70 \\
75\end{array}$ & $\begin{array}{l}2.395 \text { to } 2.692 \\
2.508 \text { to } 2.886 \\
2.706 \text { to } 3.178 \\
2.922 \text { to } 3.416 \\
3.238 \text { to } 4.037\end{array}$ & $\begin{array}{l}2.464 \text { to } 2.548 \\
2.591 \text { to } 2.740 \\
2.782 \text { to } 2.966 \\
3.067 \text { to } 3.278 \\
3.364 \text { to } 3.701\end{array}$ \\
\hline $\begin{array}{l}80 \\
85 \\
90 \\
95\end{array}$ & $\begin{array}{l}3.529 \text { to } 4.552 \\
4.247 \text { to } 5.187 \\
4.866 \text { to } 6.113 \\
6.126 \text { to } 8.004\end{array}$ & $\begin{array}{l}3.898 \text { to } 4.250 \\
4.543 \text { to } 4.740 \\
5.295 \text { to } 5.457 \\
6.348 \text { to } 6.754\end{array}$ \\
\hline \multicolumn{3}{|c|}{ Mean $=2.914$} \\
\hline
\end{tabular}


Table A-39. Uncertainty distribution for the mean particle size of invessel release material after passing through a ' $T$ ' quencher $300 \mathrm{~cm}$ deep

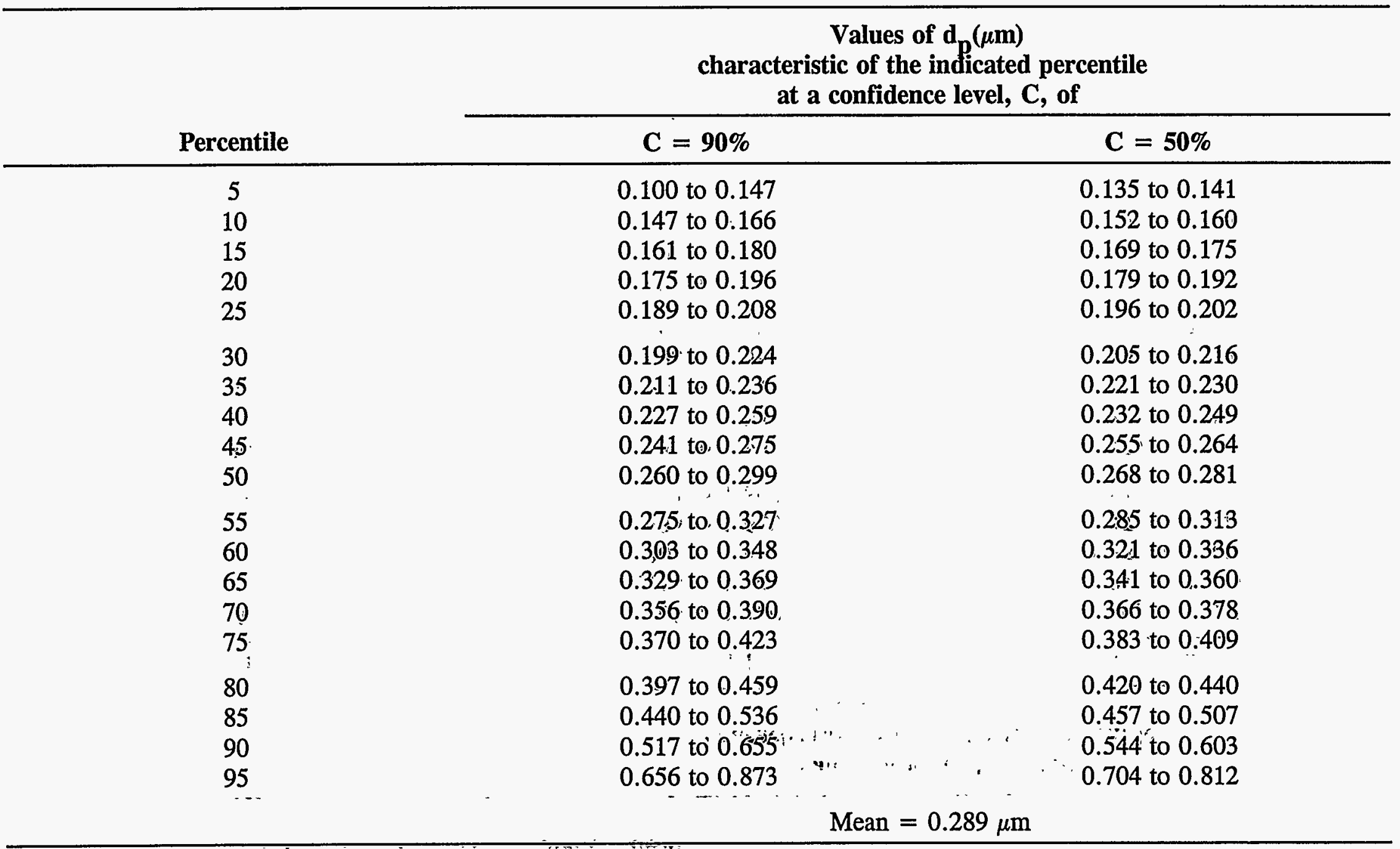


Table A-40. Uncertainty distribution for the geometric standard deviation of invessel release material after passing through a ' $\mathrm{T}$ ' quencher $300 \mathrm{~cm}$ deep

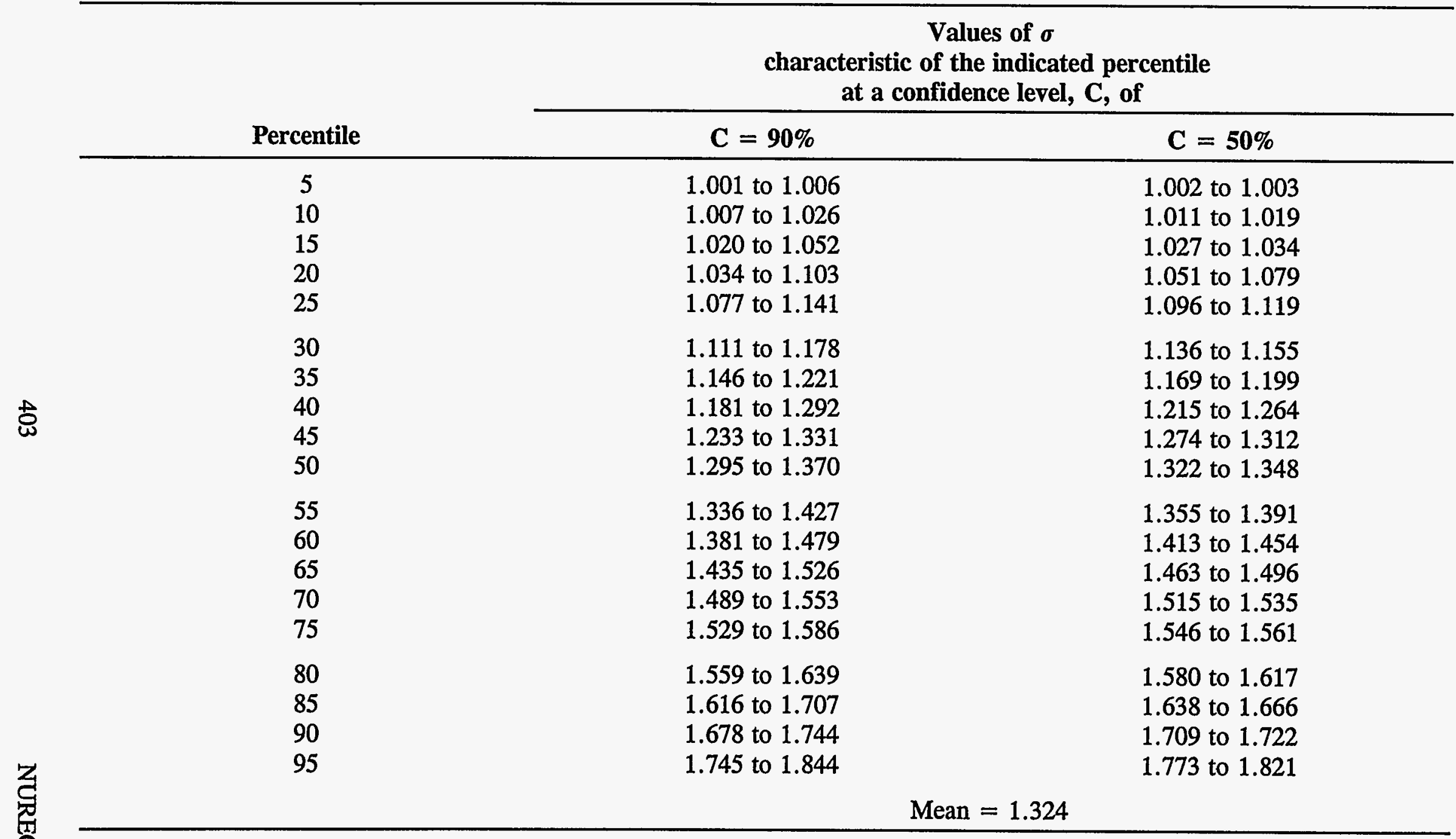


Table A-41. Uncertainty distribution for the decontamination of invessel release material during formation and equilibration of bubbles at a ' $T$ ' quencher $500 \mathrm{~cm}$ deep

\begin{tabular}{|c|c|c|}
\hline \multirow[b]{2}{*}{ Percentile } & \multicolumn{2}{|c|}{$\begin{array}{c}\text { Values of } \log _{10} \mathrm{DF}(\mathrm{FE}) \\
\text { characteristic of the indicated percentile } \\
\text { at a confidence level, } \mathrm{C} \text {, of }\end{array}$} \\
\hline & $C=90 \%$ & $\mathbf{C}=\mathbf{5 0 \%}$ \\
\hline $\begin{array}{c}5 \\
10 \\
15 \\
20 \\
25\end{array}$ & $\begin{array}{l}0.468 \text { to } 0.608 \\
0.611 \text { to } 0.713 \\
0.698 \text { to } 0.886 \\
0.802 \text { to } 1.000 \\
0.955 \text { to } 1.119\end{array}$ & $\begin{array}{l}0.518 \text { to } 0.560 \\
0.654 \text { to } 0.694 \\
0.726 \text { to } 0.804 \\
0.884 \text { to } 0.969 \\
0.988 \text { to } 1.062\end{array}$ \\
\hline $\begin{array}{l}30 \\
35 \\
40 \\
45 \\
50\end{array}$ & $\begin{array}{l}1.038 \text { to } 1.196 \\
1.137 \text { to } 1.268 \\
1.215 \text { to } 1.351 \\
1.287 \text { to } 1.420 \\
1.358 \text { to } 1.494\end{array}$ & $\begin{array}{l}1.098 \text { to } 1.157 \\
1.180 \text { to } 1.246 \\
1.254 \text { to } 1.313 \\
1.327 \text { to } 1.384 \\
1.393 \text { to } 1.462\end{array}$ \\
\hline $\begin{array}{l}55 \\
60 \\
65 \\
70 \\
75\end{array}$ & $\begin{array}{l}1.436 \text { to } 1.611 \\
1.504 \text { to } 1.686 \\
1.617 \text { to } 1.778 \\
1.706 \text { to } 1.686 \\
1.809 \text { to } 1.891\end{array}$ & $\begin{array}{l}1.478 \text { to } 1.531 \\
1.561 \text { to } 1.630 \\
1.653 \text { to } 1.724 \\
1.744 \text { to } 1.833 \\
1.851 \text { to } 1.982\end{array}$ \\
\hline $\begin{array}{l}80 \\
85 \\
90 \\
95\end{array}$ & $\begin{array}{l}1.978 \text { to } 2.179 \\
2.117 \text { to } 2.332 \\
2.294 \text { to } 2.616 \\
2.624 \text { to } 3.3419\end{array}$ & $\begin{array}{l}2.013 \text { to } 2.118 \\
2.17 \overline{8} \text { to } 2.278 \\
2.361 \text { to } 2.506 \\
2.820 \text { to } 3.092\end{array}$ \\
\hline
\end{tabular}


Table A-42. Uncertainty distribution for the decontamination of invessel release during bubble rise from a ' $\mathrm{T}$ ' quencher $500 \mathrm{~cm}$ deep

\begin{tabular}{|c|c|c|c|}
\hline & \multirow[b]{2}{*}{ Percentile } & \multicolumn{2}{|c|}{$\begin{array}{l}\text { Values of } \log _{10} \mathrm{DF} \text { (rise) } \\
\text { characteristic of the indicated percentile } \\
\text { at a confidence level, } \mathrm{C} \text {, of }\end{array}$} \\
\hline & & $\mathrm{C}=90 \%$ & $\mathrm{C}=\mathbf{5 0 \%}$ \\
\hline & $\begin{array}{c}5 \\
10 \\
15 \\
20 \\
25\end{array}$ & $\begin{array}{l}0.205 \text { to } 0.316 \\
0.318 \text { to } 0.405 \\
0.388 \text { to } 0.509 \\
0.444 \text { to } 0.571 \\
0.547 \text { to } 0.691\end{array}$ & $\begin{array}{l}0.214 \text { to } 0.277 \\
0.352 \text { to } 0.383 \\
0.416 \text { to } 0.453 \\
0.507 \text { to } 0.554 \\
0.566 \text { to } 0.648\end{array}$ \\
\hline 总 & $\begin{array}{l}30 \\
35 \\
40 \\
45 \\
50\end{array}$ & $\begin{array}{l}0.622 \text { to } 0.736 \\
0.701 \text { to } 0.903 \\
0.750 \text { to } 1.025 \\
0.925 \text { to } 1.169 \\
1.040 \text { to } 1.288\end{array}$ & $\begin{array}{l}0.674 \text { to } 0.711 \\
0.728 \text { to } 0.794 \\
0.843 \text { to } 0.968 \\
0.979 \text { to } 1.081 \\
1.095 \text { to } 1.233\end{array}$ \\
\hline & $\begin{array}{l}55 \\
60 \\
65 \\
70 \\
75\end{array}$ & $\begin{array}{l}1.185 \text { to } 1.496 \\
1.301 \text { to } 1.687 \\
1.512 \text { to } 1.838 \\
1.710 \text { to } 2.061 \\
1.875 \text { to } 2.476\end{array}$ & $\begin{array}{l}1.262 \text { to } 1.368 \\
1.412 \text { to } 1.585 \\
1.628 \text { to } 1.752 \\
1.790 \text { to } 1.888 \\
2.008 \text { to } 2.291\end{array}$ \\
\hline z & $\begin{array}{l}80 \\
85 \\
90 \\
95\end{array}$ & $\begin{array}{l}2.269 \text { to } 3.121 \\
2.654 \text { to } 3.642 \\
3.462 \text { to } 4.491 \\
4.522 \text { to } 5.621\end{array}$ & $\begin{array}{l}2.440 \text { to } 2.662 \\
3.111 \text { to } 3.419 \\
3.677 \text { to } 4.169 \\
4.842 \text { to } 5.270\end{array}$ \\
\hline & \multicolumn{3}{|c|}{ Mean $=1.678$} \\
\hline
\end{tabular}


Table A-43. Uncertainty distribution for the total decontamination of invessel release material after passing through a ' $T$ ' quencher $500 \mathrm{~cm}$ deep

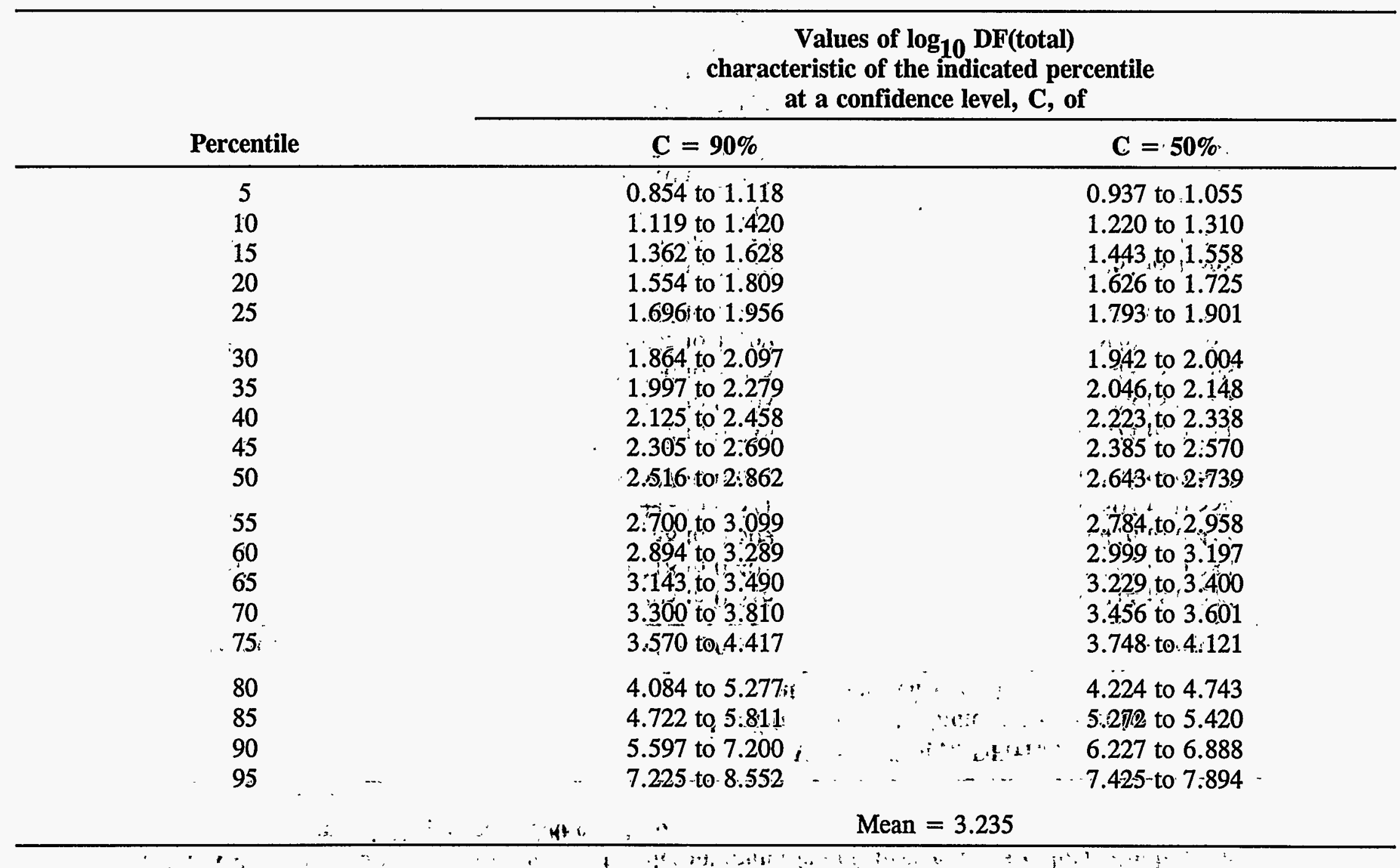


Table A-44. Uncertainty distribution for the mean particle size of invessel release after passing through a ' $\mathrm{T}$ ' quencher $500 \mathrm{~cm}$ deep

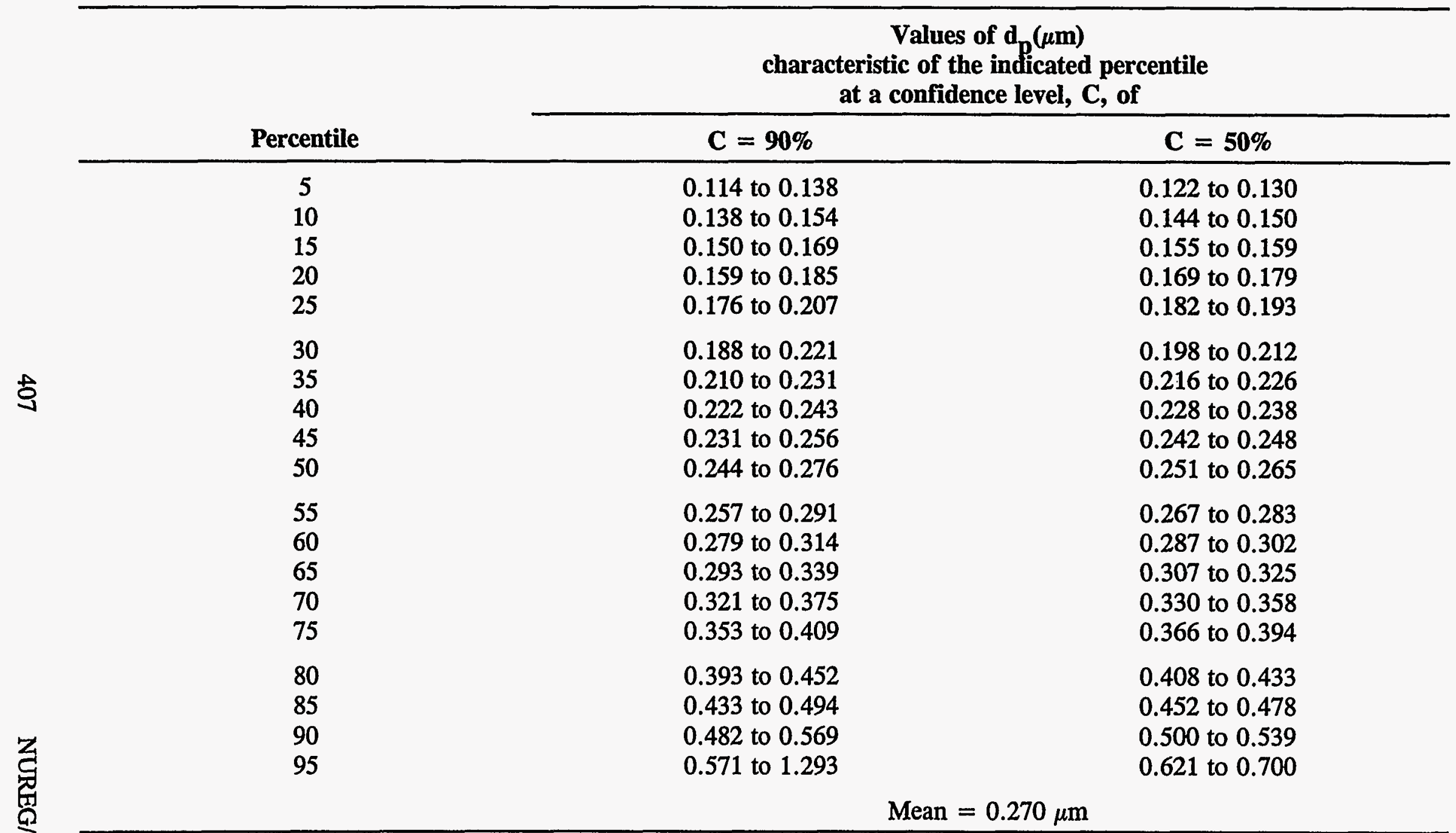


Table A-45. Uncertainty distribution for the geometric standard deviation of invessel release after passing through a ' $T$ ' quencher $500 \mathrm{~cm}$ deep

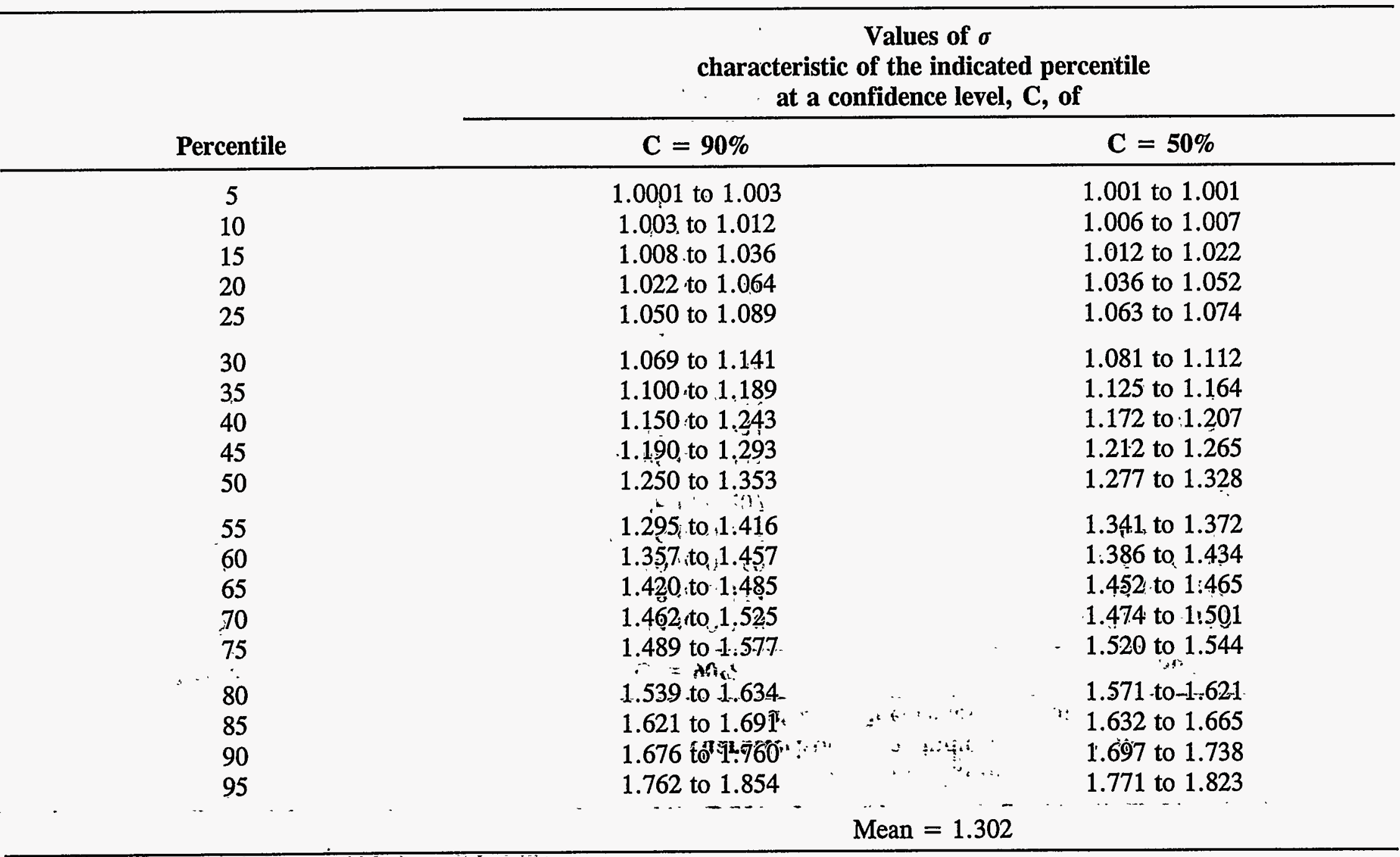

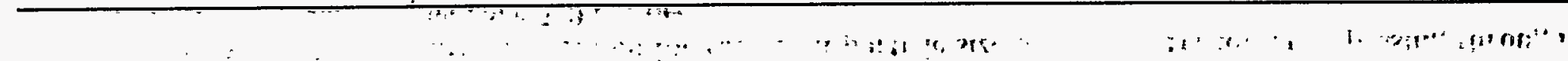


Table A-46. Uncertainty distribution for decontamination of invessel release during bubble rise from a ' $T$ ' quencher $700 \mathrm{~cm}$ deep

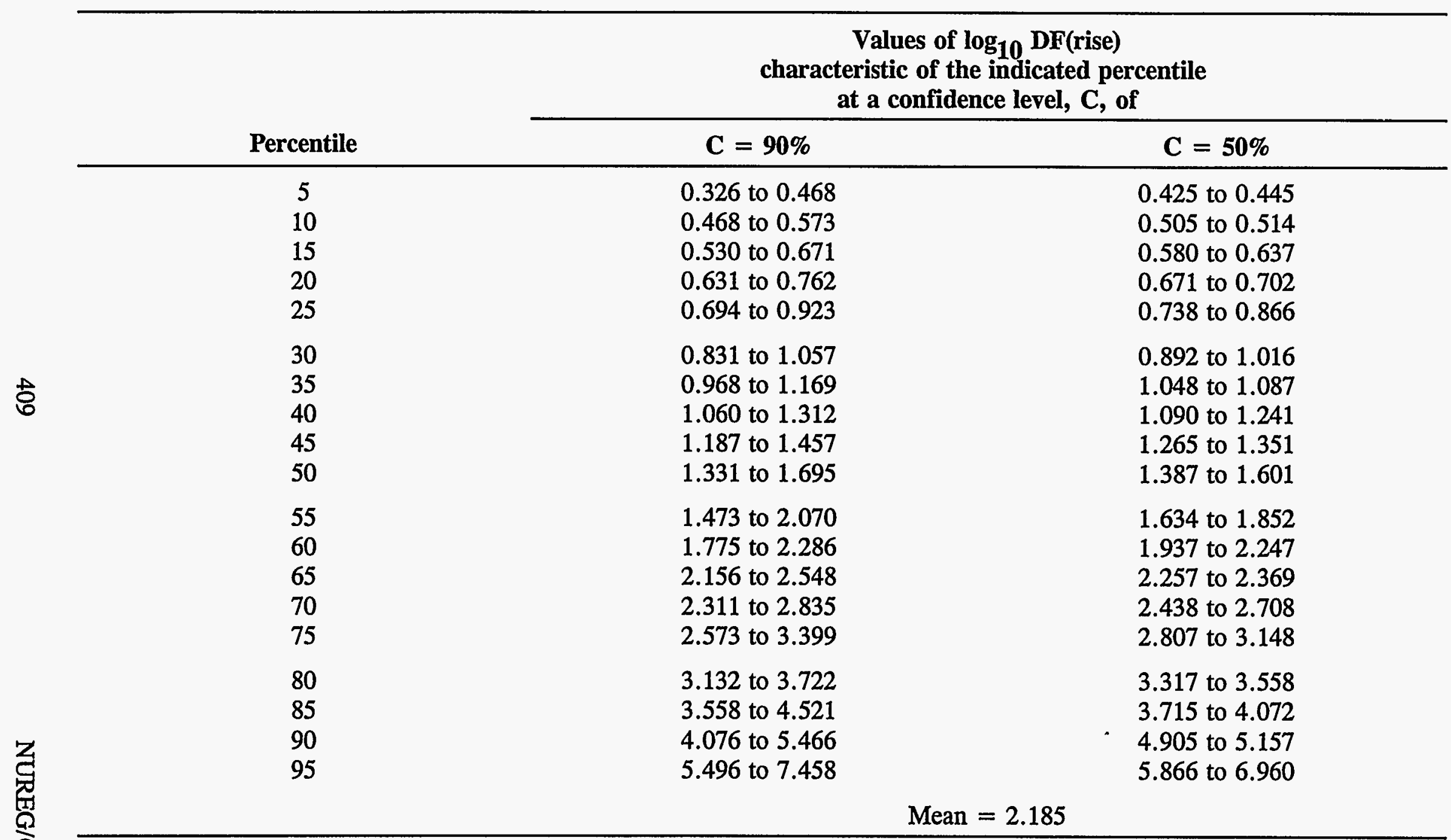


Table A-47. Uncertainty distribution for decontamination of invessel release by bubble formation and decontamination at a ' $T$ ' quencher $700 \mathrm{~cm}$ deep

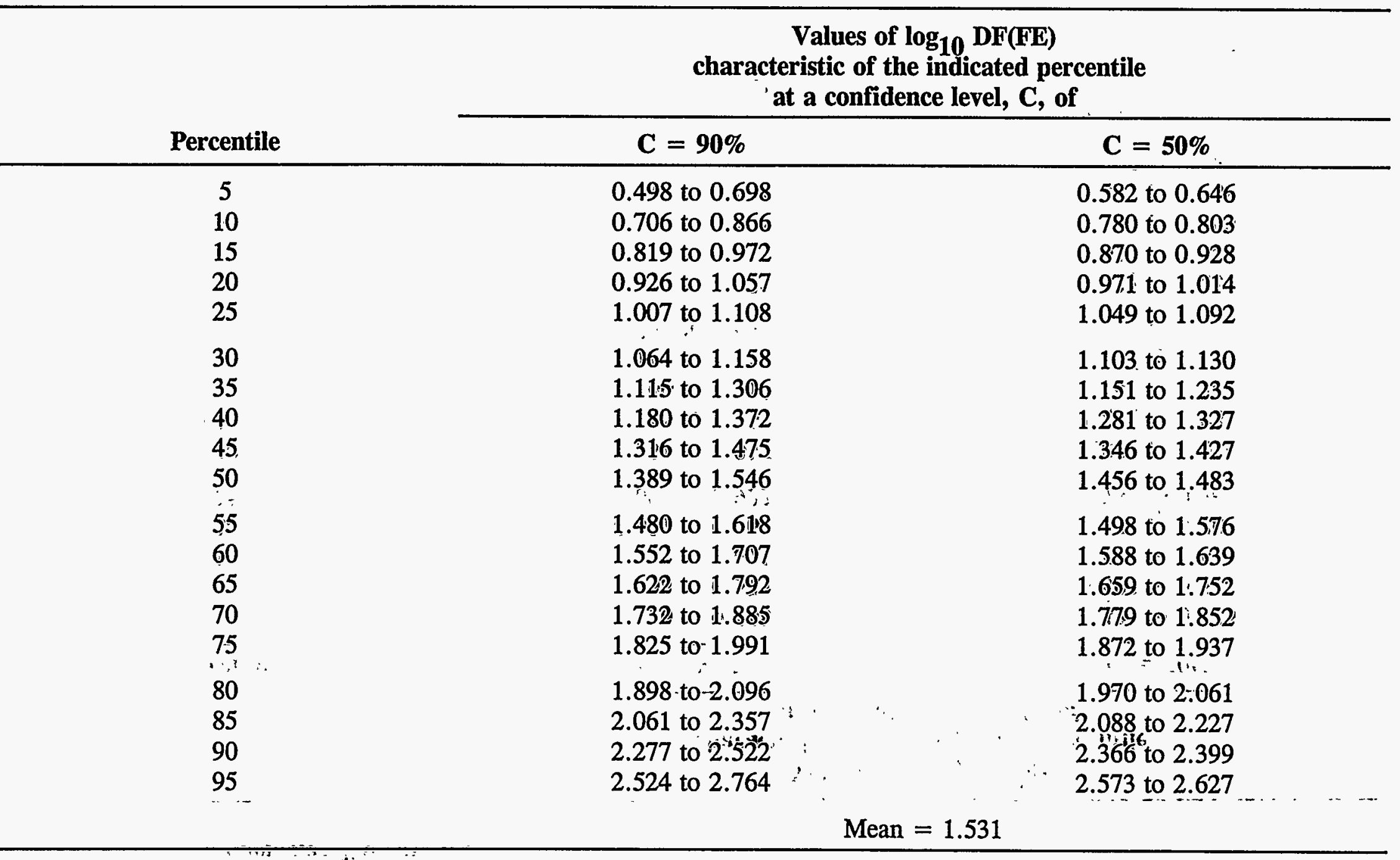


Table A-48. Uncertainty distribution for total decontamination of invessel release after passing through a ' $T$ ' quencher $700 \mathrm{~cm}$ deep

\begin{tabular}{ccc}
\hline & \multicolumn{2}{c}{$\begin{array}{c}\text { Values of } \log _{\mathbf{1 0}} \mathbf{D F} \text { (total) } \\
\text { characteristic of the indicated percentile } \\
\text { at a confidence level, } \mathbf{C} \text {, of }\end{array}$} \\
\cline { 2 - 4 } Percentile & $\mathbf{C = 9 0 \%}$ & $\mathbf{C}=\mathbf{5 0 \%}$ \\
\hline 5 & 1.298 to 1.444 & 1.351 to 1.396 \\
10 & 1.447 to 1.695 & 1.474 to 1.571 \\
15 & 1.665 to 1.851 & 1.717 to 1.808 \\
20 & 1.799 to 2.047 & 1.850 to 1.916 \\
25 & 1.901 to 2.236 & 2.043 to 2.176 \\
30 & 2.134 to 2.444 & 2.235 to 2.388 \\
35 & 2.345 to 2.599 & 2.425 to 2.504 \\
40 & 2.460 to 2.803 & 2.524 to 2.713 \\
45 & 2.632 to 3.155 & 2.778 to 2.917 \\
50 & 2.886 to 3.353 & 2.952 to 3.198 \\
55 & 3.163 to 3.616 & 3.261 to 3.494 \\
60 & 3.382 to 3.972 & 3.576 to 3.715 \\
65 & 3.642 to 4.317 & 3.867 to 4.095 \\
70 & 4.035 to 4.687 & 4.224 to 4.353 \\
75 & 4.334 to 5.182 & 4.611 to 4.931 \\
80 & 4.905 to 5.535 & 5.155 to 5.259 \\
85 & 5.248 to 6.666 & 5.535 to 6.129 \\
90 & 6.366 to 7.348 & 6.777 to 7.239 \\
95 & 7.360 to 9.838 & 7.919 to 9.084 \\
& & \\
\hline
\end{tabular}


Table A-49. Uncertainty distribution for the mean particle size of invessel release after passing through a ' $T$ ' quencher $700 \mathrm{~cm}$ deep

Values of $d_{p}(\mu \mathrm{m})$

characteristic of the indicated percentile

at a confidence level, $C$, of

\begin{tabular}{|c|c|c|}
\hline Percentile & $C=90 \%$ & $\mathbf{C}=\mathbf{5 0 \%}$ \\
\hline 5 & 0.111 to 0.127 & $0: 117$ to 0.122 \\
\hline 10 & 0.127 to 0.143 & 0.128 to 0.141 \\
\hline 15 & 0.141 to 0.158 & 0.146 to 0.151 \\
\hline 20 & 0.150 to 0.167 & 0.158 to 0.161 \\
\hline 25 & 0.161 to $0.1^{179}$ & 0.166 to 0.175 \\
\hline 30 & 0.171 to 0.200 & 0.179 to 0.187 \\
\hline 35 & $0.183^{\text {'t }}$ to 0.214 & 0.191 to 0.209 \\
\hline 40 & 0.201 to $0: 230$ & 0.213 to 0.222 \\
\hline 45 & 0.2116 to 0.248 & 0.225 to 0.240 \\
\hline 50 & 0.233 to 0.260 & 0.245 to 0.251 \\
\hline 55 & 0.249 to 0.288 & $0 ! 257$ to 0.265 \\
\hline 60 & 0.264 to 0.304 & 0.267 to 0.295 \\
\hline 65 & 0.292 to 0.326 & 0.302 to 0.311 \\
\hline 70 & $0.305^{i}$ to 0.351 & 0.319 to 0.334 \\
\hline 75 & 0.332 to 0.388 & 0.342 to 0.369 \\
\hline 80 & 0.368 to:0.431 & 0.387 to 0.405 \\
\hline 85 & 0.404 tô $0.473_{3} \ldots$ & 0.431 to 0.462 \\
\hline 90 & 0.464 to 0,617, & 0.476 to 0.537 \\
\hline 95 & 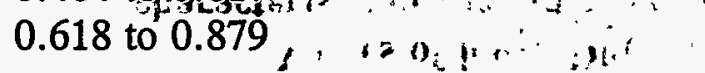 & 0.665 to 0.859 \\
\hline- & $\quad \quad$ Mean $=0.258 \mu \mu \mathrm{m}$ & $\cdots-\cdots$ \\
\hline
\end{tabular}


Table A-50. Uncertainty distribution for the standard deviation of invessel release after passing through a ' $T$ ' quencher $700 \mathrm{~cm}$ deep

\begin{tabular}{|c|c|c|}
\hline \multirow[b]{2}{*}{ Percentile } & \multicolumn{2}{|c|}{$\begin{array}{l}\text { Values of } \sigma \\
\text { characteristic of the indicated percentile } \\
\text { at a confidence level, } C \text {, of }\end{array}$} \\
\hline & $\mathrm{C}=90 \%$ & $\mathrm{C}=\mathbf{5 0 \%}$ \\
\hline $\begin{array}{c}5 \\
10 \\
15 \\
20 \\
25\end{array}$ & $\begin{array}{r}1.0001 \text { to } 1.001 \\
1.002 \text { to } 1.012 \\
1.010 \text { to } 1.029 \\
1.212 \text { to } 1.045 \\
1.035 \text { to } 1.060\end{array}$ & $\begin{array}{l}1.0002 \text { to } 1.0005 \\
1.002 \text { to } 1.005 \\
1.015 \text { to } 1.020 \\
1.029 \text { to } 1.036 \\
1.043 \text { to } 1.053\end{array}$ \\
\hline $\begin{array}{l}30 \\
35 \\
40 \\
45 \\
50\end{array}$ & $\begin{array}{l}1.052 \text { to } 1.094 \\
1.067 \text { to } 1.122 \\
1.101 \text { to } 1.149 \\
1.125 \text { to } 1.231 \\
1.154 \text { to } 1.269\end{array}$ & $\begin{array}{l}1.057 \text { to } 1.076 \\
1.087 \text { to } 1.113 \\
1.118 \text { to } 1.138 \\
1.139 \text { to } 1.167 \\
1.204 \text { to } 1.245\end{array}$ \\
\hline $\begin{array}{l}55 \\
60 \\
65 \\
70 \\
75\end{array}$ & $\begin{array}{l}1.235 \text { to } 1.359 \\
1.275 \text { to } 1.400 \\
1.368 \text { to } 1.427 \\
1.410 \text { to } 1.477 \\
1.440 \text { to } 1.495\end{array}$ & $\begin{array}{l}1.247 \text { to } 1.335 \\
1.344 \text { to } 1.377 \\
1.388 \text { to } 1.417 \\
1.425 \text { to } 1.442 \\
1.475 \text { to } 1.486\end{array}$ \\
\hline $\begin{array}{l}80 \\
85 \\
90 \\
95\end{array}$ & $\begin{array}{l}1.484 \text { to } 1.542 \\
1.533 \text { to } 1.596 \\
1.540 \text { to } 1.661 \\
1.662 \text { to } 1.738\end{array}$ & $\begin{array}{l}1.489 \text { to } 1.533 \\
1.542 \text { to } 1.576 \\
1.597 \text { to } 1.644 \\
1.681 \text { to } 1.694\end{array}$ \\
\hline \multicolumn{3}{|c|}{ Mean $=1.254$} \\
\hline
\end{tabular}


Table A-51. Uncertainty distribution for decontamination of invessel release material during bubble formation and equilibration at an ' $\mathrm{X}$ ' quencher $100 \mathrm{~cm}$ deep

Values of $\log _{10} \mathrm{DF}(\mathrm{FE})$ characteristic of the indicated percentile at a confidence level, $\mathrm{C}$, of

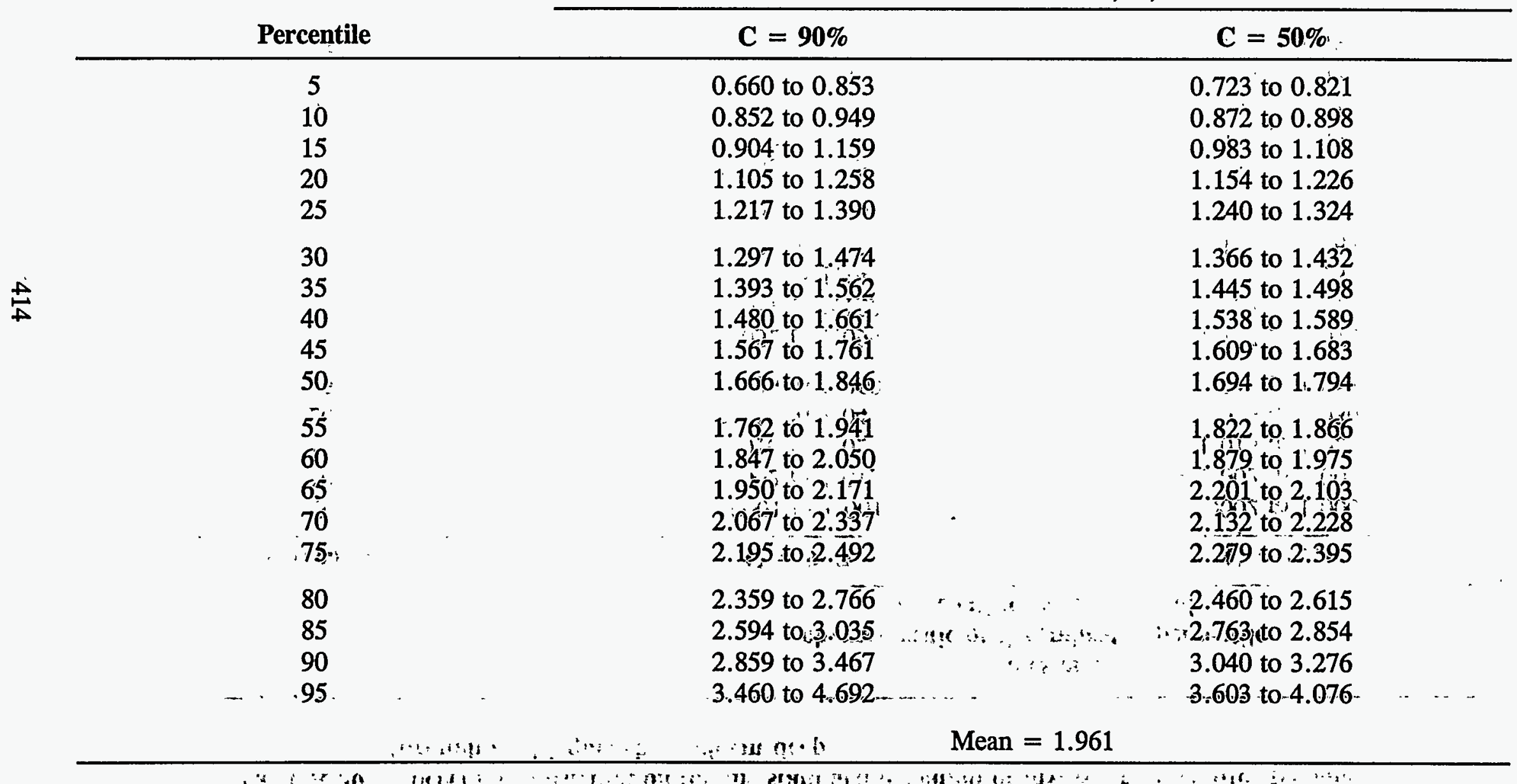


Table A-52. Uncertainty distribution for decontamination of invessel release material during bubble rise from an ' $X$ ' quencher $100 \mathrm{~cm}$ deep

\begin{tabular}{|c|c|c|c|}
\hline & \multirow[b]{2}{*}{ Percentile } & \multicolumn{2}{|c|}{$\begin{array}{l}\text { Values of } \log _{10} \mathrm{DF} \text { (rise) } \\
\text { characteristic of the indicated percentile } \\
\text { at a confidence level, } \mathrm{C} \text {, of }\end{array}$} \\
\hline & & $\mathrm{C}=90 \%$ & $\mathrm{C}=\mathbf{5 0 \%}$ \\
\hline & $\begin{array}{c}5 \\
10 \\
15 \\
20 \\
25\end{array}$ & $\begin{array}{c}0.0299 \text { to } 0.0556 \\
0.0566 \text { to } 0.0813 \\
0.0716 \text { to } 0.109 \\
0.0927 \text { to } 0.135 \\
0.120 \text { to } 0.154\end{array}$ & $\begin{array}{c}0.0343 \text { to } 0.0493 \\
0.0574 \text { to } 0.0705 \\
0.0821 \text { to } 0.0946 \\
0.107 \text { to } 0.122 \\
0.127 \text { to } 0.147\end{array}$ \\
\hline & $\begin{array}{l}30 \\
35 \\
40 \\
45 \\
50\end{array}$ & $\begin{array}{l}0.142 \text { to } 0.182 \\
0.163 \text { to } 0.209 \\
0.189 \text { to } 0.240 \\
0.212 \text { to } 0.277 \\
0.245 \text { to } 0.325\end{array}$ & $\begin{array}{l}0.151 \text { to } 0.168 \\
0.174 \text { to } 0.195 \\
0.198 \text { to } 0.227 \\
0.233 \text { to } 0.256 \\
0.269 \text { to } 0.303\end{array}$ \\
\hline & $\begin{array}{l}55 \\
60 \\
65 \\
70 \\
75\end{array}$ & $\begin{array}{l}0.277 \text { to } 0.358 \\
0.327 \text { to } 0.424 \\
0.358 \text { to } 0.467 \\
0.429 \text { to } 0.523 \\
0.472 \text { to } 0.700\end{array}$ & $\begin{array}{l}0.308 \text { to } 0.335 \\
0.343 \text { to } 0.381 \\
0.400 \text { to } 0.440 \\
0.449 \text { to } 0.477 \\
0.501 \text { to } 0.590\end{array}$ \\
\hline & $\begin{array}{l}80 \\
85 \\
90 \\
95\end{array}$ & $\begin{array}{l}0.582 \text { to } 0.834 \\
0.752 \text { to } 1.086 \\
1.027 \text { to } 1.261 \\
1.254 \text { to } 1.812\end{array}$ & $\begin{array}{l}0.654 \text { to } 0.756 \\
0.825 \text { to } 1.017 \\
1.114 \text { to } 1.206 \\
1.455 \text { to } 1.760\end{array}$ \\
\hline
\end{tabular}


Table A-53. Uncertainty distribution for the total decontamination of invessel release material after passing through an ' $X$ ' quencher $100 \mathrm{~cm}$ deep

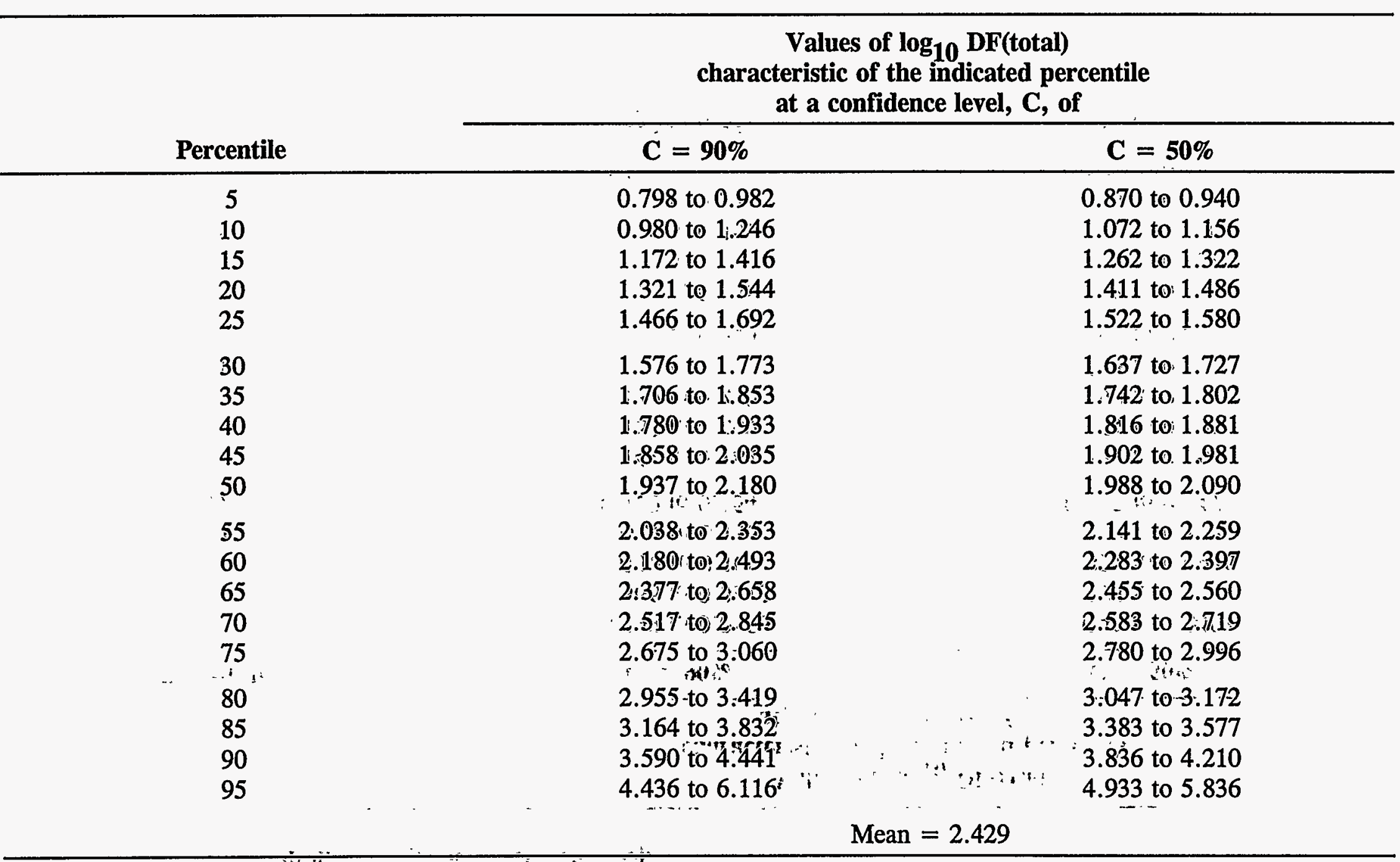


Table A-54. Uncertainty distribution for the mean particle size of invessel release material after passing through an ' $\mathrm{X}$ ' quencher $100 \mathrm{~cm}$ deep

\begin{tabular}{|c|c|c|}
\hline \multirow[b]{2}{*}{ Percentile } & \multicolumn{2}{|c|}{$\begin{array}{l}\text { Values of } d_{p}(\mu \mathrm{m}) \\
\text { characteristic of the indicated percentile } \\
\text { at a confidence level, } C \text {, of }\end{array}$} \\
\hline & $\mathrm{C}=90 \%$ & $\mathrm{C}=50 \%$ \\
\hline $\begin{array}{c}5 \\
10 \\
15 \\
20 \\
25\end{array}$ & $\begin{array}{l}0.128 \text { to } 0.156 \\
0.156 \text { to } 0.171 \\
0.167 \text { to } 0.192 \\
0.183 \text { to } 0.216 \\
0.197 \text { to } 0.226\end{array}$ & $\begin{array}{l}0.138 \text { to } 0.147 \\
0.158 \text { to } 0.166 \\
0.172 \text { to } 0.184 \\
0.192 \text { to } 0.201 \\
0.209 \text { to } 0.217\end{array}$ \\
\hline $\begin{array}{l}30 \\
35 \\
40 \\
45 \\
50\end{array}$ & $\begin{array}{l}0.214 \text { to } 0.241 \\
0.229 \text { to } 0.258 \\
0.242 \text { to } 0.269 \\
0.258 \text { to } 0.290 \\
0.270 \text { to } 0.316\end{array}$ & $\begin{array}{l}0.223 \text { to } 0.232 \\
0.234 \text { to } 0.248 \\
0.249 \text { to } 0.261 \\
0.265 \text { to } 0.276 \\
0.279 \text { to } 0.305\end{array}$ \\
\hline $\begin{array}{l}55 \\
60 \\
65 \\
70 \\
75\end{array}$ & $\begin{array}{l}0.291 \text { to } 0.337 \\
0.318 \text { to } 0.361 \\
0.339 \text { to } 0.390 \\
0.365 \text { to } 0.418 \\
0.392 \text { to } 0.438\end{array}$ & $\begin{array}{l}0.307 \text { to } 0.323 \\
0.329 \text { to } 0.348 \\
0.352 \text { to } 0.369 \\
0.376 \text { to } 0.400 \\
0.407 \text { to } 0.430\end{array}$ \\
\hline $\begin{array}{l}80 \\
85 \\
90 \\
95\end{array}$ & $\begin{array}{l}0.437 \text { to } 0.493 \\
0.464 \text { to } 0.552 \\
0.534 \text { to } 0.633 \\
0.628 \text { to } 0.828\end{array}$ & $\begin{array}{l}0.437 \text { to } 0.467 \\
0.490 \text { to } 0.531 \\
0.553 \text { to } 0.589 \\
0.694 \text { to } 0.769\end{array}$ \\
\hline
\end{tabular}


Table A-55. Uncertainty distribution for the geometric standard deviation of invessel release material after passing through an ' $X$ ' quencher $100 \mathrm{~cm}$ deep

\begin{tabular}{|c|c|c|c|}
\hline \multirow[b]{2}{*}{ Percentile } & \multicolumn{3}{|c|}{$\begin{array}{l}\text { Values of } \sigma \\
\text { characteristic of the indicated percentile } \\
\text { at a confidence level, } C \text {, of }\end{array}$} \\
\hline & $\mathrm{C}=90 \%$ & & $\mathbf{C}=50 \%$ \\
\hline $\begin{array}{l}5 \\
10 \\
15 \\
20 \\
25\end{array}$ & $\begin{array}{l}1.002 \text { to } 1.007 \\
1.007 \text { to } 1.055 \\
1.044 \text { to } 1.091 \\
1.071 \text { to } 1.141 \\
1.115 \text { to } 1.201\end{array}$ & & $\begin{array}{l}1.003 \text { to } 1.006 \\
1.023 \text { to } 1.043 \\
1.057 \text { to } 1.072 \\
1.090 \text { to } 1.125 \\
1.133 \text { to } 1.163\end{array}$ \\
\hline $\begin{array}{l}30 \\
35 \\
40 \\
45 \\
50\end{array}$ & $\begin{array}{l}1.151 \text { to } 1.255 \\
1.209 \text { to } 1.304 \\
1.262 \text { to } 1.358 \\
1.310 \text { to } 1.390 \\
1.359 \text { to } 1.422\end{array}$ & & $\begin{array}{l}1.189 \text { to } 1.230 \\
1.237 \text { to } 1.269 \\
1.281 \text { to } 1.325 \\
1.331 \text { to } 1.376 \\
1.389 \text { to } 1.412\end{array}$ \\
\hline $\begin{array}{l}55 \\
60 \\
65 \\
70 \\
75\end{array}$ & $\begin{array}{l}1.390 \text { to } 1.463 \\
1.423 \text { to } 1.526 \\
1.470 \text { to } 1.550 \\
1.527 \text { to } 1.61^{\prime} 1 \\
1.558 \text { to } 1.653\end{array}$ & & $\begin{array}{l}1.415 \text { to } 1.437 \\
1.447 \text { to } 1.503 \\
1.515 \text { to } 1.537 \\
1.543 \text { to } 1.572 \\
1.599 \text { to } 1.626\end{array}$ \\
\hline \multirow[t]{2}{*}{$\begin{array}{l}80 \\
85 \\
90 \\
95\end{array}$} & $\begin{array}{l}1.621 \text { to } 1.697 \\
1.670 \text { to } 1.782 \\
1.745 \text { to } 1.849 \\
1.849 \text { to } 1.940\end{array}$ & 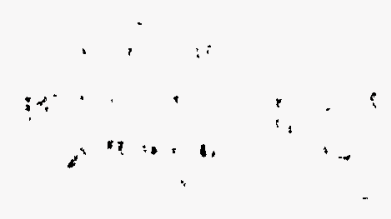 & $\begin{array}{l}1.652 \text { to } 1.674 \\
1.696 \text { to } 1.734 \\
1.784 \text { to } 1.806 \\
1.885 \text { to } 1.923\end{array}$ \\
\hline & \multicolumn{3}{|c|}{ Mean $=1.376$} \\
\hline
\end{tabular}


Table A-56. Uncertainty distribution for decontamination during bubble formation and equilibration of invessel release through an ' $X$ ' quencher $200 \mathrm{~cm}$ deep

\begin{tabular}{|c|c|c|}
\hline \multirow[b]{2}{*}{ Percentile } & \multicolumn{2}{|c|}{$\begin{array}{l}\text { Values of } \log _{10} \mathrm{DF}(\mathrm{FE}) \\
\text { characteristic of the indicated percentile } \\
\text { at a confidence level, } C \text {, of }\end{array}$} \\
\hline & $\mathrm{C}=90 \%$ & $\mathrm{C}=50 \%$ \\
\hline $\begin{array}{c}5 \\
10 \\
15 \\
20 \\
25\end{array}$ & $\begin{array}{l}0.630 \text { to } 0.822 \\
0.823 \text { to } 0.944 \\
0.912 \text { to } 1.127 \\
1.094 \text { to } 1.242 \\
1.160 \text { to } 1.365\end{array}$ & $\begin{array}{l}0.700 \text { to } 0.747 \\
0.863 \text { to } 0.897 \\
1.009 \text { to } 1.095 \\
1.127 \text { to } 1.164 \\
1.237 \text { to } 1.324\end{array}$ \\
\hline $\begin{array}{l}30 \\
35 \\
40 \\
45 \\
50\end{array}$ & $\begin{array}{l}1.306 \text { to } 1.424 \\
1.387 \text { to } 1.487 \\
1.430 \text { to } 1.575 \\
1.502 \text { to } 1.667 \\
1.587 \text { to } 1.759\end{array}$ & $\begin{array}{l}1.343 \text { to } 1.399 \\
1.417 \text { to } 1.441 \\
1.463 \text { to } 1.543 \\
1.558 \text { to } 1.610 \\
1.638 \text { to } 1.710\end{array}$ \\
\hline $\begin{array}{l}55 \\
60 \\
65 \\
70 \\
75\end{array}$ & $\begin{array}{l}1.674 \text { to } 1.843 \\
1.772 \text { to } 1.966 \\
1.867 \text { to } 2.096 \\
1.974 \text { to } 2.215 \\
2.137 \text { to } 2.382\end{array}$ & $\begin{array}{l}1.734 \text { to } 1.796 \\
1.816 \text { to } 1.900 \\
1.941 \text { to } 2.032 \\
2.073 \text { to } 2.155 \\
2.188 \text { to } 2.308\end{array}$ \\
\hline $\begin{array}{l}80 \\
85 \\
90 \\
95\end{array}$ & $\begin{array}{l}2.279 \text { to } 2.687 \\
2.547 \text { to } 3.058 \\
2.958 \text { to } 3.592 \\
3.630 \text { to } 5.406\end{array}$ & $\begin{array}{l}2.349 \text { to } 2.548 \\
2.681 \text { to } 2.886 \\
3.085 \text { to } 3.277 \\
4.019 \text { to } 4.766\end{array}$ \\
\hline \multicolumn{3}{|c|}{ Mean $=1.169$} \\
\hline
\end{tabular}


Table A-57. Uncertainty distribution for decontamination of invessel release during rise from an ' $X$ ' quencher $200 \mathrm{~cm}$ deep

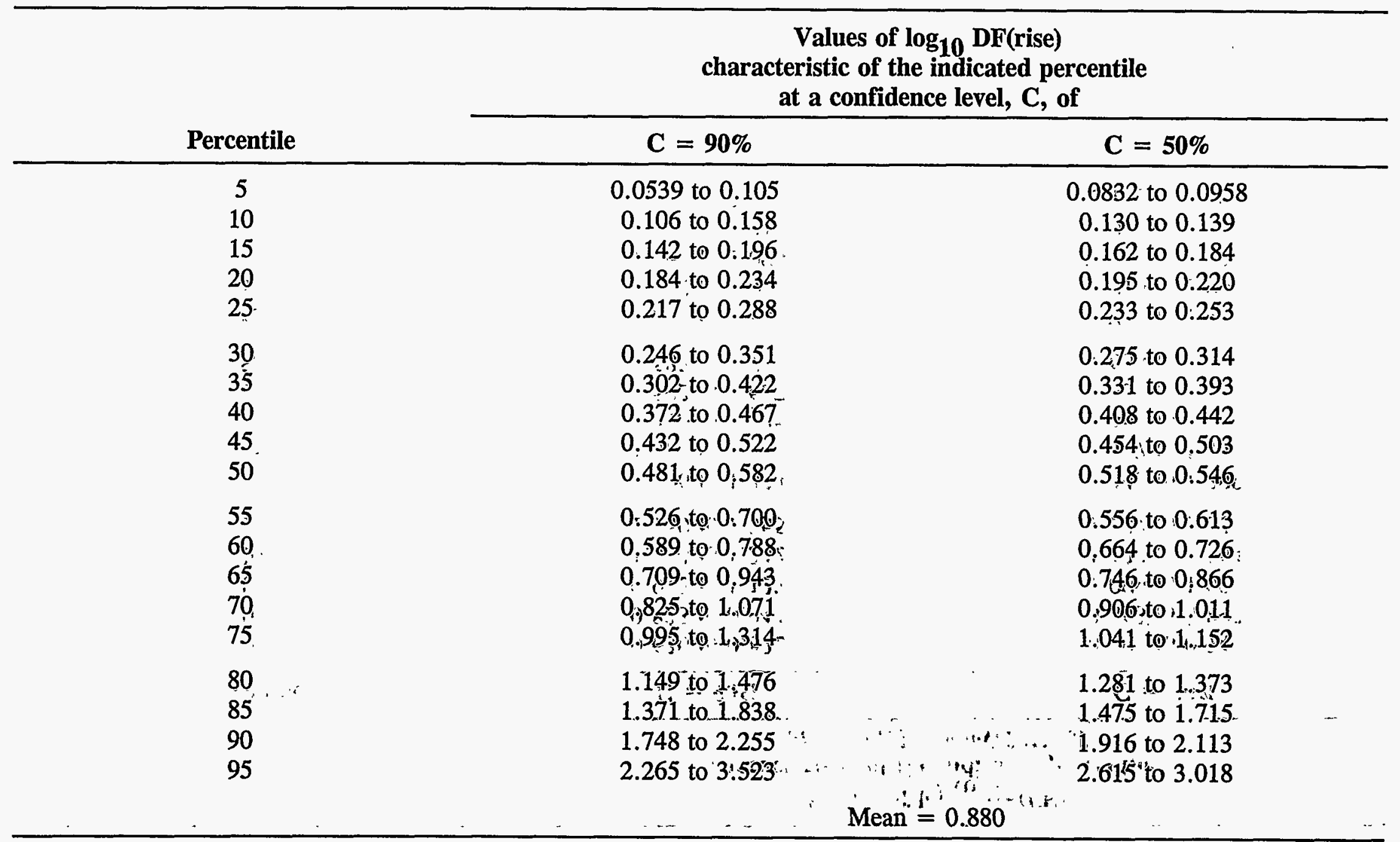

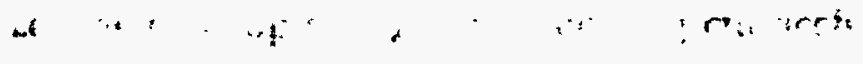

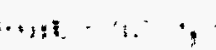


Table A-58. Uncertainty distribution for the total invessel release decontamination after passing through an ' $X$ ' quencher $200 \mathrm{~cm}$ deep

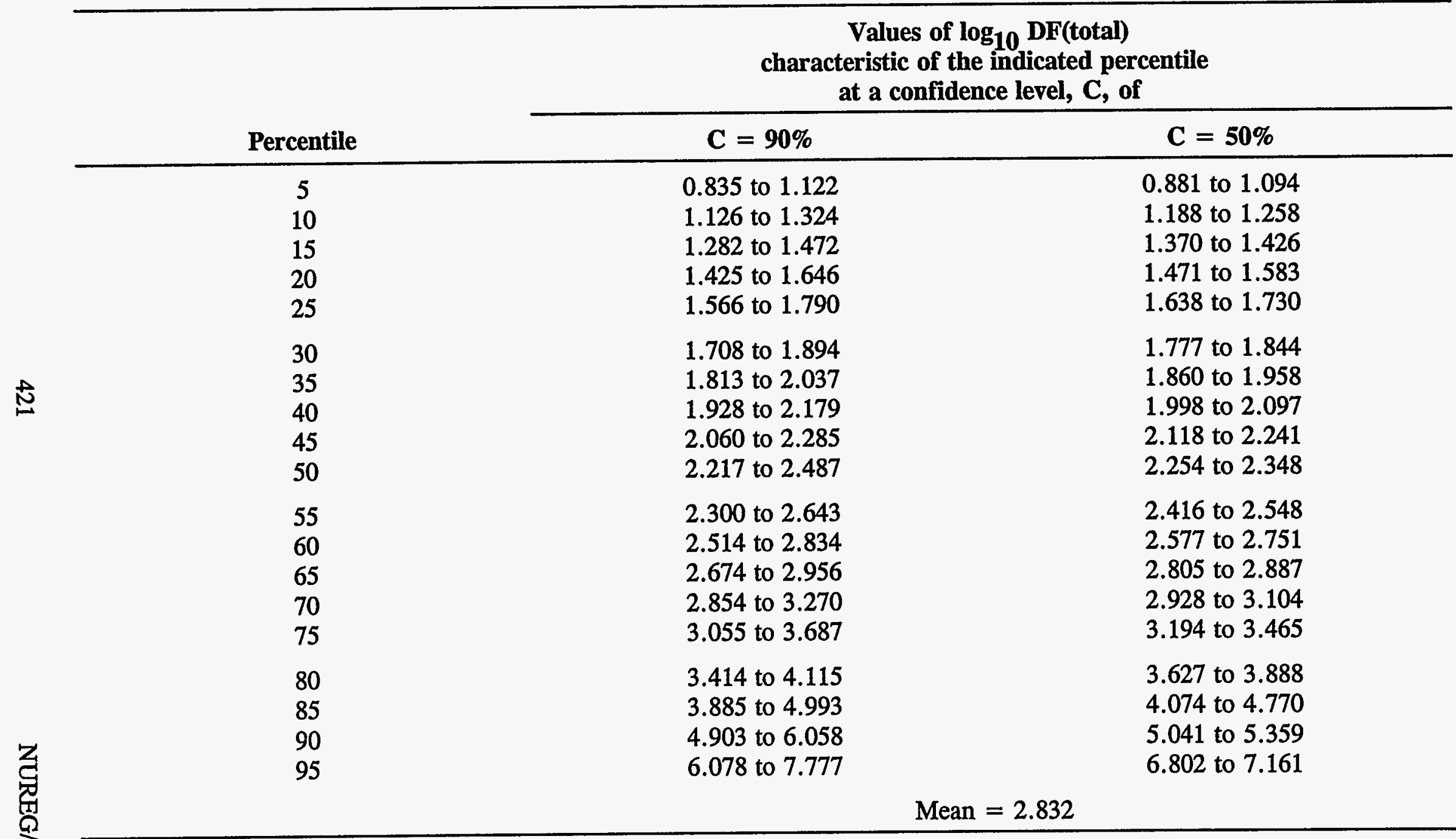


Table A-59. Uncertainty distribution for the mean particle size after passing through an ' $\mathrm{X}$ ' quencher $200 \mathrm{~cm}$ deep

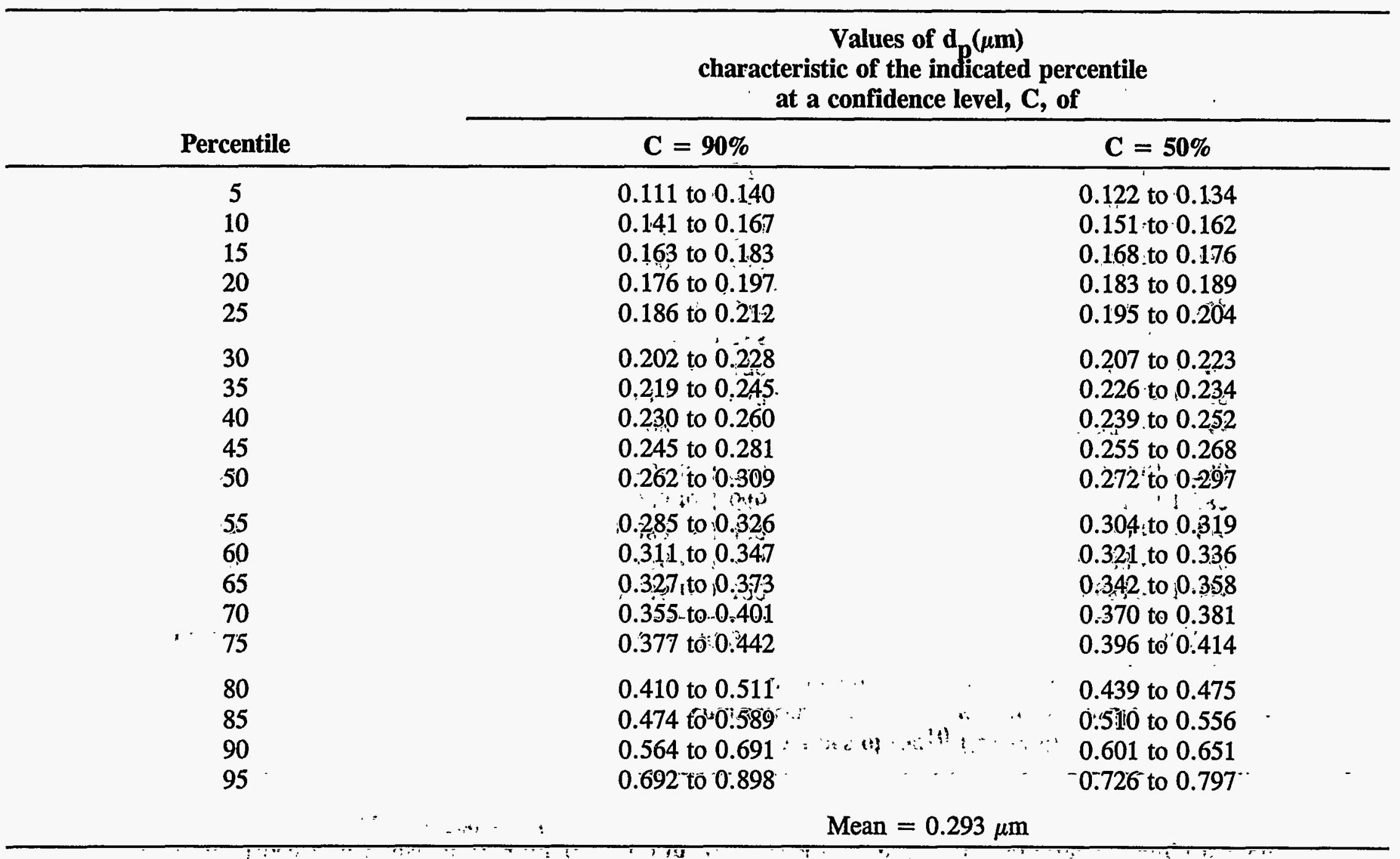


Table A-60. Uncertainty distribution for the geometric standard deviation of invessel release after passing through an ' $X$ ' quencher $200 \mathrm{~cm}$ deep

\begin{tabular}{|c|c|c|}
\hline \multirow[b]{2}{*}{ Percentile } & \multicolumn{2}{|c|}{$\begin{array}{l}\text { Values of } \sigma \\
\text { characteristic of the indicated percentile } \\
\text { at a confidence level, } C \text {, of } \\
\end{array}$} \\
\hline & $\mathrm{C}=90 \%$ & $\mathrm{C}=\mathbf{5 0 \%}$ \\
\hline $\begin{array}{c}5 \\
10 \\
15 \\
20 \\
25\end{array}$ & $\begin{array}{r}1.0005 \text { to } 1.002 \\
1.002 \text { to } 1.019 \\
1.011 \text { to } 1.053 \\
1.040 \text { to } 1.101 \\
1.067 \text { to } 1.135\end{array}$ & $\begin{array}{l}1.001 \text { to } 1.002 \\
1.005 \text { to } 1.010 \\
1.022 \text { to } 1.041 \\
1.053 \text { to } 1.075 \\
1.099 \text { to } 1.120\end{array}$ \\
\hline $\begin{array}{l}30 \\
35 \\
40 \\
45 \\
50\end{array}$ & $\begin{array}{l}1.109 \text { to } 1.180 \\
1.151 \text { to } 1.228 \\
1.184 \text { to } 1.298 \\
1.242 \text { to } 1.344 \\
1.301 \text { to } 1.388\end{array}$ & $\begin{array}{l}1.133 \text { to } 1.166 \\
1.173 \text { to } 1.200 \\
1.212 \text { to } 1.257 \\
1.278 \text { to } 1.322 \\
1.329 \text { to } 1.362\end{array}$ \\
\hline $\begin{array}{l}55 \\
60 \\
65 \\
70 \\
75\end{array}$ & $\begin{array}{l}1.347 \text { to } 1.436 \\
1.392 \text { to } 1.476 \\
1.441 \text { to } 1.508 \\
1.485 \text { to } 1.552 \\
1.532 \text { to } 1.608\end{array}$ & $\begin{array}{l}1.373 \text { to } 1.406 \\
1.419 \text { to } 1.446 \\
1.461 \text { to } 1.487 \\
1.494 \text { to } 1.538 \\
1.546 \text { to } 1.575\end{array}$ \\
\hline $\begin{array}{l}80 \\
85 \\
90 \\
95\end{array}$ & $\begin{array}{l}1.571 \text { to } 1.644 \\
1.624 \text { to } 1.697 \\
1.688 \text { to } 1.776 \\
1.778 \text { to } 1.872\end{array}$ & $\begin{array}{l}1.591 \text { to } 1.624 \\
1.642 \text { to } 1.673 \\
1.698 \text { to } 1.745 \\
1.797 \text { to } 1.835\end{array}$ \\
\hline \multicolumn{3}{|c|}{ Mean $=1.330$} \\
\hline
\end{tabular}


Table A-61. Uncertainty distribution for the decontamination of invessel release by bubble formation and equilibration at an ' $\mathrm{X}$ ' quencher $300 \mathrm{~cm}$ deep

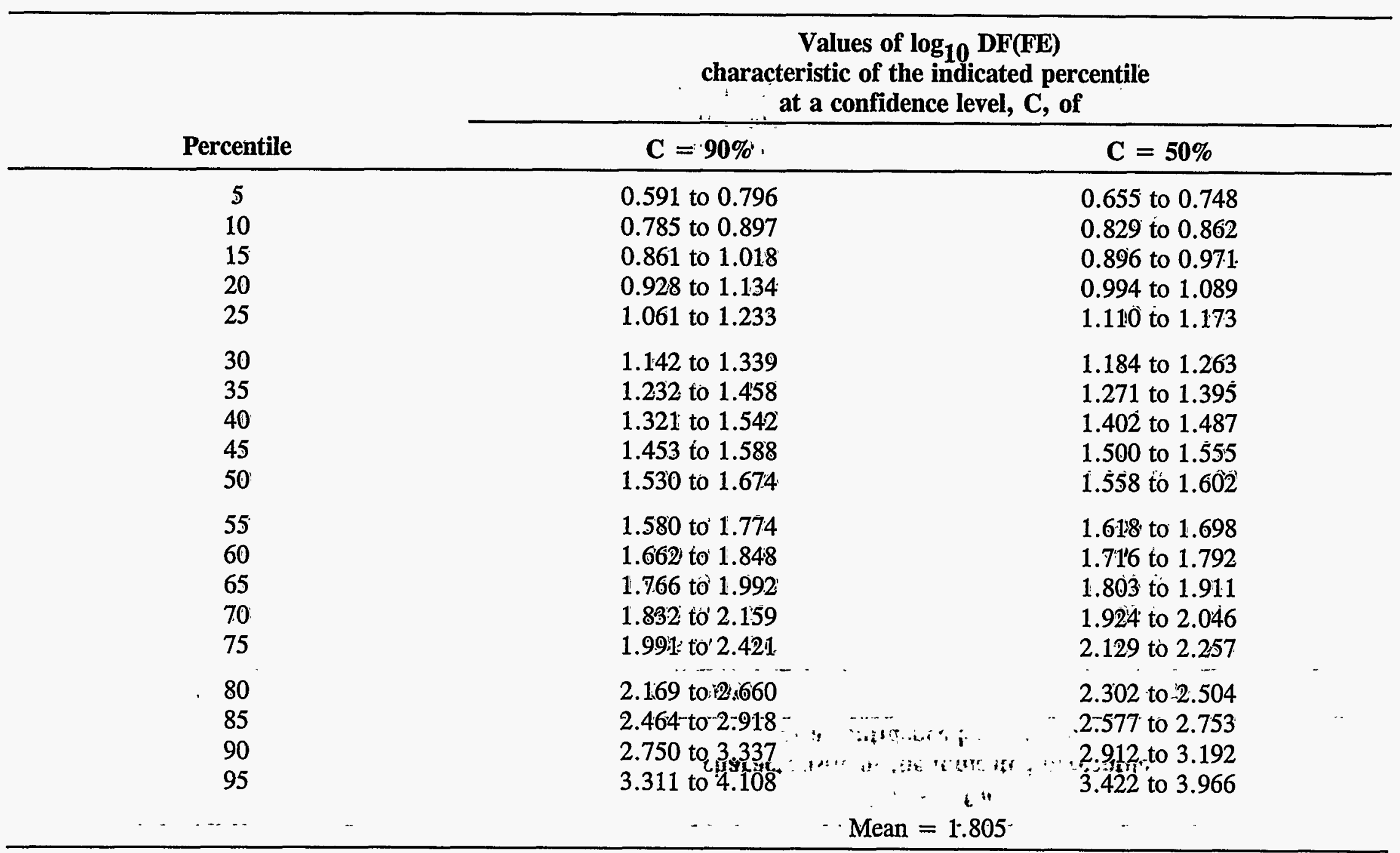

, $, \cdots, \cdots, \cdots, \cdots$


Table A-62. Uncertainty distribution for decontamination of invessel release material during bubble rise from an ' $\mathrm{X}$ ' quencher $300 \mathrm{~cm}$ deep

\begin{tabular}{|c|c|c|}
\hline \multirow[b]{2}{*}{ Percentile } & \multicolumn{2}{|c|}{$\begin{array}{l}\text { Values of } \log _{10} \mathrm{DF} \text { (rise) } \\
\text { characteristic of the indicated percentile } \\
\text { at a confidence level, } \mathrm{C} \text {, of }\end{array}$} \\
\hline & $\mathrm{C}=90 \%$ & $C=50 \%$ \\
\hline $\begin{array}{c}5 \\
10 \\
15 \\
20 \\
25\end{array}$ & $\begin{array}{c}0.0669 \text { to } 0.168 \\
0.158 \text { to } 0.233 \\
0.208 \text { to } 0.319 \\
0.269 \text { to } 0.381 \\
0.332 \text { to } 0.457\end{array}$ & $\begin{array}{l}0.0878 \text { to } 0.149 \\
0.173 \text { to } 0.211 \\
0.232 \text { to } 0.278 \\
0.310 \text { to } 0.344 \\
0.351 \text { to } 0.416\end{array}$ \\
\hline $\begin{array}{l}30 \\
35 \\
40 \\
45 \\
50\end{array}$ & $\begin{array}{l}0.392 \text { to } 0.543 \\
0.457 \text { to } 0.646 \\
0.541 \text { to } 0.731 \\
0.636 \text { to } 0.810 \\
0.703 \text { to } 0.881\end{array}$ & $\begin{array}{l}0.432 \text { to } 0.512 \\
0.523 \text { to } 0.559 \\
0.604 \text { to } 0.666 \\
0.670 \text { to } 0.751 \\
0.760 \text { to } 0.837\end{array}$ \\
\hline $\begin{array}{l}55 \\
60 \\
65 \\
70 \\
75\end{array}$ & $\begin{array}{l}0.790 \text { to } 0.999 \\
0.875 \text { to } 1.177 \\
0.988 \text { to } 1.311 \\
1.160 \text { to } 1.544 \\
1.310 \text { to } 1.813\end{array}$ & $\begin{array}{l}0.862 \text { to } 0.932 \\
0.941 \text { to } 1.062 \\
1.102 \text { to } 1.207 \\
1.224 \text { to } 1.378 \\
1.474 \text { to } 1.623\end{array}$ \\
\hline $\begin{array}{l}80 \\
85 \\
90 \\
95\end{array}$ & $\begin{array}{l}1.568 \text { to } 2.274 \\
1.875 \text { to } 2.994 \\
2.656 \text { to } 3.996 \\
3.754 \text { to } 4.804\end{array}$ & $\begin{array}{l}1.714 \text { to } 1.915 \\
2.179 \text { to } 2.660 \\
2.860 \text { to } 3.466 \\
4.060 \text { to } 4.444\end{array}$ \\
\hline
\end{tabular}


Table A-63. Uncertainty distribution for total decontamination of invessel release after passing through an ' $\mathrm{X}$ ' quencher $300 \mathrm{~cm}$ deep

Values of $\log _{10} \mathrm{DF}$ (total)

characteristic of the indicated percentile

at a confidence level, $C$, of

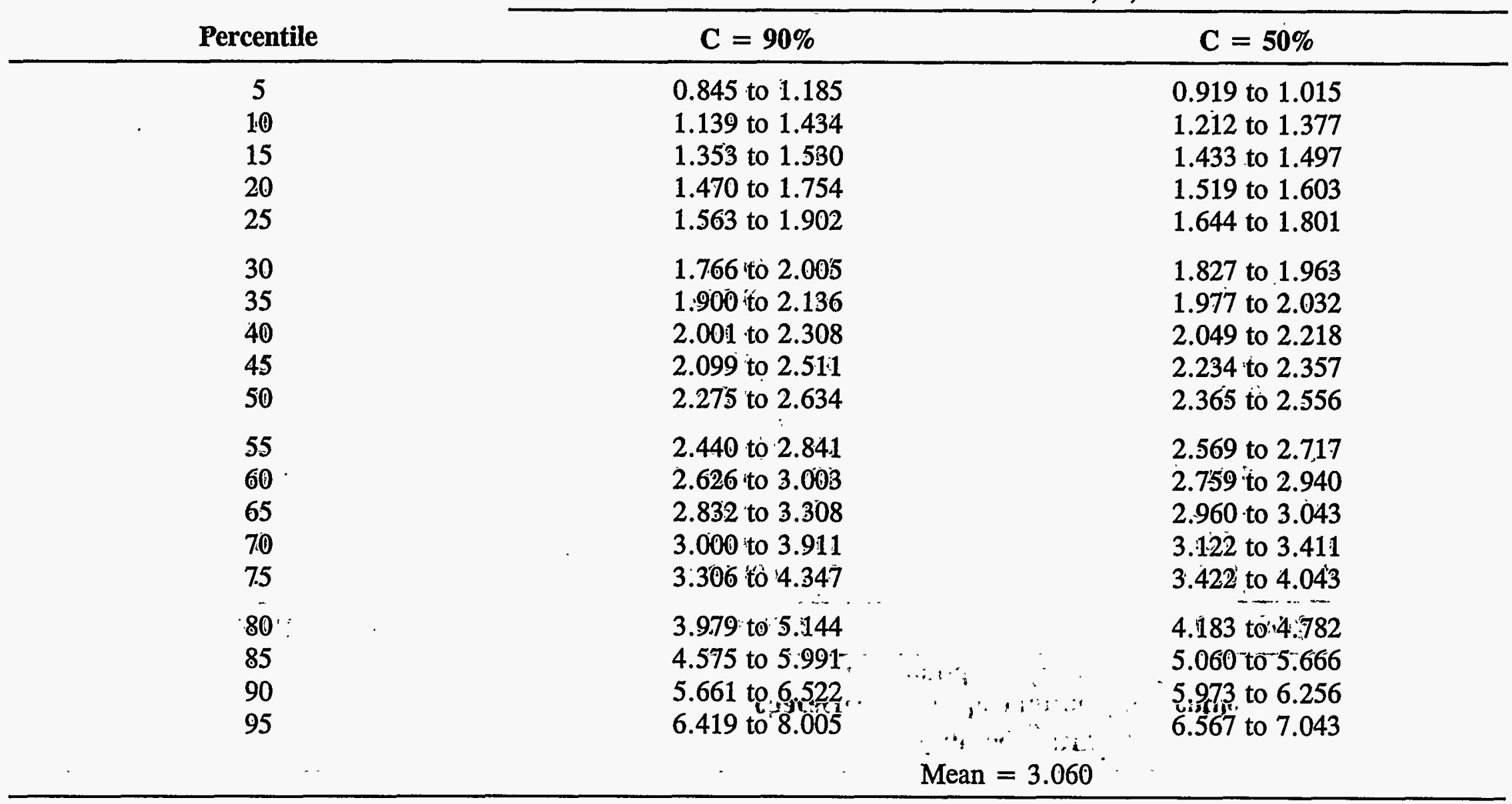


Table A-64. Uncertainty distribution for the mean particle size of invessel release after Passage through a ' $\mathrm{X}$ ' quencher $300 \mathrm{~cm}$ deep

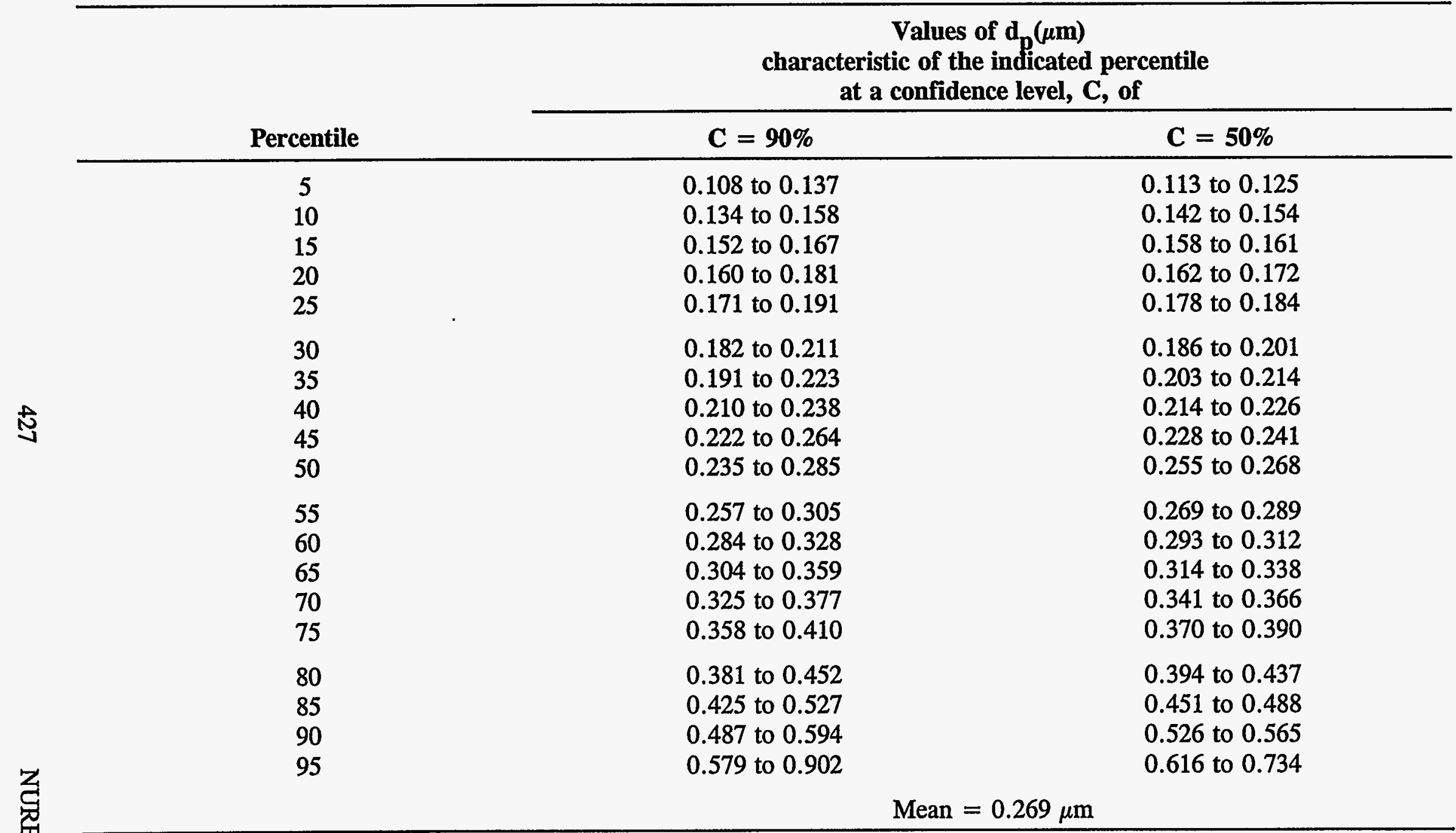


Table A-65. Uncertainty distribution for the geometric standard deviation of invessel release after passing through an ' $X$ ' quencher $300 \mathrm{~cm}$ deep

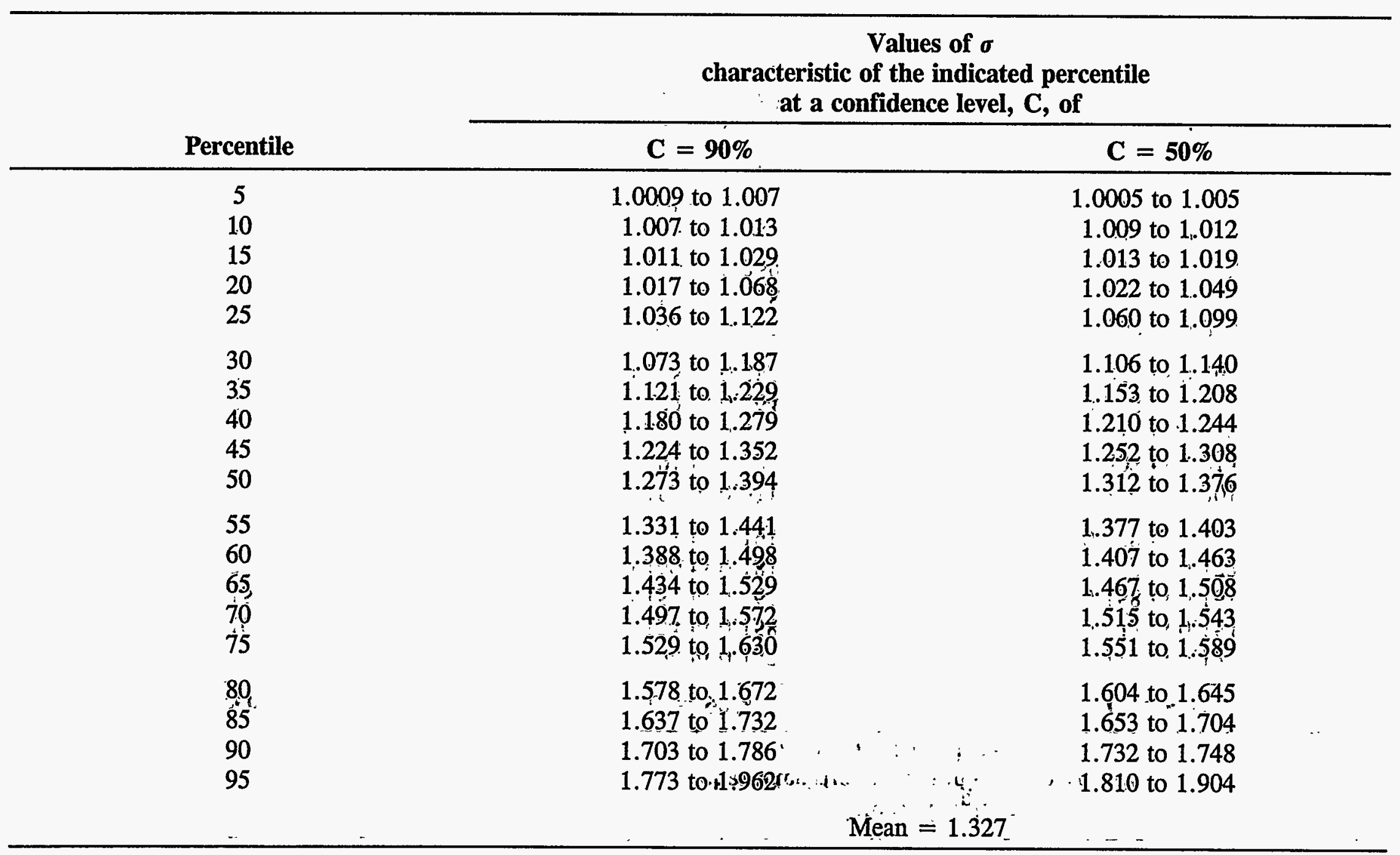

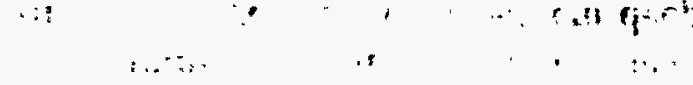


Table A-66. Uncertainty distribution for decontamination of invessel release by bubble formation and equilibration at an ' $X$ ' quencher $500 \mathrm{~cm}$ deep

\begin{tabular}{|c|c|c|}
\hline \multirow[b]{2}{*}{ Percentile } & \multicolumn{2}{|c|}{$\begin{array}{l}\text { Values of } \log _{10} \mathrm{DF}(\mathrm{FE}) \\
\text { characteristic of the indicated percentile } \\
\text { at a confidence level, } \mathrm{C} \text {, of }\end{array}$} \\
\hline & $C=90 \%$ & $\mathrm{C}=\mathbf{5 0 \%}$ \\
\hline $\begin{array}{c}5 \\
10 \\
15 \\
20 \\
25\end{array}$ & $\begin{array}{l}0.559 \text { to } 0.840 \\
0.794 \text { to } 0.920 \\
0.874 \text { to } 1.059 \\
0.928 \text { to } 1.148 \\
1.043 \text { to } 1.258\end{array}$ & $\begin{array}{l}0.725 \text { to } 0.794 \\
0.844 \text { to } 0.894 \\
0.909 \text { to } 1.004 \\
1.025 \text { to } 1.107 \\
1.114 \text { to } 1.166\end{array}$ \\
\hline $\begin{array}{l}30 \\
35 \\
40 \\
45 \\
50\end{array}$ & $\begin{array}{l}1.123 \text { to } 1.400 \\
1.198 \text { to } 1.512 \\
1.350 \text { to } 1.547 \\
1.461 \text { to } 1.647 \\
1.523 \text { to } 1.706\end{array}$ & $\begin{array}{l}1.167 \text { to } 1.307 \\
1.298 \text { to } 1.416 \\
1.413 \text { to } 1.519 \\
1.517 \text { to } 1.558 \\
1.552 \text { to } 1.649\end{array}$ \\
\hline $\begin{array}{l}55 \\
60 \\
65 \\
70 \\
75\end{array}$ & $\begin{array}{l}1.574 \text { to } 1.758 \\
1.656 \text { to } 1.939 \\
1.732 \text { to } 2.096 \\
1.842 \text { to } 2.186 \\
1.976 \text { to } 2.384\end{array}$ & $\begin{array}{l}1.647 \text { to } 1.730 \\
1.719 \text { to } 1.790 \\
1.784 \text { to } 1.954 \\
1.954 \text { to } 2.121 \\
2.121 \text { to } 2.220\end{array}$ \\
\hline $\begin{array}{l}80 \\
85 \\
90 \\
95\end{array}$ & $\begin{array}{l}2.145 \text { to } 2.638 \\
2.359 \text { to } 2.791 \\
2.653 \text { to } 3.248 \\
2.930 \text { to } 3.803\end{array}$ & $\begin{array}{l}2.245 \text { to } 2.405 \\
2.462 \text { to } 2.692 \\
2.746 \text { to } 2.922 \\
3.247 \text { to } 3.662\end{array}$ \\
\hline \multicolumn{3}{|c|}{ Mean $=1.741$} \\
\hline
\end{tabular}


Table A-67. Uncertainty distribution for decontamination of invessel release during bubble rise from an ' $X$ ' quencher $500 \mathrm{~cm}$ deep

\begin{tabular}{|c|c|c|}
\hline \multirow[b]{2}{*}{ Percentile } & \multicolumn{2}{|c|}{$\begin{array}{c}\text { Values of } \log _{10} \mathrm{DF}(\text { rise) } \\
\text { characteristic of the indicated percentile } \\
\text { at a confidence level, } \mathrm{C} \text {, of }\end{array}$} \\
\hline & $\mathrm{C}=90 \%$ & $\mathrm{C}=50 \%$ \\
\hline $\begin{array}{c}5 \\
10 \\
15 \\
20 \\
25\end{array}$ & $\begin{array}{c}0.0743 \text { to } 0.320 \\
0.275 \text { to } 0.519 \\
0.419 \text { to } 0.598 \\
0.529 \text { to } 0.679 \\
0.587 \text { to } 0.842\end{array}$ & $\begin{array}{l}0.149 \text { to } 0.278 \\
0.328 \text { to } 0.437 \\
0.465 \text { to } 0.547 \\
0.552 \text { to } 0.638 \\
0.644 \text { to } 0.732\end{array}$ \\
\hline $\begin{array}{l}30 \\
35 \\
40 \\
45 \\
50\end{array}$ & $\begin{array}{l}0.670 \text { to } 0.960 \\
0.783 \text {, to } 1.061 \\
0.897 \text { rto } 1.211 \\
1.025 \text { to } 1.355 \\
1.081 \text { to } 1.625\end{array}$ & $\begin{array}{l}0.733 \text { to } 0.878 \\
0.875 \text { to } 0.986 \\
0.981 \text { to } 1.076 \\
1.073 \text { to } 1.258 \\
1.243 \text { to } 1.404\end{array}$ \\
\hline $\begin{array}{r}55 \\
60 \\
65 \\
70 \\
75\end{array}$ & $\begin{array}{l}1.292 \text { to } 1.865 \\
1.418 \text { to } 2.126 \\
1.794 \text { to } 2.448 \\
1.931 \text { to } 2.845 \\
2.253 \text { to } 4.014\end{array}$ & $\begin{array}{l}1.397 \text { to } 1.779 \\
1.706 \text { to } 1.902 \\
1.894 \text { to } 2.231 \\
2.210 \text { to } 2.526 \\
2.533 \text { to } 3.073\end{array}$ \\
\hline $\begin{array}{r}80 \\
85 \\
90 \\
95\end{array}$ & $\begin{array}{l}2.744 \text { to } 5.498 \\
3.665 \text { to }-5.9 .22 \\
5.530 \text { to } 6.794 \\
6.200 \text { to } 7.416 \\
.\end{array}$ & $\begin{array}{l}3.184 \text { to } 4.234 \\
4.438 \text { to } 5.634 \\
5.818 \text { to } 6.167 \\
6.784 \text { to } 7.238\end{array}$ \\
\hline
\end{tabular}

$\therefore \quad \because \quad \therefore, \cdots$


Table A-68. Uncertainty distribution for total decontamination of invessel release after passing through an ' $X$ ' quencher $500 \mathrm{~cm}$ deep

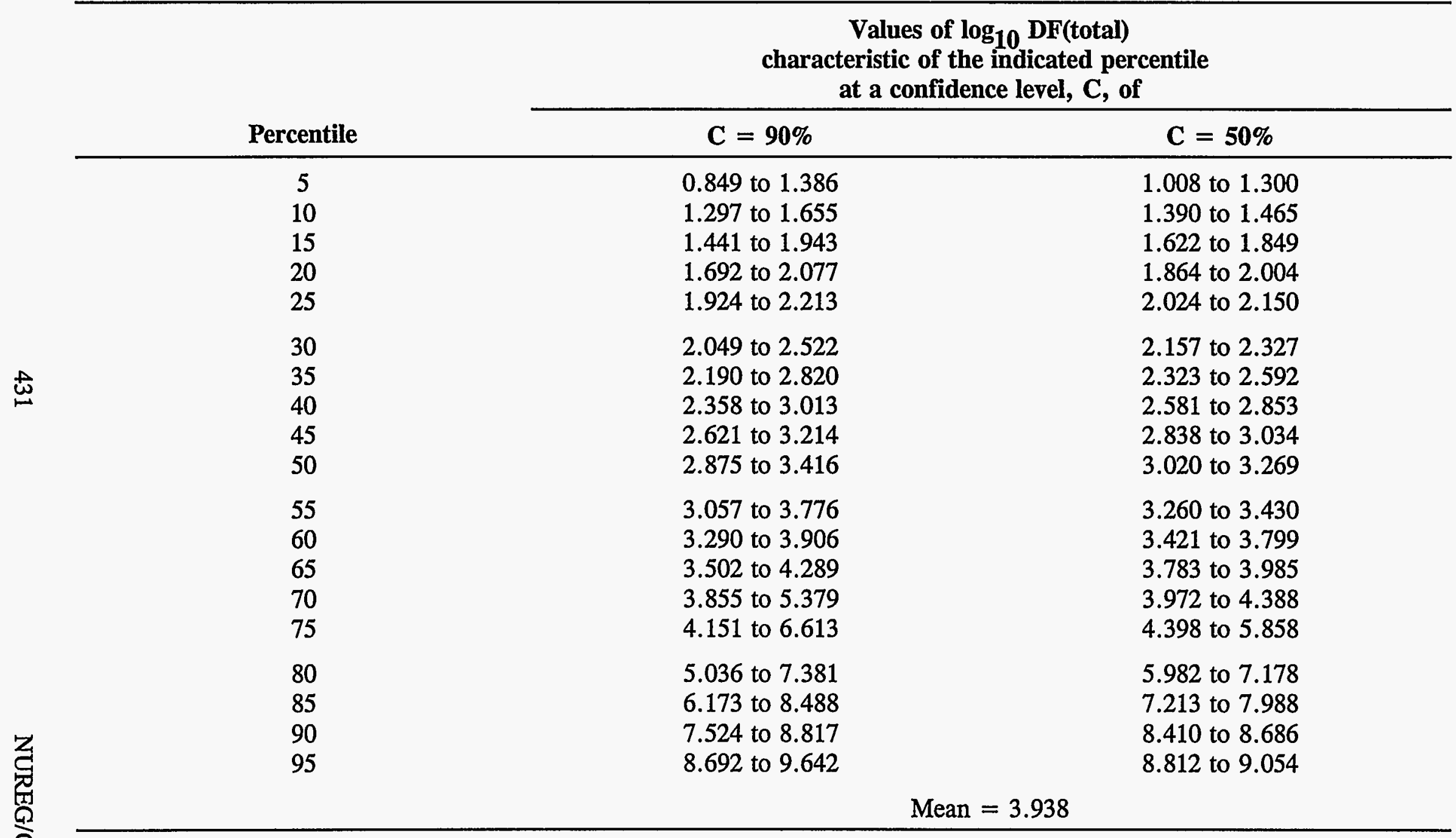


Table A-69. Uncertainty distribution for the mean particle size of invessel release material after passing through an ' $X$ ' quencher $500 \mathrm{~cm}$ deep

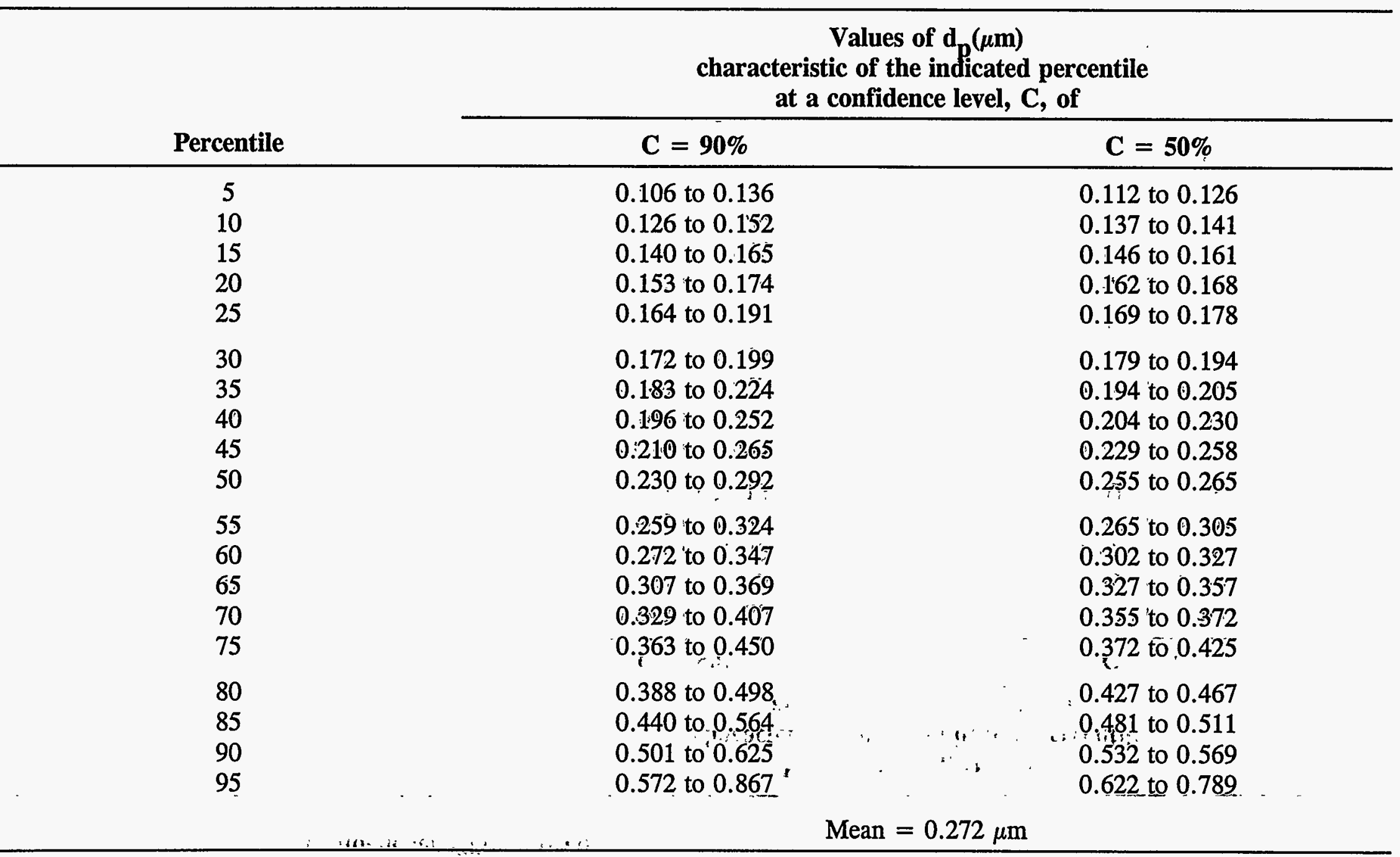


Table A-70. Uncertainty distribution for the geometric standard deviation of invessel release material after passing through an ' $X$ ' quencher $500 \mathrm{~cm}$ deep

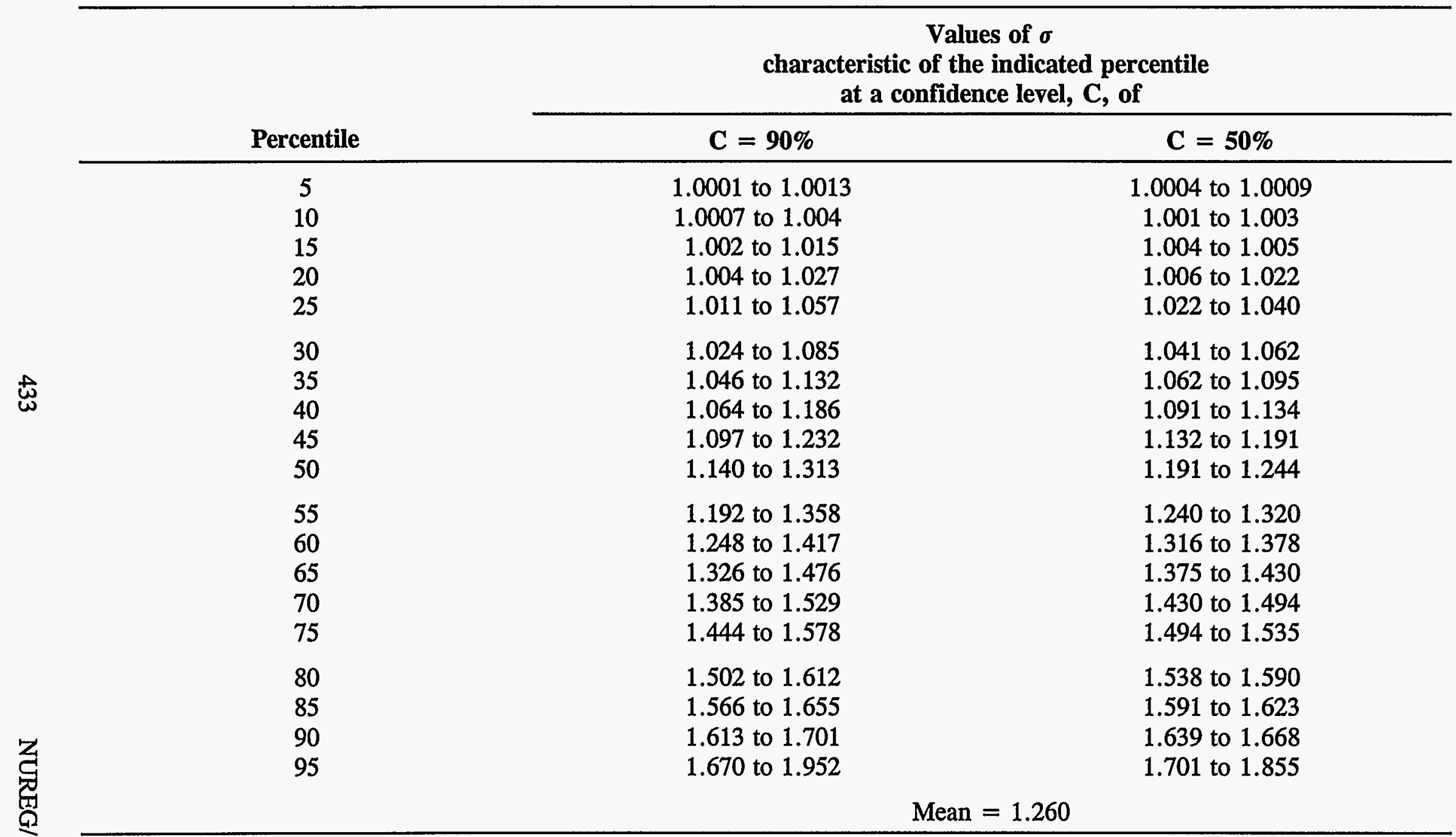


Table A-71. Uncertainty distribution for decontamination of invessel release by bubble formation and equilibration at an ' $X$ ' quencher $700 \mathrm{~cm}$ deep

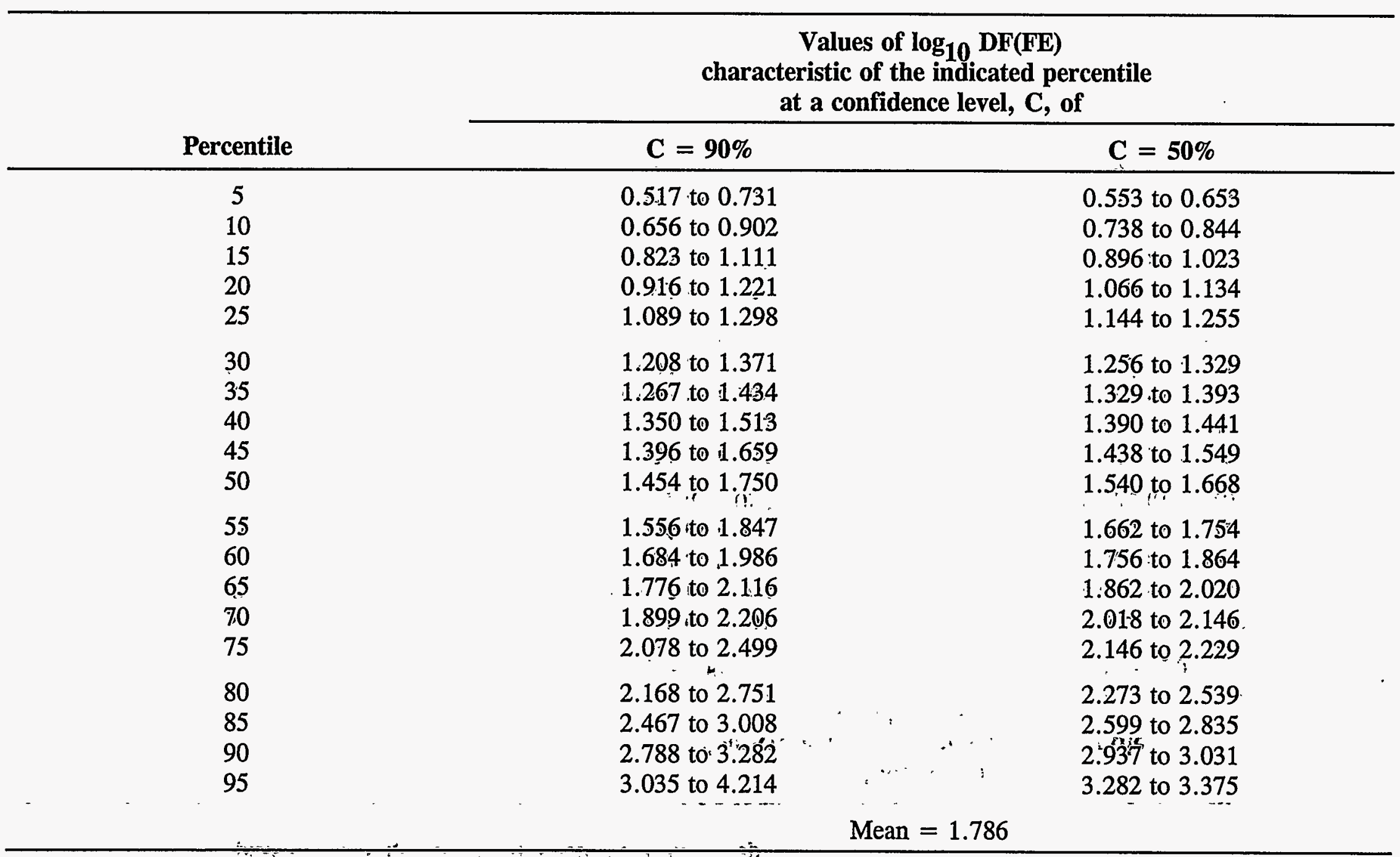


Table A-72. Uncertainty distribution for decontamination of invessel release during bubble rise from an ' $\mathrm{X}$ ' quencher $700 \mathrm{~cm}$ deep

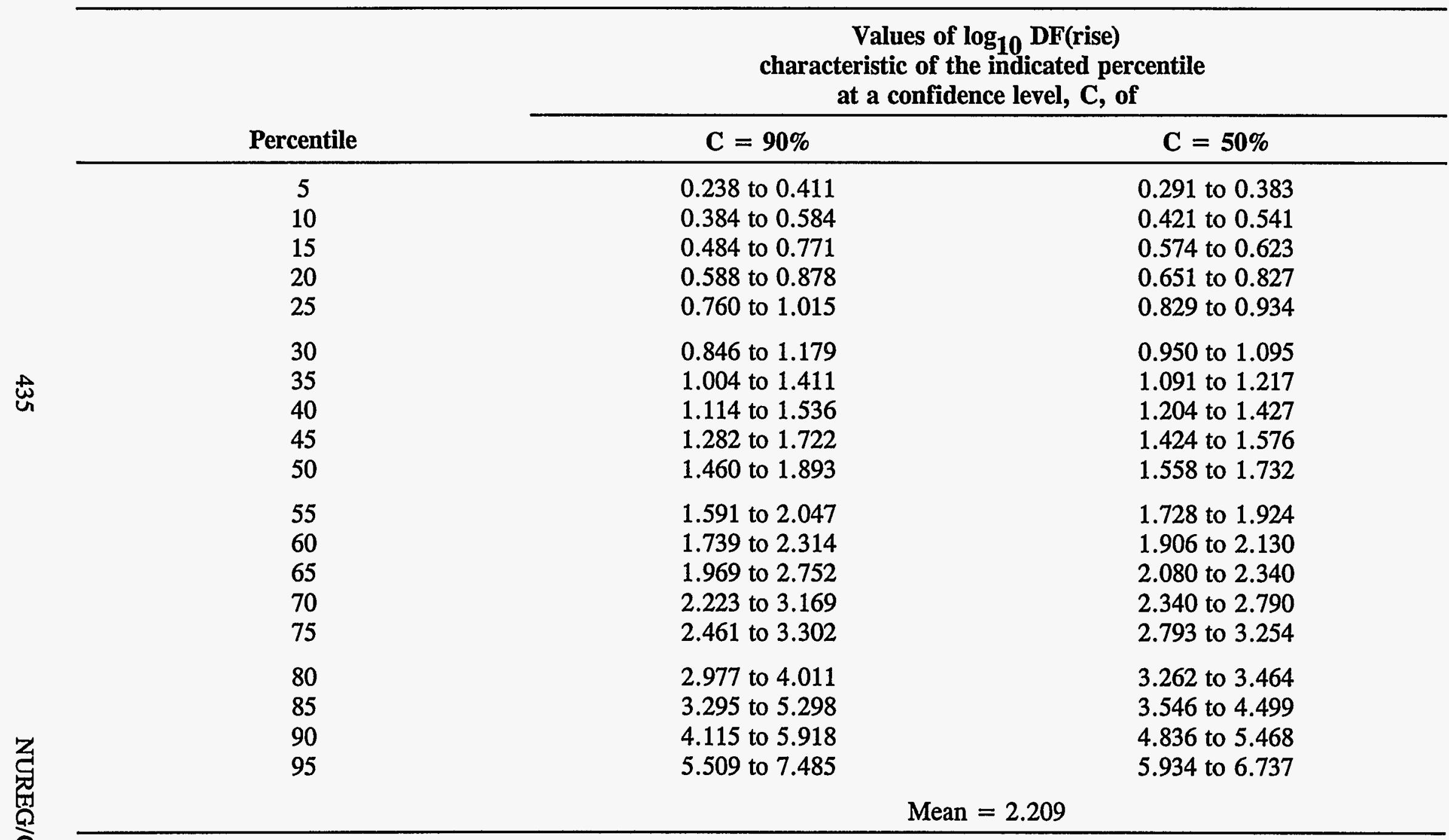


Table A-73. Uncertainty distribution for total decontamination of invessel release after passing through an ' $X$ ' quencher $700 \mathrm{~cm}$ deep

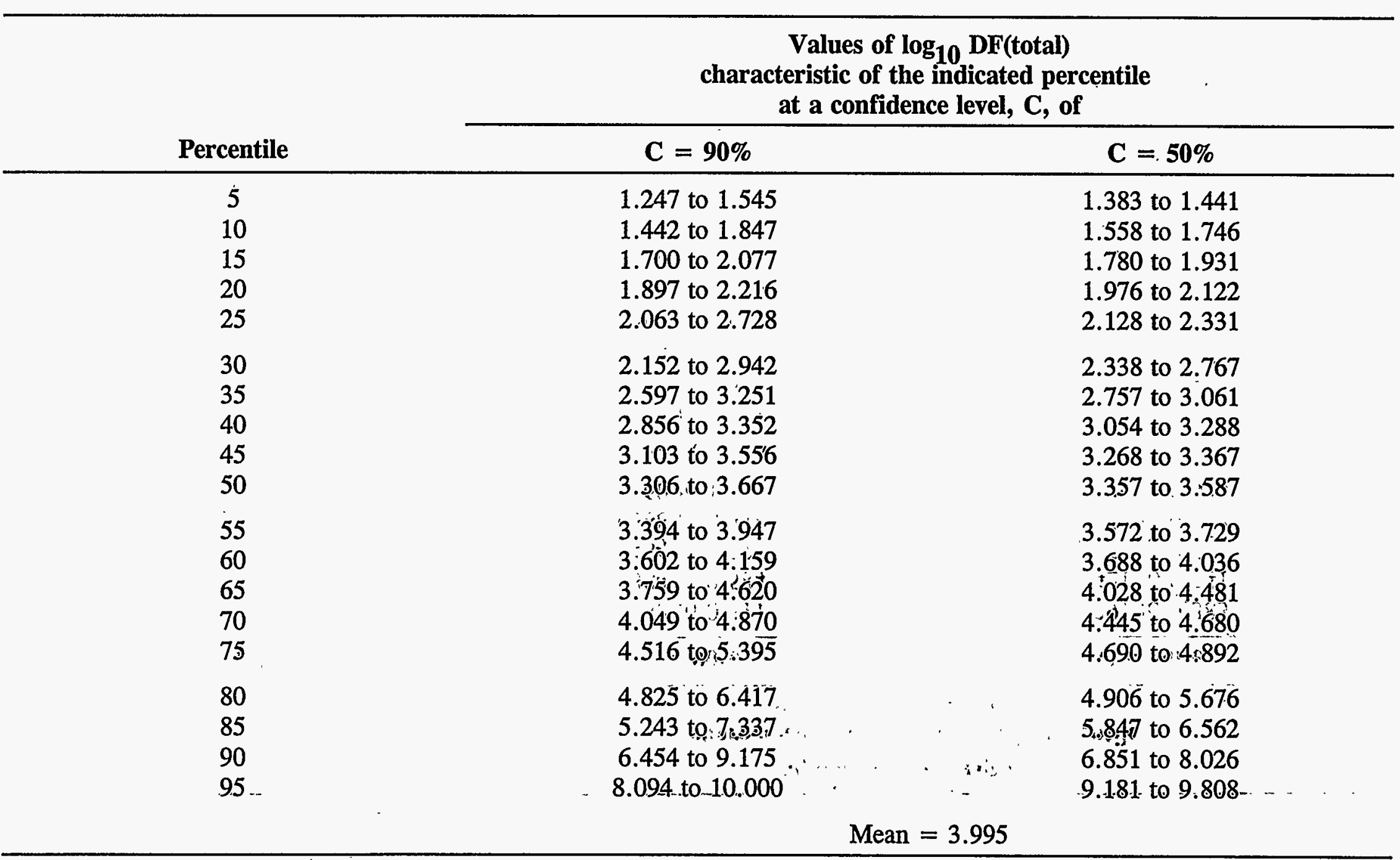


Table A-74. Uncertainty distribution for the mean particle size of invessel release after passing through an ' $X$ ' quencher $700 \mathrm{~cm}$ deep

\begin{tabular}{|c|c|c|}
\hline \multirow[b]{2}{*}{ Percentile } & \multicolumn{2}{|c|}{$\begin{array}{l}\text { Values of } d_{p}(\mu \mathrm{m}) \\
\text { characteristic of the indicated percentile } \\
\text { at a confidence level, } C \text {, of }\end{array}$} \\
\hline & $\mathrm{C}=90 \%$ & $\mathrm{C}=\mathbf{5 0 \%}$ \\
\hline $\begin{array}{c}5 \\
10 \\
15 \\
20 \\
25\end{array}$ & $\begin{array}{l}0.106 \text { to } 0.121 \\
0.117 \text { to } 0.137 \\
0.128 \text { to } 0.159 \\
0.140 \text { to } 0.172 \\
0.159 \text { to } 0.187\end{array}$ & $\begin{array}{l}0.114 \text { to } 0.117 \\
0.122 \text { to } 0.131 \\
0.135 \text { to } 0.155 \\
0.158 \text { to } 0.169 \\
0.170 \text { to } 0.176\end{array}$ \\
\hline $\begin{array}{l}30 \\
35 \\
40 \\
45 \\
50\end{array}$ & $\begin{array}{l}0.171 \text { to } 0.204 \\
0.184 \text { to } 0.222 \\
0.196 \text { to } 0.241 \\
0.209 \text { to } 0.256 \\
0.232 \text { to } 0.280\end{array}$ & $\begin{array}{l}0.176 \text { to } 0.190 \\
0.189 \text { to } 0.204 \\
0.204 \text { to } 0.230 \\
0.230 \text { to } 0.244 \\
0.243 \text { to } 0.261\end{array}$ \\
\hline $\begin{array}{l}55 \\
60 \\
65 \\
70 \\
75\end{array}$ & $\begin{array}{l}0.246 \text { to } 0.304 \\
0.262 \text { to } 0.322 \\
0.291 \text { to } 0.356 \\
0.311 \text { to } 0.369 \\
0.346 \text { to } 0.394\end{array}$ & $\begin{array}{l}0.261 \text { to } 0.287 \\
0.283 \text { to } 0.308 \\
0.307 \text { to } 0.339 \\
0.338 \text { to } 0.360 \\
0.360 \text { to } 0.376\end{array}$ \\
\hline $\begin{array}{l}80 \\
85 \\
90 \\
95\end{array}$ & $\begin{array}{l}0.367 \text { to } 0.495 \\
0.386 \text { to } 0.515 \\
0.499 \text { to } 0.616 \\
0.536 \text { to } 0.882\end{array}$ & $\begin{array}{l}0.377 \text { to } 0.422 \\
0.431 \text { to } 0.504 \\
0.510 \text { to } 0.526 \\
0.617 \text { to } 0.790\end{array}$ \\
\hline \multicolumn{3}{|c|}{ Mean $=0.260 \mu \mathrm{m}$} \\
\hline
\end{tabular}


Table A-75. Uncertainty distribution for the standard deviation of invessel release after passing through an ' $\mathrm{X}$ ' quencher $700 \mathrm{~cm}$ deep

\begin{tabular}{|c|c|c|}
\hline \multirow[b]{2}{*}{ Percentile } & \multicolumn{2}{|c|}{$\begin{array}{l}\text { Values of } \sigma \\
\text { characteristic of the indicated percentile } \\
\text { at a confidence level, } \mathbf{C} \text {, of }\end{array}$} \\
\hline & $\mathrm{C}=90 \%$ & $\mathrm{C}=\mathbf{5 0 \%}$ \\
\hline $\begin{array}{c}5 \\
10 \\
15 \\
20 \\
25\end{array}$ & $\begin{array}{c}1.00001 \text { to } 1.0013 \\
1.0004 \text { to } 1.006 \\
1.002 \text { to } 1.018 \\
1.006 \text { to } 1.027 \\
1.018 \text { to } 1.043\end{array}$ & $\begin{array}{c}1.00004 \text { to } 1.00004 \\
1.0014 \text { to } 1.003 \\
1.005 \text { to } 1.011 \\
1.012 \text { to } 1.020 \\
1.020 \text { to } 1.030\end{array}$ \\
\hline $\begin{array}{l}30 \\
35 \\
40 \\
45 \\
50\end{array}$ & $\begin{array}{l}1.022 \text { to } 1.068 \\
1.035 \text { to } 1.100 \\
1.054 \text { to } 1.126 \\
1.078 \text { to } 1.169 \\
1.115 \text { to } 1.240\end{array}$ & $\begin{array}{l}1.030 \\
1.048 \text { to } 1.049 \\
1.074 \text { to } 1.111 \\
1.109 \text { to } 1.127 \\
1.127 \text { to } 1.175\end{array}$ \\
\hline $\begin{array}{l}55 \\
60 \\
65 \\
70 \\
75\end{array}$ & $\begin{array}{l}1.128 \text { to } 1.289 \\
1.185 \text { to } 1.374 \\
1.271 \text { to } 1.403 \\
1.331 \text { to } 1.420 \\
1.388 \text { to } 1.456\end{array}$ & $\begin{array}{l}1.172 \text { to } 1.264 \\
1.258 \text { to } 1.298 \\
1.293 \text { to } 1.383 \\
1.383 \text { to } 1.409 \\
1.410 \text { to } 1: 424\end{array}$ \\
\hline $\begin{array}{l}80 \\
85 \\
90 \\
95\end{array}$ & $\begin{array}{l}1.414 \text { to } 1.522 \\
1.456 \text { to } 1: 572 ; \\
1.523 \text { to } 1.641 \\
1.618 \text { to }-1.671\end{array}$ & $\begin{array}{l}1.425 \text { to } 1.472 \\
1.485 \text { to } 1.543 \\
1.557 \text { to } 1.614 \\
1.641 \text { to }-1.662\end{array}$ \\
\hline \multicolumn{3}{|c|}{ Mean $=1.21$} \\
\hline
\end{tabular}


(Sea instuctions on the revease)

A Simplified Model of Decontamination by BWR Steam Suppression Pools

\section{NUREG/CR-6153}

3. DATE REPORT PUBLLSHED

\begin{tabular}{l|l} 
MONTH & YEAR
\end{tabular}

May 1997

4. FIN OR GRANT NUMBER

L2035

\section{AUTHOR(S)}

D.A. Powers
6. TYPE OF REPORT

7. PERIOD COVERED (nclusive Dalow)

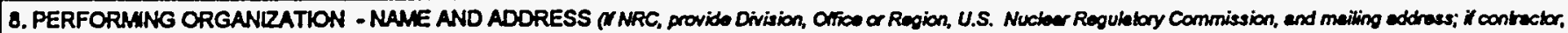
provide name and meiling eddhess.)

Sandia National Laboratories

Albuquerque, NM 87185

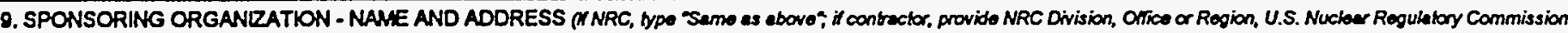
and mailing eddress.)

Division of Systems Technology

Office of Nuclear Regulatory Research

U.S. Nuclear Regulatory Commission

Washington, DC 20555-0001

10. SUPPLEMENTARY NOTES

J.H. Schaperow, NRC Project manager

11. ABSTRACT (200 words or hoss)

An uncertainty analysis of aerosol removal by nuclear reactor steam suppression pools is described. Uncertainties considered in the analyses include uncertainties in boundary conditions dictated by accident progression, uncertainties in bubble behavior, and uncertainties in aerosol properties. Uncertainty distribution for decontamination factors, aerosol particle sizes, and the geometric standard deviation of the size distributions are developed as functions of suppression pool depth. Results of the uncertainty distribution are used to construct a simplified model of decontamination by steam suppression pools.

12. KEY WORDSIOESCRIPTORS Rist words or phrases that wil assist researchers in locating the repart)

source term, decontamination, suppression pool, aerosol, bubbles, bubble swarms, plumes, shape factors, fractal geometry

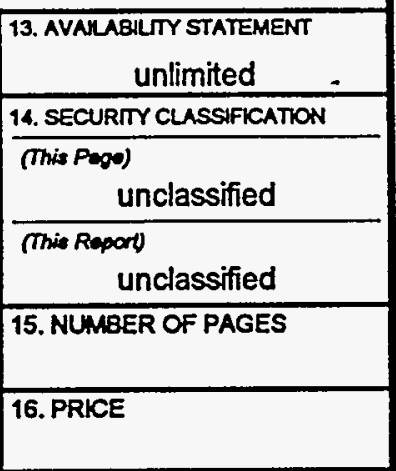

